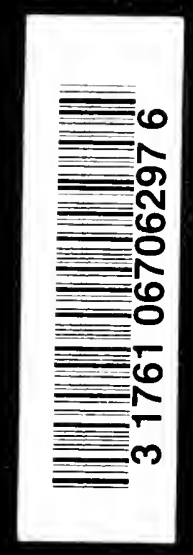




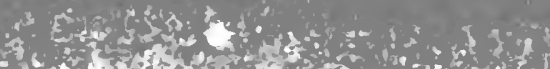

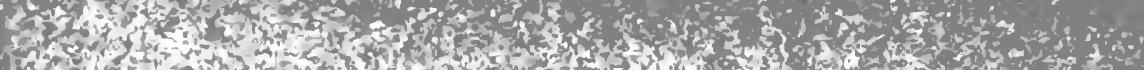

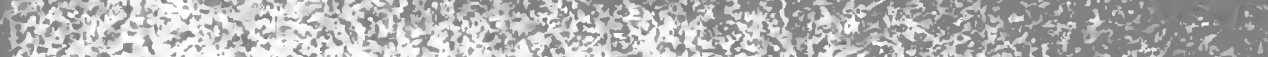

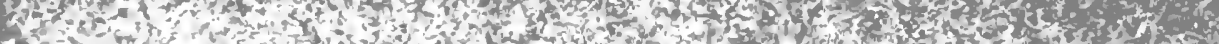

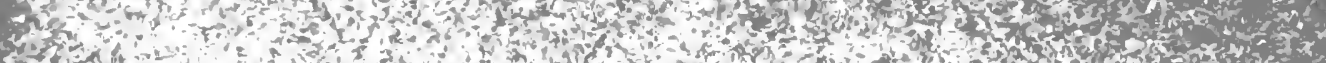

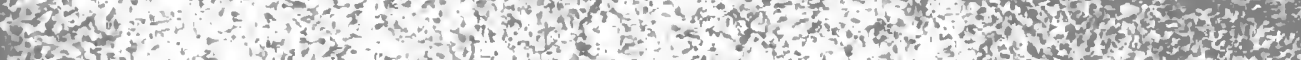

Hot

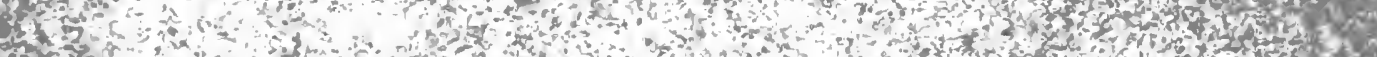

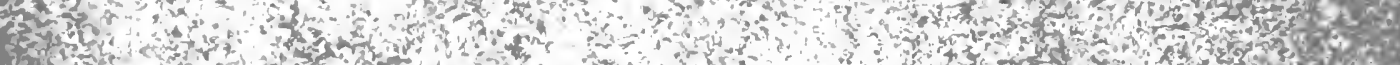

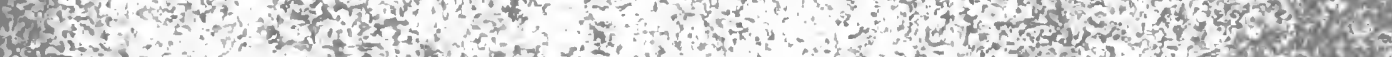
(3)

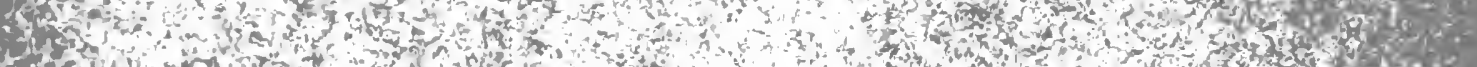

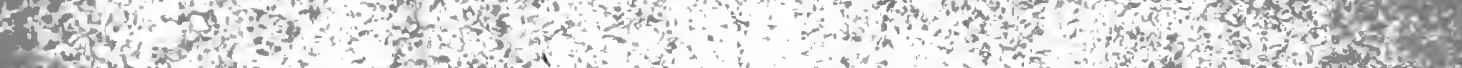
of and $y$ in. -

Sxats.

thas

5is

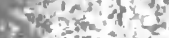

Coy.2.

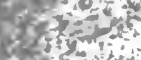

4 ,

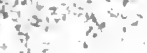

180,10

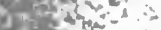

1. $x^{2}+x$

3.

sistion.

4.5.

or

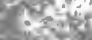

要

ats

kु)

रit

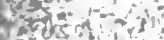

$\frac{9}{2}$

(1)

$2 \mathrm{~s}$

Then

उe

e. 80

$2 \mathrm{~s}^{2}$

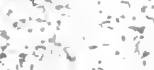

r

क

$\therefore>$

a

-

is

${ }_{-1}$ 
19.

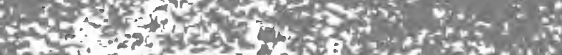

(5)

I.

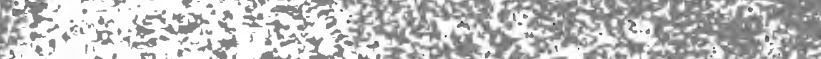

Bo

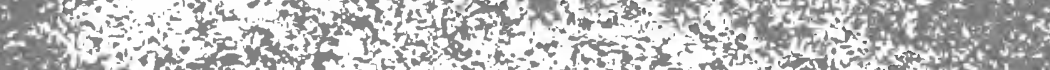

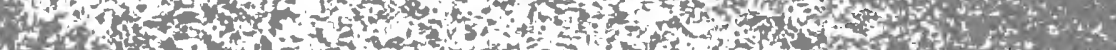

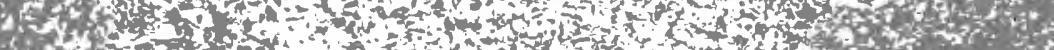

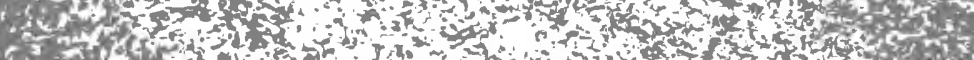

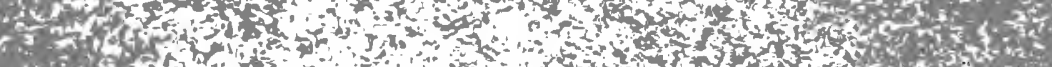

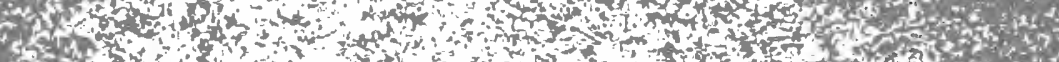

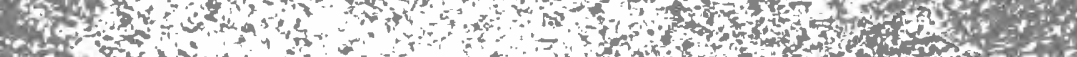

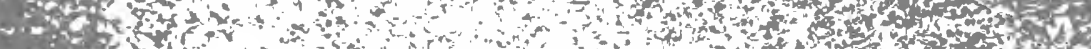

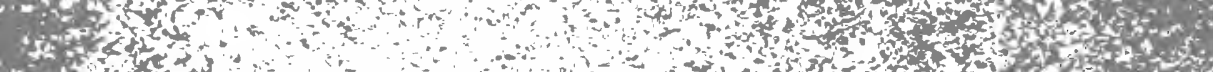
40

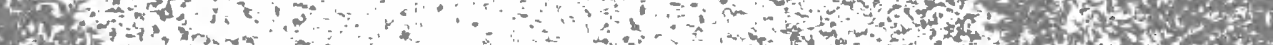

How

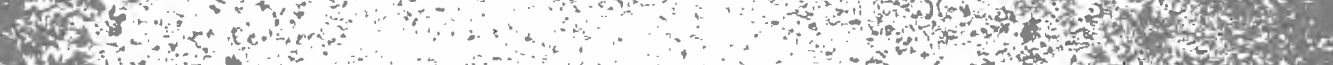

Sor.

(3)

shts

Try

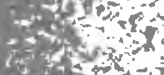

is 25

$65+5$

Ant

A s.5.

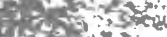

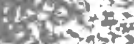

3023

(1) $3=$

textar

The

तर

at

है

cts $5=$

ass

र大

so

tow

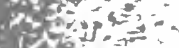

(A)

toxto

isti

is 5

10

Sis

3

- n

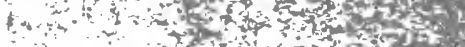

- 100

a d o

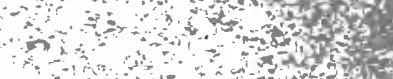

w

40

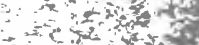

and

a

ind

a d

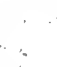

is

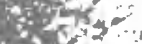

as.

s.t.

PE:

to

sis

$4 \mathrm{Fiz}$

stis

ats.

ats.

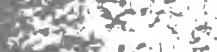

(x)

84

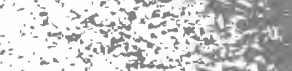

a now

si

$+x^{2}$

$0^{2}{ }^{2}$

J

tat 8

o t

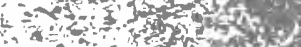

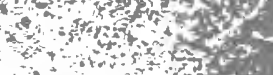

ind

ont

atiz

$+\infty x^{2}$

$B+x_{2}$

$+\infty+20$

ond

a d ond

a tond

I $=7$

50 $+5$

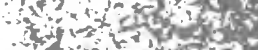

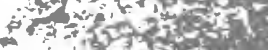

a

a

300 onstost

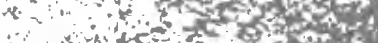

ase

int

$x+x^{2}+x_{2}$

- 


\section{I Q U I D F U E L}

AND ITS COMBUSTION 
DEDICATED AS A MARK OF ESTEEM TO

T. E. GatehOUSE, Esq., F.R.S.E., Assoc. Mem. Inst.C.E., M. Inst.M.E., M. Inst.E.E., etc

Editor in Chicf of the "Electrical Review," through whose kindness I have been able to pline on recort my vieus on the combustion of fucls and the construction and management of furnaces 


\title{
LIQUID FUEL
}

\section{AND ITS COMBUSTION}

\section{By Wм. H. BOOTH}

\author{
MEMBER OF THE AMERICAN SOCIETY OF CIVIL ENGINEERS; FORMERLY OF THE \\ NEW SOUTH WALES' GOVERNMENT RAILWAYS AND TRAMWAYS \\ OF THE MANCHESTER STEAM USERS' ASSOCIATION, OF \\ THE BRITISH ELECTRIC TRACTION COMPANY
}

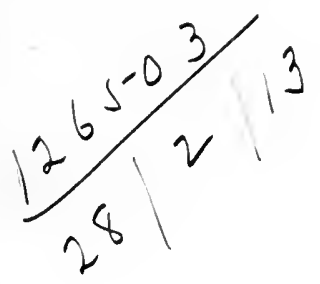

WESTMINSTER

ARCHIBALD CONSTABLE \& CO LTD

2 WHITEHALL GARDENS

I 903 
$-1.1 .911 .1$

1

$1 / 1$

BUTLER \& TANNER,

The SElWOOd PRiNTING WORKS,

FROME, AND LONDON. 


\section{Preface}

7 HE subject of Iiquid Fuel is one that has now been before the public about twenty-five years, but little had been done in this country until about twelve years ago, when Mr. Holden, of the Great Fastern Railway, began to use the tar of his oil-gas process, and found many advantages in using this hitherto almost unsaleable product. The success of this tar led him on to the use of creosote and other hydrocarbon by-products, and now he is using Texas oil.

In this book the Author has endeavoured to put together what has been done in the burning of liquid fuel, and at the risk of repetition has given descriptions of various systems and apparatus; and while no statements have been accepted unconsidered, he has not hesitated to use descriptions and statements of manufacturers in some cases with little alteration where such statements were sound and reasonable. The Author is not only indebted to the many whose names appear in the text, but also to many others who have furnished him with information, particularly Professor W. B. Phillips, Ph.D., of the University of Texas, from whose bulletins the author has drawn so copiously for information on Texas oil ; to Mr. Thomas Urquhart, of Dalny, who, as Locomotive Superintendent of the Grazi and Tsaritsin Railway, first placed liquid fuel burning on a sound basis in locomotive work, and whose papers on the subject may be found in the Proceedings of the Institution of Mechanical Engineers; to his friend Mr. B. H. Thwaite, whose researches in combustion have been so extensive.

The work of the United States Naval Department, under Rear-Admiral Melville, has been so valuable that special appendices have been devoted to a copious abstract of the coal and oil tests made by the Bureau of Steam Engineering upon a water-tube boiler as well as tests upon the ss. Mariposa.

The Author has also drawn liberally upon the bulletins of the U.S. Geological Survey for information on petroleum production.

To Mr. Alfred J. Allen acknowledgment is due for information on tar and creosote, and for tabular matter to Mr. Poole, whose excellent treatise on the Calorific Power of Fuels deals so exhaustively with coal.

Appendices are added giving the Rules of the National Board of Fire Underwriters (U.S.), and also the Rules of Lloyd's Register of Shipping.

Acknowledgments are due to the Electrical Review (London) for permission to reproduce portions of the Author's articles in that Journal on questions of combustion. To Mons. L. Bertin, of the French Navy, the Author is indebted for information as to the use of liquid fuel in the French Military Marine.

The means for utilizing Liquid Fuel are very varied, yet all practically result in, or at least aim at, one end. It has been impossible within two covers to do more than select a number of such apparatus to illustrate the principles which have been followed in achieving success. The successful combustion of liquid hydrocarbon 


\section{PREFACE}

is but an extension of the principles necessary for bituminous or hydrocarbon coal. The difference is that coal is burned partly upon the grate, and air, to burn the hydrocarbon distillates, eannot well be introdueed from below, as it can with liquid fucl which is burned in a floating condition, ancl can be fed with air from below very easily.

The difference is but one of degree, but with liquid fuel the fact that all the fuel is floating, and would produce a specially foul black smoke under the conditions in which coal is burned, has compelled the adoption of means that ought to be adopted with coal-fired furnaces.

The Author has endeavoured to connect the two practices, for in the present state of liquid fuel supply it is more than probable that its use will be parallel with the use of coal, especially in dealing with the sudden and high load peaks of electric stations. Liquid fuel cannot be universal unless the supply increases to many times what it is at present, and this points to a good future for the mixed system of firing, oil and coal being burned together in the same furnace.

It has been difficult to make a selection of apparatus to be described, but the Author trusts that he has selected a sufficient number of types practically to cover the ground and show the general trend of practice without unduly multiplying examples. Indeed the tendency seems to him to be in the direction of one general type. As regards special boilers, oil does not appear to require anything more than what is required by coal, though coal is not treated to the necessary appliances, and oil is so treated, and gains success where coal is allowed to fail.

Much that perhaps ought to appear in such a book as this has been omitted, as it appears to the Author that the question of draught, for example, is not of the same importance with liquid fuel as it is with solid fuels.

More might be said on the subject of flue-gas proportion, but this again has been so fully treated by other writers that it did not seem desirable at present to deal with it more fully. The most important detail of liquid fuel apparatus is the furnace and the provision of air, and of means to secure combustion and conserve temperature to enable combustion to be made perfect.

Mr. Horace Allen kindly revised the section on gas analysis. Students of liquid fuel combustion will find enormous masses of information in the past volumes of the Engineer, Engineering, and other technical papers. Much of this information is duplicated and historical, and the Author has found it necessary to eliminate almost all such matter and confine his space to systems now living or of recent use, or of a form recognized as useful to-day. Undoubtedly Aydon and the late Admiral Selwyn did much to urge the use of liquid fuel, but the latter injured the value of his best work by regarding steam as a combustible.

The Author is also indebted to Messrs. Colonner and Lordier, the French enginecrs, for exccllent information on liquid fuel, and indirectly no doubt to many others who are not directly traceable.

Finally, his grateful acknowledgments are due to his Publishers for the manner in whieh they have facilitated his labours throughout.

Dartmouth House,

2 Quefen Anne's Gate,

WESTMINSTER. 


\section{PREFACE}

is but an extension of the principles necessary for bituminous or hydrocarbon coal. The difference is that coal is burned partly upon the grate, and air, to burn the hydrocarbon distillates, eannot well be introdueed from below, as it can with liquid fuel which is burned in a floating condition, and can be fed with air from below very easily.

The difference is but one of degree, but with liquid fuel the fact that all the fuel is floating, and would produce a specially foul black smoke under the conditions in which coal is burned, has compelled the adoption of means that ought to be adopted with coal-fired furnaces.

The Author has endeavoured to connect the two practices, for in the present state of liquid fuel supply it is more than probable that its use will be parallel.with the use of coal, especially in dealing with the sudden and high load peaks of electric stations. Liquid fuel cannot be universal unless the supply increases to many times what it is at present, and this points to a good future for the mixed system of firing, oil and coal being burned together in the same furnace.

It has been difficult to make a selection of apparatus to be described, but the Author trusts that he has selected a sufficient number of types practically to eover the ground and shnw the coneral trend of practice without undulv multiplying examples. Inder type. As regard what is required oil is so treated,

Much that $p$ it appears to the importance with

More might so fully treated b. it more fully. T the provision of to enable combu

Mr. Horace

fuel combustion the Engineer, $E$. is duplicated an almost all such $r$ or of a form reco Selwyn did much to urge the use of liquid fuel, but the ratter injurea tne varue or his best work by regarding steam as a combustible.

The Author is also indebted to Messrs. Colonner and Lordier, the French engineers, for excellent information on liquid fuel, and indirectly no doubt to many others who are not directly traceable.

Finally, his grateful acknowledgments are due to his Publishers for the manner in which they have facilitated his labours throughout.

Dartaloutu House,

2 Quenn Anne's Gate,

IVESTMinster. 


\section{Table of Contents}

PART I PAGE

Preface

\section{CHAPTER I}

Historical Notes; The present Production of Coal ; Advantages of Liquid Fuel ; Petroleum ; General Notes ; Economies possible by the use of Liquid Fuel; The present Production of Petroleum .

\section{CHAPTER II}

The Economy of Liquid or Solid Fuel ; The Dangers of Petroleum; Air necessary for Combustion; General Principles of Liquid Fuel Combustion; Flame Analysis ; Refractory Furnace Linings; The Weir Boiler .

\section{CHAPTER III}

Liquid Fuels; The necessity for Atomizing; Varieties of Liquid Fuel; American Petroleum; Russian Petroleum ; Creosote Oils ; Tar Distillates ; Blast Furnace and Shale Oils

\section{CHAPTER IV}

Texas Oil ; Rates of Carriage on Oil ; The Analysis of Oil ; Physical Properties : Russian Oil ; Calorific Capacity of Oils ; Advantages of Liquid Fuel ; The Use of Oil on Locomotives; The World's Oil Production; The Limits of Liquid Fuel

\section{CHAPTER V}

Equivalence of Oil and Coal ; Tests of Texas Oil

\section{CHAPTER VI}

Chemical and other Properties of Petroleum ; Water in Oil ; Petroleums suitable for Fuel ; Physical Properties of Petroleum ; Specific Gravity of Petroleum

\section{CHAPTER VII}

Materials ; Cast Iron; Steel ; Firebricks ; Fireclay; Clay Analysis ; Special Forms of Bricks; Classification of Clay Goods 


\section{TABLE OF CONTENTS}

\section{CHAPTER VIII}

Combustibles and Supporters of Combustion. Carbon: its Forms and Origin; its Calorific Properties; its Combustion and Chemistry. Hydrogen: its Physical and other Properties ; its Compounds with Carbon; its Combustion; Air ; The Atmosphere; Properties of Air. Oxygen : its Compounds with Carbon; its Properties.

\section{CHAPTER IX}

Water ; its Properties; Origin and Sourees of Water Impurities ; Solubility of Salts ; Sea Water ; Useful Data

\section{CHAPTER $\mathrm{X}$}

Purification of Water ; Prevention of Scale in Boilers; The Clark Process ; The Double Process; The Economics of Water Softening; The Magnesia Salts; Iron ; Acid ;

Tests ; Boiler Compounds

\section{CHAPTER XI}

Calorifie and other Units; Thermo Chemistry; Heat; Temperature: Thermometers; Specific Heat; Latent Heat; Dissociation; Units of Heat; Units of Work; Units of Weight ; Gravity ; Compound Units

\section{CHAP'TER XII}

Calorific Power of Fuels ; Calculation of Temperatures ; Effects of Dissociation and of Variation of Speeific Heat ; Relative Volumes produced by Combustion ; Evaporative Power of Fuel; Temperatures due to Combustion; Calculation of Calorific Capacity of Fuels.

\section{CHAPTER XIII}

Smoke and Combustion; Varieties of Smoke; Its Prevention; Influence of Refractory Furnaces; The Combustion of Bituminous Fuels; Carbon Vapour; Liquid Fuels; Furnace Temperatures ; Theoretical Flame Temperature ; Total Heat generated ; Air Supply ; The Heat Properties of Carbon; The Process of Coal Combustion; Effect of Vaporizing Solid Fuels ; Flame Analysis ; The Principles of Combustion ; The Necessity of Temperature; Smoke due to Loss of Heat of Burning Gases; The Use of Coloured Glass for Flame Inspection; The Weir Boiler . . . .

\section{PART II}

\section{CHAPTER XIV}

Oil Storage on Ships; Example of Improvised Tank Steamer ; Example of Cargo Steamer ; Example of New 'Tank Steamer; Use of Liquid Fuel at Sea; Supply of Oil at Ports; Safety and Flash Point; Advantages for War Ships; Economic Advantages of Liquid Fue 


\title{
TABLE OF CONTENTS
}

\author{
CHAPTER XV
}

PAGE

Marine Furnace Gear ; Arrangement of Shell line Steamers ; Interchange of Coal and Oil ; The Flannery-Boyd System ; The Orde System ; Results of Use of Liquid Fuel at Sea ; Wallsend Slipway Company's Arrangement; 'The Lancashire Boiler with Orde's System; Körting System; Howden System.

\section{CHAPTER XVI}

Liquid Fuel Application to Locomotives ; The Holden System ; Advantage of Oil ; Method of Working; Management of Fire ; Partieulars of Oil Burning Loeomotive : Regulation of Oil Supply; 'The Atomizer ; Life of Fire Boxes; Heating the Oil ; Air Heater

\section{CHAPTER XVII}

Application of Liquid Fuel to Stationary and other Boilers ; The Lancashire Boiler ; Cornish Boiler ; Water Tube Boiler ; Locomotive Boiler ; Level of Atomizer in Mixed System; Management of Fire; United States Navy Tests; The Meyer System

\section{CHAPTER XVIII}

The Mixed System of Coal and Liquid Fucl Combustion : its use in the Italian Navy; M. Bertin's Calculations.

\section{CHAPTER XIX}

Russian and American Locomotive Practice ; The Baldwin Company's System ; The Equivalenee of Coal and Oil; Comparisons of Cost of Liquid Fuel; The Danger of Crude Oil ; The Urquhart System ; General Arrangements ; Management of Furnace ; Firebox Designs : Smoke Results on Grazi and Tsaritsin Railway . . . . . 1 (60

\section{CHAPTER XX}

American Stationary Practice with Liquid Fuel; The Billow System; Fuel Oil Pumping Systems; Double Pumping Systems; Furnace Construetion; Operating a Fuel Oil Plant; Examples of Boilers with Liquid Fuel Furnaees

\section{CHAPTER XXI}

American Stationary Practice with Liquid Fuel ; The Kirkwood System; Comparative Values of Coal and Oil ; The Aerated Fuel Proeess ; Air Pressure ; Comparison of Oil and Gas Fuels; The Springfield System.

\section{CHAPTER XXII}

English Stationary Practice with Liquid Fuel ; The Kermode System ; Analysis of Borneo Oil ; Tests of Borneo Oil ; The Hydroleum Systen ; Tests ; The Sprayer ; Result with Automobile Car; Air Supply; Application of System to Internally Fired Boilers

\section{CHAP'TER XXIII}

The Combustion of Vaporized Liquids ; The Clarkson-Capel Burner : its Various Applica- tions ; Starting Devices 


\section{TABLE OF CONTENTS}

CHAP'TER XXIV

PAGE

Comparison of Air and Steam Atomization ; The Ellis and Eaves System ; Steam Atomization ; Air Atomization; Tests

\section{CHAPTER XXV}

The Storage and Distribution of Liquid Fuel ; Tanks ; Piping ; Ventilation ; Great Wastern Railway System : Grazi and Tsaritsin Railway System; Thwaite Tank; Oil Pinmps

\section{CHAPTER XXVI}

Flue Gas Analysis ; Calculation of Volumes ; The Orsat Apparatus : its Working ; Gas Calculations ; Absorbing Solutions ; Analysis; The Ados Recorder : its Action ; Arndt's Econometer

\section{CHAPTER XXVII}

Compressed Air ; Air Compressors ; Reavell Compressor ; Principles of Compression ; Weight of Air necessary for Liquid Fuel Atomization; Adiabatic Calculation of Air ; Compound Air Compression; Volumetric Efficiency ; Power to Compress Air ; Outflow of Air . . . . . . . . . . . . . . . .

\section{CHAPTFR XXVIII}

Calorimetry and Draught; Thompson's Calorimeter ; The Berthelot-Mahler Calorimeter ; Calorimetric Determinations ; Draught ; Gauges ; Difference of Solid and Liquid Fuel in Relation to Draught

\section{CHAPTER XXIX}

Atomizing Liquid Fuels; Various Atomizers; Elementary Forms ; Vaporizers ; The Symon-House Burner; Atomizing Agents; French Trials; Air Compression ; Certain Advantages of Steam ; d'Allest Atomizer ; Fvardofski System ; Russian Atomizers ; Object of Atomizing; Anerican Practice; Thwaites System

\section{CHAPTER XXX}

Application of Tiquid Fuel to Metallurgy ; Rivet Furnace : Assaying Furnace ; Crucible Furnace; The Schwartz Oil Furnace for Melting Metals; Tests; Oil Consumption; 'Tyre Heating Furnace; Forge Furnaces; Copper Smelting .

\section{CHAPTER XXXI}

Oil Carriage by Rail ; Example of Oil Tank Wagon; Oil Carrying Steamer

\section{CHAPTER XXXII}




\section{TABLE OF CONTENTS}

\section{PART III}

APPENDICFS

PAGE

Appendix No. 1. Extracts from Report of Chief of Bureau of Steam Engineering, U.S. Navy, on Tests made upon a Boiler with Coal Firing . . . . . . . 295

Appendix No. 2. Report on Steamship Mariposa . . . . . . . . $\quad .313$

Appendix No. 3. Extract from Report of Board on Tests of Liquid Fuel for Naval Purposes (U.S. Navy) . . . . . . . . . . . . . . . $\quad$. 324

Appendix No. 4. Lloyd's Rules for Burning and Carrying Liquid Fuel . . $\quad 343$

Appendix No. 5. Rules and Permits of Various American Boards of Fire Underwriters 344

Appendix No. 6. Extract from Report of Mr. Schoen on Oil Storage . . $\quad 348$

Appendix No. 7. Extracts fron Report of Mr. Schoen on Installation of Fuel Oil $\quad 350$

Appendix No. 8. Rules and Requirements of National Board of Fire Underwriters $\quad 353$

Appendix No. 9. Controllable Liquid fired Steam Superheater . _ . . . . $\quad 394$

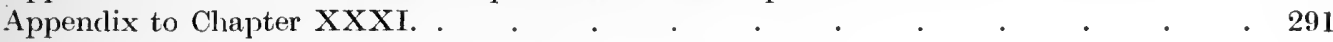

\section{PART IV}

Tables and Data 



\section{Index to Illustrations}

FIG.

0. The Weir Water 'Tube Boiler

1. Oil Storage System, ss. Murex

2. Fuel Tanks. Ordinary Cargo Boat.

4. Oil Burning Furnece, ss. Murex

5. Furnace Brickwork, ss. Murex

6. Atomizer, Rusden Eeles System . . . . . . 120

7. Furnace of ss. Trocas . . . . . . . . . . . 121

8. Service Tank, Flannery-Boyd System . . . . . . . . 122

9. General Arrangement of Water Tube Boiler, Orde's System . _ . . . . 123

9a. Bunker Pipes of Oil Supply . . . . . . 124

10. Atomizer, Orde's System . . . . . . . . . . . . . 125

11. Atomizer Trunnion, Orde's System . . . . . . . . . . . . . . . 126

12. Furnace Briekwork, Wallsend Slipway Co. . . . . . . . . . . 128

13. Typieal Oil Fuel System, Wallsend Slipway Co. . . . . . . . 129

14. I.aneashire Boiler Arrangement, Wallsend Slipway Co. . . . . . . . 130

15. General Arrangement, Körting System . . . . . . . . . . . 131

16 and 16a. Detail Arrangement Marine Boiler, Körting System _ . . . 132, 133

17. Design for Oil Furnace, Körting System . . . . . . . . . . . . 134

18. Oil Furnaee, ss. F. C. Laiesz, Körting System . . . . . . . . . . . 135

19. Atomizer, líörting System . . . . . . . . . . . . . . . . . 136

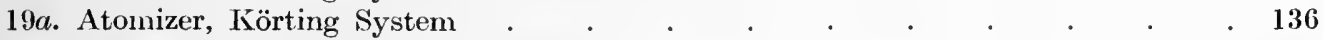

20. General Arrangement, Howden System . . . . . . . . . . 137

21. Atomizer, Holden's System . . . . . . . . . . 141

22. Great Eastern Locomotive, Holden's System . . . . . . . . . 142

23. Great Eastern Locomotive, Oil Regulator, Holden's System . . . . . 144

24. Atomizer, Stationary Form, Holden's System . . . . . . . . . 145

25. American Locomotive Firebox for Liquid Fuel . . . . . . . . . $\quad 146$

26. Great Eastern Locomotive, Holden's System . . . . . . . . . . . 148

27. Atomizer, Locomotive 'Type, Holden's Systenı . . . . . . . . $\quad$. 150

28. Macallan Variable Blast Pipe Cap . . . . . . . . . . . 151

29. Lancashire Boiler, Holden's System . . . . . . . . 152

30. Cornish Boiler, Holden's System . . . . . . . . . . . . . 153

31. Locomotive Type Boiler, Holden's System . . . . . . . . . 154

32. Water Tube Boiler with Grate Bars . . . . . . . . . . . 155

33. Water Tube Boiler without Grate Bars . . . . . . . . . . 156

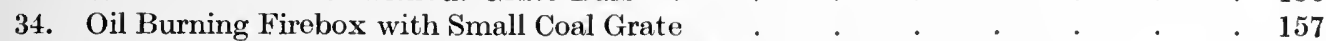

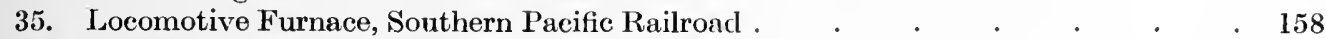

36. The Meyer System of Liquid Fuel Burning . . . . . . . . . . 161

37. Atomizer, Baldwin System . . . . . . . . . . . . . . . . 166

38. Regulating Cock for Oil, Baldwin System . . . . . . . . . . . . $\quad . \quad 167$

39. Locomotive Firebox, Baldwin System . . . . . . . . . . . $\quad$. 168

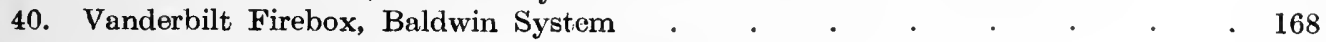


INDEX TO ILLUSTRATIONS

FIG.

41. Locomotive Firebox, Urquhart System

43. Iocomotive Firebox, Urquhart System

44. Locomotive Firebox, Urquhart System. .

45. Atomizer, Urquhart System

45a. Laneashire Boiler Furnace, Urquhart System

46. Performance Curves, Urquhart System

47. Atomizer, Billow System

47a. Underfired Tubular Boiler, Billow Systen

47b. Water Tube Boiler, Billow System .

47c. 500 HP. Heine Boiler, Billow System

48. Double Pumping I'lant, Billow System

48a. Air Tuyere, Billow System

48b. Air Regulator, Billow System

48c. Tank-hose Connection

49. General Furnace Mouthpiece Arrangement, Billow System

50. Atomizer, Aerated Fuel Process

51. Liquid Fuel Furnace, Kermode's System

51a. Enlarged Details, Kermode's System

52. Liquid Fuel Furnace, Kermode's System

53. Furnace Arrangement, Hydroleum System

53a. Furnace Arrangement, Hydroleum System

53b. Furnace Arrangement, Hydroleum System

54. Clarkson Capel Preliminary Heater

55. Clarkson Capel Burner for Fire Float .

56. Clarkson Capel Burner for Automobile

57. Clarkson Capel Burner, Open Tank System

58. Clarkson Capel Canoe Boiler .

59. Clarkson Capel System. Small Vessel

60. Clarkson Capel System, Automobile Starting Device .

61. Air Hrating System, Ellis \& Eaves System

6. Furnace Arrangement, Ellis \& Eaves Systen

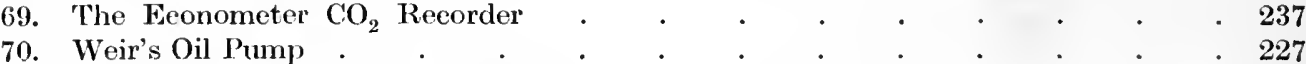

71. Electrically Driven Air Compressor ․ . . . . . . . . . . . $\quad$. 240

72. Eleetrically Driven Air Compressor _. . . . . . . . . . . . 241

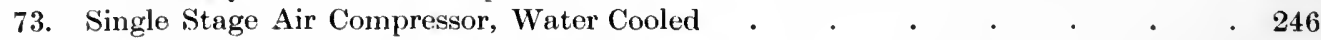

74. Single Stage Air Compressor, Unjacketted ․ . . . . . . . . . . $\quad .247$

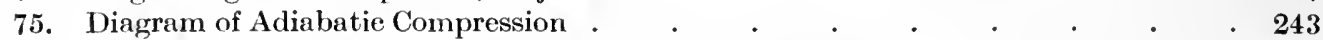

76. Diagram of Compound Compression with Intercooling . . . . . . $\quad 243$

77. Small Electrically Driven Duplex Compressor . . . . . . . . . . . 250

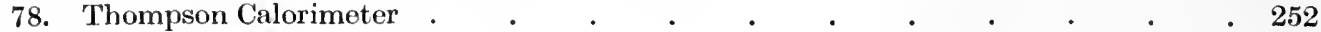

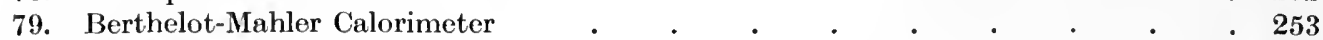

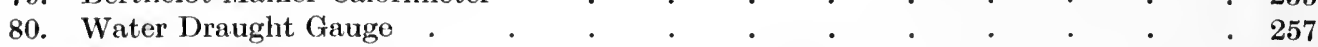

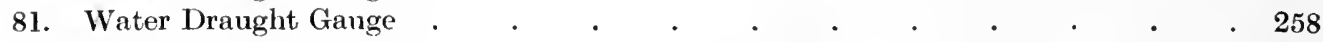

81a. Atomizer, Rusden Eeles . . . . . . . . . . . . . . . 261

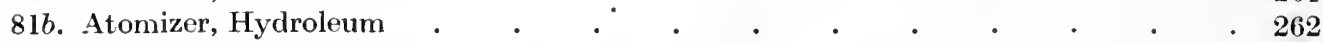

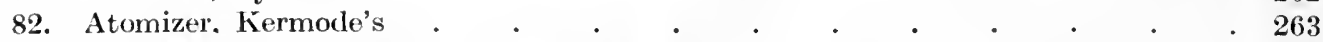

83. Rivet Furnace. Grand Trunk Railway . . . . . . . . . . . 263

84. Atomizer, Rivet Furnuce. Grand Trunk Railway . . . . . . . . 264

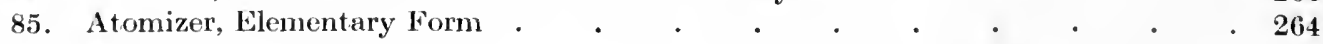

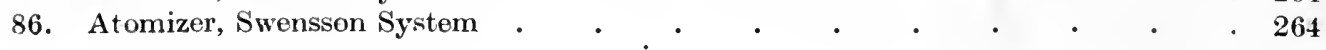




\section{INDEX TO ILI.USTRATIONS}

FIG.

87. Burner, Symon-House System . . . . . . . . 265

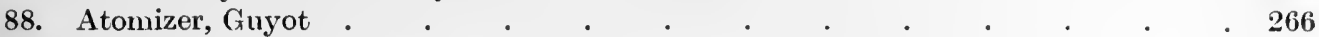

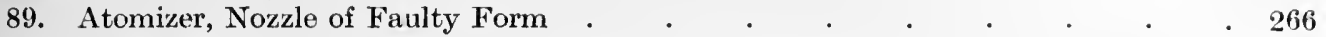

90. Atomizer, Nozzle of Good Form . . . . . . . . . . . . . 266

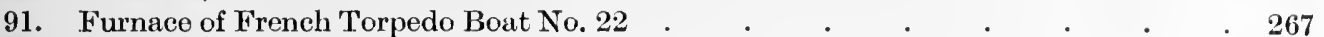

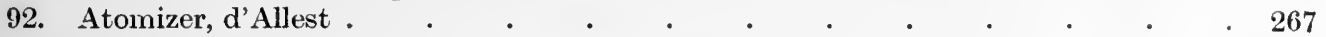

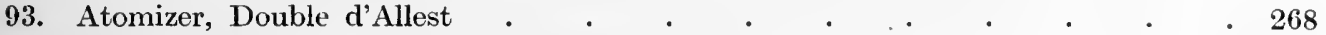

94. Guyot Small Tube Boiler, with Liquid Fuel . . . . . . . . . $\quad$. 268

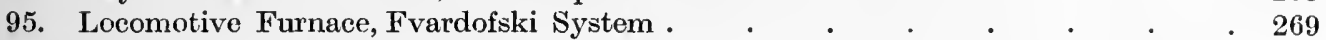

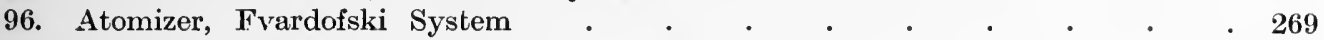

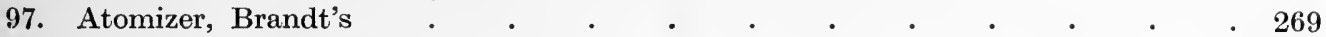

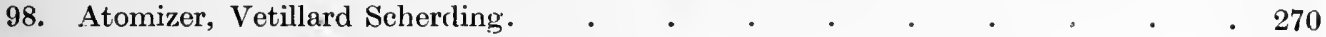

99. Atomizer, Solinai . . . . . . . . . . . . . . . . $\quad . \quad 270$

100. Atomizer, Artemeff's . $\quad . \quad$. $\quad . \quad$. $\quad . \quad$. . . . . . $\quad .271$

101. Atomizer, Berznef . . . . . . . . . . . . . . . 271

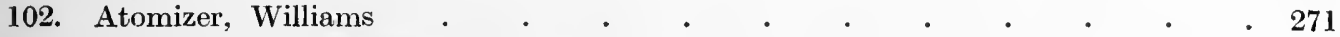

103. Atomizer, Compagnie Russe Standart . . . . . . . . . . . $\quad$. 271

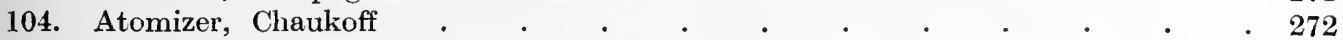

105. Locomotive Boiler tried at Cherbourg . $\quad . \quad$. $\quad . \quad$. $\quad . \quad$. $\quad 272$

106. Rivet Furnace. Great Eastern Railway . . . . . . . . . 274

107. Oil heated Brass Crucible Furnace . . . . . . . . . . $\quad$. 275

108. Assay Furnace, Bickford Burner Co's. System . . . . . . $\quad 276$

109. Assay Furnace, Bickford Burner Co's. System . . . . . . $\quad 277$

110. Schwartz Furnace . . . . . . . . . . . . . . . . . . 278

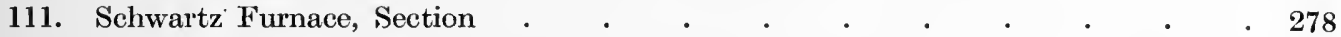

112. Tyre Heating Furnace, Urquhart Systen . . . . . . . . . 281

112a. Spray Injector for Tyre Furnace, Urquhart System _ . . . . . $\quad . \quad 282$

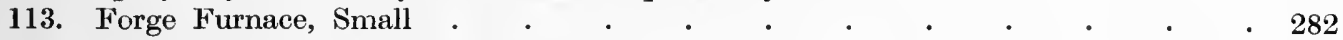

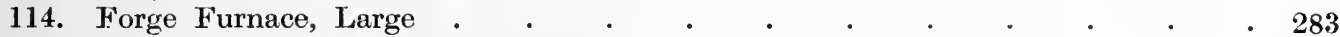

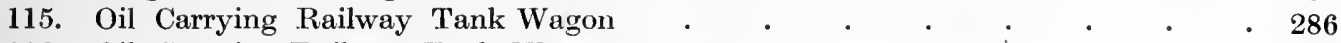

116. Oil Carrying Railway Tank Wagon . . . . . . . . . . . $\quad$. 287

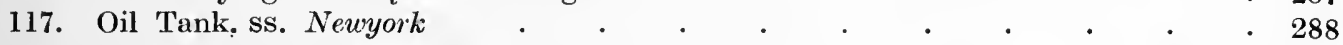

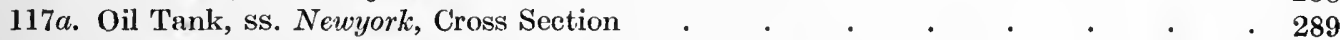

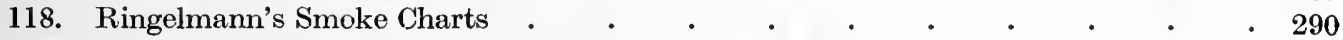

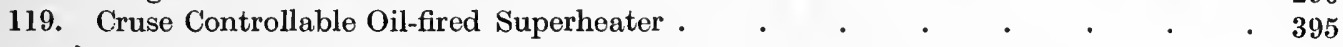

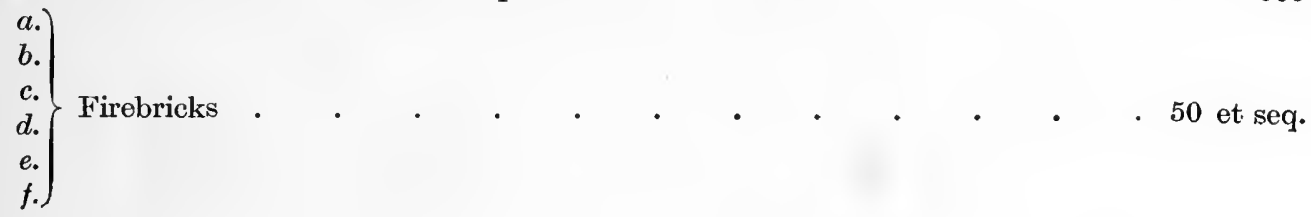




\section{Illustrations to Appendices}

FIG. APP.

1. 1. Hohenstein Coal Burning Boiler . . . . . . , . 297

3. 1. Hohenstein General Arrangement . . . . . . . . . 299

4. 1. Hohenstein Boiler, Variation of Air Pressure . . . . 301

5. 2. Atomizer, Grundell Tucker . . . . 315

6. 3. Hohenstein Boiler, Liquid Fuel Arrangement . . . . . . . . 324

8. 3. Hohenstein Boiler, Liquid Fuel Arrangement . . . . . . . . . 326

9. 3. Atomizer, Oil City Co. . . . . . . . . . . . . . 327

10. 3. Diagram of Air Pressures, Fuel Arrangement.

11. 3. Atomizer, Hayes' . . . . . . . . . . . . . 332

12. 3. Installation, Hayes' Burner . . . . . . . . . . . . . . . 333

13. 3. Atomizer, Oil City Co. . . . . . . . . . . . . . . . 334

14. 3. Atomizer, F. M. Reed . 335

119. 9. Steam Superheater, Oil-fired . $\quad . \quad+\quad . \quad+\quad . \quad 395$

\section{Appendices}

APP.

1. Melville's Coal Tests, U.S. Navy . . . . 295

2. SS. Mariposa Trials, U.S. Navy . . . . 313

3. Melville's Fuel Oil Tests, U.S. Navy . . . . . . 324

4. Lloyd's Rules for Liquid Fuel Ships . . . . . . 343

5. Rules of American Boards of Fire Underwriters. . . . . . . . . . . 344

3. Schoen's Report on Storage of Petroleum . . . . . . 348

7. Schoen's Report on Individual Installations . . . . . . 350

8. Requirements of Underwriters . . . . . . 353

9. Steam Superheater, Oil-fired Controllable . _ . _ . _ . . . . . . . 394 


\section{Index to Tables}

TABLE

I. Composition of Crude Oils . . . . $\quad .361$

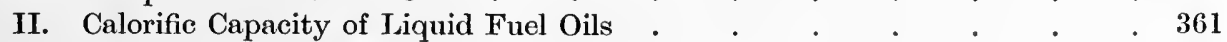

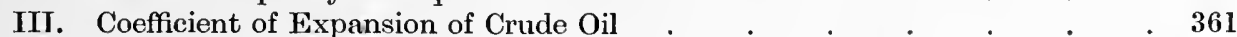

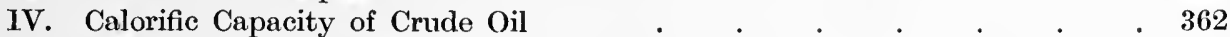

V. Table of the Properties of Gases (Kempe) . . . . . . To face 360

VI. Temperature Table . . . . . . . . . . 362

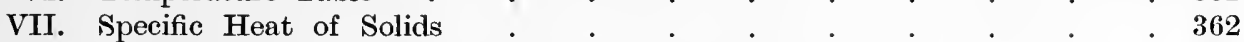

VIII. Specific Heat of Gases . . . . . . . . . . . 362

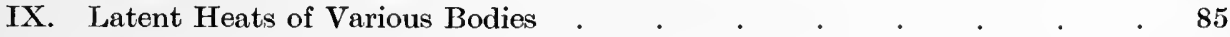

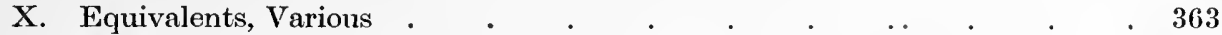

XI. Calorific Properties of Carbon . . . . . . . . . . . . . $\quad . \quad 363$

XII. Tension of Aqueous Vapour . . . . . . . . . . . . . . $\quad .363$

XIII. Volume of Gas before and after Combustion and Absorption . . . $\quad$. 364

XIV. Calculated Gas Densities and Weights per Litre . . . . . . . . 364

XV. Relative Economy Oil and Coal . . . . . . . . . . . . . 364

XVI. Russian and Pennsylvanian Oils, Analysis of . . . . . . . $\quad$. 365

XVII. Comparative Trials of Petroleum Refuse . . . . . . . . . 365

XVIII. Seventeen Trips with Petroleum Refuse. . . . . . . . . . $\quad 366$

XIX. Comparative Tests, Different Fuels . . . . . . . . . . 367

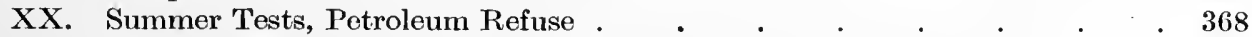

XXI. Summer Tests, Petroleum Refuse, Comparisons with other Fuels . $\quad 368$

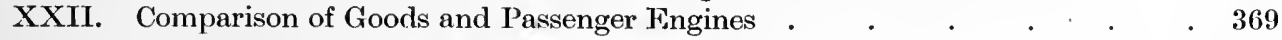

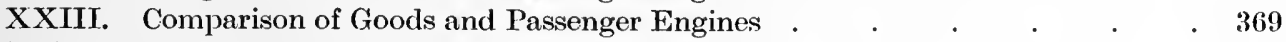

XXIV. Cost of Altering Engines to burn Liquid Fuel . $\quad . \quad$. . . . . $\quad .370$

XXV. Cost of Fuel and Repairs . . . . . . . . . . . . . 371

XXVI. Working Cost per Axle Mile . $\quad . \quad$ • . . . . . . . $\quad$. 372,373

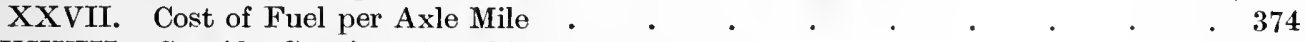

XXVIII. Specific Gravity, Astatki . . . . . . . . . . . $\quad .375$

XXIX. Cost of Evaporating 1000 lbs. of Water, Coal . . . . . . . . $\quad 375$

XXX. Cost of Evaporating 1000 lbs. of Water, Oil . . . . . . . . . $\quad$. 376

XXXI. Conversion Table, Degrees Baumè . . . . . . . . . $\quad$. 377

XXXII. Air Required for Perfect Combustion . . . . . . . . . . . $\quad$. 377

XXXIII. Heat of Combustion (B. Th. U.) and Air per Pound of Fuel . . $\quad . \quad 378$

XXXIV. Theoretical Flame Temperatures . . . . . . . . . . . $\quad$. 378

XXXV. Weight and Volume of Gases . . . . . . . . . . . 378

XXXVI. Composition of Gases by Weight and Volume . $\quad$. $\quad$. . . . . $\quad$. 378

XXXVII. Weight and Volume of Oxygen and Air for Combustion. Metric . $\quad 379$

XXXVIII. Weight and Volume of Oxygen and Air for Combustion. English $\quad . \quad 379$

XXXIX. Heat of Combustion of Gases by Weight and Volume . . . . $\quad 380$

XI. Specific Heat of Gases Referred to Water . . . . . . . . 380

XLI. Specific Heat of Gaseous Products of Combustion . . . . $\quad 380$

XIII. Specific Heat of Water . . . . . . . . . . . $\quad 380$

XLIII. Theoretical Evaporative Value of Petroleum and Coal . . . . $\quad . \quad 381$

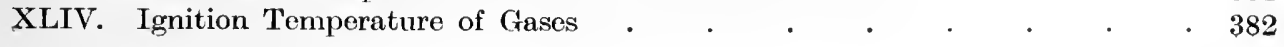




\section{INDEX TO TABLES}

TABLE PAGE

XLV. World's Petroleum Produetion . . . . . . . . 382

XI,VI. Conversion Tables for Evaporation and Combustion . . . . . 382

XLVII. Specific Gravities (various materials) . . . . . . . . . . $\quad .383$

XLVIII. Water Column due to Chimney of 100 feet . . . . . . . $\quad 383$

XIIX. Temperature Determination by Fusion of Metals . . . . . . . $\quad .383$

I. Air Required for Combustion . . . . . . . . . . . . $\quad . \quad 384$

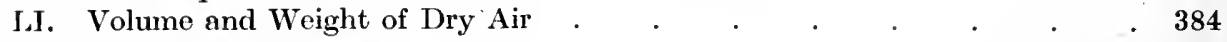

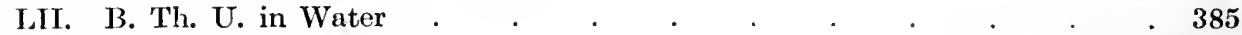

LIII. Saturated Steam Data. . . . . . . . . . . 385 et seq.

IIV. Factors of Evaporation . . . . . . . . . . . . . . . $\quad 388$

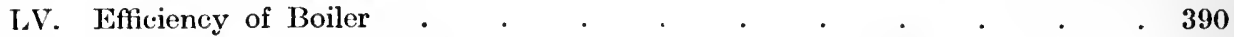

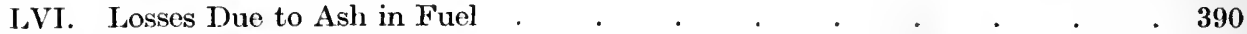

LVII. B. Th. U. in Moisture . . . . . . . . . . . . . $\quad$. 391

LVIII. Heat Balance Table ..$\quad$. $\quad . \quad$. . . . . . . $\quad$. 392

I.IX. Heat Lost in Chimney Gases (Diagram) . . . . . . : . $\quad$ : 393 
Part I

THEORY AND PRINCIPLES 


\section{Chapter I}

\section{HISTORICAL AND GENERAL}

7 HE history of liquid fuel need hardly be referred to, for it is of slight value 1 unless to confirm the generally accepted opinion of to-day, that the only satisfactory system of supplying liquid fuel is to reduce it to fine spray-to atomize it, in fact, in terms of to-day.

A paper by Mr. Aydon was read before the Institution of Civil Engineers on February 26, 1878. ${ }^{1}$ Aydon's own work was good, but the knowledge and ignorance of the period are plainly evident both in the paper itself and in the discussion. Especially is the latter feature prominent in the erroneous assertions of some regarding the conversion into valuable fuel of the steam which is employed to effect spraying. Thus there will be found seriously put forward evaporative duties of 18.38 and 19.5 pounds of water per pound of oil. Later on 25.8 pounds of evaporation are claimed, then an evaporative efficiency of $25 \cdot 2$ pounds observed is very properly stated to be equivalent to an evaporation from and at $212^{\circ} \mathrm{F}$. of 28.9 pounds of water per pound of steam. Reduced to B.Th.U. this represents 27,938, yet nowhere does it appear that liquid fuel had been found to possess a calorific capacity greater than it is known to possess to-day. All claims in excess of this appear to be attributed to the burning of the steam which is supposed capable of dissociation by means of less energy than it will produce when burned. Indeed, one contributor to the discussion strenuously claimed 46 pounds of steam per pound of oil plus one pound of steam, an altogether impossible disappearance of feed-water by evaporation, only to be explained by priming or possibly by a badly leaking blow-out tap. Suffice it to say that this paper raised a discussion so full of error and misconception, and generally so opposed to the doctrine of the conservation of energy, that it is of small value as a contribution to exact knowledge and only worthy of notice as a curiosity, except so far as its illustrations show what had been done to burn liquid fuel prior to the system of atomizing, which alone remains to us as fitted for heavy oils.

Unfortunately, however, there are still those who have not discarded the idea of burning steam. The idea still obtains hold that a jet of steam, dissociated by the heat of the furnace, will burn with a resultant heat production greater than the energy absorption of dissociation. It may very properly be argued that steam is a better agent than air to effect the atomization of the oil ; it is claimed that hydrocarbons will actually burn better when in the presence of a small amount of moisture, the moisture acting as a carrier of oxygen to the hydrocarbons. Commercially it may be convenient, or even economical, to employ steam in preference to com-

${ }^{1}$ Vide Minutes of Proceedings Inst. C.E. vol. lii. p: 177 : 


\section{LIQUID FUEL AND ITS COMBUSTION}

pressed air as an atomizing agent, especially where the waste of fresh water is of no consequence. But there are good reasons to believe that air alone, preferably heated, is fully as good to use as steam, and onee for all it should be recognized that steam is not, and cannot be, a fuel, that already it is fully burned hydrogen, and as useless and impossible of use as fuel as a piece of quicklime or a heap of furnace slag. It is quite probable that twenty-five years ago, as to-day, the use of high pressure steam was found better than low pressure steam. This was simply because of its greater temperature on the one hand, and of its greater atomizing effect on the other hand. There was nothing chemical in its effect, and to-day hot air is so much better than cold air because it is hot.

It should be further noted in respect of the claimed duty of 46 pounds evaporation, that the claimant himself stated truly that "Sextane," one of the rarer hydrocarbons, the composition of which is $\mathrm{C}_{6} \mathrm{H}_{14}$, had an evaporative efficiency of only 28.72. The claim that steam was a fuel was as clear and unmistakable as it is erroneous. Particular attention has been drawn to this phase of the liquid fuel problem because mischief inevitably arises as the result of unscientific statements; and Aydon's paper has so frequently been quoted as authoritative that it has become looked upon as a classic. So mueh of the statistical work that it contains is impossible, that it, with the discussion it evoked, eannot be considered reliable in many of the figures that may be well within the range of probability, and must be dismissed as not furnishing information of serious value to-day, though in the discussion on the paper certain speakers pointed out the errors to which attention has been called above.

In all fresh departures it is of course inevitable that many workers in the field will be men who, while possessed of great energy, and patience, and determination, are yet but poorly equipped in scientific knowledge even of the most elementary order. Many things are done which do not commend themselves to men of better information, and a long process of quite unneeessary trial and error is gone through. Sometimes, after needless expense, suecess is attained, but frequently after a discouraging expenditure of capital which renders the capitalist unwilling to incur further expense even on the very threshold of success. Too often failure alone results. So it has been with liquid fuel. Many past attempts have failed for want of elementary knowledge, combined with claims of impossible achievement which are not fulfilled in practice and result in disappointment.

The first really practical and efficient employment of liquid fuel to locomotives for steam-raising purposes appears to be due to Mr. Thomas Urquhart, of the Grazi and 'Tsaritzin Railway of Russia, to whom the writer is indebted for information. Mr. Urquhart used the spraying system and obtained good results, and his paper of $1884^{1}$ marks the beginning of the period of really useful work.

The application of liquid fuel in the Caucasus owes its sueess to a combination of causes. Russian petroleum has less light oil in its composition, and therefore produces more astatki, i.e. mazut or residuum; coal is dear in the district, and the man was present in Mr. Urquhart to render the application of liquid fuel successful, previous applications not having proved so.

Mr. Urquhart placed the use of liquid fuel on so sound a basis that his system has naturally reccived considerable attention in what follows, and many of his tables have been reproduced.

${ }^{1}$ Institution of Mechanieal Engineers, Minutes of Proceedings. 1884. 


\section{HISTORICAL AND GENERAL}

The Chicago Exhibition in the early nineties gave great impetus to the use of liquid fuel in America, for all the boilers there were arranged with oil fuel only.

In Great Britain the use of liquid fuel has not been extensive, but it has been marked by good practice and only bids fair to become extensive since the introduction of Texas oil. Previously the tendency had been to use the products of distillation of eoal or oil in the shape of tars or creosotes.

To-day liquid fuel is well established and recognized as a fuel of extreme elasticity, and one that can be burned smokelessly. It is realized that the days of experiment are past, and that no serious difficulties now remain to be overcome.

At the same time the question must be considered from a conservative standpoint, because at present and for years to come the output of petroleum will not be sufficient to make liquid fuel a serious rival of coal in every use of fuel. There is no knowledge of the possibility of extensive petroleum production in even the distant future. Petroleum wells do not endure indefinitely. They are not like artesian water wells, fed from surface rainfall, and chemists cannot assure us that they are being fed in any case from still deeper sources, nor is it decided whether petroleum is of mineral or of organic origin. The future of petroleum is thus more or less uncertain.

\section{General Considerations}

A general idea of the liquid fuel problem should therefore be obtained before attempting to gauge its merits. The Author's summing up of the question in the Electrical Review is abstracted in what follows.

There is a very considerable lack of the sense of proportion in many who discuss the question of liquid fuel without a sufficiently full knowledge of facts.

In Great Britain alone over 200 million tons of coal are raised each year. In the United States the amount is still greater. The present production of mineral "oil is a mere fraction of the 773 millions of tons of coal produced in the world. There exists among those who have oil to sell a habit of raising prices so soon as a demand has been ereated. Such an instance recently oceurred where a prospective oil user, who had based his calculations upon a price of $32 s$. per ton, found that he was expected to pay $65 s$.

Similarly, when Holden's system was applied to some South American locomotives, the price of oil was raised as soon as all the engines were known to be fitted. In that instance the sellers reckoned without their host, and in ignorance of the mechanical details of the system, and felt much aggrieved when the engines all ran out on coal alone.

Liquid fuel has undoubted advantages in many cases, and probably nowhere could it be used to better advantage than in an electric light station.

One of the principal advantages of oil is its high calorific value per pound. This, with the best oils, is double the capacity of the inferior coals, and 30 per cent. better than the best coal. The ease with which it ean be stored and moved from point to point is an advantage. - It can be fired mechanically, makes no ash or clinker, can be burned at maximum rate or entirely turned off in a moment. Further, a very large power of boilers requires very little labour in the stokehold.

Petroleum consists of a very large variety of constituents ; these are gaseous, liquid, or solid. The gas is marsh gas, $\mathrm{CH}_{4}$, and at once disappears; the lighter liquids are very volatile, and finally there are solid bodies at the end of a long series of liquids of varying degrees of volatility and specific gravity. 


\section{LIQUID FUEL AND ITS COMBUSTION}

The chemical formulæ which cover most of the constituents of petroleum are $\mathrm{C}_{n} \mathrm{H}_{2 \mathrm{n}}$ and $\mathrm{C}_{\mathrm{n}} \mathrm{H}_{2 \mathrm{n} \pm_{2}}$. These formulæ continue throughout the whole range from marsh gas, $\mathrm{CH}_{4}$, onwards.

The Texas oil is used chiefly as it is found.

The Russian oil is used in the form of astatki or residuum, the proportion left after distilling off the lighting and lubricating oils. Much of the American oil is also used in the form of residuum.

The proportion of carbon in all the liquids used as fuel varies very little from 84 per cent., the hydrogen amounting to 16 per cent. There is little else, so that petroleum is practically all combustible.

It may be laid down as a well established fact that there is at present only one way to burn liquid fucl for steam raising, and that is by atomizing the fuel in company with a sufficient amount of air around each atom. In order that the oil may atomize freely, it should be deprived of its viscidity. This is readily done by heat, and brings with it the further advantage that any water in the oil more easily separates out of hot oil than cold oil, first, because the heated oil, being more limpid, offers less resistance to the freeing of the water ; and secondly, there is greater expansion of oil than of water due to the heat, and the water gains a relatively greater specific gravity.

Warming is done by means of a steam coil, and it may be merely local warming in the vicinity of the take-off valve in the tank. It is essential that water be fairly well separated, because if it comes through the burners in any quantity it may extinguish the fires, and the next following oil is apt to ignite very explosively.

In storing oil there is always apt to be some vapour given off, and an empty tank ought not to be entered with a light.

Though not nominally of double the calorific capacity of average fair coal, oil is found in practice to be worth double the price of coal; owing to the labour cost which it saves.

This is as regards marine service, for the oil can be carried in ballast tanks, and paying cargo is carried in the coal bunker space.

For land purposes, of course, these latter considerations do not weigh, and the relative value must be placed on the performance ratio of about 16 to 10 , together with the economy of labour, cleaning, ash cartage, etc.

Above and beyond all these things, however, is the power which liquid fuel gives of immensely increasing the steam-production of a boiler at short notice.

In general practice a steam-boiler is designed with a given ratio of heating surface per unit of fuel burned. Any reduction of this ratio is accompanied by a poorer performance. Less steam is produced per pound of oil consumed. A reduction of the heating surface ratio does not, however, reduce the performance by anything like the same ratio.

If a large demand for steam is made upon a boiler for a short fraction of its working hours, it may be cheaper to consume fuel at a high rate for a fraction of the time than to employ two or even three boilers at normal rates during a fraction of the day, the extra boilers remaining idle during the rest of the day; albeit when the heavy load is past these extra boilers are retired hot and full of energy. The saving by the first method is very considerable in respect of space occupied, buildings and capital cost generally, and if not carried too far it will outwoigh the fuel cost of the short run at heavy output.

For this system of working, coal can, of course, be employed. Coal, however, 


\section{HISTORICAL AND GENERAL}

cannot be fired at abnormal rates with special ease. A mechanical stoker does not readily increase its rate of working. The better forms of stoker-on the coking principle-find it very difficult to put their whole grate surface into the new and forced condition. The sprinkler class, again, do not work so well at abnormal rates. Coal combustion is only to be regulated by draught intensity. With oil the supply is instantly variable to suit the steam required, and a boiler can be rapidly put under its fullest output rate of work. With boilers of the small tube typc, especially, their small water contents enables the engineer to leave them standing cold to within a short time of maximum output. Oil is then turned on, and in a few minutes the boiler is in full work. When a boiler is already at work the mere turn of a handle puts it into its maximum steam-producing condition.

As soon as the demand ceases the oil can be turned off, and the normal coal fire continued, or the boiler laid off entirely. By means of liquid fuel great elasticity is possible.

In a lighting station the load factor is very usually about 12 per cent. That is to say, about one-eighth of the plant is, on the average, at work all the working hours.

This excessive misproportion is remedied to any desired extent by means of accumulators, but it is not yet commercially economical to instal so high a proportion of battery power as to enable the power-plant to run at steady load all day. The peak of the load, however short in duration, cannot be surmounted without the aid of power, and it is to the height and small duration of the maximum load curve that the poor load factor of a lighting station is due. Accumulators for heavy output of short duration greatly improve the load factor, but, in any case, the number of boilers at work to tide over the peak is several times the mean number.

If, by means of liquid fuel, boilers can be heavily pushed for two, three, or four hours, the capital outlay on boilers will be much reduced. When the various points are taken into account, the boiler scheme that will probably suggest itself will be, first some boilers of the Lancashire type, economical and stcady steamers ; secondly, large tube boilers with a moderate water contents and large grate area, and with efficient steam driers or superheaters. These boilers can be heavily forced with some sacrifice of economy, but the priming due to heavy forcing must be eliminated by a good superheater. This is essential to economy. Thirdly, small tube boilers of very small water capacity, capable of being heavily forced, delivering their steam preferably above water level in the steam drum. If all these boilers are fitted with oil sprayers, the maximum demand for steam will be met with the minimum of capital outlay.

It is a common fallacy to suppose that boilers of small water capacity respond most readily to a sudden demand for steam. The claim is, it is true, often made for water tube boilers. Nothing could be more erroneous.

When a boiler is at work under full pressure, the whole of its water is at a temperature which corresponds with the pressure. 'Any addition to the furnace activity cannot add to the heat contents of the boiler, unless the pressure is allowed to rise; obviously, therefore, given the continuance of the same pressure, the boilers of large water contents will answer to an urged fire just as rapidly as a boiler of small water contents. When boilers are standing at rest, however, and cold, the boiler which contains the least water will, ceteris paribus, become most quickly hot. Such a boiler as, for example, the Solignac, which holds almost no water, can be made, by aid of oil fuel, to produce its maximum power in a few minutes after lighting up. 


\section{LIQUID FUEL AND ITS COMBUSTION}

In this respect oil has a very decided advantage over solid fuel. To secure a good fire with solid fuel there must be a thick bed of incandescent fuel on the grate, and this can only be built up with comparative slowness, and when its duty is over it remains a more or less wasted force. With oil, however, the maximum fire is instantaneous, and the only drawback is the cold brickwork of the setting, which must become hot before the maximum furnace duty is attained.

For ordinary economical work the number of heat units that a boiler can absorb per square foot of heating surface will not be changed when liquid fuel is employed, except so far as liquid fuel can possibly be burned without smoke more easily than solid hydrocarbons, such as coal, and that thereby the heating surface is maintained clean and free from dust and soot, and therefore more efficient. But mere evaporative efficiency must not be allowed to outweigh the overall, or commercial, efficiency. Exactly what governs the relation between evaporative and commercial efficiency cannot be stated positively. Indeed, commercial efficiency alone should be considered as the true basis of design. It may, however, be stated in general terms that plant which is on duty for long hours may probably be designed to work more economically as regards fuel than plant intended to work very short hours.

Let it be assumed that the boilers which are economical of fuel have an efficiency of 72 per cent., and that the small highly pushed boilers are run at 60 per cent. efficiency for three hours.

Then, in course of a year, coal is wasted which represents 12 per cent. difference of efficiency lost for three hours daily.

To enable this loss to be avoided there would be so many thousands of pounds extra capital cost in boilers, buildings, etc., and where oil is not employed, so much more labour cost as compared with oil. Properly equated at a suitable rate of interest and depreciation, the relative value of the alternative systems may be found after the manner of the Kelvin law applied to cable work. In many stations the extra labour for the heavy duty period must be difficult to arrange satisfactorily. Men are probably employed more hours than they really work, and where it may be best to use coal for 10 hours, the labour cost may make it cheaper to use oil for 4 hours of a peak load, even if, in mere fuel cost per unit, the oil is more expensive. Recent trials with liquid fuel show that there is still much to be done in reducing the air supply. The air required to burn 1 unit weight of carbon is $11 \frac{1}{2}$ units. An ordinary oil fuel requires fully 15 units with, of course, some additional excess as with solid fuel. But with oil fuel there ought to be better mixture of air and fuel, and therefore better combustion with less excess of air.

If we regard air as the fuel and coal or oil as the sustainer of combustion, as we have a chemical right to do, we shall arrive at the conclusion that, approximately, the calorific value of a fuel in actual duty done will not differ much from the chemical ratio of air required in the combustion process. The large amount of air per pound of oil arises from the large percentage of hydrogen in the oil, and it is the large capacity for oxygen possessed by hydrogen which renders the theoretical temperature of combustion so nearly like that of carbon, in spite of the high calorific capacity of hydrogen.

As regards the production of petroleum, that of the United States in the year 1901 was $69,389,194$ barrels, valued at $66 \frac{1}{2}$ million dollars. If each barrel is assumed to contain $360 \mathrm{lb}$., or say 6 barrels per ton, the total tonnage will be 11,565,000, and the value therefore, something under $23 \mathrm{~s}$. per ton, or practically $\$ 1$ per barrel. 


\section{HISTORICAL AND GENERAL}

Thus the weight of oil produced in the United States is about 5 per cent. of the weight of coal, or say $7 \frac{1}{3}$ per cent. of the calorific capacity. After the removal of the lighting and lubricating oils, the amount of fuel oil remaining will be quite small as compared with the coal output. It may be assumed that the total oil production of the world is not five per cent. of its coal production. Any idea of entirely displacing coal must be out of the question, unless the yield of oil be increased beyond any present prospects, and the use of fuel must therefore be undertaken with common sense caution, and not in any wholesale manner, to the expected exclusion of coal.

At the same time, when the limitations of the subject are recognized, it cannot be denied that liquid fuel lends itself to certain conditions as to steam raising which must render it extremely valuable and of great convenience. Marine work and electrical work are, par excellence, the two lines along which liquid fuel appears likely to advance most successfully, and in the Author's opinion steam-driven motor cars will eventually discard the dearer oils and employ the heavy oils and residuum as fuel by means of atomizers. According to present appearances the motor car or tractor offers one of the finest fields for the use of the heavy fuel oils as distinguished from the petrols or even the cheap lamp oils, such as are already used on steam cars and referred to in Chapter XXIII. Little has perhaps yet been done in this direction, but Chapter XXII. contains a slight reference to the use of heavy liquid fuels by means of the atomizing system, which alone appears likely to lead to success. 


\section{Chapter II}

\section{THE ECONOMIES OF LIQUID FUEL}

$I^{\top}$

$\mathrm{N}$ considering the application of liquid fuel every case must be taken by itself and the costs evaluated. In favour of oil there is, first, the ease and rapidity with which a liquid can be taken into store and delivered to the bunkers of a ship or the tank of a locomotive. Next there is the economy of labour, which may be almost nil in case of a single boiler with one attendant to the engine and boiler, or it may be very great where there are many boilers.

The superior calorific power of oil must then be equated with the price, and the cost per unit of evaporation found from this.

The removal of cinders and ash may or may not be a matter of cost according to the demand for them locally.

Liquid fuel possesses great elasticity of use and fits well with sudden and varied demands for power. Hence its value in railroad work, electric light work, and other power stations where loads vary greatly.

Where the mixed system is employed, as with the Great Eastern Railway, the mere question of economy, as based on the actual weight of fuel consumed, is to be found as follows:

A locomotive consumes $N$ units of coal per unit distance. When running with coal and oil, it is found to consume ( $M$ units of coal.

$$
O \text { " , oil. }
$$

The price of coal is $y$; of oil $x$ per unit.

$$
\text { Then } O \times \frac{x}{1000}+M \times y \leqslant N \times \frac{y}{1000} \text { or } x \leqslant \frac{y}{O}(N-M)
$$

The cost of oil is largely a matter of carriage. What costs three francs $=2 s .6 d$. per ton at Baku costs 185 francs $=£ 78 s$. 6rl. in France. The difference of 182 francs is made up of railway and sea carriage, handling, customs, warehousing. 'The customs stand for ninety franes, so that the same oil at an English port should not cost over $£ 316 s$.

American residues cost five to six francs more than Russian mazut, whence MM. Colonner and Lordier, who give the above figures, dismiss oil as an economical fuel pending the reduction of the tariff.

On the Southern Pacific Railroad the relative evaporation of oil and coal is $365: 274$ or 33 per cent. in favour of oil.

On the International and Great Northern four barrels of oil proved more than equal to a ton of coal, and at $12 s .6 d$. per ton and $2 s .4 d$. per barrel the economy of oil was 13 to 14 per cent. including the economy of handling and storing. The 


\section{THE ECONOMIES OF LIQUID FUEL}

only application of liquid fuel in Austria, despite its proximity to oil fields, is in the Arlberg tunnel. But the Austrian Government are also coal owners, and so also are other Austrian railroads and steam navigation companies and possibly do not encourage oil fuel.

To produce 1,000 units of steam, coal gives out more carbonic acid than oil, though of course the oil destroys quite as much oxygen and reduces the life-supporting power of the air to probably equal extent. So long as combustion is perfect and no actual poisons are made there is not much to choose between the two fuels beyond their sulphur contents. As regards the safety of oil it has been shown that oil with $117^{\circ} \mathrm{C} .=239^{\circ} \mathrm{F}$. flash-point did not ignite if fired at with shell, nor did dynamite exploded in a reservoir of this oil do more than throw up jets of oil which did not ignite.

Any danger with liquid fuels is with the oils which have not parted with their inflammable and volatile gases. This is a danger with oils when used absolutely crude. Purged of these portions, however, oil is safe, and, moreover, unlike coal, it contains no power of spontaneous combustion. Though it is claimed by some that oil does not deteriorate if kept in tanks, others do claim that a certain deterioration is produced which renders it difficult to atomize, the oil becoming more thick and viscid.

In Russia circular atomizers are often employed which give out a large hollow flame. 'The Béreznef atomizer, fig. 101 , is one of these. They have the disadvantage of being out of reach in the middle of the fire of a locomotive, and they become burned also through being in such close contact with the flame.

Steam enters below the central disc and oil flows under a head of two to three metres on the upper side of the disc.

\begin{tabular}{|c|c|c|c|c|c|}
\hline \multirow[b]{2}{*}{ DATA } & \multicolumn{5}{|c|}{ NO. OF TEST } \\
\hline & $\begin{array}{l}1 \\
3 \text { atomizers } \\
\text { Béreznef }\end{array}$ & $\begin{array}{c}2 \\
4 \text { atomizers } \\
\text { Kroupka }\end{array}$ & $\begin{array}{l}3 \\
1 \text { atomizer } \\
\text { Béreznef }\end{array}$ & $\begin{array}{l}\text { 4 } \\
3 \text { atomizers } \\
\text { Béreznef }\end{array}$ & $\begin{array}{l}5 \\
\text { 3 atomizers } \\
\text { Baschinine }\end{array}$ \\
\hline Duration of trial. Hours & $12 \mathrm{~h}$ & $10 \mathrm{~h} 30$ & $10 \mathrm{~h} 30$ & $7 \mathrm{~h}$ & $9 \mathrm{~h}$ \\
\hline $\begin{array}{l}\text { Total kilos. of oil consumed } \\
\text { Mean boiler pressures in atmo- }\end{array}$ & $2 \cdot 193 \mathrm{k}$ & $795 \cdot 7$ & $1 \cdot 104$ & $1 \cdot 183$ & $1 \cdot 183$ \\
\hline spheres . . . . . . . & $4 \cdot 5$ & $5 \cdot 0$ & $4 \cdot 5$ & $5 \cdot 0$ & $4 \cdot 75$ \\
\hline Mean temperature of feed water . & $41^{\circ} \mathrm{C}$ & $38^{\circ} \mathrm{C}$ & $46 \cdot 6^{\circ} \mathrm{C}$ & $19 \cdot 2^{\circ} \mathrm{C}$ & $20 \cdot 2^{\circ} \mathrm{C}$. \\
\hline Litres of water fed to boilers. & $31 \cdot 096$ & 11.912 & $16 \cdot 232$ & $16 \cdot 284$ & $16 \cdot 832$ \\
\hline $\begin{array}{l}\text { Kilograms of water fed to boilers. } \\
\text { Kilograms of steam produeed at }\end{array}$ & $29 \cdot 140$ & $11 \cdot 122$ & $15 \cdot 071$ & $15 \cdot 805$ & $16 \cdot 310$ \\
\hline $\begin{array}{l}\text { feed temperature } \\
\text { Kilograms of steam produced from }\end{array}$ & $14 \cdot 17$ & 14.9 & $14 \cdot 7$ & $13 \cdot 76$ & $14 \cdot 22$ \\
\hline Oil per hour per square metre of & $13 \cdot 28$ & $13 \cdot 9$ & $13 \cdot 65$ & $13 \cdot 36$ & $13 \cdot 78$ \\
\hline $\begin{array}{l}\text { grate surfaee. Kilos. } \\
\text { Steam per hour per square metre of }\end{array}$ & 0.987 & $1 \cdot 131$ & $1 \cdot 569$ & $1 \cdot 469$ & $1 \cdot 143$ \\
\hline grate surface. Kilos. . . & $13 \cdot 1$ & $15 \cdot 81$ & $21 \cdot 42$ & $19 \cdot 633$ & $15 \cdot 758$ \\
\hline (of feed water & $120^{\circ} \mathrm{C}$ & $85^{\circ}$ & $87 \cdot 3^{\circ}$ & $68 \cdot 9^{\circ}$ & $64 \cdot 6^{\circ}$ \\
\hline Temperature $\left\{\begin{array}{l}\text { of ehimney gas } \\
\text { of air above boilers }\end{array}\right.$ & $\begin{array}{l}132^{\circ} \mathrm{C} \\
27^{\circ} \mathrm{C}\end{array}$ & $\begin{array}{l}130^{\circ} \\
27^{\circ}\end{array}$ & $\begin{array}{c}139 \cdot 1^{\circ} \\
20^{\circ}\end{array}$ & $\begin{array}{l}90^{\circ} \\
27^{\circ}\end{array}$ & $\begin{array}{l}80^{\circ} \\
26.8^{\circ}\end{array}$ \\
\hline Atomizing steam per kilo. of oil. $\mathrm{K}$. & - & $0 \cdot 422$ & $0 \cdot 364$ & - & - \\
\hline Heating surface. Square metres & 185 & 60 & 60 & 115 & 115 \\
\hline
\end{tabular}

1 square metre $=10 \cdot 76$ square feet. Kilograms per square metre $\div 5=$ pounds per square foot nearly. 


\section{LIQUID FUEL AND ITS COMBUSTION}

The advantage of this form is said to be its constant output.

Too much mazut produces smoke, too much steam is wasteful. There is a certain fixed ratio of oil and steam to give the best result. The Issaïef atomizer, which resembles the Béreznef, will feed 50 to 100 kilos. of oil per hour (110 to $220 \mathrm{lb}$.), and it consumes nearly 0.4 kilos. $=88 \mathrm{lb}$. of steam at 4 to 5 atmospheres pressure per kilo. of oil $(2 \cdot 2 \mathrm{lb}$.). The table, page 11, is given by M. Keller, of Moscow, as the result of tests made with various atomizers.

M. Bertin, in dealing with the effieiency of liquid fuels, points out that a fuel containing 85 per cent. of carbon and 14 per eent. of hydrogen will consume the oxygen of 7.56 cubic metres of air to satisfy the carbon, and of 2.72 metres to satisfy the hydrogen, or $10 \cdot 28$ cubic metres in all. By adding 40 per cent. exeess of air, or 14.4 eubic metres $=18.7$ kilos. of air per kilo. of oil, then eombustion will be perfect and smokeless.

'The Author's own figure for the weight of air chemically necessary for the above sample would be 14.7 nearly, and 40 per cent. excess would inerease this to 20.56. M. Bertin's figure of 18.7 appears to represent about 27 per cent. air excess.

The theoretical temperature of combustion will be

$$
\frac{11000}{(18 \cdot 7+1) \times 0.23}=2480^{\circ} \mathrm{C} .=4496^{\circ} \mathrm{F} \text {. }
$$

If the gases leave the boiler at $300^{\circ} \mathrm{C} .=572^{\circ} \mathrm{F}$. the loss of heat will be $\frac{300}{2480}=12 \cdot 10$ per cent. of the total, which is equivalent to an increased efficiency of 6.65 per cent. as compared with coal. He further estimates a gain of 1.9 per cent. over eoal in the absence of ashes and their cooling (on board ships).

The efficieney of a boiler estimated at 75 per eent. for eoal beeomes 0.835 for oil firing or $0 \cdot 75+0.0665+0 \cdot 019=0.835$.

But good eombustion and utilization still further favour oil in the ratio $\frac{.835}{.65}=1.28=m ; m$ becoming then $r=1.20 \times 1.28=1.53$; the figure 1.20 being the chemical ratio of power of coal and oil. In Torpedo-boat No. 62 (French) M. Bertin, however, only obtained $m=1 \cdot 11$ and $r=1 \cdot 33$. The causes of the differenee are found in the nature of the flame of oil, which has less radiating power than the flame of coal, and the powerful effeet of the directly heated coal furnace is sacrificed, and to secure the same results an undesirable extension of heating surface would be necessary.

Secondly, the flame of oil is long if care be not taken suitably to arrange the burners. It may pass between the tubes and become extinguished, and the gases partly burned may even relight in the chimney. 'The chemical action and reactions of a burning spray of oil may be very much complicated by dissociation or even by exothermic formations which may delay heat production. Later when combustion beeomes aetive as shown by the light giving power of the flames it will be more or less rapid according to the perfection of air admixture and will last for a time $=t$, during which the jet, travelling at a high velocity, $v$, passes through a distance $L=v t$ which may be yards in length.

Thus the course of the gas must be long or it may escape too hot to the chimncy. Hence arises the necessity of cutting short the flame by early admixture and high temperature so as not to lose the benefit of the boiler-heating surface.

It is for this purpose that in most successful oil-burning furnaces the jet of 


\section{THE ECONOMIES OF LIQUID FUEL}

atomized oil is directed upon a brick obstruction of some kind so as to spread the flames and cause them to fill the furnace space and lick round the plate surface. Locomotive fireboxes may be studied, as in fig. 25, to show how this effect is secured before the gases escape to the small tubes.

General Principles of Iiquid Combustion.-A review of the wholc subject, in the light of chemical knowledge, of the claims of manufacturers and of users of liquid fuel enables us to state that successfully to burn a liquid it must be finely pulverized, to do which it must be heated sufficiently to destroy its tenacity and enable the spraying agent, air or steam, to tear it up and disperse it in a fine spray intimately mixed with air. The correct amount of air must be admitted to burn the liquid, and this is one of the advantages of employing air as the atomizing agent. Where sufficient air cannot be introduced with the fuel it must be admitted from below as through grate bars covered with broken bricks. Steam, preferably superheated, is undoubtedly the most convenient to employ as the atomizing agent, but on the salt seas it has the disadvantage of wasting from 3 to 5 per cent. of the steam made by the boilers, and this loss must be made good by evaporators. As with bituminous coal, which, like oil, is a complex hydrocarbon, liquid fuel should be burned in furnaces more or less protected from immediate loss of heat to the boiler surfaces by means of linings or baffles of firebrick. Iiquid fuel, however, is more easy to burn completely than is coal, because it can be more intimately mixed with the necessary air. The interior of a combustion chamber should show a clear white incandescence with little apparent flame and no smoke or unburned gases coming from the chimney. If looked into through a piece of violet-coloured glass, the interior of the combustion chamber with its brick linings should show a light lavender colour indicative of perfect combustion with the production of actinic rays indicative of high chemical action. A chilled fire, such as is produced where a boiler is placed close.upon the furnace of a coal fire will show very little light indeed through a violet glass, its flames being cut down from several feet in length to a few inches only in many instances, the flames of yellow and reddish intensity being resolved into streams of dun-coloured gas which throw off no light of sufficient actinic power to penetrate the glass.

Much difference of opinion exists in regard to the flash-point of the oil to be used. Crude oil is so widely different a product according as it comes from one or another locality that no rule can be laid down as to its safety or otherwise. Those crude oils, which, like the Pennsỳlvania oil, give a large proportion of gasolene and other volatile compounds are not used in their crude form because they pay better to refine, the heavier residuum being used as fuel and being much safer. 'The use of volatile liquids is only undesirable on the score of safety. Some of the crude oils, as for example those of the Beaumont field of Texas, contain so little of the lighter oils that they are used as fuel in their crude form. The one thing to note is that the more highly volatile oils have an element of danger from which the heavy oils are free, and this danger intensifies the results of every possible accident that may occur, especially those which arise from rupture of an overhead tank and the gravitation of the oil to lower points. The whole question is really very simple, and resolves itself into exactly the same conditions as the coal question, namely an intimate mixture with air in sufficient quantity and a proper conservation of the temperature pending full combustion. Fortunately for liquid fuels, these items are not only easy to realize, but, failure, when they are not realized, is far more disastrous and complete than in the case of solid fuels. Hence the really 


\section{LIQUID FUEL AND ITS COMBUSTION}

simple problem of burning bituminous coal has never been properly solved except in a few cases. At the same time it is perfectly easy of solution, but if not solved it does not produce the same bad effeets as does the faulty combustion of liquid fuel. In regard to this question, the Author would like to point out that, where coal is burned in a refraetory furnace, it should be capable of burning perfectly, with less excess of air, and coal ought to give results more nearly approaching its true value than it does do in ordinary faulty daily practice. Probably all the comparisons given in this book, exeept, perhaps to some extent, those of locomotives, are too favourable to liquid fuel, which is supplied with those essentials of perfect combustion that are withheld from coal by ignorance, cupidity or earelessness.

This question of refractory linings is essential, and it is secured in practice by bridge walls, overarching and, where fire-bars are left in place, by eovering these with broken firebrick or by whole bricks laid on edge.

It does not seem possible to introduce all the necessary air with the fuel. A chemical minimum of fifteen pounds of air is necessary to supply the oxygen for the average hydroearbon liquids, but probably at least 5 to 10 per cent. excess is required in the best practice, and this must come in below the oil spray and should not be introduced in a single large stream, but divided up into numerous fine streams through perforated plates or through a mass of broken bricks or loose laid brickwork. In fig. 33 is shown the arrangements of air admission at the floor of a watertube boiler furnace which is in the right direction. The Weir boiler, fig. 0 p. 107, is also suitably arranged for liquid fuel as regards the lining of the furnace and combustion-chamber. Where liquid fuel is used alone the fire-grate would be covered with bricks laid on edge or simply broken into pieces of 2 -inch eubes, and the atomizers would be arranged similarly to those of fig. 8. The general conditions that have been evolved are well shown in the various locomotive and stationary boiler furnaces illustrated in Part II.

In the Weir small water-tube boiler the sides of the $\Lambda$-shaped furnace are lined in firebrick blocks which are threaded upon the middle widely spaced tubes which form the walls of the furnace proper.

The first row of the main body of tubes is similarly protected to form a refractory wall for the combustion chamber. Thus both the furnace and combustion-chamber are fully refractory on two sides. Such a boiler as this can be worked with coal entirely, with oil alone, or upon the mixed system, the brick linings enabling combustion to be carried out with smokeless and economical perfection.

By means of sight-holes the furnace can be examined while at work and the admission of air gradually increased until the gases become clear, clean, brightly incandescent red, and the opposite end of the furnace shows up clearly. So long as there is smoke-formation the opposite brickwork cannot be seen. As soon as combustion is perfect it appears clear and bright red, and the air should then be gradually cut down in quantity until an oceasional streak of dark-coloured gas begins to show, thus proving that under the conditions of the furnace the air has then been reduced to a possible minimum.

Under the existing conditions of boilers it would appear that to insure smokeless combustion of liquid fuel, not more than 2 to $3 \mathrm{lbs}$. should be consumed per hour per cubic foot of combustion space. This will have considerable bearing upon the question of furnaces with or without fire-grates, the latter type more easily sccuring the requisite volume. The above figure may be borne in mind when considering the question of furnace dimensions, 


\section{Chapter III}

\section{LIQUID FUELS}

TNDER the term liquid fuel may be included every substance which is combustible and can be made liquid without serious difficulty. The list therefore includes-

1. Animal oils and fats, such as neatsfoot, whale oils, tallow.

2. Fish oils, such as shark and cod.

3. Vegetable oils, such as almond, linseed, rape, cotton.

4. The whole class of spirituous liquors distilled from fermenting starchy substances, such as the potato spirit so largely manufactured in Germany for industrial and motor car purposes.

5. Vegetable essential oils, as cajeput, eucalyptus oil, turpentine and other distillation products of wood.

6. Coal gas tar, creosote, coke oven tars, blast furnace tars, and the tar from oil gas manufacture and other products of the destructive distillation of fuels, including the more volatile naphthas.

7. Petroleum and other mineral oils found liquid in nature or distilled from bituminous shales.

The first five sections above enumerated may be at once rejected, not because of any unsuitability as fuel, but because, by reason of price and their greater value in the arts, they cannot compete with the products of classes 6 and 7 , which alone will be considered in this volume.

In a work of this nature, also, it would not be possible to take notice of all the uses of liquid fuels. Among the first five classes enumerated are many substances that are employed as fuel either in lamps or in motors or in the laboratory of the chemist. All these uses will be left out of consideration as well also as the consideration of those products. under heads 6 and 7 , which are employed similarly to those of class 4 in internal combustion motors. The contact point may be said to be drawn at the lamp oil series of petroleum products. The lighting paraffins are employed for the purpose of giving light in lamps; for producing power in internal combustion engines. as in the many forms of oil, as distinguished from petrol engines ; and also for steam-raising purposes, as in the burner of the Clarkson system. For the purposes of this book, therefore, liquid fuel includes the products under sections 6 and 7 which do not possess a volatility or refinement greater than those of the heavy paraffin series or lighting oils.

The crude mineral oils of course contain such volatile constituents, and may be used in their crude form, but usually the superior value of the distillates leads 


\section{LIQUID FUEL AND ITS COMBUSTION}

to these being first separated, the coarse residuum known as astatki or mazut being the oil so much used as fuel. Having been deprived of its more volatile, portions, it is rendered safer to carry and to use. 'Thus, apart from its use in steam generation for special purposes, refined petroleum will be excluded from consideration, and the term "liquid fuel " for purposes of this book will, with the above exception, be practically confined to the more or less thick and viscid products, such as tars and petrolcum residuum, or certain of the crude petroleums, such as the Texas oil, which is used undistilled.

The special inclusion of lamp oil, especially the low grades of oil which have no moral justification for use in lamps, is warranted by the special cases of the motor car, the steam canoe and the fire engine.

An expenditure of $£ 14$ per ton for fuel is not warranted except under special circumstances. Such a special circumstance exists in motor cars where the more dangerous petrol spirit at a higher price is replaced in the steam launch, and especially in the fire engine, where petroleum enables steam to be got up quickly, and the price of fuel need hardly be considered in such an emergency as extinguishing a fire which is being fed by very much more expensive stuffs than petroleum.

Liquid fuel has long been used for lighting purposes, being burned by means of fibrous wicks which bring the liquid into the centre of the flame by which it is vaporized. Tallow and other animal fats are made into candles and the solid fat is rendered liquid by the flame, which radiates sufficient heat downwards for this purpose. The liquid is then drawn up by the capillary action of the wick, vaporized and burned. There is always vaporization or its equivalent prior to combustion.

A liquid will not burn when cold, and cannot be ignited in mass. If heated to the point of ebullition and supplied with air, it will of course burn fiercely and uncontrollably. The art of burning liquid fuel consists in heating only the portion which is to be immediately burned and exposing it to contact with air. Unlike coal, it is not possible to burn it at many surfaces. A coal fire is made up of many pieces of coal, each burning over its whole surface. Liquid fuel will not lie on a grate in separate pieces. If, however, a layer of liquid were heated to vaporizing point, or nearly so, on a finely perforated plate, and highly heated air were forced through the perforations, the liquid would no doubt burn freely with strong flame, but the mass of heated liquid would be difficult to control. Hence in practice we arrive at those systems which employ a jet of air or steam to split up a stream of liquid into fine globules in presence of a sufficient supply of air. Each globule burns superficially and becomes heated by its own combustion and the general heat of the furnace, and this principle appears to be the best and most effective method of burning liquids. Indeed it is perhaps the best method of burning anything, first to reduce it into particles so fine that their bulk bears a small ratio to their surface area, whereby each particle is brought close to the air which it requires.

\section{Atomizing.}

The necessity for atomizing arises purely from the insufficient area of the fuel otherwise treated. A fire composed of lumps of coal is full of interstices, and the area of the fuel exposed to air is much greater than the area of the fire-grate. 


\section{LIQUID FUELS}

Liquid fuel cannot be burned on a grate because it would fall through the grate. It cannot be burned on a flat surface because, being liquid, it tends to flow together and presents only an upper surface to the air. The use of trough-shaped bars along which the liquid flows and through which streams of air are admitted does not get over the difficulty of small exposure of surface.

There is no incandescent mass through which air is flowing to carry off the fuel in a burned state and to maintain the mass incandescent. If the whole of the liquid mass in a furnace did become incandescent, or even approached that point, it would distil in the form of vapour, and, if provided with air, would burn away uncontrollably, probably with great evolution of smoke. The more easily combustible or volatile portions would disappear first and the remainder would probably be left over unconsumed. Thus if the fire is to be controllable, the fuel must be supplied as it is consumed, so that at no time is there any serious amount of burning fuel in the furnace and the production of steam is at once regulated by a simple regulation of the fuel supply. This end is secured by atomizing the fuel and discharging it into the furnace mixed with air, so that each atom of fuel is in contact with air, and combustion is easily effected. It will be found that with all the heavy liquid fuels atomizing is essential.

\section{Vaporizing.}

With lighter oil, as the cheap lamp oils used in steam motor cars, the liquid is supplied through a coil of pipe heated by the flame itself and is converted into vapour, which burns freely when mixed with air. With this oil it is not found that a deposit of carbon takes place in the retort coil, as would be the case with heavier oils. The lighter oils already prepared by distillation at a moderate temperature can thus be burned without atomizing, but, after all, their resolution into the form of vapour may be taken as the most complete form of atomization, and atomization is really a substitute for vaporization.

\section{Liquid Fuels Containing Oxygen.}

Glycerine $\mathrm{C}_{3} \mathrm{H}_{8} \mathrm{O}_{3}$, molecular weight 92 , might be used as a fuel if it were not of value in the arts. It only possesses about half the calorific capacity of carbon or 4,317 calories per kilo. $=7,770$ B.Th.U. per pound; being inferior to the alcohols.

The reason of this is that it contains, of the above weight of 92 , the elements of water to the extent of 54 , or say $58 \cdot 7$ per cent. of its total weight.

Alcohol $\mathrm{C}_{2} \mathrm{H}_{6} \mathrm{O}$ is another oxygenated compound which is coming into use for motor car work, for which its clean-burning quality and odourlessness renders it very suitable. For general steam-raising it is, of course, too costly.

\section{Varieties of Liquid Fuel.}

In nature liquid hydrocarbon is found both tree and absorbed. The free liquid is obtained by overtlow from boreholes put down to the oil-bearing stratum, or it is raised by pumping. When not free it is obtained by distillation from bituminous shales: The latter have been more employed for lighting or illuminating and lubricating purposes. The free oil or petroleum has gradually forced its way into consideration as a fuel, having been employed now for many years in Russia. In addition to the natural oils, there are many hydrocarbons formed in the arts 


\section{LIQUID FUEL AND ITS COMBUSTION}

which have a high value as fuel. Of these there is the tar of the gas-works, a black viscous liquid which separates out from the gas in the process of cooling. It is formed in the hydraulic main and in the pipe coolers and condensers. A somewhat thinner tar is produced in the condenser of oil-gas plant as a product of the destructive distillation of oil in the Pintsch gas process. Where blast furnaces are fed with coal in place of coke, tar is produced in the condenser pipes of the residuals plant, and in modern coke ovens a tar is also produced from the gas driven off the coal.

Crude petroleum contains many hydrocarbon compounds varying from the formula $\mathrm{CH}_{4}$ up to $\mathrm{C}_{11}, \mathrm{H}_{37}$, the general formulæ being $\mathrm{C}_{\mathrm{n}} \mathrm{H}_{2 \mathrm{n}}$ and $\mathrm{C}_{\mathrm{n}} \mathrm{H}_{2 \mathrm{n}+2}$ in an isometric series of many numbers. When subject to distillation some of the compounds are split up and certain compounds have been found to contain as much as 95 per cent. of carbon.

\section{American Petroleum Fuels.}

In the United States the oils principally sold for fuel purposes are the byproducts of crude oil : their gravity varies from $23^{\circ}$ Baumé to about $34^{\circ}$.

The oils of lower gravity are known usually under the name of Reduced Fuel Oil, and one of gravity 23 was found to analyze as follows-

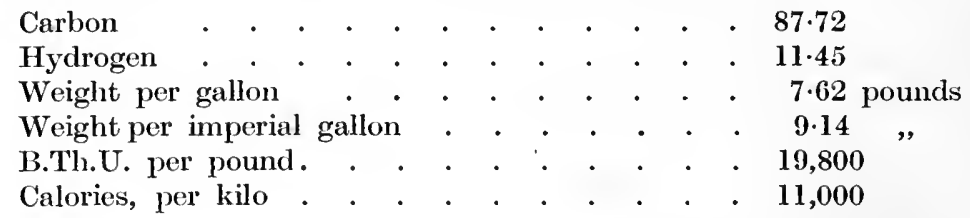

The oils of higher gravity are known as Distillate Fuel Oil, and one at the extreme end of the scale, or 34 Baumé, analyzed as follows-

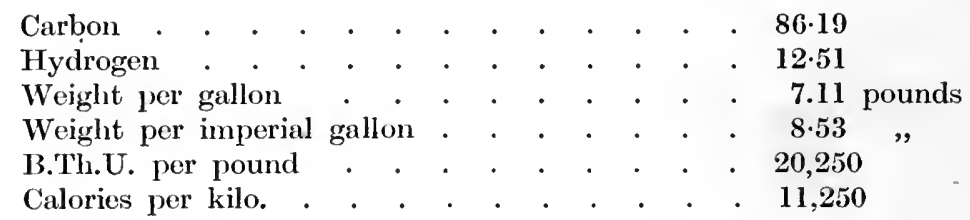

Oil being sold by the gallon and not by weight, it follows that an oil of 23 gravity contains 151,066 B.Th.U. and one of gravity 34 contains 143,988 B.T'h.U. per U.S. gallon.

'Thus the heavier oil possesses the greater calorific capacity per gallon. It would be better practice to sell oil by weight or to state calorific eapacities per gallon. Obviously for marine work the best oil is that which contains the greatest heat producing capacity per unit of volume, for this implies so much more efficiency of bunker capacity.

Approximately the two extreme oils named contain per imperial gallon (of 10 lb. water)-

$$
\begin{array}{cl}
\text { Gravity } & 23^{\circ} \mathrm{B}=181,340 \text { B.Th.U. } \\
,, & 34^{\circ} \mathrm{B}=172,870 \text { B.Th.U. }
\end{array}
$$

An average oil, therefore, will measure about one million B.Th.U. per cubic foot or $35,000,000$ units per 35 eubic feet of space. A ton of coal which occupies 
about 35 cubic feet contains about $33,000,000$ units of heat. In heat capacity, therefore, oil has the advantage over coal, quite apart from the fact that oil can be stored in small ballast tanks, and the coal bunker capacity of a ship can then be used for paying cargo.

\section{Texas and California Oils.}

These oils are used as they are found, that is to say, principally in crude form.

Determinations have been made of the calorific effect of a few of these crudes, and two are here subjoined-

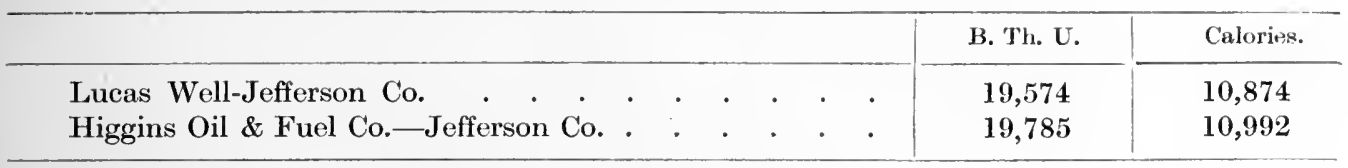

The above two wells are both in the Spindle Top district.

Texas oil is high in sulphur, containing this element to the extent of 2 per cent. It is said that no injurious effects are produced upon fire-boxes or boilerplates generally, and it appears rational that this should be so. The furnace products never pass away except at a temperature above that of saturated steam, and it appears unlikely that the dry hot furnace gases should condense to moisture on the boiler-plates, especially of highly heated high pressure boilers. Care is of course always necessary that furnace gases shall not make contact with any surface water cooled below $100^{\circ} \mathrm{F} .=38^{\circ} \mathrm{C}$. Otherwise corrosion may occur. Dry sulphur oxides, however, seem to be innocuous.

For forge purposes, however, high sulphur oils form a scale upon the metal and render it dirty. It is claimed, however, that except in special cases these oils may be used without difficulty. Iron when hot has so close an affinity for sulphur that sulphurous oils ought only to be employed with caution. The effect of sulphur is to render the metal red-short or brittle at a red heat, and it is liable to give rise to blown holes in cast iron.

The tables I, II, III, and IV are given by Mr. Boverton Redwood, whose works may be consulted in all that relates to the chemistry of petroleum, which is too wide a subject fully to be dealt with here.

Six thousand heat units are, states Dr. Engler, rendered latent in liquefying carbon, but this appears doubtful, for the conversion of solid carbon into gaseous carbon is not proved to render latent more than 5,817 B.Th.U. per pound, though Berthelot states that there may be a further amount which he denotes as $e$. It is improbable that the liquid form of carbon will absorb so much as 6,000 units. As regards water, the latent heat of liquid is only about one-seventh the latent heat of vaporization. Is it not probable that a considerable difference exists also in the case of carbon?

\section{Russian Petroleum.}

Russian oils may be said to be the inverse of the American oils, for while the latter contain about 25 per cent. of residuum the former contain 75 per cent. Mr. Redwood says that astatki or residuum varies from 35 to 60 per cent. of the crude oil, and is really the chief product of the Russian oils.

The specific gravity of crude petroleum, according to Mr. Redwood, varies from 0.771 to 1.020 and the following general values are given by him- 


\section{LIQUID FUEL AND ITS COMBUSTION}

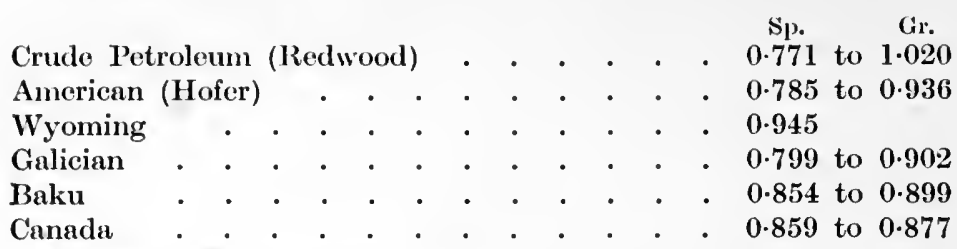

The percentage of residue in various oils is given as follows-

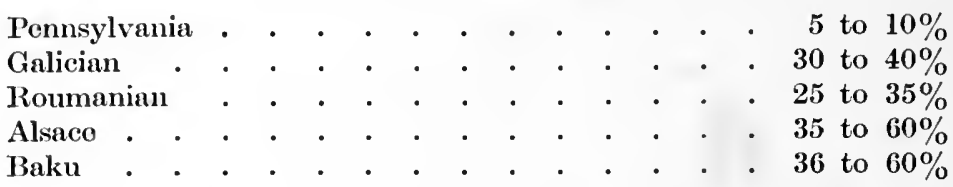

The composition of oil is thus very varied, and the newly-discovered fields of Texas yield oils which are much employed as fuel in their crude state.

\section{Creosote Oils.}

Properly speaking, creosote is that distillate from coal tar which is intermediate between crude naphtha and pitch.

It is sometimes called dead oil and heavy oil, because its specific gravity is greater than unity.

In a wider sense creosote oil is understood to include the heavier oils from bituminous shales as well as the liquid deposited from coke oven and blast furnace gases. The Scotch furnaces employ a hard bituminous coal as fuel, and much tar is collected from the gases. These various oils are all combustible, and though by no means properly called creosote, the distinction is not of importance as regards their value as fuel.

True creosote is probably too valuable as an antiseptic in wood preservation to allow of its very extensive use as fuel.

Coal tar creosote consists of that part of the tar which distils between $200^{\circ} \mathrm{C}$. and $300^{\circ} \mathrm{C}$., and includes various naphthalene bodies, etc. In colour it is yellow green and fluorescent. Its specific gravity is 1.10 to 1.024 according to quality, the London made oils being heavier than provincial oils, simply because London is supplicd largely with Newcastle coal, while country oils are from Midland coals of different quality.

As regards the constituents of creosote, the chief are naphthalene, carbolic acid and cresylic acid, and the composition of these bodies is as follows-

Creosote.

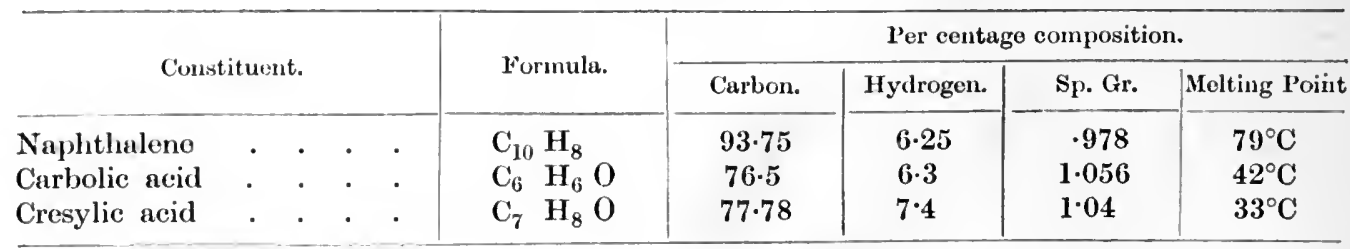

The forcgoing is a very brief and crude summary of the properties of creosote oils. Full information is to be found as regards the chemistry of the coal tar com- 


\section{LIQUID FUELS}

pounds in Vol. II of Allen's Commercial Organic Analysıs. The above will serve to show that these tar products are largely combustible.

Blast furnace oil has a specific gravity of 0.988 ; shale oil creosote is similar. Coal tar from gas works has a specific gravity of 1.10 to 1.20 and is very complex in composition. London tar contains from 2.5 to 8 per cent. of ammoniacal liquor, 0.5 to 3.4 per cent. of light oils, 17 to 23 per cent. of creosote and carbolic oils, 13 to 17 per cent. of anthracene oils, and 58 to 62 per cent. of pitch.

The distillates from coal, bituminous shale and wood all contain more or less oxygenated bodies. Coal and shale distillates contain some nitrogenized bodies. Petroleum, on the other hand, contains only hydrocarbons.

Shale tar has a specific gravity of 0.865 to 0.894 according to the method of retorting practised. It consists of a complex mixture of hydrocarbons of the paraffin order $\mathrm{C}_{\mathrm{n}} \mathrm{H}_{2 \mathrm{n}+2}$; of the olefin order $\mathrm{C}_{\mathrm{n}} \mathrm{H}_{2 \mathrm{n}}$ and of hydrocarbons $\mathrm{C}_{\mathrm{n}} \mathrm{H}_{2 \mathrm{n}-2}$ with some oxygenated bodies.

About thirty gallons of oil can be distilled from each ton of shale. 


\title{
Chapter IV
}

\section{TEXAS OIL}

\begin{abstract}
A CCORDING to the Bulletin of the University of T'exas, the production of oil $A$ in that State did not amount to as much as 100 barrels in any one year until 1896, when it reached 1,450 barrels. In 1897 there were 65,975 barrels; in $1898,546,070$; in $1899,660,013$; in $1900,836,039$; in 1901 , about $4,850,000$ barrels. The great increase in 1901 was due to the opening of the Beaumont field, the first well in which began to flow January 10 . Since that time and to the end of March, 1902, the Beaumont production has been about 9,000,000 barrels so far as can be now ascertained. The production to the end of 1900 was practically confined to the Corsicana field, Navarro county. In 1901 the Corsicana field produced about 850,000 barrels and the Beaumont field about 4,000,000 barrels. During the first quarter of 1902 the production in the Beaumont field was about 5,000,000 barrels, (a barrel holds 40 to 42 American gallons, or 33 to 35 English gallons approximately), exceeding by a million barrels the entire production of that field in 1901. As practically all the Beaumont oil comes into the market for fuel purposes, the 5,000,000 barrels produced during the first quarter of 1902 are equivalent to $1,250,000$ tons of coal, on the basis of four barrels of oil per ton of coal. Without taking into consideration the residuum from the refineries at Corsicana of the heavy oils from the Powell district in the Corsicana field, the fuel equivalent of the oil produced at Beaumont during the first three months of this year (1902) exceeds the entire coal output of the State in any one year. The tankage in the Beaumont district, taken at $4,890,000$ barrels, is equivalent to $1,225,000$ tons of coal. In other words, the quantity of oil that can be held in tanks in the Beaumont districts exceeds in fuel value the entire coal output of the State during any one year.

These figures mean that the industries of the State which are dependent upon cheap fuel have this at command, and that so long as the price of crude oil remains between twenty and twenty-five cents a barrel, f.o.b. tank ears, there is likely to be an active competitor in the fuel market. Some contracts let in the spring of 1902 called for the delivery of Beaumont crude oil at distanees of 250 to 300 miles for forty-four and a half cents a barrel, which would mean coal at $\$ 1.77$ a ton= 7s. 4d. Allowing that the average spot value of coal, i.e., f.o.b. mines, for the last eight years is $\$ 1 \cdot 75$, which is a close approximation to the actual figures, then four barrcls of crude oil are delivered at 300 miles from the wells for a price representing the value of a ton of coal at the mines, no allowance being made for transporting the coal to points of consumption. This would mean that the coal miner makes the




\section{TEXAS OIL}

consumer a present of the freight charges, or that the railroads distribute the coal gratuitously.

\section{Carriage of T'exas Oil.}

The Railroad Commission of 'Texas in 1901 established rates on crude petroleum in tank ears as follows-

\section{Commodity Tariff No. 27b-Crude and Fuel Petroleum, Carloads.}

Rates, in cents per 100 pounds for the transportation of carload shipments of crude and fuel petroleum, in cans (boxed), in barrels, or in tank ears, by railroads between points in Texas. Column No. 1 contains rates to apply on shipments transported over a single line of railroad, or over two or more lines of railroad which are under the same management or control. Column No. 2 applies to shipments transported over two or more lines of railroad not under the same control.

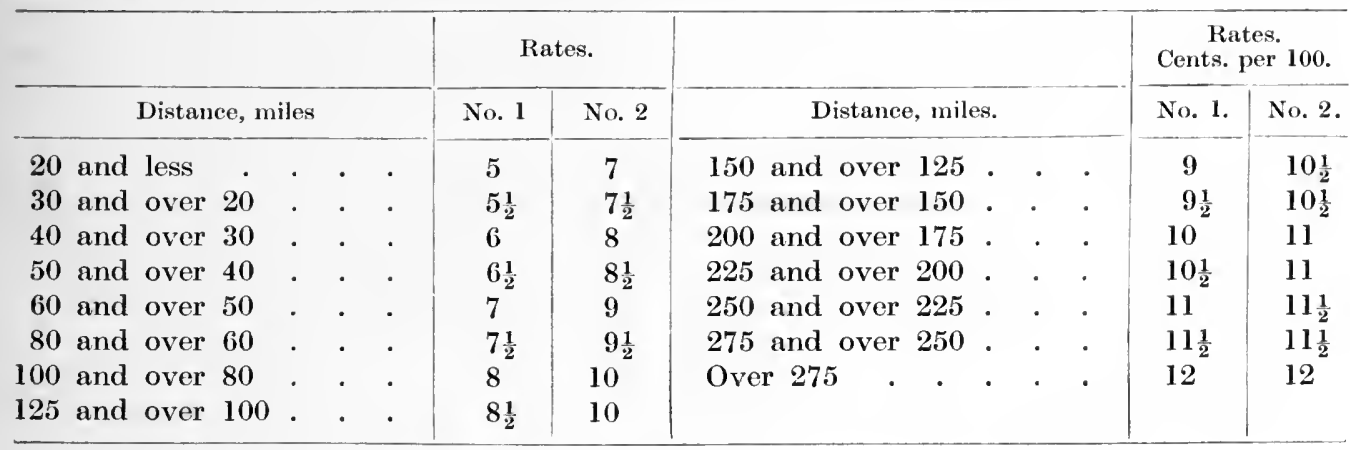

\section{Exceptions.}

Fuel oil, carloads, minimum weight 40,000 pounds per car, from Gladys to Beaumont, $2 \frac{1}{2}$ cents per 100 pounds.

Rates on shipments transported more than 275 miles from or to points in differential territory shall be made by adding to the maximum common point rate of 12 cents per 100 pounds the differential rates set forth in the following table-

Differential Rates, in cents per 100 pounds.

\begin{tabular}{|c|c|c|c|c|}
\hline \multicolumn{3}{|c|}{ Distance, miles. } & , & Rates. \\
\hline 50 and less & . & . & . & 1 \\
\hline 100 and over 50 & . & . & . & 2 \\
\hline 150 and over 100 & . & . & . & 3 \\
\hline 200 and over 150 & . & . & . & 4 \\
\hline 250 and over 200 & . & . & . & 5 \\
\hline 300 and over 250 & . & . & . & 6 \\
\hline Over 300 . . . & . & . & . & 7 \\
\hline
\end{tabular}

\section{Minimum Carloads.}

The minimum weight of shipments transported over lines of standard gauge shall be 38,000 pounds per car; provided that, when the actual weight of the petroleum contained in the car loaded to its full capacity shall be less than 38,000 pounds, then the actual weight of such shipments shall be charged for at the weight determined by the cars in which they were transported over lines of standard gauge.

The weight of $6 \cdot 4$ pounds per gallon shall be used in determining the carload weights above provided for. 


\section{LIQUID FUEL AND ITS COMBUSTION}

In Commodity-Tariff 17A the Railroad Commission of. Texas also established rates of "oil, petroleum and products, viz. coal, or carbon, benzine, benzole, petroleum (lubricating), naphtha and gasoline in tank cars furnished by shipper, straight or mixed carloads ; also in barrels and cases, and petroleum in glass (boxed) in jacketted cans or tin cans boxed, straight or mixed carloads." The rates are $2 \tilde{5}$ cents per 100 pounds from Houston and 28 cents from Galveston, maxima to 'Iexas common point territory. The Galveston rate applies also to Texas city, Velasco, Port Arthur and Sabine Pass.

Taking the weight of crudc petroleum as 6.4 pounds per gallon, this gives 5,937 gallons as the minimum carload weight for standard gauge lines. The weight of the 38,000 pounds is 19 tons of 2,000 pounds each. For transporting this quantity of oil, in tank cars, 100 miles over a single line of road or over two or more lines under the same management or control, the freight charge would be 8 cents $=4 d$. per 100 pounds, or $\$ 3.04=12 s$. $6 \mathrm{~d}$. per car. For transporting it 200 miles the charge would be 12 cents $=6 d$. per 100 pounds, or $\$ 4.56=18 s$. $6 d$. per car; for hauling 20 tons of coal 100 miles the charge is $\$ 1 \cdot 80=7 s .6 d$. ; 200 miles, $\$ 2 \cdot 80=11$ s. $6 d$.; 300 miles, $\$ 3 \cdot 80=15 s$. $6 d$.

This establishment of the rates on crude oils in tank cars was the result of a hearing before the Commission, August 3, 1901, at which were present the representatives of many of the oil and coal companies. Some relief was sought by the oil operators, and rates were fixed according to the testimony at that hearing.

\section{The Chemistry of T'exas Petroleum.}

In Bulletin No. 4, Contributions from the Chemical Laboratory of the University of Texas, Dr. Edgar Everhart gave the results of an examination of the Nacogdoches oil, the analysis having been made by Mr. P. H. Fitzhugh. The report says-

"The oil has a brownish-red colour. The odour is peculiar, but not so offensive as the crude petroleum of Pennsylvania. At ordinary temperature the oil is mobile, but not so much so as ordinary petroleum. Submitted to extreme cold the oil still retains its liquidity, but becomes less mobile. The temperature of the oil was reduced to less than zero (Fahrenheit) without it losing its flowing qualities.

"At no temperature attainable in the laboratory by artificial means could any solid paraffin be separated. The oil does not gum on exposure to the air. It is not adapted to the production of illuminating oil ; its value consists in its use as a lubricant.

"About four pounds of oil was subjected to distillation over the naked flame in a retort connected with proper condensers. The temperature was carried up to $680^{\circ} \mathrm{F}$. At intervals of $45^{\circ}$ each distillate was removed and its weight deter. mined. The results of the distillation were as follows-

\section{Analysis of Nacogdoches Oil.}

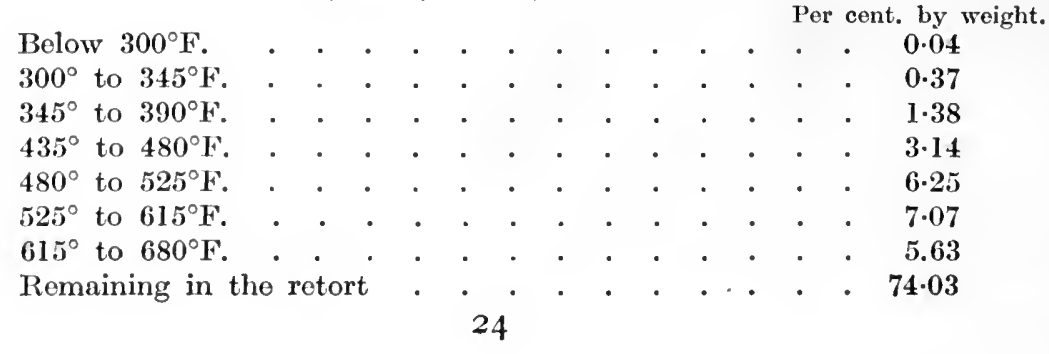




\section{TEXAS OIL}

"A consideration of the above figures shows in the first place that the crude petroleum of Nacogdoches is practically free from naphtha, which distils off below $250^{\circ} \mathrm{F}$. Four pounds of this oil carried to a temperature $50^{\circ}$ higher vielded only a few drops of a light oil, amounting to 0.04 per cent. of the total amount taken. In the Pennsylvania crude pretoleum the illuminating oil comes off between $250^{\circ}$ and $500^{\circ} \mathrm{F}$., and, on an average, amounts to about 55 per cent. The Nacogdoches petroleum between the same degrees of temperature yields only a little over 7 per cent. Three-fourths of the oil does not boil until a temperature above the boiling point of mercury is reached. Above $400^{\circ} \mathrm{F}$. and even lower the distillate is not pure white, but is somewhat coloured. This colour deepens on exposure to the atmosphere. The distillate exhibits a beautiful fluorescence. Attempts were made to render the distillates colourless by refining them with oil of vitriol, etc., as is done with ordinary petroleum, but the results obtained were not satisfactory. Some of the crude oil was subjected to distillation until but a small residue was left in the retort. This residue had the consistency of thick pitch, and was of a black colour.

"The density of the petroleum at $62 \cdot 6^{\circ} \mathrm{F}$. is 0.9179 , compared with water as unity. The density of Pennsylvania oil is usually about 0.794 to $0 \cdot 840$. The co-efficient of cubical expansion, as determined by Mr. Fitzhugh, is 0.02568."

In $1890 \mathrm{Col}$. Wm. L. Prather, Waco, McLennan county, found oil at a depth of 265 feet, which was analyzed by Dr. Edgar Everhart, of the University of Texas, with the following results-

\section{Fractions by Distillation.}

Specific gravity at $78^{\circ} \mathrm{F}=.0 \cdot 836$.

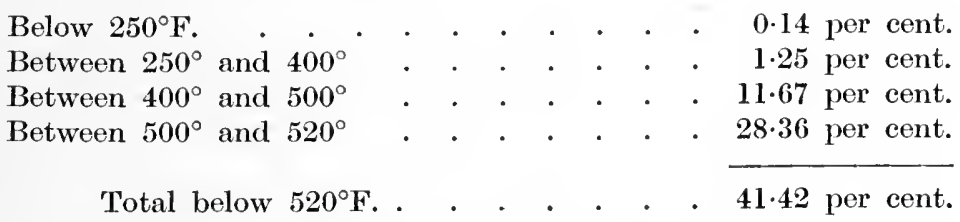

The portion coming over towards the end of the distillation was rich in paraffin. The portion remaining in the still, amounting to 58 per cent., consisted principally of paraffin and paraffin oil.

Some have asserted that the present capacity of the wells in the Beaumont district is not less than 500,000 barrels a day, and on this basis they calculate that the yearly yield could be $182,500,000$ barrels. This, of course, is a great deal of oil, being more than three times the total production of the United States in 1899, and considerably in excess of the production of the world during that year. There are few actual facts upon which such an assertion can bc predicted, and it is not to be held that anything like so large an output can be reached.

\section{Properties of Petroleum.}

W. B. Phillips, Ph.D., of the University of Texas, to whom the author is indebted for much information, says-

"In weight (specific gravity), taking water as 1,000, it varies from 650 , as in certain oils from Koudako, Russia, to 1,020, as in the oil from the island of Zante. The range of specific gravity is, however, for the most part, between 770 and 940 . 


\section{LIQUID FUEL AND ITS COMBUSTION}

A gallon of crude petroleum will vary in weight from 6.41 pounds to 7.83 pounds for the United States gallon, and from $7 \cdot 20$ to $9 \cdot 40$ pounds for the Imperial gallon. Exclusive of the weight of the barrel, the 42 gallons, ordinarily spoken of as a barrel of oil, will weigh from $269 \cdot 22$ pounds to $328 \cdot 86$ pounds.

"With regard to the ease with which it flows, crude petroleum may be quite mobile as in the light-coloured varieties, or quite viseid as in the black varieties. The temperature at which it becomes solid ranges from $82^{\circ} \mathrm{F}$., as in oil from Burma, to several degrees below zero. The flash-point (the lowest temperature at which inflammable vapours are given off) varies from below zero as in certain oils from Italy, Sumatra, etc., to $370^{\circ} \mathrm{F}$. as in oil from the Gold Coast, Africa. The ordinary range of the flash-point, however, does not show such extreme limits.

If we take the oils whose flash-point lies below $60^{\circ} \mathrm{F}$. we find that the specific gravity ranges from 771 to 899 , the average being 838 . On the other hand, the oils whose flash-points are above the boiling-point of water have a range of specific gravity from 921 to 1,000 , the average being 959 . It is a remarkable fact that a Roumanian oil with a flash-point of $24^{\circ} \mathrm{F}$. should have had a specific gravity of 899 . It is a general rule that a low specific gravity accompanies a low flash-point. In none of the examples examined, whose flash-point was above the boiling-point of water, was it found that the specific gravity fell below 921 , the average being 959 . There is a close connexion between specific gravity and flash-point, for the presence of lighter oils, which are given off at a low temperature and are more inflammable, tends to reduce the weight of the oil as compared with water.

The boiling-point of crude petroleum varies from $180^{\circ} \mathrm{F}$., as with certain Pennsylvania oils, to $338^{\circ} \mathrm{F}$. as with oil from Hanover, Germany. The point at which oils become solid varies from $82^{\circ} \mathrm{F}$., as with oil from Burna, to below zero, as with oil from Italy and Sumatra.

The content of carbon varies from 79.5 per cent. to 88.7 per cent. of hydrogen; from 9.6 per cent. to 14.8 per cent. of sulphur from 0.07 per cent. to above 2.00 per cent., and in rare cases even above 3.00 per cent. ; of nitrogen from 0.008 per cent. to $1 \cdot 10$ per cent.

Hydrocarbons of the olefin series occur in nearly all kinds of petroleum, but are specially characteristic of Russian petroleum from Baku.

While the production of petroleum in Russia is about 70,000,000 barrels a year, not more than $15,000,000$ to $17,000,000$ are refined, the remainder going into direct use for fuel purposes.

Mabery has shown that the distillate from Beaumont oil coming over between $266^{\circ}$ and $275^{\circ} \mathrm{F}$, gave hydrocarbons of the acetylene and benzine series, and the same was true of the distillate coming over between $311^{\circ}$ and $320^{\circ} \mathrm{F}$. $\mathrm{He}$ also found this oil to contain 2.16 per cent. of sulphur and more than 1.00 per cent. of nitrogen.

There is no hard and fast line on the one side of which may be placed certain oils and on the other side certain other oils. The chemical properties shade into each other, and only a general statement can be made that the oils from Pennsylvania fall into the paraffin series and the Russian into the olefin series, while the Beaumont oil is a third class distinguished by the presence of members of the acetylene and benzine groups.

Bituminous coal contains much less carbon and hydrogen and much more oxygen than petroleum. Anthracite coal has about the same amount of carbon as petroleum, but much less hydrogen and oxygen. 


\section{TEXAS OIL}

Analysis of Petroleum from Corsicana, Texas.

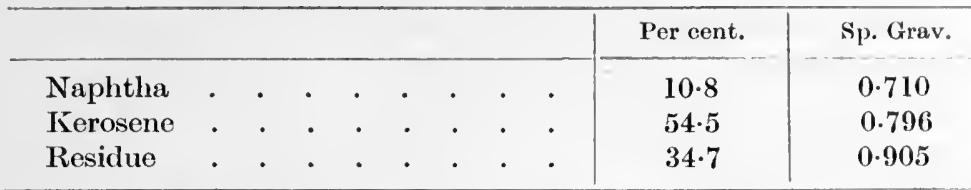

The specific gravity of the crude oil was $0 \cdot 8206$, water being $1 \cdot 0000$.

Mr. E. H. Earnshaw made a more elaborate analysis of the Corsicana oil, with the following result-

Analysis of Petroleum from Corsicana, Texas.

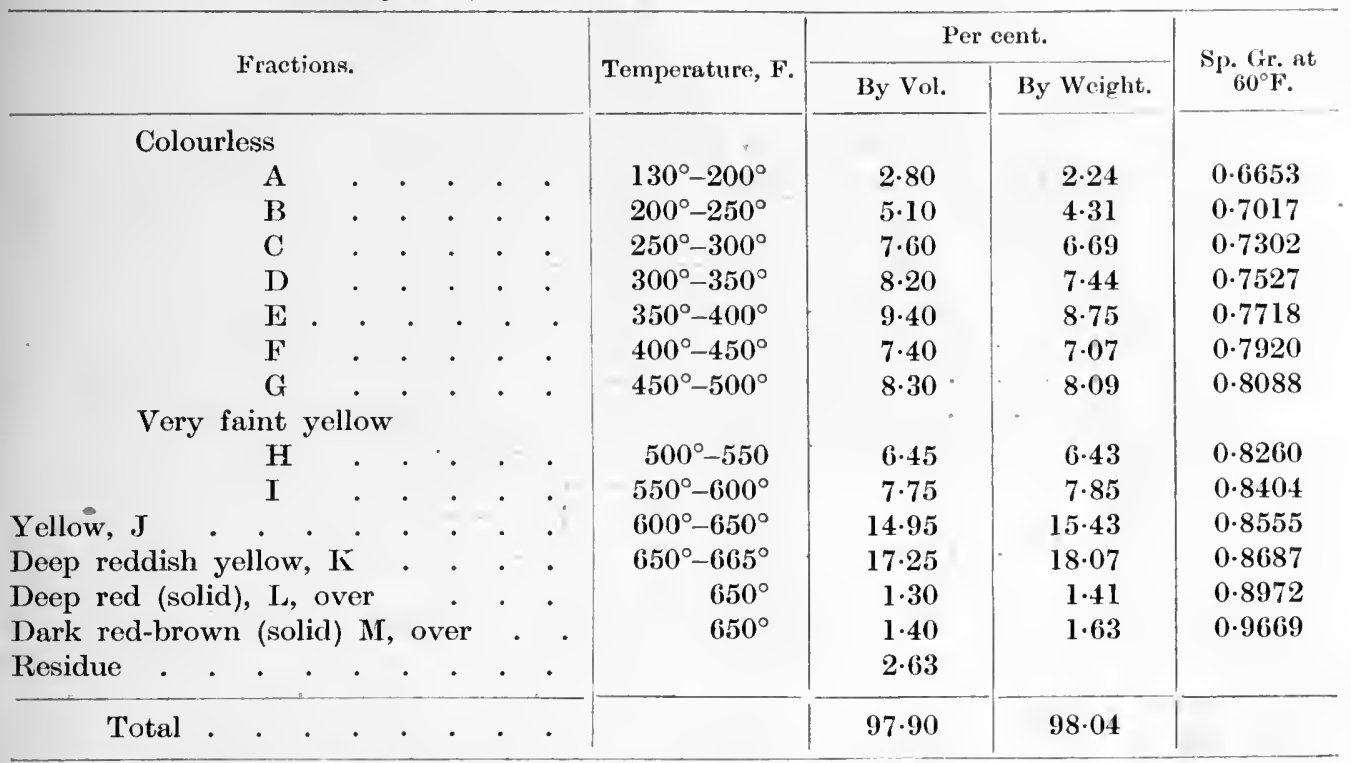

Mr. Thiele's remarks on the oil were as follows--

"The oil is very dark brown and opaque, but thin and fluid at $60^{\circ} \mathrm{F}$. The specific gravity at $60^{\circ} \mathrm{F}$. is 0.8292 . The oil is closely related to the oil from Washington district, Penn., but contains asphaltum or bodies very similar to it.

"The Nacogdoches oil is heavy, specific gravity 0.915. The colour is black, and there is much sulphuretted hydrogen.

"The oil from Saratoga, Hardin county, is heavier than the Nacogdoches oil, the specific gravity being 0.995 . It is black and rich in asphaltum.

"The oil from Sour Lake, Hardin county, has a specific gravity of 0.963 , and an analysis of it is as follows-

Analysis of Petroleum from Sour Lake, Hardin County, Texas.

\begin{tabular}{c|c|c|c|c}
\hline Fractions. & Temperature F. & Per cent. by Vol. & Specific Gravity. & \multicolumn{1}{c}{ Colour, etc. } \\
\hline 1 & & & \\
2 & $212^{\circ}-266^{\circ}$ & 0.07 & & Yellow \\
3 & $266^{\circ}-320^{\circ}$ & 0.03 & & Yellow \\
4 & $320^{\circ}-392^{\circ}$ & 1.59 & 0.684 & Yellow \\
5 & $392^{\circ}-572^{\circ}$ & $19 \cdot 49$ & 0.840 & Yellow; blue fluorescence \\
6 & $572^{\circ}-641^{\circ}$ & $5 \cdot 15$ & 0.782 & Dark yellow \\
7 & & $71 \cdot 11$ & 0.978 & Blaek \\
\hline Residue & & 97.44 & & \\
\hline
\end{tabular}




\section{LIQUID FUEL AND ITS COMBUSTION}

In the Journal of the Society of Chemical Industry, Vol. XIX. No. 2, February 28, 1900, Mr. Clifford Richardson has an article entitled "Notes on Texas Petroleum," from which the following is taken-

\section{Corsicana Oil.}

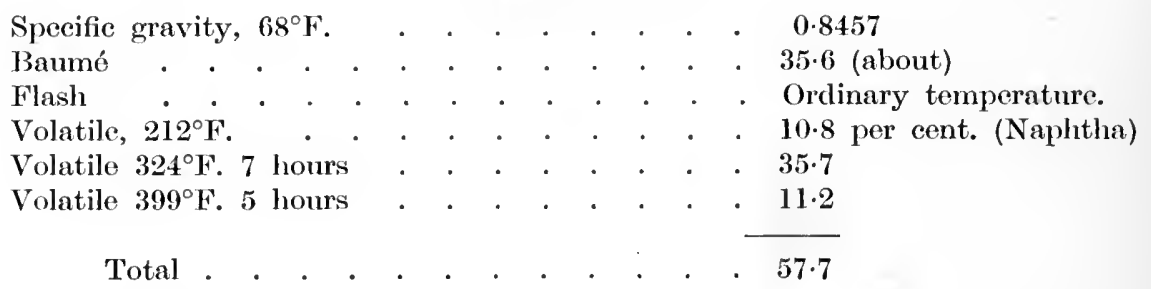

Residue, after heating to $323^{\circ} \mathrm{F}$., flows readily at $68^{\circ} \mathrm{F}$., has the appearance of containing paraffin. After heating to $399^{\circ} \mathrm{F}$. residue has a quick flow at $77^{\circ} \mathrm{F}$.

Sour Lake Oil.

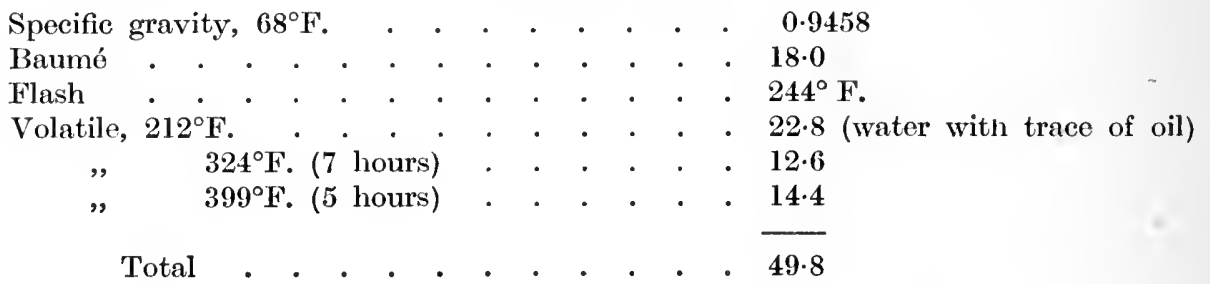

Residue after heating to $324^{\circ} \mathrm{F}$ flows readily at $70^{\circ} \mathrm{F}$. After heating to $399^{\circ} \mathrm{F}$. residue flows readily at $77^{\circ} \mathrm{F}$.

The specific gravity of Corsicana petroleum is a little heavier than that from near Dudley, Noble county, Ohio, 0.8457 to 0.8333 . It is about the same as that of the lighter forms of California oil found in the Pica canon, California. It is considerably heavier than that from the Pennsylvanian fields. It flashes at the ordinary temperature, and distils off a considerable percentage of naphtha below the temperature of boiling water.

Distilled under ordinary presure, without particular precautions to prevent cracking, Mr. Thiele found-

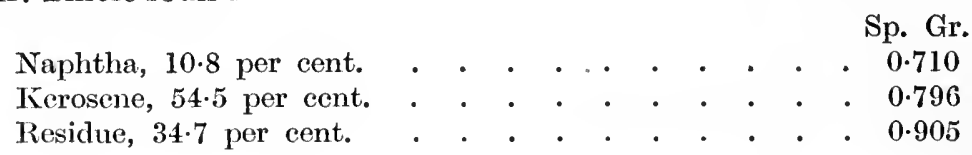

Twenty grams of the oil, when heated for seven hours in an air-bath at various temperatures, in a crystallizing dish $2 \frac{1}{4}$ inches in diameter by $1 \frac{1}{2}$ inches high, left a residue of 43.3 per cent., which flowed readily at $77^{\circ} \mathrm{F}$. The residuum resembles that from Penusylvania and Ohio petroleum, and apparently contains paraffin scale. It is to a certain extent asphaltic, however. The crude, when distilled under a pressure of 1 inch of mercury, volatilized 51.2 per cent. at a temperature of $356^{\circ} \mathrm{F}$, but at that point began to "crack." Ohio oil, on the contrary, did not begin to "crack" until $455^{\circ} \mathrm{F}$. was reached at atmospheric pressure ; but the Sour Lake oil broke up at the same point as did the Corsicana. It is, therefore, a less stable oil than eastern petroleums.

The Sour Lake oil is a very heavy crude petroleum, 18B, and corresponds in 


\section{TEXAS OIL}

many respects with some of the heavier California oils of Summerland and Los Angeles in appearance and properties. It flashes at a low point for such a heavy oil, $244^{\circ} \mathrm{F}$. As taken from the wells, it contains a very large amount of water.

\section{Properties of various Petroleums.}

The following table gives a comparison of different oils taken from Sadtler's Industrial Organic Chemistry, page 18-

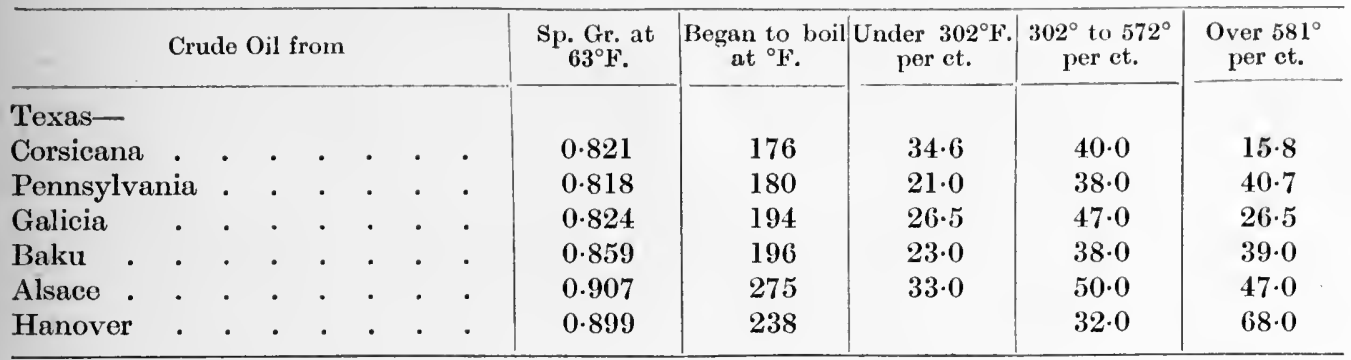

Dr. W. H. Harper, Professor of Chemistry in the University of Texas, gives an analysis of a sample of Corsicana oil submitted to him in March, 1900 :

Colour, very dark brown, almost black ; opaque except in thin layers; greenish fluorescence.

Viscosity, not determined, but the oil very mobile at $32^{\circ} \mathrm{F}$.

Sediment, none.

Water, none.

Flash-point, $73^{\circ} \mathrm{F}$.

Specific gravity at $63 \cdot 5^{\circ} \mathrm{F}$., $0 \cdot 8586$, equivalent to $33^{\circ}$ Baumé.

\section{Russian Oil.}

In 1880 the production of crude oil on the Aspsheron Peninsula was $3,055,247$ barrels ; in $1885,14,179,833$; in $1890,29,217,126$; in $1895,47,713,983$; and 1899 , $66,452,240$. The total Russian production in 1899 was $68,752,240$, the other 2,300,000 barrels coming from the Grossni district in the Caucasus. The average yield was-in the Baku district, 172,661 barrels a day from 1,357 wells, or about 127 barrels per day per well. In the United States the average yield per day was about 156,000 barrels from about 82,000 wells, say, two barrels a day. It takes 60 American wells to produce in one day as much as one Russian well.

In 1899, in the Baku district, there were completed 370 wells of an average depth of 911 feet, and yielding, on the average, 202 barrels each per day. In 1898 the number of wells completed was 258 , of an average depth of 937 feet, and an average yield of 653 barrels per day. The average daily production of the Baku flowing wells was 37,202 barrels in 1898 , and 26,445 barrels in 1897 , as against 122,413 and 146,216 barrels respectively for the pumping wells in 1899 . The production of the flowing wells in 1899 was about one-sixth of that of the pumping wells.

\section{Calorific Capacity of Petroleum.}

It is pretty well established that the B.Th.U. in petroleum will vary from 17,000 to 20,000 , one experiment on petroleum giving 20,110 . The value taken in Texas, as already remarked, is 18,500 B.Th.U., or 10,277 calories. The scientific investigation of the coals, etc., used there, with respect to their heat units, has not 


\section{LIQUID FUEL AND ITS COMBUSTION}

progressed very far ; but from the data to hand it is not thought that, on the average, the B.Th.U. in the coals will be above 12,600 , if indeed above 10,800 , and are taken, for the present, at 11,700. For the lignites a lower value must be taken, and for the present this will be 9,900 .

Some of the Alabama coals have 13,500 B.Th.U.; good McAlester coal (Indian Territory) may be taken at the same; New Mexico coal at 12,000; and lignite at 9,900. On this basis one barrel of crude petroleum, weighing $320 \mathrm{lb}$. net, would be equivalent to $438 \mathrm{lb}$. of Alabama coal, and the same amount of McAlester coal, $493 \mathrm{lb}$. of New Mexico coal and $598 \mathrm{lb}$. of lignite. A ton, 2,000 lb., of Alabama coal would then be equivalent to 4.56 barrels of petroleum ; a ton of McAlester coal to 4.56 barrels; a ton of New Mexico coal to 4.06 barrels; and a ton of lignite to 3.34 barrels. In other words, from $3 \frac{1}{3}$ to $4 \frac{1}{2}$ barrels contain as many heat units as a ton of the best coals and lignites of American Southern States.

Experiments made in California with a view to testing the relative value of the California oil and the coal with which it comes into competition, showed that a ton of Nanaimo coal, giving 12,031 B.'Th.U., was equivalent to a minimum oil consumption of 3.45 barrels and a maximum consumption of 3.87 barrels. Recent experiments on Texas petroleum showed it to have 19,160 heat units, and this would be equivalent to 4.29 barrels per ton of Indian Territory coal. In Russia the usual equivalent is $3 \cdot 12$ barrels per ton of coal.

There is considerable variation in the quality of coal offered in the market, and these differences are often observable in coal from the mine, due, perhaps, to carelessness in mining and handling, and to the absence of rigid inspection. In countries where the coal is sold on the basis of the heat units it contains these discrepancies are not so potent or so widespread. Variations in the quality of oil from the same well are by no means so marked as in the case of coal from the same mine. Where the oil from different wells has a somewhat different value in heat units the practice of piping different oil into the same storage tanks tends to advance uniformity, just as in the case of the pig-iron mixer in steel plants with respect to pig-iron of varying composition.

The value of oil as compared with coal varies somewhat with the nature of the work to be done. It has been observed, for instance, that in puddling and steelheating furnaces $2 \frac{1}{2}$ barrels of Los Angeles oil were equivalent to 2,000 pounds of Wellington coal from British Columbia, while for steaming purposes it took three barrels of the oil for one ton of the coal. In some establishments in Los Angeles the proportion rose to $3 \cdot 62$ barrels per ton; in others, to $3 \cdot 10$. On the Southern Pacific Railway in California it has been found that four barrels of California oil were equivalent to one ton of Nanaimo, British Columbia, coal. The lowest consumption of oil per ton of coal that has been found is $2 \frac{1}{2}$ barrels, while the highest is 4 barrels. An average ratio can be established only when all the conditions are known ; but, in a general way, it may be said that from $3 \frac{1}{2}$ to 4 barrels of oil should be equivalent to a ton-2,000 pounds of good soft coal. The lower figures may be reduced under good practice and with good management and the best appliances to $3 \frac{1}{3}$ barrels; while under bad management, etc., the higher figure may reach $4 \frac{1}{2}$ barrels.

\section{Advantages of Liquid Fuels.}

Mr. H. Tweddle (Engineering and Mining Journal, N.Y., Vol. LXVIII.) sets forth the advantages to be derived from the use of liquid fuel under eleven heads. 


\section{TEXAS OIL}

His remarks were directed ehiefly to the use of sueh fuel on vessels, but may be applied with equal foree to almost every kind of manufacturing establishment and to locomotives. The advantages claimed are as follows:

1. Diminished loss of heat up the funnel (or chimney), owing to the clean condition in which the boiler tubes can be kept, and to the smaller amount of air which has to pass through the eombustion-chamber for a given fuel eonsumption.

2. A more equal distribution of heat in the combustion-chamber, as the doors do not have to be opened, and, eonsequently, a higher efficiency is obtained ; unequal strains on the boiler tubes, etc., due to undue heating are also avoided.

3. With oil there is no danger of having dirty fires on a hard run.

4. A reduetion in the cost of handling fuel, as this is done meehanically or by gravitation.

5. No firing tools or grate bars are necessary; consequently the furnace lining, brick work, ete., last longer.

6. Absence of dust, ashes and elinkers.

7. Petroleum does not deteriorate on storing, while coal does, especially soft coal. This opinion is not universal, however.

8. Ease with which the fire can be regulated from a low to a most intense heat in a short time.

9. Lessening of the amount of manual labour in stoking.

10. Great increase of steaming eapacity, the difference being as much as 35 per cent. in favour of oil.

11. The eleventh point made by Mr. Tweddle is that of the absence of sulphur or other impurities, and longer life to plates, etc.; but eonsidering the fact that the amount of sulphur in some of the oils now being used as fuel is in excess of the sulphur in ordinary coals, this point is not well taken. Sulphur is objectionable in any fuel, whether coal or oil, and of the two may be more objectionable in oil than in coal, for a portion of the sulphur in coal remains in the ashes, and is not consumed.

If erude petroleum, or the residue from refining plants, is to come into use on a large scale as fuel, there are some considerations that must be weighed, in addition to its fuel value, viz. its initial price, f.o.b. tanks or wells, transportation charges, and the like. If a certain freight rate per ton mile is established for coal, and it is sought to establish a rate for oil, why should there not be some standard of fuel value to which both are to be referred? Some coals are better than others, some oils are better than others. In the one case it may require $4 \frac{1}{2}$ barrels of oil to equal a ton of coal as fuel, in the other case the ratio may be much less. If the eoal has a high heating value, manifestly it will require a much larger amount of oil to balance it than if the coal has a low heating value. Perhaps the times are not ripe for the fixing of freight rates based on heat units, but the plan has certainly much to recommend it.

Profiting by the experiences in California and elsewhere in the use of oil for fuel, many industrial establishments in Texas have changed, or are about to change, from coal to oil. Among the first to adopt the new fuel was the American Brewery, Houston. This establishment has a battery of four boilers, two 200 h.p. and two 350 h.p. The oil used was the residue from the refining plant at Corsicana, and it was estimated that 75 barrels a day would be required, inasmuch as the coal eonsumption was about 25 tons a day. After running for a while, it was stated that 


\section{LIQUID FUEL AND ITS COMBUSTION}

the steaming capacity of the two $200 \mathrm{~h}$.p. boilers using oil was equivalent to the steaming capacity of the two 350 h.p. boilers using coal, and that the saving of oil was about 33 per cent. The Star Flour Mills, Galveston, also installed oil burners in April, 1901, using about 35 barrels a day for a 350 h.p. engine. At Gonzales, the Sunset Brick and Tile Company put in oil-burners for a large brick-kiln the latter. part of May, 1901. At Brenham, oil-burners were installed for the large plant of boilers used by the ice factory, oil mill and electric light works. The Hutchins Hotel, Houston, changed from coal to oil, the battery consisting of two $100 \mathrm{~h} . \mathrm{p}$. boilers. The Magnolia Brewery, Houston; the Houston Electric Street Railway; and the City Brewery, San Antonio, changed from coal to oil ; and many other plants in the State have the matter under consideration.

The first locomotive equipped for burning oil was delivered to the Gulf, Beaumont and Kansas City Railway, June 20, 1901, and belonged to the Gulf, Colorado and Santa Fé Railway. It was No. 065, and pulled a passenger train out of Beaumont on June 21. Up to the time of its reaching Beaumont it had travelled 450 miles, and had consumed 42 barrels of oil, the tank having this capacity. The Southern Pacific Railway is to burn oil west of El Paso, but it is said that California oil will be used. This road has had a greater experience in the use of oil for locomotives than any other railway in the country, and when the arrangements are made for burning oil between El Paso and Los Angeles, a distance of about 800 miles, this road will be equipped with oil-burning locomotives from El Paso to Portland, Oregon, a distance of more than 1,700 miles.

A large consumption of oil for fuel purposes may be anticipated, especially on the part of railroads and industrial establishments, and the competition of the new fuel with coal will certainly make itself felt. Already some of the railroads bringing coal into Lower Mississippi Valley from Alabama have made sweeping reductions in freight rates, in order to meet oil at New Orleans, etc. These reductions amount to about one-half of the former rates.

\section{Oil Production of the World.}

\begin{tabular}{|c|c|c|c|c|c|c|c|c|}
\hline \multicolumn{7}{|c|}{ Country. } & \multirow{2}{*}{$\begin{array}{c}\text { Year. } \\
1899\end{array}$} & \multirow{2}{*}{$\begin{array}{c}\begin{array}{c}\text { Production in Brls. } \\
\text { of } 42 \text { gals. }\end{array} \\
68,752,240\end{array}$} \\
\hline Russia . . . & . & & . & . & . & . & & \\
\hline United States & . & & . & . & . & . & 1899 & $57,070,850$ \\
\hline Austria Hungary & ry & & . & . & . & . & 1898 & $3,304,510$ \\
\hline Roumania & . & & . & . & . & . & 1899 & $1,470,000$ \\
\hline Sumatra . & . & & . & . & . & . & 1899 & 361,610 \\
\hline India . & . & & . & . & . & . & 1898 & 542,068 \\
\hline Java. & . & & . & . & . & . & 1899 & 350,000 \\
\hline Japan . & . & & . & . & . & . & 1898 & 265,000 \\
\hline Germany & . & & . & . & . & . & 1899 & 192,232 \\
\hline Italy . . & . & & . & . & . & . & 1898 & 14,489 \\
\hline Great Britain & . & & . & . & . & . & 1898 & 1,900 \\
\hline Grand & tot & & & . & . & . & & $132,823,899$ \\
\hline
\end{tabular}

In 1899 there were 159 steamers, tonnage 393,717 , and ten sailing vessels, tonnage 11,321, engaged in general trade. Of the steamers built in 1899 , the Strombus, for the Shell Line Company, had a tonnage of 8,500.

of the total exports of crude oil in 1899, France alone took 73 per cent.; 


\section{TEXAS OIL}

Spain came next with 8.5 per eent.; Mexico next with 7 per eent.; Germany took about 3 per cent. ; while Cuba took almost as much as Germany. France, Spain, Mexico, Germany and Cuba took about 94 per cent. of the total amount of erude oil exported.

According to the U.S. Geological Survey Bulletin, by Mr. F. H. Oliphant (1902), the world's production of petroleum in the year 1901 was $165,385,733$ United States barrels, of which quantity the production of various countries was as follows-

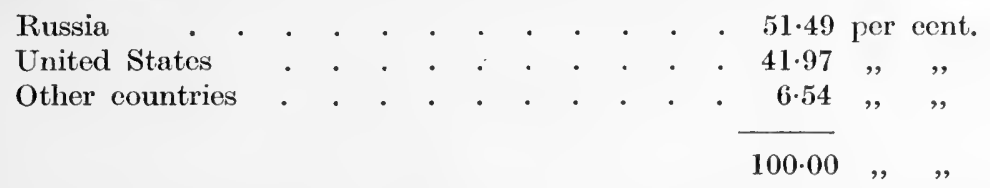

Whereas in 1895 the Russian production was only 87.2 per cent. of the United States production, it had increased to 122.7 per cent. in 1901, as above.

The U.S. barrel of 42 U.S. gallons (=35 Imp. galls.) holds about 320 pounds. Assuming 7 barrels to one ton, the world's production is $23,626,533$ tons.

In the year 1900 Russia produced only $17,500,000$ tons of coal, whereas the United States produced 270,000,000 tons (2,000 pounds). As two-thirds of the Russian oil is used as fuel, the production of oil is equivalent to $16,000,000$ tons of coal. Assuming a ratio of $1,333: 2,000$, the equivalent in coal of the world's production of $23 \frac{1}{2}$ million tons of oil is $31 \frac{1}{2}$ million tons, a figure which includes all the illuminating oils. Approximately, the fuel product will not exceed 60 per cent. of the whole production, so that about $20,000,000$ tons $(2,240$ pounds $)$ of coal may be taken to represent the world's fuel oil production. The attitude of the engineer to the liquid fuel problem, while open and liberal, must be conservative in face of the foregoing figures. Oil eannot be a universal fuel, but it can be of the utmost value in certain conditions, and it affords peculiar facilities to the electrical engineer in dealing with the peaks of the load of a lighting station, and especially those sudden unforeseen peaks that arise from sudden fogs.

In Table XLIII the world's production of petroleum in 1900 and 1901 is given in some detail.

The table gives some idea of the rate of growth of production, and shows that this is moderate. We know that old wells begin to decrease their output, and new bore holes are constantly required to keep up the supply.

Doubtless there are unfound areas of production yet to be tapped, but the present position is to be summed up in the one word " moderation." 


\section{Chapter V}

\section{TES'IS OF TEXAS OIL EFFICIENCY}

A REPOR'T by Professor Denton states that the number of barrels of oil equivalent to 2,240 pounds of coal was 4.23 for one h.p. per about twenty square feet of heating surface, and 4.12 for one l.p. per 10 square feet of heating surface ; and it appears that the average consumption of oil per ton of coal is four barrels, and that under some eonditions this falls to 3.50 barrels. There may be consumers who use even less than this, but it is not thought that they represent the average praetiee.

The Report was made to the Hon. Charles A. Towne, President of the Export Oil and Pipe Line Company, Beaumont, Texas, under date of December 26, 1901, but was not issued until February, 1902. The oil was used to operate a boiler at the plant of the West Side Hygeia Ice Company, West 19th Street, N.Y. City. There were three return tubular boilers, each 6 feet in diameter and 18 feet long, containing about 1,900 square feet of heating surface, two being used at a time to provide about 180 boiler h.p. from buekwheat eoal, with natural draught under a very steady load throughout each 24 hours. One of these boilers was fitted for the tests with the Williams Oil Burner (fig. 102).

\section{Operation of the Boiler.}

The preparations for the use of the oil being eompleted on Monday, November 25,1901 , the boilers were immediately lighted, steam quickly raised, and from one-half to more than the whole of the boiler h.p. required by the faetory was then generated until the following Saturday night without the slightest hitel, the burners being under the charge of Mr. Williams, the patentee of the burner. During this period evaporation tests at various powers were made.

\section{Time required to raise Steam.}

The boiler was allowed to cool from Saturday, November 30, to the following Wednesday, when the briekwork of the setting was eold, and the water in the boiler at $64^{\circ} \mathrm{F}$. The time to raise 85 pounds of steam was then determined to be 59 minutes. In a similar test made later with a coal fire, started with a very liberal supply of dry wood, steam was raised in 1 hour 17 minutes.

\section{Effect of the Oil on the Boiler and Furnace.}

After the steam-raising test, the boiler was operated 24 hours with oil, to use up all that remained of the 117 barrels provided for the evaporative test. It was 


\section{TESTS OF TEXAS OIL EFFICIENCY}

then cooled, and the oil burning apparatus removed to prepare the furnace for comparative coal evaporative tests. The boiler and furnace were then examined. No trace was found of any action of the oil on the boiler. There was no oily matter on the internal briekwork, nor any diseoloration of the latter, and there was less than 1-64th of an inch of soot in the tubes, which had been swept clear of ashes at the beginning of the use of the oil.

The tests with the oil were made at capacities varying from 112 h.p. to 220 h.p. The boiler was 6 feet in diameter and 18 feet long of the horizontal return tube type. It had 100 tubes $2 \frac{1}{2}$ inches in diameter and a grate surface of $45 \cdot 5$ square feet, i.e. 6 feet 6 inches by 7 feet 0 inches. Height of chimney, 70 feet high by 42 inches square. Omitting the data with respect to the use of the buckwheat (anthracite) coal, the résumé of the tests is as follows-

Résumé of Tests with Beaumont Crude Oil.

\begin{tabular}{|c|c|c|c|c|c|}
\hline Duration, liours . & $3 \cdot 5$ & 8 & 11 & 13 & 11 \\
\hline Horse power . $\quad . \quad . \quad . \quad . \quad . \quad$. & $146 \cdot 9$ & $122 \cdot 7$ & $189 \cdot 7$ & $138 \cdot 0$ & $220 \cdot 1$ \\
\hline Steam pressure (gauge) lb. & 87. & 86 & 86 & 86 & $86 \cdot 5$ \\
\hline Feed temperature, degs. F. . . & $69^{\circ}$ & $90^{\circ}$ & $70^{\circ}$ & $90^{\circ}$ & $74^{\circ}$ \\
\hline Chimney temperature, degs. F. . & $374^{\circ}$ & $360^{\circ}$ & $398^{\circ}$ & $370^{\circ}$ & $425^{\circ}$ \\
\hline 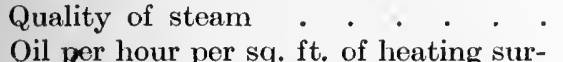 & dry & dry & dry & dry & dry \\
\hline face, lb. ${ }^{\circ} \cdot{ }^{\circ} \cdot{ }^{\circ}$ steam per hour, from and $212^{\circ}$ & $0 \cdot 181$ & $0 \cdot 135$ & $0 \cdot 226$ & $0 \cdot 063$ & $0 \cdot 263$ \\
\hline per sq. ft. of heating surface, lb. & $2 \cdot 73$ & $2 \cdot 09$ & $3 \cdot 52$ & $2 \cdot 56$ & $4 \cdot 08$ \\
\hline $\begin{array}{l}\text { Heating surface per h.p. sq. ft. } \\
\text { Total dry steam per lb. of fuel as fired }\end{array}$ & $12 \cdot 6$ & $16 \cdot 5$ & $9 \cdot 8$ & $13 \cdot 5$ & $8 \cdot 45$ \\
\hline from and at $212^{\circ} \mathrm{F}, \mathrm{lb} . \quad . \quad$. & $15 \cdot 29$ & $15 \cdot 53$ & $15 \cdot 55$ & $15 \cdot 71$ & $15 \cdot 49$ \\
\hline $\begin{array}{l}\text { Per cwt. of steam used by burner } \\
\text { Net lb. of dry steam per lb. of fuel fired }\end{array}$ & $3 \cdot 6 \%$ & $3 \cdot 1 \%$ & $4.8 \%$ & $3.5 \%$ & $4 \cdot 8 \%$ \\
\hline from and at $212^{\circ} \mathrm{F}$. . . . & $14 \cdot 74$ & $15 \cdot 05$ & $14 \cdot 80$ & $15 \cdot 16$ & $14 \cdot 75$ \\
\hline
\end{tabular}

Other data and results are as follows-

\section{Dimensions and Proportions.}

Grate surface, sq. ft. . . . . . . . . . . . . . . $45 \cdot 5$

Water heating surface . . . . . . . . . . . . . . 1,860

Position of damper . . . . . . . . . . . . . . wide open

Area of opening of ash pits, sq. ft. . . . . . . . . . . . 1.8

\section{Average Pressures.}

Steam pressure, by gauge, lb. . . . . . . . . . . . 86.5

Draught pressure, inches of water . . . . . . . . . . 0.37

Average Temperatures, Fahr.

Fire room . . . . . . . . . . . . . . . . . . 53.1

Feed water entering boiler . . . . . . . . . . . . . 74.0

Chimney gases . . . . . . . . . . . . . 42.5

Fuel.

Weight of fuel as fired, lb. . . . . . . . . . . . 5,393

Steam.

Quality of steam . . . . . . . . . . . . . dry 


\section{LIQUID FUEL AND ITS COMBUSTION}

\section{Water.}

Total weight of water fed to boiler, lb. . . . . . . . . . 70,798

Factor of evaporation . . . . . . . . . . . . . . . . $\quad$ 1.180

Equivalent water evaporated into dry stean from and at $212^{\circ} \mathrm{F}$. . $\quad 83,542$

\section{Economic Results.}

Feed water per lb. of fuel as fired, lb. . . . . . . . . . . 13.13

Equivalent evaporation from and at $212^{\circ} \mathrm{F}$. per lb. of fuel as fired, lb. . $\quad 15 \cdot 49$

Equivalent evaporation from and at $212^{\circ} \mathrm{F}$. per lb. of combustible, lb. . $\quad 15 \cdot 49$

\section{Efficiency.}

Efficieney of boiler and furnace, or heat per $\mathrm{lb}$. of fuel as fired, divided by calorific value per $\mathrm{lb}$. of fuel . . . . . . . . . . 78.5\%

Efficiency of boiler, or heat absorbed by boiler per lb. of combustible, divided by ealorific value per $\mathrm{lb}$. of combustible . . . . . . $78.5 \%$

\section{Hourly Quantities.}

Fuel as fired per hour, lb. . . . . . . . . . . . . . . . 490·3

Fuel as fired per hour per sq. foot of grate, lb. . . . . . . . . 10.78

Combustible per hour per sq. foot of heating surface, lb. . . . . 0.263

\section{Horse Power.}

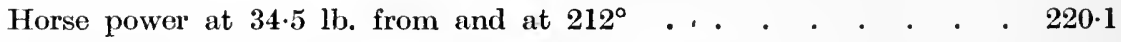

Heating surface per horse power sq. feet . . . . . . . . 8445

Composition of Fuel.

per cent.

Carbon . . . . . . . . . . . . . . . . . . . 85.03

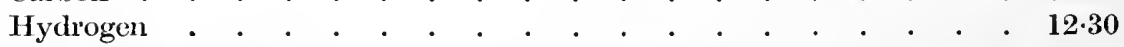

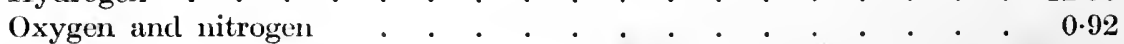

Sulphur . . . . . . . . . . . . . . . . . . 1.75

\section{Heat Balance.}

Utilized in production of steam . . . . . . . . . . . . . 14,963

Due to combustion of hydrogen. . . . . . . . . . . . . . .

Wasted in superheating water products . . . . . . . . . 113

Wasted in dry chimney gases . . . . . . . . . . . . 1837

Radiation and imperfect combustion . . . . . . . . . . 902

Heat per lb. of fuel as fired, by ealorimeter . . . . . . . . . . . . $\quad$ 19,060

Heat per lb. of combustible, by calorimeter . . . . . . . . 19,060

The weight of oil per gallon was 7.66 pounds, or 322 pounds per barrel of 42 American gallons of 231 cubic inches. The net evaporation per pound of oil from and at $212^{\circ} \mathrm{F}$. was $15 \cdot 1$ pounds. The net evaporation per pound of Pennsylvania bituminous coal in the best boilers at 10 square feet of heating surface per h.p. is 9.5 pounds of water from and at $212^{\circ} \mathrm{F}$. The net evaporation per pound of the semibituminous coals, such as Pocahontas, New River, Cumberland and Clearfield, is 10.0 pounds of water, which may be increased to 10.5 and 11 pounds by mechanical stokers, or smoke-preventing devices. 


\section{TESTS OF TEXAS OIL EFFICIENCY}

Professor Denton calculates the comparative costs of oil and coal as follows-

Price of conl per ton of $2,210 \mathrm{lb}$.

$$
\begin{aligned}
& \$ 1 \cdot 00=4 /- \\
& 1 \cdot 50=6 /- \\
& 2 \cdot 00=8 /- \\
& 2 \cdot 50=10 /- \\
& 3 \cdot 00=12 /- \\
& 3 \cdot 50=14 /- \\
& 4 \cdot 00=16 /- \\
& 4 \cdot 50=18 /-
\end{aligned}
$$

$$
\begin{aligned}
& \text { Equiv. price of oil per brl, of } 42 \text { gallons } \\
& \$ 0 \cdot 29=1 / 21 \\
& 0.43=1 / 91 \\
& 0.56=2 / 4 \\
& 0 \cdot 71=2 / 11 \text {, } \\
& 0.85=3 / 6 \frac{1}{2} \\
& 0.99=4 / 1 \frac{1}{2} \\
& 1 \cdot 13=48 / 1 \\
& 1 \cdot 28=5 / 4
\end{aligned}
$$

These figures apply to bituminous coals mined west of Ohio and used in Western and South Western States. In comparison with small sizes of anthracite, Pittsburg bituminous and Maryland and West Virginia semi-bituminous coals, and most or all British coals, oil must be sold at a less price, inasmuch as these fuels are of a better quality than Western and South Western coals. It follows, therefore, that for inland consumption, where the competition would be with fuels of less value, from the standpoint of available heat units, the price of oil could be higher than in Eastern markets and along the Upper Atlantic seaboard. Thus, in competition with coals mined west of Ohio at $\$ 3.00$ per ton, oil should be sold at 85 cents per barrel; but in competition with No. 1 buckwheat and pea (anthracite) at $\$ 3.00$ per ton, the price would have to be 67 cents ; while with the best semibituminous coal, largely used in ocean traffic and by manufacturing establishments in the East, the price of oil would have to vary from 64 to 58 cents if the coal was sold at $\$ 3 \cdot 00$. In the above, $\$ 1$ has been called equal to $4 s$.

In Texas, oil has been contracted for at $44 \frac{1}{2}$ cents per barrel, delivered at points as far off as 250 to 300 miles from Beaumont, competing successfully with coal from Indian territory, Arkansas and Texas at prices varying from $\$ 4.50$ to $\$ 6 \cdot 00$ per ton.

\section{Evaporative Duty.}

Professor Denton's results show that the net evaporation ranged from $14 \cdot 74$ to $15 \cdot 16$ pounds of water per pound of oil, the h.p. varying from 112 to 220 and the burner steam consumption from $3 \cdot 1$ to 4.8 per cent. of the boiler output. The boiler utilized about 78 per cent. of the heat of the fuel, which may be considered the bast average boiler practice. It is also to be observed that the results in actual practice showed that 98 per cent. of the total heat of combustion of the oil, as determined by the calorimeter, was accounted for by the steam production, the chimney gases, and a reasonable allowance for radiation. Professor Denton thinks that for a higher horse-power a net evaporation of 14.8 pounds of water is the best economy that can be expected from the use of oil as fuel with steam jet burners. This may be contrasted with 11.79 pounds yielded by excellent No. 1 buckwheat coal.

Considering the objections that have been raised against the use of crude oil, on account of its content of sulphur, it may be said that many excellent steam coals carry from 1.5 to 2 per cent. of sulphur, and that the average life of a boiler does not seem to be impaired by their use. The amount of sulphur in the oil used by Professor Denton was 1.63 per cent. Allowing that a coal contains 1.7 per cent., an oil would have to contain $2 \cdot 6$ per cent. in order to put as much sulphur into the products of combustion as the coal, equal horse-powers being assumed. It has been ascertained that the use of coal carrying more than 3 per écnt. of sulphur does not 


\section{LIQUID FUEL AND ITS COMBUSTION}

cause any greater depreciation of fire-boxes, etc., than a coal of 1.7 per cent. of sulphur, and the sulphur equivalent in oil corresponding to 3 per cent. in coal is above 6 per cent. The objections to the use of crude oil, based on its sulphur content, do not appear to be well founded, in so far, at least, as concerns the integrity of fire-boxes, etc. Probably sulphur products are only seriously harmful when cooled to moisture point.

The inflammability of the crude oil has also been the subject of critical investigation. There was no inflammable vapour given off below $142^{\circ} \mathrm{F}$. in Professor Denton's experiments ; and he does not think that a pool of oil in a boiler room would become ignited from a lighted match or from the dropping of a live coal into it. It is also stated that a surplus of oil at the burner gave rise merely to a thick smoke; there was no explosion or excess of pressure.

One more point of a most important nature was brought out by Professor Denton's test. It was not a new point, for other comparative tests have established the fact, and it is well known to those who study the economies of fuel consumption. It is the difference between the distribution of heat units arising from the combustion of oil and coal ; in other words, the comparative efficiency of oil and coal referred to the heat balance.

\begin{tabular}{|c|c|c|c|c|}
\hline & \multicolumn{2}{|c|}{ Oil. } & \multicolumn{2}{|c|}{ Coal. } \\
\hline & B.Th.U. & $\%$ & B.Th.U. & $\%$ \\
\hline $\begin{array}{l}\text { Utilized in production of steam } \\
\text { Evaporation of moisture in fuel and due }\end{array}$ & 14,963 & $78 \cdot 5$ & 8,636 & $71 \cdot 4$ \\
\hline to combustion of hydrogen & 1,245 & $6 \cdot 5$ & 277 & $2 \cdot 3$ \\
\hline Wasted in superheating water products & 113 & 0.6 & 23 & 0.2 \\
\hline Wasted in dry chimney gases . . . & 1,837 & $9 \cdot 7$ & 1,981 & $16 \cdot 4$ \\
\hline Wasted in unconsumed carbon in ash & - & - & 768 & $6 \cdot 3$ \\
\hline Radiation and imperfect combustion . & 902 & $4 \cdot 7$ & 415 & $3 \cdot 4$ \\
\hline $\begin{array}{l}\text { Heat per pound of fuel as fired, by } \\
\text { calorimeter } \\
\text { Heat per pound of combustible, by }\end{array}$ & 19,060 & $100 \cdot 0$ & 12,100 & $100 \cdot 0$ \\
\hline calorimeter $\cdot$. & 19,060 & - & 14,680 & - \\
\hline
\end{tabular}

An analysis of this table shows that in the production of steam more heat units were given off by the oil than corresponded with the total number of heat units in the coal, and that the percentage of heat units used was 78.5 of those in the oil, as against 71.4 of those in the coal ; in other words, there were so many more heat units in the oil than in the coal, and these were so much more available, that it was possible for the oil to devote to steam raising alone more heat units than the coal contained, and still leave 21.5 per cent. for other emergencies inseparable from the conduct of the operations. The saving of the heat ordinarily wasted in dry chimney gases is especially noteworthy, for the oil shows a waste of $9 \cdot 7$ per cent., as against $16 \cdot 4$ for the coal.

It is to be concluded, therefore, that in comparison with coal yielding 12,100 B.Th.U. per pound as fired, and 14,680 per pound of combustible, there is a decided economy in the usc of crude oil under the conditions maintained in this test.

The fact that returns from consumers of oil in the State show a difference of 43 per cent. (i.e. from 3.5 to 5 ) in the number of barrels of oil equivalent to a ton of good soft coal, is evidence that ordinary experience cannot be relied on to afford anything more than a rough approximation. If the ordinary steam installations 


\section{TESTS OF TEXAS OIL EFFICIENCY}

were provided with smoke-preventing devices and mechanical stokers, it is highly probable that the economy in the use of oil would not be so pronounced. It is in respect of comparing things that have not been reduced to a common denominator that the argument in favour of oil loses some of its strength. When one has not secured from coal all the economy possible, it is manifestly unfair to compare the results with those obtained from oil used under conditions in every way favourable to this fuel. With no arrangements for preventing smoke, with no mechanical appliances for sending the fuel to the fire-box in the cheapest and most effective manner, with no special care to prevent the loss of carbon as unconsumed carbon in the ashes, it is no wonder that the advantages to be secured by the use of oil are so obvious.

Mr. Phillips adds that if all the economies possible in the use of the solid fuels were inaugurated and maintained, it would be found that the comparison between these and oil would not be so strongly in favour of the latter fuel. It has been observed, for instance, that when smoke-preventing appliances are installed, either alone or in connexion with mechanical stoking, but more particularly when mechanical stoking is used, a saving of more than 20 per cent. has been regularly obtained-that is, when these economic devices were employed with ordinary coals there was a saving in the fuel account of more than 20 per cent., and this was for the regular practice. It is much to be doubted whether ordinary practice with the solid fuels has attained its maximum economy. There are some establishments, of course, where the greatest attention is paid to all possible economies in fuel consumption, but these form the exceptions.

We do not compare the two fuels on the same basis, for ordinary boilers are set and fired without much regard to economy. We do not give sufficient attention to the production and saving of heat obtained from the solid fuels, and when it comes to a comparison between these and oil we have not the data for arriving at the real truth. When the change is made to oil, and it is found that so many barrels will do the work of so many tons of coal at such and such a price, we are inclined to pronounce at once in favour of the oil. But the question at once arises whether the results from the two fuels have been reduced to a common denominator, whether they are on the same basis, whether we have taken into consideration all the economies possible in the two cases. We may allow that the heat units in oil are more easily available for steam-raising purposes than the heat units in coal, and that, per unit of heating power, we get better results from oil than from coal. We may go further, and allow that in most cases there is sufficient economy in the use of oil to warrant the installation of oil-burning appliances, but it does not follow that a given set of conditions applies to every establishment. When we have once ascertained what we can get from the oil, we are ready to calculate the relative advantages in the use of the two. It is, after all, a matter of dollars and cents, and each particular installation must be considered in and for itself. 


\section{Chapter VI}

\section{THE CHEMICAL AND OTHER PROPERTIES OF PETROLEUM}

$\mathrm{N}$ a work of this description a deep study of the chemistry of liquid fuels is not necessary.

Petroleum is a mixture of a series of hydrocarbons of the following types-

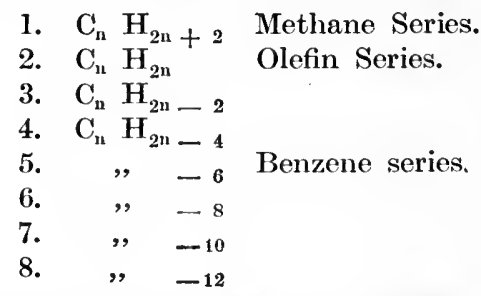

Those named occur in the greatest quantity and most frequently. The first is a light gas in the form $\mathrm{CH}_{4}$, and as the values of ${ }_{n}$ in each series grow larger the members of the various series become liquid and finally solid.

Thus of the first or Methane series the first four are gaseous, Methane, Ethane, Propane and Butane. Series 1 is liquid when ${ }_{n}=5$ to 25. Above ${ }_{n}=25$, the solids begin and generally in all the series a higher value of ${ }_{n}$ implies a higher boiling point, and this rises with some regularity from ${ }_{n}=9$, by about $20^{\circ} \mathrm{C} .=36^{\circ} \mathrm{F}$. for each additional carbon atom. Hence the ease with which fractional distillation can be carried on, the light oils (gasoline, etc.) distilling off up to $150^{\circ} \mathrm{C}$., the illuminating oils up to $300^{\circ} \mathrm{C}$, and the residuum being fuel oil, which still contains the lubricating oils.

Dr. Paul, in discussing Aydon's paper, suggested that liquid fuel had an advantage over solid fuel to the extent of 6,000 B.Th.U. per pound, which he elaimed as the latent heat of liquefaction, but this is elsewhere shown to be nearer the latent heat of evaporation of carbon while the latent heat of liquefaction is scarcely credited with more than 5 per cent. extra ealorific power, and, as pointed out by Mr. C. E. L. Orde, the Bombe calorimeter does not show anything like Dr. Paul's figure. It is also probable that when carbon and hydrogen of the liquid hydrocarbons united, they produced heat which more than eounterbalances the effect of the latent heat of liquefaction. Indeed, methane gas, $\mathrm{CH}_{4}$, is known to produce, when burned, very much less heat than calculation would appear to indicate.

\section{Water in Oil.}

Fuel oil and water do not readily separate. They do not differ much in 


\section{THE CHEMICAL AND OTHER PROPERTIES OF PETROLEUM}

specific gravity, and the oil is so viscous that the globules of water cannot force their way out of it. But oil is rendered more liquid by heat; it also expands more than water, and the separation is better effected by heating the oil. This is best done locally near the surface of the oil in the bunker, so that the heated oil is soon drawn off for use and heat is not wasted in raising the temperature of the whole bunker.

The heat value of oil is reduced $13 \cdot 14$ B.Th.U. for each one per cent. of water,

Thus 1 pound of oil worth 18,831 B.Th.U. mixed with 10 per cent. of water, gives a mixture the value of which per pound is $(18,831 \times 0.9)-131.4=16,816.5$ B.Th.U., a difference of $1,915 \cdot 5$ B.Th.U., or a loss of nearly two pounds of evaporation from and at $212^{\circ} \mathrm{F}$. Water also reduces the flame temperature, and thereby lengthens the flames and moves the point of highest temperature further along the flues and so diminishes the value of the heating surface. Mr. Orde lays down the conditions which show perfect combustion as an opaque dazzling white flame for six inches from the nozzle, becoming semi-transparent and almost violet in colour at middle length, shading off to red at the end. With water mixed in, the violet colour does not appear (see chapter on Smoke) and the flame becomes dark red and smoke-fringed.

It is stated by $\mathrm{Mr}$. Orde that at a temperature of $140^{\circ} \mathrm{F} .=60^{\circ} \mathrm{C}$. it required seven days to separate the water completely in a tank of oil. Hence the use of a surface float as in Fig. 9.

Mr. Orde's figures for the calorific value of various oils as found by the calorimeter, are as follows, and show a practical identity of value in all as may be expected from their chemical composition-

\begin{tabular}{|c|c|c|c|c|c|c|c|c|c|c|c|c|}
\hline Borneo & . & - & • & - & & • & & - & . & & 18,831 & B.Th.U \\
\hline Texas . & . & • & $\cdot$ & - & $\cdot$ & - & ${ }^{\circ}$ & - & - & & 19,242 & ," \\
\hline Caucasus & . & . & . & . & . & . & . & . & . & . & 18,611 & \\
\hline Burma & . & . & . & . & . & . & . & . & . & . & 18,864 & , \\
\hline
\end{tabular}

According to Pelouze and Cahours there are thirty different hydrocarbons in petroleum, principally of the type $\mathrm{C}_{n} \mathrm{H}_{2 n+2}$. For ${ }_{n}=1$ and ${ }_{n}=2$ the substance is a gas. For ${ }_{n}=3$ the boiling point is $0^{\circ} \mathrm{C} .=32^{\circ} \mathrm{F}$. For ${ }_{n}=5$ the liquid is very volatile, the lightest isolated by the above chemists being $\mathrm{C}_{5} \mathrm{H}_{12}$, boiling at $30^{\circ}$ C. $=77^{\circ} \mathrm{F}$. The fuel oils commence at $\mathrm{C}_{8} \mathrm{H}_{18}$, and go on to $\mathrm{C}_{15} \mathrm{H}_{32}$ beyond which $\mathrm{C}_{20} \mathrm{H}_{42}$ to $\mathrm{C}_{28} \mathrm{H}_{58}$ are semi-solid. The point of ebullition rises $20^{\circ} \mathrm{C} .=36^{\circ} \mathrm{F}$. for each increment of carbon from $\mathrm{C}_{8} \mathrm{H}_{18}$, which boils at $117^{\circ}=53^{\prime} 3^{\circ} \mathrm{F}$. to $197^{\circ} \mathrm{C} .=386^{\prime} 6^{\circ} \mathrm{F}$.; for $\mathrm{C}_{12} \mathrm{H}_{26}$; and $257^{\circ} \mathrm{C}=494^{\prime} 6^{\circ} \mathrm{F}$. for $\mathrm{C}_{15} \mathrm{H}_{32^{\circ}}$. Similarly the specific gravity increases continually though less regularly than the boiling point from $\mathrm{C}_{5} \mathrm{H}_{12}$ for which it is $0 \cdot 63$, to $\mathrm{C}_{15} \mathrm{H}_{32}$ for which it is 0.83 . The density of the hydrocarbon vapours relative to air are 0.5 for $_{n}=1$ to 7.5 for $_{n}=15$, or a growth of 0.5 for each grade.

The Russian oils do not follow the same empirical composition as the American, but belong rather to the ethylene series $\mathrm{C}_{\mathrm{n}} \mathrm{H}_{2 \mathrm{n}}$ and the isomers, and to the benzene series $\mathrm{C}_{n} \mathrm{H}_{2 n-6}$, of which benzene $\mathrm{C}_{6} \mathrm{H}_{6}$ is the characteristic member. In "cracking" the oils during distillation even lower forms are found : $\mathrm{C}_{n} \mathrm{H}_{2 n-8} ; \mathrm{C}_{\mathrm{n}} \mathrm{H}_{2 \mathrm{n}-10}$, which occur in the residues of distillation. Water may exist in the proportion of 5 per cent. for Baku oil to 10 per cent. for Borneo, but mineral matter is always small and ash scarcely cxceeds 0.3 to 0.4 per cent. 


\section{LIQUID FUEL AND ITS COMBUSTION}

By " cracking," the liquid distilled becomes more and more stable, and the final residue is a mere coke.

Petroleum distils more easily when superheated steam is blown through the still while below the "eracking" point. The effect is peculiar to steam and cannot be secured with air. It appears to be a sort of solution of the petroleum by the steam, and M. Bertin, of the Freneh Marine Militaire, considers that this affords an explanation of the superior power of steam in atomizing liquid fuel. A study of distillation shows three sorts of petroleum suitable for fuel.

(A) The natural oils which have parted with their volatile portions under the influence of sun and air and become natural mazout.

Borneo oil which flashes at $100^{\circ} \mathrm{C} .=212^{\circ} \mathrm{F}$. is directly employed as fuel and Texas oil appears to possess little other value than as fuel.

(B) Distillation residues or mazouts which result from boiling off all the more volatile portions.

(C) American distilled oils as per page 18. These oils are very homogeneous and regular, but they emit inflammable vapours below the temperatures at which they boil.

\section{The Physical Properties of Petroleum.}

These have already been partly treated of under the previous head, but it may be added that in common with all hydrocarbons and fats, petroleum and other liquid fuels become more fluid and lose much of their viseidity when heated. Their fluidity inereases rapidly with heat. Hence the better atomization possible with heated oils. Tests at Cherbourg on mazout at different temperatures show that the amount of flow of oil through an orifice of annular form half a millimetre wide was as follows in eubic centimetres per minute-

\begin{tabular}{|c|c|c|c|c|}
\hline & $6^{\circ} \mathrm{C}$ & $15^{\circ}$ & $35^{\circ}$ & $76^{\circ}$ \\
\hline Flow & 2.5 & 6.5 & 32 & 188 \\
\hline
\end{tabular}

With water at $19^{\circ} \mathrm{C}$. the flow was $4300 \mathrm{c}$. em.

Mazout is easily heated, its specifie heat being 0.42 .

Petroleum also has a rapid expansion coefficient, as much as 0.0007 per degree Centigrade. This helps it to rid itself of water because, by heating the oil, both its sp. gr. and its resistance are reduced, and any water can the more easily gravitate out.

Though petroleum has been supposed to be unaffected by storage, mazout changes when exposed to air even more rapidly than coal, according to M. Bertin, losing its fluidity and parting with some of its calorifie power : experiment seems to be wanting in regard to such changes taking place in elosed tanks and not exposed to air. Any loss that may have been experienced may perhaps be attributed to a gradual evaporation of lighter oils still remaining. The lighter oils do possess the highest calorific eapacity, and their loss would therefore to some extent reduce the ealorific eapacity of the residue.

In Russia the sp. gr. of oil for steam raising purposes at $17 \cdot 5^{\circ} \mathrm{C} .=63.5 \mathrm{~F}$. must not exceed 911 to 912 , and oil must contain no water or sand or alkali. When reecived the temperature must not exceed $50^{\circ} \mathrm{C} .=122^{\circ} \mathrm{F}$. and the flash point must be above $140^{\circ}$ or $150^{\circ} \mathrm{C} .=284^{\circ}$ to $302^{\circ} \mathrm{F}$. 


\section{THE CHEMICAL AND OTHER PROPERTIES OF PETROLEUM}

Certain railroads stipulate a density of 905 to 915 at $14^{\circ} \mathrm{R} .=63.5^{\circ} \mathrm{F}$. There is no viscosity clause.

The Navigation Co. Caucase Mercure ask for a density of 926 . The Russian Navy accepts a flash point of $100^{\circ} \mathrm{C} .=212^{\circ} \mathrm{F}$. and a density of 950 . In America the minimum flash point of $200^{\circ} \mathrm{F}$. is usual $=93 \cdot 3^{\circ} \mathrm{C}$.

\section{Water in Oil.}

To determine the water $q$ the density $d$ is found of the sample. After heating for some time at $103^{\circ} \mathrm{C} .=217^{\circ} 5^{\circ} \mathrm{F}$. the density is again found $=d_{2}$. The quantity of water $q$ is determined by this relation $(1-q) d_{2}+q=d$.

The coeffieient of expansion per degree C. is assumed to be $0.000735=0.000408$ per degree $\mathbf{F}$. 


\section{Chapter VII}

\section{MATERIALS}

T $\mathrm{N}$ the utilization of fuels for steam raising purposes it is necessary to have a knowledge more or less full of the whole of the materials which will be employed either as fuels or structurally. Something must also be known of the environment in which such substances will be employed.

A list of substances with which the engineer will be required to deal therefore includes, besides the fuel itself, air, water, cast iron, steel, firebrick, etc.

The conditions include the ordinary atmospheric temperatures and moisture, the pressure of the atmosphere, and so on.

The units in which ideas are expressed must also be clear.

With this object separate sections have been given to the subjects of Water, Air, and Heat in its various forms, to carbon and hydrogen, the only two practicable fuels. A few notes are given below concerning some of the other materials.

\section{Cast Iron. -}

This is the form in which iron is obtained when first reduced from its ores. It is a more or less complex alloy of iron with silicon, sulphur, phosphorous and carbon in various states of aggregation. It is one of the best and most convenient materials for fire bars, and though it melts at the ordinary temperature of a furnace, the bars are kept cool by the air rushing between them. Cast iron cannot therefore be employed in the furnace itself. It is rapidly destroyed by the action of the fire even when not directly in the flame. It should not be employed in the retort in which to heat and to gascfy even the light burning oils. Cast iron tubes have been tried for this purpose and have been found to become choked by a deposit of carbon, which may probably be due to some affinity between the carbon in the iron and that in the oil.

Cast iron should also never be employed as a material for any vessel exposed to internal pressure. It is brittle and devoid of extensibility and not therefore suitable for structures the giving way of which is likely to produce serious results.

For light parts of machinery cast iron may be used, the castings being toughened or malleableized by a process which removes their carbon, but the process has little or no effect in making material that is reliable as a structural material. It is, after all, merely improved cast iron. Malleable iron will resist heat better than cast iron as in the tuyeres of an air blast exposed to high temperatures. 


\section{MATERIALS}

Steel.

Steel is par excellence the material for all parts of boilers. Like cast iron, it will not withstand furnace temperatures except when backed by water as in the case of the plates of a boiler. It can be used for superheater tubes and will bear dull red temperatures for some time, but, if possible, steam should always be passing through the pipes when they are in the course of the heated gases.

Steel tubes only $\frac{1}{16}$ in. thick are employed by the Clarkson Capel Syndicate as the retort coil in which paraffin is vaporized. These coils are in the zone of flame and vaporize the oil on its way to the burner which they surround. They possess a fair durability owing to the heat absorbing power of the vaporizing liquid, and they are found to keep free of carbon deposit.

\section{Fire Bricks.}

The most important material for the furnace engineer is fireclay. High furnace temperatures will render even many fireclays liquid at the surface.

In a properly set boiler for coal burning the whole interior of the furnace and combustion chamber will be more or less fluxed and run partially into drops or stalactites, which hang from projecting edges. With liquid fuel, firebrick is a most necessary material for promoting combustion. It is a bad conductor of heat, and has the property of resisting high temperatures known as refractoriness. Fireclay is a material which is found beneath seams of coal.

Ordinary fireclays contain 58 to 62 per cent. of silica, 36 to 38 per cent. of alumina and from 1 to 3 per cent. of ferric oxide.

A large contents of silica denotes a good and refractory brick.

Dowlais firebrick contains no less than $87 \frac{1}{2}$ per cent. of silica and less than 2 per cent. of alumina, the remainder being oxide of iron with a trace of lime and magnesia.

Ganister, which is so much used in steel work, contains 89 per cent. of silica, $5 \frac{1}{2}$ of alumina, $2 \frac{1}{2}$ of iron oxide, and $2 \frac{1}{2}$ per cent. of material which is lost in burning.

A brick used in France is made from diatomaceous earth which is nearly pure silica. These French bricks are very porous and light, and when dry will float in water.

'The best fireclay comes from Stourbridge in England, Glenboig in Scotland, and Dinas in Wales.

Makers of fire brick are accustomed to supply a great variety of shapes, and blocks can be had for seating purposes or for furnace work, notably for over-fire arches and combustion chambers.

Fire bricks are also made specially for threading on water tubes so as to build up refractory walls upon water tubes for the purpose of securing the correct direction of gases and for promoting perfect combustion and smokelessness. It is said that carborundum is very refractory indeed, and that when finely powdered and made into a paint with soluble glass or silicate of soda, and painted on bricks, it will greatly assist in their preservation. Or the bricks may be dipped in the solution. The carborundum surface is then most refractory.

Far too little attention is paid by engineers to the fire bricks they use, and very heavy expenses are incurred in maintaining furnaces in order, expenses quite needless if proper attention is paid to the selection of the bricks.

In most cases when a furnace is to be repaired bricks are purchased from the 


\section{LIQUID FUEL AND ITS COMBUSTION}

nearest wharf, where they have lain exposed to rain and weather for weeks or even months. In their fully water-saturated condition they are at once built into the furnace and exposed at once to the full heat, with the result that the interior of the bricks is disintegrated and the bricks split up at once.

Speaking generally, it may be said that when a fire brick is made it should be fired at a temperature as high as that to which it will be exposed when at work.

The composition of the bricks has a great influence upon their durability in certain surroundings. A silica brick will run like treacle in certain surroundings and an alumina brick will fail in others, but a brick of alumina is as refractory as one of silica-indeed, more so as regards its ability to withstand high temperatures.

Having secured the right kind of brick, a sufficient supply ought to be kept in store to enable them to become dry before use. When built into place a slow fire only must be made and the heat gradually got up so as to allow the bricks to dry thoroughly before being highly heated. Whon a boiler is laid off from work it should be closed completely up by shutting the dampers and leaving the boiler itself and its surrounding brickwork to cool as slowly as possible.

The most troublesome detail of a furnace is the arching over the fire of a water tube boiler. The usual form of water tube boiler is very smoky, and to cure this the furnace must be covered by a brick arch, and a capacious combustion chamber must be employed beyond this, so that the furnace gases and the air admitted above the fire may become well mixed and burned at a high temperature. Even with the best of bricks these arches are apt to fail when first fired, the face of the bricks dropping off.

Messrs. E. and J. Pearson, of Stourbridge, make a special brick for these wide flat arehes and supply a special cement for use in putting them together. The cement is easily fluxed by heat and cements the whole surface of the arch into a solid face so that pieces of the brick cannot fall out. In time the whole arch welds into a solid mass.

Such an arch ought never to be built of any but properly shaped bricks. If plain rectangular bricks are used the arch pressure becomes concentrated upon the intrados and tends to flake off the bricks and deprive the arch of its sustaining power. The bricks should therefore be of taper form so that they fit close in the arch. What are known as blocks are used for these arches and for similar purposes, and the above fire brick manufacturers make special arch blocks with a tongue and groove joint for better security.

In the formation of all important fireclay blocks that will be exposed to stress, as is an arch, it is of serious importance that the clay be properly pugged into the mould. It is bad practice to put a block of clay into the mould and put it under mechanical pressure so as to force it to fill the mould. When this pressure method is followed the plastic clay will be internally fractured. Shearing planes are developed which form planes of cleavage or fracture. The movement may be very slight, but lines of wcakness will be developed and the homogencous continuity of the mass of the clay will be destroyed. When burnt, the adhesion along these planes of weakness will be imperfect and when at work such a block will fail. A homely parallel to this cleavage action is secn in the ordinary cake of fancy soap. These cakes of soap are formed by pressure from semiplastic slabs of approximately the same shape as the pressed cake. In the process of pressing to finished stamped form the mass of soap is compelled to shear internally along several planes, and when put into use these soap cakes invariably develop numerous lines of weakness and fall 


\section{MATERIALS}

into several pieces and shear off into slabs according to the direction of the shear lines.

In meehanieal engineering the same effect of lines of shearing caused by working stcel at too low a temperature can be seen in steel balls, which frequently appear to have suffered internal shear by some process of pressure in course of manufacture and fail along surfaces the structure of which certainly lends support to this view.

So it is with fireclay lumps, and these ought certainly to be pugged into the moulds so that there may be no internal lines of weakness along which failure is sure to oeeur.

A really good arch should last a year if built from a firm springing. The thrust of an arch is eonsiderable and must all be taken by the side walls, which, not as a rule carrying the weight of the boiler, may not be very stable, and it is desirable to tie them down to the foundation by through vertical bolts so as to form a stiff unyielding support for the arch springing.

The subjeet of fire brick is one that has not been studied by engineers. Steel melters and others who deal with high temperatures have paid attention to the question. The burning of coal for steam raising purposes has, however, bcen so invariably carried out at eomparatively low temperatures that the importanee of fire brick has not been perceived. When a steam engineer begins to experience trouble with his furnace side wall lining he casts about him for some means of meeting that trouble, and his efforts usually take the shape of a water box. High temperature he regards, when it occurs, as a disagreeable ineident, to be cheeked and avoided. If he understood combustion he would welcome the temperature as a means of securing more perfect combustion and would endeavour to meet the trouble by the provision of suitable fire brick.

The high temperatures which are obtainable with oil fuel are likely to bring the fire brick problem into greater prominence and to direet attention to this most important material.

Some fire bricks in a very hot furnace will soften and melt away under long sustained heat. Others, more refractory or infusible, erack and split up under sudden temperature ehanges. A good brick becomes surface glazed but the body remains rough and porous. A granular nature and porous texture are considered essential, and fire bricks are not made of all new clay. Old bricks are granulated and mixed up with the new clay so that the neessary texture is secured.

Fireclay is a mixture of siliea and alumina in varying proportions, each constituent possessing its own peculiar characteristies. Usually silica exists in the proportions of about two-thirds to one-third of alumina. The presence of alkaline matter is prejudicial and induces fluxing. Thus lime is intensely refractory of itself and so is magnesia, but both of these infusible substanees fuse easily with silica, as also do oxide of iron, soda, potash and other alkalies. These impurities of fireclays must be avoided. Mixing two clays of good quality will not necessarily prove a suecess.

Siliea, if otherwise pure, gives perhaps the most refractory bricks, and certain French fire brieks are made from infusorial earth which consists of the minute siliceous shells of the diatomaceæ. These French bricks, when dry, will float in water, their speeific gravity being under 1,000, owing to the numerous voids and pores, but these bricks are very tender and do not stand well at the firegrate level where a tougher and harder brick is necessary. The Dinas brieks of South Wales are very siliceous buti are liable to split up if suddenly cooled, and are therefore some- 


\section{LIQUID FUEL AND ITS COMBUSTION}

what unsuitable for hand fired furnaces, but should be excellent for mechanicallystoked furnaces with self-cleaning grates. Probably the best boiler furnace brick is one high in silica, yet containing a fair proportion of alumina and frec from alkalics. Such a brick combines the properties of infusibility and toughness for puddling furnaces, coke ovens, gas retorts and other high temperature uses, and it must be remembered that the kind of furnace advised by the author for bituminous fuel combustion, and adopted from sheer necessity with liquid fuel, is exposed to temperatures more resembling those of metallurgical furnaces than the starved temperatures of the common unscientifically set steam boiler.

A sample of the clay from the Glenboig Star Mine, as analysed by Edward Riley, F.C.S., after calcination, gave the following results-

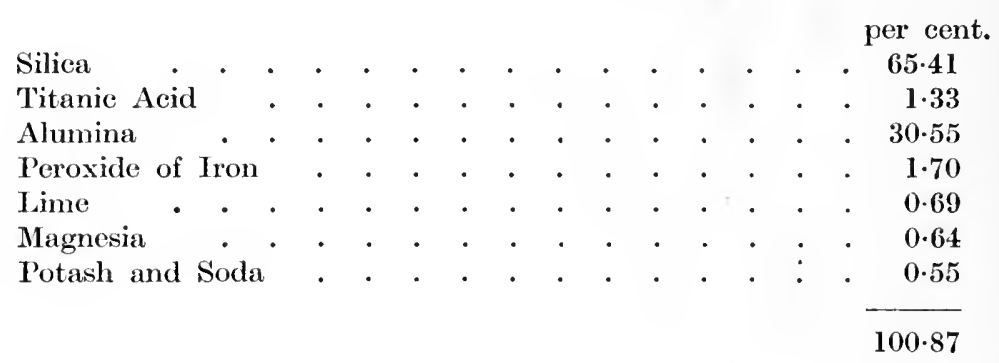

Sir Frederick Abel analysed a Glenboig brick, at the Royal Arsenal, Woolwich, as follows. The brick was taken from stock -

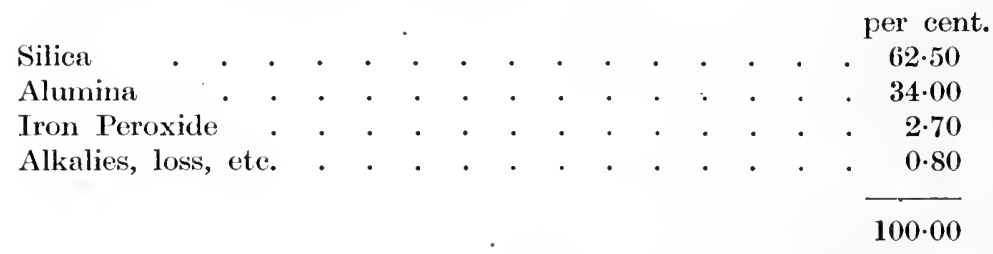

Mere analysis, however, does not tell everything. For instance, in this last analysis the silica and alumina were largely in chemical combination, and this is more valuable than the mere mechanical combination of the constituents.

To make a good brick the clay must be suitably weathered so that any iron nodules may separate out. The clay is rendered smoother and more solid for articles requiring such qualities, as seating blocks; and for high temperatures, porosity is given by the addition of old bricks.

All defects of shape are produced in the drying stove after moulding. Stoving is therefore a most important operation, and a brick must be practically dry before firing which is gentle at first until the bricks are hot and perfectly dried out. Then the kiln is put on to full fire and the temperature must be maintained until the bricks cease to shrink. A brick which has not been fired at a full temperature may shrink further if put to work at a higher temperature. The total shrink from the moulded size is about $8 \frac{1}{3}$ per cent. of the bulk or about 2 per cent, linear measure. In any case no shrinkage should remain in a brick or it will shrink when put to work and pull the brickwork in pieces.

Professor Abel, F.R.C., gave various analyses of fireclays as per the annexed 


\section{MATERIALS}

\begin{tabular}{|c|c|c|c|c|c|c|c|c|c|c|c|}
\hline \multicolumn{8}{|c|}{ Description of Fircelay. } & \multirow{2}{*}{$\frac{\text { Silica. }}{59 \cdot 10}$} & \multirow{2}{*}{$\frac{\text { Alumina. }}{35 \cdot 76}$} & \multirow{2}{*}{\begin{tabular}{|c|} 
Iron Peroxide. \\
$2 \cdot 50$
\end{tabular}} & \multirow{2}{*}{\begin{tabular}{|} 
Alkalies, Loss, \\
ete. \\
$2 \cdot 64$
\end{tabular}} \\
\hline Kilmarnock & & . & . & . & . & . & . & & & & \\
\hline Stourbridge & & . & & . & . & . & . & $65 \cdot 65$ & $26 \cdot 59$ & $5 \cdot 71$ & $2 \cdot 05$ \\
\hline , & & . & . & . & . & . & . & $67 \cdot 00$ & $25 \cdot 80$ & $4 \cdot 90$ & $2 \cdot 30$ \\
\hline , & & . & . & . & . & . & . & $66 \cdot 47$ & $26 \cdot 26$ & $6 \cdot 33$ & $0 \cdot 64$ \\
\hline, & & . & . & . & . & . & . & $58 \cdot 48$ & $35 \cdot 78$ & $3 \cdot 02$ & 0.72 \\
\hline ", & . & . & . & . & . & . & . & $63 \cdot 40$ & $31 \cdot 70$ & $3 \cdot 00$ & 1.90 \\
\hline Newcastle & . & . & . & . & . & . & . & $59 \cdot 80$ & $27 \cdot 30$ & $6 \cdot 90$ & $6 \cdot 00$ \\
\hline , & . & . & . & . & . & . & . & $63 \cdot 50$ & $27 \cdot 60$ & $6 \cdot 40$ & $6 \cdot 50$ \\
\hline Glenboig & . & . & . & . & . & . & . & $62 \cdot 50$ & $34 \cdot 00$ & $2 \cdot 70$ & $0 \cdot 80$ \\
\hline
\end{tabular}

From which the excellence of Stourbridge and Glenboig bricks is plainly evident in the small percentage of alkalies.

For the following miscellaneous information the author is indebted to the Glenboig Company-

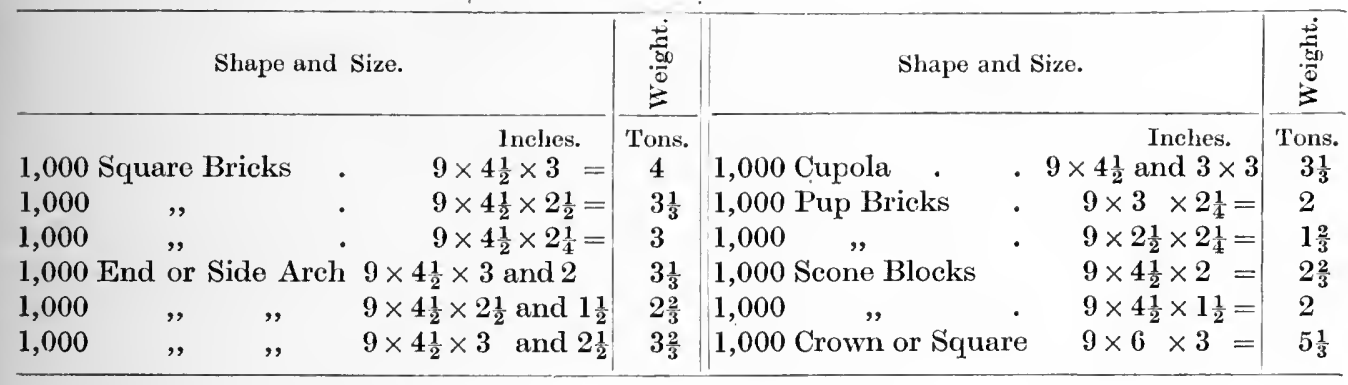

One Inch $=$ Millimetres 25.4. $\quad$ One Ton $=$ Kilogrammes 1,016 .

\section{MISCELLANEOUS WEIGHTS AND MEASUREMENTS.}

STACKED LOOSE.

1,0009 inch $\times 4 \frac{1}{2}$ inch $\times 2 \frac{1}{2}$ inch $=66$ cub. ft.

1,0009 in. $\times 4 \frac{1}{2}$ in. $\times 3$ in. $\times 3$ in. $=80$ cub. $\mathrm{ft}$.

BUILT WITH FIRECLAY.

1 square yard 9 in. work requires 109 bricks 9 in. $\times 4 \frac{1}{2}$ in. $\times 2 \frac{1}{2}$ in. and 2 cwts. Ground fireclay, or 92 bricks 9 in. $\times 4 \frac{1}{2}$ in. $\times$ 3 in. and $1 \frac{2}{3}$ ewts. ground fireclay.

A rod (English) of brick $=11 \frac{1}{2}$ cub. yds.

$A$ rood (Scotch) of brick $=16 \mathrm{cub}$. yds. FOR PAVING.

1 yard superficial requires 16 tiles 9 in. $\times 9$ in. 18 tiles 12 in. $\times 6$ in. $\times 2$ in.

32 bricks 9 in. $\times 4 \frac{1}{2}$ in. $\times 3$ in. laid flat. 48 bricks 9 in. $\times 4 \frac{1}{2}$ in. $\times 3$ in. laid on edge.
One 9 inch $\times 4 \frac{1}{2}$ inch $\times 3$ inch $=9 \mathrm{lbs}$. $17 \frac{1}{2}$ cub. ft. blocks $=1$ ton 334 bricks $=1$ load.

1,500 to $2,000=1$ railway truck.

3,100 to 3,2009 in. $\times 4 \frac{1}{2} \times 2 \frac{1}{2}$ in. bricks $=1$ railway truck (Continental).

6 to 8 tons ground fireclay $=1$ railway truck. 8 bags ground clay $=1$ ton. 3 casks ground clay $=1$ ton.

21 cub. ft. of dry ground fireclay, firmly packed $=1$ ton.

Fireclay suffers no deterioration of quality from rain.

For shipment it is packed in barrels or bags. The usual shipping size of firebrick is $9 \mathrm{in}$. $\times 4 \frac{1}{2}$ in. $\times 2 \frac{1}{2}$ in.

The Glenboig Company make special silica bricks from English chalk flints which weigh 2 tons $12 \mathrm{cwt}$. per 1000,9 in. $\times 4 \frac{1}{2} \mathrm{in} . \times 2 \frac{1}{2}$ in. They also make a highly refractory brick from Gartcosh clay, which analyses as below, according to W. Wallace and Jno. Clark, Ph.D., F.C.S., etc.- 


\section{LIQUID FUEL AND ITS COMBUSTION}

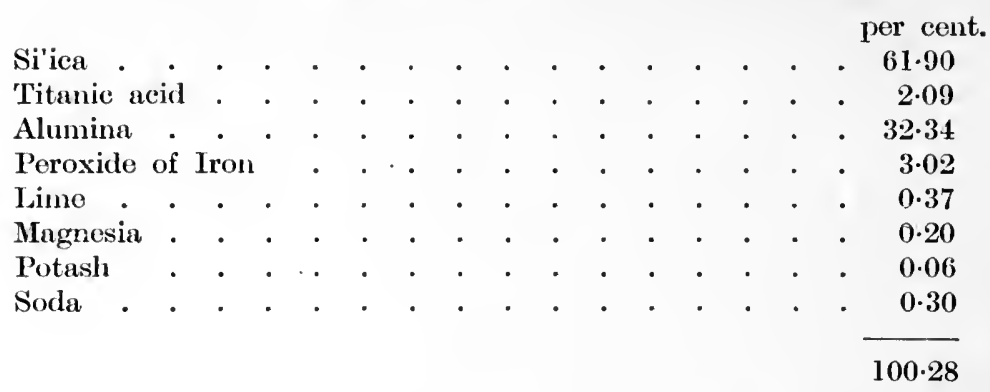

The proportion of alkalies is thus small and the brick is solid and has small shrinkage from the mould and weighs 131 pounds per cubic foot. The ganister bricks of the Company, which are made from what appears to be a soft sandstone, analyse as below-

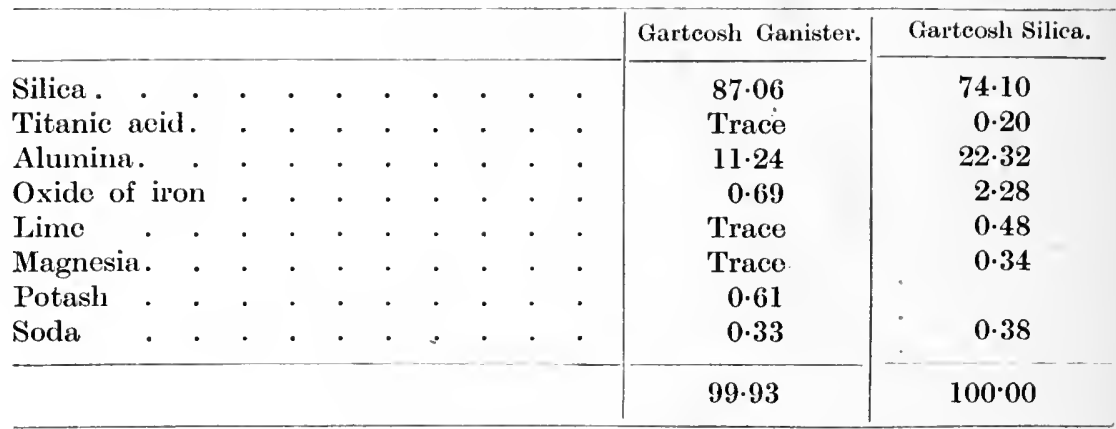

Bricks for Oil Fired Furnaces.

Where bricks are applied to oil fired furnaces the intense local heat of the oil furnace of course burns the brickwork away in time, or rather melts it on the surface immediately in contact with the flame, causing it to run down and hang in the form of stalactites, but it takes a considerable time to wear through nine inches of brickwork, and the cost of the bricks is more than compensated for in the increased efficiency of the furnace.

It is often the case, says Mr. Page, of Stourbridge, to whom the author is much

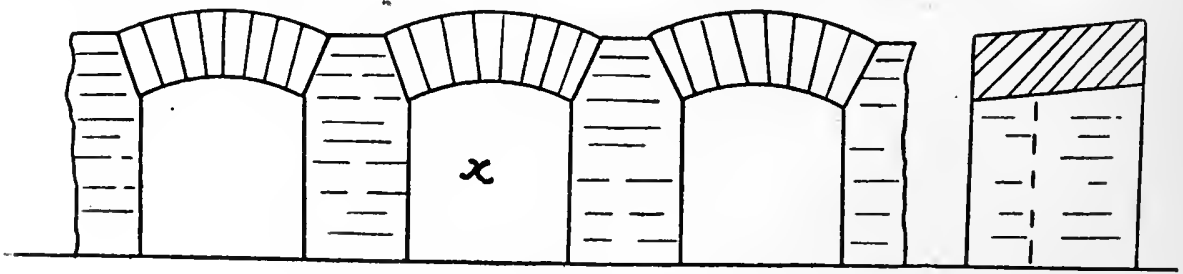

(a)

indebted, that furnaces and combustion chambers lined with firebrick come to grief through being badly built rather than from the bad quality of the bricks used; at the same time, good work will not make up for bad bricks. The usual type of liquid fuel furnace for kilns is as shown in the annexed illustration $(a)$, the burner being so set that the fuel in vaporized form is more or less concentrated in the centre arch at $x$. The consequence is that the intense heat is localized and the brick work 


\section{MATERIALS}

runs down into slag. Various methods have been tried to get over the difficultyone is to cover the grate with broken fire brick, or coke, but this was not altogether

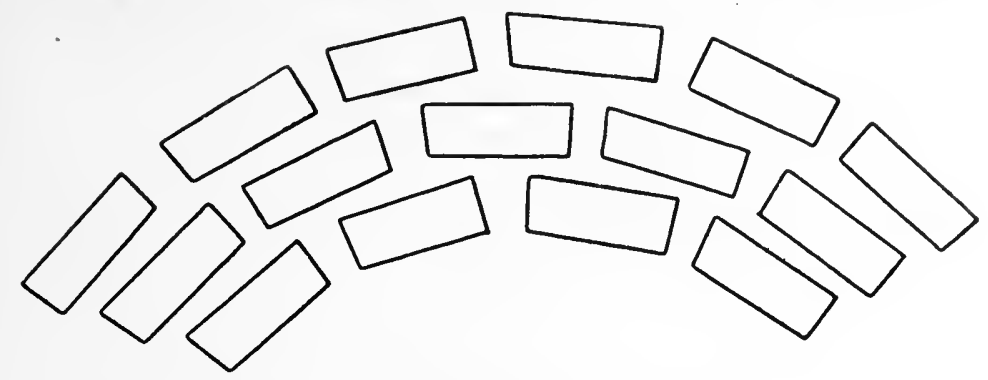

(b)

successful. Another idea is to protect the piers of the arches with bricks piled up
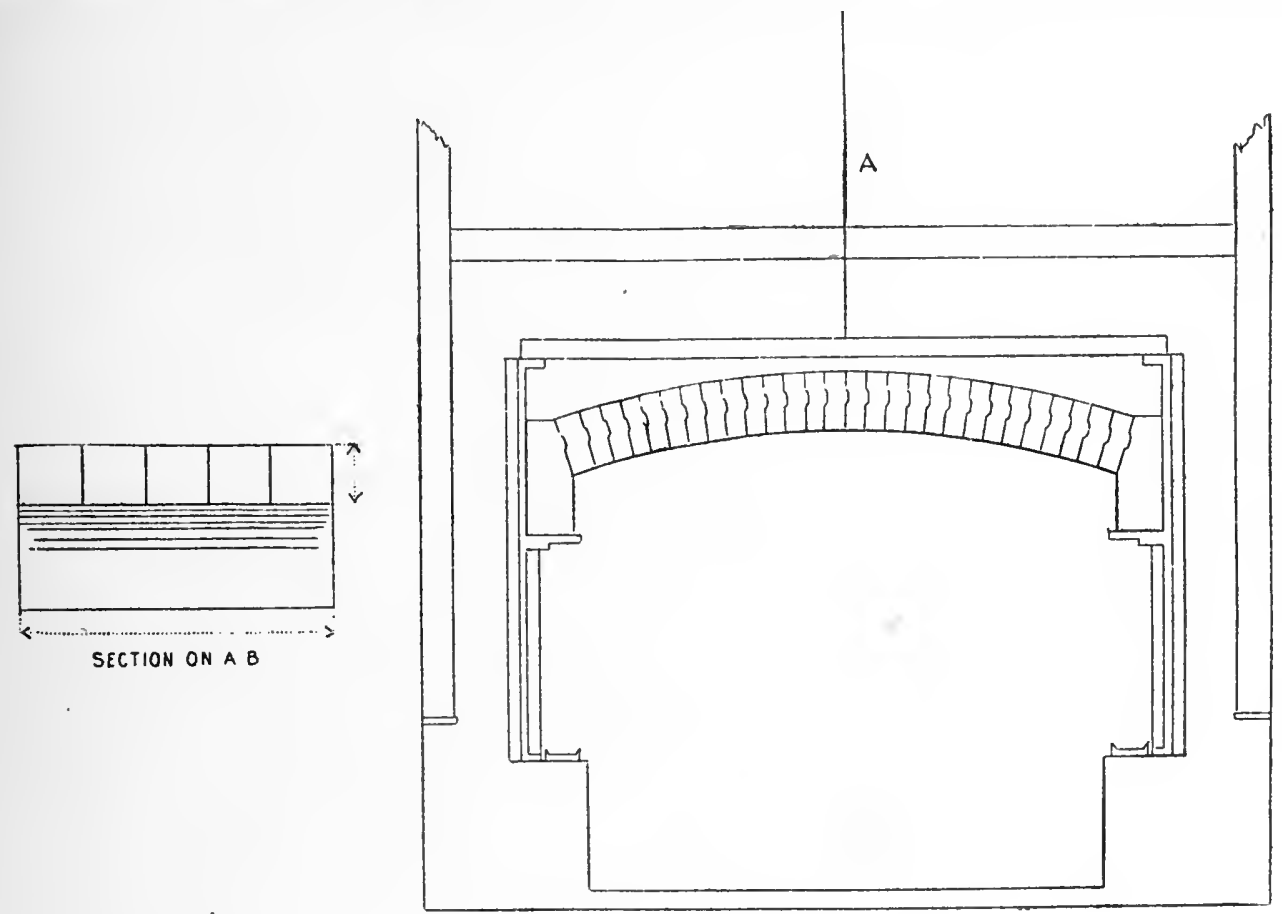

ELEVATION

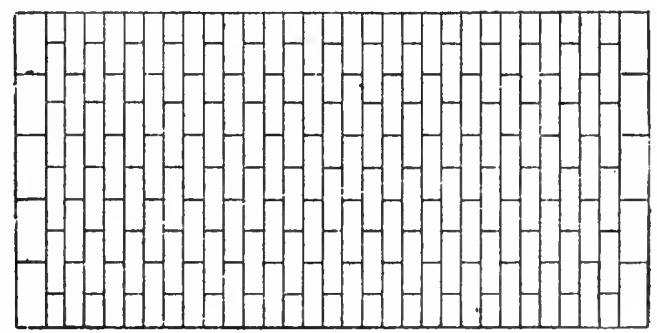

$\underset{B}{P \perp A N}$

(c)

loosely in semicircular form with the concave side facing the burner, stacking them 


\section{LIQUID FUEL AND ITS COMBUSTION}

with a space between each one, and crossing the open space with another row of bricks, as shown in plan, Fig. (b), thus distributing the heat over a large area of brick surface.

The bricks would melt after a time, but they could be raked out and a fresh lot put in, and the arches would be saved considerably.

In the case of over-fire arches, Fig. $(c)$, for water tube boilers having a wide span, the best type of brick to use is what is known by the name of the Bullhead or Endwedge, as shown in Fig. $(d)$, or the special bricks of Fig. $(f)$.

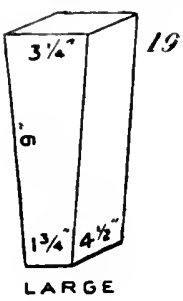

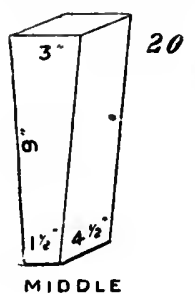

$(d)$
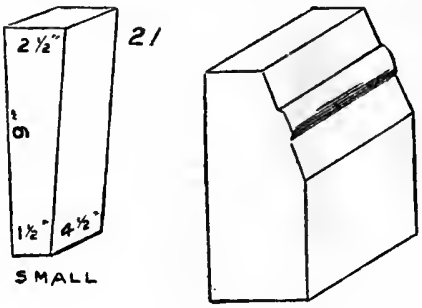

SPRINGER

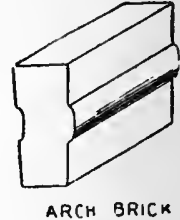

$(f)$

In all cases fire bricks should be set with as little jointing material as possible, and for arches the bricks should be specially made to work to the desired radius. Any attempt to use ordinary rectangular bricks is fatal. The pressure becomes con-

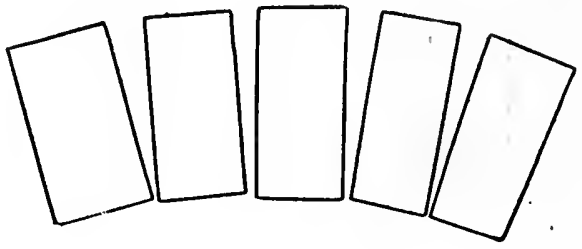

$(g)$

centrated on the under side of the arch, as in Fig. $(g)$, and the mass has no rigiditybricks begin to fall out and the arch is ruined.

The bricks should be set with finely ground fireclay made up with water to the consistency of thick paint. The brick should be dipped in this, and then rubbed into contact with its neighbours.

Firclay is made up into specially shaped bricks and lumps for different purposes, and bricks and blocks can be made to meet the special requirements in furnace work, but unequally proportioned lumps must be avoided on account of internal stresses, fireclay having its limitations in this respect, as explained above, just as cast iron has. The best plan is to consult a reputable maker. The most usual course is to decide on all other points of construction and make the best job possible on what are gencrally considered incidentals, such as furnace linings, whereas by taking the limitations of a necessary material into consideration in the first place, much expense and trouble may be saved.

Improperly made bricks and lumps lack homogeneity, and often contain planes of cleavage developed in bricks forced into shape by mechanical pressures. These, being internal, are not seen, but the unequal strains brought on the structure of the brick by heating on one side or end only develop the weakness and cause a block to "fly" or break up into several pieces.

Good fire bricks should have sharp angles and give a metallic ring on being 


\section{MATERIALS}

rubbed together. They should be kept some time before use in a dry place. Bricks sodden with rain and heated up quickly will tend to burst.

Various substances having been suggested as substitutes for fire brick, it may not be out of place to say something as to the varieties of fireclay goods.

The following is the classification generally adopted-

$\begin{aligned} & \text { I } \text { Silicious fireclay goods. } \\ & \text { II Aluminous ," , , } \\ & \text { III Argillaceous ," , } \\ & \text { IV Carboniferous , , , }\end{aligned}$

Nos. I and II are the most generally used.

No. IV is a mixture of carbon and clay, the carbon being in a crystallized state as used for arc lamps, etc., or amorphous as graphite, the latter being used for the manufacture of crucibles, etc. Carbon blocks have been suggested, but, apart from the excessive cost, the carbon combines with any free oxygen in the furnace gases and is consumed.

No. II. A mixture containing a greater portion of alumina than pure clay. This also is too costly for general use.

Lime is sometimes used as furnace lining for electrical kilns and will withstand the intense heat of the voltaic arc, but as it retains the property of being hydrated in air, its use is necessarily very limited. This class of fireclay goods is known as basic.

Silicious fireclay goods are composed almost exclusively of silica.

Argillaceous fireclay goods are composed of silica and alumina, and are next in degree of refractoriness to aluminous goods.

It should be borne in mind that the foregoing are each adapted to particular purposes, and the proper admixture of clays for any desired purpose is a matter that only long experience and scientific knowledge can determine, the physical as well as the chemical propertics of clay having to be taken into account.

\section{Siloxicon.}

The latest refractory material is Siloxicon, a product of the electric furnace consisting of carbon, silicon and oxygen formed at a temperatue of $4,000^{\circ}$ to $5,000^{\circ} \mathrm{F}$. and therefore very refractory at ordinary temperatures. It is a loosely coherent mass as formed and is ground to pass a $40^{2}$ sieve. It is an amorphous grey-green compound when cold, becoming light yellow at $300^{\circ} \mathrm{F}$. It is insoluble in molten iron, neutral to acid and basic slag, indifferent to all save hydrofluoric acid, and is unattacked by hot alkaline solutions. It is formed into bricks by simple pressure, when damp, and fired. It is neutral to clays and will not oxidise, and appears likely to form a valuable furnace lining where oil fuel is employed. 


\section{Chapter VIII}

\section{COMBUSTIBLES AND SUPPORTERS OF COMBUSTION}

\section{Carbon.}

CARBON is an elementary substance which has the following properties. Its atomic weight is 12 and it is tetravalent in chemistry.

It is found free in Nature in various forms, but is usually considered to exist only in three allotropic modifications, viz.-

(1) The Diamond.

(2) Graphite.

(3) Charcoal.

The diamond is practically pure crystallized carbon. Graphite is some distance from the diamond but is not entirely amorphous, whereas charcoal is an amorphous substance, and is considered to include all other forms of carbon, including gas retort carbon and anthracite coal. Carbon also occurs combined in the rocks in immense quantity. The whole of the carboniferous limestone rocks, the chalk and other lime rocks, are chiefly constituted of carbonate of lime $\mathrm{Ca} \mathrm{CO}_{3}$, and contain 12 per cent. of their weight of carbon. The atmosphere contains 4 volumes in 10,000 of carbon dioxide gas, or approximately 1 in 10,000 of carbon. The weight of carbon in the atmosphere is thus about eight hundred thousand millions of tons, or about equal to 1,000 years of the present rate of coal consumption of the world.

The atmosphere is the source whence alone plants obtain their carbon, and it is the sink into which all fuels are ultimately discharged when burned, and into which animals expire the waste earbon rejected as $\mathrm{CO}_{2}$ in their breath. It is by the agency of plant life, and plant life alone, that carbon is extracted from the air and again fixed in solid unoxydised form, as woody fibre. The green colouring matter of plants has, in the presence of sunlight, the power of decomposing the carbonic acid of the air, appropriating the carbon to itself for the formation of woody tissue, and setting free the oxygen for the support of man and animals. Prior to the formation of the large coal deposits of the earth, the air was very much more charged with carbonic acid than at present, and probably plant life was much more luxuriant at that period and coal was quickly deposited. Only by aid of plants can the balance be maintained. Without the laying down of fresh stores of coal the whole of the existing coal as burned will be returned to the atmosphere, and, it is perhaps conceivable, might reduce the present energy of the human race and effect its own cure by allowing Nature once more to store up carbon at a rate in excess of its combustion by man. 


\section{COMBUSTIBLES AND SUPPORTERS OF COMBUSTION}

Liquid fuel, found as it is so generally in the presence of salt, is thought to have been deposited from seaweed, and there is no reason to suppose otherwise than that its formation is still in progress in the ocean depths, and that in the formation of petroleum another agency is at work which is carrying out the purification of our atmosphere and perhaps deferring indefinitely the period when the air will no longer support life in its present vigour.

The following figures give the relation of the various forms of carbon in calorific value or heat absorption-

\section{Combustion.}

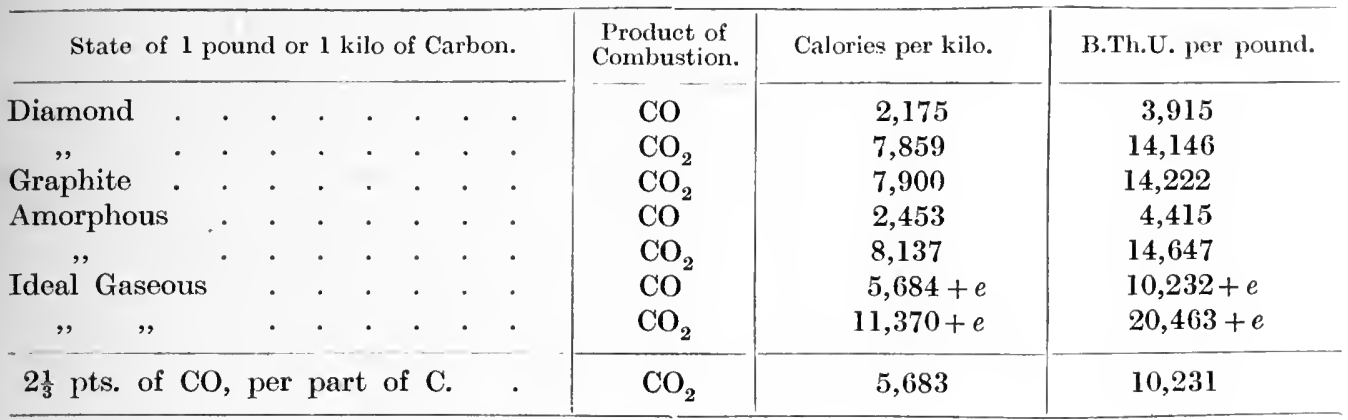

Heat Absorbed by Metamorphic Conversion.

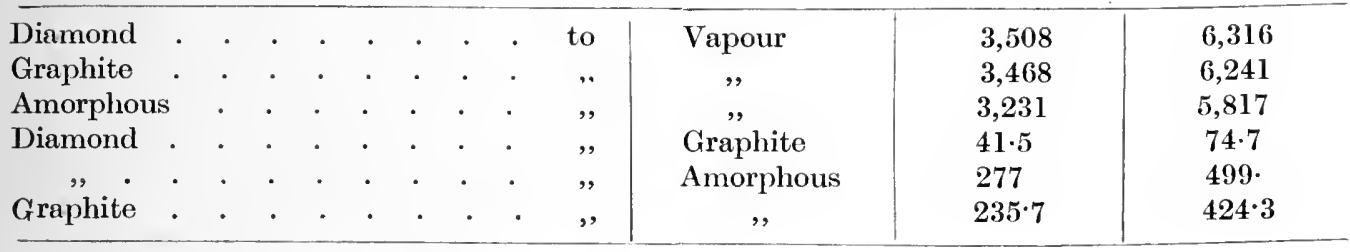

The above figures are calculated from the determinations by Berthelot of the heat of combustion and formation of the molecule (see Thermochimie, par M. Berthelot, Paris, 1897).

As it requires heat to split up the erystalline structure of the diamond and convert it into graphite, and again more heat to convert it into amorphous form, so the diamond when burned produces less heat than graphite or charcoal. The differences, namely 74.7 and $424 \cdot 3$, are the amounts of heat necessary to destroy all crystalline structure. The figures show that graphite is much nearer to the diamond than it is to charcoal in its possession of definite molecular structure. When the diamond crystallized it gave out heat, and like all crystalline bodies, it is exothermic. Except that these facts point the appropriate lesson that form and state are dependent upon heat, either apparent or latent, no further interest centres on the crystalline modification of carbon, which is too scarce to employ as a commercial fuel. The first oxidation of ordinary carbon with one atom of oxygen to $\mathrm{CO}$ produces 4415 B.Th.U. $=2,453$ cal. per pound and per kilogram respectively.

The second oxidation produces a further 10,231 B.Th.U. $=5,684$ cal. The total heat produced by complete combustion is thus 14,647 B.Th.U. $=8,137$ cal.

The difference $(5,684-2,453)$ between the two oxidations is 5,817 B.Th.U. $=$ $3,232 \mathrm{cal}$., and Berthelot considers that this difference is less than the latent heat 


\section{LIQUID FUEL AND ITS COMBUSTION}

of vaporizing carbon by an unknown amount. In the absence of a knowledge of what it amounts to, it is usual to say that the difference is the latent heat of vaporizing carbon just as 966 is the latent heat of steam.

To liquefy carbon must also absorb heat, but frec liquid carbon is unknown. Solid carbon burns directly to dioxide gas without going through the intermediate liquid state, exactly as a piece of ice will disappear in a dry cold wind below freezing temperature without passing through the intermediate state of water. The liquid state is not imperative, and carbon is only found liquid when combined with other substances. It forms a liquid with sulphur as carbon bisulphide $\mathrm{CS}_{2}$. It is liquid with hydrogen and oxygen in alcohol, and it is liquid with hydrogen alone in the many hydrocarbons with which we are at present concerned. By so much as the liquid form already represents heat rendered latent in reducing a solid to a liquid, by just so much should liquid fuel possess a greater calorific value per unit of its contained carbon than a similar weight of solid fuel. The same argument applies with equal force to the hydrogen, but to some extent conversely. The calorific capacity of hydrogen is given in terms of the gas burned as gas. In solid coal the hydrogen is solid, and it is scarcely correct to calculate the calorific capacity of a solid fuel in terms of its hydrogen at gas value, for undoubtedly heat is absorbed in rendering the hydrogen gaseous from its solid combined state in coal. Similarly, in liquid fuel the hydrogen is in liquid form and must be gasefied. It is possible that the benefit derived from the liquidity of the carbon is neutralized by the liquidity of the hydrogen.

We may assume for argument that the ratio of liquid carbon to gaseous carbon approximates the ratio of liquid and solid water. Whence $5,817 \times \frac{142}{966}=855$ B. Th. U. per pound $=475$ cal. per kilo., as the advantage of liquid fuel over solid fuel in respect of its carbon contents being liquid in place of solid. This represents a better efficiency of possibly 5.84 per cent., so that it seems probable that the liquid form of fucl does not add much to its efficiency.

The properties of carbon are summarised in the following table-

\section{Properties of Carbon.}

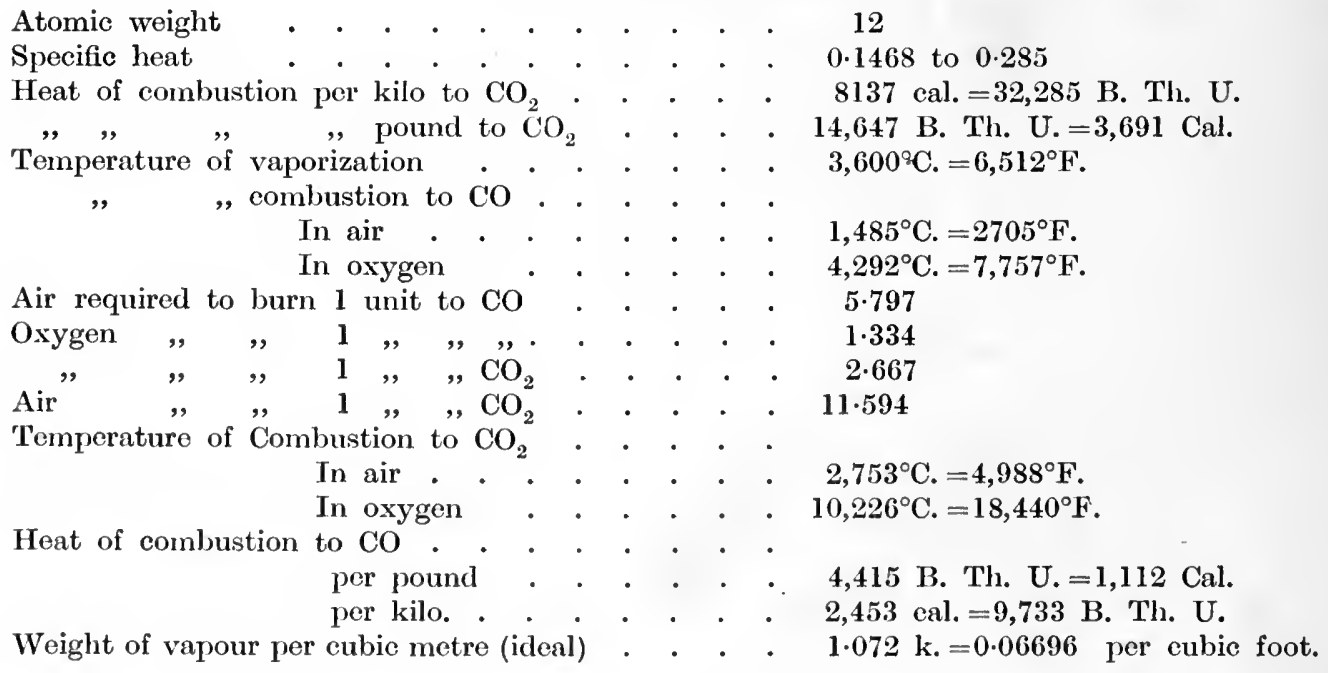

The atomic weight of carbon being 12 and that of oxygen 16, the formula 


\section{COMBUSTIBLES AND SUPPORTERS OF COMBUSTION}

for carbon monoxide $=\mathrm{CO}$ tells that there are 12 parts by weight of carbon in each 28 parts of the gas.

Hence 1 pound of carbon unites with $1 \frac{1}{3}$ pounds of oxygen to produce $2 \frac{1}{3}$ pounds of gas.

When burned to dioxide $=\mathrm{CO}_{2}$ there are 12 parts of earbon to each 32 parts of oxygen, and 1 part of carbon unites with $2 \frac{2}{3}$ parts of oxygen to produce $3{ }_{3}^{2}$ parts of gas.

As oxygen is not available for steam production except in the form of air, and as it is not desired to produce $\mathrm{CO}$, the essential figures to remember are that each unit weight of carbon demands a minimum of nearly 11.6 units of air.

In the foregoing table the temperatures given are simply those calculated on the assumption that the specific heat of the gases produced remains the same at all temperatures and that combustion is complete. Neither assumption represents actual facts, for the process of combustion is delayed as temperature rises, and even if it were not, the specific heat increases and holds back the temperature. As, however, in practice there are so many effects of dilution, the calculation of total heat can be correctly done on a basis of constant specific heat. If a final temperature of great intensity is found, a correction can always be applied after all calculation has been made.

The various figures given in this book differ somewhat from many previously accepted figures, owing to the progress of the science of thermo-chemistry; the figures given herein being those given by Berthelot in his work, Thermochimie, 1897 .

Carbon burned to $\mathrm{CO}$ or directly to $\mathrm{CO}_{2}$ does so with simple incandescence. No flame is produced. Carbonic oxide $=\mathrm{CO}$, however, if formed by the burning of carbon with insufficient air, will burn with a blue flame if provided with air.

The hydrocarbon gases burn with a reddish, a yellow, or a white flame, according to surroundings and temperature, the flame consisting of glowing carbon in an atmosphere of hot gas.

\section{Hydrogen.}

Hydrogen shares with carbon the monopoly of the term fuel, for there are no commercial fuels except carbon and hydrogen or their joint compounds. Hydrogen is a gas. Its atomic weight is 1 , and being the lightest known element, it serves as the unit of atomic comparison.

Its physical and other properties are as follows-

Atomic weight and density

Specific heat. Constant vol.

, , , pressure

Weight per litre

" " cubic foot

Cubic feet per pound.

Litres per kilogram

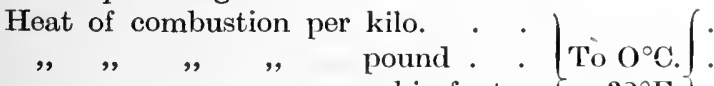

, , , , ,

Specific gravity, water $=1$ litre

Point of vaporization

, , freezing or liquefaction
1

$2 \cdot 4146$

$3 \cdot 410$

0.08961 grams $=0.000089 \mathrm{k}$.

0.00559 pound $=0.002536 \mathrm{k}$ $178 \cdot 83=5,063 \cdot 4$ litres.

$11,160=394 \cdot 15$ cubic feet.

34,500 cal. $=136,900$ B. Th. U.

62,100 B. Th. U. $=15,650 \mathrm{cal}$.

347 B. Th. U. $=87.45 \mathrm{cal}$.

3.091 cal. $=12 \cdot 264$. B. Th. U.

0.0714 when liquefied.

$33^{\circ}$ abs. C. $=60$ abs. $\circ$.

$16 \cdot 7^{\circ}$ abs. C. $=30^{\circ}$ abs. F. 


\section{LIQUID FUEL AND ITS COMBUSTION}

Temperature of combustion

(nominal) in oxygen.

Ratio of air required to burn 1 unit weight

$$
\begin{aligned}
& 6,762^{\circ} \mathrm{C} .=12,202^{\circ} \mathrm{F} . \\
& 2,513^{\circ} \mathrm{C} .=4,554^{\circ} \mathrm{F} .
\end{aligned}
$$

$34 \cdot 785$

$2 \cdot 39$

$8 \cdot 00$

$0 \cdot 50$

29,150 cal. $=115,434$ B.Th.U.

52,290 B.Th.U. 13,177 eal.

Calorific Capacity.-Hydrogen forms very numerous compounds with carbon, and these compounds are usually treated of under the head of organic chemistry, for it is from the products of living organisms that they are derived. The tars are derived from coal, itself a vegetable product, and the mineral oils appear to be the result of marine organisms.

The heat of combustion of hydrogen is 62,100 B.Th.U. per pound. This value assumes that the products of combustion are rejected in a liquid state. In furnace work, however, the gases of combustion always leave at temperatures above $100^{\circ} \mathrm{C}$., and consequently the gases carry off with them the latent heat of evaporation. This reduces the available heat of burning hydrogen to 52,290 B.Th.U. per pound or 29,150 cal. per kilogram, or say 293 B.Th.U. per cubic foot and 2.612 cal. per litre. This fact must be borne in mind when calculating results.

Syoke Production.-Hydrogen ignites at a temperature below that necessary to ignite carbon. Its affinity for oxygen is greater, and, in presence of an insufficient supply of air, the hydrogen of a hydrocarbon fuel will first secure its share of oxygen and the carbon will appear as soot. Sudden cooling of a hot hydrocarbon gas is also said to produce soot, but it is questionable if soot is really produced without a certain amount of combustion of the hydrogen.

The following table gives the temperature of ignition of a few of the hydrocarbon gases according to Mayer and Munch-

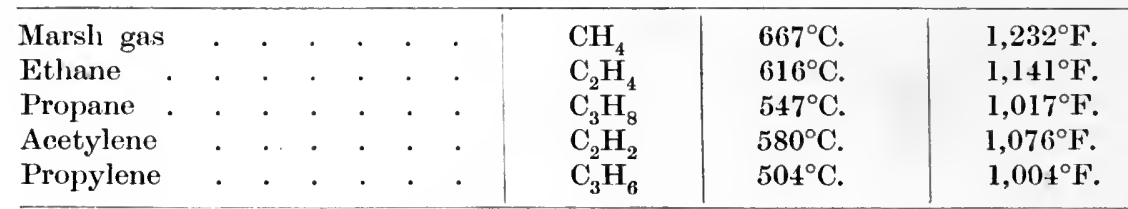

Hydrogen burns with a transparent blue flame. Its compounds with carbon burn with a light-giving flame consisting of incandescent carbon particles carried in an atmosphere of gas.

These hydrocarbons are exceedingly numerous, and range from gases of small density through every shade of liquid to solids like naphthalene and paraffine wax. The empirical composition of all the hydrocarbons of the liquid petroleums is $\mathrm{C}_{\mathrm{n}} \mathrm{H}_{2 \mathrm{n}}$ or $\mathrm{C}_{\mathrm{n}} \mathrm{H}_{2 \mathrm{n}} \pm_{2}$, etc. (See Chemistry of Liquid Fuels.)

It follows from this that the percentage of carbon and hydrogen in a petroleum of any degrec of refinement does not vary far from 84 of carbon and 16 of hydrogen corresponding with a mean formula of $\mathrm{C}_{7} \mathrm{H}_{16}$

Air.

Oxygen being necessary for combustion, there is only one source whenee it can be obtained in large quantity, viz., the atmosphere. 


\title{
COMBUSTIBLES AND SUPPORTERS OF COMBUSTION
}

The atmosphere contains by volume-

\author{
$20 \cdot 84$ vols. of oxygen) \\ $79 \cdot 16, "$, nitrogen) ratio 1 to $3 \cdot 8$.
}

There are also small quantities of other gases the principal of which is carbon dioxide $\mathrm{CO}_{2}$, which is present to the extent of only 0.0004 , and may be neglected for present purposes.

By weight the atmosphere contains-

$$
\begin{aligned}
& 23 \cdot 15 \text { parts of oxygen) } \\
& 76 \cdot 85 \text {, }, \text { nitrogen) ratio } 1 \text { to } 3 \cdot 3196
\end{aligned}
$$

The mean atmospheric pressure at sea level is assumed by Rankine to be 14.704 pounds per square inch, at a temperature of $32^{\circ} \mathrm{F} .=0^{\circ} \mathrm{C}$. The mercury barometer then stands at 29.922 inches. At this pressure water boils at $212^{\circ} \mathrm{F}$. $100^{\circ} \mathrm{C}$. The metrical atmosphere also measured at $0^{\circ} \mathrm{C}$. is $760 \mathrm{~mm}$. of mercury column $=29.922$ inches. At the ordinary temperature of $57^{\circ} \cdot 8 \mathrm{~F}$ : the mercury barometer of $30^{\prime \prime}=1$ atmosphere, and at all ordinary temperatures and for purposes of steam engineering it may be called 30 inches.

Expressed in metric measures, one atmosphere is 1.0333 kilos per square centimetre at Paris.

A mercury column giving 14.704 at London will give $14.6967=1.0333$ kilos at Paris and $14 \cdot 686$ at New York.

The barometric height varies slightly with the latitude.

To reduce for any other latitude the formula is as follows-

$$
H=760 \times \frac{\left(1+0.00531 \operatorname{Sin}^{2} 48^{\circ} 50^{\prime}\right)}{\left(1+0.00531 \operatorname{Sin}^{2} \mathrm{~L} .\right)} ; \text { where }
$$

$48^{\circ} 50^{\prime}$ is the latitude of Paris.

The pressure and density of the atmosphere varies with the elevation above sea level, and may be thus calculated-

$$
\mathrm{H}=60,000(1 \cdot 477-\log \mathrm{R}) \text {; where }
$$

$R$ is the elevation in feet above sea level;

$\mathrm{H}$ is the barometric height in inches at elevation $\mathrm{R}$. and $1 \cdot 477=\log 30$.

High elevation requires consideration in regard to the relative volume of air for furnace supply.

Air at all temperatures for purposes of furnace work behaves as a perfect gas.

The weight of a cubic foot of dry air at $62^{\circ} \mathrm{F}$. is 532.5 grains. If saturated with moisture the weight is 529 grains. The specific gravity of air is 819 times less than water and one pound of air measures $13 \cdot 146$ cubic feet at $62^{\circ} \mathrm{F}$.

The standard barometric pressure of 1 atmosphere or 14.6967 pound per square inch at Paris $=1.0333 \mathrm{k}$. per $\mathrm{cm}$. is curiously approximate to $1 \mathrm{k}$. per $\mathrm{cm}_{2}$. or to 14.21 per square inch. metre.

Approximately 1 atmosphere is equal to a pressure of $1 \mathrm{k}$. per square centi-

The density of air relative to hydrogen is 14.44 , its specific heat is 0.2375 at constant pressure, and $0 \cdot 1686$ at constant volume. One pound of air measures 12.385 cubic feet at $0^{\circ} \mathrm{C} .=32^{\circ} \mathrm{F}$, and 1 cubic foot weighs 0.08073 pound. It liquefies at $81 \cdot 6^{\circ} \mathrm{C}$. absol., and remains liquid up to $133^{\circ} \mathrm{C}$. absol. under a pressure of 39 atmospheres. 1 litre of air weighs 1.292743 grams at $0^{\circ} \mathrm{C}$. and $760 \mathrm{~mm}$. 


\section{LIQUID FUEL AND ITS COMBUSTION}

\section{Oxygen.}

Oxygen is the active constituent of the atmosphere in promoting combustion. It combines with most elements to form oxides with evolution of heat. The atomic weight of oxygen is 16 and it forms one stable oxide with hydrogen- $=\mathrm{H}_{2} \mathrm{O}$ (see water) and two oxides with carbon, viz.-

(1) Carbon monoxide or carbonic oxide $=\mathrm{CO}$, which contains 12 by weight of carbon and 16 by weight of oxygen, and

(2) Carbonic acid or carbon dioxide $=\mathrm{CO}_{2}$, containing 12 by weight of carbon to 32 of oxygen.

The density of oxygen is 16 ; its weight per eubic foot is 0.08926 pound at $0^{\circ} \mathrm{C} .=32^{\circ} \mathrm{F}$. and 11.203 cubic feet weigh one pound.

Its specific heat at constant pressure is 0.217 and at constant volume $0 \cdot 1548$. It can be liquefied at $92^{\circ}$ absol. $\mathrm{C}$, and under a pressure of 50 atmospheres remains liquid up to $160^{\circ} \mathrm{C}$. absol. One litre of oxygen at $0^{\circ} \mathrm{C}$. and $760 \mathrm{~mm}$. weighs 1.4293 grams. Oxygen boils at $92^{\circ} \mathrm{C}$. absol. under atmospheric pressure.

\section{Nitrogen.}

This gas constitutes about four-fifths of the atmosphere. It is a colourless gas and very inert. It does not support combustion, but aets by dilution to restrain its intensity and to reduce the temperature.

Its density is 14 , specific heat $=0.244$ at constant pressure, and 0.173 at constant volume. It weighs 0.07845 per cubic foot and 1 pound equals 12.763 cubic feet. It liquefies at $80^{\circ} \mathrm{C}$. absol. and remains liquid up to $128^{\circ} \mathrm{C}$. absol., under 33.6 atmospheres. One litre of nitrogen weighs 1.2505 grams at $0^{\circ} \mathrm{C}$. and $960 \mathrm{~mm}$.

The weight of nitrogen in the atmosphere is $3 \cdot 32$ times that of oxygen. It is, therefore, the cause of much dilution of the products of a furnace and reduces the theoretical temperature of combustion to a figure much below that of combustion in oxygen.

It has been claimed that at high temperatures the nitrogen unites with oxygen in the furnace, but there is no good reason to suppose that such is the case and every reason to hope it never may be. 


\section{Chapter IX}

\section{WATER}

STEAM is produced by heating water to such a temperature that the elasticity $S$ of the water vapour becomes greater than the superincumbent air pressure of about 14.7 pounds per square inch at the level of the sea. (See Air).

Pure water is not found in nature but is closely approximated in rain caught on hill tops distant from towns, and in streams which flow off the barren country associated with granitic rocks, the Millstone Grits, and certain other geological strata. Water is an oxide of hydrogen and its chemical formula is $\mathrm{H}_{2} \mathrm{O}$. It eonsists of 2 parts by weight of hydrogen to 16 parts of oxygen, and it is produced when hydrogen is burned, the combustion setting free a large amount of heat. (See Hydrogen).

Water being so universal in nature, and being a liquid, is used as the unit point in many physical data. The specific gravity of all other substances is referred to that of water as unity. So also is the specifie heat of all other substances, and excepting its constituent hydrogen alone, the specific heat of water is the highest of any known body. The amount of heat necessary to raise the temperature of 1 kilogram of water from $0^{\circ} \mathrm{C}$. to $1^{\circ} \mathrm{C}$. is denominated the great calorie or simply the calorie, the little ealorie having reference to the weight of one gram only and being employed by chemists and physicists.

Similarly the heat necessary to raise the temperature of one pound of water from $32^{\circ} \mathrm{F}$. to $33^{\circ} \mathrm{F}$. is ealled the British Thermal Unit or B. Th. U. Thus 1 calorie $=3.9683 \mathrm{~B}$. Th. U. and $1 \mathrm{~B}$. Th. U. $=0.252$ calorie.

\section{Weight.}

One gallon of pure distilled water at $62^{\circ} \mathrm{F}$. weighs 10 pounds by Act of Parliament. The American or old wine gallon weighs $8 \frac{1}{3}$ pounds and measures 231 cubic inches, as compared with the British Imperial $10 \mathrm{lb}$. gallon of 277.479 cubie inches (Chaney). One cubic decimetre of water or 1 litre weighs, by law, 1 kilogram, the kilo. being $2 \cdot 204$ pounds. Thus $1,000 \mathrm{k}$. weigh very nearly 1 ton.

A column of water 1 foot high exerts a pressure at the base of 0.434 pounds per square inch. Thus a pressure of 1 pound per square inch represents a eolumn of 2.3 feet. Hence an atmosphere of pressure is equivalent to 33.8 feet of water column.

\section{Compressibility.}

Water is nearly incompressible, the co-efficient at $0^{\circ} \mathrm{C} .=32 \mathrm{~F}$. being $\cdot 000052$, and at nearly $53^{\circ} \mathrm{C} .=127^{\circ} \mathrm{F} .=0 \cdot 0000441$. It is thus negligible: 


\section{LIQUID FUEL AND ITS COMBUSTION}

\section{Expansion.}

Water changes its volume with change of temperature, but not to an amount that is of serious account in steam enginecring.

\begin{tabular}{|c|c|c|c|c|c}
\hline Temp. & Weight. & Temp. & Weight. & Temp. & Weight. \\
\cline { 2 - 3 } $212^{\circ} \mathrm{F}$. & $59 \cdot 71$ & $350^{\circ}$ & $55 \cdot 52$ & $500^{\circ}$ & $49 \cdot 61$ \\
250 & $58 \cdot 81$ & 400 & $53 \cdot 64$ & 550 & 47.52 \\
300 & $57 \cdot 26$ & 450 & $50 \cdot 66$ & 62 & $62 \cdot 2786$ \\
\hline 102 & 62.00 & 158 & $61 \cdot 00$ & 203 & 60.00 \\
\hline
\end{tabular}

The foregoing table gives the weight per cubic foot of water at various temperatures, showing that the maximum expansion in the open air does not reach 5 per cent.

Water attains its maximum density at $4^{\circ} \mathrm{C} .=39^{\circ} 1 \mathrm{~F}$.

It becomes solid at a temperature of $0^{\circ} \mathrm{C} .=32^{\circ} \mathrm{F}$., the freezing point of water being employed in fact as the $0^{\circ}$ of the Centigrade thermometers.

Ice has a specific gravity of 0.922 and a specific heat of 0.504 . To reduce 1 pound of ice at $32^{\circ} \mathrm{F} .=0^{\circ} \mathrm{C}$. to water also at $32^{\circ} \mathrm{F}$. requires 142 B.Th.U. $=35 \cdot 78$ calories. The latent heat of water is thus said to be 35.78 calories or 142 B.Th.U. per pound or 78.86 calories per kilogram:

\section{Specific Heat.}

The specific heat of water called 1.00 at $0^{\circ} \mathrm{C} .=32^{\circ} \mathrm{F}$. is not uniform, but increases slightly with increase of temperature, as per the following table:-

\begin{tabular}{|c|c|c|c|}
\hline \multicolumn{4}{|c|}{ Specific Heat of Water. } \\
\hline Temp. F. & Specific Heat. & T'emp. F. & Specific Heat. \\
\hline $32^{\circ}$ & $1 \cdot 0000$ & $248^{\circ}$ & $1 \cdot 0177$ \\
\hline 50 & 1.0005 & 266 & $1 \cdot 0204$ \\
\hline 68 & 1.0012 & 284 & $1 \cdot 0232$ \\
\hline 86 & $1 \cdot 0020$ & 302 & $1 \cdot 0262$ \\
\hline 104 & $1 \cdot 0030$ & 320 & $1 \cdot 0294$ \\
\hline 122 & $1 \cdot 0042$ & 338 & $1 \cdot 0328$ \\
\hline 140 & $1 \cdot 0056$ & 356 & $1 \cdot 0364$ \\
\hline 158 & $1 \cdot 72$ & 374 & $1 \cdot 0407$ \\
\hline 176 & 1.0089 & 394 & $1 \cdot 0440$ \\
\hline 194 & $1 \cdot 0109$ & 410 & $1 \cdot 0481$ \\
\hline 212 & $1 \cdot 0130$ & 428 & $1 \cdot 0524$ \\
\hline 230 & $1 \cdot 0153$ & 446 & $1 \cdot 0568$ \\
\hline
\end{tabular}

As at the above temperatures the bulk of water is increased in a much greater ratio than the specific heat, the total heat per cubic foot will decrease somewhat with rise of temperature.

\section{Solubility.}

Water is a solvent of many substances. Most gases are soluble to a greater or less cxtent, and usually more so at low temperatures. Hydrogen forms a notable exception to this, being equally soluble at various temperatures. There is, however, no known exception to the rule that the solubility is proportional to the pressure.

The co-efficient of absorption of gas in water is the relative volume absorbed 
by one volume of water at $0^{\circ} \mathrm{C} .=32^{\circ} \mathrm{F}$. and $760 \mathrm{~mm}$. pressure $=1$ atmosphere $=$ $14 \cdot 7$ pounds per square inch.

The following table is given by Bunsen for the solubility of gases-

\begin{tabular}{|c|c|c|c|c|c|}
\hline Degrees Cent. & $0^{\circ}$. & $5^{\circ}$. & $10^{\circ}$. & $15^{\circ}$. & $20^{\circ}$. \\
\hline Hydrogen. . . . & $0 \cdot 01930$ & 0.019 & $0 \cdot 01930$ & 0.01930 & 0.01930 \\
\hline Oxygen . . . & 0.04114 & $0 \cdot 03628$ & $0 \cdot 03250$ & $0 \cdot 02989$ & $0 \cdot 02838$ \\
\hline Nitrogen . . . . & 0.02035 & $0 \cdot 01794$ & $0 \cdot 01607$ & $0 \cdot 01578$ & $0 \cdot 01403$ \\
\hline Atmospheric air . & 0.02471 & $0 \cdot 02179$ & $0 \cdot 01953$ & $0 \cdot 01796$ & $0 \cdot 01704$ \\
\hline Carbonic acid . . & $1 \cdot 7967$ & $1 \cdot 4497$ & $1 \cdot 1847$ & $1 \cdot 0020$ & $0 \cdot 9014$ \\
\hline Carbonic oxide . & $0 \cdot 03287$ & $0 \cdot 02920$ & 0.02635 & $0 \cdot 02432$ & 0.02312 \\
\hline Carburetted hydrogen & & & & & \\
\hline Carburetted hydrogen & 0.05449 & $0 \cdot 04885$ & $0 \cdot 04372$ & 0.03909 & $0 \cdot 02499$ \\
\hline$\underset{\text { Sulphuretted hydro- }}{\mathrm{C}_{2} \mathrm{H}_{4}} \cdot$ & $0 \cdot 2563$ & $0 \cdot 2153$ & $0 \cdot 1837$ & $0 \cdot 1615$ & $0 \cdot 1488$ \\
\hline gen $\mathrm{SH}_{2} \cdot$ & $4 \cdot 3706$ & $3 \cdot 9652$ & $3 \cdot 5858$ & $3 \cdot 2326$ & $2 \cdot 9053$ \\
\hline Sulphuric acid . & $68 \cdot 861$ & $59 \cdot 816$ & $51 \cdot 383$ & $43 \cdot 564$ & $36 \cdot 216$ \\
\hline Ammonia, $\mathrm{NH}_{3}$. & $1049 \cdot 6$ & $917 \cdot 9$ & $812 \cdot 8$ & $727 \cdot 2$ & $654 \cdot 0$ \\
\hline
\end{tabular}

As the total heat contained in one pound of steam is nearly 1,200 B. Th. U., this amount of heat is more or less thrown away when steam is used to atomize liquid fuel. The gases never leave a furnace below $212^{\circ} \mathrm{F}$., and every pound of steam carries off its load of 966 units of latent heat to the chimney. Air being already a gas, and being necessary to combustion, causes no loss in this manner, but it requires power to compress air and some steam is thereby used, but, especially at sea, such steam can be condensed and does not therefore lead to a loss of fresh water. No extra work is thrown upon the evaporation plant. Water may be split up by heat into its two constituent gases. In this process of dissociation or decomposition exactly as much heat is absorbed as was produced by the combination of the gases when the water was formed. This plain chemical fact is quite ignored by those who dream about the use of steam for fuel and who imagine that steam jets introduced into a furnace will decompose and burn with any effect in increasing the total heat production of the furnace. Steam thus employed is useful as a mechanical draught producer only, or there may be some truth that hydrocarbons burn better in the presence of moisture. But no further claim is in any sense tenable.

\section{Sources of Water.}

Though pure water does not exist in Nature, there are certain natural waters which are practically pure, as for example the water of Loch Katrine or the supply of the city of Manchester, which is practically pure and non-scaling, and only calls for a little alkali to correct slight corrosive effect due to possibly peaty acids.

Water from chalk and limestone areas, and from the Keuper Marl, is hard and produces much incrustation. Water from wells under London, though from the chalk, is barely one-third the hardness of water from wells where the chalk extends to the surface. The presence of the lower tertiary beds above the chalk appears to account for this. Water from tidal estuaries is now apt to be very corrosive owing probably to the decomposition of the chloride salts into acids by the high temperature of modern boilers. The presence of sewage is not per se 


\section{LIQUID FUEL AND ITS COMBUSTION}

harmful to a boiler. At Warrington some steam users have a special pumping plant to pump the Mersey water to their works, and attribute the excellence of the water to the presence in it of the sewage of Manchester and other towns, but in this connection it should be remembered that the Mersey and its tributaries flow almost wholly over rocks of the Millstone Grit or New Red Scries, and that the sewage has as basis a soft water. supply and is probably alkaline from the waste of bleach works. In Oldham, water is derived from the sewers as a regular thing.

The effect of water containing sulphate of lime may be seen in boilers at Burtonon-'Trent. 'These are often of a glistening white inside, and thick with scale, under which may be found the familiar black oxide of iron produced by the presence of this scale. As it will usually cost a minimum of $6 d$. per 1,000 gallons to purchase water, this must be set against the cost of a free supply with treatment, and usually, if the free supply is hard, the purchased water will frequently also be hard. But where a good water can be purchased it may be economised by means of surface condensation, and very little need be purchased if proper use is made of the roof area for supplementing the supply.

\section{Useful Figures.}

In the calculations of the steam engineer it is convenient to remember that the square of the diameter of a pipe or a pump barrel gives the weight of water in a yard length of pipe. Thus a six-inch pipe holds 36 pounds or $3 \cdot 6$ gallons per yard. Again 1 pound of coal should evaporate 1 gallon of water; 1 gallon of water will give steam to work in the best engine yet made at the rate of $1 \mathrm{~h} . \mathrm{p}$. hour. 2 gallons will serve an ordinary compound engine per h.p. hour and 3 gallons a good condensing engine for each h.p. hour. Approximately too, 1,000 B. Th. U. generated represents one pound of steam, so that the number of thousands of units capacity of a pound of fuel represents the theoretical evaporation in pounds of water.

As the latent heat of steam is practically $1,000 \mathrm{~B}$. Th. U. at a temperature of $100^{\circ} \mathbf{F}$., it will be perceived that to convert water into vapour at ordinary atmospheric environment must demand 1,000 heat units. This principle is made use of in the atmospheric condenser, wherein steam in the pipes is deprived of its latent heat by means of films of water outside the pipes, which are kept cool by the absorptive action of the wind which carries off much of the outer water, and the act of vaporization abstracts heat from that left behind. Thus the loss of one pound of, perhaps, a cheap cooling water, will save an equal weight of water inside the condenser for boiler feeding purposes. In any case a surface condenser of some sort is a means of feeding a boiler with water that contains no incrusting material, though its contained oil from the cylinders is an objection to its use, and this should be removed.

\section{Solubility of Salts.}

As a rule this increases with the temperature, but at a slow rate, except for sodium chloride and a few other exceptions. For the sulphates of magnesium and potassium and the chlorides of barium and of potassium, solubility is proportionate to the increase of temperature.

With sulphate of soda the solubility first increases and then falls off again. The solubility of calcium sulphate decreases with temperature. 


\section{WATER}

The following table gives the solubility of a few salts at various temperatures in parts per 100 .

The solubility at $212^{\circ} \mathrm{F}$. is really at a higher temperature, being the solubility at boiling point which is always raised slightly by the solution of a salt.

\begin{tabular}{|c|c|c|c|c|c|c|c|c|c|c|}
\hline & & & & & & & & \multicolumn{3}{|c|}{ Temperature. } \\
\hline & & & & & & & & $32^{\circ} \mathrm{F}$ & $70^{\circ} \mathrm{K}$ & $212^{\circ} \mathrm{F}$. \\
\hline Calcium Chloride . & . & . & . & . & & . & . & 400 . & - & - \\
\hline Magnesium Sulphate & . & . & . & . & & . & . & $24 \cdot 7$ & $35 \cdot 0$ & 130 \\
\hline Potassium Carbonate & . & . & . & . & & . & . & 100 & $80 \cdot 0$ & - \\
\hline , Chlorate . & . & . & . & . & & . & . & $3 \cdot 33$ & $8 \cdot 0$ & 60 \\
\hline Chloride . & . & : & . & . & & . & . & $29 \cdot 21$ & $34 \cdot 0$ & 60 \\
\hline Nitrate. & . & . & . & . & & . & . & $13 \cdot 32$ & $30 \cdot 0$ & 240 \\
\hline , Sulphate & . & . & . & . & & . & . & - & $12 \cdot 0$ & 26 \\
\hline Sodium Carbonate. & . & . & . & . & & . & . & $6 \cdot 97$ & $21 \cdot 7$ & $45 \cdot 1$ \\
\hline „, Bicarbonate & . & . & . & . & & . & . & $6 \cdot 9$ & $9 \cdot 6$ & - \\
\hline Chlorido . & . & . & . & . & & . & . & $35 \cdot 5$ & $36 \cdot 0$ & $39 \cdot 6$ \\
\hline , Sulphate & . & . & . & . & & . & . & $5 \cdot 02$ & $22 \cdot 0$ & $42 \cdot 6$ \\
\hline Barium Chloride & . & . & . & . & & . & . & $35 \cdot 0$ & - & $60 \cdot 0$ \\
\hline Calcium Carbonate. & . & . & . & . & & . & . & .0036 & - & - \\
\hline , Sulphate . & . & . & . & . & & . & . & .23 & - & .21 \\
\hline Magnesium Chloride & . & . & . & . & & . & . & $200 \cdot 00$ & - & $400 \cdot 00$ \\
\hline , Carbonate & . & . & . & . & & . & . & .02 & - & - \\
\hline
\end{tabular}

\section{Sea Water.}

Sea water contains 38 parts per 1000, of dissolved matter; of this from 25 to 28 parts are common salt $\mathrm{NaCl}$.

The Black Sea contains only $17 \cdot 7$ parts, the Caspian Sea $14 \cdot 0$, and the Baltic $6 \cdot 7$, owing to the large fresh water rivers which flow into them. The other salts of sea water are magnesium chloride, calcium sulphate, magnesium sulphate, potassium sulphate and chloride, bromide of soda, the carbonates of lime and magnesia, and traces of other salts and organic substances.

\section{Hardness.}

By this term is meant 1 grain per gallon of lime carbonate $\mathrm{CaCO}_{3}$. Temporary hardness is that which can be reduced by boiling. Permanent hardness is not reduced by boiling.

\section{Pipes.}

The ordinary velocity of flow of water in pipes may be taken as 72 inches per second. This velocity is to be reduced 1 inch per second for each 20 pounds pressure. Thus in feed pipes at 160 pounds pressure, the velocity will be $72-8=$ 64 inches. Practical considerations demand, except where several boilers are fed through one pipe, that the pipes shall be much larger than would give such a velocity in many cases.

Pipes less than $1 \frac{1}{2}$ inches are rarely advisable for feed pipes, and if pipes are liable to be scaled up they ought to be made initially larger than necessary to allow of a considerable deposit of scale without unduly diminishing their capacity. 


\section{LIQUID FUEL AND ITS COMBUSTION}

Useful Data regarding Water.

1 gallon . . . . 10 pounds.

1 American gallon. . 8.321 pounds.

1 cubic foot . . . . 62.2786 feet.

1 gallon . . . . 277.479 cubic inches.

1 American gallon. . . 231 cubic inches.

1 litre . . . . . 2.204 pounds.

1 foot column . . . 0.434 per square inch.

1 pound per square inch . 2.304 feet head.

1 gallon . . . . 0.1606 cubic feet.

1 pound . . . . 0.01606 , ",

1 cubic foot. . . 0.0278 ton.

1 ton . . . . 35.97 cubic feet.

(Diameter of pipe in inches) $^{2}$. Pounds per yard nearly.

$1^{\circ} \mathrm{C}$. per kilogram . . . 1 Calorie.

$1^{\circ} \mathrm{F}$. per pound . . . 1 B. Th. U.

Specific heat at $0^{\circ} \mathrm{C} . \quad . \quad 1 \cdot 00$.

, , Ice . . . 0.504 .

Specific gravity at $0^{\circ} \mathrm{C} . \quad . \quad 1 \cdot 000$.

,,$\quad$ Ice . . 0.922 .

1 atmosphere . . . $33 \cdot 8$ feet. 


\section{Chapter X}

\section{WATER PURIFICATION}

\section{Incrustation.}

$\mathrm{T}$ THE presence of scale in a steam boiler is a cause of poor evaporative duty and therefore a waste of fuel, for all are agreed that iron is a better material for boiler plate than flagstone. If the question of eliminating the scale-forming elements were better understood, there would be more frequent cases of it being undertaken. Where water is intended for dietetic purposes there is some amount of objection to the use of certain of the materials employed in water softening when certain peculiar kinds of scale-forming substances are contained in the water. For most manufacturing purposes, however, there is no objection to the use of any substance that will not injure the boiler, and this is more especially the case where steam is sought merely for motive power purposes. There are several scaleforming materials found dissolved in water, and they cannot all be removed by the same means, and, as usually presented, the question is rather too much complicated by the endeavour to treat the whole subject at once, in place of taking the various impurities separately, as if each were the only impurity present that required dealing with, though we may very well inquire into the methods of dealing with waters containing more than one scale-forming impurity. Speaking generally, there is nothing wrong in this detailed method of treating the question, for even if a water contains both carbonate of lime and sulphate of lime in equal or any other proportion, it is easy to ignore the latter and treat for the former only, by doing which we should remove one substance and reduce the amount of scale formed by the proportion of the impurity removed. To use a mechanical simile, we may sieve out buckwheat coal from a ton of mixed coals of all sizes, and leave the pea coal in the mixture. By the use of a larger sieve, we can then sieve out the pea coal. We need not, unless we wish, use the larger sieve first, so eliminating both the small coals together. So in the water softening process we may use a single chemical process and remove one substance, or we may use a double process and remove two or more substances together. As a rule, the most usual impurity in water, and the only one of account in most chalk waters, is carbonate of lime, and, as it is easiest and cheapest to remove, it will be best to deal first with it.

Strictly speaking, this carbonate of lime is nearly insoluble in water, and upon this fact depends the process of removing it from solution. This sounds contradictory and demands explanation. We must know first what it is, of what it is chemically composed. First, what is lime? Lime is the oxide of the metal calcium, and this is a yellow metal of extremely small weight, its specific gravity being only three-fifths that of aluminium. It is very oxidisable, and is not found in nature as a metal. It burns to lime. In 56 pounds of lime $(\mathrm{CaO})$ there are 40 


\section{LIQUID FUEL AND ITS COMBUSTION}

pounds of calcium and 16 pounds of oxygen. Carbon when burned yields carbonic acid gas, in 44 pounds of which there are 12 pounds of carbon. Now, lime has a strong affinity for carbonic acid, and absorbs it greedily from the air; hence the use of lime water to sprinkle down wells in which the air is impure with carbonic acid (choke damp) ; 56 pounds of lime will absorb 44 pounds of this gas; becoming carbonate of lime. (Expressed in chemical symbols, to understand which it is not necessary, and they may be skipped without rendering the matter much less understandable; the combination is expressed thus-

$$
\begin{aligned}
\text { Lime }+ \text { Carbonic Acid } & =\text { Carbonate of Lime. } \\
\mathrm{CaO}+\mathrm{CO}_{2} & =\mathrm{Ca} \mathrm{CO}_{3^{\circ}}
\end{aligned}
$$

This absorption of carbonic acid is what takes place when mortar hardens. When, however, limestone is burned, the carbonic gas is driven off by heat and simple lime caustic or quick lime is produced. Carbonate of lime being practically insoluble in watcr, how then is it formed therein? Carbonic acid gas is very soluble in cold water, so that one gallon of water at freezing point will absorb $1 \frac{8}{10}$ gallons of the gas, or 500 pounds of water will absorb 1 pound of gas. All natural waters contain this gas, and such waters will dissolve carbonate of lime, so that, if we wish to dissolve 100 pounds of carbonate of lime, we shall want as much water as will contain 44 pounds of carbonic gas. Let us suppose that a certain sample of water contains 10 grains of carbonate of lime per gallon (of 10 pounds). Then this implies the presence of $4 \frac{4}{10}$ grains of carbonic gas. But a gallon of water may contain as many as 140 grains of the gas, so that there is no difficulty in it dissolving the above amount of lime. Now, if we require to render the carbonate insoluble we must take away the excess of carbonic acid gas which renders it soluble. Water may be freed from this gas by boiling, for, though very soluble in cold water, it is not at all soluble in boiling water. When therefore we feed a boiler with water that contains carbonate of lime, we speedily render this lime salt insoluble, for the gas is boiled away and goes off at the steam outlet, and the lime salt is left behind in a very finely divided state, and finally it settles down at the quietest part of the boiler as mud, some of it is blown out as mud, some is scummed off the surface before it has settled, and a lot of it stays behind and forms scale, and heat is lost both by blowing off hot water and by the resistance of the scale to the passage of heat. Getting the carbonate out of solution is therefore an easy and simple matter, and if we first boiled all the feed in an open tank and let the deposit settle or filtered it out before we pumped the feed into the boiler, we should have a clean boiler. But such a course would cost money in the shapc of heat, and we could not use feed heaters in the flues, and yet we ought to deposit the carbonate before it enters the boiler. There is a simple way of doing this; we can abstract the excess of carbonic acid gas by some other substance, and there are two substances will do this, and may ordinarily be employed. One of these is caustic soda, the oxide of the metal sodium; the other is caustic or quick lime, already described. Both act on similar lines.

To remove 100 pounds of carbonate of lime we add 80 pounds of ordinary caustic soda (Sodium hydroxide). The process is thus set down in chemical symbols-

$$
\begin{aligned}
& \text { Carbonate of Lime + Carbonic Gas + Caustic Soda. } \\
& \mathrm{CaCO}_{3}+\mathrm{CO}_{2}+2 \mathrm{HNaO}= \\
& \text { Carbonate of Lime + Carbonate of Soda + Water. } \\
& \mathrm{CaCO}_{3}+\mathrm{Na}_{2} \mathrm{CO}_{3}+\mathrm{H}_{2} \mathrm{O} \text {. } \\
& 68
\end{aligned}
$$




\section{WATER PURIFICATION}

The soda absorbs the spare carbonic acid gas, and the carbonate of lime is deposited, being now insoluble, and the caustic soda parts with the water it formerly contained and becomes carbonate of soda. Now, carbonate of soda in its hydrated form is very soluble in water, and may be allowed to accumulate some time before depositing. It is, however, liable to cause priming, and there are reasons to believe that it acts to the disadvantage of steam raising, so that for one evil we have, after all, only got another, which there is reason to believe may cause overheating of the plates. Not so, however, if we use caustic lime.

To remove 100 pounds of lime carbonate from water we need to use 56 pounds of dry quick lime or 74 pounds of dry slaked lime. It is best to weigh off the proper weight of fresh burned lime and then slake it. By adding the caustic lime to the water the free gas is absorbed and the caustic lime itself becomes carbonate of lime, and not only does the original carbonate of lime become deposited, but also the 56 pounds added lime, which has absorbed the 44 pounds of gas, and there is thus a total of 200 pounds of insoluble lime carbonate deposited. (This is the formula-

$$
\begin{array}{ccc}
\text { Carbonate of Lime } & + \text { Carbonic Acid }+ \text { Lime }=\text { Carbonate of Lime. } \\
\mathrm{CaCO}_{3} & +\mathrm{CO}_{2} & \left.+\mathrm{CaO}=2 \mathrm{CaCO}_{3}\right) .
\end{array}
$$

Nothing is left in the water except the small amount of carbonate which is soluble in even pure water. As an illustration of quantities, we will suppose an electric power station of 500 horse power using feed water containing 10 grains of removable earbonate of lime per gallon of 10 pounds. The engines consume 32 pounds of water per h.p. hour and work ten hours at a mean of 500 h.p. Anyway, they are known to use 16,000 gallons of water per day, and as there are 7,000 grains in a pound, the weight of carbonate to be removed is $16,000 \times 10 \div 7,000=$ say 23 pounds per day, or about three tons annually. The quicklime for this, at the rate of 56 per 100 of carbonate is 12.88 , or say 13 pounds, and the amount annually is under 2 tons, thus showing a big monetary saving as compared with the $2 \frac{1}{2}$ tons of caustic soda at a much higher price, which would be required. In every way, therefore, the lime is to be preferred to the soda, for it does not leave a salt in solution gradually to concentrate to possible danger point. Any one wishing to carry out the softening of a carbonate water should therefore have a sample of the ordinary feed supply analysed by a brewery chemist or other competent man, and learn the number of grains of lime carbonate in each gallon. If then he multiplies by the daily consumption, he will obtain the total weight per day, and, knowing that, he then weighs out, for each day's use, 56 parts of freshly burned lime or 74 parts of slaked, but dry, lime for each 100 parts of lime carbonate to be removed.

If too little lime is added, the result will be that only a portion of the impurities will be deposited, and if only a very little lime be added the water may, it is claimed, be made actually harder. The reason of this is that there may be actually more earbonic acid gas in the water than what is necessary to keep the impurities in solution, and if only a little lime be added it also may be converted into the carbonate and go into solution, for it is really bicarbonate of lime that is soluble. Hence the desirableness of adding enough lime just to make the water faintly alkaline, for this shows that an excess of lime has been added. Usually it would appear that the carbonic acid gas is present in a feed water merely in such quantity as will convert the lime carbonate to the bicarbonate form, but it might happen that a volume of entirely free gas was present. If this were so, the amount of 


\section{LIQUID FUEL AND ITS COMBUSTION}

eaustic lime to be used would be greater than the 56 per cent. already named of the soluble carbonate, for an additional amount would be needed to absorb the free gas. As a general rule, the addition of the 56 per cent. is about right; the final quantity can be determined by testing the finished softened water, as will be shown later. What now demands attention is the means to be adopted for carrying out the softening process, and there is nothing in this but can be arranged by any one with ordinary eare. There is nothing to be afraid of in undertaking the matter.

Coming now to the practical part of water softening, there are several methods employed for the admixture of lime with carbonate waters, all of which are in principle the same, though differing in detail. Broadly speaking, the process is either continuous or non-continuous; it is automatic or non-automatic; and the adoption of one or the other or a choice of some midway system must depend on the quantity to be softened and other considerations.

It may be as well to state that the rapidity of the process and the subsequent elarification are greatly facilitated if the lime is first added in excess and the mixture brought to its proper condition by the addition of more hard water, that is to say, it is better to add 12 pounds of lime to 8,000 gallons of carbonate water and correct the over liming by a further addition of 2,000 gallons of the water, than it is to add 10 pounds of lime to 10,000 gallons of water and add later 2 pounds of lime to complete the softening. Also the slaking of quicklime should not be done too long before use, as the lime begins to absorb carbonic acid gas from the atmosphere, and by so much loses its efficiency. If a small quantity of water is required daily, say a few gallons only, the whole of the operation of softening would consist in having a couple of tanks holding each a day's supply with 2 or 3 inches to spare at top and bottom for sediment and margin, and mixing therein at one operation the water and lime necessary to effect the deposit. This tank full of water would soon settle and could be drawn off. Usually the process requires to be more or less continuous, and some apparatus is then required. When space is no object, and a couple of tanks of a day's capacity can be laid down, one of these ean be used each day into which to run the water for settlement, the other being drawn from for use. With a well yielding during ten hours sufficient for a day's use, the filling will take ten hours' pumping, and the following would be the operation by various systems. In one there is slaked over night the weight of lime for next day's process. In the morning this is placed in a cylinder containing an agitator, and the cylinder is filled with water, the agitator-a vertical spindle with projecting arms --keeping up a constant mixture of lime. To this mixer is attached a pump of such capacity as will empty the ressel in rather less time than is required to fill the large tank with water to be treated. This discharge of the lime pump passes into the stream of well water and through a few baffle plates in a short trough, and falls into a cylinder placed upright in the large tank: but freely open at the bottom, whence the mixed water is distributed over the floor and deposition of the carbonate assisted. This is probably the most certain method to employ if fully burned fat lime can be procured, for it adds an excess of lime during the first portion of the operation, and gradually brings up the mixture to a balance at the latter end. Where the lime is uncertain in quality, or for other reasons, another system is used depending on the fact that a stream of water passing through an excess of lime will take up about 65 grains per gallon, or become about two-thirds saturated. Hence, if a proportion of the whole supply be sent through a tall mixer containing any amount of lime, it will carry off its 65 grains per gallon, and if we know the total 


\section{WATER PURIFICATION}

daily weight of lime that is needed, we ean pass the necessary proportion up through the mixer, whence it overflows and rejoins the main stream at the baffle trough and goes forward as before.

The proportions going each way can be regulated by taps or by a tongue piece in a flat levelled trough through which the whole water passes, the tongue being swivelled to divert the proper proportion through the lime mixer, very usually about one-eighth. Thus to remove 16 grains of carbonate per gallon from 1,000 gallons there is required of lime $56 \times 160$ grains, or 8,960 grains. As each gallon of limed water carries 65 grains, we shall need 141 gallons of this, or about a seventh of the total quantity. Here again, as we start every time with a mixer full of water that has been some hours standing, the limed water is more nearly saturated and there is an excess of lime during the first part of the day. The two foregoing may be termed the semi-continuous process. In the wholly continuous process no large tanks are employed, but the water passes continually onward to use or to the store tank. In one such continuous process the hard water meets the limed portion in the exact proportion necessary, and flows with it down a cylinder placed in a tank, and the water is spread over the bottom of this tank, and slowly rises to the overflow. The overflow is simply a carefully levelled trough placed all round near the tank top, and the edge of the trough skims off the top layer of water gently and without disturbance, the area of the tank being such that the mean upflow of water will not exceed 12 inches per hour. Thus, for a rate of 1,000 gallons per hour a tank 12 feet 8 inches square would be required. With a smaller tank than this there might be a slight clondiness of the effluent water, due to non-settlement of some of the finer particles of carbonate, and, where space is an object, filters of close woven cotton cloth are used to complete the process. If it requires 10 hours for a depth of 30 inches of water to deposit, it will only require one hour to clear a layer only 3 inches thick. Some systems are based on this idea, the travelling water passing between trays set a short distance apart, each tray receiving the deposit of the film of water above it. These devices shorten the time, it is true, but not to the extent above indicated, for, given a tank of say 20 feet in length during the passage along which the deposit only sank six inches, the removal of the softened water at the surface only would secure a clear effluent. Moreover, the water entering a tank is always admitted at the bottom and without any upflowing energy, and thus the use of division trays is not always requisite.

In one form of apparatus the depositor is a vertical tank divided by inclined plates rivetted alternately to the opposite sides, the direction of flow being reversed in turning from plate to plate and the deposit remaining behind to be blown off by a pipe at each turn, and generally the endeavour is made to secure the equivalent of a considerable duration of time. In another continuous system the passage of the water to be treated over a small water-wheel is made to give motion to mechanism which delivers a given quantity of finely ground lime directly into the stream of hard water, with which it is mixed and passed into the settling tanks. The effect is the same as in the other systems, and the various differences are often so many additions to a simple process to give grounds for claims of superiority in effecting sales of apparatus to steam users. There are, however, no patents covering the process ; merely a few covering certain forms of apparatus. In anything carried out in the direction of water softening, it is to be borne in mind that no process, patented or otherwise, will give a better result than the mixing in the tank of hard water the proper weight of lime reduced to a cream, and stirring the 


\section{LIQUID FUEL AND ITS COMBUSTION}

lot until complete admixture is secured; then leaving the whole to settle. Other systems may be more convenient, and space and labour may be economised by adopting them, but the broad prineiple remains unaffeeted.

\section{Carbonate of Magnesia.}

This substance is soluble in water to the same extent as carbonate of lime, and is very frequently found with it, but in smaller quantity. As the molecule of each carbonate requires an equal quantity of earbonic acid gas to keep it in solution, it follows that, per molecule, an equal amount of lime will be required to effeet precipitation. But the molecule of magnesian carbonate weighs 84 as against the 100 of the lime carbonate, from which it follows that if we multiply the weight of magnesian carbonate by $\frac{100}{84}$ we shall reduce it to its equivalent of lime earbonate. Hence the rough rule that where magnesia is present it must be treated exactly as if it were lime carbonate. Actually, we must add nearly 20 per cent. to the weight of magnesian carbonate and treat this inereased weight as lime carbonate. A water eontaining 16 grains of the latter and 4 of the former is equivalent to a water containing 20.74 of lime earbonate, and will be then treated as already described under that head. Mr. J. A. Wanklyn considers magnesia to destroy more soap than lime in the ratio of 75 to 42 , but others dispute this. But the power to destroy soap need not necessarily imply any greater power of destroying caustic lime, and the chemical equivalent is the one to work with in estimating for caustic lime. The following table gives the solubility of the carbonates and oxides of lime and magnesia at $60^{\circ} \mathrm{F}$. and $212^{\circ}$ in grains per 10 pounds of water.

\begin{tabular}{|c|c|c|c|c|c|c|c|}
\hline & & & & & & $60^{\circ} \mathrm{F}$ & $212^{\circ} \mathrm{F}$. \\
\hline Calcium Carbonate & & & & & & & \\
\hline $\begin{array}{c}\mathrm{CaCO}_{3} \text { Chalk } \\
\text { Ditto Bicarbonate }\end{array}$ & & . & . & . & . & $2 \cdot 5$ & $1 \cdot 5$ \\
\hline $\begin{array}{l}\mathrm{CaCO}_{3}+\mathrm{CO}_{2} \\
\text { Calcium Oxide }\end{array}$ & . & . & . & . & . & 60 . & 0 \\
\hline $\begin{array}{l}\mathrm{CaO}=\text { Caustic Lime } \\
\text { Magnesium Carbonate }\end{array}$ & & . & . & . & . & 93 . & - \\
\hline $\begin{array}{c}\mathrm{MgCO}_{3} \\
\text { Ditto Bicarbonate }\end{array}$ & . & . & . & - & . & 1.5 & 1.5 \\
\hline$\underset{\text { Magnesium Oxide }}{\mathrm{MgCO}_{3}+\mathrm{CO}_{2}} \cdot$ & . & : & . & . & . & 50 & 0 \\
\hline MgO Magnesia & . & . & . & . & . & 0.15 & - \\
\hline
\end{tabular}

The figures seem to show that the solubility is measured in atoms of the characteristic constituent of the two carbonates, but the similarity does not extend to the oxide of magnesia, this being nearly insoluble. We are, however, only interested here in scale-forming substances, not with those salts that are not usually found in water, and thus it is the earbonates of lime and magnesia that form the chief concern of the steam user. It is these two substanees, and some say more particularly the latter, that form what is known as floury deposit in steam boilers, which is liable to give rise to danger in the shape of overheated plates, by combining with oil to form a curious spongy non-heat eondueting mass that adheres to plates and keeps off the water.

In a boiler free from oil these carbonates are just separated out from the water in so finely divided a state that the particles do not sink, but are earried 


\section{WATER PURIFICATION}

about by the water until they reach a quiet place, where they settle in the form of soft mud. This is apt to become baked on the plates, and is then more difficult to remove. It is on the long floating of the fine particles that depends the successful action of the Mechanical Boiler Cleaners of the Hotchkiss type, that have been found good in treating waters from the chalk rock that is much charged with lime carbonate. The impurities are carried to a quiet place which is placed outside the boiler, where they settle and can be blown off without the waste of the large amount of water which goes to waste from an ordinary blow-out placed usually at the worst end of a boiler, and not near the quieter back end, where it might prove more effective.

\section{Sulphate of Lime.}

Lime forms another compound that is a bad scale producer; this compound is the sulphate (its chemical formula is $\mathrm{CaSO}_{4}$ ). It can be produced by acting on lime with sulphuric acid. The scale formed from this substance in a steam boiler is apt to be hard and crystalline and tough. In nature it is found as gypsum, which, when burned, becomes the familiar plaster of Paris. It is soluble in water to the extent of 0.23 parts in a hundred, and it does not deposit by boiling at ordinary temperatures, and hence is said to give rise to permanent hardness in water. At $400^{\circ} \mathrm{F}$., however, sulphate of lime is deposited, and water may be softened by heating it to that temperature. In a high-pressure steam boiler there is in fact only soft water, for both the principal scale formers have been boiled or heated out of solution. Sulphate of lime cannot be removed, however, by the use of caustic lime. To remove sulphate, it is necessary first to decompose it, and this can be effected by the use of carbonate of soda. Sulphuric acid has a greater affinity for soda than for lime. Hence, if soda be added to a solution of lime sulphate, the constituent leaves the lime base and converts the soda into sulphate of soda, whilst the carbonic acid gas, driven out of the soda, takes up with the lime to form carbonate of lime, which, being insoluble, is deposited. The sulphate of soda, however, is exceedingly soluble, 100 parts of water dissolving a maximum of 50 parts of the salt at about $90^{\circ} \mathrm{F}$, though a smaller amount is soluble at higher temperatures. Except, therefore, the water is required for potable purposes or for some manufacturing process in which soda sulphate would be chemically objectionable, there is not much objection to the presence of this soluble salt ; indeed; even for potable water the presence of the salt is not held to be an objection, in small quantities. In 136 parts by weight of lime sulphate there are 40 of calcium; and the addition of 106 parts of carbonate of soda results in the production of 100 parts of carbonate of lime and 142 of soda sulphate.

Taking 1,000 gallons of water containing 23 parts per 100 , there will be 23 pounds of sulphate to be dealt with. Expressed in grains per gallon so as to correspond with the table already given of carbonate solubility, this becomes 161, and hence would produce, when softened, $161 \times \frac{142}{136}=168 \cdot 1$ grains of soda sulphate; or about 0.0024 . This is less than $2 \frac{1}{2}$ parts per 1,000 , and would admit probably of being concentrated one hundred-fold before deposition set in. A large cylinder boiler worked ten hours a day is approximately boiled dry twice a day. Fed with the above softened water containing the residual soda sulphate, it might be run fifty days or more before the water became salt saturated. One weekly blow-out, and a complete blow every month, would probably render it safe, but no boiler should be worked without an occasional hydrometer test for density, as practised 


\section{LIQUID FUEL AND ITS COMBUSTION}

at sea. A case came under the writer's notice where an unsuspected saline feed became concentrated and filled the boiler, when cold, with salt crystals. The liability of a feed water to change its character is a danger to be constantly guarded against. In the case of a Sheffield boiler the concentration within it of water drawn from an acid polluted stream caused its rapid destruction with fatal results, for the acid, of course, did not evaporate. Having newly purehased the up-stream works where the explosion occurred, the owners only used the same proportion of soda that was found to neutralise the acidity lower down stream, and disaster followed, the upper-works boiler being corroded so thin as to collapse.

Where sulphate alone has to be dealt with, it is merely necessary to use carbonate of soda, as pointed out above, in the proper ratio of nearly 80 of dry soda ash per 100 parts of sulphate. If common or crystal soda be employed, the proportion is more nearly 215 per cent. of the weight of sulphate, or nearly one part in 200 of water. This, of course, is for a water fully charged with sulphate of lime. For lesser quantities the amount of soda required is correspondingly reduced. There is a chemical reaction to which the writer has never seen attention drawn, but which might with advantage be investigated as to its bearing on the watersoftening question, and that is that sulphate of lime forms a double salt with sulphate of soda, known as glauberite when it occurs in Nature. This salt is nearly insoluble in water, from which it would appear that if we added to a sulphate water only sufficient soda to reduce one half of the lime sulphate to soda sulphate, these two sulphates might unite to form the double insoluble salt which would deposit. If this action should take place, it would economise just half the soda, and would give a softened water free from sulphate. This is mentioned merely, but no positive knowledge is to hand that such action occurs or that any one has particularly investigated it.

In dealing with a sulphate or permanently hard water by means of soda, it has so far been assumed that the water contains sulphate alone, and any carbonate of lime has been left out of consideration. We might, however, soften a water of its temporary hardness by means of lime, and then deal with its permanent hardness by means of soda, or we might reverse the order, and deal with the permanent hardness first. What we are coming to, and what needs to be pointed out in order to be avoided, is that, if we use the quicklime for the one operation and the carbonate of soda for the other, the two processes must be entirely distinct and separately conducted. We cannot, in fact, say some ehemists, mix the lime and soda together and let the two processes go on side by side, for were this to be attempted, the soda would simply convert the lime into carbonate and itself beeome caustic soda. Nevertheless, the two processes may be earried on together, but to do so we must slightly change the nature of one ingredient.

\section{The Double Process.}

In order best to carry out the removal of both temporary and permanent hardness in one operation, it is requisite to use caustic lime and caustic soda in suitable proportions. The two in combination must be sufficient to absorb all the free carbonic acid gas in the water. This eonverts the caustic lime into carbonate of lime, which, of course, precipitates, and it converts the eaustic soda into carbonate of soda, and this then attacks the sulphate of lime as explained above. Recognizing the practicableness of the double process, it follows that we must use so much eaustic soda as will, when turned into earbonate, just deal with 


\section{WATER PURIFICATION}

the lime sulphate, and we must then use caustic lime in quantity sufficient to absorb what carbonic gas has not been taken up by the caustic soda. An example will make the action plain. Suppose a water contains 16 grains of lime carbonate and 16 of lime sulphate per gallon of 10 pounds. We know, from what we have previously learned, that for each 136 parts of sulphate of lime we require to employ 106 parts of carbonate of soda. (The action is $\mathrm{CaSO}_{4}+\mathrm{Na}_{2} \mathrm{CO}_{3}=\mathrm{Na}_{2} \mathrm{SO}_{4}+\mathrm{Ca}$ $\mathrm{CO}_{3}$ ). Now, in 106 parts of carbonate of soda there are required 80 parts of caustic soda, and the carbonic acid gas necessary to convert caustic into. carbonate is 44 parts per 80 parts of caustic (thus $\mathrm{H}_{2} \mathrm{Na}_{2} \mathrm{O}_{2}+\mathrm{CO}_{2}=\mathrm{Na}_{2} \mathrm{CO}_{3}+\mathrm{H}_{2} \mathrm{O}$ ). The result of combining caustic soda with the gas is carbonate of soda and water.

Coming back, then, to the 16 grains per gallon of sulphate, we shall want $\frac{80}{136} \times 16=9 \cdot 4$ grains of caustic soda and $\frac{44}{136} \times 16=5 \cdot 18$ grains of carbonic gas.

We have seen that it requires 44 parts of this gas to maintain 100 grains of lime carbonate in solution. By removing 5.18 grains of gas we shall therefore remove from solution $\frac{5.18}{44} \times 100=11 \cdot 77$ grains of lime carbonate.

There will now remain in solution 5.23 grains of lime carbonate, and this must now be dealt with as already explained by adding the proportion of quicklime, namely, $\frac{56}{100}$ of $5 \cdot 23=2.92$ grains per gallon. By this combined system we may employ just what is necessary of caustic soda to remove the lime sulphate by converting the caustic into the carbonate by means of the gas in the water itself, and we shall save a portion of the lime otherwise wanted for the precipitation of the lime carbonate. The two processes are carried on simultaneously, both the lime and the soda being mixed in proper proportions. Apart from the greater cheapness of the combined method, it would not even be possible simultaneously to carry out a double system with caustic lime and with carbonate of soda as re-agents, for the lime would rob the soda of its gas and become carbonated and unable to do its work on the water. In the double system the caustic lime first absorbs the gas it requires, and the caustic soda takes the remainder, and then the sulphuric acid of the lime sulphate takes up the soda, and the lime, set free by the acid, takes up the gas so soon again rejected by the soda. (Expressed as a general chemical equation, the following equation shows the beginning and end of the operation, but we cannot know really what are the intermediate steps. $\quad\left[2\left(\mathrm{CaCO}_{3}+\mathrm{CO}_{2}\right)+\mathrm{CaO}\right]+2(\mathrm{NaHO})$ $+\mathrm{CaSO}_{4}=4\left(\mathrm{CaCO}_{3}\right)+\mathrm{Na}_{2} \mathrm{SO}_{4}+\mathrm{H}_{2} \mathrm{O}$. $)$

Where equal weights of the two lime salts exist in any sample of water, the eaustic soda necessary for the sulphate of lime will first remove fully two-thirds of the lime carbonate also. In all eases where the weight of lime sulphate exceeds one and one-third times the weight of lime carbonate in the water, then the addition of the caustic soda in quantity sufficient for removing the lime sulphate will also remove all the carbonate, and any further proportion of lime sulphate will demand carbonate of soda for its removal.

In round numbers, where the proportion of temporary to permanent hardness is 8 to 11 , caustic soda will completely soften. Where the ratio is $(8+x)$ to 11 , then lime and caustic soda are wanted, and for ratios of 8 to $(11+x)$ caustic and carbonate of soda must be used.

\section{The Economy of Softening.}

A few words as to the economies of softening. Of coal saved we need only say that this is considerable, both by reason of cleaner boiler plates and less blowing out of hot water. Then the destruction of the boiler is infinitely less. As regards 


\section{I.IQUID FUEL AND ITS COMBUSTION}

cost of softening, one pound of lime is as effective as $\mathbf{4}_{4}^{3}$ pounds of carbonate of soda, and an estimate of the prices of the two shows that one shilling spent on lime will go as far as $£ 4$ spent on soda. For manufacturing purposes, where soap is used, the expenditure of a farthing is said to save for London water about 30 pounds of soap.

A dyer of fire wools has said that much of the success of the Germans in dyeing was due to the care they take in water purification, especially for delicate colours, and he showed his own productions in dyed wools, stating that he could obtain $6 d$. more a pound of wool dyed than other dyers, and that he didn't care a farthing for German competition, as it was all a matter of pure water, and this he had secured.

Unless a boiler is worked at a considerable pressure so that the temperature of deposit of lime sulphate is reached, then the sulphate is not at once deposited on entering the boiler, as is the carbonate. The sulphate is deposited because the water that had held it has been boiled away; each molecule of water evaporated leaving its molecule of lime sulphate behind.

Dr. Angus Smith, who dealt with the subject many years ago, thus summarized the results. For 1 grain of sulphate of lime per gallon use $779 \cdot 4$ grains of carbonate of soda per 1,000 gallons of water. For 1 grain of carbonate of lime per gallon use 630 grains caustic soda per 1,000 gallons of water.

Dr. Smith quotes dry caustic soda, but his figures have been translated into those necessary for the hydroxide of commerce ( $\mathrm{HNa} O$ ) not $\mathrm{Na}_{2} \mathrm{O}$.

\section{The Magnesia Salts.}

For the magnesia salts Dr. Smith says-

For cach grain of carbonate of magnesia per gallon use 750 grains caustic soda per $1 ; 000$ gallons.

For each grain of sulphate of magnesia per gallon where there are no carbonates use $883 \frac{1}{3}$ grains of carbonate of soda per 1,000 gallons.

This last is, however, also very soluble, and we may usually neglect it for steam boiler purposes.

When either the sulphate of lime or magnesia exists in company with carbonates, it is not necessary to add any soda to precipitate the sulphates unless they exist in a greater proportion than 11 of sulphate to 8 of carbonate, as already explained. Merely the excess of sulphate requires carbonate of soda adding in addition to that formed from the caustic soda added to precipitate the carbonates.

Briefly, however, where we have to deal with lime carbonate, as is so very usually the case, the use of caustic lime is the best and cheapest. It is employed on a large scale by some of the water supply works in the chalk districts of England, notably at the Colne Valley works near London, which pump water from a well sunk in the chalk rock. It ought to be employed by the London Water Companies, but is not, and the water is quite unfit to use. It will not wash and is not fit for potable purposes.

Iron.

Where iron exists as an impurity in water, it will be removed by the lime process.

In water that comes, however, from a sandy soil, as, for example, much of the water from the Lower Greensand formation in the country south of London, iron in 


\section{WATER PURIFICATION}

soluble form exists in large quantity. Upon exposure to the air the soluble oxide of iron takes up a further atom of oxygen, and is converted thereby into a different and insoluble oxide, which gives the water first a cloudy, dirty appearance, and in about 24 hours completely precipitates and leaves the water bright and clear. Such water as this can only be purified by aeration, as the soluble iron salt would pass through the filter. In using such water it is therefore necessary to provide a double storage system of 24 hours, the water having 24 hours to purify itself before use. When such water is first pumped it is best to allow it to fall through a considerable depth of brushwood, or to use some means of exposing it to a large surface of air by finely subdividing it. This increases the rapidity of oxidation, and of course reduces the period of standing. If carefully drawn off, such water does not require filtration.

\section{Acid Water.}

Water is frequently of a slight natural acidity and sometimes exceedingly corrosive from peaty acids, and boilers have been allowed to be thus eaten away, rather than the owner would incur the expense of sufficient soda to neutralize the acid. In cases of this sort possibly the cheapest way of reducing the acidity is to add lime in a caustic state or allow the feed water to percolate through a mass of limestone chips or chalk, or to add powdered chalk to the water. In time a scale would be formed in the boiler, but this need not be allowed to become too thick, for the acid water used without treatment for a time would probably remove or loosen the scale, and treatment could be resumed. All these points, however, are rather for the engineer in charge to consider and work out, and cannot be dealt with in a general way. Of all impurities in water, acid is the worst. Scale can be seen and measured, but the effects of acid are deceitful. Boilers that have been fed with acid water may be seen in which the surface of the plates has maintained its smoothness in a remarkable degree, and yet wasting has gone on to a serious extent, and produced equal results upon plates and rivet heads alike. Usually, however, corrosion is more desultory, and its effects can be more truly estimated, but it is always dangerous.

.With present-day high pressures and temperatures the feed to a boiler after passing through the flue feed heater is heated so near to the depositing point that it will sometimes reject its lime carbonate immediately on entering the boiler, forming a thick pulverulent incrustation round the feed pipe and upon the boiler shell at that locality, and rapidly choking the feed pipe. Microscopic examination of the powder will disclose the peculiar and characteristic crystal of lime carbonate or calcite. This deposit may prove dangerous. It is the practice with some engineers to employ a series of trays in the boiler into which the feed is discharged, so as to fall from tray to tray, in which process it becomes heated to depositing point and the deposit remains in the trays. It is, however, a distinct economy to employ an economiser or flue feed heater. This, if properly worked, should heat the feed sufficiently to cause deposit of lime in the economiser itself. Hence the softening process should precede feed heating by an economiser, but, as heat assists the softening process, there is no reason why the water to be softened should not be pumped through a worm on its way to the softening tanks, the worm being exposed to the first rush of the exhaust steam to the condenser. Where non-condensing working is practised, there is no excuse for not heating the feed by means of the exhaust steam. 


\section{LIQUID FUEL AND ITS COMBUSTION}

Tests.

In order to test the perfect action of the process of softening a carbonate water by means of lime, it is usual to employ nitrate of silver solution or phenolphthalein, the former producing a brown colour in an overtreated sample and the latter a brilliant pink. By reducing the treatment until the test solutions show a faint trace of delicate straw colour or the faintest possible pink, it may be known that the process has been carried out just sufficiently. Pronounced colour shows an excess of re-agent.

\section{Boiler Compounds.}

Those nostrums should as a general rule be carefully avoided. They usually consist of some mixture of alkali and organic matter with a view to producing a slippery and non-adhesive mud. 'They are apt to cause overheating of plates, and any good in them is so diluted with water that, at the excessive prices asked for them, they are very costly indeed. Occasionally a local produet will be found beneficial on local waters. Scale may often be detached by heating a boiler with a strong dose of soda to the boiling point and leaving it to cool down again, perhaps twice in succession. It is also claimed with reason that if a boiler be well wetted, so that the scale is saturated with water, the scale will be detached by freezing the boiler, on the principle that the freezing of the water in the scale will detach it from the plates by expansive action as well as disintegrate the scale. A heavily scaled boiler will clean itself in due time if fed with a non-scaling water, the scale coming loose in slabs.

When the Porter Clark or lime process is employed, there always remains in the softened water a small amount of lime in an uncarbonated state, which is apt to settle in the feed pipes and choke them. The Archbutt-Deeley addition to the process provides for the addition of carbonic acid gas to the softened water in order that the lime may be recarbonated, and this is said to be effective in preventing the deposit complained of. Waters that contain organic matter cannot be so readily softened as water fresh from a well, because of the presence of albumenoid matter. In such cases it is customary to assist the process of softening by the addition of a small amount of alum to the reagents employed. The alum serves to coagulate the organic matter, and precipitation is rendered more rapid and possibly more complete than if no organic matter had been present.

Some of the deposit should always be left in the tanks and mixed up in every fresh charge of water. The carbonate crystals of the old deposit serve as a nucleus to which the nascent crystals will attach themselves. The particles in suspension are thus heavier, and deposition goes on more rapidly and perfectly. Where there is not ample time for complote settlement, the treated water-should be drawn off by means of a floating mouthpiece held about half an inch below the water surface and carried by a jointed pipe. This serves to gather the water from the surface, where it clears rapidly and allows the clarification of the lower depths to continue. Subject to conditions of space, the softening tanks should be for the same reason preferably shallow and of large area rather than deep and of small area.

Sal ammoniac should not be used in a steam boiler as a disencrustant. To reduce sulphate of lime it has been suggested to employ trisodium phosphate two parts to three of the calcium sulphate chemically, thus : $2 \mathrm{Na}_{3} \mathrm{PO}_{4}+3 \mathrm{CaSO}_{4}=$ $2\left(\mathrm{PO}_{4}\right) \mathrm{Ca}_{3}+3 \mathrm{Na}_{2} \mathrm{SO}_{4}$, the sulphate of soda remaining in solution and the phosphate of lime depositing as mud. Fluoride of soda has also been employed as a 


\section{WATER PURIFICATION}

compound in boilers as follows: $2 \mathrm{NaF}+\mathrm{CaSO}_{4}=\mathrm{CaF}_{2}+\mathrm{Na}_{2} \mathrm{SO}_{4}$, the fluoride of lime depositing as slush.

Compounds of soda salts and organic matters such as stareh, glue, barks, ctc., should be strictly avoided as liable to cause dangerous overheating of the plates and collapsed furnaces. Grease must be avoided ; it forms spongy deposits with ecrtain salts, and is very dangerous. Kerosene is said to have a rotting effect on scale, but should be very carefully and sparingly used.

When a boiler has become encrusted it may be freed by boiling in a strong solution of caustic soda and cooling slowly down. This will soften and loosen the scale, so that it may be removed.

But prevention is better than cure, and the best plan is to treat water before it enters the boiler, on the lines already described. 


\section{Chapter XI}

\section{CALORIFIC AND O'THER UNITS}

\section{Thermo Chemistry.}

$\mathrm{T}$

HE sulject will only admit of slight treatment in a work of this description. It has been exhaustively treated by Berthelot, espccially in his Thermochimie of 1897 ; therein he gives the thermal equivalent of almost all known hydrocarbons and other elements and compounds. When the calorific capacity of a fuel is tested it will often be found to depart from expectation. Two fuels may have the same composition yet produce very different effects. Thus acetylene and benzene have exactly the same ratio of hydrogen to carbon in their composition, their formula being $\mathrm{C}_{2} \mathrm{H}_{2}$ and $\mathrm{C}_{6}, \mathrm{H}_{6}$, but their atoms are differently put together, and they produce very different amounts of heat when burned. Acetylenc is very much more endothermic than benzene, that is to say, it actually absorbs heat when first compounded, and this latent heat appears to add to its calorific output when burned. Benzene and ethylene are also endothermic, but the other fuel hydrocarbons and alcohols are exothermic, and having given out heat when formed they give out correspondingly less when destroyed by combustion. Thermochemistry teaches us to consider all substances from a monistic point of view, sceing in every gas latent heat to preserve it as a gas without which heat it would fall to the state of a liquid. Similarly we recognize that latent heat prevents liquids becoming solid.

We realize that the conversion of solid coal into gas, such as occurs when coal is burned, demands an enormous heat absorption. Thus it is that the first oxidation of solid carbon to monoxide develops less than half the heat of the second oxidation. The same or even more heat is developed by the first oxidation, but disappears in changing the solid carbon and solid hydrocarbons into gas. We are enabled to appreciate the difficulties that stand in the way of perfect combustion of bituminous fuels when we perceive the heat absorption of the gasification they endure before they burn. Thermo-chemistry points out why the calorific capacity of liquid and of gaseous fuels is better than of solid fuels; it teaches us to study the phenomena of specific heat and helps us to understand and account for an infinite variety of apparent inconsistencies and to clear away the mists from our earlier views. As, however, in engineering we can only deal with approximations, it is sufficient for ordinary purposes to base most calculations on approximations, and it is useful to be able to calculate the approximate expectation of calorific capacity of a fuel of any type. The formula of the French chemist Dulong may still be employed as substantially accurate. It is- 


\section{CALORIFIC AND OTHER UNITS}

Calories $=x=8,080 \quad \mathrm{C}+34,500 \quad\left(\mathrm{H}-\frac{\mathrm{o}}{8}\right)$ where $\mathrm{C}=$ weight of carbon, $\mathrm{H}=$ weight of hydrogen and $\mathrm{O}=$ weight of oxygen in 1 kilo of the fucl, or, if expressed in British Thermal Units-

B.Th.U. $=x=14,500 \mathrm{C}+62,100\left(\mathrm{H}-\frac{0}{8}\right)$, where $x=$ the thermal units, $\mathrm{C}=$ the weight of carbon; $\mathrm{H}=$ the weight of hydrogen, and $\mathrm{O}=$ the weight of oxygen in one pound of the fuel.

The Verein Deutscher Ingenieure use a modified formula-

$x=8,100 \mathrm{C}+29,000\left(\mathrm{H}-\frac{\mathrm{o}}{8}\right)+2,500 \mathrm{~S}-600 \mathrm{E}$, thus allowing for the sulphur and for the hygroscopic water and for the fact that the hydrogen products are produced as steam. Mahler found an average of 44 fucls as follows-

$$
x=\frac{8,140 \mathrm{C}+34,500 \mathrm{H}-3,000(\mathrm{O}+\mathrm{N})}{100}
$$

which in B.Th.U. becomes when simplified-

$$
x=200 \cdot 5 \mathrm{C}+675 \mathrm{H}-5,400 \text {. }
$$

Calculation has now given way to actual measurement of a sample in the Berthelot bomb or other form of calorimeter.

We learn from thermo-chemistry why it is that the latent heat of steam diminishes with higher pressure, realizing that the difference is due to the absence of performance of external work.

A few of the leading particulars referring to the gases most related to power engineering are re-tabulated in Table $V$ from the author's more extended table in Kempe's Year Book.

As a science thermo-chemistry recognizes no fuel as such. It has regard merely to the heat effects of chemical combination. Our ideas are often too relative. We live in a huge atmosphere of diluted oxygen, and we are accustomed to turn jets of hydrogen into that atmosphere, and, by its means, to burn them. But did we live in an atmosphere of hydrogen, we should then turn jets of oxygen into the hydrogen and the oxygen would then be said to burn. Combustion is usually restricted to carbon and hydrogen simply because these are the two substances we find in Nature on a sufficiently large scale to burn by means of the atmospheric oxygen. Moreover, both these substances produce harmless gases when burned, namely, steam and carbonic acid. Neither of them will support life, but they are not poisonous. A London fog tells us at once that we could never use sulphur as a fuel, for even the little of it which exists in coal renders the fog very irritant to the eyes and other tissues of the body. Carbon and hydrogen, however, are harmless and powerfully calorific.

By aid of thermo-chemical researches we learn that the various hydrocarbons have either absorbed or given off heat when they combined. If the former, they are said to be endo-thermic; if the latter, exo-thermic. We learn also to make allowance for the different states of our fuel and to realize that a gas ought to be superior to the same relative proportions of liquid fuel, and this again to solid fuels. But methane, $\mathrm{CH}_{4}$, is a gas, and yet it produces when burned an amount of heat very considerably less than it ought to produce, seeing that its hydrogen is still gaseous and its carbon is also gaseous. Instead of about 16,600 units of heat it produces 13,343 units only, despite the benefit of vaporization of its carbon.

The explanation is that when its elements combined they gave out actually more heat than was neccssary to vaporize the carbon, and the excess of heat was dissipated at the time, and before methane can burn with oxygen, its constituents 


\section{LIQUID FUEL AND ITS COMBUSTION}

must be separated by means of heat. The heat necessary to do this reduces the heat of combustion. The different behaviour of acetylene arises from its formation at high temperature and its absorption of heat in formation, sueh heat becoming apparent when the gas is destroyed by combustion with oxygen.

\section{Heat.}

We do not know what heat is, but we know its effeets and we assume it to consist in atomic or moleeular vibrations.

The effeets of heat as they are apparent to our senses or to our reasoning powers are variously named. First may be placed temperature. When a body is said to be hot it can eommunicate heat to bodies at a less temperature. Temperature and quantity of heat have no particular relation to each other. A pound of lead may be hotter or have a higher temperature than a pound of iron or of water, and may be able to part with heat to those bodies. Yet it may possess much less quantity of heat because lead has a lower specific heat.

The same substance in two different states at the same temperature, as ice at $32^{\circ}$ and water at $32^{\circ}$, possesses a different amount of heat in these two states. The differenee is expressed as latent heat, and quantity of heat generally is expressed as units of heat, and we speak of the heat of combustion and the mechanieal equivalent of heat, and must therefore define all these.

\section{Temperature.}

The boiling point at which the $212^{\circ}$ of the Fahrenheit thermometer is fixed is that of pure water under the mean atmospheric pressure of 14.7 pounds per square inch. The Centigrade thermometer is marked zero at the temperature of melting ice and $100^{\circ}$ at the boiling point, the atmosphere being the pressure of 760 millimetres of a mercury column. Thus $1^{\circ} \mathrm{F} .=\frac{5}{9}$ of a degree Centigrade. The mercury thermometer is available from $40^{\circ} \mathrm{F}$. to $600^{\circ} \mathrm{F}$., and even higher if the upper part of the tube be filled with compressed nitrogen. For higher temperatures it is neeessary to employ pyrometers, which act by recording the difference of expansion of diverse metals or the pressure of heated air, or by electrical means. Metallic thermometers are not very satisfactory. In steam engineering, temperatures are met with from $32^{\circ}$ to $600^{\circ} \mathrm{F}$. in the engine-room, from $350^{\circ}$ to $3,000^{\circ} \mathrm{F}$. between the chimney and the furnace. By temperature is meant that state of a body due to heat, in which the said body can transfer heat to other bodies of less temperature. Temperature is a heat effect that is apparent to the sense of touch, and only by temperature can heat be transferred from one body to another, and the transfer is always from the hotter body to the less hot body. In this way heat can be transferred from a body containing less actual heat to one that contains more heat. Thus a mass of one pound of iron heated to a temperature of $132^{\circ} \mathrm{F}$. contains 12.98 heat units. A similar mass of water at a temperature of $82^{\circ}$ contains 50 heat units, the heat content being in each case measured from a datum of $32^{\circ} \mathrm{F}$. Yet if we immerse the iron in the water, heat will leave the iron whieh eontains so little heat and will enter the water that eontains so much heat, and will raise the temperature of the water. A clear distinction must be made between temperature and quantity of heat. Temperature ean be measured by a thermometer, but speeific heat can only be aseertained by equalising the temperature of the substanee whose specifie heat is sought with that 


\section{CALORIFIC AND OTHER UNITS}

of a mass of water. The final temperature enables the specific heat of the substance to be compared with that of water. There are three thermometric seales, namely-

The Celsius or Centigrade, which divides the distance between freezing and boiling of water at sea level into $100^{\circ}$ degrees, the freezing point being $0^{\circ}$.

The Reaumur scale, still much used in Russia, divides the same distance into 80 parts, also starting from $0^{\circ}=$ freezing point of water.

The Fahrenheit scale divides the same distance into $180^{\circ}$ parts, but starts the zero mark at $32^{\circ}$ below freezing. Hence the boiling point is $212^{\circ}$. It is frequently necessary to convert one reading to another. The following are the formulæ for doing so, C., $\mathrm{R}$. and $\mathrm{F}$. being the respective readings on each scale.

To convert Centigrade to Reaumur-

$$
\text { C. }{ }^{\circ} \times \frac{4}{5}=\mathbf{R} .^{\circ}
$$

To convert Reaumur to Centigrade-

$$
\text { R. }{ }^{\circ} \times \frac{5}{4}=\text { C. }{ }^{\circ}
$$

To convert Centigrade to Fahrenheit-

$$
\left(\mathrm{C}^{\circ} \times \frac{9}{5}\right)+32^{\circ}=\mathrm{E} .^{\circ}
$$

To convert Fahrenheit to Centigrade-

$$
\left(\mathrm{F}^{\circ}{ }^{\circ}-32^{\circ}\right) \times \frac{5}{9}=\mathrm{C} .{ }^{\circ}
$$

To convert Fahrenheit to Reaumur-

$$
\left(\mathrm{F} .^{\circ}-32^{\circ}\right) \times \frac{4}{9}=\mathrm{R}^{\circ}
$$

To convert Reaumur to Fahrenheit-

$$
\left(\mathrm{R}^{\circ} \times \frac{9}{4}\right)+32^{\circ}=\mathrm{F} .^{\circ}
$$

It is particularly necessary not to forget the addition or subtraction of the $32^{\circ}$ of the Fahrenheit freezing point when converting temperatures, but it is also necessary to remember not to do so when converting mere statements of differences of temperature. Thus if water is cooled $50^{\circ} \mathrm{C}$. this means it has been cooled through $90^{\circ} \mathrm{F}$., not through $90^{\circ}+32^{\circ}$. This point is often confused by writers and leads to very erroneous statisties.

By temperature we thus understand that a body in a certain state is in a certain condition of molecular vibration. Different bodies are differently affected by heat. Some bodies are placed in the state of molecular vibration known as temperature with less heat than others. Thus water requires more heat than any other substance, excepting only hydrogen. The relative amounts of heat to plaee bodies in a given state of vibration are called their capacity for heat or specific heat.

In Table VI are given a few characteristie temperatures.

\section{Specific Heat.}

By specific heat is meant the number of heat units necessary to raise 1 pound of a substance $I^{\circ}$ Fahrenheit, and as water has the highest specific heat of any solid or liquid it is taken as the basis. The specific heat of water is measured at the temperature of maximum density $39 \cdot 1^{\circ} \mathrm{F}$. by some writers, including Rankine, but $32^{\circ}$ is probably more usual. The difference is unimportant. The specific heat of all bodies increases slightly with increase of temperature, a fact due to the increased molecular movement, and there is often very considerable difference between the specific heat of the same body solid and liquid, notably in the case of water, the specific heat of ice being only $0 \cdot 504^{\circ}$. 


\section{LIQUID FUEL AND ITS COMBUSTION}

It has been shown that if the specific heat of a solid be multiplied by the ehemical equivalent of that solid, the result will be approximately a result that has been of some value in determining which of various values is the true chemical equivalent of the substance. For compounds the result is approximately 3 . As 1 pound of water requires 1 unit of heat to raise its temperature $1^{\circ}$, its specific heat is thus said to be unity. All other substances are referred to water as a basis. Thus when we say that lead has a specific heat of 0.0314 we mean that to heat a pound of lead to a certain temperature only requires about 3 per cent. of the amount expressed in B.Th.U. that would be required to raise the temperature of an equal weight of water by the same amount. It is necessary to know the value of the specific heats of brick, iron, fuel and its products, in order to calculate pyrometric effects, furnace temperatures, etc. For the purpose the Table VII of specific heats will usually serve. More extended tables are found in most pocket books.

Gases have two specific heats : that at constant volume and that at constant pressure, the latter being greater and due to the work done in expanding to constant pressure. Table VIII gives the specific heat of the more usual gases met with in combustion.

The specific heat of all substances appears to increase with heat, more especially in the ease of the gases. This is not of much importance in boiler work but is considerable in gas engine research. In high temperature work the inerease must be considered, but no error is introduced by neglecting the change when results are finally stated at low temperatures. The increase of specific heat with temperature is most marked in the ease of the more easily liquefied gases.

Speeific heat, then, is the relative amount of heat necessary to give to bodies a given temperature. 'The specific heat of water is called one, or unity, and that of other bodies is stated as the fraction of unity relative to water. Most substances about a furnace, as firebrick, have a specific heat of about $0 \cdot 2$. The total heat in any body is thus the product of its mass, its temperature and its specific heat as compared with some substance at another temperature and in the same state physically. Thus ice, water and steam, which are chemically identical, differ in their physical states and cannot be so compared. The specific heat of ice is only about 0.504 and that of steam is 0.480 . Ice at $32^{\circ} \mathbf{F}$. may have heat added to it until it becomes water at $32^{\circ} \mathrm{F}$.

Water at $212^{\circ} \mathrm{F}$. will absorb heat and become steam at $212^{\circ} \mathrm{F}$. In both these cases we see no change of temperature due to the additional heat, but we see a change of physical eondition. One pound of ice has absorbed 142 B.Th.U. of heat to enable it to exist as water. Any further heat then added will increase the temperature milil $212^{\circ} \mathrm{F}$. is reached. Then we may add $965 \cdot 7$ B.Th.U. to the water with no change of temperature, but we get the water in the still higher physical state of steam. In each ease the heat has become hidden or latent. It is not apparent as temperature, but is occupied in keeping the molecule liquid or gaseous as the ease may be. Heat which thus disappears in ehanging the state of a body is termed latent heat.

\section{Latent Heat.}

Latent heat is thus the specific heat of the changed state of a body. It is not stated, however, as is speeific heat, in terms of the ratio to water, but in actual 


\section{CALORIFIC AND O'THER UNITS}

heat units per unit of weight, as in calories per kilogram or B.Th.U. per pound. Thus the latent heat of water is said to be $142 \cdot 6$, because the melting of 1 pound of ice demands 142.6 B.Th.U. It is important to know the latent heat of a fow substances. Some are given in 'Table IX bclow, those marked § being hypothetical and not definitely determined.

\begin{tabular}{|c|c|c|c|c|}
\hline & \multicolumn{2}{|c|}{ Per Pound. } & \multicolumn{2}{|c|}{ Per Kilo. } \\
\hline & B.Th.U. & Cal. & Cal. & B.'I'H.U. \\
\hline Ice to water, both at $32^{\circ} \mathrm{F}$. & 1,426 & $35 \cdot 93$ & 792 & $314 \cdot 3$ \\
\hline Water to steam, $212^{\circ} \mathrm{F}$. & $965 \cdot 7$ & $243 \cdot 3$ & $536 \cdot 4$ & $212 \cdot 8$ \\
\hline Carbon to gas . . & 5,817 & 1,466 & 3,231 & 1,282 \\
\hline Oxygen to gas $\S$. & 444 & 111.9 & $246 \cdot 7$ & 9,784 \\
\hline Hydrogen to gas $\S$ & 7,320 & 1,845 & 4,066 & 1,613 \\
\hline Nitrogen to gas $\S$ & 521 & $131 \cdot 3$ & $289 \cdot 4$ & $114 \cdot 8$ \\
\hline Water to $\operatorname{gas}^{1}$ & 6,900 & 1,739 & 3,833 & 1,521 \\
\hline
\end{tabular}

Heat becomes latent not merely by such a process as actual boiling of water by heat. It becomes latent equally when water is converted to vapour by absorption in dry air : the heat must come from somewhere in such a case, and it comes primarily from the air or from the wooden floor on which water has been sprinkled for cooling purposes. If steam be heated above its saturation temperature it will now only absorb about 0.480 of a unit. Hence the specific heat of steam is barely half that of liquid water. After a very considerable further addition of heat, a point is reached where the temperature again ceases to rise; but again here is a change of state. The water is split up into constituent elements of oxygen and hydrogen, and one pound of steam will absorb 6,900 thermal units during the splitting up of its chemical affinities, showing the great energy of chemical changes, for to melt ice requires 142 heat units per pound; to vaporize the water requires $965 \cdot 7$ heat units, and to decompose it demands 6,900 . No matter how it occurs that a body changes its state, heat is given out or absorbed. To set free the solid hydrogen or solid water locked up in a piece of coal demands heat which is rendered latent. Thus heat is rendered latent when carbon is vaporized, and when again carbon is reduced from its state of carbonic acid gas to the solid form of wood by the action of the living forces of a tree, the heat is again set free by the solidification of the carbon; but the heat rendered latent in the decomposition of a body is known as the heat of dissociation, and, like latent heat, is expressed in actual heat units.

\section{Dissociation.}

'The heat absorbed in any process of chemical dissociation is an exact equivalent of the heat which is set free when the same substances eombine. Thus if 1 pound of hydrogen unites with 8 pounds of oxygen to produce 9 pounds of water, the heat of combination is 62,100 B.Th.U., and therefore the heat of dissociation of water is $62,100 \div 9=6,900$ B.Th.U.

There now remains to consider only the

\section{Unit of Heat.}

The unit of heat is merely an arbitrary measure of comparison. In British

1 From solid condition in coal. 


\section{LIQUID FUEL AND ITS COMBUSTION}

measures it is the amount of heat necessary to raise the tempcrature of 1 pound of water through $1^{\circ} \mathrm{F}$. at or near $32^{\circ} \mathrm{F}$.

In the metric system it is the amount of heat necessary to raise the temperature of 1 kilogram of water through $1^{\circ} \mathrm{C}$.

As 1 kilogram $=2.204$ pounds and $1^{\circ} \mathrm{C} .=\frac{9}{5} \mathrm{~F}$. the ratio of the two units is $2 \cdot 204 \times 9 \div 5=3.968$, the reciprocal of which is 0.252 .

The British Thermal Unit is written B.Th.U., and the metric unit is called the calorie and is written cal. Therefore 1 cal.=3.968 B.Th.U., and 1 B.Th.U= 0.252 eal. For near approximation the ratio of $4: 1$ may be cmployed.

The heat unit is employed to express latent heat of combustion of or dissociation.

It is necessary to have a statement of the relation of the heat form of energy or

\section{Unit of Work.}

The unit of work is expressed in the form of the earth's attraction.

For the purpose of the engineer the attraetion of the earth is measured by the pull exerted at sea level in the latitude of London upon a piece of metal which is called the pound. The work done in lifting one pound through a height of one foot is a unit of work and is called the foot pound. Heat and mechanical work are mutually convertible. Dr. Joule, of Manchester, by the agitation of water by means of falling weights, ascertained that the unit of heat or B.Th.U. is the equivalent of 772 pounds raised one foot, or 772 foot pounds at the latitude and elevation of Manchester, and, with very slight variation, of no account in engineering, at any spot on the earth's surface. Joules' determination of 7.72 was made by means of thermometers less perfect than those now procurable, or his figure would have been $\mathbf{7 7 8}$ foot pounds, as since found by Rowland.

The mechanical equivalent of $\mathbf{7 7 2}$ foot pounds per degree Fahrenheit becomes 1,389.6 foot pounds per degree Centigrade.

Expressed in terms metrical altogether or in kilogram Centigrade units, the equivalent is $3,063.54$ foot pounds or 423.55 kilogram metres.

Thus the calorie is $423.55 \mathrm{~km} .=3.968$ B.Th.U.

With the more modern figure of 778 foot pounds $=1$ B.Th.U. $=3,087 \cdot 3$ foot pounds. Per calorie $=426 \cdot 84$ kilogram metres, so that 1 B.Th.U. $=107 \cdot 78$ metre kilograms.

\section{Weight.}

Like the British pound, the kilogram is simply a piece of metal, and work units are done in raising it against the pull of gravity. Hence the kilogram metre whose relation to the foot pound is $7 \cdot 231 \cdot 1$. kilos.

The kilogram is $2 \cdot 2$ pounds (actually $2 \cdot 2046212$ ). The pound is thus 0.4536

'The metre or unit of length is $39 \cdot 370432$ inches, or say 3 feet 3 inches, and $\frac{3}{8}$ very nearly for easy remembrance and mental calculation.

The American yard is said to be 36.001 British inches, an inappreciable difference in engineering but noticeable in mechanical fine work.

Errors in converting units are most likely to oceur when units are compound, as when converting pounds per square inch to kilos per em. ${ }^{2}$ 


\section{CALORIFIC AND OTHER UNITS}

Very closely the English ton of 2,240 pounds resembles the French tonne of $1,000 \mathrm{k} .=2,204 \cdot 6$ pounds.

Also $1 \mathrm{k}$. per linear metre is equal nearly to 2 pounds per linear yard, and 9 calories per cube metre is very elosely 1 B.Th.U. per cubie foot.

\section{Gravity.}

Gravity $=G$ at Greenwieh is $32 \cdot 19078$ feet per second acceleration per second, usually written $32 \cdot 2$ per sec. ${ }^{2}$

The expression $\sqrt[2]{2 G}$ may be approximated as 8 .

Metrically, $G=9 \cdot 8117$ metres per second ${ }^{2}$ at Greenwich.

The true value at any other latitude (L), in centimetres per second ${ }^{2}$ is-

$$
980 \cdot 6056-2 \cdot 5028 \mathrm{Cos}^{2}(\mathrm{~L})-0 \cdot 000003 \mathrm{H} \text {, }
$$

where $H$ is the height above sea level in centimetres.

Other compound units that are useful are as follows-

1 B.Th.U. per sq. ft. $=2 \cdot 713$ eal. per square metre.

$1 \quad " \quad$ " pound $=0.556$ cal. per kilogram.

To find the number of cubic feet of air at $62^{\circ} \mathrm{F}$. ehemically consumed for one pound of fuel, take the percentage of carbon, hydrogen and oxygen in fuel. To the carbon add three times the hydrogen and subtract four-tenths of the oxygen and multiply the remainder by 1.52. The product is the cubic feet of air (A).

Thus $\mathrm{A}=1.52(\mathrm{C}+3 \mathrm{H}-0 \cdot 4 \mathrm{O})$.

The weight of air per cubic foot is $A \times 13 \cdot 14$ in pounds.

The total weight of gaseous products per pound of fuel is found by multiplying the percentage of earbon by $0 \cdot 126$ and that of the hydrogen by $0 \cdot 358$. The sum gives the total gases $(\mathrm{W})$, thus $\mathrm{W}=0.126 \mathrm{C}+0.358 \mathrm{H}$.

The total volume is found by multiplying the carbon percentage by 1.52 and the hydrogen by 5.52 ; the sum of these is the total volume (V) in eubic feet at $62^{\circ} \mathrm{F}$., thus $\mathrm{V}=1.52 \mathrm{C}+5 \cdot 52 \mathrm{H}$.

The volume at any other temperature $(\mathrm{T})$ is $\mathrm{V}^{\prime}=$

$$
\mathrm{V} \frac{\mathrm{T}+461}{523}
$$




\section{Chapter XII}

\section{'THE CALORIFIC POWER OF FUEL}

\section{Calorific Formula.}

$\mathrm{D}^{\mathrm{u}}$ ULONG and Petit and subsequently Favre and Silbermann determined the calorific capacity or heat of combustion of many substances with more or less accuracy. Dulong endeavoured to find a formula for calculating the heat of combustion of any fuel of which the chemical composition was known.

The capacity given by him to carbon was 7,295 calories. The latest determination of Berthelot is 8,137 and that for hydrogen is 34,500 .

Dulong's formula for fuel according to its composition was with the correction to modern coefficients.

$$
\text { Cal. }=8,137 \mathrm{C}+34,500\left(\mathrm{H}-\frac{0}{8}\right) \text { where }
$$

$\mathrm{C}$ is the carbon in 1 kilogram of fuel and $\mathrm{H}$ and $\mathrm{O}$ are the hydrogen and oxygen respectively, it being assumed that the oxygen is already combined with hydrogen and that so much of the hydrogen is already useless. Any error would appear to be on the safe side, and the formula assumes the return of all the gases to $0^{\circ} \mathrm{C}$.

In actual practice, of course, the gases pass at a temperature of over $100^{\circ} \mathrm{C}$., and the water is in the form of vapour, and the calorific capacity of hydrogen is often taken as only $29,150 \mathrm{~B}$. $\mathrm{TH}$. to allow for the heat absorbed in vaporization of the water.

In Germany, Dulong's formula is used in the form-

$$
\text { Cal. }=8,100 \mathrm{C}+29,000\left(\mathrm{H}-\frac{\mathrm{o}}{8}\right)+2,500 \mathrm{~S}-600 \mathrm{~W} .
$$

where $S$ is the sulphur present, and $W$ is the weight of hygroscopic water.

Seeing that in coal the hydrogen is as solid apparently as the carbon, it appears correct to take something off the co-efficient of hydrogen to allow for the heat absorbed in gasefying it, and in the above formula the subtraction of 150 calories perhaps helps to make this formula coincide very closely with calorimetric results.

Possibly also the rounding off of the co-efficient for carbon from 8,137 to 8,100 helps to correct for the vaporization of the carbon compounds which are exothermic when first formed and do not give up the full heat value of their separate hydrogen and carbon. Thus both marsh gas, $\mathrm{CH}_{4}$, and ethane, $\mathrm{C}_{2} \mathrm{H}_{6}$, give out heat when formed and require it again when dissociated, and coal is so complex a body, as are also liquid fuels, that very little positive knowledge can be assumed: it is sufficient to know that the formula last given is a very fair approximation to the truth. 


\section{THE CALORIFIC POWER OF FUEL}

\section{The Calculation of Temperatures.}

'The temperature of combustion of any substances depends upon the calorific capacity of the burning material, the total weight of the products formed, and the specific heat of the products. The calculation of the theoretical tempcrature is therefore simple.

The specific heat of all bodies, and particularly of gascs, increases with temperature, and this reduces the temperature actually obtained. Though hydrogen has so high a calorific capacity, it does not produce a specially high temperature as compared with carbon, for in the first place it demands 8 times its own weight of oxygen, and secondly the specific heat of the product, stcam gas, is also high, viz., $0 \cdot 479$.

The calculation of temperature for hydrogen burned with oxygen is thus-

$$
\mathrm{T}=\frac{29,150}{9 \times 0.479}=6,762^{\circ} \mathrm{C} .=12,202^{\circ} \mathrm{F} .
$$

These are tempcratures very much in excess of anything secured in the laboratory, which has not reached $3,000^{\circ} \mathrm{C}$. (even under a pressure of 10 atmospheres).

With air, however, the oxygen is accompanied by a weight of nitrogen $3 \cdot 32$ times its own weight, and to burn 1 unit of hydrogen requires 8 pounds of oxygen and 26.56 of nitrogen, the specific heat of which is 0.244 . The calculation for temperature is thus-

$$
\mathrm{T}=\frac{29,150}{(9 \times 0 \cdot 479)+(26 \cdot 56 \times 0 \cdot 244)}=2513^{\circ} \mathrm{C} .=4,554^{\circ} \mathrm{F}
$$

The calculation for carbon turned to carbonic oxide is similarly derived from the heat capacity $=2,453 \mathrm{cal}$. The oxygen necessary is $1 \frac{1}{3}$ times the weight of the carbon consumed, and as the calorific effect of the first oxidation of carbon is 2,453 calories per kilogram we obtain-

$$
\mathrm{T}=\frac{2,453}{2 \cdot 333 \times 0 \cdot 245}=4,292^{\circ} \mathrm{C} .=7,757^{\circ} \mathrm{F} .
$$

when burned with oxygen, the total product being $2.33 \mathrm{k}$. of carbonic oxide of $0.245 \mathrm{sp}$. heat. Then, with air containing $3 \cdot 32$ times as much nitrogen as oxygen, we have-

$$
\mathrm{T}=\frac{2,453}{(2 \cdot 333 \times 0 \cdot 245)+(1 \cdot 333 \times 3.32 \times 0 \cdot 244)}=1,485^{\circ} \mathrm{C} .=2,705^{\circ} \mathrm{F} .
$$

Where the amount of air is in excess of the chemical minimum a further term must be inserted in the denominator; as neither the nitrogen nor the oxygen of the excess air is altered they may be considered together. The sp. heat of air is 0.237 , and the weight per unit of fuel being $W$, we have the new term in the denominator $(\mathrm{W} \times 0.237)$, and the temperature of the final product is reduced simply because of the greater weight of final gases over which the heat generated per unit of fuel is distributed. In Table XI are given the calorific capacities of the various forms of carbon and of hydrogen together with the resulting temperatures of combustion with a minimum of oxygen or equivalent air. The values are given per gram, litre, pound and cubic foot for combustion to carbonic oxide $=\mathrm{CO}$ and to carbonic acid $=\mathrm{CO}_{2}$ for carbon, and to water (vapour) and water (liquid) for hydrogen.

These temperatures are not attained in practice. St. Clair Deville considers 


\section{LIQUID FUEL AND ITS COMBUSTION}

that they are prevented from occurring by the dissociation which is said to occur at high temperatures. A certain temperature is attained and further combustion ceases until some of the heat has been dispersed, when further combustion proeeeds. Berthelot, while not ignoring dissociation, is rather of the opinion that the inability to attain theoretical temperature arises from the proved increase of the specific heat of all bodies, and especially of gases at high temperatures. Probably both causes have effect.

With liquid fuels which contain so much hydrogen the calorific capacity of the hydrogen cannot exceed 29,100 cals. or 52,290 B.Th.U., because the aqueous vapour always passes away as vapour.

One pound of water vapour contains-

$1,091 \cdot 7+0 \cdot 305\left(' \mathrm{~T}-32^{\circ}\right)$ B.Th.U. where $\mathrm{T}$ ' is the temperature Fahrenheit.

Similarly where $\mathrm{T}$ is the temperature Centigrade 1 kilogram contains $606.5+$ $0.305 \mathrm{~T}^{\circ}$ calories, whence can be caleulated the heat lost where saturated steam is thrown away. But in a furnace the waste gases are much above saturation temperature, and all vapour above $212^{\circ} \mathrm{F}$. must be calculated to absorb at least $0 \cdot 480$ of a thermal unit or calorie per pound or per kilogram for each degree Fahrenheit or Centigrade beyond $212^{\circ} \mathrm{F}$. or $100^{\circ} \mathrm{C}$. respectively.

In calculating furnace temperatures there must always be added the temperature of the atmosphere to the calculated temperature, which is based on the datum of $0^{\circ} \mathrm{C}$. The usual atmospheric temperature is $15^{\circ} \mathrm{C} .=60^{\circ} \mathrm{F}$. for convenience, a sufficient approximation. The total amount of water to be allowed for in any fuel sample is nine times the weight of hydrogen in the sample plus all the water. Water should be nil with liquid fuel warmed sufficiently to cause the water to separate.

In calculations of the hydrocarbon gases the figures given above are combined; thus for benzene, $\mathrm{C}_{6} \mathrm{H}_{6}$, the calorific capacity is 10,052 from the gas or 9,960 cal. from the liquid. This substance requires in all 3.077 times its weight of oxygen and produces 3.385 parts of $\mathrm{CO}_{2}$ and 0.6923 of $\mathrm{H}_{2} \mathrm{O}$ or 4.077 in all.

The calculation for temperature is therefore-

$$
\frac{9,960}{(0 \cdot 6923 \times 0 \cdot 479)+(3.385 \times 0 \cdot 217)}=9,343^{\circ} \mathrm{C} .=16,849^{\circ} \mathrm{F} .
$$

when burned in oxygen.

With air there is an added weight of nitrogen equal to $3 \cdot 077 \times 3 \cdot 32$, the specific heat of which is $0 \cdot 244$.

This product, $3.077 \times 3.32 \times 0.244$, is added in the denominator, and the resulting temperature is found to be $2,798^{\circ} \mathrm{C} .=5,040^{\circ} \mathrm{F}$.

Any excess of air above that chemically necessary is then allowed for by means of the extra term in the denominator $(W \times 0 \cdot 237)$.

\section{Relative Volume of Gases produced by Combustion.}

When a fucl contains carbon only the volume of the gases produced by perfect combustion is identical with the air admitted to the furnace, for in producing carbon dioxide two volumes of oxygen produce two volumes of carbonic acid, or $\mathrm{C}+\mathrm{O}_{2}=\mathrm{CO}_{2}$, which, like almost all compound gas, occupies two volumes. 


\section{THE CALORIFIC POWER OF FUEL}

When combustion is imperfect and earbonic oxide is formed, the result is $\mathrm{C}+\mathrm{O}=\mathrm{CO}$, or again two volumes from only one volume of oxygen, and the waste gases exceed the volume of air supplied.

Sulphur in a fuel leads to no ehange in volume. Hydrogen 2 volumes forms with 1 volume of oxygen 2 volumes of gas or $\mathrm{H}_{2}+\mathrm{O}=\mathrm{H}_{2} \mathrm{O}=2$ volumes of water vapour. But when flue gases are collected the water vapour condenses and there is a diminution of volume.

Each unit of hydrogen in fuel requires 8 units of oxygen.

Expressed metrically, 1 gram of hydrogen will consume 8 grams of oxygen. As oxygen weighs 1.43 grams per litre each, 1 gram of hydrogen will cause to disappear $5 \cdot 6$ litres of oxygen or nearly $0 \cdot 2$ eubic feet.

This volume disappears, and the total volume of gases must be inereased by the addition of the volume of oxygen destroyed by hydrogen.

Though not of mueh account in respect of coal, the large percentage of hydrogen in liquid fuel renders the waste gases, when cooled, very much less in volume than the original volume of air. Thus an ordinary oil may contain 12 per cent. of hydrogen or 120 grams per kilogram. This will destroy 960 grams of oxygen or 672 litres for each kilogram of liquid fuel. In ealculating the percentages of the total gases this volume of vapour must be allowed for. Per pound of fuel containing say $12 \frac{1}{2}$ per cent. of hydrogen exactly one pound of oxygen will be used, measuring 11.2 cubic feet. Thus, should the apparent volume of air be 260 eubic feet the actual volume would be $271 \cdot 2$.

The table of gases, Table V, will be useful in such ealculations.

\section{Evaporative Power of Fuel.}

The evaporative power of fuel is usually stated in terms of the water evaporated from and at $100^{\circ} \mathrm{C} .=212^{\circ} \mathrm{F}$, at which temperature all the added heat becomes latent and disappears at the rate of 537 ealories per kilogram of water, or $965 \cdot 7$ B.Th.U. per pound. The theoretical duty is thus obtained by dividing the calorific power of the fuel by these numbers-

Hydrogen should evaporate $\frac{29150}{537}=54.28$ times its weight of water. Carbon should evaporate $\frac{8137}{537}=15 \cdot 15$ times, and the best coals have a capacity of about $15 \frac{1}{2}$ times, the highest values corresponding with the highest proportion of hydrogen when this is not neutralized by being already in combination with oxygen. Liquid fuel may run as high as 22 evaporation.

The actual evaporation secured will fall short of the theoretical from 15 per cent. in the very best exceptional cases to 30 per cent. in good but heavily worked boilers, the results obtained depending upon the perfection of combustion, the avoidance of excessive air and the proportions and conditions of the boiler. A good result with coal is $10 \frac{1}{2}$, which corresponds with about 15 for good liquid fuel. Coal often falls as low as 8 and liquid fuel as low as 12.

Reference is made elsewhere to the supposed superior efficiency of liquid fuel as compared with solid fuel, in regard to the fact that Nature has supplied the latent heat of liquidity, but it is also shown that probably the effect is small, the latent heat of liquidity being only a fraction of that of vaporization. Gaseous fuels, therefore, should be expected to give higher values than liquid fuels. The formulæ for calculating the calorific effect of a fuel give a result greater than the actual calorimetric values of hydrogen and carbon. In a liquid fuel the earbon should 


\section{LIQUID FUEL AND ITS COMBUSTION}

give more than its nominal solid rating, but, on the other hand, the rating of hydrogen at 29,150 cals. is obtained from hydrogen gas, and, in a liquid fuel, the hydrogen has been deprived of its latent heat of gasefication, and by so much must lose effect when burned, and, per pound, the hydrogen loses much more than is gained per pound of carbon. Solid fuels, of course, lose still more, but the difference between liquid and solid fuels is not very great in respect of their difference of physical condition. Where liquid fuel secures its high calorific value is in its very high percentage of hydrogen and its freedom from oxygen and ash. The absence of oxygen is a proof of the full efficiency of the hydrogen, except so far, of course, that the hydrogen is combined with the carbon and the combination when effected was exothermic.

As a sample of liquid fuel calculation, a petroleum may be taken, such as a heavy Baku oil, with 87.0 per cent. of carbon and 13 per cent. of hydrogen. The excess of air will be assumed to be 50 per cent. beyond theoretical requirements. The oil was tested to give 10,843 calories by Mahler.

Calculated by the improved Dulong formula we have-

$$
\text { Cal. }=(8,100 \times 0 \cdot 87)+(29,000 \times 0 \cdot 13)=10,817,
$$

which corresponds very closely with the calorimetric test.

Had the full values of 8,137 and 29,150 been enployed, the result would have been slightly above the actual finding, and for a very pure hydrocarbon it is probable that calculation and tests will not prove to be far apart.

The temperature secured by this oil with the 50 per cent. air excess will be-

$$
10,817
$$

$\overline{(\cdot 87 \times 3.66 \times 0 \cdot 217)+(\cdot 13 \times 9 \times 0.479)+(3 \cdot 36 \times 3.32 \times 0 \cdot 244)+(5.575 \times 0 \cdot 237) .}$

In the formula the first term of the denominator gives the heat absorbed by the $\mathrm{CO}_{2}$ formed from 0.87 of carbon, and the oxygen consumed is $0.87 \times 2.66=$ $2 \cdot 32$. The second term gives the heat absorbed by the steam produced from 0.13 of hydrogen, and the oxygen consumed is $0 \cdot 13 \times 8=1 \cdot 04$. The third term gives the heat in the nitrogen which accompanies the consumed $3 \cdot 36$ of oxygen, $36=14.51$

The total weight of air used is thus $3 \cdot 36+(3 \cdot 36 \times 3 \cdot 32)=11 \cdot 15$. + Then 50 per cent. of this, or $5-575$, is put into the fourth term with the specific heat co-efficient of air. Working out, the result is-

$$
\frac{10,817}{5 \cdot 296}=2,042^{\circ} \mathrm{C} .=3,708^{\circ} \mathrm{F} .
$$

as the theoretical temperature of the fuel when supplied with 50 per cent. excess of air. 'This shows how very greatly temperature is reduced by excessive air supply. Even if it be granted that this temperature is as much as would actually be attained in practice owing to the rise of the specific heat of gases with the temperature, the fact remains that the furnace temperature would be more nearly maintained along the flues. The absorption of heat by the boiler, lowering the temperature, would set free the heat which has become latent under the term specific heat, and the curve of temperature drop would be much less steep.

But beyond all this there is a final chimney temperature beyond which it is not commercially practicable to reduce the gases, and if by using too much air we double the weight of rejected gases, these, at a given temperature, will carry off 


\section{THE CALORIFIC POWER OF FUEL}

just twice as much heat as would be carried off by half the weight. Thus, if the chimney temperature is $450^{\circ} \mathrm{F}$. or $400^{\circ}$ above the atmospherie temperature, each pound of gas runs away with approximately $400 \times 0.237$ B.Th.U.=94.8 B.Th.U., which is about 1,560 B.Th.U. per pound of carbon fuel burned or approximately 9 per cent. of the heat, on the assumption that the chemical minimum of air has been used. But had the air supply been doubled the heat thrown away would have been doubled also, and a loss of about 18 per cent. would have been incurred.

Excepting that it is important to have clear ideas upon the effect of air supply in reducing temperature, it does not much concern the engineer to know what theoretical temperatures are secured, though he must be on his guard against unduly low temperatures in the furnace, and be prepared to guard against this by proper design, such as keeping heat absorbing surface away from the furnace until combustion is sufficiently perfect to enable this to be done.

The engineer is usually concerned with the evaparative efficiency of a fuel, and calculates this from and at the boiling point of $100^{\circ} \mathrm{C} .=212^{\circ} \mathrm{F}$. The heat of evaporation of a kilogram of water is 536.5 cals. or 965.7 B.Th.U. per pound. The evaporative power of a fuel is therefore to be directly obtained by dividing its unit calorific capacity by the heat of vaporization of water from and at $100^{\circ} \mathrm{C}$.

Thus for pure carbon the figure obtained is-

$$
\begin{aligned}
& \mathrm{E}=\frac{8,137}{536 \cdot 5}=15 \cdot 165, \text { or, in British figures } \\
& \mathrm{E}=\frac{14,647}{965 \cdot 7}=15 \cdot 167,
\end{aligned}
$$

the slight discrepancy being due simply to errors in the equivalents for want of unimportant decimals.

The actual evaporation of a steam boiler never approaches the calculated figure within 20 per cent. This 20 per cent. of loss of effect is due to several causes :

(1) The whole of the fuel is not burned perfectly.

(2) The waste gases are sent away to the chimney at a temperature considerably above that of the atmosphere at which the fuel and air is supplied.

(3) There is a large excess of air in the waste gases.

(4) Much heat is lost by radiation from the boiler and brickwork and, with solid fuels, in ashes and clinkers.

M. Clavenad has a peculiar method of calculating calorific capacitics. He points out that the figures of 8,000 and 34,500 for the solid and gaseous states of carbon and hydrogen respectively are incorrect for liquid hydrocarbons. The heat disengaged by gaseous carbon when burned is equal to that disengaged by four atoms of hyclrogen gas.

The atomic weight of carbon being 12, and one kilogram of hydrogen having a power of 34,500 calories, then 1 kilo of carbon in a gaseous hydrocarbon will possess-

$$
\frac{34,500 \times 4}{12}=11,500 \text { calories. }
$$

In the complete combustion of carbon the first reaction, $\mathrm{C}+\mathrm{O}=\mathrm{CO}$, produces as much heat as the second, $\mathrm{CO}+\mathrm{O}=\mathrm{CO}_{2}$. The weight of carbon in one kilo of 


\section{LIQUID FUEL AND ITS COMBUSTION}

$\mathrm{CO}$ being $0.428 \mathrm{kilo}$, and the combustion of this from $\mathrm{CO}$ to $\mathrm{CO}_{2}$ producing 2,431 calorics therefore 1 kilo of carbon completely burned must produce-

$$
\frac{2,431 \times 2}{0.428}=11,360 \text { calories. }
$$

Hence M. Clavenad takes the calorific power of gaseous hydrocarbon as 11,500 or 11,360 for the carbon, and 34,500 for the hydrogen, figures which, however, will not fit with actual determination because of the disturbing effects of cxothermism as in the case of marsh gas, $\mathrm{CH}_{4}$, which falls much short of calculation.

Mahler has shown in the table below that the calculated calorific capacity on the assumption of $\mathrm{H}=34,511$ and $\mathrm{C}=7,860$ is greater than experiment shows to be the casc.

The difference $\mathrm{P}-\mathrm{p}$ is less for crude oil than for products industrially produced. The calorific power of the various oils studied ranges from 10,300 calories for crude Russian to 11,100 for American crude.

According to Colonner and Lordier the relative weights of different fuels to give equal evaporation are-

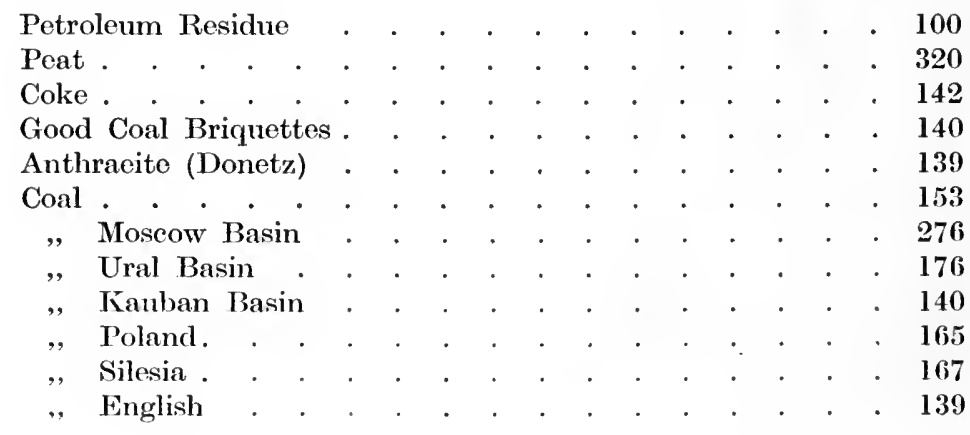

\section{ANALYSIS}

AND HEAT OF COMBUSTION OF VARIOUS PETROLEUMS.

\begin{tabular}{|c|c|c|c|c|c|c|c|c|c|c|c|c|}
\hline & C. & I. & $\mathrm{O}+\mathrm{N}$ & $\begin{array}{l}\text { Wa- } \\
\text { ter. }\end{array}$ & Ash. & C. & II. & $\mathrm{O}+\mathrm{N}$. & $\begin{array}{c}\text { Calor } \\
- \text { Ob- } \\
\text { served. }\end{array}$ & $\begin{array}{l}\text { rific Power } \\
\text { After al- } \\
\text { lowing } \\
\text { for Cin- } \\
\text { ders, etc. }\end{array}$ & $\begin{array}{ll}\mathrm{P} & \mathbf{3 4 5} \mathrm{H} \\
+ & 78,60 \\
\mathrm{C} .\end{array}$ & $\begin{array}{l}\text { Differ- } \\
\text { enee } \\
\mathbf{P}-\mathbf{P} .\end{array}$ \\
\hline Heavy Ameriean Oil & 86,894 & 13,107 & - & — & - & 86,894 & 13,107 & - & 10,913 & 10,913 & 11,352 & 439 \\
\hline Refined ,, ,, & 85,491 & 14,216 & 0,293 & - & - & 85,491 & 14,216 & 0,293 & 11,047 & 11,047 & 11,624 & 577 \\
\hline Ameriean Petrol & 80,583 & 15,101 & 4,316 & $?$ & - & $?$ & ? & $?$ & 11,086 & 11,086 & 11,543 & 457 \\
\hline , Crude. & 83,012 & 13,889 & 3,099 & ? & - & $?$ & $?$ & $?$ & 11,094 & 11,094 & 11,316 & 222 \\
\hline Heavy Baku Oil & 86,700 & 12,944 & - & - & $0 \cdot 35$ & 87,005 & 12,989 & - & 10,805 & 10,843 & 11,320 & 477 \\
\hline Novorossisk Oil & 84,906 & 11,636 & $3,4 \pi 8$ & $?$ & - & $?$ & ? & $?$ & 10,328 & 10,328 & 10,688 & 360 \\
\hline N.S.W. Sekest Oil : & 74,574 & 10,576 & 3,913 & ? & 10,937 & 8.3 .732 & 11,875 & 4,393 & 9,246 & 10,381 & 10,678 & 297 \\
\hline Ozokerite (13oryslav). & $8.3,510$ & 14,440 & 0,100 & $?$ & 1.95 & 85,170 & 14,720 & 011 & 10,946 & 11,163 & 11,773 & 610 \\
\hline
\end{tabular}

Goutal's formula for ealculating the calorific value of fuel from its eomposition is-

$$
\mathrm{P}=82 \mathrm{C}+\mathrm{aV} ; \text { where }
$$

$\mathrm{P}=$ calorific power in ealories.

$\mathrm{C}=$ percentage of fixed earbon.

$\mathrm{V}=$ percentage of volatile matter. 


\section{THE CALORIFIC POWER OF FUEL} fuel.

$a=a$ variable co-efficient depending on the amount of ash and water in the

Using the formula-

$$
V^{\prime} \times=\frac{V \times 100}{C+V}
$$

the following values are obtained for (a).

$V^{\prime}=5,10,15,20,25,30,35,38,40$.

$a=145,130,117,109,103,98,94,85,80$.

This formula is applieable to solid fuels, and Mr. J. B. C. Kershaw, of the West Lancashire Laboratory, who forwards it to me, eonsiders it fits well with actual experimentally determined facts. 


\section{Chapter XIII}

\section{SMOKE AND COMBUSTION}

\section{The Combustion of Hydrocarbons.}

\section{W}

HEN hydrocarbon fuels are burned there may be formed smoke of two distinct varieties. The first is the greenish-yellow fume which is driven off coal when placed upon a fire. This fume is simply hydrocarbon gas with its contained tars, and ean be burned. It is the usual smoke produced by the domestic fireplaee, and burns freely when an under fire becomes hot and the gases are once fairly alight.

The other variety of smoke is the black smoke which deposits soot. Soot is a flocculent variety of carbon which is produced by the sudden cooling of heated hydrocarbon gases. In the furnace of a boiler wherein the green gases are well ignited they are allowed to come into contact with the cold surfaces of the boiler and soot is formed. Had the green gases been supplied with air intimately mixed, they would have burned eompletely with no smoke, if they were not cooled down by the boiler. When a boiler furnace is of correct form, the eombustion of the hydroearbon gases can be seeured when a proper admixture of air is carried out, and in the Laneashire, Cornish, and other shell boilers, smokeless combustion ean be approximated if the draught is good. The means of admitting air is usually a grid in the furnace door. The air thus admitted sweeps over the whole surface of the fire and becomes blended with the gases given off the green coal, and perfect combustion will take place if there is sufficient free space beyond the bridge in which flame can burn unhindered by eold water pipes.

If, however, the draught is poor, the fresh air drawn in over the fire through the door will be insufficient in quantity, and smoke will be produced. About 3 to 4 square inches of air openings are necessary for each square foot of grate surface.

When insufficient draught is due to the smallness of the chimney or flues, or to bad briekwork, it ean be remedied by repairs, or by the use of a small steam jet, to induce a flow of air through the door grid.

If, however, the poor draught is due to the necessity of elosing the dampers to moderate the intensity of the fires, it is then necessary to reduce the area of the firegrate, so that the ehimney draught may be made more intense on the smaller area, the damper being kept open. This keeps up the draught sufficiently to eompel the air to flow in at the door grids in ample volume. The same effect may sometimes be secured by fitting dampers to the ash-pit opening so as to control the intensity of the fires even with a full open chimney damper. The full draught power then remains available to draw in air through the door grids to burn the 


\section{SMOKE AND COMBUSTION}

hydrocarbon gases above the fire. Any draught less than $\frac{1}{2}$-inch water-gauge, or say a velocity of 30 feet per second, will usually make it impossible to burn coal without smoke.

In no case can smoke be prevented where the gases rise vertically from the fire and pass directly between the tubes of a water-tube boiler, for the necessary mix ture of air has not been secured. Belleville tried to effect a mixture by blowing high pressure air jets into the furnace in order to mix up the gases, but the method is faulty, and cannot be a success where the tubes are so nearly above. The same principles apply to the combustion of liquid fuel, with certain differences due to the method of firing. With liquid fuel the supply of gas is uniform and continuous, and the fuel is supplied in exceedingly small particles intimately mixed with air to begin with, and supplied with a further volume of air from below. A uniform high temperature is maintained in the locus of combustion by a sufficient mass of firebrick work in the form of arches or chequer work.

The production of soot is well illustrated by the system of manufacture of lampblack, which is carried on by burning a large number of oil lamps in a confined space with an insufficient supply of air at a low temperature. Soot is thus formed, not alone by cooling heated hydrocarbon gas, but by attempting to burn it with an insufficient air supply.

Oil fuel will produce dense smoke when not supplied with sufficient air, but in all the approved methods of combustion the requisite air is supplied, and can be regulated very exactly. Combustion also takes place at a high temperature, and the flame produced is comparatively short, and combustion can be completed in a comparatively restricted space, as in the firebox of a locomotive, which can be perfectly fired by oil fuel without any change from the conditions found necessary with coal. All manner of contrivances have been patented for the prevention of smoke, but few, if any, have realized the all-important detail of temperature, for without sufficient temperature in addition to the proper mixture of air in a furnace of correct form, there can be no perfect combustion.

All smoke troubles may be attributed in general terms to the too early application of the heat absorbing surfaces of the boiler to the yet unconsumed gases. While the foregoing arguments apply more particularly to coal, their principles are equally applicable to oil. Anthracite coal which contains no hydrocarbons burns away altogether at the grate surface with an intensity of temperature very much in excess of that of any bituminous coal.

The latter must be distilled on the grate, and much heat is absorbed in the gasefication of the hydrocarbons. The zone of combustion is very much extended, the temperature at the grate is less, and it is necessary to conserve the heat generated on the grate in order to keep hot the hydrocarbon gases, so that these also may burn and not be wasted. With liquid fuel the gasefication is already partially effected, and combustion is rendered more perfect by heating the liquid and also heating the air by which it is atomized. Thus, if the oil and air be both heated to $200^{\circ} \mathrm{F}$., the temperature of combustion will be higher by about $150^{\circ} \mathrm{F}$. than if both oil and air were supplied at the ordinary atmospheric temperature. 'The following extract from the Author's paper on the subject of hydrocarbon combustion in the Electrical Review of August 30, 1901, may be of interest in this connexion with the subject of furnace temperatures.

The Electrical Review, conmenting on the theory put forward by the author, - says- 


\section{LIQUID FUEL AND ITS COMBUSTION}

"The article upon the combustion of bituminous fuels places the subject in an entirely fresh light. We believe that this is the first time that the trouble and difficulty of burning bituminous coals have been attributed to the cause now advanced. Hitherto the trouble has been simply assumed to be due to the fact that the combustion of bituminous fuels is extended along a considerable length, and that the cooling effect of water surfaces prevents perfect combustion; but it has never, to our knowledge, been pointed out that the volatile constituents of coal, gaseous when distilled off, are locked up in solid form in a lump of coal. In a piece of coal there exists solid carbon, solid hydrogen, and solid oxygen. Prof. Dewar has shown how great is the amount of heat required to be taken from the so-called permanent gases in order to reduce them to liquid form, and how it is still more difficult to render them solid. Yet in a piece of coal there are several of the so-called permanent gases reduced to a state of apparently stable and permanent solidity. It matters nothing that this solidity has been brought about in Nature's laboratory of green leaves; there the fact is, and the solid coal will only dissolve into vapour at the expense of heat, exactly as a lump of ice dissolves to water or to vapour at the expense of the heat in surrounding bodies.

"Carbon vapour generates, when completely burned, more than 20,000 units of heat per pound. Solid carbon generates less than 15,000 units. If, therefore, a piece of solid carbon be gasefied before combustion, it will absorb nearly 6,000 heat-units per pound in the process, and will, when burned as gas, give out over 20,000 units. The net result is under 15,000 units. Now, carbon can be easily boiled off into gas if combined with hydrogen-easily, that is to say, so far as regards a moderate temperature. Without hydrogen, carbon gasefies at the high temperature of $3,600^{\circ} \mathrm{C}$. With hydrogen, it gasefies at $1,000^{\circ} \mathrm{F}$, , or less. Nevertheless it absorbs, or renders latent, the same amount of heat in each case, and it can only obtain this heat from an outside source. In gas making it obtains it from the retort heating furnace. In the steam boiler it obtains it from the incandescent fuel on the grate. Properly conducted, in suitable furnaces, the final heat product is the same, but the solid carbon, burning on the grate, is compelled to add about 6,000 heat-units to each pound of the volatile hydrocarbons, in order that these may burn, later on, with an increased intensity. Hitherto, careless thinkers have pronounced the hydrocarbons so difficult of combustion that it was not worth while attempting to burn them, and their deliberate waste has been advocated. It is now clear that if the volatile parts of coal could be caused to escape entirely unburned, the fuel efficiency might be as low as 25 per cent., for the volatile hydrocarbons carry with them, not merely their own calorific capacity, but also the latent heat bestowed upon them by the solid carbon they leave burning on the grate. This view enhances the importance of completely burning the hydrocarbons. It also puts a much more hopcful aspect on the possibility of doing this, for it explains why so many well-meant efforts have been hopelessly wrong. If want of suceess has been plainly due to following wrong methods, the outlook is so much the more hopeful than if failure had accompanied correct methods. It only remains to follow correct methods for success to be assured.

"In dealing with liquid fucls, perfect combustion has been much easier to secure than it has been in the case of solid fuels, consisting only partially of volatile hydrocarbons. The theory now advanced scrves partially to explain this. Liquid hydrocarbons are already well advanced along the path of vaporization, just as ice is a long way advanced towards the state of vapour when it has been melted down. 


\section{SMOKE AND COMBUSTION}

to the intermediate state of water. Coal, petroleum, and illuminating gas are related to each other, as are ice, water, and steam. Judged by its empirical formula, petroleum should not have a calorifie effect superior to that of coal, such as it possesses. The explanation, of course, is that, being already liquid, there is so much less heat required to gasefy it than is the case with solid coal.

"Everything in fuel combustion is quite consistent with the new theory, which is based simply on figures obtained by physical and chemical experiment. It is a little startling to find that average samples of bituminous coals may produce barely a fourth of the heat of their combustible constituents upon the grate itself. True, nearly half the heat is generated by the fixed carbon which burns on the grate, but so much of this goes to evaporate the remainder of the fuel that nearly threefourths of the heat effect of bituminous fuel is exerted beyond the surface of the fuel on the grate. Some long flaming coals there are whose flame extends 90 feet from the fire ; these are the coals that make most smoke under unfavourable conditions. The drier shorter flaming coals will complete their combustion in much less space. High temperature in all is essential."

\section{Furnace Temperatures.}

An argument in favour of the necessity of refractory furnaces for bituminous fuel is that only a proportion of the total calorific capacity of a bituminous coal is generated on the grate, and therefore the fuel which burns on the grate is debited, not only with its own combustion, but also with the splitting up of the hydrocarbons and other volatiles, and raising them to such temperatures as will enable them to burn at a second zone of combustion. It is difficult to gain acceptance of these views, and it is certain that furnace and boiler designers have not, as a rule, even recognized the facts that give rise to them. Perhaps one of the best arguments will be to take the case of some actual fuel, calculate its various calorific capacities, and follow its combustion throughout.

An average of 18 analyses of Newcastle coal gives the following figures-

Fixed carbon

Volatile carbon

Hydrogen

Oxygen

Nitrogen

Sulphur

Ash

Calorific capacity

\begin{tabular}{|c|c|c|}
\hline $48 \cdot 84$ & pe & \\
\hline $33 \cdot 29$ & , & ", \\
\hline $5 \cdot 31$ & , & ," \\
\hline $5 \cdot 69$ &, & ," \\
\hline $1 \cdot 35$ & , , & ," \\
\hline $11 \cdot 24$ & ," & ", \\
\hline $3 \cdot 77$ & & , \\
\hline
\end{tabular}

The calorific capacity of amorphous carbon is about 14,647 B.Th.U. per pound; therefore the capacity of the 48.84 per cent. of fixed carbon in the above samples must be 7,150 B.Th.U. Now so far as regards the fire upon the grate, these 7,150 heat-units are all we have to work with. By their means we have to split up the hydrocarbons, or rather we have to draw on them for the heat which becomes latent in converting the solid coal to the gaseous hydrocarbon. Moreover, a piece of coal is all solid, and, exeepting the ash, it all becomes gaseous. Therefore, subtracting for cinders 3.77 per cent., there remains 47.4 per cent. of volatile solid matter, which ultimately passes off in a gaseous state. The customary allowanee of air is about 18 pounds per pound of coal. This also must be heated up to the general temperature by the heat developed in the grate by the fixed carbon only. 


\section{LIQUID FUEL AND ITS COMBUSTION}

The theoretical flame temperature of earbon when burned in an exaet sufficieney of air (i.e. $11 \frac{1}{2}$ pounds per pound) is $4,892^{\circ} \mathrm{F}$. We can readily calculate the net temperature of all the products in the usual manner, though the result will be approximate only. We may assume 1 pound of coal, and we will add the eustomary. 18 pounds of air, so as to produce a final 19 pounds of the total furnace products. As the tempcrature of combustion of earbon in air is $4,892^{\circ} \mathrm{F}$., when using 11.6 times its weight in air the temperature with 18 pounds of air will be

$12 \cdot 6$

$19 \times 4,892=3,245^{\circ} \mathrm{F}$. But with the heat produced by $48 \cdot 84$ per cent. of the coal, we

have to carry the further load of volatile fuel and inert ash that is not burned on the grate, together with its similar proportion of excess air. The temperature of $3,245^{\circ} \mathrm{F}$. $x \cdot 4884=1,584^{\circ} \mathrm{F}$, and this is the maximum temperature of the products of eombustion, assuming that they escape uncooled. This is a maximum figure, beeause whereas the temperature of combustion in air, namely $4,892^{\circ}$, is that due to a minimum of air, the reduced temperature involved by the use of exeess of air as above calculated is really too great in part proportion as the specific heat of nitrogen is greater than that of carbonic acid; nitrogen, of eourse, forms by far the greater proportion of the furnace products, and it has a specific heat of $0 \cdot 244$, as compared with carbonic acid, $0 \cdot 217$. Steam also, which is formed on the grate and does its share in reducing the temperature, has the high specific heat of $0 \cdot 480$, any free hydrogen that may escape has 3.410 , and the hydrocarbons have also very high specific heats, for example, olefiant gas, 0.418 ; marsh gas, 0.593 .

It is thus clear that the temperature of the gases as they flow to the bridge is quite low, and so far no deduction has been suggested for the vaporization of fully half the solid fuel into gaseous form. What, in fact, is the effect of the latent heat of evaporating carbon, hydrogen, oxygen, from the solid? for this is really what happens when bituminous coal is burned.

To evaporate carbon requires 5,817 British Thermal Units per pound, this being the difference between the calorific capacity of carbon burned to its monoxide, and of this monoxide burned to dioxide respectively. Hydrogen and oxygen combined require 11,000 heat-units per pound of hydrogen to raise them from the solid to the gaseous state.

Let the figure of $7,000^{1}$ units of latent heat per pound be assumed for the whole of the volatile constituents of coal, that is to say, for all that part which does not burn direetly on the grate. This proportion was found above to be $47 \cdot 4$ per eent. of the whole, so that, per pound of fuel, 3,318 heat-units $(\cdot 474 \times 7,000)$ must disappear in evaporating the volatile carbon, the oxygen, hydrogen, and other gases which exist in solid form in coal.

1 Possibly the figure of 7,000 may be too high, except for the carbon and hydrogen compounds. The value of carbon is as above about 6,000 , as evidenced by the difference between the heat prodiced by burning carbon to its first oxide, and then again to its second oxide. That for hydrogen must be over 7,300, but the values for oxygen and nitrogen are low. Lechatelier determined the molecular specific heats of the elements as $6 \cdot 65+a t$, where $a$ is the constant, and $t$ is the absolute temperature at which the measurement is taken. $a$ was given by him as 0.001 for a considerable number, but he gave values for $a=0.008$, and there is ample proof in Berthelot's great work that at high temperatures the specific heats of some substances may be double and treble the customary figure of $6 \cdot 65$. As the distillation of coal in a furnace is clesired to be effected at at least $1,000^{\circ}$ or $1,500^{\circ} \mathrm{F}$. (say $5500^{\circ} \mathrm{C}$. to $800^{\circ} \mathrm{C}$.) the specific heats will be something higher than $6 \cdot 65$. 


\section{SMOKE AND COMBUSTION}

But we have already found that the total heat generated by the 48.84 per cent. of fixed carbon produces 7,150 heat-units. The difference between the heat generated by the fixed carbon and that absorbed by the volatile hydrocarbons of these particular Newcastle coals is thus only 3,832 units. This is all the heat that remains available for raising the temperature.

Now we have found an ultimate temperature of 1,584 when not allowing for the latent heat of gasefication. We must correct this. It is less in the ratio of $3,832: 7,150$, or $849^{\circ} \mathrm{F}$. That is to say, if bituminous coal be burned on a grate and those parts of the coal which volatilize and burn as flame be gathered unburned, the temperature of the whole production of the furnace, including 18 pounds of air per pound of fuel, would only be $849^{\circ}$, or considerably less than that necessary for ignition.

In the first place, this tells us that it is of the first importance to diminish the supply of air to a minimum.

By passing only half the air through the grate and adding the remainder as required to the evolved gases at a subsequent point, we can at once practically secure double the above temperature, or say $1,600^{\circ}$, a temperature at which ignition is possible. Moreover, even 9 pounds of air is 35 per cent. in excess of the allowance necessary to burn the fixed carbon of a pound of bituminous coal, so that it would be liberal practice to pass only half. the total air through the grate. Some of the heat developed on the grate is at once radiated to the boiler surfaces; hence my constant contention that furnaces should be lined wholly or partially with refractory material in order to conserve the necessary temperature.

It must not, again, be overlooked that some of the evolved hydrocarbons do burn on the grate and at the fire surface. In fact, they commence to burn at once, and continue to burn to the end so long as conditions are maintained favourable to continuous combustion.

Rankine's estimate of air as found in ordinary practice was 25 pounds per pound of fuel. The so-called chemical minimum is $11 \frac{1}{2}$ pounds. I have assumed 18 pounds as good practice, but as low or lower than 15 pounds has already been recorded by Mr. Michael Longridge.

If, however, we pass 9 pounds of air through the grate and, say, a further 6 pounds over the grate, in fine streams, to assist the combustion of the hydrocarbons, and take care that we do not abstract heat faster than it is generated by the burning gases, we ought to be able to secure perfect combustion with less than 18 pounds of air per pound of coal. There is no known reason why we should not. The impossibility of smokeless combustion has been widely and inflnentially urged, but never so much as by those engineers who cram their heating surfaces right upon the fire and never trouble their brains to inquire why it is that a thermometer shows the same continuous reading of $32^{\circ} \mathrm{F}$. in a vessel of melting ice with a flame under it until all the ice is melted. A piece of coal, like a piece of ice, is simply so much solidified gas, and absorbs heat greedily while vaporizing, but it cannot be burned, like so much solid carbon, but must have length and space in which to mix and combine with the oxygen of the air.

The following figures, based on Berthelot's investigations, will be useful in this connexion, for they show the enormous differences which exist between matter in its several states. Carbon, existing as it does free in Nature in at least three solid allotropic modifications, is a peculiarly interesting example. We do not know it as a liquid or as a gas except in combination. Its three solid forms of crystalline, 


\section{LIQUID FUEL AND ITS COMBUSTION}

graphitic, and amorphous, show by their variations of "latent" heat how great is the effeet of form, even when the various forms affect one state alone. 'The gaseous state of carbon and the heat necessary to put it into that state are easily argued from the difference of heat disengagement in the two oxidations. As the table shows, the oxidation of 1 pound of earbon (diamond) produces 3,915 British thermal units when the product is monoxide. The heat disengaged by complete oxidation is 14,146 units. The difference of $10,231-3,915=6,316$ units, and this is obviously the minimum heat of vaporization of the diamond. Similarly, for the amorphous forms of carbon, the first oxidation produces 4,415 units, and the complete oxidation produces 14,647. Here the same difference is 5,817, and the greater heat evolution represents the energy necessary to recrystallize the diamond. Thus we learn that when the diamond crystallized it evolved heat, and we learn that the difference between graphite and the diamond is less than between graphite and amorphous earbon. In fact graphite is about six-sevenths along the road to becoming diamond.

Heat Generated by the Combustion of 1 pound of Carbon.

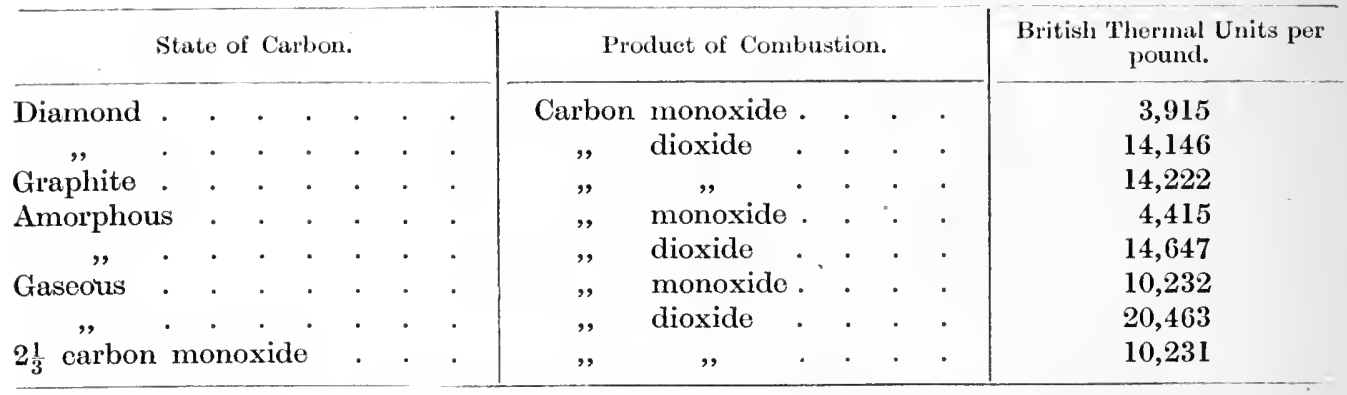

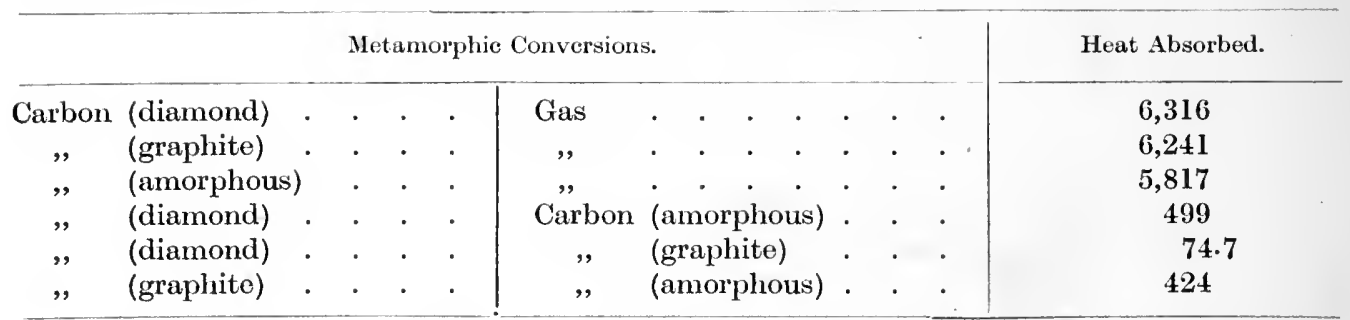

Stated briefly, it may be said that about half the weight of a bituminous fuel burns upon the grate itself, and produces half the total heat of combustion; but that owing to the heat of formation of gaseous hydroearbons, and generally to the vaporization of solid fuel, which absorbs so much heat, only about one-fourth of the total heat of combustion is sent off from the grate as sensible heat. The remaining three-fourths are developed between the fire surface and the extreme range of combustion. This range varies, of course, with the short or long flaming quality of the coal. Anthracite coal, which is entirely of solid earbon, and is therefore almost wholly burned upon the grate, will produce a temperature at the surface of the grate very considerably higher than bituminous eal will produce continuously. This is the reason why so much trouble is experienced with the grate bars when anthracite is used. It is evident that every fresh charge of bituminous coal has a very chilling effect upon the fire, and this is especially the ease with intermittent firing. The ehilling effect of a fresh charge of anthracite is merely that due to the heating of solid fuel, and is comparatively trivial. The bad effect of anthracite eoal upon grate 
bars is usually attributed to some specially bad quality in the coal itself ; but this is probably quite an erroneous idea, the real cause being simply the high temperature, which melts the cast iron bar. This explanation receives confirmation in the fact that bars go very quickly when they stand above the general surface of the grate, projecting their upper edge into the body of the fire. 'The thermo-chemical properties of coal do at least afford ample ground for accepting this as the true explanation of the effects of anthracite coals. They also afford the fullest proof of the necessity for special attention being given to the combustion of bituminous fuels. Knowing how very effective the first exposed heating surface has always been found to be, it becomes casy to understand that, in a water-surrounded furnace, so much heat may be abstracted from the fire that the combustion of the gases beyond will be very seriously checked if not entirely prevented.

The Author is unaware of any previous recognition of thesc principles in the combustion of coal. It has long seemed that fuel combustion was carried out very erroneously. While the cooling effect of the distillation of bituminous fuels always presented itself as intensifying the mischicvous effects of cold surface surroundings, the latter had always appeared amply sufficient to account for smoke without seeking further for thermo-chemical reasons. But the persistent refusal of the modern school of boiler men to look the matter of combustion of bituminous fuels squarely in the face has induced further research, and shown me that the question of burning bituminous fuels is even more complicated than had appeared. It has also shown me that past practice has been even more irrational and more hopeless than $I$ had imagined, as well as pointing to a more hopeful future.

The question of combustion is further complicated by the variation of the specific heat of gases at high temperatures.

Recognized and worked upon by Bunsen and others, the subject has been most thoroughly investigated by M. Berthelot, to whose great work, Thermochimie, it is hardly necessary to say the Author is much indebted. That the specific heat of gases does increase with temperature there is now no doubt. At ordinary furnace temperatures the effect is not great, but such as it is, is in the direction of keeping down temperatures below what they would appear to be when calculated on the basis of constant specific heat at all temperatures. This point is only raised here, as it serves to emphasize the fact that furnace temperatures are always lower than ordinary rough calculations make them.

First, only half the coal is burned actually on the grate; secondly, the other half and the excess of air work ever to reduce the temperature ; thirdly, there is the reducing effect of vaporizing half the fuel, and this is simply enormous, and has never before been recognized as considerable, if indeed it has even been allowed to suggest itself ; fourthly, there are the very active heat-absorbing surroundings of watercooled plates or pipes. All these causes work together, with the further assistance of the increment of specific heat, to reduce the products of bituminous coal to a temperature below that at which perfect combustion is possible. The combined action is so powerful that even so-called smokeless Welsh coal will smoke in boilers of the Belleville type.

In any case, even if the effect of vaporizing the solid fuel has been overestimated, the fact remains that it nearly approaches the figures given, and must prejudicially affect the furnace temperature. It teaches us at once the complication involved in burning bituminous coal, and the hopelessness of those forms of furnace that attempt to extract heat from the fire within a short distance of the fire itself. 


\section{LIQUID FUEL AND ITS COMBUSTION}

\section{Flame Length.}

It may be added that the length of flame from a burning hydrocarbon is largely determined by the intensity of the combustion, as well as by the perfection of the air admixture. A well mixed gas burning at a high temperature will produce a short flame, whereas the same gas burned in water-cooled boiler flues will produce exceedingly long flames. By using suitable furnaces with refraetory linings, combustion may be made to complete itself in a short distance. It does not follow beeause a eertain fuel produces a flame 60 or 80 feet in length that it will be necessary to line the combustion space to a distanee of 60 or 80 feet.

The very fact of lining it for one-tenth that length might so promote rapid combustion as to shorten the flame to even less than one-tenth. Once, however, that the initial temperature is redueed below a certain figure, the length of flame cannot be kept within bounds. This is important to remember, for even a hot flame will be extinguished after it has encountered the cold tubes of a water tube boiler. In comparing water tube and cylinder boilers, it should be noted that the area of cold surfaces over the fire of a eylinder boiler, either internally or externally fired, is a very small proportion of the whole heating surface. In the ordinary form of water tube boiler, where the gases rise directly between the water tubes, the proportion of cold surface at once encountered by them is very great. Apart from the errors already pointed out, the vertical rise of the gases from the fire is bad practiee.

The water tube boiler need not of necessity be thus badly arranged. It can be set to give the most perfeet combustion. Perfect combustion only takes place at a ligh temperature.

\section{Flame Analysis.}

The vibration veloeity of light, by which is meant those etheric waves which are eapable of making their existence felt to our organs of vision, varies from four hundred billion oscillations per second to nearly eight hundred billions; that is to say, about one octave alone comes within the capacity of the eye to discern. The lower number corresponds with the extreme red of the spectrum, the higher frequency with the extreme violet. Beyond the extreme red is a.long range of oscillations-rays invisible to the eye-which manifest themselves as heat. Beyond the extreme violet rays exist a long series of invisible rays known as actinic or chemieal rays. These are the rays which are most energetic in producing chemieal effects. They are the active rays in photography, and are those which produce sunburn and the like effect from exposure to electric light. As these ultra-violet rays produce chemical effects, so are they produeed by ehemical aetion. The more intense the act of chemical eombination, as in the burning of earbon, the greater will be the actinism of the light produced. Very high temperatures produced by combustion approach a white colour the more elosely as the temperature rises, and to some eyes -fatigued by too much observation of molten east iron-the clearance of the final hot slag gives a peculiar neutral light lavender colour indicative of the high temperature of a eommon foundry cupola.

The proportion of rays of any partieular colour in a furnace will indieate the intensity of the action which is going on within that furnace. It is extremely difficult for the most highly experienced eye to discern the full aetion of a furnaee at high temperature-not perhaps so much beeause of inability to estimate the relative amounts of eolour present as because of the superabundance of heat rays 


\section{SMOKE AND COMBUSTION}

which accompany the chemical rays, and generally the dazzling effect of even moderate temperatures.

The extreme brightness of the steel furnace has necessitated the use of blue or violet coloured glass to enable the workmen to watch the progress of the melt without discomfort.

Engineers have not accepted as they ought to accept the teachings of physics as an aid to correct practice. Science and practice have been kept apart. The scientific man is apt to thank heaven when he makes a discovery that he believes cannot be put to the slightest possible good, and the man of practice gibes at his scientific brother, and they do not learn from each other. Moreover, the professional teacher, when he steps down into the arena of practical engineering, appears to leave behind him the scientific knowledge he has been teaching, and the practice of the quondam man of science partakes of the crudest efforts of the tyro. He appears to find a difficulty in applying his past teaching to his present practice, and not to have a sufficient fund of practical adaptability to conform his practice to his past teachings. In the combustion of fuels, this neglect of scientific teaching is almost universal. The man of science finds that the combustion of fuel, especially of bituminous coal, is carried out along extremely unscientific lines. He accepts these wrong lines, and there is no case of any serious attempt on the part of any professedly scientific man to put the art of fuel combustion upon a sound basis. Accepting the crude appliances among which he descends, he is apt to conclude that the hydrocarbons of bituminous coals cannot be utilized, and hence the assertion is sometimes made that the hydrogen of bituminous coals cannot be counted upon as useful calorifically. The conclusion thus arrived at is probably erroneous, even on the basis upon which it is built.

Hydrogen ignites so very much more readily than carbon, and at so low a temperature that the probability is the hydrogens do burn, and in doing so they snatch the available oxygen from the surrounding air and deprive the nascent carbon of any opportunity of combustion, causing it to deposit as soot. Unless there is sufficient temperature there is no hope of burning bituminous coal or oil, as it very easily can be burned, without the formation of smoke. This is, perhaps, too crude a method of expressing the needs of the case, but when the most important industrial operations are absolutely neglected by our supposed teachers and leaders of scientific practice, it devolves upon those to whom science is less familiar, but more attractive, to step into the breach. Temperature is so closely connected with actinism that the analytical investigation of the light of a furnace will give a fair insight into its conditions of temperature. By means of transparent media of suitable composition light may be analyzed in a manner that will afford great assistance in arriving at sound engineering conclusions and practice. Such media are coloured glasses. A ruby-coloured glass will cut off all rays of light of higher vibration than ruby colour. Only the lower end of the spectrum will be visible through such a glass. On the other hand, by means of a violet-coloured glass, all the less active rays than violet will be eliminated, and the most brilliant of furnaces may be thereby rendered easily visible, its interior being coloured the peculiar lavender grey colour, or approaching this tint, which marks the ultra-violet end of the spectrum. The more perfect the combustion, the larger will be the proportion of violet light emitted by the flames.

In a well-designed furnace, the whole internal surface of which is brilliantly incandescent, light proceeds from every portion of the area and from the flame 


\section{LIQUID FUEL AND ITS COMBUSTION}

itself. 'There are no non-luminous areas. Oecasionally in the mass of flame dark streaks may be seen. 'These represent streams of burning gas, which, while incandescent, are below the violet stage. They may be traced to a point of disappearance, and they would probably radiate some light if the colour of the glass were less violet and more blue.

Let the observation now be transferred to a less perfect furnace, such as that of the common setting of the water tube boiler, where the flames rise vertically among the tubes from the grate surface, and good combustion is impossible. With the unprotected eye the flames will appear to be giving light all the way from the fire surface to between the tubes. Combustion appears fair. If, however, these light-giving flames be examined by the aid of violet glass, they will be cut down to short tongues of flame projecting but little above the fire surface. Even these tongues of flame give forth little illumination. Above the flames the gases appear to be simply dark-coloured streams of gas, soot laden and murky. The violet glass or analyzer has cut out all the rays of small actinic power and small temperature, with the result that the only remaining light rays are those immediately above the furnace.

The effect of radiation is to eool the flames below the range of violet long before they have risen to the level of the tubes. Apparently there is nothing but radiation to explain the reduction of temperature.

This method of analysis of the products of the fire is useful, not merely because it enables a furnace interior to be visually examined with ease and comfort, but because it shows so clearly the effect of a good design and the bad influence of premature cooling. It affords most conelusive testimony to the benefits that accrue from proper design, and should be an effectual silencer of those who argue that smoke is one of the unfortunate inevitables of combustion in place of being but a proof of ignorant and careless design and neglect of the plainer principles of chemical science.

The use of violet-coloured glass is essential. It is not simply that it is requisite to reduce the amount of light which meets the eye and renders vision impossible. Such a result could be attained by means of glass otherwise coloured, as by smoke, so that it is less transparent, but still not diffusive, as is ground glass:

Violet glass or the higher blue colours are necessary because of their specially analytical properties. I am not prepared to say that perfeet combustion cannot occur at temperatures below those which are associated with the light rays that can traverse violet glass. It is, however, very probably true that the violet degree of actinism must be very fully developed if combustion is to be perfect, and this degree of actinic effect cannot be associated with temperatures that can be secured in any furnace so arranged that the gases rise vertically from the grate surface to pass between the water pipes before they have been thoroughly commingled and burned in a free space. Thus the ordinary arrangement of water-tube boilers is absolutely hopeless and impossible. A single inspection of such a furnace through the analyzer will effectually convert any open mind, and point the necessity for better practice.

Mr. Weir, of Glasgow, designed the small tube boiler shown in the fig. 0 , with the necessities for combustion before him. It will be observed that in this boiler the gases from the coal must pass through a large firebrick-lined furnace and combustion chamber before they reach the tubes. Combustion is thus assured by a sufficient eonservation of temperature. The principles which underlie perfect 


\section{SMOKE AND COMBUSTION}

combustion are here assured, and smokelessness results. 'The same principles applied to liquid fuel are followed by equally happy results.

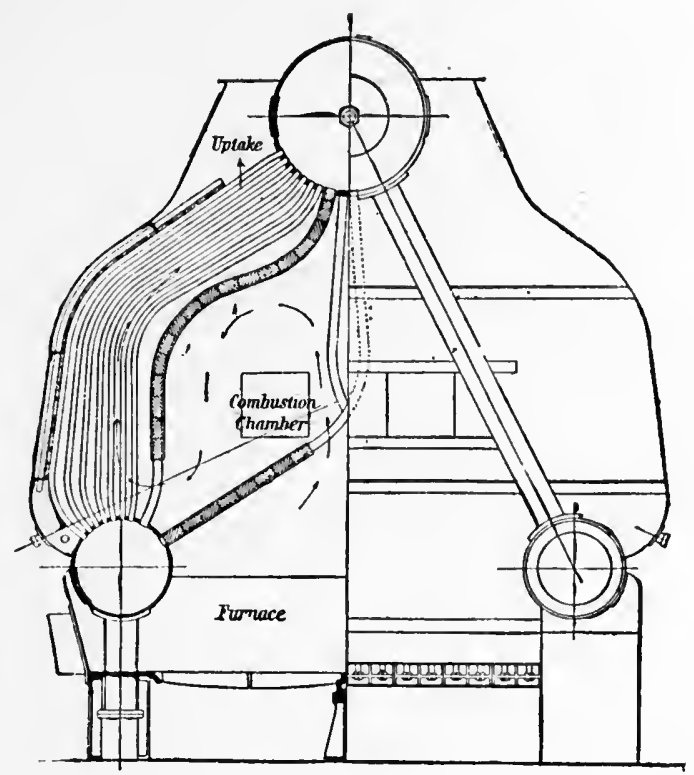

Fig. 0. Weir Smalt Tube Boiler, with Refractory Combustion Chamber.

The walls of the furnace are lined with firebrick slabs, threaded on the inside row of tubes, and beyond the furnace chamber is a further combustion chamber also lined with firebrick. The hydrocarbon gases have thus a long distance to travel before they is a further combustion chamber also lined with firebrick. The hydrocarbon gases have thus a long distance to travel before they reach any serious area of cool tube surface : the furnace is maintained at a high temperature, and there is large space for the combustion of the gases in a hot chamber, whereby alone combustion can be secured perfect. This boiler can be fixed either from side or ends, and represents the latest and most improved practice in water-tube boilers, recognizing the principles essential to
perfect combnstion. The lot gases travel along the length of the tubes, completely enveloping them. The outer casing is of firebrick slab with an outer sheet of steel. The following shows result of tests of two of these boilers with coal-

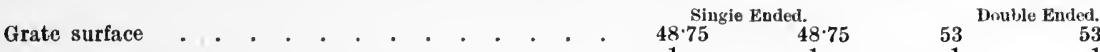

$\begin{array}{lrrr}48 & 48.75 & 53 & \text { Double Ended, } \\ 1 & 1 & 1 & 53\end{array}$

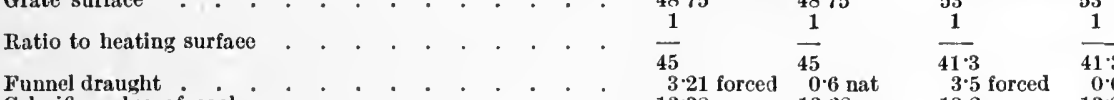

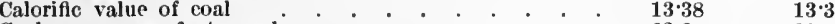

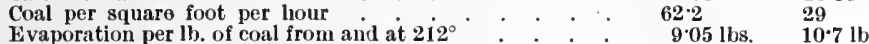

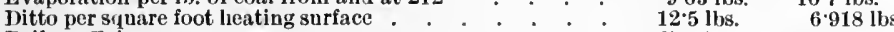

Boiler efficiency.

Fire thickness

$67 \cdot 65$

Funnel temperature

12 ins. $\quad 12$ ins.

Steam pressure, lbs.

285

$13 \cdot 2-13 \cdot 2$

$63 \cdot 4+29 \cdot 1$

$8 \cdot 65 \mathrm{lbs} . \quad 9 \cdot 76 \mathrm{lbs}$.

13.27 lbs. $\quad 6.86 \mathrm{lbs}$.

$65 \cdot 5$

9 lns. $\quad 9 \mathrm{ins}$

$\begin{array}{rr}9 \text { lns. } & 9 \text { ins. } \\ 930^{\circ} \mathrm{F} . & 780^{\circ} \mathrm{F} .\end{array}$ 

Part II

PRACTICE 



\section{Chapter XIV}

THE USE OF OIL FUEL AT SEA

\author{
Oil Storage on Ships.
}

$\mathrm{O}^{1+4}$

BVIOUSLY the double bottom of a ship now used for water ballast is the place in which to carry oil fuel, leaving other spaces free.

As each fuel tank is emptied it can be filled with water. Lloyds' Register of Shipping publishes certain rules applicable to existing vessels, which are reproduced in Appendix 4. Both Lloyds and the Board of Trade are placing only necessary safeguards, and are not opposing the use of liquid fuel. Sir Forteseue Flannery states that the peculiarly penetrative qualities of petroleum do not attach to the more viscous fuel oil, which he avers to be as easy to retain as water and by the same class and quality of riveted work.

Additional water-tight subdivision is, however, advised as a safeguard against the scend of a half-empty oil tank, but in small or medium ships the usual subdivision is thought sufficient.

In fig. 1 is shown the system of storage adopted on the ss. Murex, a vessel with all her tanks adapted to earry either general cargo or refined oil, but not originally planned for using liquid fuel, for which purpose she was converted by the Wallsend Slipivay and Engineering Company. There is no double bottom below the cargo tanks, which extend to the skin of the ship, but the bottom is double at $A$ and $B$ below the engines and boilers, and cofferdams, $C, D$, are put in at the fore and aft ends of the eargo space, and, with the fore and aft peaks $E$ and $F$, have been arranged to take the fuel oil. Service tanks $G$ and $H$ were placed in the 'tween decks.

The flange $J$ is coupled up to the pipe from the store tank, and oil passes by pipes $K$ to the various tanks, whence a pump lifts it to the service tanks, which are

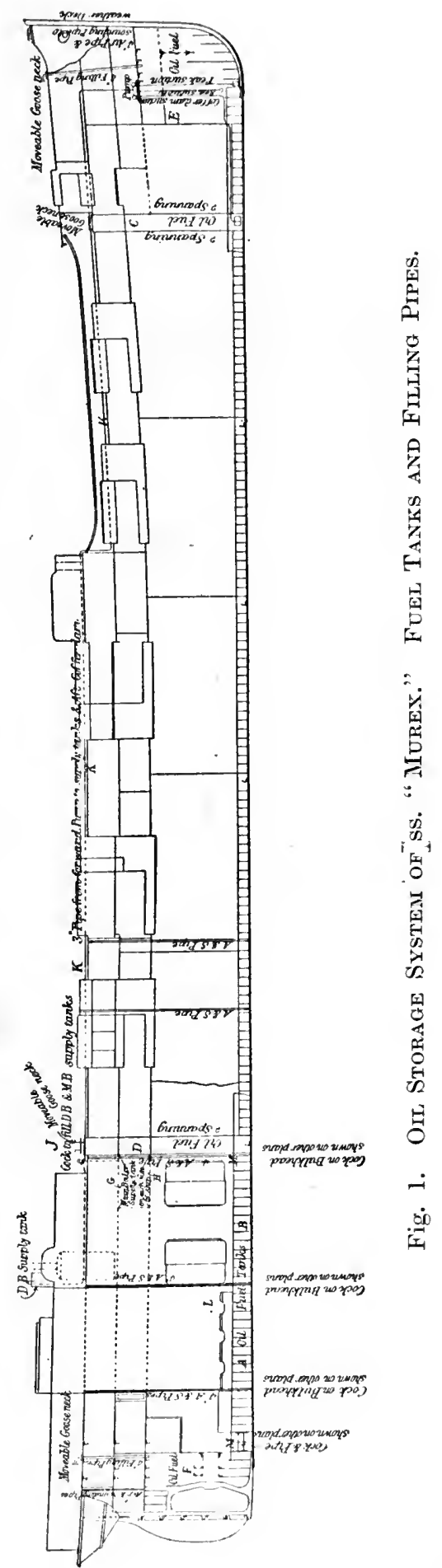




\section{LIQUID FUEL AND ITS COMBUSTION}

provided with overflow pipes, steam heater coils, and water drain pipes as described under the head of storage.

All leakage in the power compartment is intercepted by the drainage wells, so that the ordinary bilge is kept free. These intercepting wells have their own suction and delivery pipes. The ordinary cargo fuel tanks are illustrated in fig. 2.

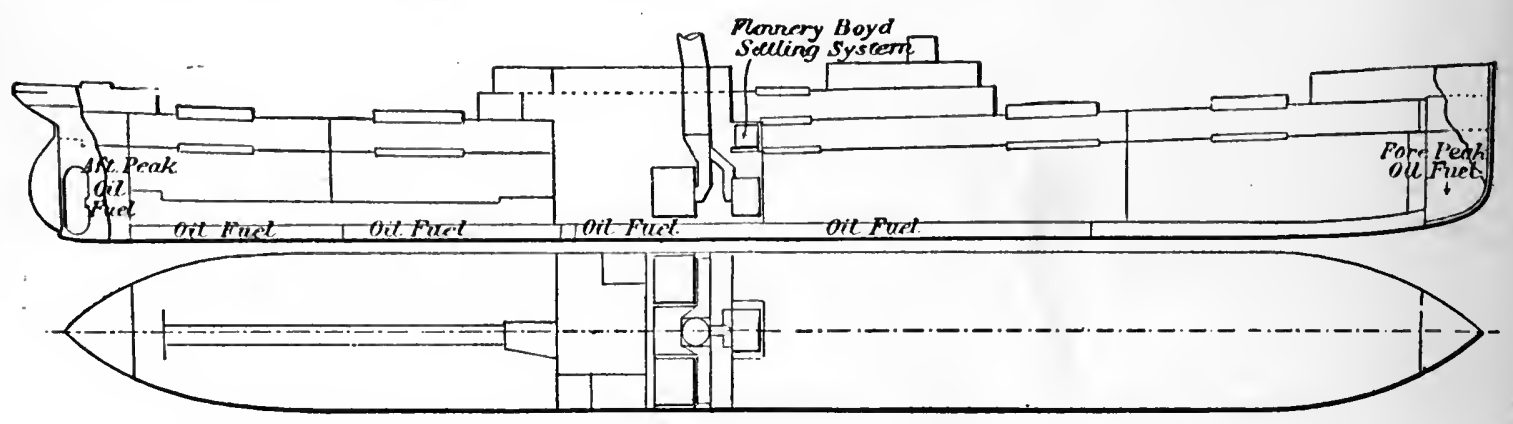

Fig. 2. Oil Fuel Tanks of Ordinary_Cargo Steamship. Flannery-Boyd System.

In fig. 3 is shown how the oil fuel is stored in a regular oil tank steamer on the Flannery-Boyd system, the oil to be used being carried in the fore and aft peaks

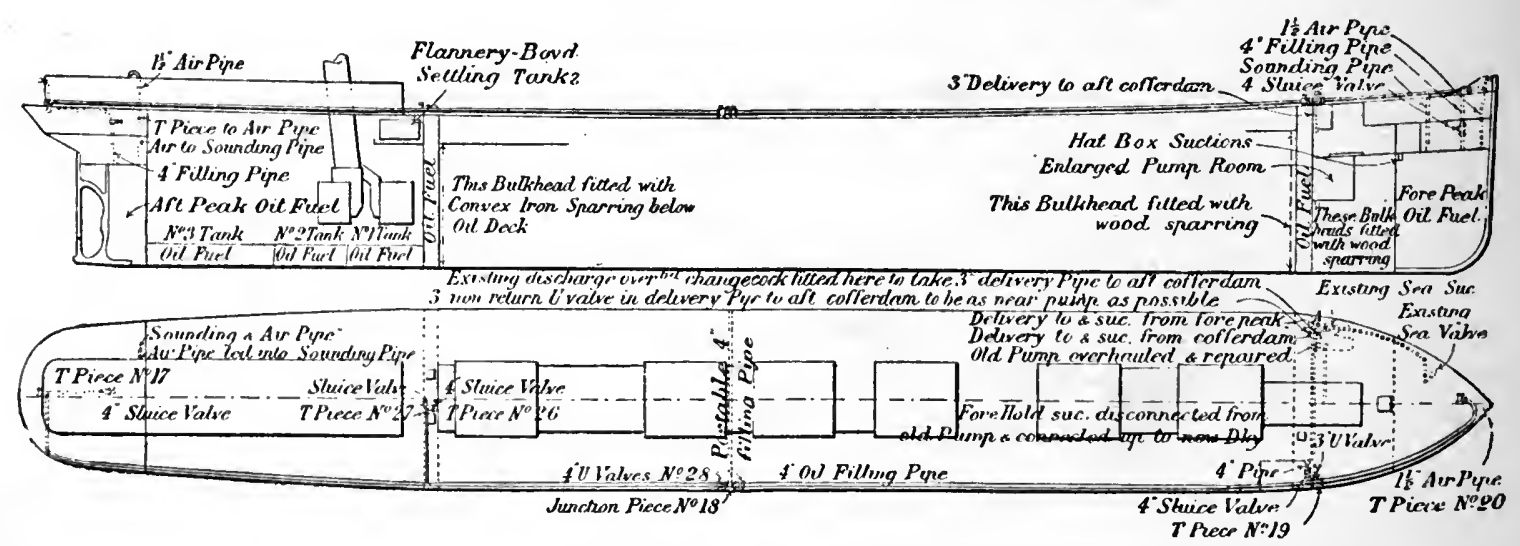

Fig. 3. Oil Fuel Storage on Oil Tank Steamship. Fuannery-Boyd System.

and in the ballast tanks under the engines and in the division bulkheads, the cargo of oil being carried in the remainder of the ship.

Between the oil tanks and the remainder of the ship it is considered necessary to place a cofferdam. In a tank steamer the rest of the ship means the engine and boiler compartments. These cofferdams are simply two transverse stiffened bulkheads extending across the ship and properly filled with water as a safeguard against leakage of oil. But in practice these cofferdams are often filled with fucl oil, a practice upon which doubts may be expressed, for apparently this destroys much of the safety intended to be given. Oil fuel is also carried in the double bottom below the engine compartments, which again is a point open to discussion, for it is very properly urged that a vessel might become injured by going aground, and such 


\section{THE USE OF OIL FUEL AT SEA}

injury might extend to the inner plating and flood the boiler compartment with oil, to the very serious risk of explosion.

It certainly seems sounder and safer practice to exclude oil from both the power compartment bottoms and from the cofferdams, the latter being kept perhaps narrower than they are now.

Where the fuel oil is of a specially heavy class, there might not be much risk even if it did leak into the firehold, and good residuum or astatki would be something of a safeguard between the main tanks of crude oil and the boiler room. Be this as it may, the presence of a narrow water space outside the oil fuel cofferdam would give a better margin of safety.

The riveting of oil-tight plating is usually 3 to $3 \frac{1}{4}$ diameters in pitch. Old ships, to be rendered fit for oil carrying, which have rivet spacings of 7 to 8 diameters, may thus have a new rivet put into each spacing. Such ships usually require additional deck beams as a rule. Ships should have not less than eight water-tight compartments, and the separating bulkheads, if oil tanks, ought to be connected directly to the skin of the ship, all possible empty spaces being avoided. Oil is filled into tanks so as to stand 2 feet above the upper deck level in the expansion trunks. The gases driven off from oil are heavy, and tend to settle at the bottom of any space into which they obtain access. A thorough system of ventilation is required to get rid of such gases. Air should be admitted through cowl heads to the upper part of the place to be ventilated and removed from the lower part. It will dilute and carry off the accumulated gas. Such air outlets should have induction openings to assist the current. The general direction of air movement in a ship is from aft forward, and advantage may be taken of this in arranging the ventilation.

Great care is needed to joint all oil pressure pipes carefully. 'The screw threads should be good, and ought to make tight joints with only a little smear of litharge and glycerine, or Venetian red and shellac. Such pipes must not be concealed beneath floor plates, in bilges, or behind casings, but ought to be fully exposed to view, in order that any want of tightness may be easily perceived.

An oil eargo being so easily mobile with movement of the ship, it is necessary that the tanks should be full, so that there nay be no surging. Hence the use of expansion trunks to permit of this and allow expansion without waste or pressure being the result. Surging plates must be employed in those compartments, which may not be always full, as the fuel tanks, and no compartment should occupy too much of the length of a ship without a bulkhead. Similarly bulkheads are stiffened from one to the other by longitudinal plates, which serve to check any tendeney to transverse surging, or scending, to use the nautical term. The ordinary cargo boat, fig. 2, when fitted for fuel oil, is re-riveted when necessary, and the oil fuel is carried in the double bottom, and can be replaced, as consumed, with water ballast. Oil is also carried in the fore and aft peaks.

\section{Recent Oil Steamers.}

One of the latest examples of an oil steamer is the ss. Trocas, which has been fitted for liquid fuel by the Wallsend Slipway and Engineering Company, Ltd., the system adopted being the Flannery-Boyd with Rusden \& Eeles burners.

The ship is an oil-earrying vessel of 347 feet in length and 45.7 feet beam, and at full load carries 6,000 tons of oil.

One of the greater obstacles in the way of fitting old steamers with liquid fuelburning arrangements is the difficulty of constructing suitable spaces to carry the 


\section{LIQUID FUEL AND ITS COMBUSTION}

liquid fuel. Ordinary coal bunkers are of course not suitable, as the riveting and plating is not oil-tight. In the Flannery-Boyd system the oil is carried in all the ballast tank spaces throughout the ship, namely, the fore and aft peaks, the double bottom ballast tanks under the engines and boilers, the forward ballast tank adjacent to the fore peak, and the forward and aft eofferdam.

The main diffieulty in earrying liquid fuel in these spaces is that some water always remains in a ballast tank, owing to the difficulty of completely draining it. This water becomes mixed with the liquid fuel, and passing to the burners eauses dangerous explosions, and generally puts out flame. It is therefore necessary to eliminate the water. To do this two settling tanks of large capacity are placed in the 'tween decks amidships, adjacent to the boiler room bulkhead. These tanks are fitted with heating coils to enable the liquid fuel to be heated to a sufficient temperature to allow of the water freely separating. The water then settles to the bottom of the tank, and ean be drained off.

Each tank is made of suffieient size to eontain half a day's supply, so that half a day is allowed for the water to become separated. From these separation or service tanks the oil gravitates to the burners, and is sprayed by a jet of steam.

Each furnace is fitted with two burners, and the furnace arrangements are such that the eomplete coal burning gear remains intact when burning liquid fuel, so that the system of either coal burning or liquid fuel burning can be resorted to at will.

If the vessel is burning liquid fuel, and it is found necessary from economical reasons to resort to coal burning, it is only necessary to rake a few broken firebricks from the bars and disconnect the burners and light a eoal fire. This operation can be earried on, without stopping the vessel, at sea ; the whole operation in a large vessel can be earried out within an hour.

The ss. Trocas has three large single-ended boilers and one donkey boiler. The large boilers have each three furnaces, and the small boiler has two furnaces. All are fitted for liquid fuel.

In Chapter XXXI. a recent example of an oil tank steamer will be found illustrated.

\section{Use of Liquid Fuel at Sea.}

Sir Fortescue Flannery states in his 1902 paper to the Institution of Naval Arehitects that the use of astatki was eommenced in 1870 on the Caspian Sea and Volga, and about 400 vessels are now equipped. As the Volga is a fresh-water river, steam can be used as the pulverizing agent without evil results in scale. Progress has been slow because the supply of oil was for years very small, but over $7,000,000$ tons annually are now used as fuel in Russia, and the world's production has much increased of late years, and in addition to the British Admiralty, the Italian and German Admiralties have taken up the study and experiment. The Hamburg-American Line have four steamers fitted for liquid fuel, and the North German Iloyd have two. The Dutch Navy have combined liquid fuel with coal in two destroyers, and Dutch mail and eargo boats in the East are regular users of oil.

\section{Supply.}

"Storage and supply systems of this fuel are in regular use, or in course of arrangement, at the ports of London, Barrow, Southampton, Amsterdam, Copenhagen, New Orleans, Savannah, New York, Philadelplia, Singapore, Hong Kong, Madras, Colombo, Suez, Hamburg, Port Arthur, 'Texas, Rangoon, Caleutta, Bombay, 


\section{THE USE OF OIL FUEL AT SEA}

Alexandria, Bankok, Saigon, Penang, Batavia, Surabaya, Amoy, Swatow, Fuchow, Shanghai, Hankow, Sydney, Melbourne, Adelaide, Zanzibar, Mombassa, Yokohama, Kobé, and Nagasaki, and storage arrangements are projected in South African and South American ports.

"The supply to these stations will be drawn as regards the ports east of the Suez Canal from Borneo and Rangoon, and as regards those west of the Canal and in South America from the Texas fields, South African stations being neutral as regards the heavy charges of the Suez Canal, and therefore likely to draw their supply from Borneo or Texas with equal economy. The South American stations will probably be supplied from the Texas and Californian fields."

The question of safety and flash-point is of importance. The British Admiralty have hitherto required a flash-point of $270^{\circ} \mathrm{F}$., Lloyds' register of $200^{\circ}$ now reduced to $150^{\circ}$, while the German authorities have accepted as safe $150^{\circ}$. Fuel of the lower flash has been in constant use for four years in British and Dutch mercantile vessels with complete immunity from accident. It is not desirable to fix a flash point higher than is really necessary for safety, because high-flash points are obtained by removing the more volatile parts of the liquid, so as to leave a thick and sluggish residuum, which requires much power to pulverize it into spray.

\section{Comparative Advantages for War Vessels.}

Sir Fortescue continues: "The problem that confronts every designer of a warship is the combination of the maximum speed, armament, ammunition supply, protection, and range of action in the smallest and least expensive hull, and any reduction of weight and space of these is a saving which acts and reacts favourably upon the problem. The comparisons between coal and oil fuel realized in recent practice are that 2 tons weight of oil are equivalent to 3 tons weight of coal, and 36 cubic feet of oil are equivalent to 67 cubic feet of coal as usually stored in ships' bunkers; that is to say, if the change of fuel be effected in an existing war vessel, or applied to any design without changing any other of the data than those affecting the range of action, the range of action is increased 50 per cent. upon the bunker weight allotted, and nearly 90 per cent. upon the bunker space allotted.

" The coal protection of cruisers, if an advantage - a matter of opinion-would disappear with the use of liquid fuel, because it would be for the most part stowed below the water line, if not wholly in the double bottom. The double bottom and other spaces, quite useless except for water stowage, would be capable of storing liquid fuel, and the space now occupied by coal bunkers would be available for other uses.

"The ship's complement would be reduced by the almost complete abolition of the stoker element and the substitution of men of the leading stoker clrss to attend to the fuel burners under the direction of the engineers, and the space of stokers' accommodation, the weight of their stores, together with the expense of thcir maintenance, would be saved. The number of lives at risk and of men to be recruited and trained over a long series of years would be reduced, without reducing the manœuvreing or offensive or defensive power of vessels of any class in the fleet.

"Re-bunkering at sea-so anxious a problem with coal-would be made easy, there being no difficulty in pumping from a store ship to a warship in mid-ocean in ordinary weather. Three hundred tons an hour is quite a common rate of delivery in the discharge of a tank steamer's cargo under ordinary conditions of pumping.

"The many parts of the boiler fronts and stokehold plates, now so quickly 


\section{LIQUID FUEL AND ITS COMBUSTION}

corroded by the process of damping ashes before getting them overboard, would be preserved by the action of the oil fuel, and the same remark applies to the bunker plating, which now so quickly perishes by corrosion in way of the coal storage.

"Liquid fuel, if burned in suitable furnaces with reasonable skill and experience on the part of the men in charge, is smokeless. It is easy to produce smoke with it, but this is evidence of its being forced in combustion, or of the detailed arrangements of the furnace being out of proper proportion to each other. In regard to smokelessness, it is, when used under conditions eustomary in the merchant service, not inferior to Welsh coal, and superior to any other coal ordinarily in use.

"The cost of oil in the East is less than the cost of Welsh coal when the cost of transport and Suez Canal dues are added to the original price of coal as delivered in a Welsh port."

It is only since Texas oil has been discovered that the successful competition of oil has appeared probable to the west of the Suez Canal. In the mercantile marine advantage is gained by a reduction of the stokehold complement, a crew of thirty-two being reducible to eight.

The big and fast Atlantic liners find it difficult to get coal to their boilers in sufficient quantity for the firemen to burn, and they lose time in consequence, even when their engines and boilers are in perfect order. This difficulty disappears with oil, and there is a saving of space previously occupied by men and stores.

Allowing 3 tons of eoal to be equal to 2 tons of oil, a first-class Atlantic liner will gain 1,000 tons for freight, as well as the whole of the bunker space. That is, with oil in the peaks and ballast tanks, there will be a gain of 100,000 cubic feet of paying space, and for most ships at-least a fourth of the coal bunker space could be used for eargo. There is in addition the saving in time when coaling. Oil is pumped in without the help of a man. No fires require to be cleaned; there are no ashes to be removed.

The advantages are thus summed up by a firm of engineers who instal liquid fuel apparatus, and as the statements they make are perfectly true, they may be printed practically in extenso, and are applicable to both marine and locomotive practice, as well as to stationary work.

"Aside from the economy over the use of coal resulting from the less aetual cost of oil, where this is the case, and the amount of which can be readily figured out for each locality, there are fundamental economies resulting from the facts that oil is much more readily handled than coal; it can be stored at a less cost, does not deteriorate when stored (as does coal), and the fire room cost is nuch reduced. Fires made by oil are perfectly steady, and the steam pressure is constant, while the temperature of the stoke-hold in steamships is lower, owing to the fact that the furnace doors are never opened and hot cinders and ashes are not pulled out into the room. In addition to these fundamental advantages, there are also other more particular advantages resulting from the use of this fuel.

" 1 . Diminished loss of heat up the stack, owing to the elean condition of the tubes and to the smaller amount of air which has to pass through the furnaces for a given calorific eapacity of fuel.

" 2. More equal distribution of heat in the combustion chamber, as the doors do not have to be opened; consequently there is a higher efficiency. The heat is easier on the metal walls of the boiler, being better diffused over the whole surface.

" 3 . Reduction in cost of handling fuel, which is done mechanically by pumps. 


\section{THE USE OF OIL FUEL AT SEA}

"4. No firing tools or grate bars are used," consequently the furnaee lining suffers no damage.

" 5 . No dust or ashes to fill the tubes or diminish the heating surface, or to be handled and earted away.

"6. Liquid fuel does not suffer when stored, while deterioration of coal under atmospheric influence is well known, not to mention the expense and shrinkage in handling, labour of feeding fires, removing clinkers, ete.

"7. Ease with which the fire can be regulated from a low to an intense heat in a short time.

" 8 . Lessening of manual labour to the firemen.

" 9 . Great increase of steaming eapacity, as conelusively proved by many factories in Pennsylvania and Ohio having to inerease their boiler eapacity by about 35 per cent. when returning to the use of coal on account of the high cost of oil."

1 Grate bars may be employed, under certain conditions, as explained elsewhere. 


\section{Chapter XV}

\section{MARINE FURNACE GEAR}

$7 \mathrm{HE}$ use of steam or of air for atomizing is a mixed question. Steam is more convenient and is naturally first used, but it becomes so severe a drain on the fresh water supply that it is practically inadmissible at sea.

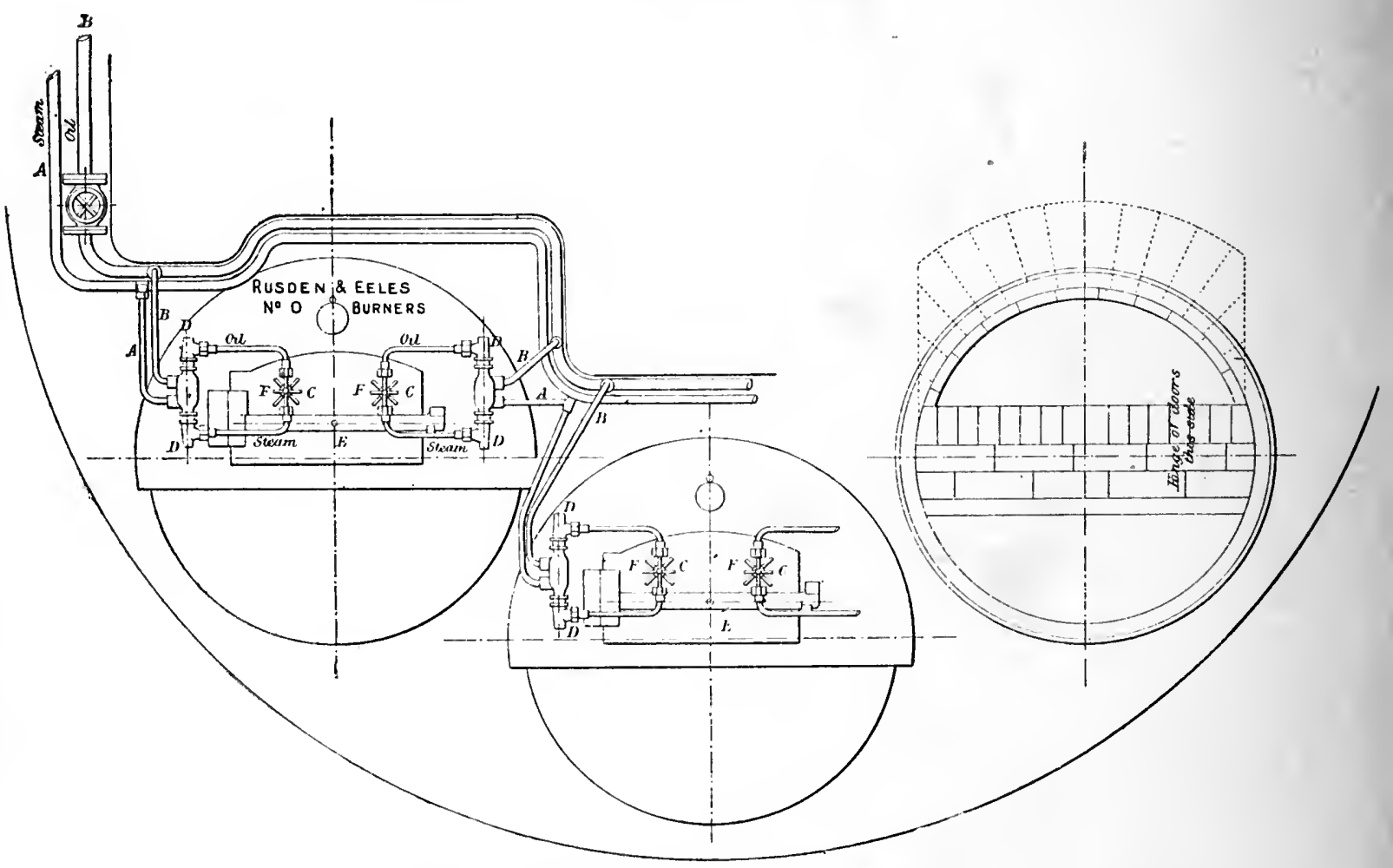

Fig. 4. Furnace Fronts of ss. "Murex"

The elaim that its oxygen is set free by the fire and burned with advantage to the evaporative efficiency of the boiler cannot be for a moment entertained or maintained. Needless it is, almost, to say that the dissociation of water or steam absorbs exactly as much heat from the fire as is given baek by the recombination.

Some makers of atomizing apparatus claim to secure a softer flame with steam, but so far as our chemical and physical knowledge extends, air ought to be superior. It requires, however, to be first compressed, and it also seems desirable that it 


\section{MARINE FURNACE GEAR}

should be heated to near the flash point of the fuel in order that this may at once be in a condition to burn freely as soon as atomized.

The ships in the Caspian Sea use steam, but are never far from land. Fuel may be injeeted under pressure and break up against an obstaele at the furnace mouth, or it may be vaporized by heat before reaching the furnace mouth.

In Mr. Howden's modification, fuel is injeeted under pressure mixed with air previously heated by the waste ehimney gases, and this system has been fitted
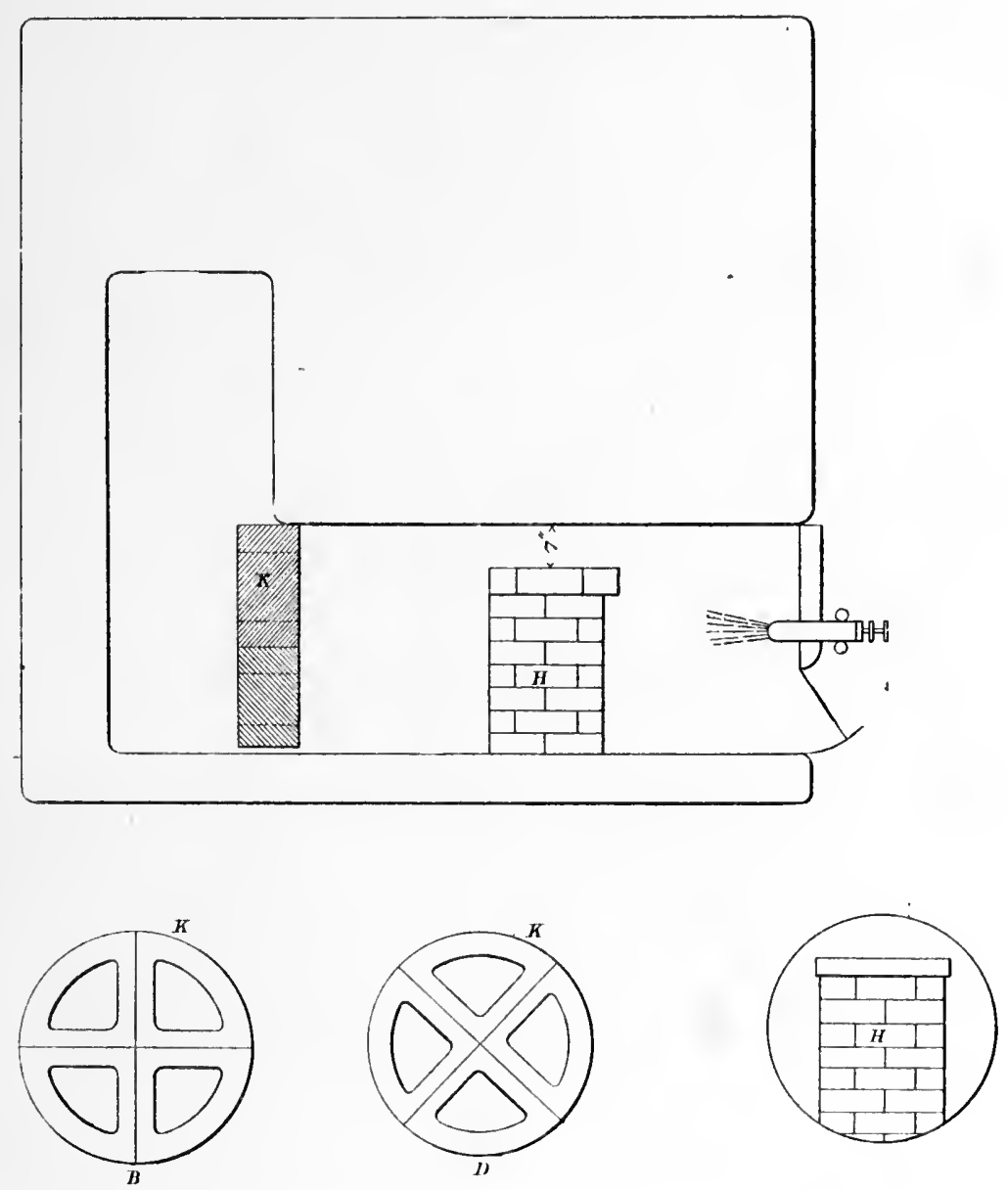

Fig. 5. Arrangement of Furnace Brickwork, ss. "Murex"

to the North German Lloyd steamers Tanglier and Packman; by Workman, Clark \& Co., of Belfast.

In the ss. Murex already named; which arrived in the Thames in the spring of 1902 from a voyage of 11,800 miles, from Singapore viâ the Cape, the furnaces were never touehed. Her coal consumption averaged 25 tons per day. With oil fuel the daily consumption is 16 tons only. The fuel supply arrangements, fig. 4; eonsist of steam pipes $A A A A$, oil pipes $B B B B$, and burners $C C C C$, hung on swivels $D$, so as to be adjustable in position, and to allow the doors to open upon the same axis or hinge centre. Coal ean be reverted to, when the burner 


\section{LIQUID FUEL AND ITS COMBUSTION}

orifices $F F^{\prime} F$ are closed by the pivoted slides. In fig. 5 is shown the brick work $H H$ in the form of pillars and arches against which the flames first impinge. At $K K K$ are further baffle bridges to keep the flame from too severely striking the back of the combustion chamber carrying the stay nuts, the tube ends, rivet seams and parts liable to injury from excessive local heat.

The form of burner is the

\section{Rusden-Eeles}

type, fig. 6, with adjustable annular orifices both for steam and oil. They possess that apparent essential quality of adjustability while at work in order to secure

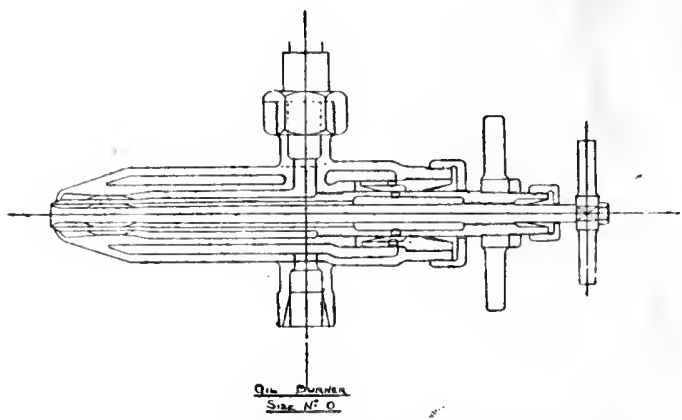

Fig. 6. Rusden-Eeles Atomizer

the most perfect possible conditions of eombustion. The oil annulus is surrounded by a steam jacket, and steam enters the middle chamber and escapes into the furnace round the central stem $P$ which is drawn back by revolving the wheel $N$, and allows an annular spreading steam jet to escape round the flaring end of the stem $P$. Oil finds its way to the little ring chamber immediately at the nozzle, and is direeted down the sloping ends of the slide directly upon the steam jet which pulverizes it and spreads it in the furnace. The oil slide is drawn back by revolving the handle $L$.

The packing rings $B$ and $J$ are self-explanatory and prevent back flow of oil or of steam at the spindles.

\section{Interchange of Coal and Oil.}

To permit the ready interchange of coal and oil the ss. Trocas was fitted as in fig. 7, the coal grates remaining and being eovered with 8 inehes of broken brick. The brickwork $B, C$ and $D$ always remains in place.

To change over from oil to coal the burners are swung back to clear the furnace door, the broken briek is raked out and ordinary coal firing resumed. In twentyeight minutes after steaming full speed under oil the Trocas was again at full speed under coal.

It is, however, found as the result of experience of long voyages that it is better not to let the firebars remain in when using oil, for, at the worst, the change over can be made in a few hours and better results obtained from oil with the more approved arrangement. The general arrangement of the ss. Trocas is that of fig. 4 .

It is estimated by Sir Fortescue Flannery that the atomizing steam will amount 


\section{MARINE FURNACE GEAR}

to 0.2 pound per i.h.p. per hour. The waste is made up by large evaporators; usually in three interchangeable sections which should be worked steadily.

'Two burners in each furnace are found to give better results than one larger

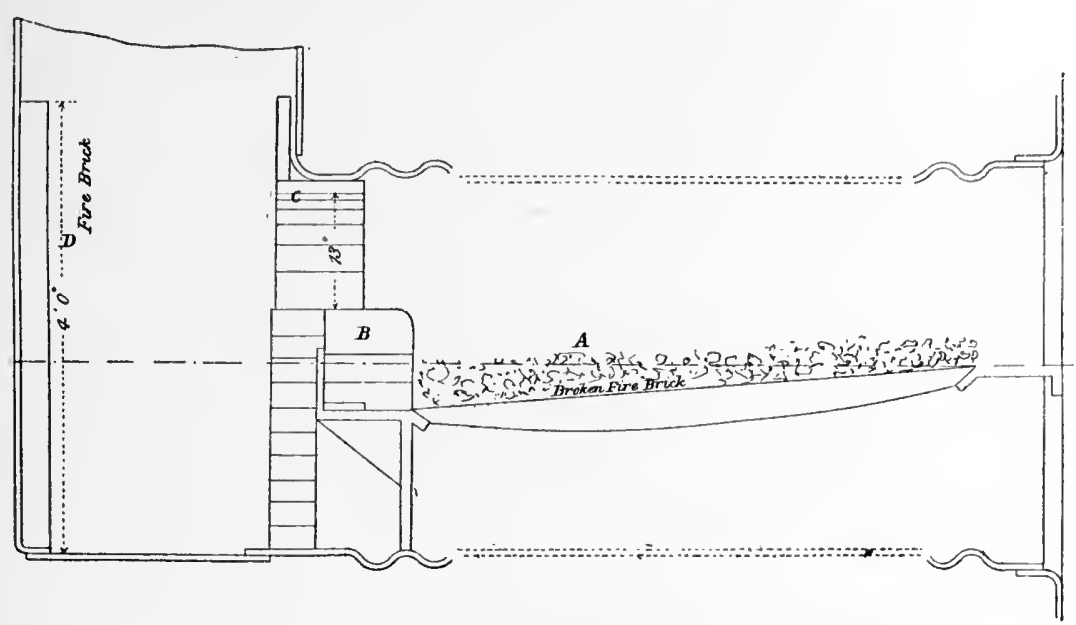

Fig. 7. Furnace Arrangement of ss. "Trocas"

burner, being more easily adjustable and maintaining continuity of flame. There is also greatly diminished chance of extinguishment of the flames by an accidental access of water from imperfectly dried oil.

\section{The Flannery-Boyd System for Steam Ships.}

The chief object of the system is to separate from the oil fuel the water which may have become mixed with it in any manner and also to enable oil fuel to be carried in ballast tanks or other compartments of a vessel where water is usually carried as ballast or for trimming purposes.

To get rid of the water two or more settling tanks are used, in which the oil is allowed to remain a sufficient length of time to permit of the water being deposited. In each tank a heating apparatus is introduced to assist the action, as it has been found by heating the oil within certain limits the water is more quickly deposited, owing to the expansion of oil being greater than that of water, and also beeause the oil is made less viscous by heat. Two or more tanks must be used, so that while the water is being deposited in one tank the dried oil in the other may be fed to the burners. The system is applicable, of course, to all or any system of burning oil.

It is illustrated in fig. 8 in diagrammatic form, showing the various pipe arrangements, etc., the oil feed pump 3 drawing from the ballast tank 1 through a pipe 4 and delivering by pipes 5 to the service tanks 22 , whence the oil gravitates by way of pipes 7 to the oil burner supply pipes 9 . Overflow pipes 13 carry back any surplus oil to the main tanks, and water separated in the service tanks is discharged.by way of pipes 12 . feet.

The service pipes are kept free of pressure by vent pipes 14, carried up several

The general arrangement of an oil ship is described under the head of carriage of oil, and one of the latest examples, the ss. Newyork, is illustrated in fig. 117, Chapter XXXI. 


\section{LIQUID FUEL AND ITS COMBUSTION}

The Orde System.

In figs. 9, 9a, 10, 11 are shown various arrangements of oil fuel burning by Sir W. E. Armstrong, Whitworth, and Co., of Newcastle-on-Tyne, according to the system of Mr. C. E. L. Orde.

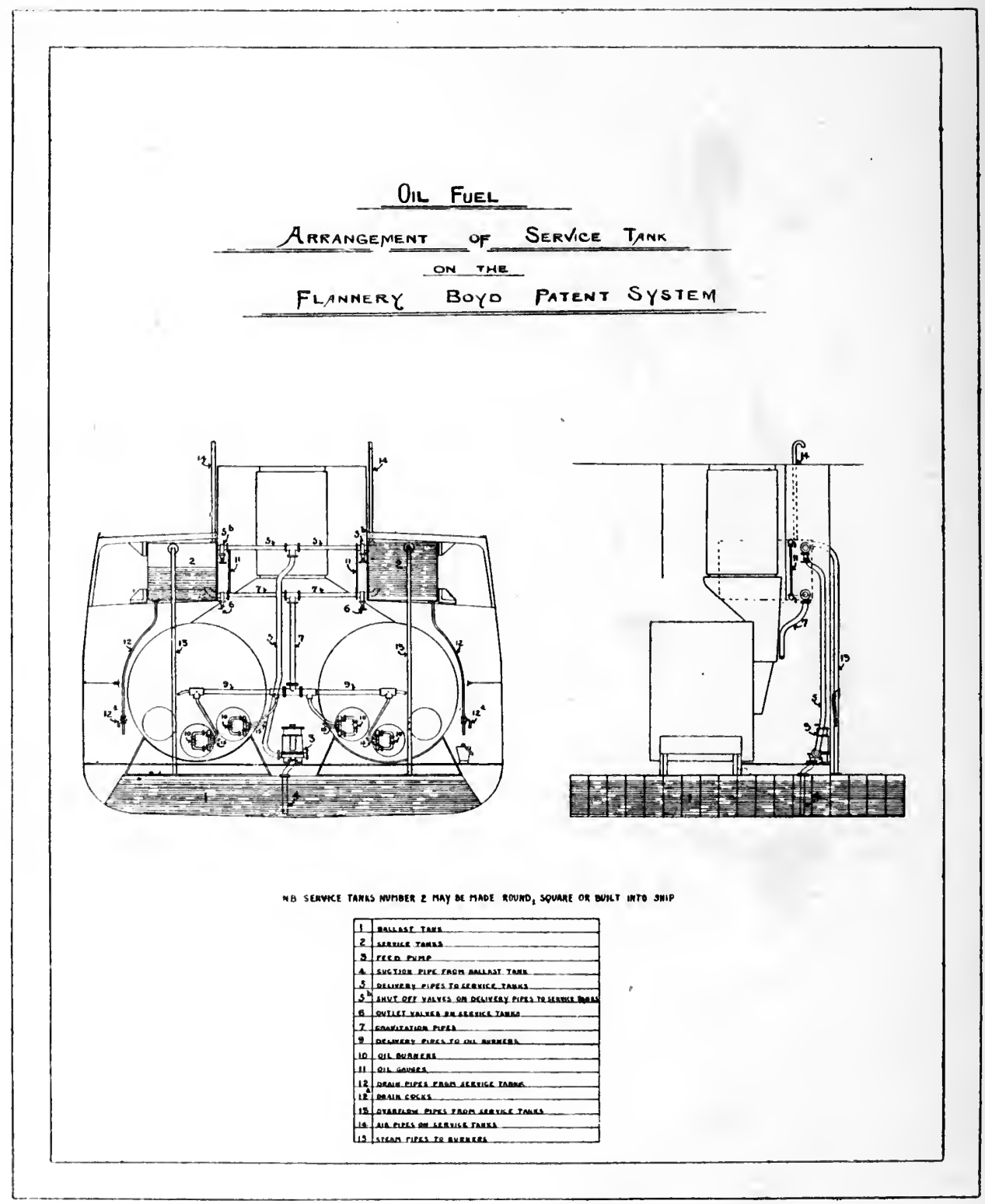

Fig. 8.

Fig. 9 shows the general arrangement for a water tube boiler. Steam, superheated in the casing by means of a pipe carried round the stean dome, is taken to a subsidiary steam header whence braneh pipes issue to five separate burners. Oil is fed by similar pipes from a second header supplied from the bunker or oil 


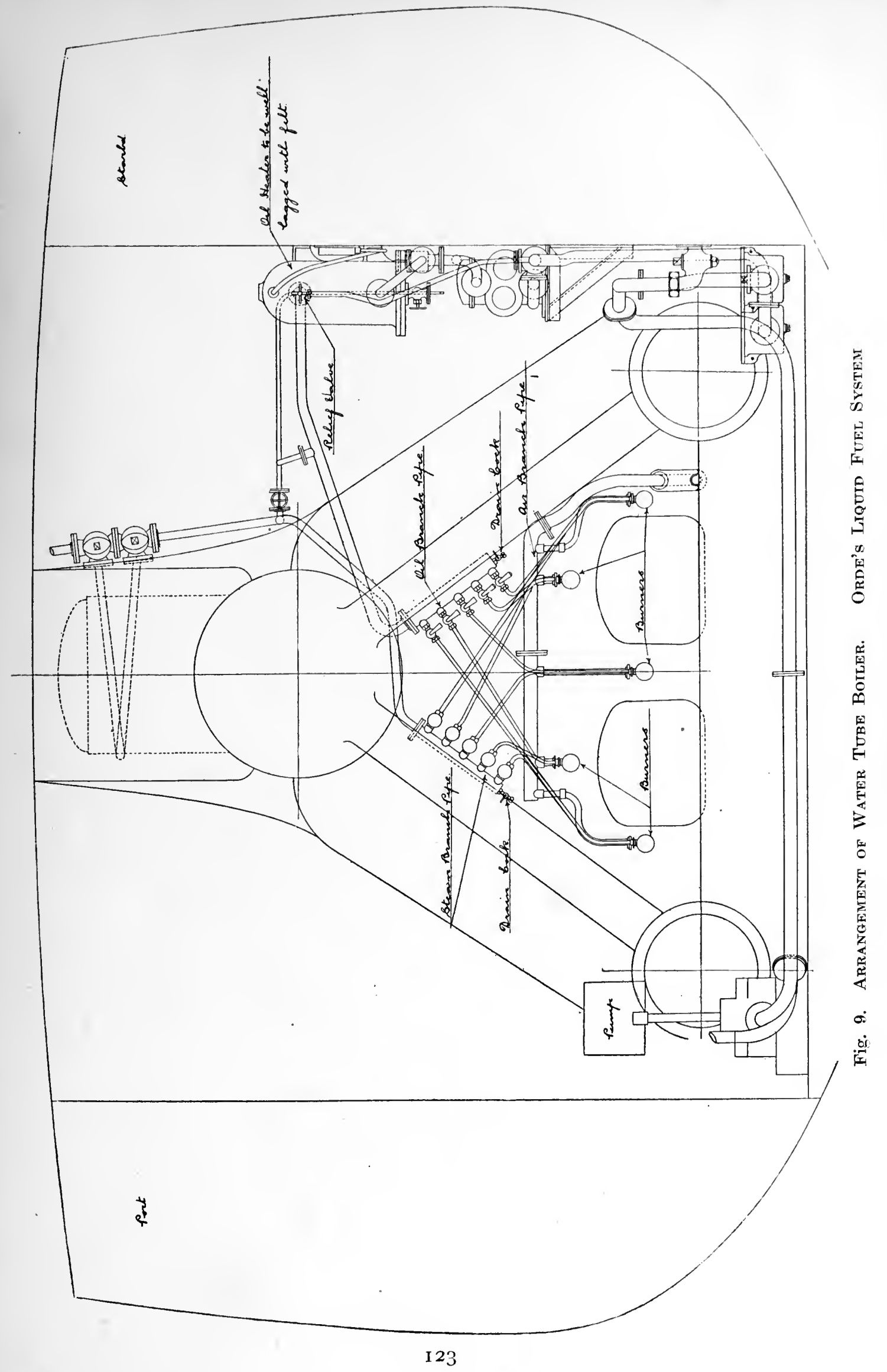




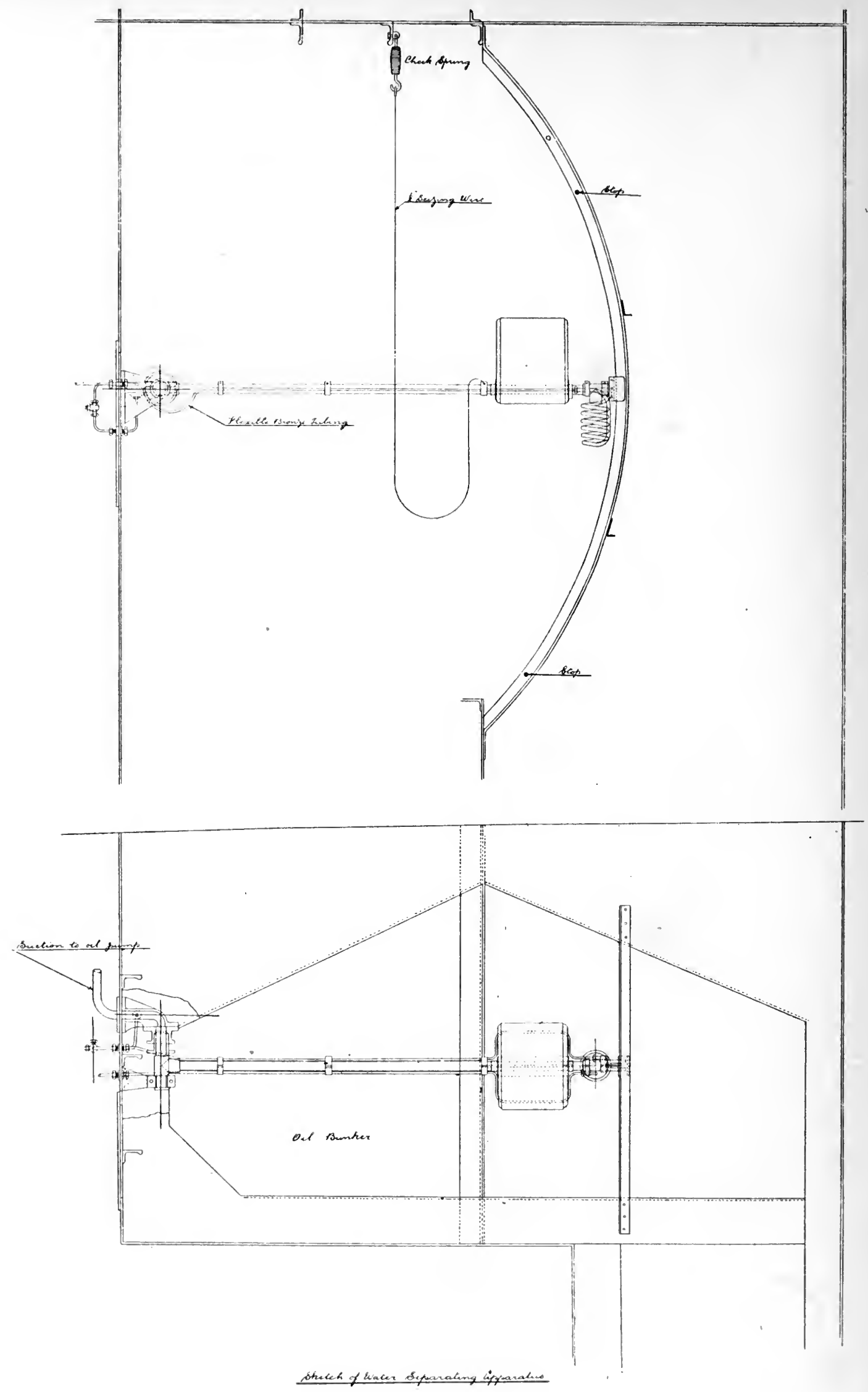

Fig. 9a. Fuel Oil Bunker. Draw-ofy Pipe and Float

124 


\section{MARINE FURNACE GEAR}

tank through a heater seen on the right. This heater eontains exhaust steam, and heats the oil on its way to the burners. The oil is drawn off from the tank as in fig. 9a by means of a floating arm, which always takes the highest oil from an area which is heated by a steam pipe coil placed under the intake of the oil pipe. The heat thins the oil and allows any enclosed water to drop away, thus securing dry oil. A small pump forees the oil to the distribution system, a relief pipe earrying any
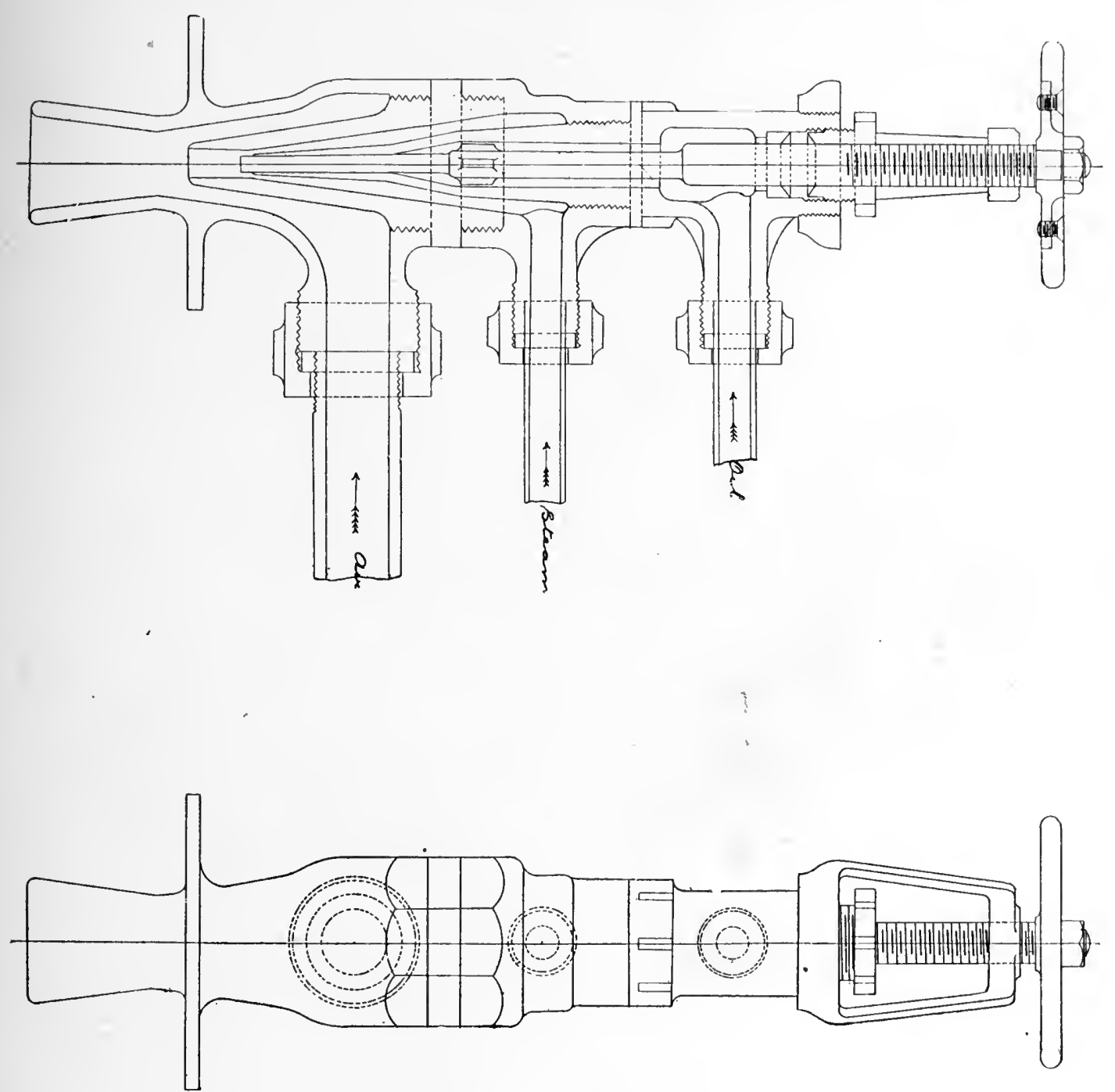

Fig. 10. Atomizer. Orde's System

excess back to the pump suction. Air is supplied to the burners by a separate pump on the left, being heated in the ash pit through which the pipe is laid. The copper steam pipe to the float is flexible to allow for the float movement, and the float is kept steady laterally by a piece of angle iron bent to a circular form to suit the path of the float arm. Blow through steam pipes are fitted for elearing the oil pipes when required. The atomizer, fig. 10 , is triple, oil entering through the centre passage 

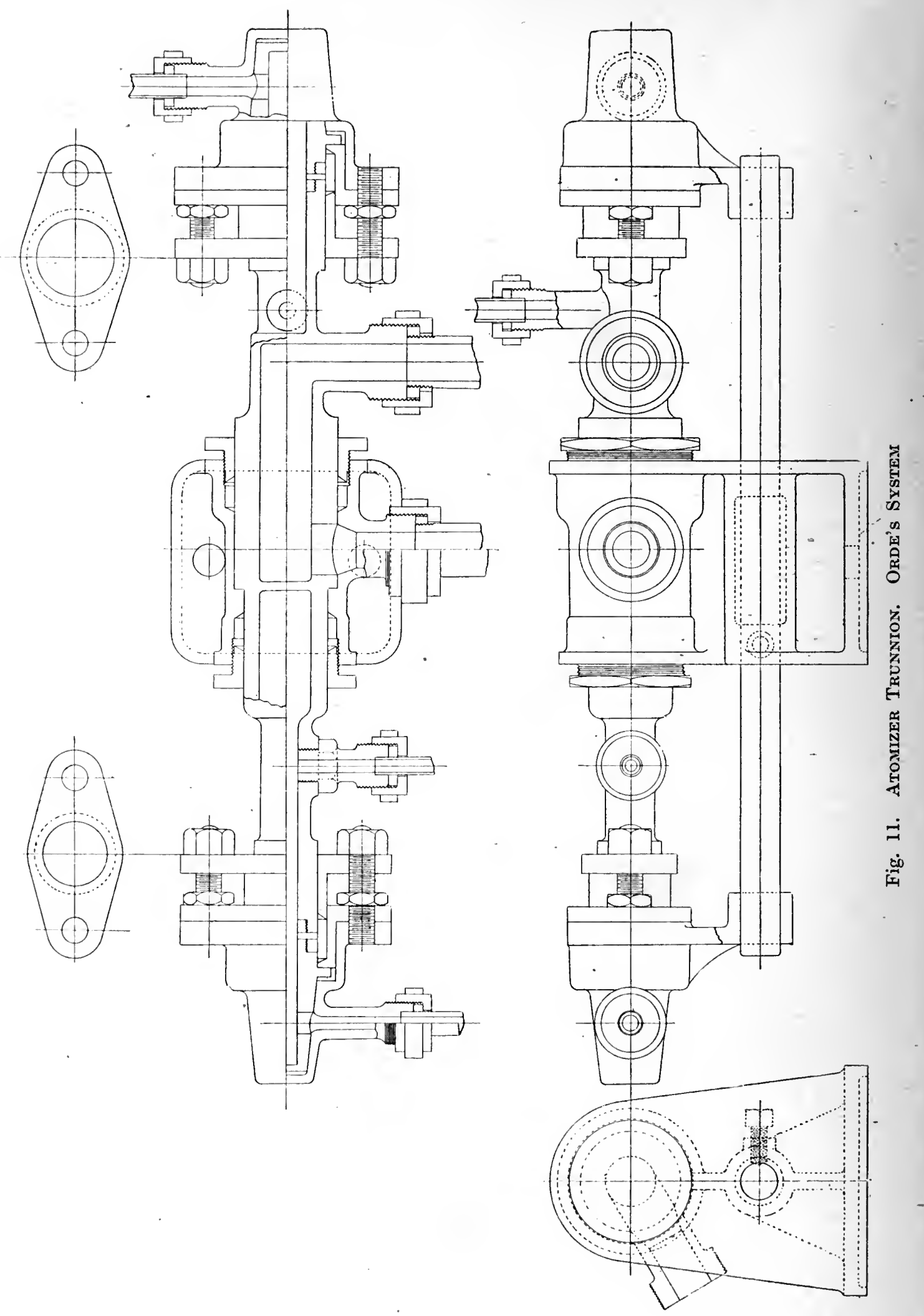


\section{MARINE FURNACE GEAR}

with needle regulating spindle. Steam comes outside the oil through an annular passage and air is introduced outside the whole, the mixture being blown through the spreading orifice as spray. The oil does not eome through as a solid jet into the combining nozzle, but as a thin annular shell jet easily atomized. The atomizer, however, differs from some others which admit air at the eentre. The trunnion for the atomizer is shown in fig. 11 .

Highly superheated steam is intended to be used (preferably $600^{\circ} \mathrm{F}$.).

The annexed table gives a few results of actual use of oil at sea. It is extracted from a paper by Sir F. Flannery, in the Transactions of the Institution of Naval Architects.

\begin{tabular}{|c|c|c|c|c|c|c|}
\hline Ship. & System. & $\begin{array}{c}\text { Oil per I.H.P. } \\
\text { per hour. }\end{array}$ & $\begin{array}{l}\text { Coal per } \\
\text { I.H.P. }\end{array}$ & $\begin{array}{l}\text { Heating Sur- } \\
\text { face. }\end{array}$ & I.H.P. & $\begin{array}{l}\text { Per cent. of } \\
\text { gain by use } \\
\text { of oil. }\end{array}$ \\
\hline F. C. Laeizz & Körting & $\begin{array}{l}\mathrm{lb} . \\
1 \cdot 408\end{array}$ & $\begin{array}{l}\text { lb. } \\
1.93\end{array}$ & $\begin{array}{l}\text { sq. ft. } \\
7560\end{array}$ & 2200 & 27 \\
\hline Sithonia & Howden & 1.065 & $1 \cdot 49$ & 6924 & 2500 & $28 \cdot 6$ \\
\hline Murex & Rusden-Eeles & $\begin{array}{c}1.3 \\
16\end{array}$ & 25 tons & 5202 & - & $36 \cdot 0$ \\
\hline Syriam & ,, & 1.32 & - & 2480 & 800 & 一 \\
\hline Khodoung & Orde & $1 \cdot 08$ & $1 \cdot 67$ & 2700 & 960 & $35 \cdot 5$ \\
\hline
\end{tabular}

In eaeh case, except the Sithonia, which had quadruple engines, the engines were triple expansion.

In fig. 12 is shown an arrangement of furnace and eombustion chambers brickwork, by the Wallsend Slipway and Engineering Company, for a marine boiler, the bars being removed. In fig. 13 the general arrangement of a ship is given which was fitted with the furnace arrangements shown in figs. 4 and 7.

\section{Lancashive Boiler with Orde's System.}

The Laneashire boiler as arranged by the Wallsend Slipway and Engineering Company for burning oil with or without a grate is given in fig. 14 .

A single injeetor is applied to each furnace door, the grate is covered with broken brick, and at the middle of its length a brick baffle is built, round and through which the flames escapes, and after passing a low bridge at the rear of the grate escapes unimpeded.

Without a grate, the furnace is fitted with a briek oven and striking bridge, beyond which is a cellular baffle of brick which gives a final mixing to the gases before they are quite consumed.

A gravitation tank is placed about 10 feet above the level of the atomizers with suitable valves, vent pipe, overflow and gauge. The supply pipe to the atomizer has a strainer in its course.

These various arrangements differ very little from those of other engineers, the ehief object being the atomizing and the arrangement of the firebriek oven and bridges.

\section{The Köting System.}

In this system, as fitted to the Hamburg-American ss. F.C. Laeisz, the water is first separated out of the oil which is raised by a pump, and is heated to $60^{\circ} \mathrm{C}=$ $140^{\circ} \mathrm{F}$. by a heater on the suction pipe, and it is filtered before it reaches the pump 


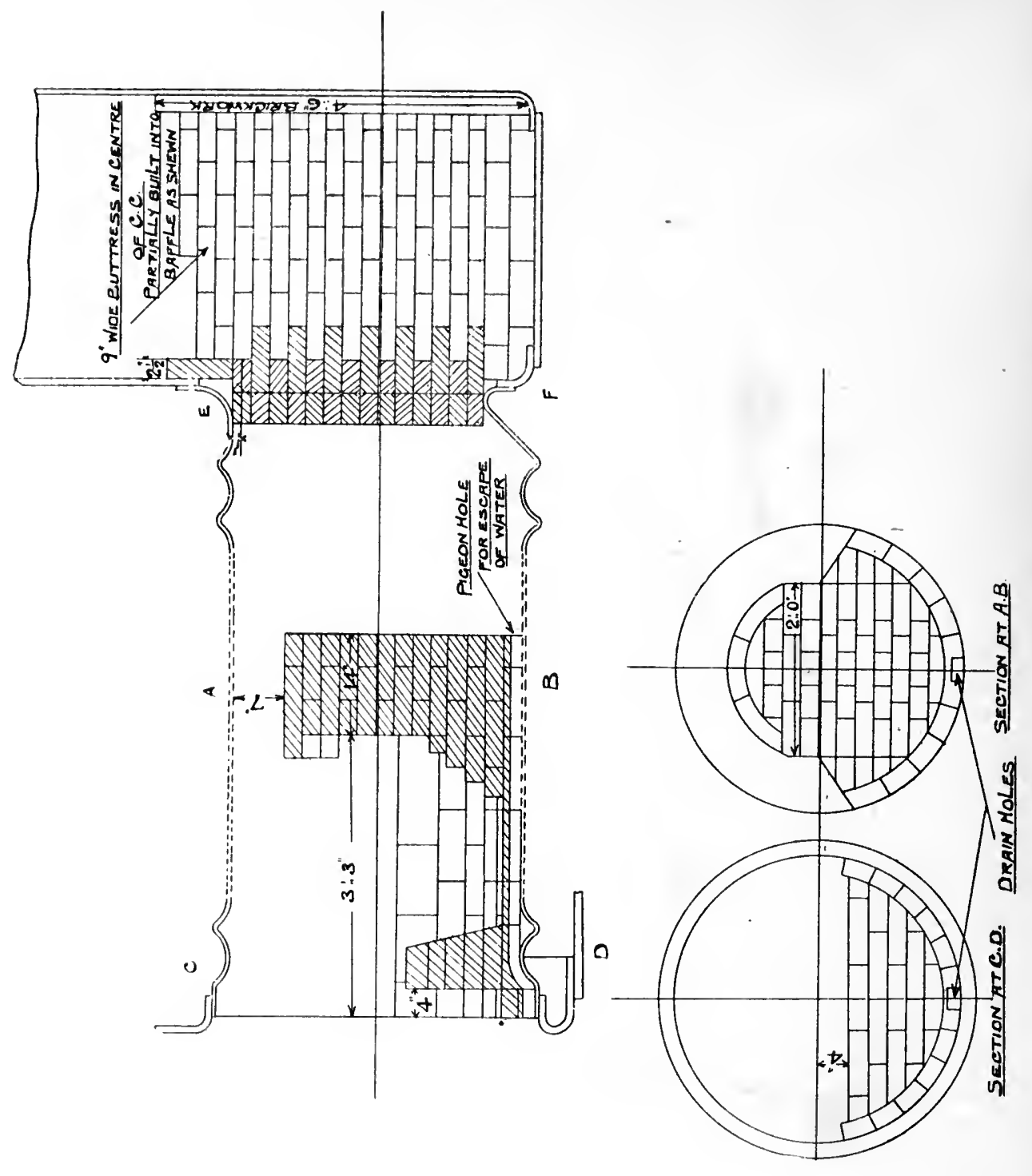

垈 


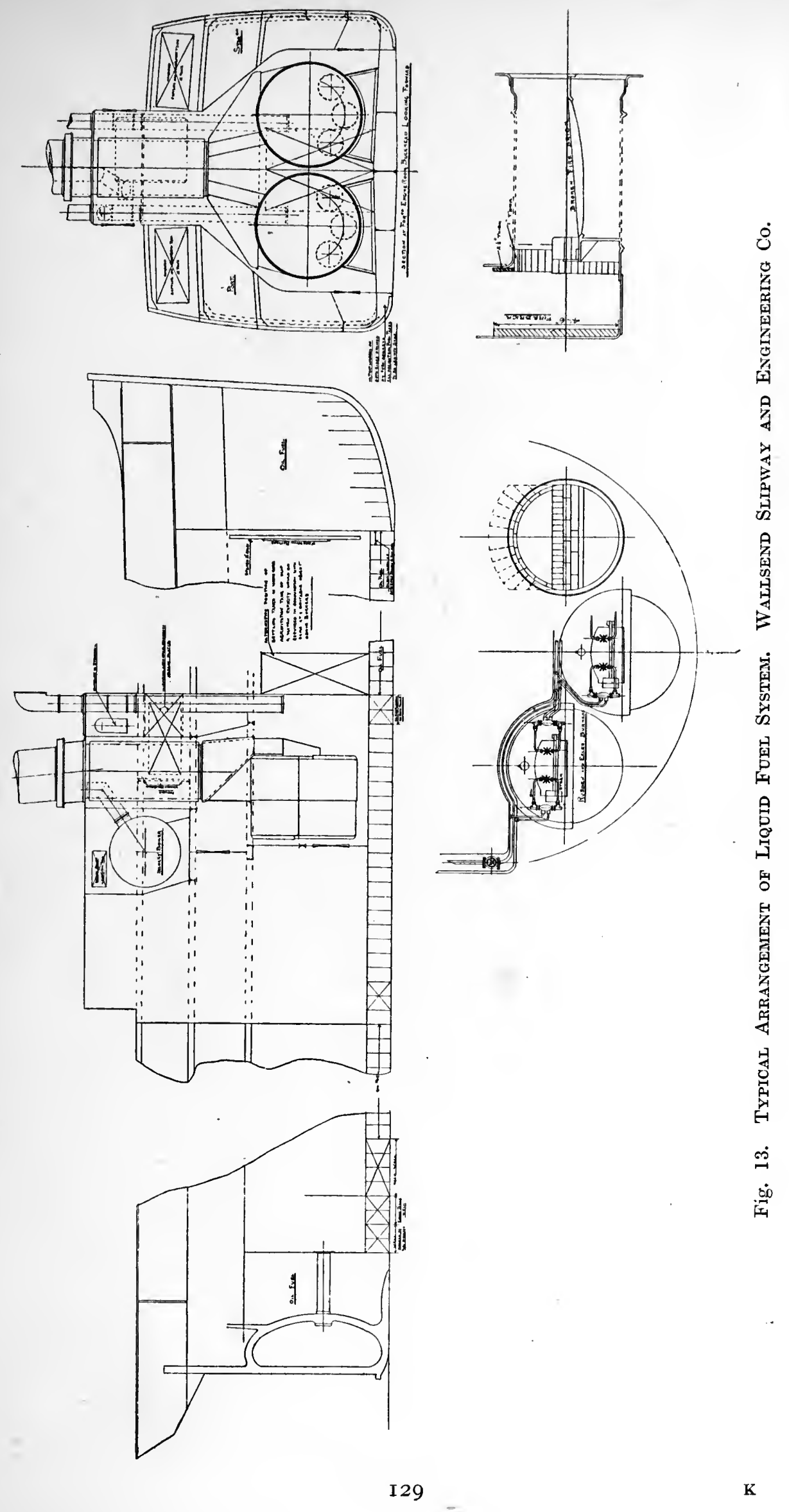



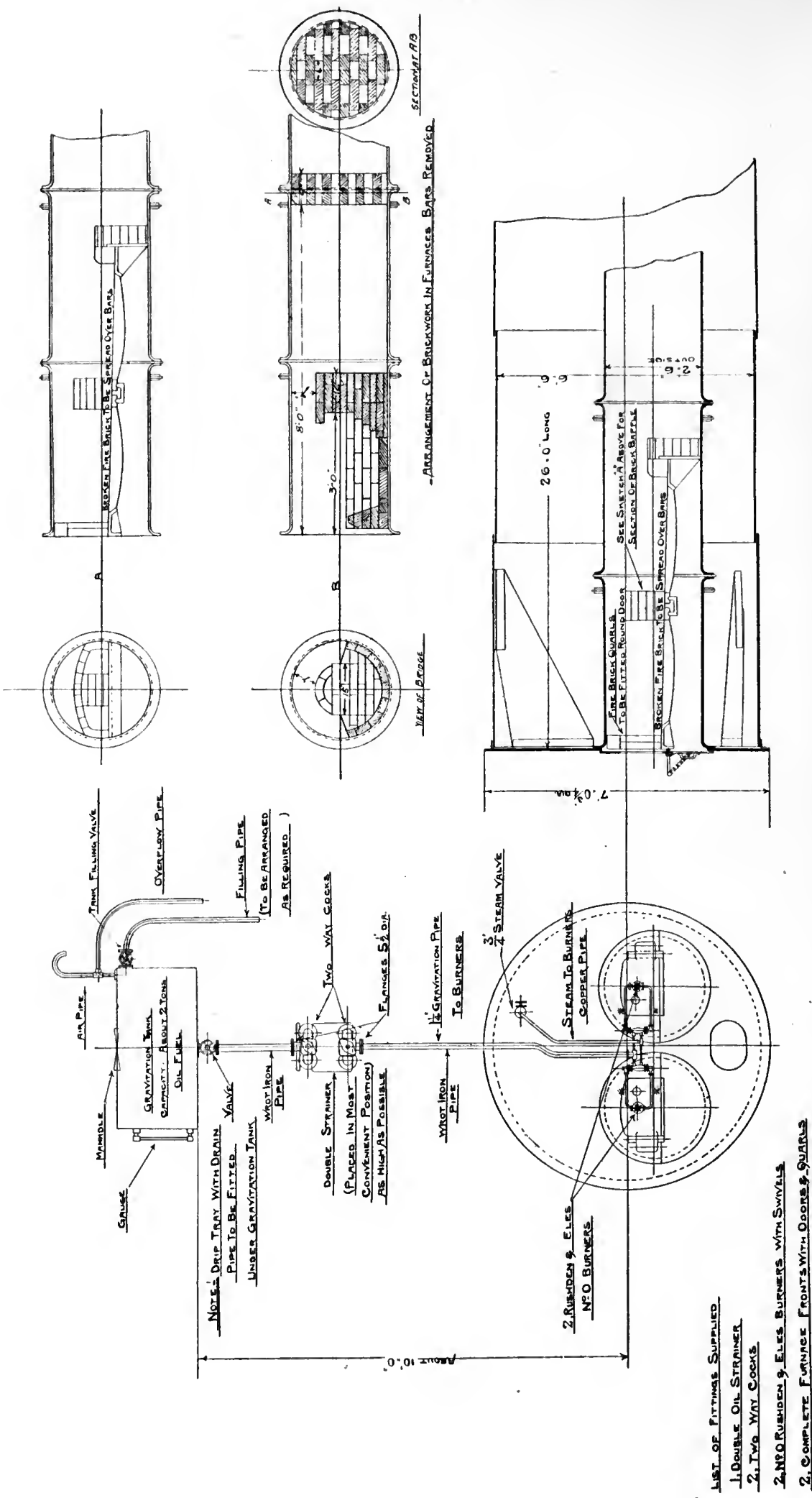

Fig. 14. Oif. Fuel Arrangement for Lancashine Boller, Orde's System.

Watlusend Slupway and Engineering Co. 


\section{MARINE FURNACE GEAR}

valve, and is thence delivered to a second heater, which raises its temperature to $90^{\circ} \mathrm{C} .=$ $194^{\circ} \mathrm{F}$., and after a second filtration and under a pressure of thirty pounds per square inch, is injected round a screwed needle, which causes the hot oil to spray itself. The bars are omitted, and the furnace lined in fire-brick and the air is admitted through adjustable perforated gratings. The whole is shown in figs. 15, 16, 16a, $17,18,19,19 a$. The same company have now four vessels so fitted.

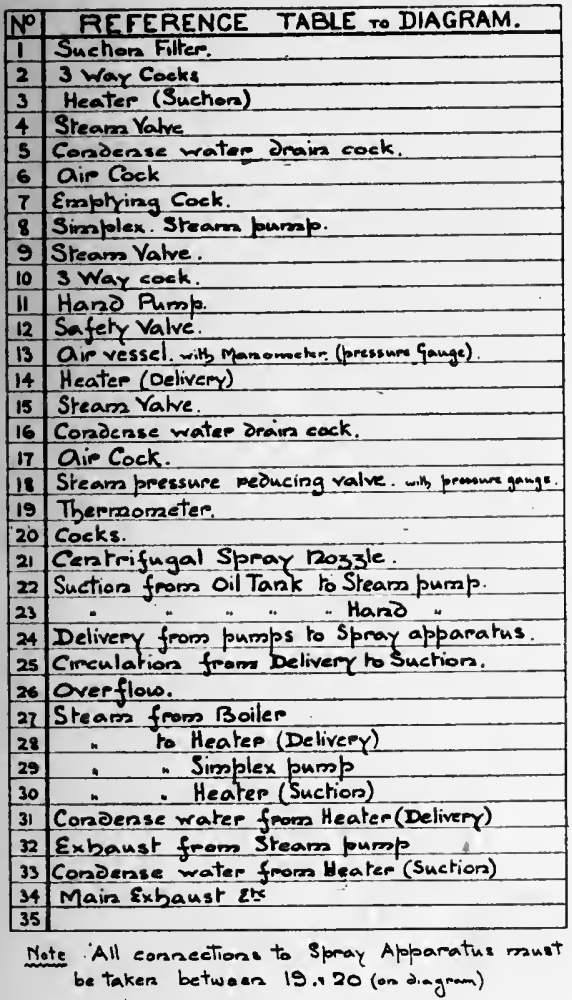

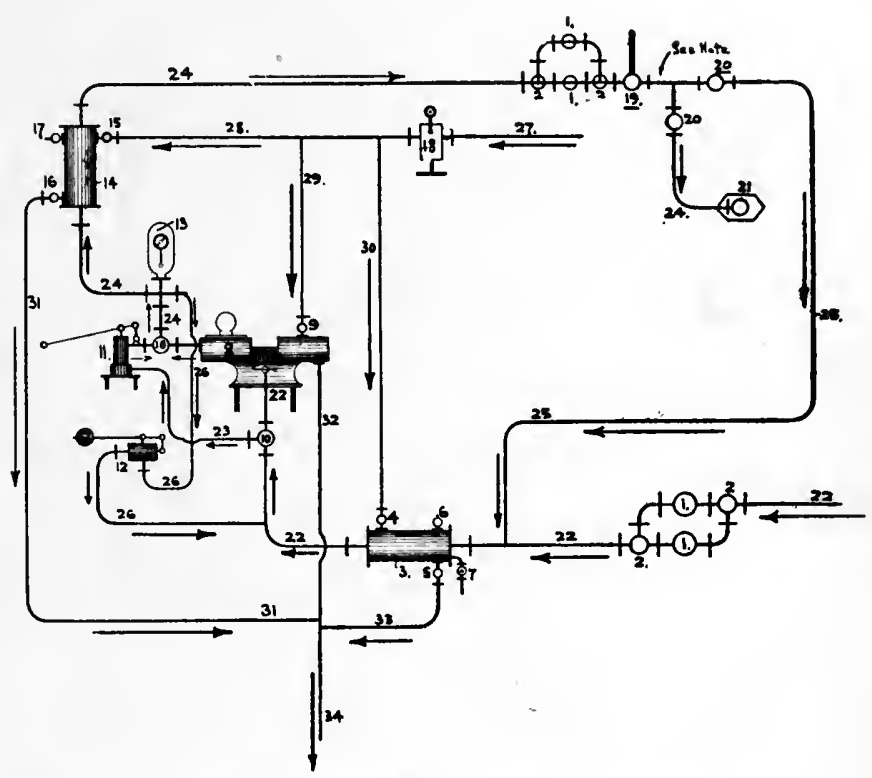

Diagrammatic Aprangement of Korting's Centrifugal Spreay Apparatus - for Oil Buprizs

Fig. 15. Diagrammatic Arrangement of Körting's dentrifugat Spray Apparatus for Otr Burning

The front of the oven is a disc of fire-brick with a small opening through which the spray is delivered and air is admitted. In this system the oil is made to spray itself and is claimed to be sufficiently atomized by the pressure and the action of the screwed needle round which it escapes. The general arrangement is as in fig. 15, and in figs. 16, 16a is shown the detail for a marine treble flue boiler, showing the two oil heaters in series on the suction and pressure sides of the pump. In fig. 17 is a design arranged by the Wallsend Slipway and Engineering Company for the Körting System, no brickwork in this case being built in the combustion chamber, but merely in the oven of the furnace.

The furnace of ss. F.C. Laeisz is shown in fig. 18 with the furnace lining and the brickwork of the combustion chamber also'. In fig. 19 the Körting sprayer is shown in section, and with its spirally wound needle which throws the oil into rapid rotation and causes it to spread widely at the nozzle, exactly as in the case of the Körting water cooling sprayers. The oil is first heated to $130^{\circ} \mathrm{C} .=266^{\circ} \mathrm{F}$., according to Mr. Orde, and forced at a pressure of 50 pounds through the nozzles. It is con- 


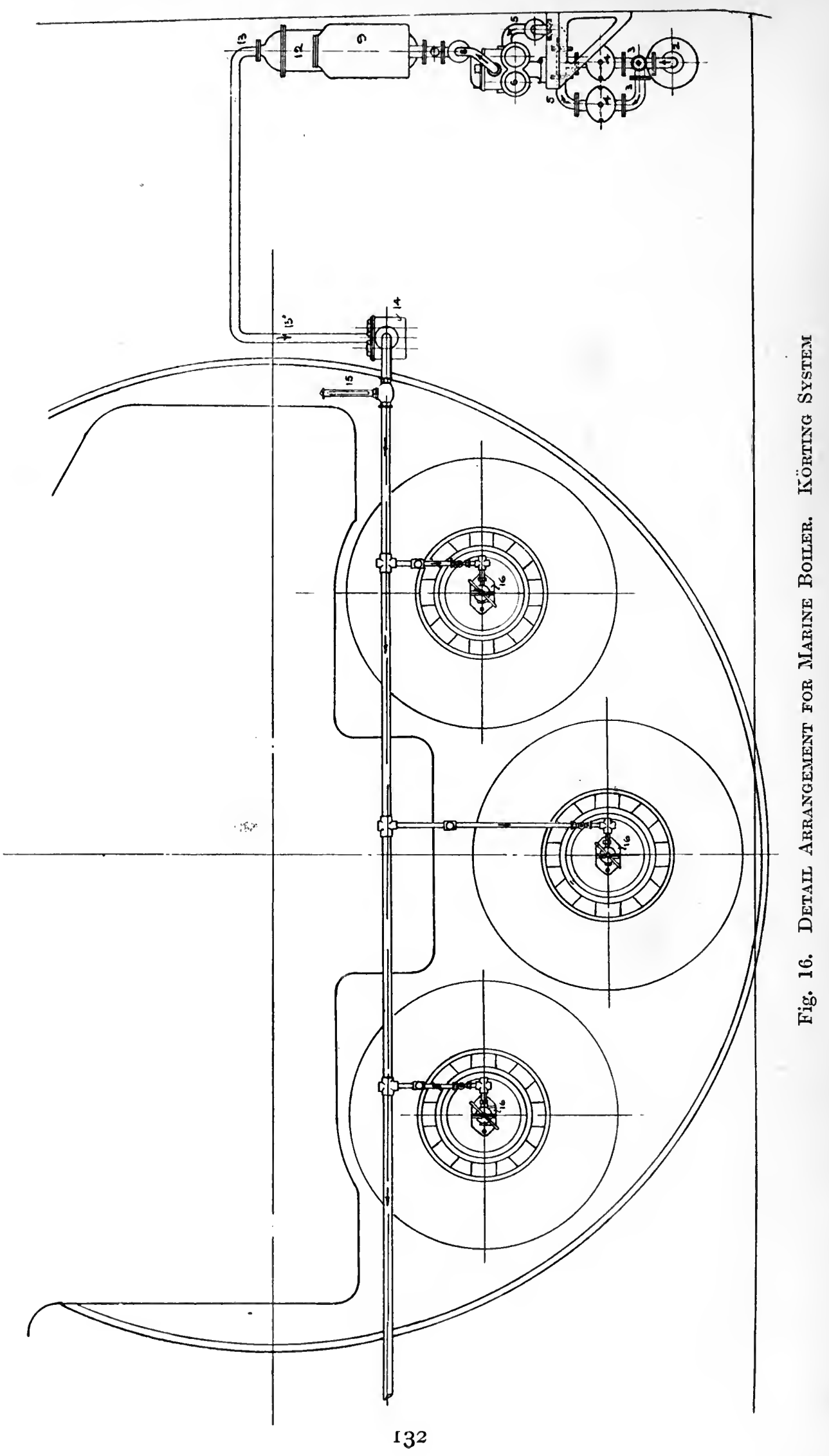




\section{MARINE FURNACE GEAR}

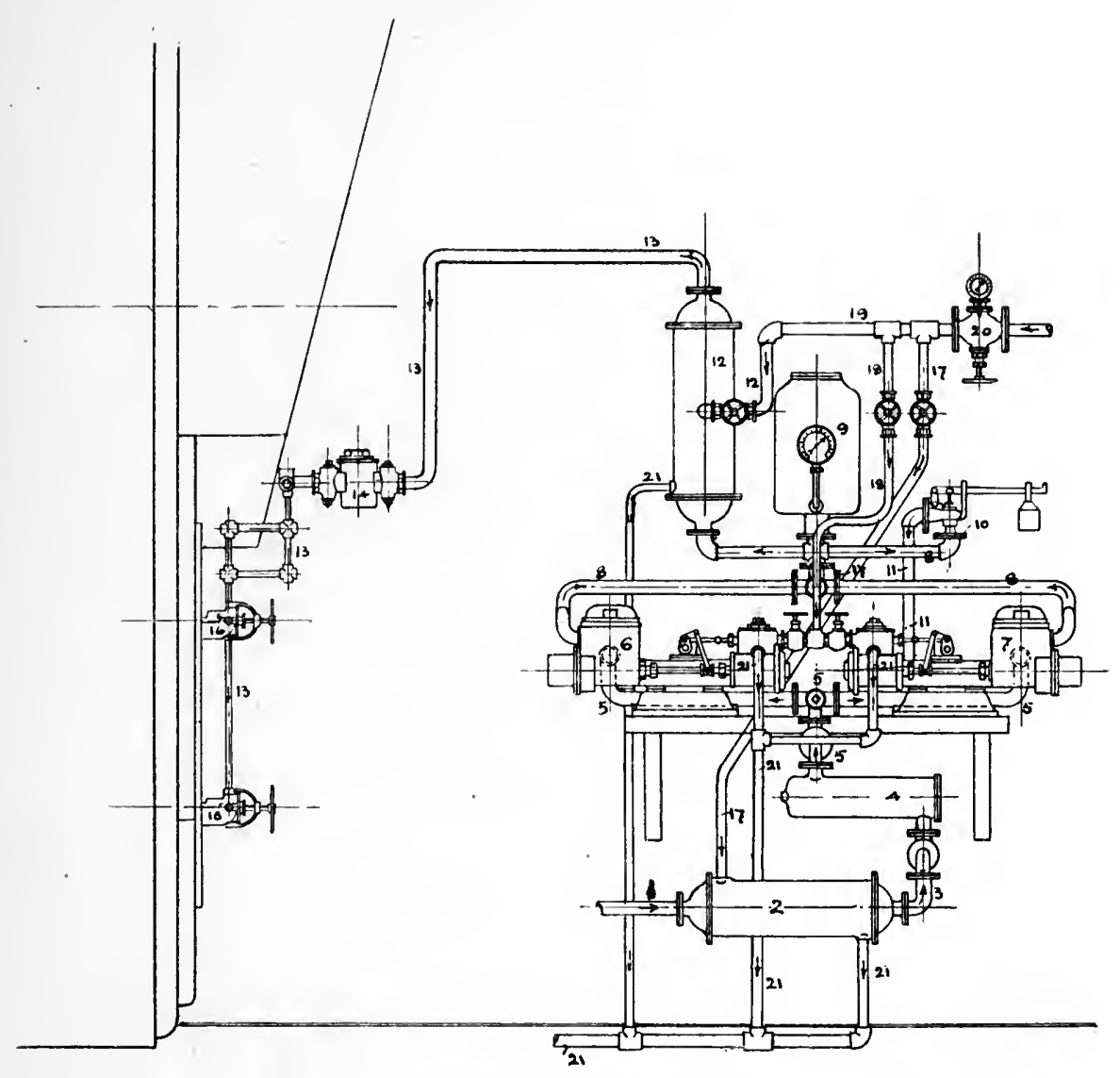

Fig. 16a. Detail Aminaenent for Marine Boiler. Körting System

REFERENCE NUMBERS.

1. Suction connexion to Storage Tanks.

2. Primary Heater on Suction Connexion.

3. Connexion between Heater and Filter:

4. Filter.

5. Connexion between Fiter and Pump.

6. Duplex Pump.

7. Duplex Pump.

8. Connexion from Pumps to Air Vessel. Relief Valve and Heater.

9. Air Vessel.

io. Relief Valve.

11. Connexion between Relief Valve and Suction Yipe.

12. Secondary Heater on Pressure Connexion.

13. Connexions from Heater to Spray Apparatus.

14. Strainer.

15. Thermometer.

16. Spray Apparatus.

17. Steam Pipo to Primary Heater on Suetion Pipe.

18. Steam Pipe to Pumps.

10. Steam Pipe to Secondary Heater on Pressure Pipe,

20. Steam Pressure-Reducing Valve.

21. Exhanst Diseharge from Pumps and Heaters.

22. Returu Pipe from Spray Apparatus to Storage Tanks. 


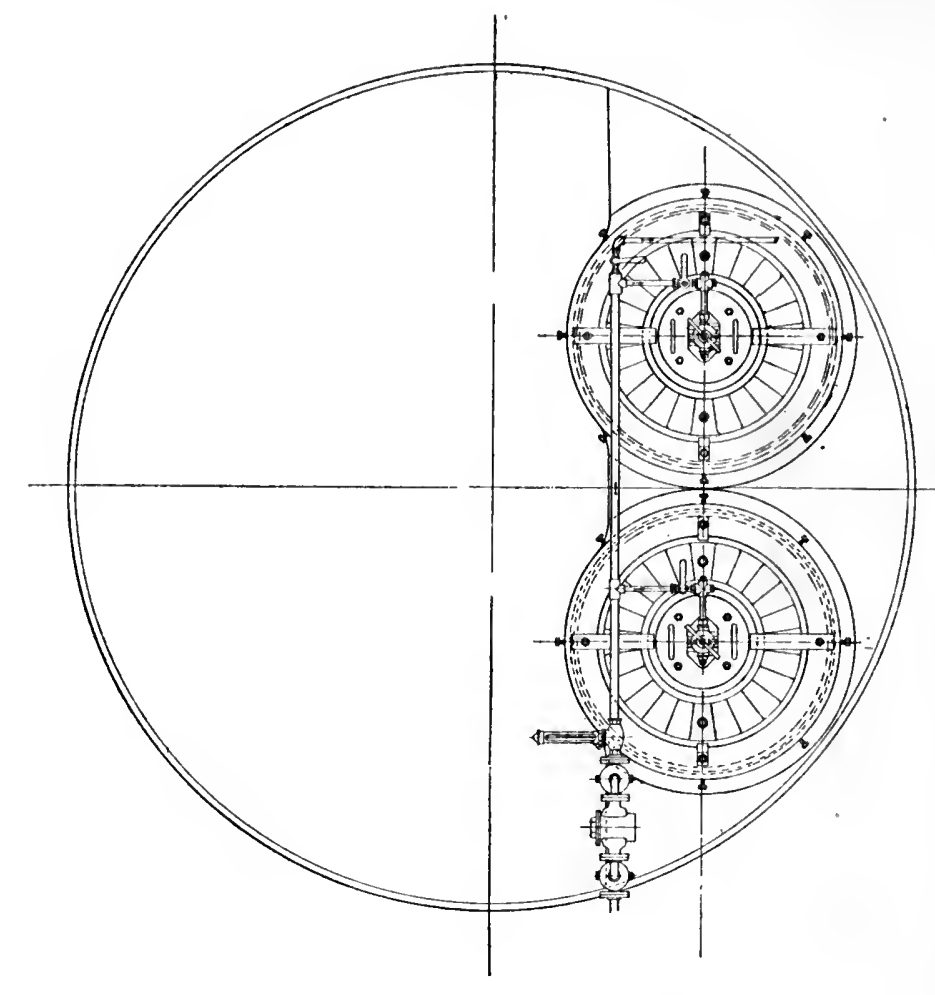

造

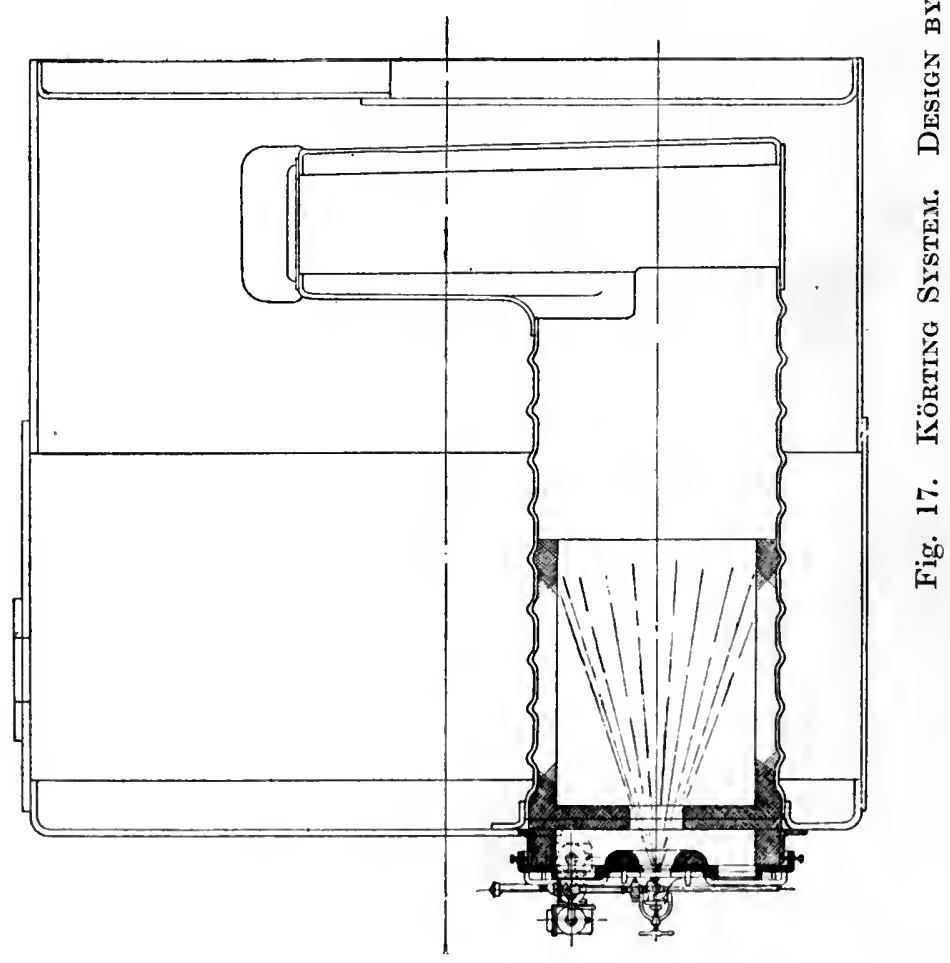




\section{MARINE FURNACE GEAR}

sidered essential to line the furnace in order to secure perfect combustion and insure

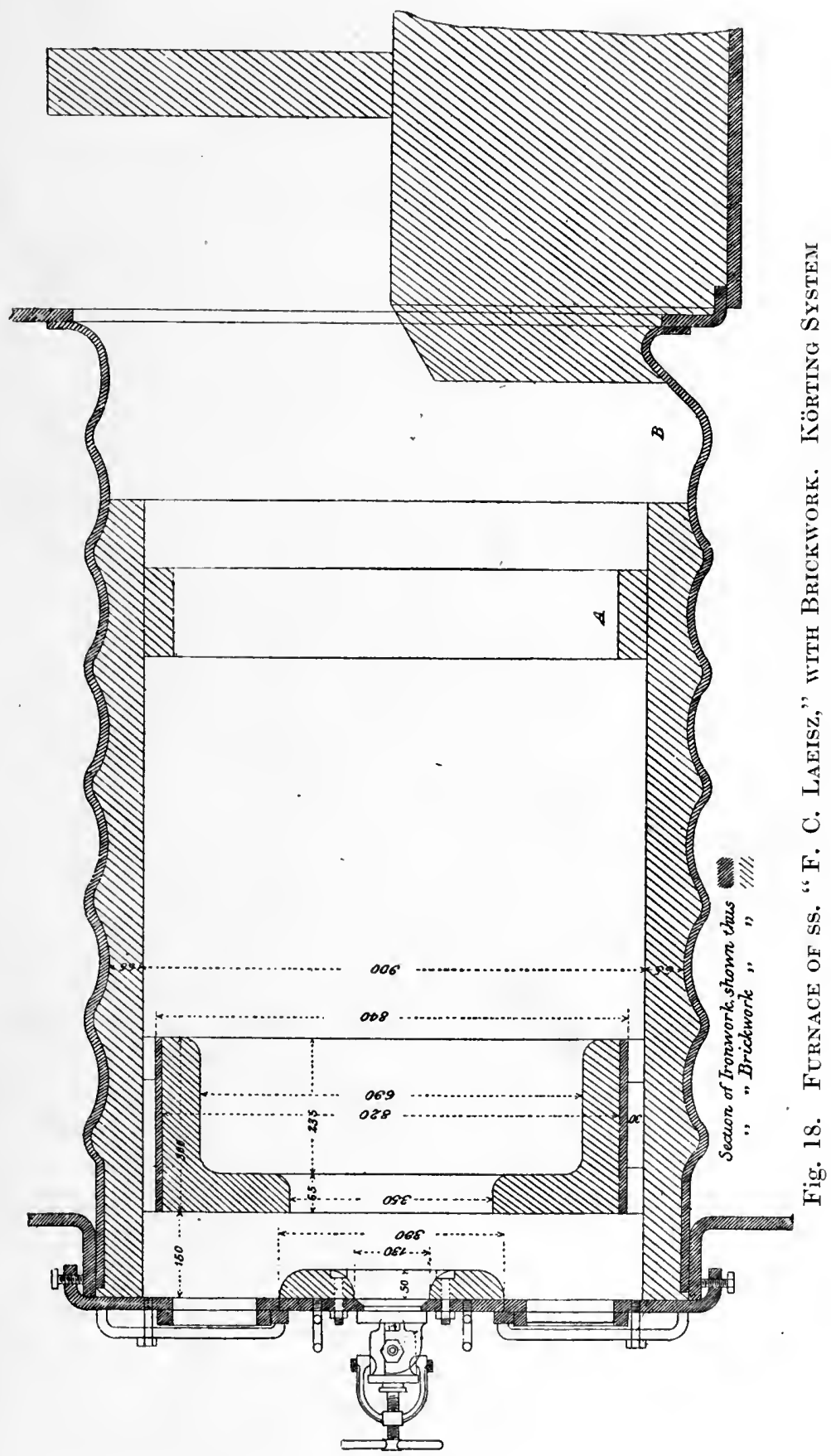

that all the oil is vaporized before it reaches the chilling zone of unprotected water cooled plates. 


\section{LIQUID FUEL AND ITS COMBUSTION}
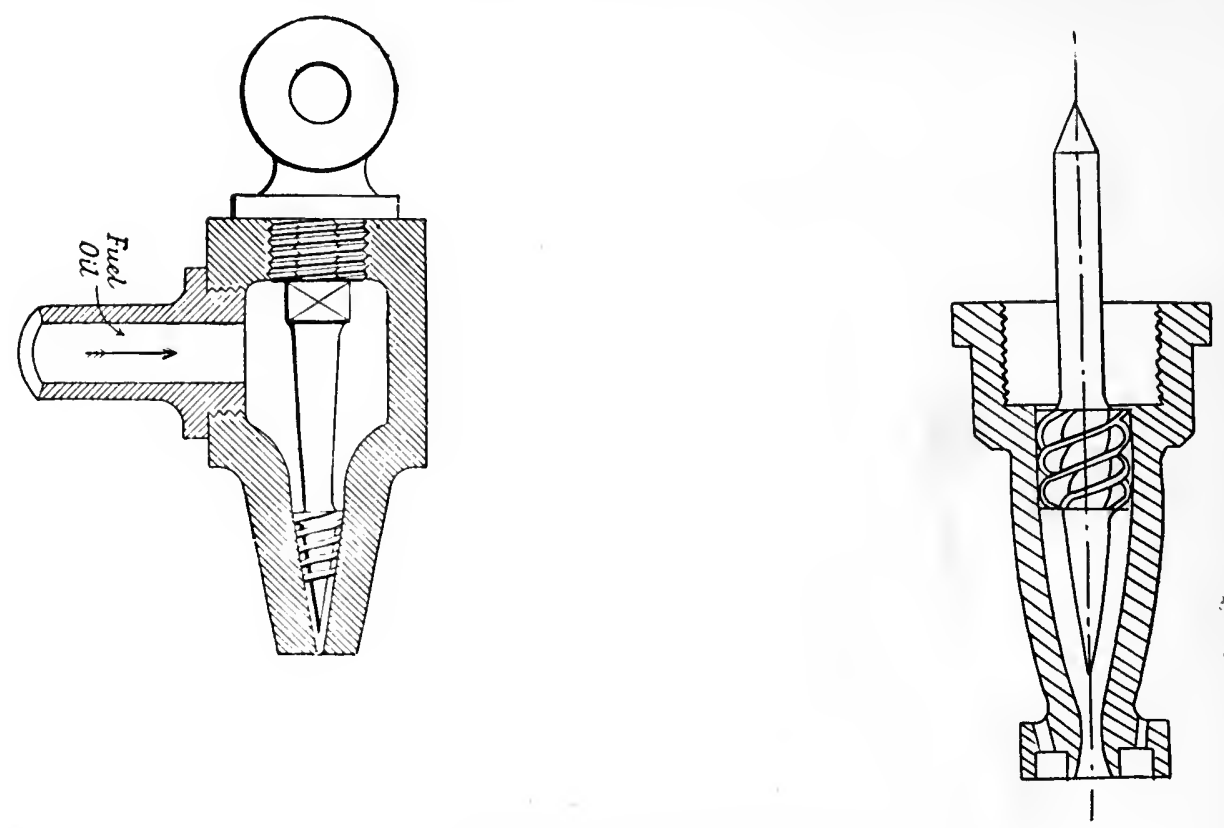

Fig. 19. Körting Atomizer

Fig. 19a. Körting Atomizer

The diameter of the jet orifice is 1 to $3 \mathrm{~mm}$., and in later forms there is a crown or disc set round the nozzle and pierced with holes of $1.25 \mathrm{~mm}$ : diameter, through which air is intrained. The output under a pressure of six kilos $=84 \cdot 4$ pounds, was as follows when tried at Cherbourg-

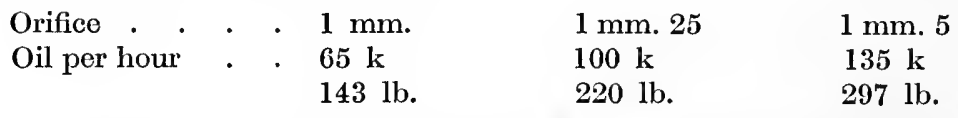

Tried on the locomotives of the Vladi-Kavkaz Railway these atomizers with double jets sprayed $230 \mathrm{kilos}=506 \mathrm{lb}$. per hour under a pressure of only $4 \cdot 2 \mathrm{k}=59 \cdot 8 \mathrm{lb}$. From the trials made by the French Navy it appears that these mechanical atomizers work very regularly and, moreover, silently, if the oil is first filtered and heated to $80^{\circ} \mathrm{C} .=176^{\circ} \mathrm{F}$. They are recommended for getting up steam, the force pump being hand worked until such time as steam is produced sufficiently to work the pulverisers.

M. Bertin lays stress on the benefit of supplying oil to a burner at a considerable pressure and at a high velocity, for even with air or steam atomizers the fine jet will atomize more easily, for an oil pressure of three kilos, for example, permits of a velocity four times as much as is given by a head of 2 metres.

\section{The Howden System.}

In the Howden system, a general arrangement of which is given in fig. 20, for combined coal and oil firing, a modified Körting jet is employed. The closed ashpit system is employed for the forced draught of the boilers according to the well-known Howden system, and this of course provides an ample air supply to enter the furnace around the oil nozzle. When solid fuel is to be used alone and the sprayers are removed, this air opening is closed by a plug, as shown in the figure at the lower right hand of fig. 20. The use of solid fuel in combination with oil appears to afford 


\section{MARINE FURNACE GEAR}

a favourable opportunity for sprayers of the Körting type, beeause there is a com-
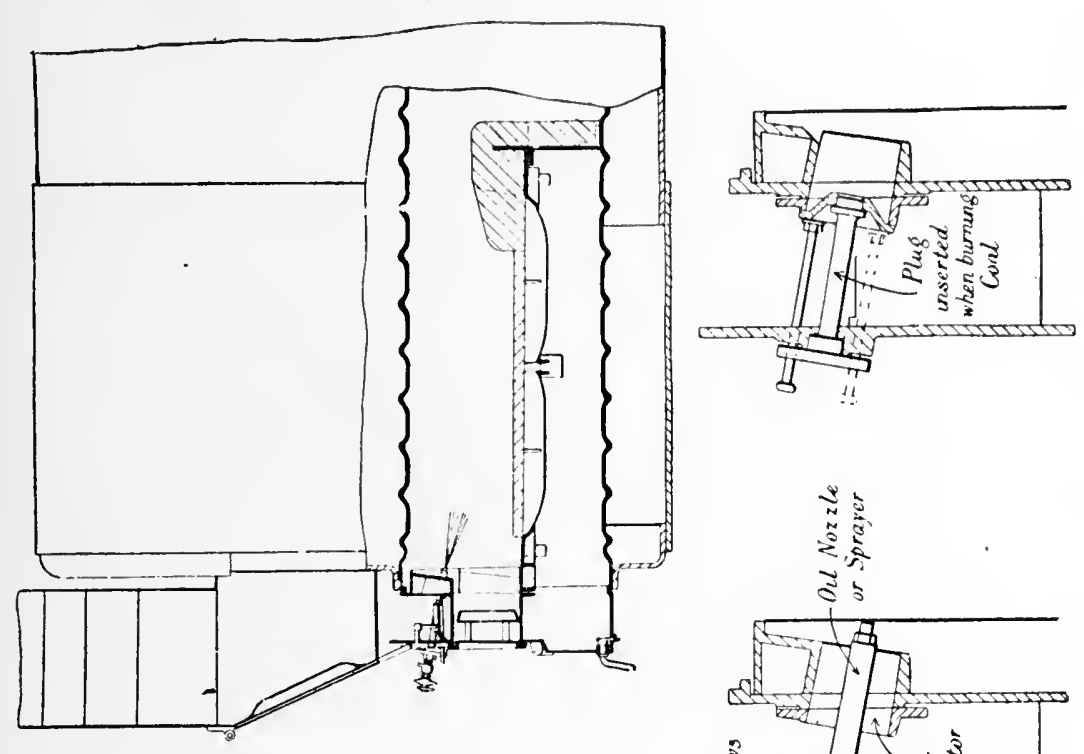

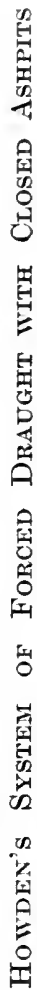
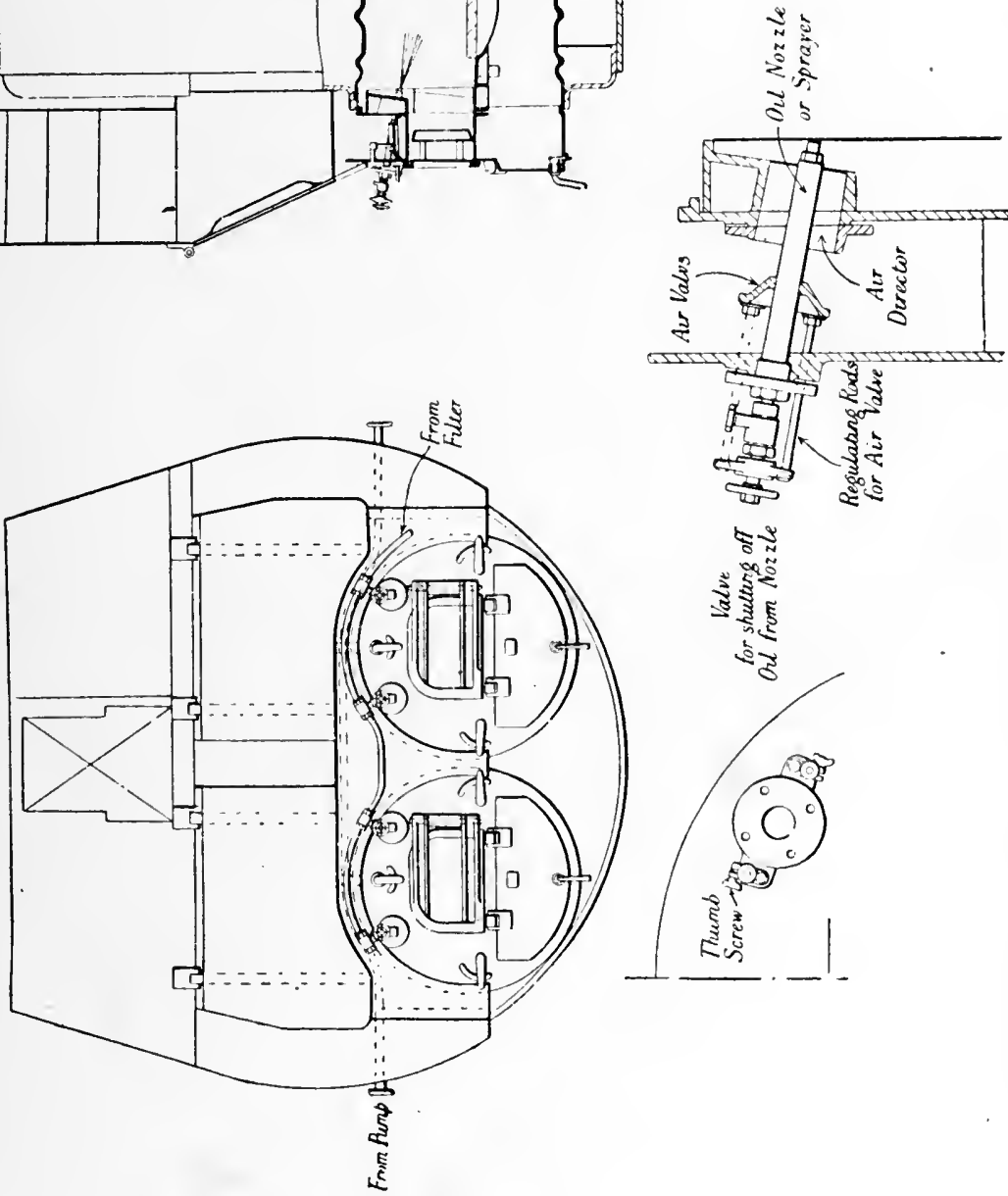

要

$\ln 51260$

i

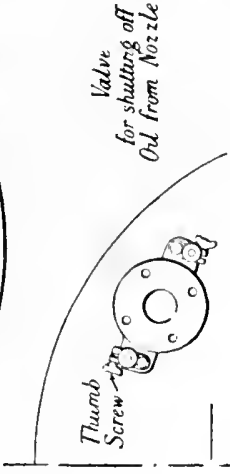

䆖

点

$\underset{5}{\mathrm{~S}}$

忽

๙ิ

$\dot{00}$

bustible bed on which any unduly large globules of oil may fall. In fig. 20 the grate is shown eovered with fire-brieks for use with liquid fuel alone. 


\section{Chapter XVI}

\section{LIQUID FUEL APPLICATIONS TO LOCOMOTIVE BOILERS}

\section{The Holden System}

$I^{1}$

$\mathrm{N}$ this system, which was the first to come into extensive use in Great Britain, the object has been to combine liquid and solid fuels so that either or both can be used indifferently without a moment's notice of the ehange.

Mr. Holden, of the Great Eastern Railway of England, was troubled to dispose of the tars produced by oil gas apparatus, and primarily devised his system for getting rid of this; but he has used many liquids for fuel, ineluding coal tar, blast furnace tar and oil, shale oil, creosote and green oils, astatki and crude petroleum. Locomotives thus fitted are very clean to work, make no dust, smoke or sparks, have little wear of tubes or fireboxes and have little ash and clinker to remove. Steam can be raised rapidly, adjusted at an even pressure, and waste at the safety valve is prevented. Any boiler can be fitted for liquid fuel without alteration of furnaee, though it is desirable in the locomotive to add a fire-brick lining on the tube plate below the arch.

The fire is made up thin with coal and about 120 pounds of broken chalk, a commodity cheap enough in South England or East Anglia. The ashpit damper is kept sufficiently open to maintain the fire bright.

There is nothing striking to be seen from the footplate, with the exception of an extra fitting on the firebox casing, carrying four steam cocks and two small wheel valves about the firedoor level on each side thereof. Looking into the firebox there is seen, however, only a light fire of coal upon the grate, and yet this engine is to run the down train in a few minutes' time and has yet to get up full steam pressure.

A hinged plate appears under the fire door; and on lifting this there are visible two holes through the firebox outer casing leading into the firebox. They are disposed equidistant on each side of the centre line 21 inches apart, and they are 5 inches diameter and 10 inches above the grate surface. In each hole is a ring of pipe perforated on the front side so as to direct numerous jets of steam forward into the firebox. These cause an indueed current of air. In the centre of each of the rings there is the nozzle of an injector. These are steam worked and inject oil into the firebox, mixed with air, which enters at the rear of the injectors by an indiarubber hose connexion from the vacuum brake if this is used.

The steam inlet to each injector is on the inside, steam coming by a single pipe, which branches off by square turns right and left to the injeetors. Oil enters by separate pipes worked by the two independent regulating wheel valves, which stand above the footplate at the fire door level. Each valve is thus independently ad- 


\section{LIQUID FUEL APPLICATIONS TO LOCOMOTIVE BOILERS}

justable, but both ean be worked together by a special gear, instantly to open and close, if necessary, at stations and other stops. Otherwise the oil apparatus is controlled from the four cocks mentioned above. One of these turns steam on to the injector supply; another, by similarly arranged right and left branch pipes, turns on steam to the air injecting rings first named; and a third admits steam into a warming coil in the oil tank for the purpose of bringing the oil to a state sufficiently liquid to flow freely to the injectors, and also to destroy its viscidity to enable it to be sprayed sufficiently fine by the action of the steam and the air injected with it. The fourth serves as an oil pipe clearer, and can be used to blow back steam through the oil fuel pipes to the tank to clear any obstruction or to blow back oil which has cooled in the pipe or to warm the pipe, and to blow through the oil passages of the injectors as shown.

The Great Eastern Railway favours the Westinghouse brake, but has a number of engines fitted with the automatic vacuum brake in order to be able to run the cars of other companies. This fills a Board of Trade requirement.

The mode of working the oil burning apparatus is as follows: the engine comes up from the shed with the light coal fire with which steam has been made. It is clear and red and the firebrick arch is well heated, and the fire made up with chalk lumps as usual. When desired to burn oil, the steam is first set blowing through the injector. The delivery of the injectors is directly forwards and sideways, the nozzle having two orifices. No oil is therefore sent against the firebox sides, but only towards the brick arch and towards the middle of the box, the two inclined jets approaching each other. After the steam is turned on, the oil admission valves are slowly opened and the oil is sprayed and ignites apparently at once, the whole firebox being filled with a dazzling white flame as seen through the sighthole in the door.

If this alone is done, there is smoke at the funnel from insufficient air supply. This is instantly checked by turning steam into the ring jets which draw in a further large quantity of air through the five inch openings, and smoke can be reduced to any desired extent down to total disappearance. This is a specially valuable feature in economy, for while it is so desirable to prevent smoke, it is equally undesirable to admit too much air, and this can be regulated to a nicety, merely enough air to stop the smoke being injected, or even only enough to reduce the smoke to an occasional suspicion of it. There need be no waste due to excess of cold air unnecessarily introduced.

As now set going, there is rapid steam production, and nothing further is necessary to be done, but the engine will continue to produce steam as long as the oil is supplied. The light coal fire is kept going by an occasional shovel of coal, or a little chalk is added, as required.

Though the whole apparatus is thus exceedingly simple, if it were possible for it to be put out of order in the middle of a trip, the fireman would commence to shovel coal upon the existing bed of fire which has been, as usual, started with the customary care as to using lumps of chalk on the grate, and the engine would run on as an ordinary coal burner without a hitch or stoppage.

When on a trip, if steam is high, the injectors can be instantly stopped on arriving at a station, or, if the steam is low, continued at full blast as when running, and the fire kept up to a maximum efficiency and steam got up during the wait. There is less dependence on the blast pipe, and a variable blast nozzle is used, the simple movement of a lever in the cab swinging a hinged cap over the pipe top and 


\section{LIQUID FUEL AND ITS COMBUSTION}

reducing the nozzle from $5 \frac{3}{4}$ inches to 5 inches diameter when necessary for coal burning.

Should any oil by chance be unburned and travel so far as the brick arch, and even run down it, it cannot live and travel over the firebrick protection of the lower tube plate without vaporization and combustion, hence this protection, which is the one slight difference observable from common practice, a difference, however, of no importance or injury to the engine's coal burning properties.

There is no projection of any oil upon the firebox sides, neither is there any local intense combustion as exists in such systems as vaporize the oil before igniting, and thereby produce local plate wasting. On the contrary, the whole interior of the firebox is filled with flame, and no special ignition point, or rather, combustion area, is apparent. Heating is therefore general, and temperature even.

Though nominally a pound of oil has not the steam making power of two pounds of coal, nor perhaps could it be shown to have, in a prolonged test; yet in practice, one pound of oil is found to be equal to double the quantity of coal, owing to the facility of regulation and the saving at the safety valve and of the back pressure from reduced blast pipe resistance. All these points are favourable to the oil, which has the further advantage of cleanliness and greatly reduced labour all round, for it makes no unconsumable refuse, requires no stoking beyond the keeping up of the small bed of coal fire, which seems to have such an advantage, where liquid fuel supplies are doubtful in quantity and uncertain in price, over any system of oil burning which rejects coal entirely.

In the ordinary work of the Great Fastern Railway the run between London and Cambridge-about 56 miles-will be made with one firebox full of fuel made up ready for the run and untouched. This will bring the train to its destination, and if it were known that the engine would be shedded at once the steam might be pretty well reduced and the fire left to finish nearly dead. Here comes in the advantage of liquid fuel. Even if steam be down and the fire nearly out, the turning of a handle or two will put the engine in readiness to take out any train in five minutes after notice, and thus an engine may be worked to the economy it would be if about to be shedded, and yet be ready for a full-power run almost instantly. As the fireman remarked, "She will keep steam as far as Doncaster without an effort, and then be just as fit to run a further 200 miles as when she started."

On the occasion of the author's run to Cambridge on No. 760, the Doncaster Express started out from Liverpool Street with a train of seventeen vehicles, weighing, exclusive of engine and tender, 537,600 pounds, or 240 English tons (269 American tons).

The total train weight was thus 704,508 pounds, but six vehicles were slipped at Broxbourne, and the remainder of the journey made with 11 only. The run to Cambridge was made in 75 minutes, including the slow-up for Broxbourne slip and several signal blocks, none of which, however, involved actual stoppage.

The fireman's work consisted in a very little use of the shovel to keep up the thin fuel bed on the grate, and in attention to the oil apparatus at the slow-ups to prevent the waste of steam at the safety valve.

About 120 pounds of chalk is put upon the grate for lighting up, and it would secm that this quantity could be increased and the firebed worked to a very considerable degree of what would be called dirtiness if not for the daily lighting up, that is, the engine could be run night and day until the grate was almost completely impervious to air, only enough air being needed to keep the thin fire reasonably 


\section{LIQUID FUEL APPLICATIONS TO LOCOMOTIVE BOILERS}

red. For lighting up, however, the fire is started in a clear grate, as usual, and the month's average (November) of fuel, including lighting up, is $12 \cdot 2$ pounds of oil per mile and 11 pounds of coal, or a total of $23 \cdot 2$ pounds of fuel. Nine other engines of the same class and the same range of duties averaged 34 pounds of coal per mile for the same month. Thus one pound of oil was practically equivalent to two pounds of coal.

Mr. Holden states that his early experiments convinced him that, for oil burning to be a success, the apparatus for the purpose must be independent of any firebox alterations, or, indeed, of anything which would prevent instant return to coal or solid fuel, or its use in lighting up. Hence his special injector to break up the oil into a fine spray withont the use of brick work, hitherto common as a means of giving an extended surface of exposure to the oil. This breaking up of the oil is enhanced by the several small ring jets which converge on the issuing jet of oil, and both spread and mix it with air and diffuse the flame throughout the firebox, so preventing local heating.

The injector, entirely of gun metal, is clearly shown in section in fig. 21. Oil
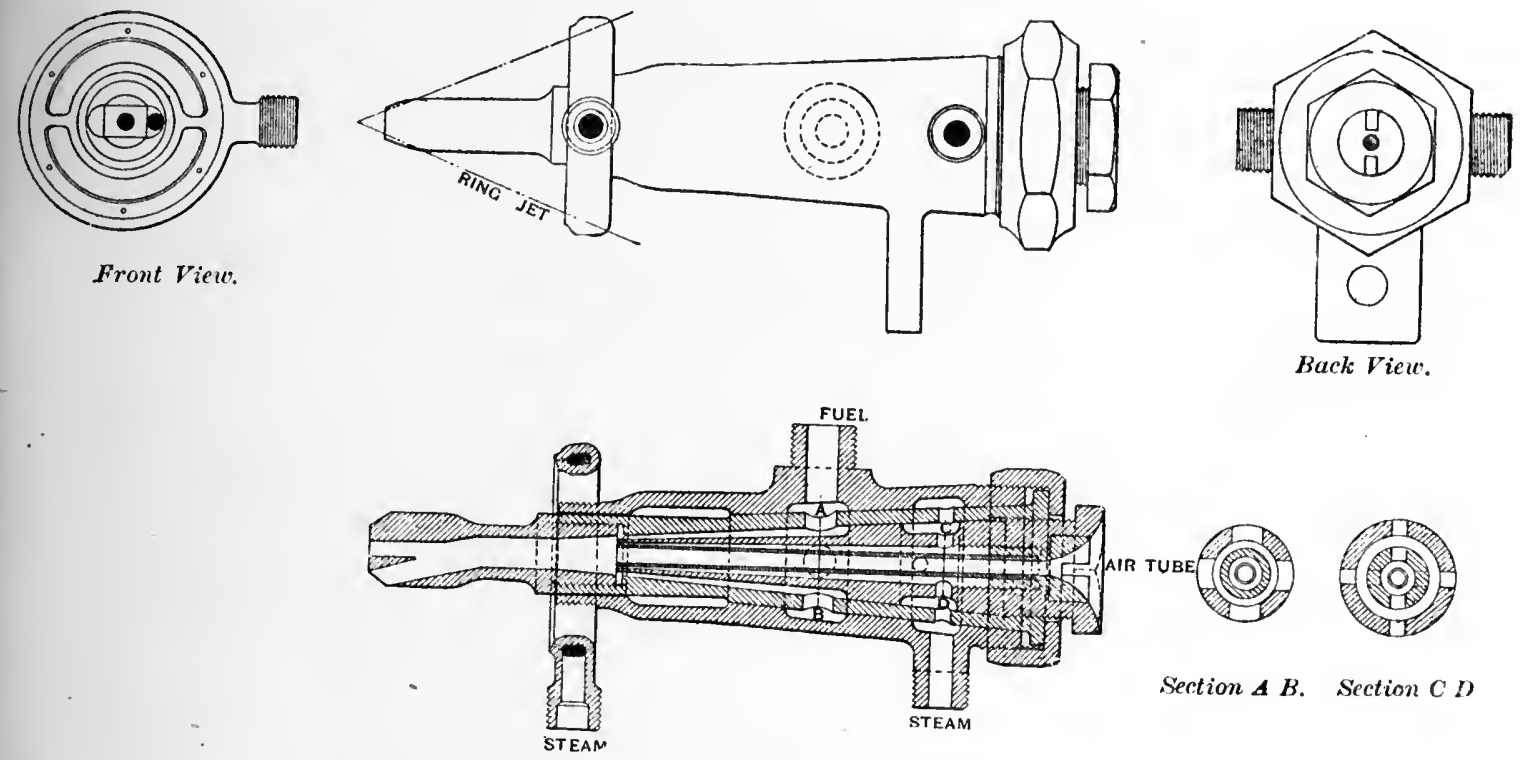

Fig. 21. Holden Atomizer

enters at the side some way back of the steam nozzle and outside this. Steam, therefore, comes inside a thin ring of oil at the mixing nozzle and through the inner tube comes the vacuum brake air which, expanding as it becomes heated, still further aids the breaking up of the oil into spray. The ring jets of steam induce a further supply of air on the exterior of all, and so is obtained an alternation of air, oil, and air, which promotes admixture and thorough combustion. The whole inside of the injector is removable and ean be replaced with a spare set in a few minutes when running. Removal of the brake hose connexion allows the injector nozzle to be cleared by a wire while actually at work, this being the main reason of the through passage which has been utilized, also for the purposes of the vacuum brake. As the engines of the Great Eastern Company were the first express engines 

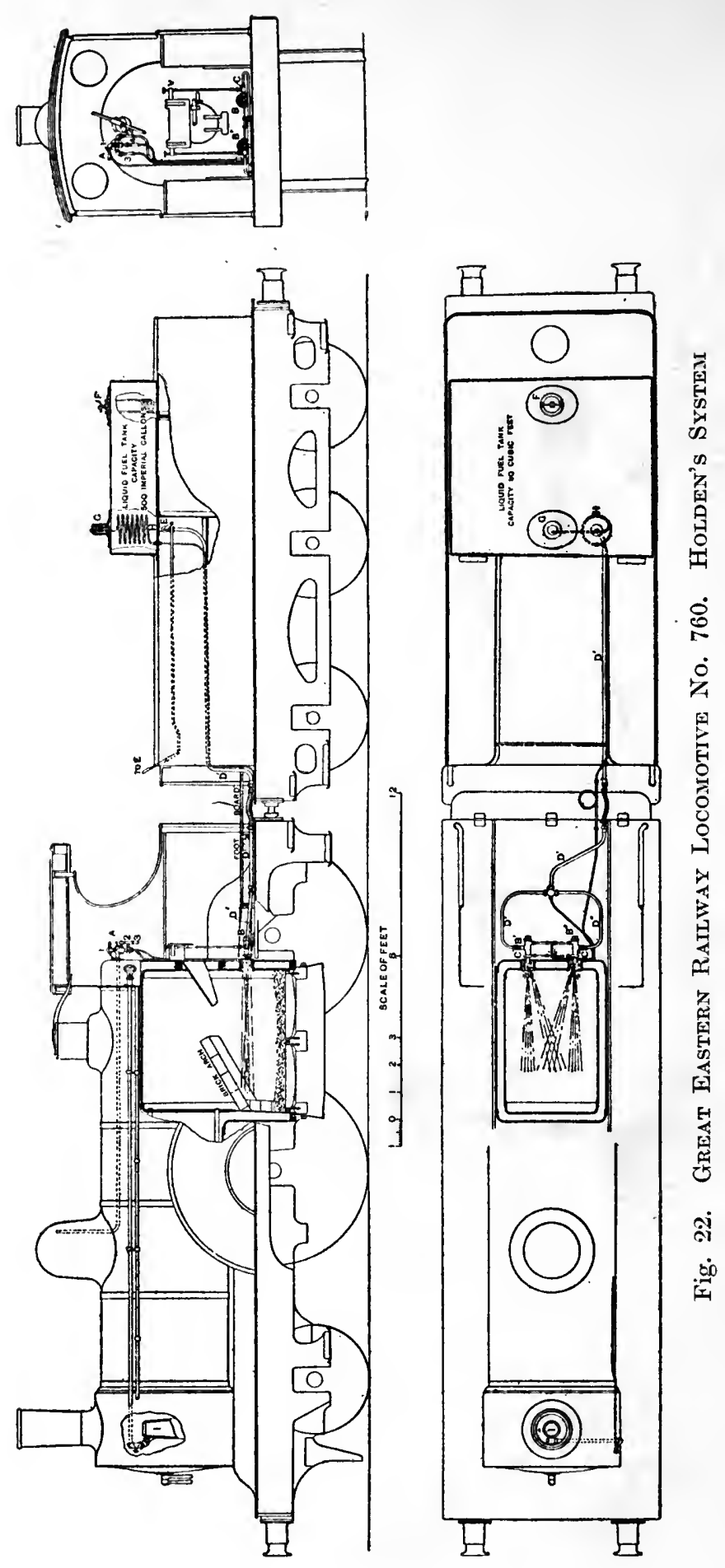

A. Stcam fitting with four cocks : 1. Stcam to warmer in fael tank

2. Stean to rings on injectors.

3. Stcan to jets in centre of injectors.

4. Stealu to clear fuel jipes and injectors.

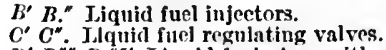

G. Air inlet.

Ii. Air inlet.

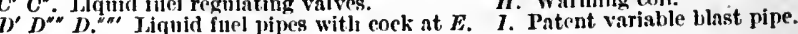
$F$. Afanhole with flling hole. 


\section{LIQUID FUEL APPLICATIONS TO LOCOMOTIVE BOILERS}

to burn liquid fuel, the general dimensions of No. 760 class, fig. 22 , will perhaps be of interest. They are as follows-

Cylinders, diameter

$$
\text { , stroke }
$$

Boiler, diameter outside

, length of tubes (steel)

, diameter of tubes

, number of tubes

Firebox length

, breadth

, height

Grate surface

Leading wheels

Driving wheels

Coupled trailers

Wheel base

Weight on leading wheels

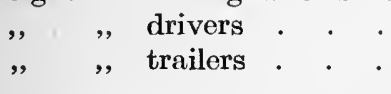

Total

Weight of tender

Capacity, water

$$
\begin{array}{ll}
, & \text { oil } \\
, & \text { coal }
\end{array}
$$

Steam pressure

, ports

" lap

Valve travel

$$
\begin{array}{rrrr}
1 & \mathrm{ft} & 6 \mathrm{in} . \\
2 & , & 0 & , \\
4 & , & 4 & , \\
10 & , & 4 & , \\
& , & 1 \frac{5}{8},, \\
256 & \\
5 & , & 37 & \\
3 & , & 4 \frac{1}{2},, \\
5 & , & 7 \frac{1}{2},, \\
17.9 & \text { sq. } \\
4 & \mathrm{ft} . & 0 & \mathrm{in} . \\
7 & , & 0 & , \\
7 & , & 0 & ,, \\
16 & , & 6 & ,
\end{array}
$$

31,472 ,

30,324
72,800 pounds in worlsing order. 2,640 gals. (English or 10 lb. gals.) 500 gals.

4,500 pounds.

140,

$1 \frac{3}{8}$ in. $\times 15$ in.

$\frac{7}{8}$

$3_{4}^{3}$ in.

Blast nozzle, $5 \frac{3}{4} \mathrm{in}$. in diameter, redueible to $5 \mathrm{in}$. for coal burning when required.

Specifie gravity of liquid fuel, 1.09 to $1 \cdot 11$, aecording to mixture.

Minimum gradient 1 in 70 at Bethnal Green.

Weight of train to Broxbourne, exelusive of engine and tender

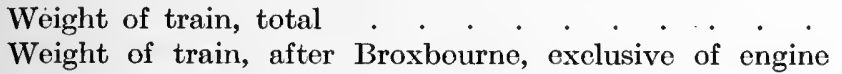

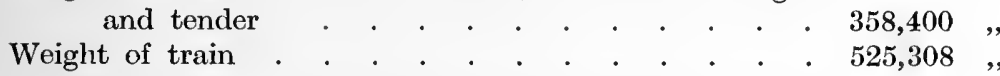

Weight of heavy exeursion trains worked on Great Eastern

Railway by No. 760 during the season, train only, 806,400 pounds, total

\section{7,601 pounds.}

704,508 ,

973,308,

It should be added that the brackets of the oil regulating valves were movable vertically, though this is not elear in the figure. The two brackets were connected to a hand wheel common to both, and were dropped by a single movement of the wheel, thus shutting off both oil valves and putting them again in action without varying their individual adjustment. Later arrangements differ somewhat, the combined motion being given by a lever as in fig. 23 .

This single wheel is used for the station stoppages, after which each injector can be set going again exactly as before the stop, so dispensing with fresh regulation. The injector steam to be dry comes from high up in the dome. The variable blast nozzle is shown open as for oil burning.

When liquid fuel has been and is employed in locomotive work, the absence of a bed of incandescent fuel on the grate is a cause of very serious temperature 

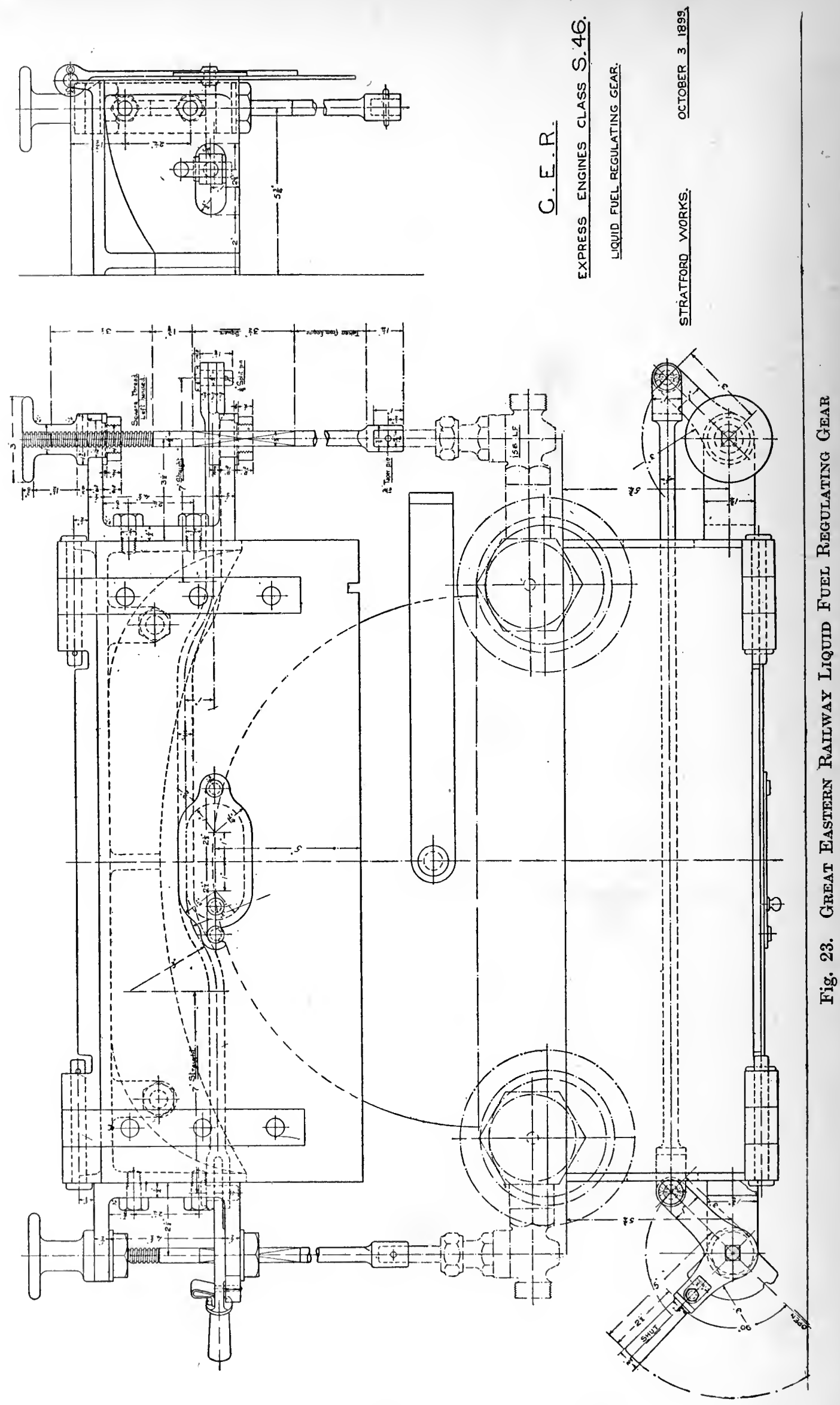


\section{LIQUID FUEL APPLICATIONS TO LOCOMOTIVE BOILERS}

range in the firebox when the oil is shut off at stops. Where a solid fire is maintained on what may be termed the combined system, there is always an incandescent fire to prevent undue cooling when the oil is stopped, and this appears in itself alone a valuable feature in the system, quite apart from the question of lighting up in the ordinary way and the power of using solid fuel if necessary at any time so to do.

The burner or atomizer is shown in figs. 21, 24. Fig. 24 is the stationary form, and consists of a cone body $A$ to the interior of which the oil is admitted through a specially designed regulating valve $B$. Inside the body an annular steam jet is introduced, which possesses a central passage for assisting in the supply of air and also for enabling a wire to be passed through the burner without shutting off either oil or steam. At the front, just behind the nozzle, a hollow ring $(C)$ is attached, and to this steam is admitted and allowed to escape from six very fine jet holes, for better atomizing and distributing the oil. The jets induce a considerable current of air, which is mixed with the spray as it emerges from the nozzle and ensures complete and smokeless com-

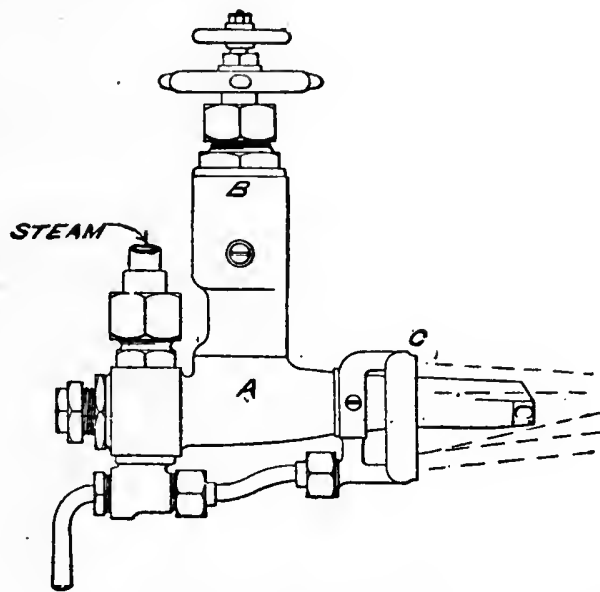

Fig. 24. Atomizer.

Holden's Stationary Type bustion. The steam supplied to the ring is taken through a branch from a small regulating valve attached to the rear of the burner, so that only one pipe is required from the boiler ; the small jets in front of the ring are at different angles, which have been found to be most efficient in practice.

The valve $B$ used for regulating the flow of the oil fuel is of special construction, found desirable after many attempts with different forms of cocks and valves. To pass regular quantities of thick viscous fluid through the "crooked passage" formed by the half open plug of a common cock is impossible, and, consequently, some form of "Straightway" valve is necessary. In the example, a small reservoir of oil is formed by the body of the valve, and a tube with a slit in it is moved up and down inside. The proportion of cut exposed in the oil reservoir regulates the supply. With this valve very fine adjustments in the flow of oil fuel are possible.

The Holden apparatus is now largely used on stationary, locomotive and marine boilers. The Roumanian Government alone have over 250 locomotives fitted on this system.

In fig. 25 is shown the firebox, about 8 feetlong, of an American locomotive, which may be compared with the firebox of the Great Eastern Railway locomotive. In this American box the tube plate and sides of the box are lined with brick, and there are two air inlets at the bottom of the box opening into the ash pit which has the usual front and back dampers. In these narrow boxes there is only room for one atomizer. Oil alone is intended to be used in this furnace, and the area of brickwork is necessarily larger than in the mixed system, where the bars are covered with more or less self-incandescent fuel. 'The fire-brick arch, which has been but slowly adopted in American coal burning engines, is of necessity a part of the oil burning furnace. In some locomotives there is also a small arch over the atomizer to 


\section{LIQUID FUEL AND ITS COMBUSTION}

protect the fire door. In certain locomotives with still longer boxes there will be a wall of brick about 6 feet in front of the atomizer, and the arch springs from this wall, so that there is a combustion space between the wall and the tube plate.

With Texas oil the Great Eastern locomotives have hauled fast trains on a consumption of $17 \cdot 6$ pounds per mile, as against 34 pounds of coal, the train load being 225 tons $(2,240 \mathrm{lb})$. On a test run with a train of 620 tons a four coupled passenger engine consumed 31 pounds of Texas oil per mile. 'These engine are fitted with air heating arrangements. On the Japanese Government railways, Borneo oil

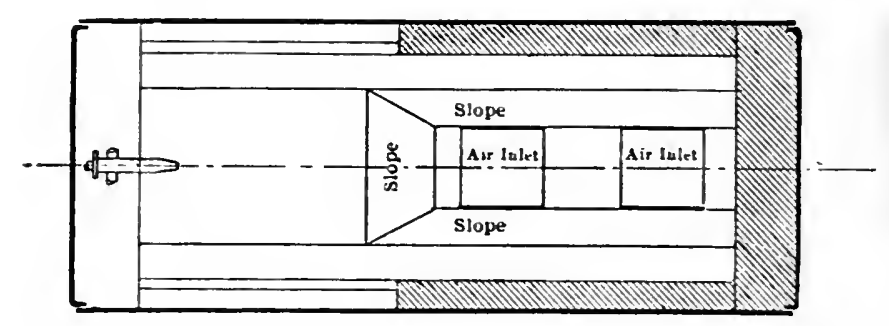

on the Holden system showed an evaporation as high as 14.42 and averaged $12 \cdot 6$ the year round as against 6.4 pounds for coal.

Quoting from the annual report of the .Tapanese Government, the adoption of oil fuel for an estimated annual locomotive mileage of $7,000,000$ would sare 448,000 yen per year, or

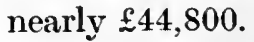

An important item in connexion with oil fuel on locomotives is the lengthened life of the internal firebox. After some service the sides of an ordinary firebox present a series of convex surfaces between the stays, which are each and all subjected to constant abrasion by the small ashes, sparks, etc., drawn from the fire by the action of the blast. As a result of this wearing away of the surface of the plate, it gradually be-

Fig. 25. Fire-Box of Americax Oil-Burnixg Locomotive

comes thinned, and eventually cracks develop between the stay holes, with the consequence that the box must be patched or renewed after a comparatively short existence. With oil fired engines an extension of time of some 50 per cent. can be secured, as no such destructive action exists. These remarks on abrasion apply equally to the tubes, smoke box, chimney, etc., and the economies in this direction are of considerable value when large numbers of locomotives are affected.

On the long fast runs it is difficult to keep a steady steam pressure with a coalburning engine during the later portions of the journey, owing to the " dirty " grate. 


\section{LIQUID FUEL APPLICATIONS TO LOCOMOTIVE BOILERS}

With oil burners the fire is of equal intensity throughout, and as clean at the end of the day as at the start, and an engine can be run indefinitely as regards the fire.

The average life of copper fire boxes of five G.E. Rly. engines, No. 754 to 758 , with coal, was found to be $5 \frac{1}{2}$ years, and that of two other sister engines, No. 760 and 765 , using liquid fuel, was respectively 8 years 4 months and 8 years.

The form of atomizer used on later locomotives is that of fig. 27. This burner is designed to vaporize the lighter portions of the oil, and to carry out this operation sufficiently quickly to prevent the burner being choked by coke which might be formed if the decomposition process is carried too far. The oil enters by the first branch on the burner and passes through a long tapered cone surrounded for the greater part of its length by an annular space open at the lower end, through which steam is allowed to pass from a second branch on the burner casting.

The steam is highly superheated and raises the temperature within the inner cone before it passes through the orifice from which it escapes and comes in contact with the oil.

The oil and the steam then pass along together at a sufficiently high velocity to induce a current of heated air through the third branch of the burner. The air thus drawn in by the aspirating action of the jet, allows the oil vapour on the outer surface of the jet to ignite and thus raises the temperature of the whole of the jet so that as soon as this is allowed to come in contact with the air for combustion, which passes through the firebars, ignition takes place immediately, and the combustion is completed.

In fitting these burners to ordinary boilers they are connected by means of pipes to a hinged joint or trunnion. This does not require any special description beyond that the ports in the moving portion are so arranged that when the burner is swung out of position, the supplies of steam and oil are cut off, so as to prevent the risk of fires in the stokehold.

Where, as is often the case, a crude oil contains water in such quantities as to extinguish the fires there is considerable danger. The oil following immediately after is-if the furnace temperature is sufficiently high-violently exploded, or, if the furnace is allowed to become too cold, the oil falls through the ashpits and on to the stokehold floor, where it spreads out into a thin film probably at a temperature approaching the flash point, and therefore in a highly inflammable state.

The specific gravity of most fuel oils being 0.86 to 1 the rate of settling at low temperatures is very slow, but the difference in the specific gravity becomes much more marked if the temperature is raised, and a very usual practice has been therefore to heat up the whole contents of the oil bunker or tank to such a temperature as without approaching the flash point of the oil, will make the density difference sufficient very much to accelerate the settling rate.

The objection to this practice is that a large amount of heat is required, the radiation surface of a bunker of any size being considerable; the heating process at its best is slow, and unless it is completed before any of the contents are drawn off, the lower layers of the tank will consist either of pure water or oil with a large percentage of water mixed up with it.

To obviate this difficulty, a floating suction is used which consists of a long pipe pivoted upon the side of the bunker or tank, and guided in the vertical plane by means of a tee or angle iron set to correct radius.

The suction pipe has a small steam pipe led along its side, which terminates in the coil immediately below the suction opening. The steam passes through this 

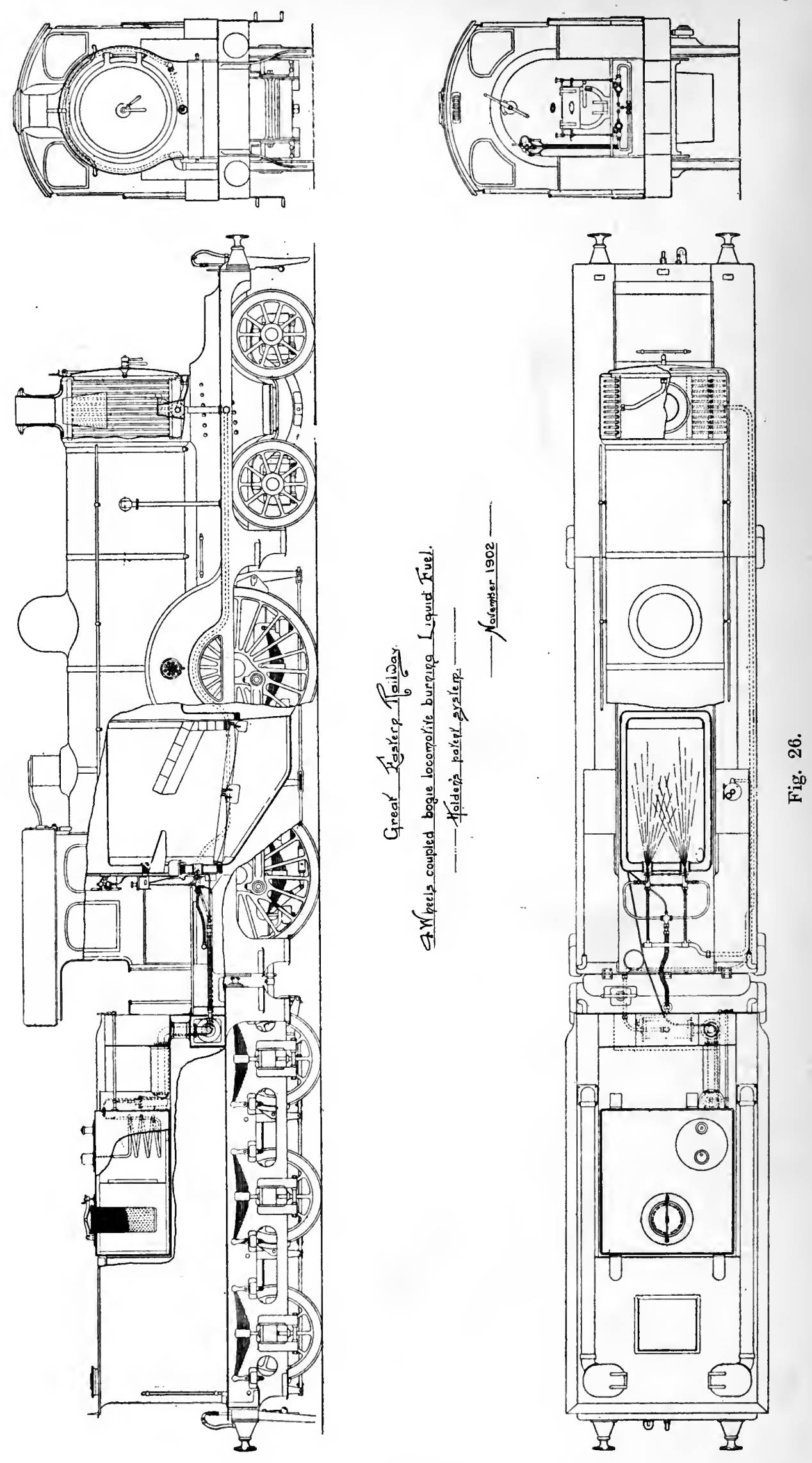


\section{LIQUID FUEL APPLICATIONS TO LOCOMOTIVE BOILERS}

and heats the oi immediately below the orifice of the suction pipe, and this oil rises up into the pipe and leaves the water behind it. The float is proportioned and arranged to keep the mouth of the pipe about 6 inches below the level of the oil in the tank.

This apparatus is certain in action and requires but little heat, as this is only applied to that portion of the oil immediately under the mouthpiece of the suction pipe, and there is little or no radiation from the bunker sides, and the heated oil at once moves off to be used while still hot. See fig. 9a for similar device.

The latest general arrangement of a Great Eastern Railway locomotive is that of fig. 26, which shows the application to a locomotive with firebox 2 feet 6 inches wide. For a smaller firebox one atomizer only is necessary.

The apertures in the firebox are made by inserting a copper tube beaded over at the ends, into this a wrought iron ferrule is drifted which makes a perfectly tight joint.

The nozzle of the atomizer is placed about $\frac{1}{2}$ in. above the centre of the aperture, and the face of the ring $\frac{3}{4}$ inches from the front of same.

When liquid fuel is used alone, steam is first raised in the boiler by a wood and a coal fire to 25 pounds or 30 pounds pressure, the fire is levelled over and covered with a layer of broken fire-brick of not more than 3 inches cube spread, so that it is thinnest about the centre of the firebox, and well packed round the sides and corners. A few pieces of waste or wood are thrown in to cause a flame before the liquid fuel is introduced.

Dry steam is taken to a steam fitting, two cocks on which admit steam to the cones and rings on the injector respectively; a third cock blows steam through the fuel pipes and atomizer should they become choked; and there is a cock for the steam coil placed in the tank to prevent the fuel solidifying in cold weather.

The fittings for a locomotive, as illustrated, consist of the following-

2 atomizers and regulating valves.

1 steam fitting.

1 stop cock on tank.

1 four way piece.

2 tee pieces.

2 copper tubes and ferrules.

For a locomotive with firebox under 2 feet 6 inches wide, the following fittings are required-

1 atomizer and regulating valve.

1 steam fitting.

1 tee piece.

1 copper tube and ferrule.

1 stop cock in tank.

The air heater is shown in the smoke box, fig. 26 , and consists of a number of tubes laid round the smoke box crown and springing from two headers into one of which the air is drawn and out of the other it passes to the atomizer.

The regulating gear is shown in fig. 23 , this being the latest form so arranged that a simple movement of the lever closes both oil valves without affecting their separate adjustment when open. 


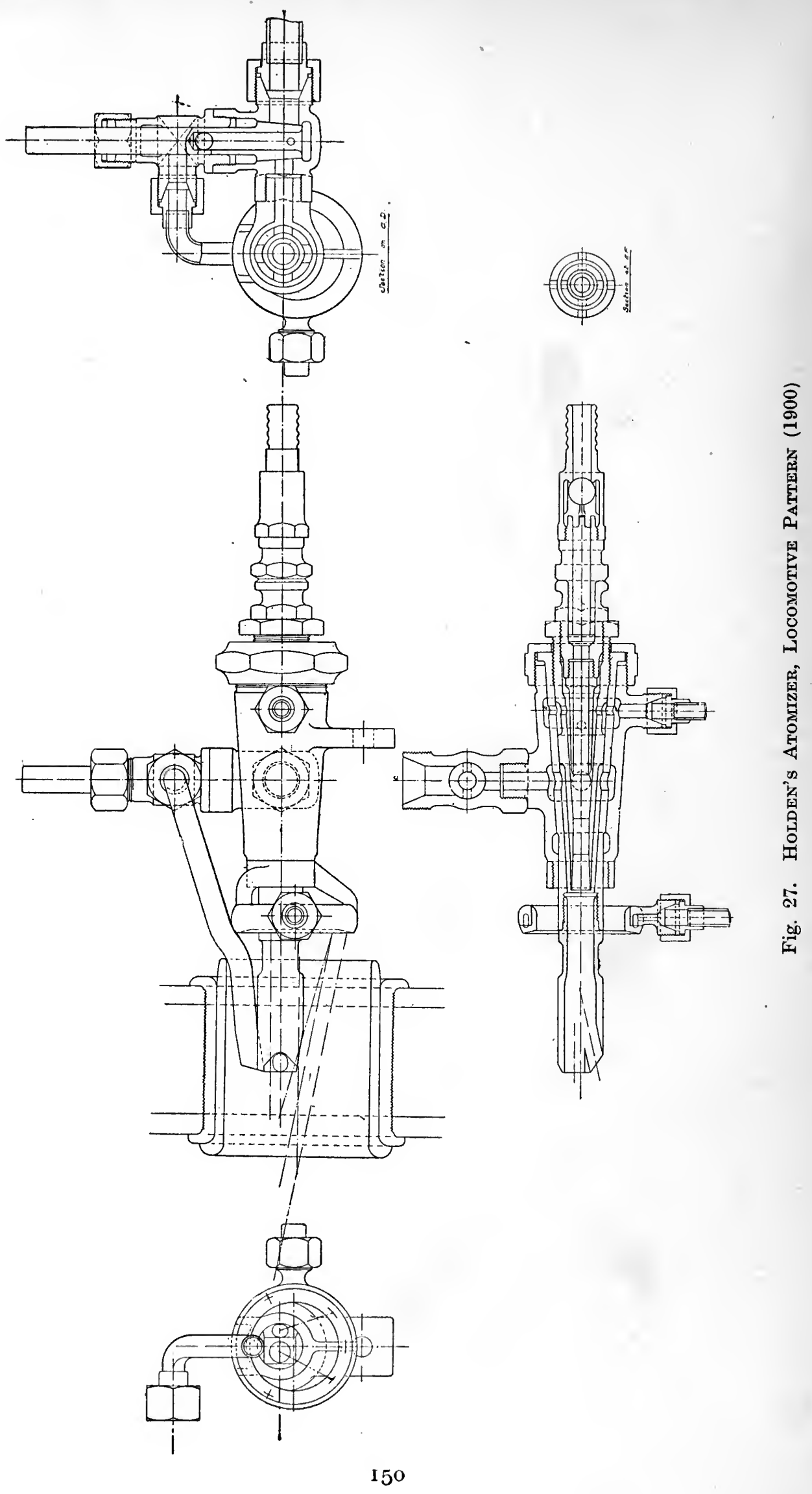




\section{Chapter XVII}

\section{LIQUID FUEL APPLICATION TO STATIONARY AND OTHER BOILERS (HOLDEN'S SYSTEM)}

\section{The Lancashire Boiler.}

$\triangle \mathrm{S}$ already suggested, oil fuel can be best utilized under steam boilers by in1 jecting it in spray form into the furnace by a steam jet or jets. Here perfect combustion can be secured by the proper admission of air and the intervention of a highly heated fire-brick bridge or screen. 'The furnace can be arranged to burn oil fuel above the ordinary grate, or preferably along the usual level of the firebars, so that the whole of the cubical contents of the furnace can be secured for combustion.

Fig. 29 shows the arrangement of the oil-fuel apparatus with Holden's Burners on a Lancashire boiler. The burners are placed at the front of the brick lined extensions, to which heated air is conveyed from large tubes passing down the outer flues. The fire-brick construction is simple and easily introduced for an ordinary sized boiler with a grate of, say, 7 feet long. A striking bridge pillar with inclined face is built up about 2 feet 6 inches inside the furnace; next, a screen with large clear opening about 1 foot 6 inchos behind the former; and finally, a second screen with oblique perforations to direct the gases along the inner surface of the flue. The central portion of this last screen is recommended to be built solid. On boilers thus arranged, with fair working conditions, an evaporation of from 14 to 15 pounds of water per pound of Texas fuel oil (from and at $212^{\circ} \mathrm{F}$.) is readily obtained.

On a large boiler of this type burning north country "smalls" and evaporating only $6 \cdot 5$ pounds of water per pound of coal, the Texas fuel oil has secured an evaporation of $\mathbf{1 5 . 2 5}$ pounds of water per pound of fuel.

\section{The Cornish Boiler.}

In fig. 30 a Cornish boiler is shown with liquid fuel and the fire-bars are left in and covered by a layer of fire-brick or chalk as a base for the fire in case it may be necessary to return to solid fuel at any time. Any internally fired boiler may be treated by either method. Where the bars are left in there ought to be a damper fitted to the opening of the ash pit to regulate the admission of air.

In these furnaces the injector is placed about 8 or 10 inches above the grate surface and about $\frac{1}{2}$ inch above the centre of the 4 -inch opening cut through the furnace door. The injector is inclined so as to point to the second or third brick from the top of the bridge. Dry steam, preferably superheated, is admitted by a 


\section{LIQUID FUEL AND ITS COMBUSTION}

valve $C^{1}$, the cock $C^{2}$ being to clear the fuel pipe and injector when choked, and the pipe $C^{3}$ being for steam to warm the oil in the tank.

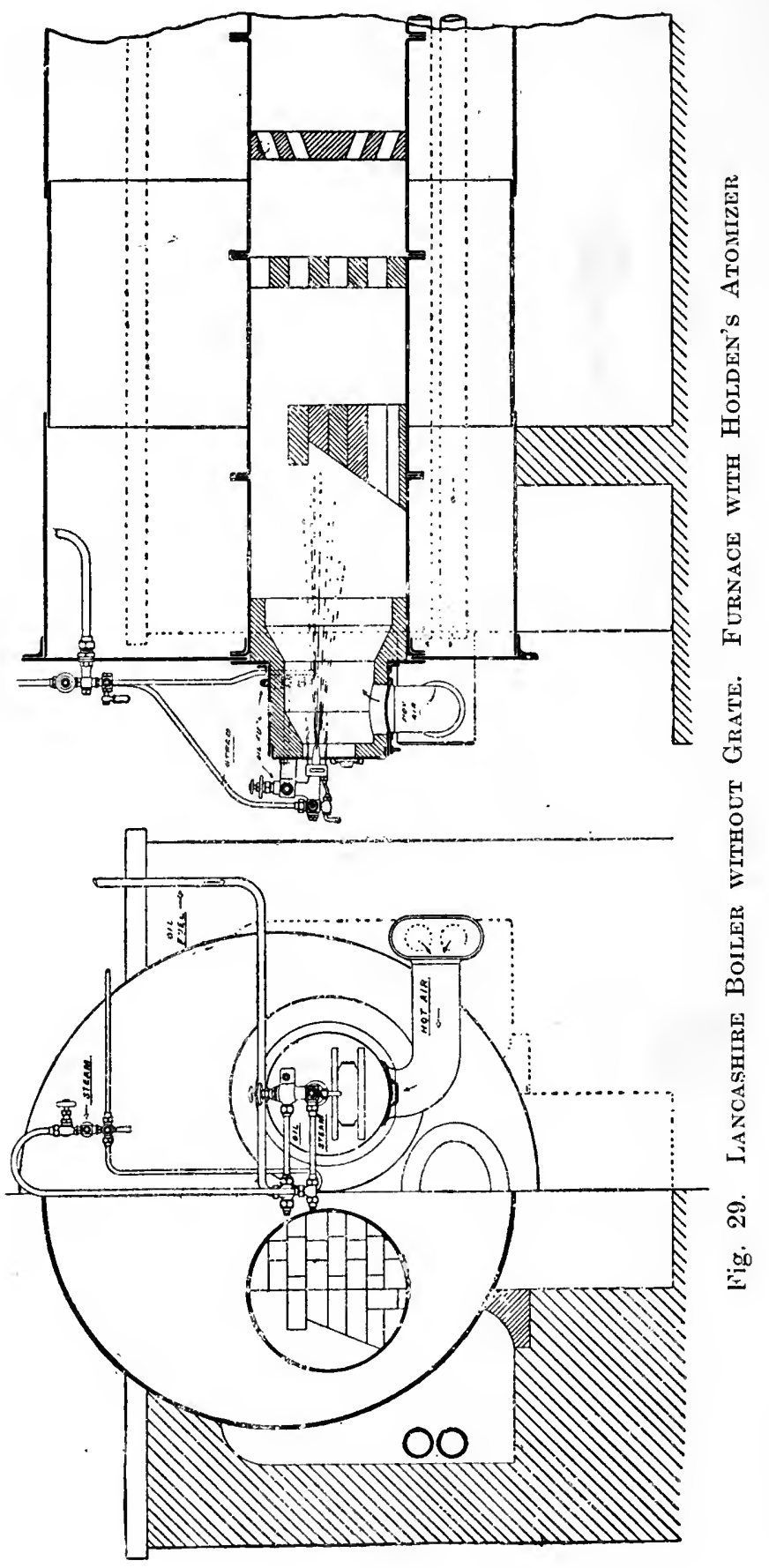

Generally, as regards the firing of internal furnace boilers, the fuel is blown in on a line about parallel with the grate surface and 8 to 10 inches above it, as 


\section{APPLICATION TO STATIONARY AND OTHER BOILERS}

shown in the illustration of the Cornish furnace and also in fig. 31 of the stationary form of the locomotive type boiler.

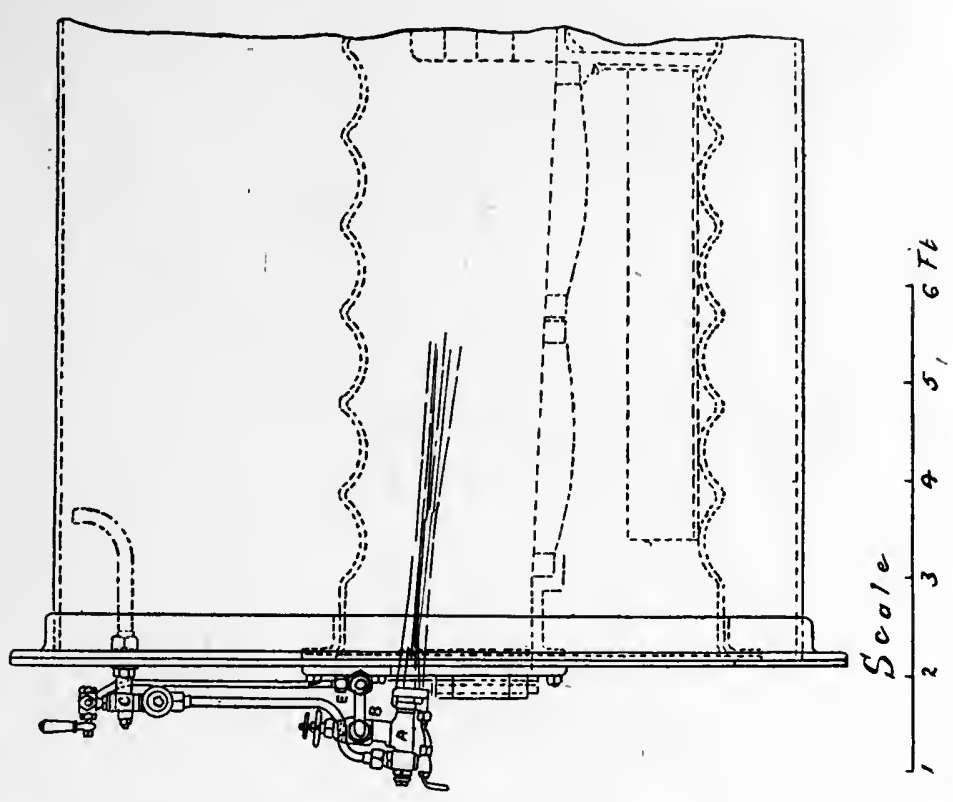

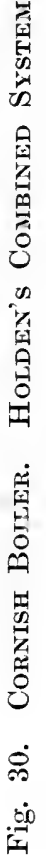

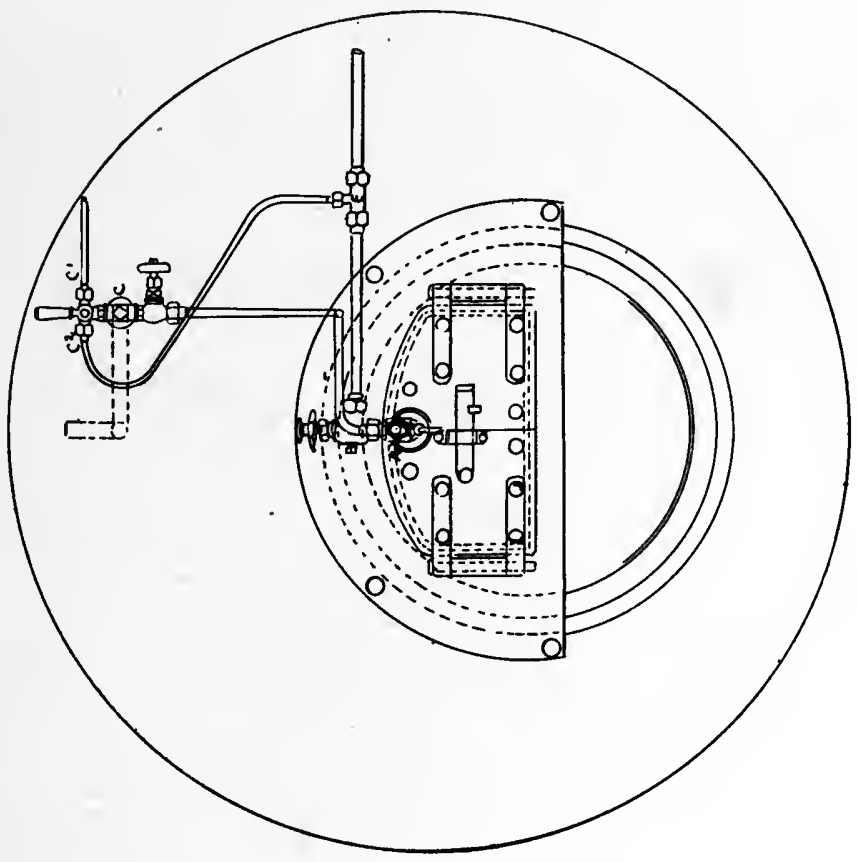

In the vertical boiler of large size the atomizer is usually placed below the 


\section{LIQUID FUEL AND ITS COMBUSTION}

fire-door opening, but in small vertical boilers it must be placed through the door.
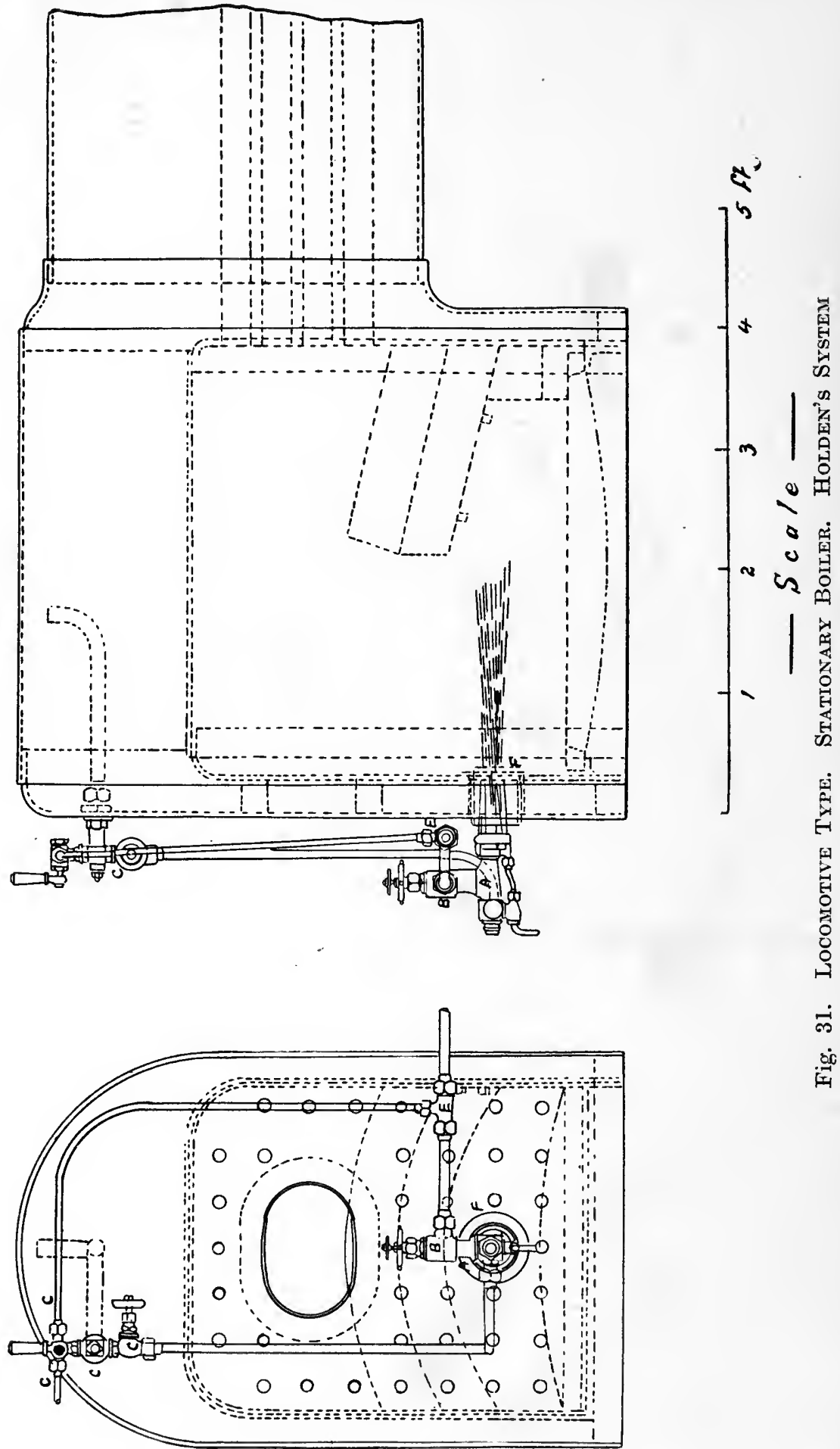

के

运

In either case the opposite half circle of the furnace must be lined with fire- 


\section{APPLICATION TO STATIONARY AND OTHER BOILERS}

brick to the height of about half the furnace diameter to form the necessary incandescent surface on which any unburned oil can strike.

\section{The Water Tube Boiler.}

Fig. 32 shows an arrangement of oil burners for a water tube boiler where liquid fuel is intended to be used in conjunction with coal, so that while working

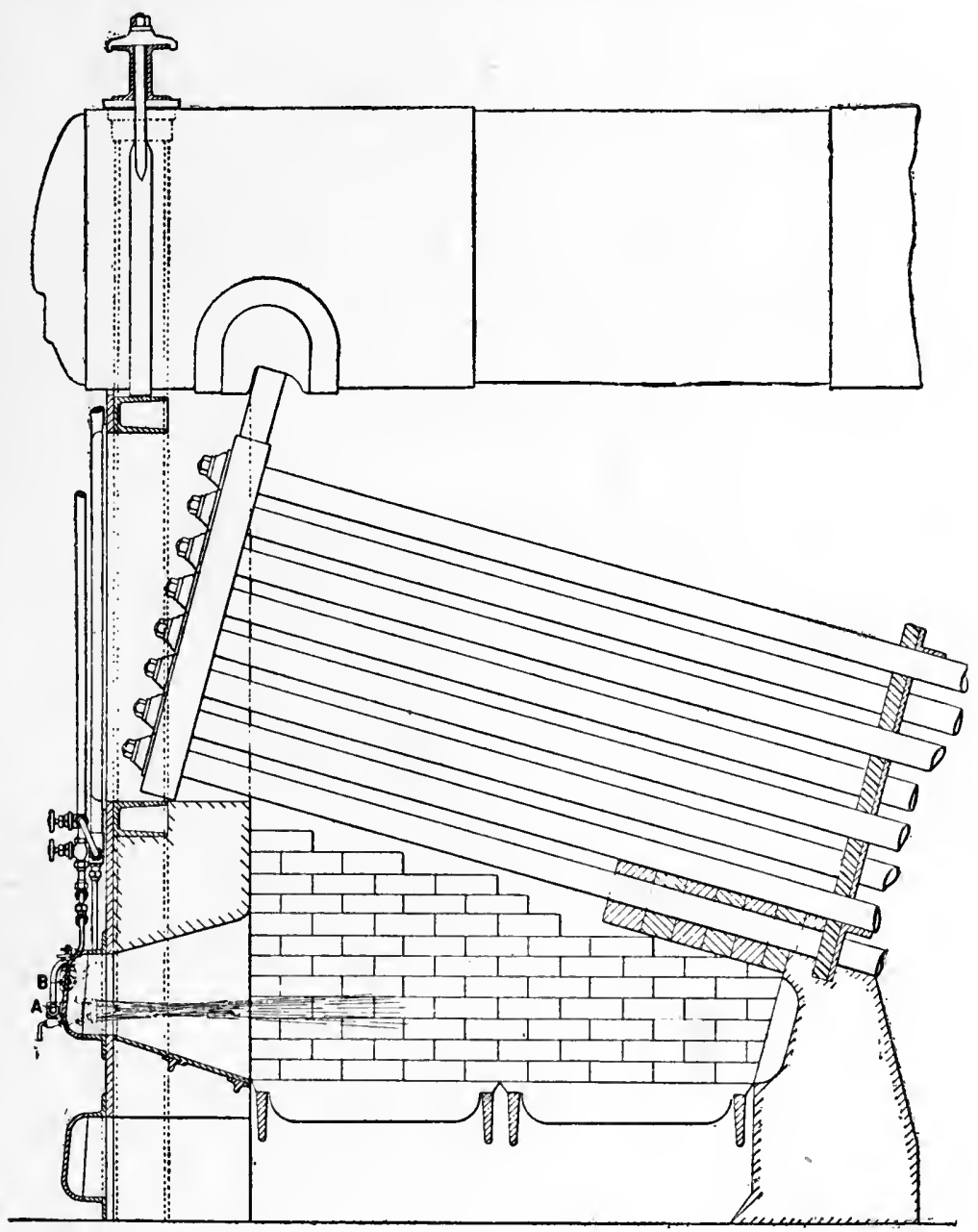

Fig. 32. Water Tube Boller for Coal and Oll Burning. Holden's Combined System with Grate

at full power the evaporation of the boiler may be somewhat increased; by starting the liquid fuel burners, and when the fires become dirty the maximum power ean still be maintained by increasing the consumption of the liquid fuel as the fires get dull. Here the steam passes through the superheating coil in the uptake, and from there passes to a stand pipe, called usually the "steam branch pipe," from which small branches are led to each burner and the supply is controlled by five small valves on the steam branch pipe.

For the water tube boiler without grate bars the arrangement of fig. 33 is em- 


\section{LIQUID FUEL AND ITS COMBUSTION}

ployed, there being an additional arch of fire-brick brought forward from the bridge to prevent too early a passage of the gases among the tubes. The author would

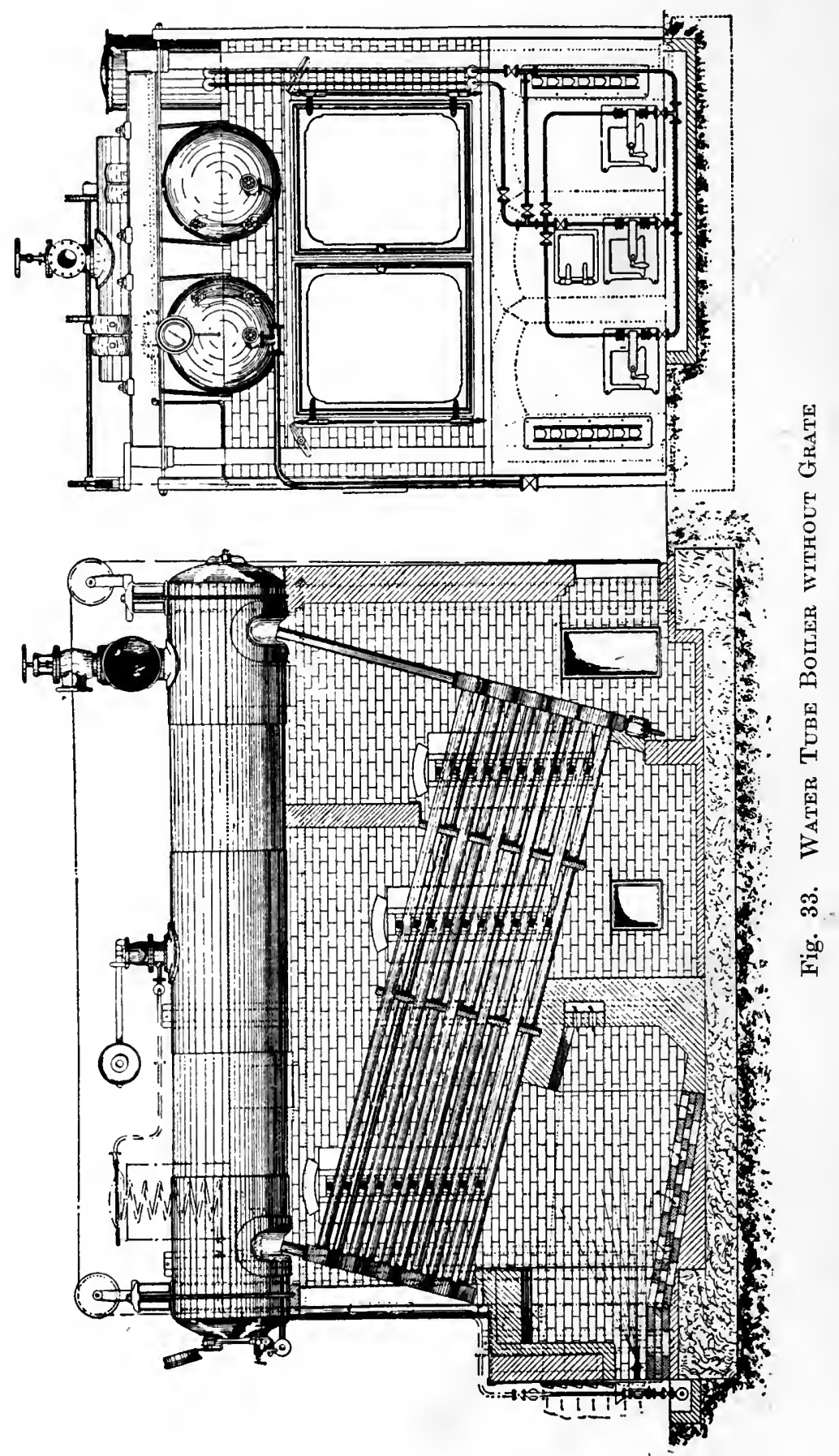

extend this (and also the first arch) further than shown in fig. 33, it being impossible either with coal or oil to secure smokeless results where the hydrocarbon 


\section{APPLICATION TO STATIONARY AND OTHER BOILERS}

gases pass too quickly among cold tubes. Nor is there space and time for such complete combustion with a minimum of fuel as is desirable.

In fig. 34 is given a section of an oil furnace arranged with a small grate for lighting up purposes only. This is intended for use where liquid fuel is alone to be employed, the small grate serving simply for lighting up purposes. It may be added that in locomotive work generally the steam blast may be made less intense when oil fuel is used, and on the Great Eastern Railway, the MacAllan movable cap (fig. 28) is employed. This is folded over the blast pipe orifice, which it reduces from $5 \frac{3}{4}$ to 5 inches diameter.

It is found that the position of the atomizer is important. If too high the combustion is vibratory, and an

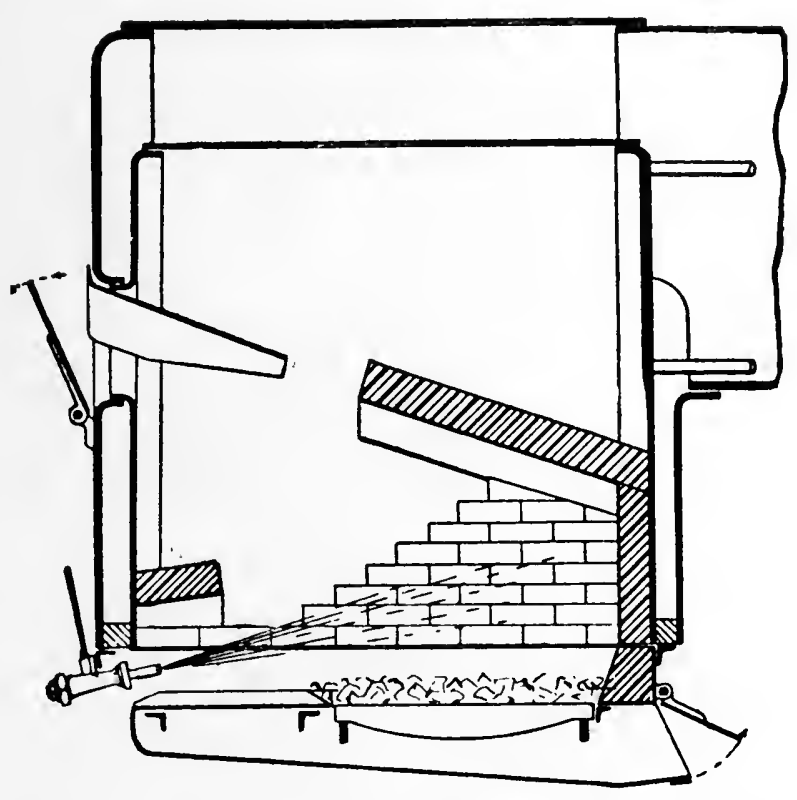

Fig. 34. IAQUid Fuel Burning Locomotive with Small Lighting-up Grate intolerable humming sound is produced by the many rapid explosions due to non-continuous combustion. Mr. Holden lays it down that the oil fire must be along the plane of the coal fire for the best results, and not too high above it. The Cromer express is worked by an oil burning locomotive at an expenditure of 190 gallons of tar residues of

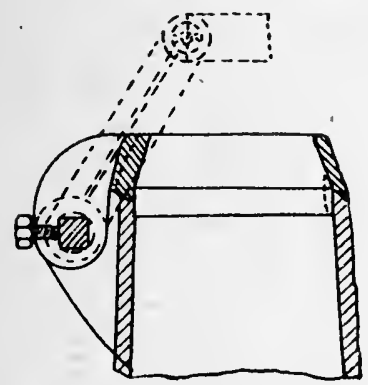

Fig. 28. MacAllan VariABLE BLAST CAP specific gravity $1 \cdot 10$. This is equal to $14 \cdot 4$ pounds of liquid per mile, in addition to about $6 \mathrm{cwt}$. of coal or 5 pounds per mile. Some 5 to 6 cwt. of broken bricks are spread on the grate for this journey of 138 miles in 175 minutes, the train of 17 cars weighing 271 tons empty, exclusive of the locomotive, which weighs 51 tons 14 cwt. 2 qrs., and the tender, which weighs 35 tons 17 cwt., the total weight being nearly 360 tons unloaded.

Owing to its large proportion of hydrogen, the production of carbon dioxide is less, and this is held to be an advantage of liquid fuel for working tunnels, and the Arlberg tunnel is so worked by 32 engines. It must not, however, be overlooked that hydrogen destroys three times as much oxygen as is destroyed by a pound of carbon, and produces but little more calorific effect per pound of oxygen consumed, so that it is equally destructive of the vital properties of the air and introduces an excess of nitrogen in place of an excess of carbon dioxide. The physiological effect of the carbon dioxide is less to be feared than the absence of oxygen which it implies. Too much, therefore, should not be made of this supposed advantage of liquid fuel, the danger being due to the ahsence of oxygen. 


\section{LIQUID FUEL AND ITS COMBUSTION}

\section{Locomotive Boiler.}

Fig. 35 is the fire-box used for liquid fuel on the Southern Pacific Railroad, the oil being sprayed into the front of the fire-box below the mud ring and under the usual brick arch and directed against a sloping brick lining of the back plate. The sides of the box are cased in bricks, and there are openings for air in the brick
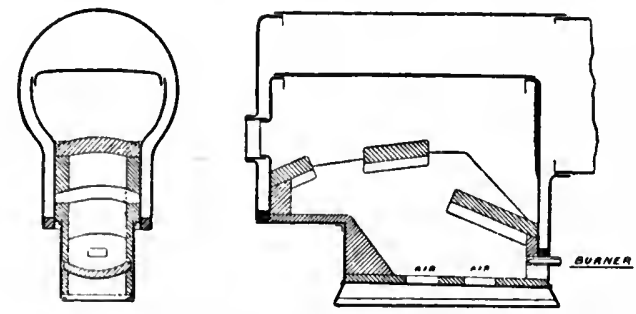

Fig. 35. Locomotive Fire-Box fOR OIL Fuel, Southern Pacific Railroad bottom to admit air under the flame. A central brick arch baffle is thrown across the middle of the fire-box, and an arch is thrown across just below the fire-door. The plates of the upper part of the box are bare, and the results are said to be satisfactory.

According to Mr. Holden the fuel supply should be above the level of the atomizers. This is a point with which all do not agree, as some consider that the fuel ought always to be pumped to the atomizers, and that no oil should be able to flow by gravity with the attendant risks in case of rupture.

Unless there is an independent source of steam available, steam should be raised in the boiler by an ordinary fire until a pressure of, say, 25 pounds per square inch is obtained, when the liquid fuel apparatus may be started.

All cocks and valves being closed, the cocks of the steam fitting connected with the fuel injector are to be first opened. The main liquid fuel cock on the tank may now be opened and the fuel admitted to the injector by slowly opening the regulating valve. To start with a clear flame, the incandescent fuel on the bars must be moderately bright, and not dull red.

If coal and oil are to be burned, a thin bright fire should be maintained on the bars free from holes, and the corners and sides of the grate are to be kept well covered. If oil only is to be used, the remains of the lighting up fire should be gradually covered with broken fire-brick (about 2 inch pieces) keeping the base thus formed thinnest under the lines of jets from the injector, or say, at the centre of the grate; the sides and corners being closed round with small pieces of firebrick.

As the fire-brick bridge or arch attains a red heat more liquid can be injected and less steam used. To shut off the apparatus the liquid fuel cock on the tank is first closed, then the regulating valve on the injector, and finally the cocks on the steam fitting are shut off.

The oil burners must not be started before ascertaining that there is a flame in the furnace ; if doubtful, a few pieces of wood or some oily waste should be set alight in the furnace bcfore applying the oil fuel:

The above rules are equally applicable to all systems of oil burning. A common danger with oil is the risk of gases accumulating in the furnace and leading to explosion when the dampers are opened and flame produced. As with coal, the accunulation of gas may be prevented by drilling a two inch hole near the top of the damper, so that when the damper is closed there is always a vent through it which will stop any accumulation of gas.

\section{United States Navy Tests.}

Special attention may be directed to Appendices 1, 2, 3, extracted from RearI 58 


\section{APPLICATION TO STATIONARY AND OTHER BOILERS}

Admiral Melville's Report of 1902 of the Bureau of Steam Engineering. Though the water tube boiler does not appear to be of the best design, it appeared to be satisfactory in its freedom from overheated tubes, and the same boiler was used both for coal and oil tests, and the tests were carried out by a disciplined body of men, and are good comparative tests. The summary of both coal and oil tests are given in these appendices, and as they cover a wide range, they may be studied with advantage. It is to be noted that the percentage of $\mathrm{CO}_{2}$ in the chimney gases ranged from $7 \cdot 15$ up to 13.77 for coal and from 5.5 to $10 \cdot 1$ for oil. Oil was thus apparently inferior in respect of the proportion of excess air required, but it was also, as it ought to have been under such circumstances, superior in showing a less ratio of $\mathrm{CO}$. This inferiority of oil is apparent only as shown later.

Probably the combustion was more perfect in the furnace and the temperature higher with oil, for on the whole the chimney temperature was less with oil, as though the transmission of heat were more perfect, and the final boiler efficiency in terms of the percentage of fuel heat absorbed was thus about equal in each case.

The furnace arrangements as shown by fig. 3, appendix 3, show that a large opening is provided for air in the front wall below the burning oil, and it may be suggested that the admission of air in large streams is equally undesirable as the same method with coal. Indeed, in the author's opinion, there is much to be said for the admission of air through a grate, well covered with sharply broken firebrick as in the Holden system of mixed coal burners. The air would become heated by its passage upwards through the broken fragments and finely divided. The area of this under grate need not be excessive. Probably it would be best kept short so as to admit air near the front of the furnace and so allow it the opportunity of mixing better with the burning gases above it. 'The furnace should be made to secure the same swecping action of all the gases in the furnace so as thoroughly to intermix them. In the detailed tables, which are too voluminous to reproduce, the proportion of air appears to be given at a lower figure than in the summary, some of the coal tests showing as little as 12.8, 13.2 and 14.4 pounds of dry air per pound of carbon, amounts which would point to absolute insufficiency when the hydrogen of the coal is taken into account. The discrepancy, of course, is due to the condensation and removal of the hydrogen, which leaves as a load upon the carbon that portion of the nitrogen which came in with the oxygen that disappeared in forming steam. As liquid fuel contains so large a percentage of hydrogen, the dry chimney gas from liquid fuel will contain an undue proportion of nitrogen, and the percentage of $\mathrm{CO}_{2}$ in the chimney gases as shown in the summarized tables is made smaller in the case of both coal and oil, but the oil is the more affected, and columns 56 to 60 of the coal summary must not be compared with columns 44 to 48 of the oil tests summary.

Pocahontas coal only averages about 4 per cent. of hydrogen and the New River coal under 5 per cent., these coals resembling Welsh smokeless to some extent. The oil, however, contains 12.41 per cent. of hydrogen as well as less oxygen.

\section{Calculation of Air.}

If the air for this fuel be calculated, it will be found as follows-

$$
\begin{aligned}
\text { Oxygen for the carbon } 83 \cdot 26 \times 2 \cdot 667 & =222.00 \\
\text { " , " hydrogen }\left(12.41-\frac{3 \cdot 83)}{8} \times 8\right. & =95.44 \\
\text { Total } & 317 \cdot 44 \text { per } 100 \text { pounds. }
\end{aligned}
$$




\section{LIQUID FUEL AND ITS COMBUSTION}

Air required $317.44 \times 4 \cdot 32=1,371 \cdot 34$, or say, 14 pounds per pound of oil.

The actual dry chimney gas per pound of oil is $(2 \cdot 22 \times 4 \cdot 32)+(0.9544 \times 3 \cdot 32)$ $=12 \cdot 76$ pounds.

This cuts out the hydrogen and the oxygen it consumes, but leaves the nitrogen as a load on the carbon. The total dry gas per pound of carbon is thus $12 \cdot 76 \div$ $0 \cdot 8326=15 \cdot 33$, to which the pound of carbon itself being added gives $16 \cdot 33$ pounds of dry chimney gas, which may be laid down as the chemical minimum per pound of the carbon. The summary of the oil tests shows from 50 to 100 per cent. in excess of this in column 48. As, however, some of the nitrogen has come in with the air to satisfy the oxygen, column 50 gives a more favourable appearance to this point.

To the weight in column 50, however, we should require to add the water formed from the hydrogen or $\left(12 \cdot 41-\frac{3 \cdot 83}{8}\right) \times \cdot 09=1 \cdot 07$ pounds per pound of oil, and this added to column 50, would give the total chimney gases per pound of fuel.

Thus the analysis of chimney gas for $\mathrm{CO}_{2}$ in the case of oil is deceptive unless account be taken of the hydrogen. We have found above that 13.71 pounds of air is the chenical minimum per pound of fuel of the order given. If to this we add 1 pound for the fuel itself and $\mathbf{0 . 2 6 6}$ to satisfy the sulphur, we find practically that 15 pounds of air is the chemical minimum for oil fuel. Column 50, if increased by the 1 pound for water formed, would vary between 21 and nearly 37 pounds of total products, the former representing an addition of 33 per cent. of excess air and the latter of no less than 133 per cent; but this was exceptional, and for No. 9 the test of a burner that was admittedly not perfected.

Throughout all the tests a good deal of smoke was formed. This seems to point to too direct escape of the products of combustion, and there can be little doubt that a longer distance is required between the burners and the first contact with the cold boiler surfaces.

Regarding the conclusions drawn, it is to be noted that the atomizing agent, whether steam or air, should be hot, and that high pressure steam is better than low pressure steam ; also that the tendency is to force the oil forward at a considerable pressure to the burners and compel it to escape, by a fine opening, thereby probably tending to atomize itself somewhat.

The practice in America generally is towards pumping the oil to the burners rather than allowing it to flow by gravity.

It will also be noticed that air at a modcrate pressure appears to be as competent to atomize oil as steam at a high pressure. No explanation of this is given, but it is partially due to the greater density of air and probably in part to the fact that air is a supporter of combustion and induces earlier combustion or ignition.

\section{The Meyer System:}

This is shown in fig. 36, and is a modification. of the Körting system. Oil is supplied by the Körting system and air is admitted through specially placed blades in an extension of the furnace front, the air being heated in a surrounding jacket, which is arranged with spiral divisions. The air is delivered to the surface in a whirling manner, and the system has been two years at work on several Dutch 


\section{APPLICATION TO STATIONARY AND OTHER BOILERS}

steamers with success and similar general types of apparatus have been running in the Roumanian service.

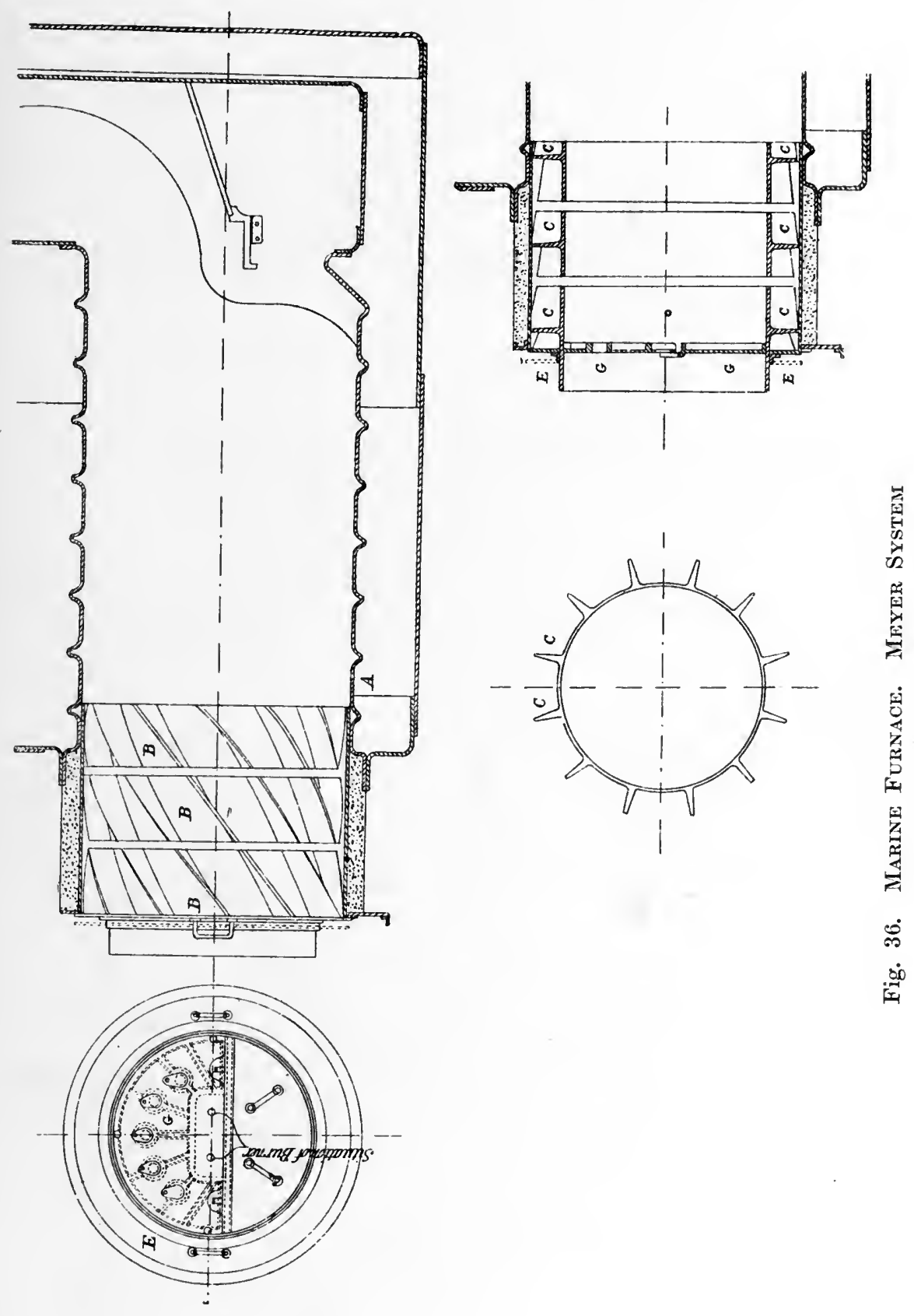




\section{Chapter XVIII}

\section{'THE MIXED SYSTEM OF COAL AND LIQUID FUEL COMBUSTION}

$\mathrm{T}$ HERE is more in the mixed system than mere convenience. The use of solid and liquid fuel in the same furnace together modifies the conditions for each fucl.

For coal the efficiency of combustion is better, and for oil the heat is better utilized.

Combustion on the grate may be imperfect, but the oil atomizer so mixes up the gases from the grate with the air admitted through and above it, that combustion is much improved and the excess of air is used by the oil.

Where the oil is only a fifth of the coal; the coal equivalent of the oil appears enormous.

According to M. Bertin, where 5 kilos. of coal would ordinarily develop each 7,800 calories, they will produce 9,200 calories, a gain of 7,000 calories. The excess of air supplied with the 5 kilos. of coal would be 20 cubic metres, and this would suffice for the added kilogram of oil, and this would produce 11,000 calories with no further air supply. A total of 18,000 calories, compared with the original output of 7,800 calories per kilo. of coal, makes the ratio of oil to coal appear $2 \cdot 31$. Obviously a part of this is due to coal, but it may fairly be credited to the system.

The limit of perfect use of air is found when the oil is one third of the coal, and the ordinary four metres cube of excess air still furnishes the theoretical 11 metres cube for the oil, the apparent equivalence of coal and oil becomes-

$$
\frac{1,400 \times 3+11,000}{7,800}=1.95
$$

These ratios are not perhaps secured in practice, but they serve to point to the possible advantages of the mixed system and what should be aimed at.

With half and half coal and oil the ratio becomes $1 \cdot 77$, a figure that has been approached in certain experiments at Indret. Ratios of 3 and over which have been claimed cannot, as M. Bertin says, be justified on any hypothesis. Nor is the total consumption of the oxygen supplied at all closely approached in general practice.

The proportion of free oxygen to carbonic acid is an indication of the excess of air admitted. The ratio of the air admitted to that used is -

$$
\begin{aligned}
& \frac{\mathrm{CO}_{2}+\mathrm{O}}{\mathrm{CO}_{2}}=1+\frac{\mathrm{O}}{\mathrm{CO}_{2}} \text { per volume and } \\
& \frac{\mathrm{CO}_{2}+\mathrm{O}}{\mathrm{N}}=\frac{20 \cdot 8}{79 \cdot 2} \text { per volume. } \\
& \frac{162}{662}
\end{aligned}
$$




\section{COAL AND LIQUID FUEL COMBUSTION}

'These figures neglect the hydrogen.

With coal burned at the rate of 100 kilos. per metre ${ }^{2}$ of grate, if the oxygen measures 8 per cent., and with 200 kilos., say 5 per cent., the fire is too thin or the draught too great. With 1 or 2 per cent. of carbonic oxide the fire is too thick and the draught poor. Both oxygen and $\mathrm{CO}$ present together indicates bad furnace arrangements.

A test at Indret of the trial boiler of the Jeanne d'Arc with coal alone gave the following results-

\begin{tabular}{|c|c|c|c|c|c|}
\hline \multirow{2}{*}{$\begin{array}{l}\text { Coal per hour } \\
\text { per inctre }{ }^{2} \text { of } \\
\text { grate. }\end{array}$} & \multicolumn{4}{|c|}{ Percentage in volume. } & \multirow{2}{*}{$1+\frac{\mathrm{O}}{\mathrm{CO}_{2}}$} \\
\hline & $\mathrm{CO}_{2}$. & co. & o. & N. & \\
\hline $90 \mathrm{k}$. & 11 & 1 & 6 & 82 & $1 \cdot 54$ \\
\hline 140 & 11 & 1 & 5 & 83 & $1 \cdot 45$ \\
\hline 200 & 13 & 0.5 & 4 & $82 \cdot 5$ & $1 \cdot 30$ \\
\hline
\end{tabular}

The same boiler on the mixed system gave the results below-

\begin{tabular}{|c|c|c|c|c|c|c|c|}
\hline \multicolumn{2}{|c|}{ Per hour per metre ${ }^{2}$ of grate. } & \multirow{2}{*}{ Air Pressure. } & \multicolumn{4}{|c|}{ Percentage of gas. } & \multirow{2}{*}{$1+\frac{\mathrm{O}}{\mathrm{CO}_{2}}$} \\
\hline Carbon. & Petroleum. & & $\mathrm{CO}_{2}$. & $\mathrm{CO}$. & o. & N. & \\
\hline \multirow{3}{*}{$75 \mathrm{k}}$. & $37 \mathrm{k}$. & $10 \mathrm{~mm}$. & 10 & 0 & 8 & 82 & $1 \cdot 80$ \\
\hline & 30 & 10 & 10 & 0 & 8 & 82 & 1.80 \\
\hline & 37 & 10 & 10 & 0 & 8 & 82 & $1 \cdot 80$ \\
\hline \multirow[t]{3}{*}{100} & 50 & 20 & $8 \cdot 5$ & 0 & $9 \cdot 5$ & 82 & $2 \cdot 12$ \\
\hline & 66 & 25 & $8 \cdot 5$ & 0 & $9 \cdot 5$ & 82 & $2 \cdot 12$ \\
\hline & 35 & 25 & 11 & 0 & 7 & 82 & $1 \cdot 64$ \\
\hline \multirow[t]{2}{*}{150} & 55 & 30 & 11 & 0 & 7 & 82 & $1 \cdot 64$ \\
\hline & 75 & 40 & 11 & 0 & 7 & 82 & $1 \cdot 64$ \\
\hline
\end{tabular}

With oil alone Mr. Orde found as below-

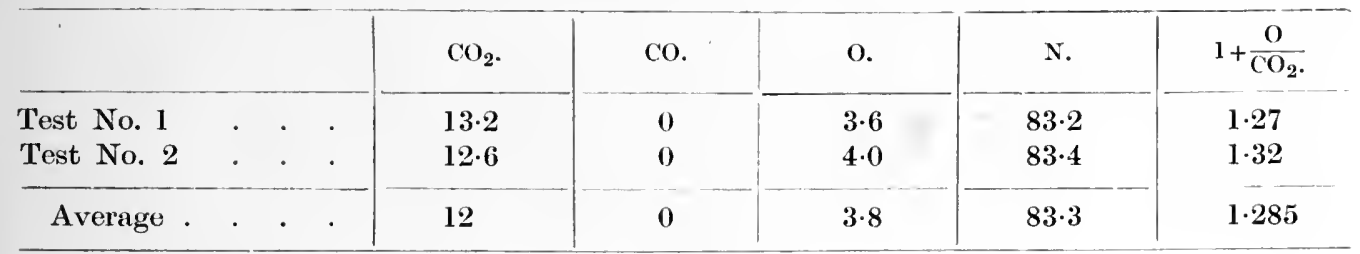

a better result, after all, than the mixed system produced.

Though not yet beyond the experimental stage in the British Navy, the mixed system has been tried and abandoned in the Italian Navy. It has been installed in the German Navy also.

In calculating the apparent effect of mixed fuel, M. Bertin assumes the case of a boiler working 1 hour and a weight of water $=a$ per kilo. of coal ordinarily, $b=$ the water evaporated per kilo. of mixed fuel, $x=$ the evaporation attributed to one kilo. of oil, $\mathrm{C}=$ weight of coal burned per metre ${ }^{2}$ of grate, $\mathrm{D}=$, oil , , , , The vapour produced by C + D of mixcd fuel, assuming $a$ to be as in the ordinary coal fired boiler, will be $\mathrm{C} a+\mathrm{D} x$. 


\section{LIQUID FUEL AND ITS COMBUSTION}

'Then per kilo. of mixed fuel we have

$$
\underset{\mathrm{C}+\mathrm{D}}{\mathrm{C} a+\mathrm{D} x}=b, \text { which gives } x=\frac{(\mathrm{C}+\mathrm{D}) b-\mathrm{C} a}{\mathrm{D}}=b+\frac{\mathrm{C}}{\mathrm{D}}(b-a)
$$

Whence, if $R$ is the ratio of oil to coal, we have

$$
\mathrm{R}=\frac{x}{a}=\frac{b}{a}+\frac{\mathrm{C}}{\mathrm{D}}\left(\frac{b}{a}-1\right)
$$

'Tests in the Furieux made to determine $\mathbf{R}$ gave the following results-

\begin{tabular}{c|c|c|c}
$\frac{\mathrm{I}}{\mathrm{C}}$ & $a$ & $x$ & $\mathrm{R}={ }_{a}^{x}$ \\
\hline 0.00 & 9.05 & - & - \\
0.45 & 9.05 & 11.34 & 1.25 \\
0.64 & 9.05 & 14.2 & 1.56
\end{tabular}

The figure 1.56 was greater than the figure found for oil when used alone, but this was not confirmed by tests at Cherbourg made on a Godard boiler with too forced a draught and badly arranged oil sprays, for the effect $b$ of the mixed fuel was even inferior to that of coal alone, which shows how much the efficiency depends on good arrangement.

The value of $R$ was sought at Indret by $M$. Brillie in a series of tests extending from the end of 1896 to early in 1900, in view of applying mixed firing to boilers of Du Temple Guyot type in the new cruisers.

The atomizers had air induction passages as in the Orde atomizer, fig. 10, but no air heating. The flames kept short and the heat kept well in the furnace, and high values of $R$ were reached as 1.6 for a rate of combustion of 100 kilos. of coal and 50 kilos of oil per metre ${ }^{2}$ of grate. ${ }^{1}$

The tests, however, were too short for exactitude.

Other tests made only upon engine power are, however, available.

Let $c$ be the coal per horse power ordinarily.

$, e \quad, \quad, \quad, \quad, \quad, \quad$ in the mixed system.

, $d$ oil , ,, ,, ,, ,, , ,

Then $d$ takes the place of $c-e$ in the production of one horse power, so that

$$
\mathrm{R}=\stackrel{c-e}{d}
$$

\begin{tabular}{|c|c|c|c|c|c|c|c|c|}
\hline \multirow{3}{*}{$\begin{array}{l}\text { Air pressure } \\
\text { Coal alone }\end{array}$} & \multirow{3}{*}{ h. } & \multicolumn{3}{|c|}{ 1st Series. } & \multicolumn{3}{|c|}{ 2nd Scries. } & \multirow{2}{*}{$\frac{3 \mathrm{rd} \text { Series. }}{50 \mathrm{~mm}}$} \\
\hline & & $15 \mathrm{~mm}$ & $13 \mathrm{~mm}$ & $12 \mathrm{~mm}$ & $25 \mathrm{~mm}$ & $26 \mathrm{mmn}$ & $29 \mathrm{~mm}$ & \\
\hline & & $1,337 \mathrm{k}$ & $1,337 \mathrm{k}$ & $1,337 \mathrm{k}$ & $1,354 \mathrm{k}$ & $1,354 \mathrm{k}$ & $1,354 \mathrm{k}$ & $1,506 \mathrm{k}$ \\
\hline Mixed (Coal & $e$. & 0,979 & 6,914 & 0,581 & 0,713 & 0,721 & 0,652 & 1,219 \\
\hline Petrolm. & $d$. & 0,379 & 0,388 & 0,494 & 0,405 & 0,474 & 0,655 & 0,434 \\
\hline System (Total $\mid e+d$ & & 1,358 & 1,302 & 1,075 & 1,118 & 1,195 & 1,307 & 1,653 \\
\hline Equivalent $\left.=R \cdot=\begin{array}{c}c-e \\
d\end{array}\right\}$ & & 0,94 & 1,09 & 1,53 & 1,58 & 1,33 & 1,07 & 0,66 \\
\hline
\end{tabular}

The following table, a resumé of Navy tests on the locomotive type of boiler or torpedo boat No. 109 at Cherbourg, is of interest-

1 Kilos per metre ${ }^{2} \div-5=$ pounds per square foot nearly. 


\section{COAL AND LIQUID FUEL COMBUSTION}

The interest lies in the falling off at high pressures, the furnace being too short satisfactorily to burn the oil at such rapid movement of the draught.

Where 60 kilos. of oil were used to 80 kilos. of oil with draught but little forced, $R$ was found to be..1.5, and the mixed system took the place of forced draught, with a result equal to the combustion of 170 kilos. of coal only, a result thought very encouraging. Very discordant results were obtained on the Milan, the Surcouf, the Pakin, and the Forbin. On the Milan especially oil proved very unsuitable to the furnaces of the Belleville boiler, as might be anticipated. On the Surcouf, on the contrary, the result of mixed fuel was to reduce total fuel consumption nearly to half that of coal alone.

M. Bertin does not express any final opinion on mixed systems, but claims that where employed it is essential to success that all the details should be simple so as to avoid the danger of error on the part of a little trained personnel, such as the opening or closing of certain valves, always in their power to do. 


\section{Chapter XIX}

\section{RUSSIAN AND AMERICAN LOCOMO'TIVE PRACTICE WITH LIQUID FUEL}

\section{The Baldwin Co.'s System.}

$7 \mathrm{HE}$ Baldwin Locomotive Co. consider that, while opinions upon atomizers differ as to central jet burners such as the Urquhart, the relative position of the oil supply and other details, their own burner is a satisfactory one, and has been applied

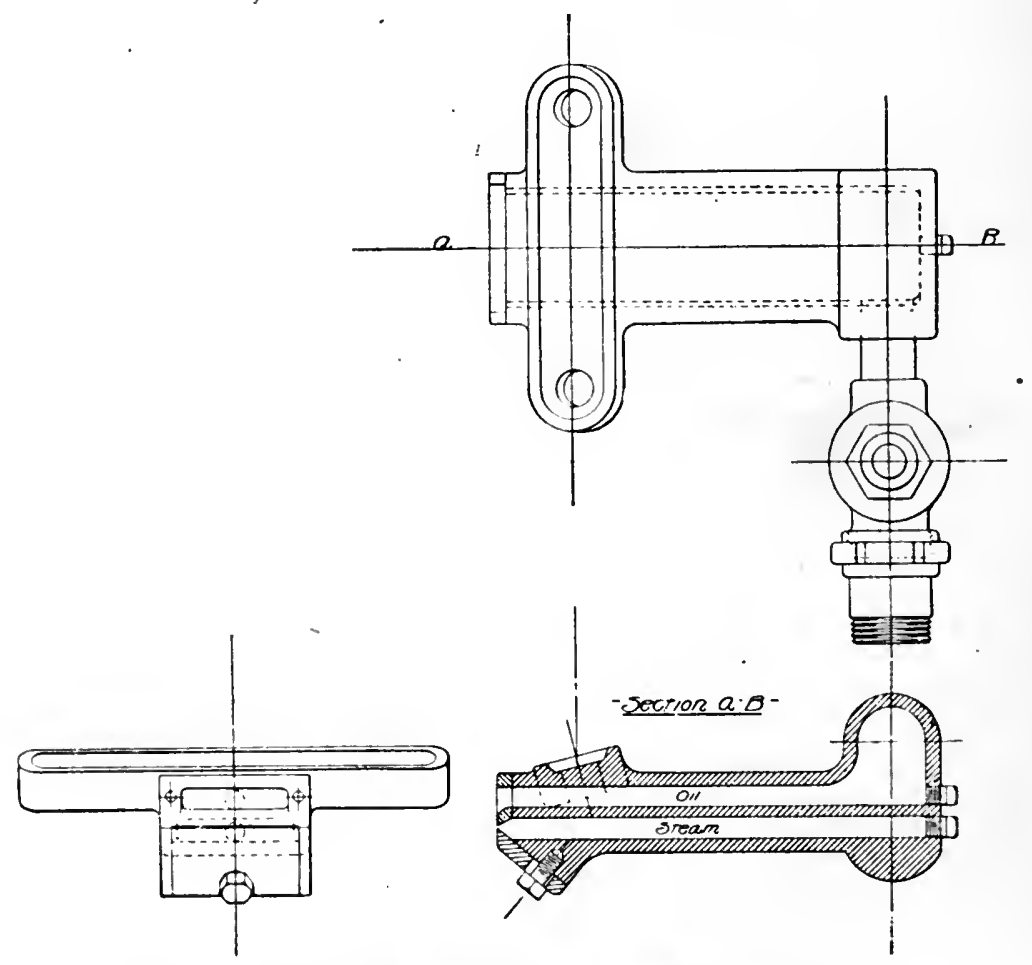

Fig. 37. Atomizer. Baldwin Locomotive Co.

to some 250 locomotives in Russia and the United States. This burner is shown in fig. 37 .

It is rectangular in section with two longitudinal passages, the upper one for oil, 166 


\section{RUSSIAN AND AMERICAN LOCOMOTIVE PRACTICE}

the lower one for steam. The oil is regulated by a plug cock on the feed pipes, the handle of which extends to the cab within easy reach of the fireman.

Steam is admitted to the lower port of the burner through a pipe so connected to the boiler as at all times to insure the introduction of dry steam. The valve controlling the steam is placed in the cab close to the fireman's seat. A free outlet is allowed for the oil at the nose of the burner ; the steam outlet, however, is contracted at this point by an adjustable plate which partially closes the port, and gives a thin wide aperture for the exit of the steam. This arrangement wire-draws the steam and increases its velocity at the point of contact with the oil, giving a better atomizing effect. A permanent adjustment of the plate can be made for each burner after the requirements of service are ascertained. The moving of the plate is not then required except for cleaning purposes. The oil, as it passes through the burner, is heated to a certain extent by the effect of the steam in the lower portion, and flows freely in a thin layer over the orifice. It is here caught by the jet of steam issuing from the lower port, and is completely broken up and atomized at the point of ignition. The oil is carried into the fire-box in the form of vapour, where it is thoroughly mixed up with air and burns freely.

It is computed that one inch of breadth of slit will serve for 100 square inches of cylinder area, so that the breadth of a burner is $B=D^{2} \times \cdot 007854$. As only one burner is used, American fire-boxes being narrow, it is apparently the case that one cylinder is intended to be taken, and not the area of both cylinders. $\mathrm{D}=$ diameter of cylinder. cock.

Large oil-pipes are used so as to deliver a full supply as far as the regulating

To permit of fine adjustment of the eock its orifice is not circular but square, with the diagonals vertical and horizontal as shown in fig. 38 .

The necessary changes to fit an engine to use liquid fuel according to the views of the Baldwin Co. are shown in fig. 39. The atomizer is attached below the mud ring, and the spray is directed upwards into the firebox which is fitted with a brick arch, a liner of fire-brick and a base filling the front half of where the grate usually is placed. A small

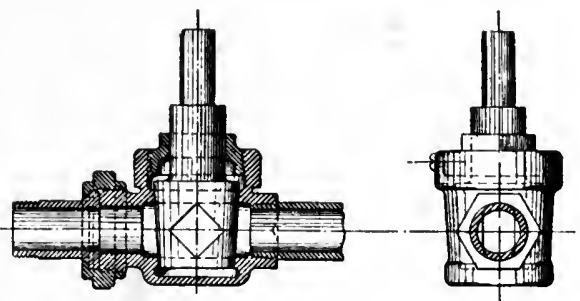

Fig. 38. Oil Regulating Cock. Baldwin Locomotive Co. hearth is also placed to catch any drip from the burner, and from the lower corner of the bridge there is built, to protect each side sheet, a triangular wall of bricks extending with its lower point to the back plate. The side walls form the sides of the fire-brick combustion chamber. The "ash-pan" is retained with its air dampers to admit air below the fires, and the dampers should shut tight. The inner side of the fire-door is lined with a plate of fire-brick.

In the Vanderbilt box, fig. 40, which is simply a corrugated circular furnace, the arrangement of fire-brick is very similar to the above, but the fuel is sprayed parallel to the fire-box bottom liner. The sprayer is inserted through the closing plate of the furnace mouth, which is also brick protected. The arch and bridge wall are kept well behind the back tube plate, and the space forms a further combustion chamber for the flames.

An ash-pan of modified form is employed as shown. It is recommended not 


\section{LIQUID FUEL AND ITS COMBUSTION}

to leave too little space between the arch and the crown sheet; otherwise the flames will be too severely projected upon the crown sheet and generate too severe a local
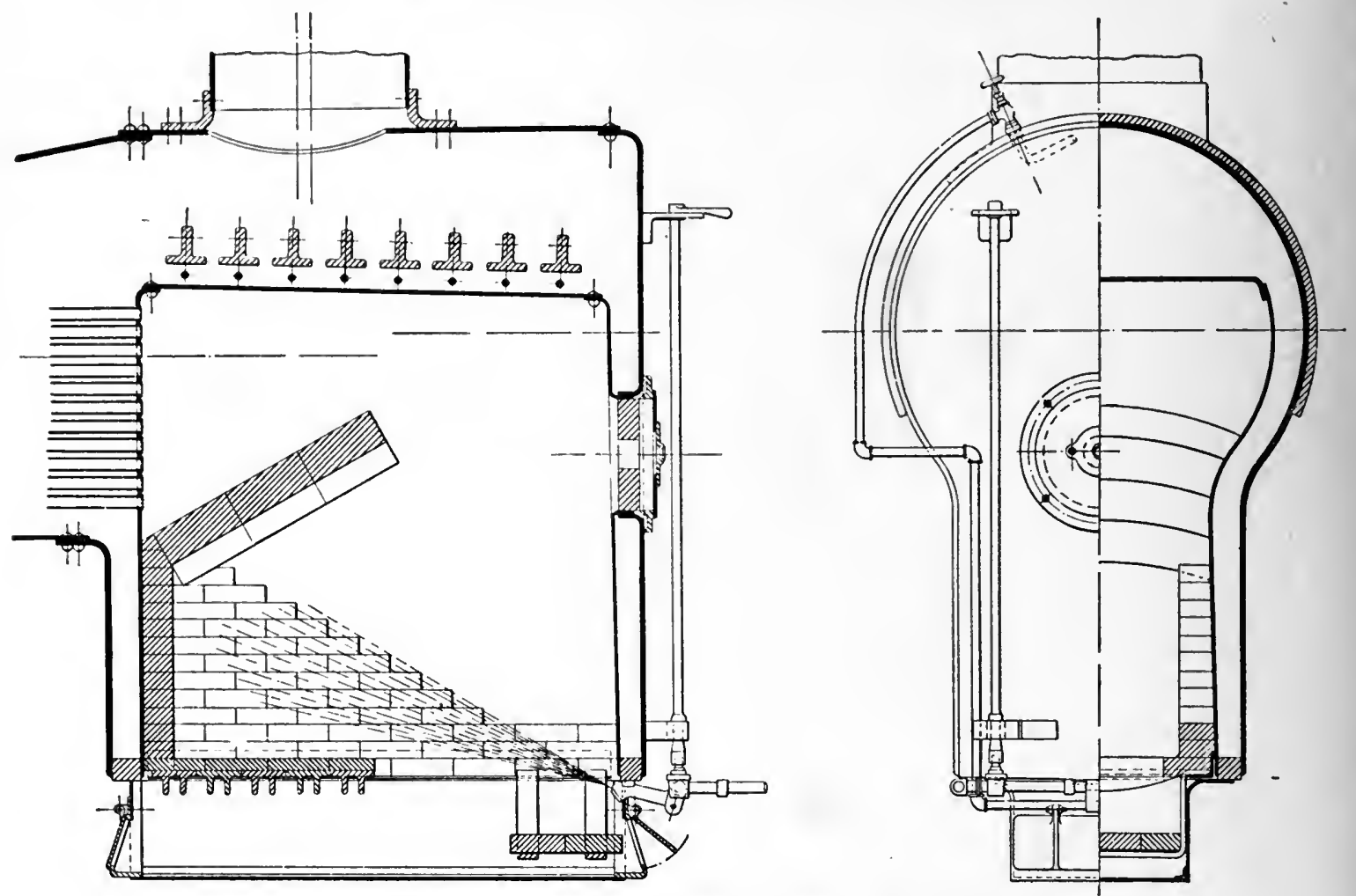

Fig. 39. Locomotive Fire-Box for Liquid Fuel. Baldwin Locomotive Co.
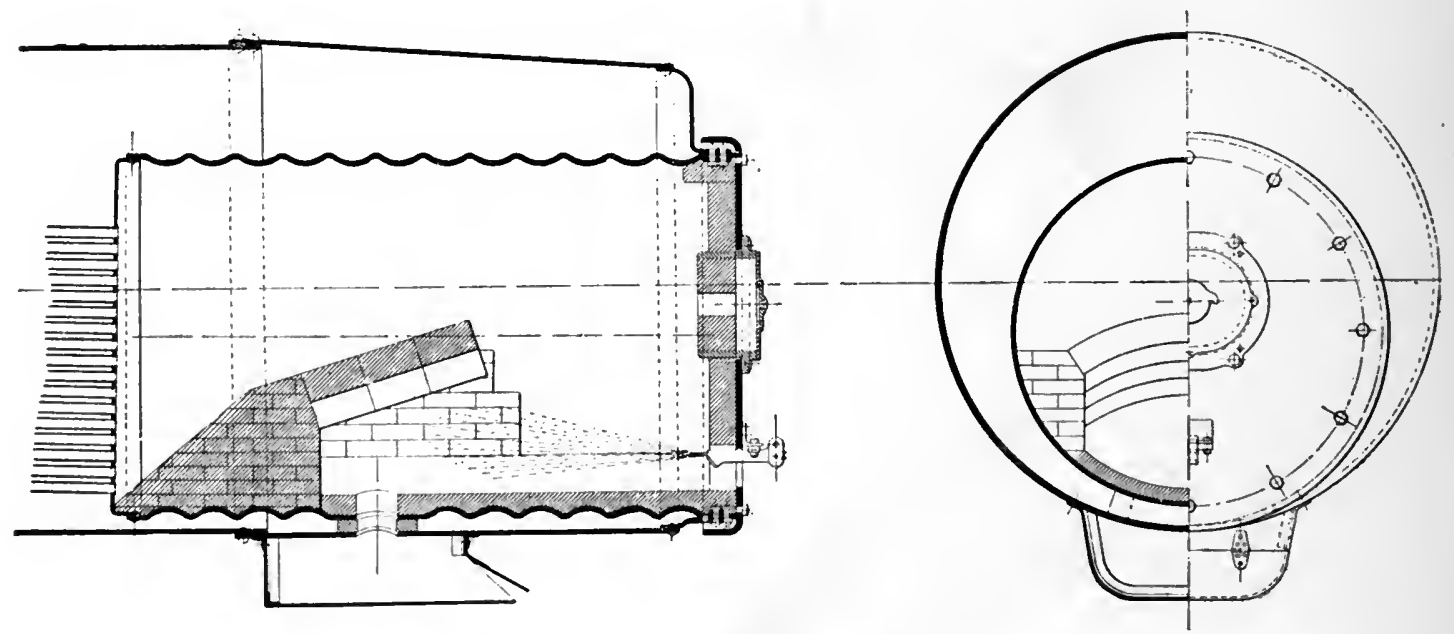

Fig. 40. Vanderbilt Fire-Box for liquid Fuel. Baldwin Locomotive Co.

heat. The weight and volume of oil for a given mileage will be about half that necessary for coal. 


\section{RUSSIAN AND AMERICAN LOCOMOTIVE PRACTICE}

The following information is from the report of the Committee of the American Railway Master Mechanics' Association for 1899-

Fuel oil can be used in almost any form of fire-box, the best location for the burner being just below the mud ring, spraying upward into the fire-box. In some recent experiments with oil of $84^{\circ}$ gravity, $140^{\circ} \mathrm{F}$. flash, and $190^{\circ} \mathrm{F}$. fire test, in which the boiler had 27 square feet grate area and 2,135 square feet of heating surface, 8 per cent. being in the fire-box, it was found that there were about 39 pounds of oil burned per square foot of grate area, about 0.45 pounds per square foot of heating surface per hour, the equivalent evaporation from and at $212^{\circ}$ being about $12 \frac{1}{2}$ pounds of water per pound of oil. It was also computed that there should be about onethird of an inch width of burner for each cubic foot of cylinder volume.

Or volumes of both cylinders in cubic feet $\div 3=$ width of burner in inches.

This was for ordinary locomotives. For compound engines the amount of steam is 10 per cent. and of fuel 20 per cent. less, and in the foregoing formula only the h.p. cylinder volume ought to be considered. Generally the Baldwin Co. accept oil as worth double its weight of worth of coal, a ratio perhaps a trifle high for English practice and coal.

They give a formula for compound locomotives as follows as a guide to an approximate idea of the value of oil fuel as compared with coal.

Cost of coal per ton (of $2,000 \mathrm{lb}$.) + cost of handling (say 50 cents) $\times 10.7 \times 7$.

$$
2,000 \times \text { evaporative power of coal. }
$$

$=$ Price per American gallon at which oil will be the equivalent of coal. To find the pricc per English gallon multiply by 1.2 .

It must be remembered in these computations that the cost of both oil and coal is considered at the place where they are delivered to the engine, and not at the place where they are purchased by the railroad company.

The following gives the weight and volume of crude petroleum based on a specific gravity of 0.91 , which is about the average of the Texas oil, as well as that received from South America.

Weight and Volume of Crude Petroleum

\begin{tabular}{c|c|c|c|c}
\hline Pound. & U.S. Liquid Gal. & Barrel. & Gross Ton. & Impl. Gal. \\
\cline { 2 - 4 } 1 & $\cdot 13158$ & $\cdot 0031328$ & .0004464 & .1096 \\
$7 \cdot 6$ & $1 \cdot 000$ & $\cdot 02381$ & .003393 & $\cdot 83$ \\
$319 \cdot 2$ & $42 \cdot 000$ & $1 \cdot 000$ & $\cdot 1425$ & $35 \cdot 00$ \\
$2,240$. & $294 \cdot 720$ & $7 \cdot 017$ & $1 \cdot 00$ & $245 \cdot 60$ \\
\hline
\end{tabular}

For convenience in obtaining the correct approximate weight of oil, the gravity conversion table No. XXXI may be useful.

In American practice where railroads are so dirty with ash and cinders thrown from the locomotives by the powerful blast employed, the use of oil should give an advantage to any line adopting it that cannot be so securely counted on in Great Britain, where ash throwing is less prevalent.

The use of oil also puts a stop to the choking of the tubes of the boiler and permits, if desired, smaller tubes to be employed, which are now inadmissible on account of liability to choke.

Tubes of one inch diameter might be used if enough could be got in to give the requisite area. 


\section{LIQUID FUEL AND ITS COMBUSTION}

The economy of oil is not merely a question of fuel economy.

Table No. XV gives the economy of oil at its relative value compared with coal on both the the fuel account and all ascertained economies, the second value being based on 1 pound of coal being worth 2 of coal in place of $1 \frac{3}{4}$, as on the mere fuel account. The extra economies include repairs on locomotives and ash handling.

Dr. Dudley's formula for relative price is-

$$
\begin{aligned}
& \mathrm{P}=\text { price of oil per barrel. } \\
& \mathrm{W}=\text { weight per gallon in pounds. } \\
& \frac{2,000 \times \mathrm{P}}{\mathrm{W} \times \mathrm{N} \times \mathrm{R}}=\mathrm{C} ; \text { where } \begin{array}{l}
\mathrm{N}=\text { gallons per barrel. } \\
\mathrm{R}=\text { ratio of oil to coal }=13 \text { or } 2 \text {. according to condition }
\end{array} \\
& \text { taken. } \\
& \mathrm{C}=\text { price of coal per ton of } 2000 \text {. }
\end{aligned}
$$

For tons of 2,240 lbs use this number in the numerator in place of 2,000. The weight $W$ multiplied by $N$ will be the same in either American or English gallons, and the barrel is always the same, so that only the pounds per ton need be changed, the priee of coal and oil of course being given in the same equivalents, either dollars or shillings.

$$
\text { Hence } \mathrm{P}=\frac{\mathrm{W} \times \mathrm{N} \times \mathrm{R} \times \mathrm{C}}{2,000 \text { (or } 2,240 \text { for long tons })}
$$

The Baldwin Co. do not recommend crude oil for use in locomotive work for three reasons, namely, it is more dangerous, it has an exceedingly unpleasant odour, and it is not so economical. As is well known, crude oil contains more or less volatile matter which vaporizes quite readily. With the necessary use of lanterns and open lights round about locomotives, there would be more or less danger of explosions. Furthermore, in the case of a wreck, if the oil tank was ruptured, it would be almost impossible to prevent a fire. As to the odour of the crude oil, it would certainly be extremely unpleasant to ride behind a locomotive fed with Lima crude oil. The reason why crude oil is not so economical as reduced oil is because oil is usually sold by volume, and a gallon of erude oil, instead of weighing $7 \cdot 3$ pounds, weighs from say $6 \cdot 25$ to $\mathbf{6} \cdot 5$ pounds, and, as the heat is directly in proportion to the weight of combustible, a barrel of crude oil will not give so much heat as a barrel of reduced oil. The oil which is now used on the Grazi-Tsaritzin Railway, and is believed to be quite safe to use, is an oil not below $300^{\circ} \mathrm{F}$. fire-test. It is fair to add that crude oil can be used on stationary boilers where it is kept in tanks and brought to the boilers in pipes.

In regard to these points the arguments appear sound, in view of the disastrous American experiences of burning railway wrecks, and the one English experience at Abergele; but all crude oils are not so unpleasant as the Lima oil referred to, and the unpleasant odour should not live through the furnace. Still the fire risk of crude oil, with its volatile constituents left in, is a danger to be avoided.

The formulie and tables, which result from the comparison of the value of coal and oil in cash go far towards explaining why petroleum has not been used to a much greater extent as a means of heat production. In America at the present time, says Dr. Dudley (1888), it is really more expensive to obtain the same amount of heat from oil than it is from coal.

In experiments on the Pennsylvania Railroad, it was found with oil at 30 cents per barrel, that it cost nearly 50 per cent. more to take the same train of cars 100 miles by means of oil than by means of coal. 


\section{RUSSIAN AND AMERICAN LOCOMOTIVE PRACTICE}

The total coal consumption of the Pennsylvania Railroad, including all its ramifications, is about 8,000 tons per day. If, now, this was changed from coal to oil, the Pennsylvania Railroad would use over 26,000 barrels of oil per day, and this 26,000 barrels is over one-third and at present nearly one-half, of the daily oil production of the United States, so that the lack of supply will, for a long time to come, prevent the use of oil to anything but a limited extent. But in Russia the residuum is 75 per cent. of the crude oil, whereas in America it forms but 25 per cent., and the Russian fire test is $320^{\circ}$ to $240^{\circ} \mathrm{F}$. There was at the time Dr. Dudley wrote (1888) one Russian well which flowed more per day than the total United States production, which was little above 50,000 barrels per day. But in 1900 the yield was over 200,000 barrels, and it has been increasing ever since, and Dr. Dudley's figures must be discounted to-day. From 1859 to 1900 -practically 40 yearsAmerican output has totalled 1,007 million barrels nearly, and the total Russian production since 1880 , or 23 years since, when the amount produced became of commercial importance, has been 676 million barrels.

In 1898 the Los Angeles Terminal Railway report that oil at 75 cents per barrel cost $11 \cdot 1$ per mile as against 28.3 cents the average cost of coal.

\section{The Urquhart System.}

To Mr. Urquhart, of Dalny, Scotland, the former Locomotive Engineer of the Grazi-Tsaritzin Railway of Russia, is due the first notable success in liquid fuel combustion. ${ }^{1}$

Mr. Urquhart brought the system to the notice of engineers in a paper read at Cardiff in 1884.

According to this paper, the percentage of astatki in Russian oil is 70 to 75 per cent., while Pennsylvania oil contains but 25 to 30 per cent., the two products being the complement of each other. It is known from the chemistry of the oils that this fact is quite consistent with approximately equal proportions of carbon and hydrogen, and Table XVI is given to illustrate this. The following is an abstract of Mr. Urquhart's paper-

"Comparing naphtha refuse and anthracite, the former has a theoretical evaporative power of 16.2 pounds of water per pound of fuel, and the latter of 12.2 pounds at a pressure of $8 \mathrm{~atm}$. or 120 pounds per square inch ; hence petroleum has, weight for weight, 33 per cent. higher evaporative value than anthracite. Now in locomotive practice a mean evaporation of from 7 pounds to $7 \frac{1}{2}$ pounds of water per pound of anthracite is generally obtained, thus giving about 60 per cent. of efficiency, while 40 per cent. of the heating power is lost. But with petroleum an evaporation of $12 \cdot 25$ pounds is practically obtained, giving

$$
\frac{12 \cdot 25}{16 \cdot 2}=75 \text { per cent. efficiency. }
$$

Thus in the first place petroleum is theoretically 33 per cent. superior to anthracite in evaporative power; and secondly, its useful effect is 25 per cent. greater, being 75 per cent. instead of 60 per cent. Weight for weight, the practical evaporative value of petroleum is at least from

$\frac{12 \cdot 25-7 \cdot 50}{7 \cdot 50}=63$ per cent. to $\frac{12 \cdot 25-7.00}{7 \cdot 00}=75$ per cent. higher than that of anthracite.

1 Proceedings of the Institute of Mechanical Engineers, 1884. 


\section{LIQUID FUEL AND ITS COMBUSTION}

\section{Spray Injector.}

Steam, not superheated, being the most convenient for injecting the spray of liquid fuel into the furnace, it remains to be proved how far superheated steam or compressed air is really superior to ordinary saturated steam, taken from the highest point inside the boiler, by a special internal pipe. In using several systems of spray injectors for locomotives, he invariably noticed the impossibility of preventing leakage of tubes, accumulation and inequality of heating of the firebox.

The work of a locomotive is very different from that of a marine or stationary boiler, owing to the frequent changes of gradient on the line, and the stoppages at stations, which render firing with petroleum very difficult ; and were it not for properly arranged brickwork inside the fire-box, the spray jet alone would be quite inadequate. Hitherto the efforts of engineers have been mainly directed towards arriving at the kest kind of "spray injector" for so minutely sub-dividing a jet of petroleum into a fine spray, by the aid of steam or compressed air, as to render it easy of ignition. For this object nearly all the known spray injectors have very long and narrow orifices for petroleum as well as for steam ; the width of the orifice does not exceed from $\frac{1}{2} \mathrm{~mm}$. to $2 \mathrm{~mm}$., or $0.02 \mathrm{in}$. to $0.08 \mathrm{in}$., and in many instances is capable of adjustment.

With such narrow orifices it is clear that any small solid particles which may find their way into the spray injector along with the petroleum will foul the nozzle and check the fire. Hence in many of the steamboats on the Caspian Sea, although a single spray injector suffices for one furnace, two are used, in order that when one gets fouled the other may still work; but of course, the fouled orifices require incessant cleaning out.

Locomotives.-In arranging a locomotive for burning petroleum, several details require to be added in order to render the application convenient. For getting up steam, to begin with, a gas pipe of $1 \mathrm{in}$. internal diameter is fixed along the outside of the boiler, and at about the middle of its length it is fitted with a three way cock having a screw nipple and cap. The front end of the longitudinal pipe is connected to the blower in the chimney, and the back end is attached to the spray injector. Then by connecting to the nipple a pipe from a shunting locomotive under steam, the spray jet is immediately started by the borrowed steam, by which at the same time a draught is also maintained in the chimney. In a fully equipped engineshed the borrowed steam would be obtained from a fixed boiler conveniently placed and specially arranged for the purpose of raising steam. In practice steam can be raised from cold water to $3 \mathrm{~atm}$. pressure $=45$ pounds per square inch, in twenty minutes. The use of auxiliary steam is then dispensed with, and the spray jet is then worked by steam from its own boiler; a pressure of $8 \mathrm{~atm} .=120$ pounds is then obtained in from 50 to 55 minutes from the time the spray jet was first started. In daily practice, when it is only necessary to raise steam in boilers already full of hot water, the full pressure of 7 to $8 \mathrm{~atm}$. is obtained in twenty to twenty-five minutes. While experimenting with liquid fuel for locomotives, a separate tank was placed on the tender for carrying the petroleum, having a capacity of about 3 tons. But a separate tank on the tender, even though fixed in place, would be a source of danger from the possibility of its moving forwards in case of collision. It was therefore decided, as soon as petroleum firing was permanently introduced, to 


\section{RUSSIAN AND AMERICAN LOCOMOTIVE PRACTICE}

place the tank for fuel in the tender between the two side compartments of the water tank utilizing the original coal space. For a six-wheeled locomotive the capacity of the tank is $3 \frac{1}{2}$ tons of oil, a quantity sufficient for 250 miles, with a train of 480 tons gross exclusive of engine and tender. In charging the tender tank with petroleum, it is of great importance to have strainers of wire cloth in the manhole of two different meshes, the outer one having openings of, say, $\frac{1}{4}$ in., the inner say of $\frac{1}{8}$ in. [ In later English practice the strainer is much finer than this (Author).] These strainers are occasionally taken out and cleaned. If care be taken to prevent any solid particles from entering with the petroleum, no fouling of the spray injector is likely to occur, and even if an obstruction should arise, the obstacle, being of small size, can easily be blown through by screwing back the steam cone in the spray injector far enough to let the solid particles pass and be blown out into the fire-box by steam. This expedient is easily resorted to even when running; and no more inconvenience arises than an extra puff of dense smoke for a moment, in consequence of the admission of too much fuel. Besides the two strainers in the manhole of the petroleum tank on the tender, there should be another strainer at the outlet valve inside the tank, having a mesh of $\frac{1}{8}$ in. holes.

In lighting up, certain precise rules must be followed, in order to prevent explosion of any gas accumulated in the fire-box. Explosions often take place through negligence ; but they amount simply to a puff of gas, driving out smoke through the ash-pan dampers, without any disagreeably loud report. This is prevented as follows. First clear the spray nozzle of water by letting a small quantity of steam blow through, with the ash-pan doors open; at the same time start the blower in the chimney for a few seconds, and any gas will immediately be drawn up the chimney. Next, place on the bottom of the combustion chamber a piece of cotton waste or shavings, saturated with petroleum and burning with a flame. Then open first the steam valve of the spray injector, and next the petroleum valve gently, the first spray of oil coming on the flaming waste ignites without any explosion whatever, after which the fuel can be increased at pleasure. By looking at the top of the chimney, the supply of petroleum can be regulated by observing the smoke. The general rule is to allow a light blue smoke to escape, showing that neither too much air is being admitted nor too little. The combustion is under the control of the driver, and the regulation can be so effected as to prevent smoke altogether. While running it is indispensable that the driver and fireman should act together, the latter having at his side of the engine the four handles for regulating the fire, namely, the steam wheel and the petroleum wheel for the spray injector, and the two ash-pan door handles in which there are notches for regulating the air admission. Each alteration in the position of the reversing lever or screw, as well as in the degree of opening of the steam regulator or the blast pipe, requires a corresponding alteration of the fire. Generally the driver passes the word when he intends shutting off steam, so that the alteration in the firing can be effected before the steam is actually shut off ; and in this way the regulation of the fire and that of the steam are virtually done together. This care is necessary to prevent smoke, which is nothing less than a waste of fuel. When, for instance, a train arrives at the top of a bank which it has to go down with the brakes on, exactly at the moment of the driver shutting off steam and shifting the reversing lever into full forward gear the petroleum and the steam are shut off from the spray injector, the ash-pan doors are closed, and if the incline be a long one, the revolving iron damper over the chimney top is moved into position, closing the chimney, though not hermetically. The 


\section{LIQUID FUEL AND ITS COMBUSTION}

accumulated heat is thereby retained in the fire-box ; and the steam even rises in pressure, from the action of the accumulated heat alone. As soon as the train

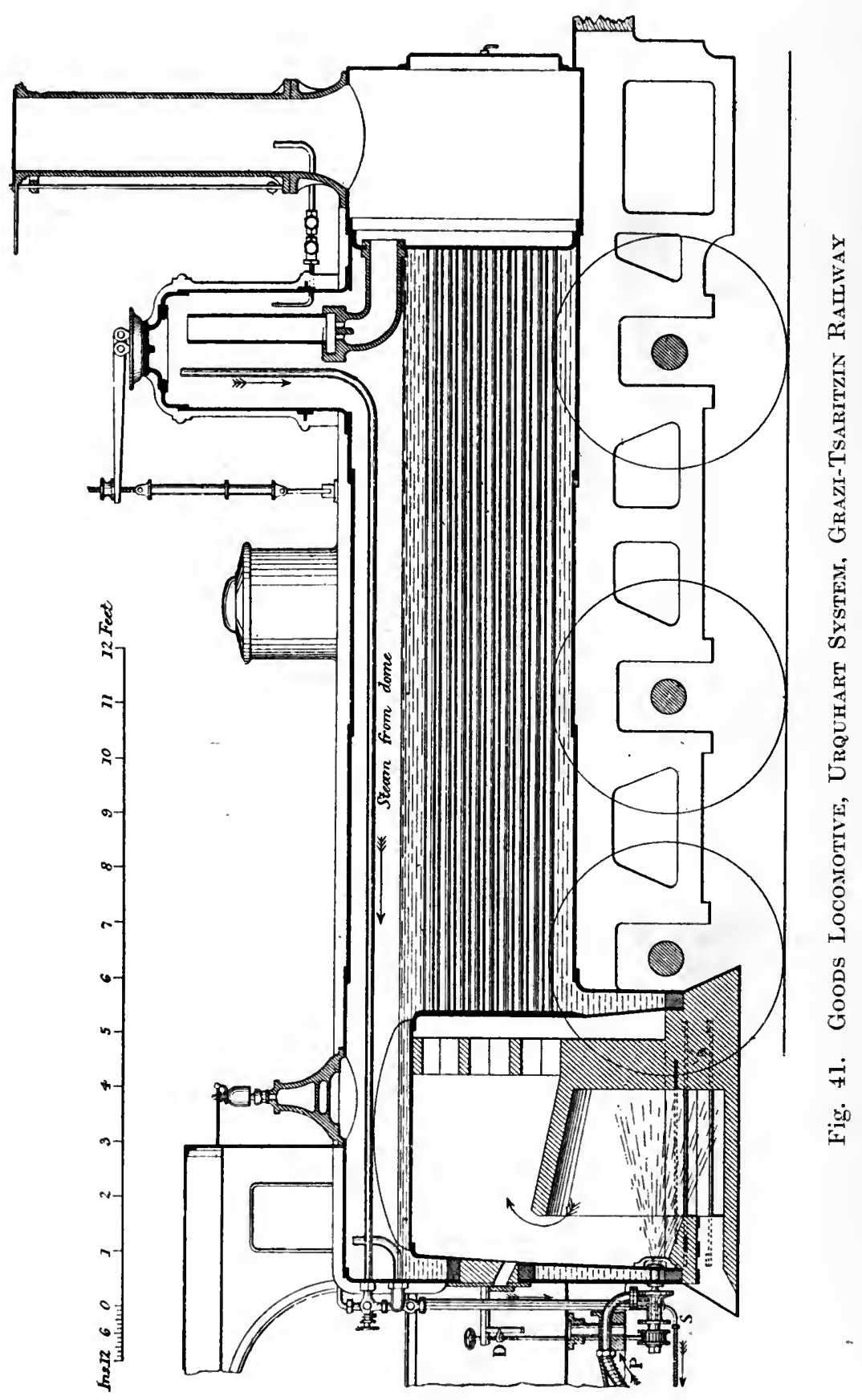

reaches the bottom of the incline and steam is again required, the first thing done is to uncover the chimney top ; then the steam is turned on to the spray injector, 


\section{RUSSIAN AND AMERICAN LOCOMOTIVE PRACTICE}

and next a small quantity of petrolcum is admitted, but without opening the ashpan doors, a small fire bcing rendered possible by the entrance of air around the

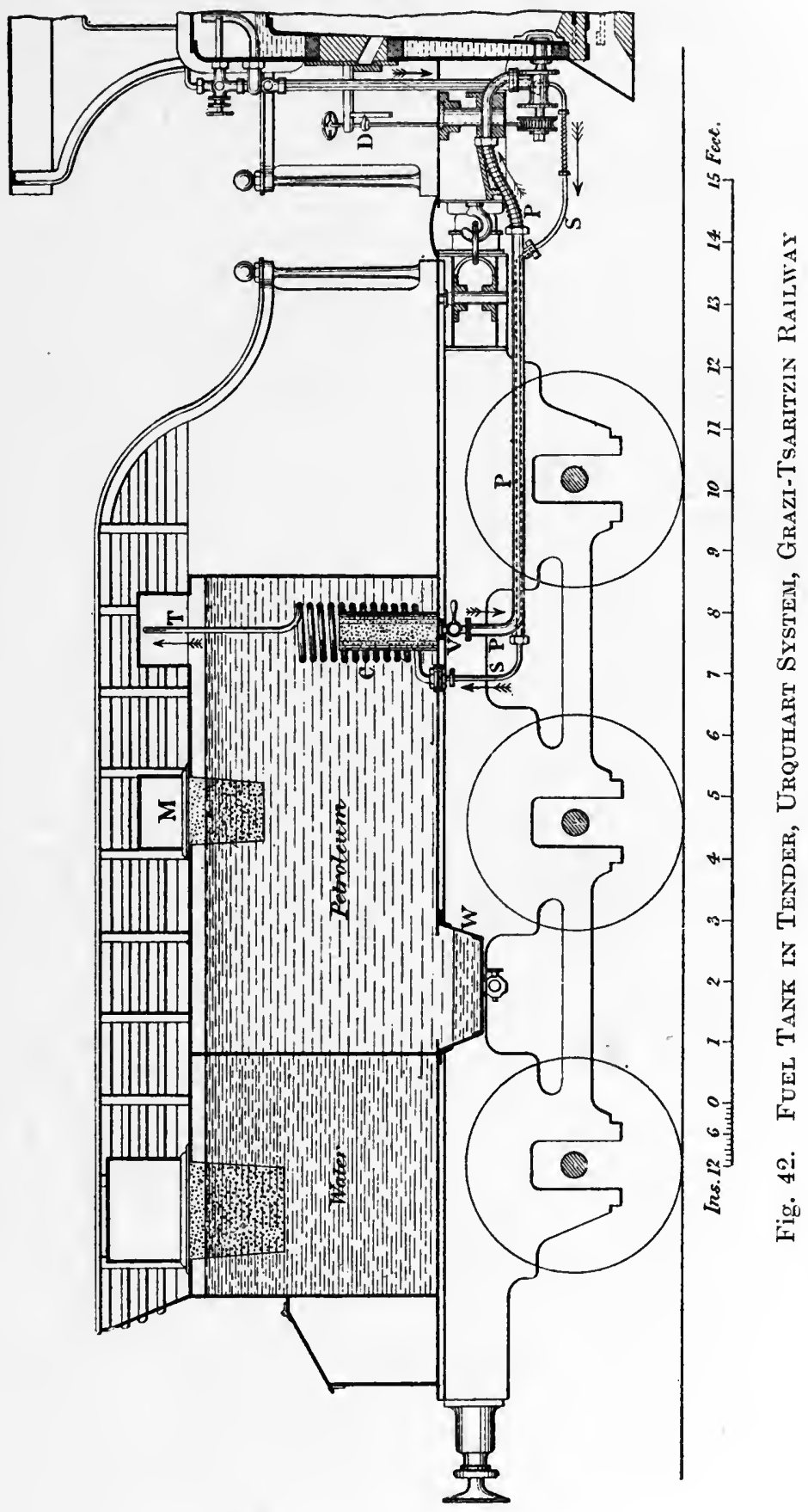

spray injector, as well as by possible leakage past the ash-pan doors. The spray, immediately on coming in contact with the hot chamber, ignites without any audible 


\section{LIQUID FUEL AND ITS COMBUSTION}

explosion; and the ash-pan doors are finally opened, when considerable power is required, or when the air otherwise admitted is not sufficient to support complete combustion. By looking at the fire through the sight hole it can always be seen at night whether the fire is white or dusky ; in fact, with altogether inexperienced men it was found that after a few trips they could become quite expert in firing with petroleum. The better men contrive to burn less fuel than others, simply by greater care in attending to all the points essential to success.

As might be expected, several points have arisen which must be dealt with in order to ensure success. For instance, the distance ring between the plates around the firing door is apt to leak, in consequence of the intense heat driven against it and the absence of water circulation; it is therefore either protected by having the brick arch built up against it, or, better still, it is taken out altogether when the engines are in for repairs, and a flanged joint is substituted, similar to that used in the engines of the London and North Western Railway. This arrangement gives better results, and occasions no trouble whatever."

Table XVII shows the comparative results from different fuels.

The fire-box arrangement of the goods locomotive is shown in fig. 41. The sprayer points downwards upon the hearth which is built in the ash-pan, and continuous with the bridge and arch. A block of brickwork is placed under the sprayer and below that is a passage for air. The bridge is continued up to the crown of the box, but is perforated, and the whole of the front tube plate is exposed to heat. The fire-box surface is $82 \mathrm{sq}$. ft. Total heating surface, 1,248 sq. ft. "Grate" area, 17 sq. ft. Weight, 36 tons in running order. Pressure, 120 to 135 pounds. 151 tubes $13 \mathrm{ft} .10 \mathrm{in}$. long, $\times 2$ in. outside diameter.

Fig. 42 shows the petroleum tank in the tender, the heating coil $\mathrm{C}$ surrounding the filter whence the oil is drawn through a cock $V$ and pipe $P$ to the sprayer. Steam goes by way of the pipe $S$ and escapes at $T$. W is the collector for water.

Fig. 43 shows another furnace arrangement, in which the brickwork of the firebox sides is made cellular, and air is admitted also below the sides by lateral openings $\mathrm{K}$ with regulating dampers. The fire-doors are quite blocked, and only a sight hole left at $\mathrm{H}$.

A later design is that of fig. 44. This includes a lined ash-pan, bridge and overarch, with a passage through it for air admitted by the forward ash-pan damper. Lateral arches are also provided in order that the side sheets of the fire-box may be exposed to the heated gases. No part of the fire-box is in fact actually in touch with the fire-brick, yet the burning oil is completely enclosed with a brick oven. As very usual in Continental practice, the engines had the closing cap to the chimney top. This is used to retain heat in the fire-box at times of standing, and should be a most effectual damper. With liquid fucl employed without solid fuel, the closing of the chimney must be very efficient in retaining the heat of the brickwork, and this damper is used when running down hill, and on again turning the oil spray into the furnace it is at once ignited by the hot brickwork. It will be noticed that there is a pointer and scale on the spindle of the regulating valve $D$. This enables the oil to be regulated by night. The Author has noticed on the Great Eastern Railway, however, that even when apparently quite dark, the chimney top can be seen quite sufficiently to judge of smoke.

The form of injector used is shown in fig. 45. It consists of a central steam jet, an annular passage for oil and an outer annulus for air. The steam jet is regulated by screwing to and fro the steam cone by a worm and wheel on the regulating handle 

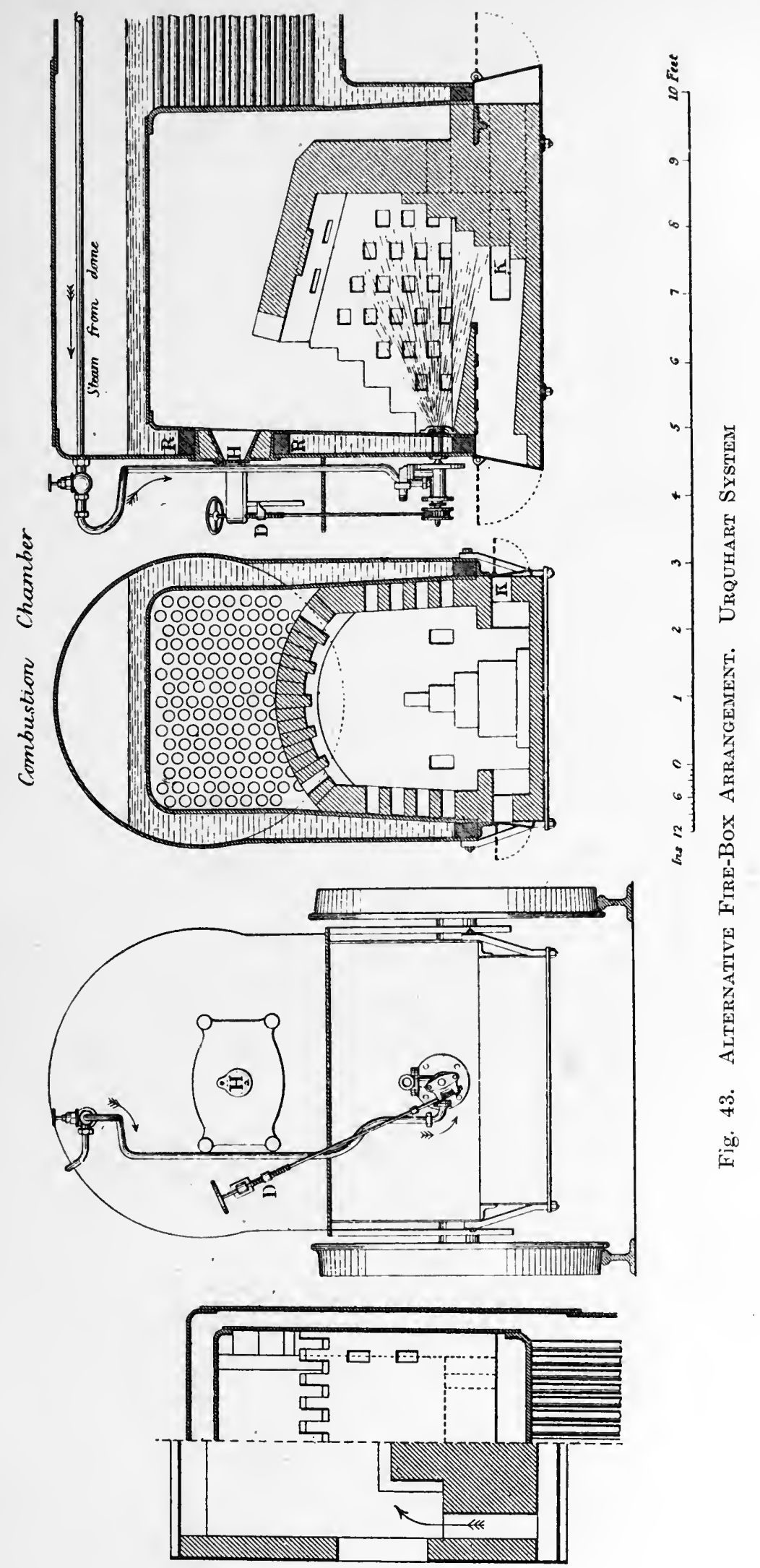


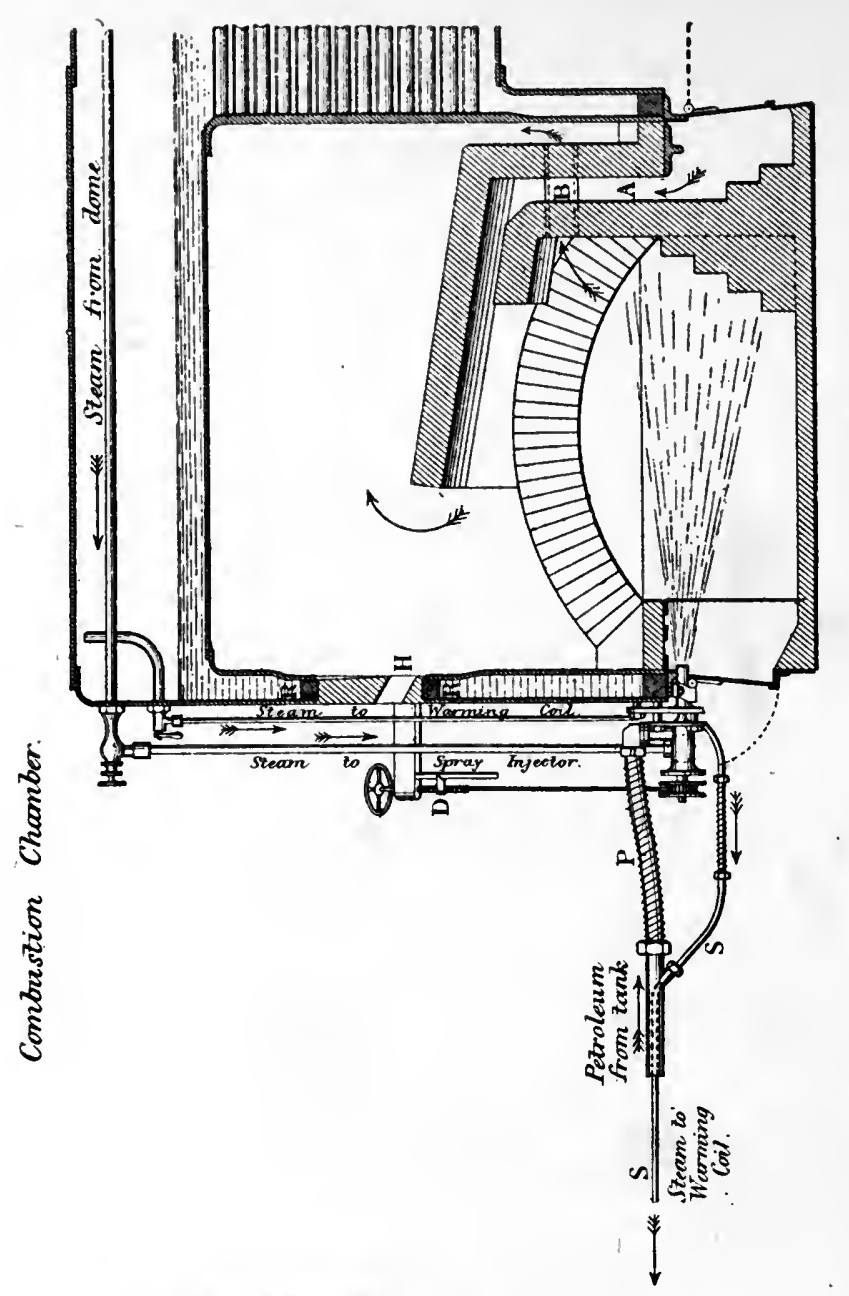

-7.
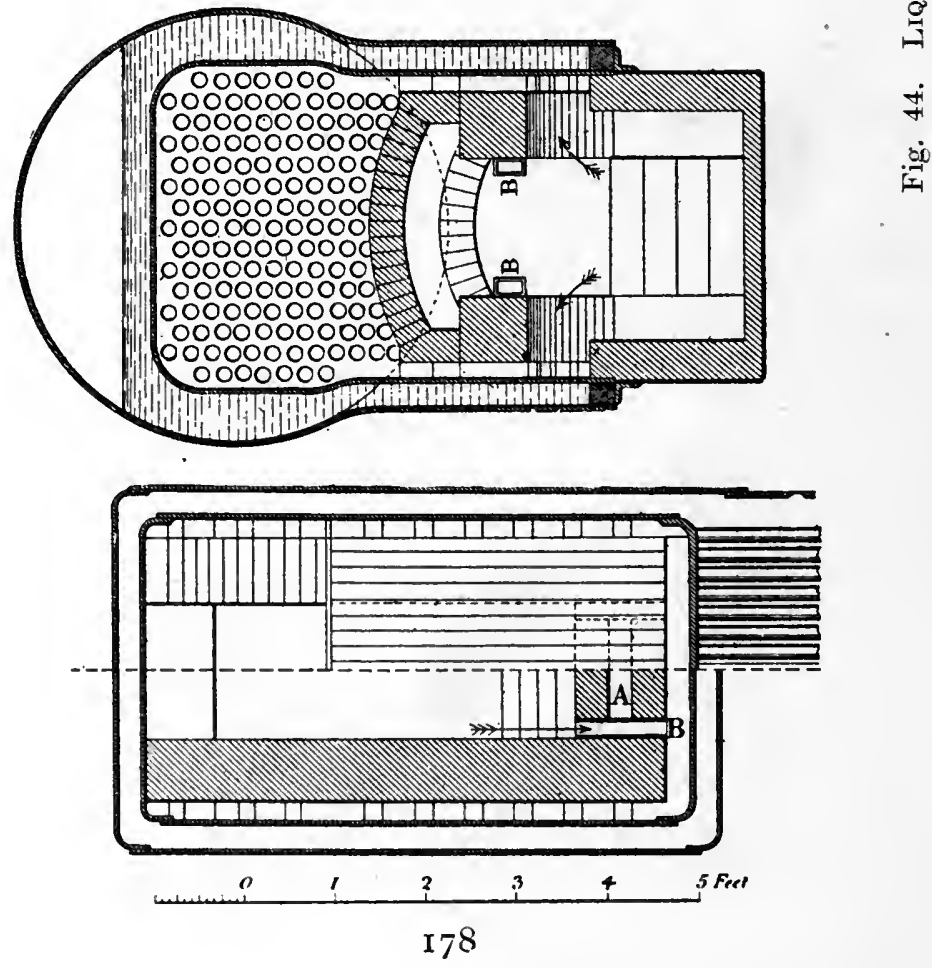


\section{RUSSIAN AND AMERICAN LOCOMOTIVE PRACTICE}

and spindle. The steam cone can readily be removed for clearing purposes, or the back plug can be taken out while the sprayer is at work, with little delay, a wire being introduced to remove any possible obstruction that the steam will not discharge.

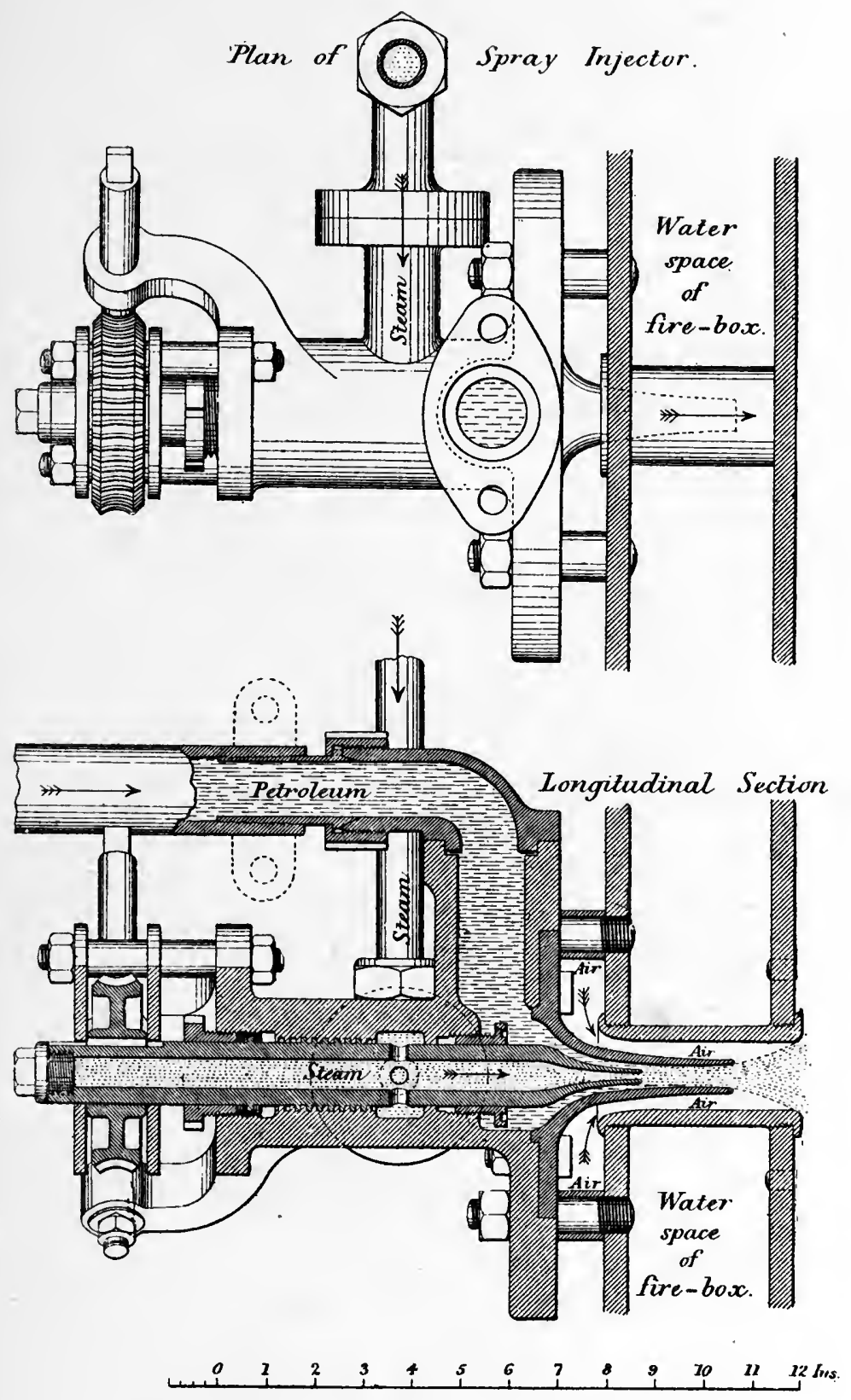

Fig. 45. Atomizer. Urquhart's

In Table XVIII will be found the results of a series of seventeen running tests showing a mean of $39 \cdot 15$ pounds of oil per mile during very cold weather, and it is to be noted in this connexion that when the oil is shut off, cold air must be also shut out of the fire-box, or waste of fuel will ensue. 


\section{LIQUID FUEL AND ITS COMBUSTION}

Table XIX of comparative results with various fuels, under similar conditions, affords a useful series of figures showing an eeonomy of 41 per cent. for oil over anthracite in weight and 55 per cent. in cost, and a still greater economy over bituminous coal of 49 and 61 respeetively.

The summer trials of oil are given in Table XX, and show only 32 pounds per train mile and a fuel efficieney of 70 per eent., and in Table XXI are given comparisons with other fuels.

Tables XXII and XXIII give comparisons of passenger and goods engines, showing economies of 45 and 57 per cent. over anthracite and bituminous coal, figures ehanged to 57 and 67 in an engine arranged to warm the air slightly, and Mr. Urquhart thinks the air ought to be heated, and this is well established as good practice.

The fuel eonsumption of all kinds appears high, but this is attributable to long

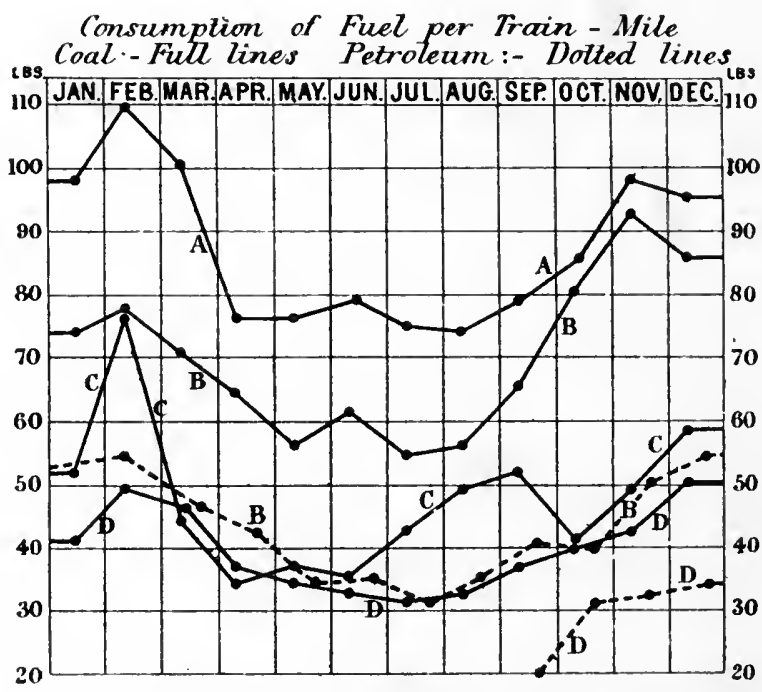

$$
\begin{aligned}
& \text { A Giods Engme, } 8 \text { wheels coupled, Goods Train }
\end{aligned}
$$

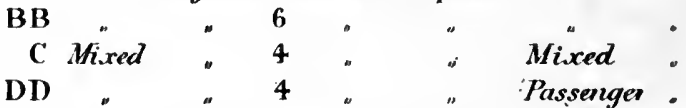

Fig. 46. Locomotive Performances with Coal and Otl Fuel. Urquhart's Systen, Grazi-'Tsaritzin Railway

waiting on a single line and to the weight of trains, often as mueh as 720 tons, and the exposed country, with strong side winds.

Table XXIV of costs of alterations will be useful, as will also Table XXV of fuei and repairs, while Tables XXVI and XXVII give useful information on the basis of truek axle miles run.

Considerable space has been given to this system and to the figures and draw. ings, beeause though now old and dating back nearly 20 years, Mr. Urquhart had the eorrect principles of combustion fully before him, and laid out his arrangements with a perfection that cannot be much improved upon to-day. He saw clearly what was necessary, and this may be summed up in the words, Atomizing, Air and Temperature. Hence the success he attained, and the correctness of his arrangements and conclusions. 


\section{RUSSIAN AND AMERICAN LOCOMOTIVE PRACTICE}

In fig. 46 are given a few eurves showing the consumption of eoal and of petroleum, and in Table XXVIII some useful data on speeifie gravity.
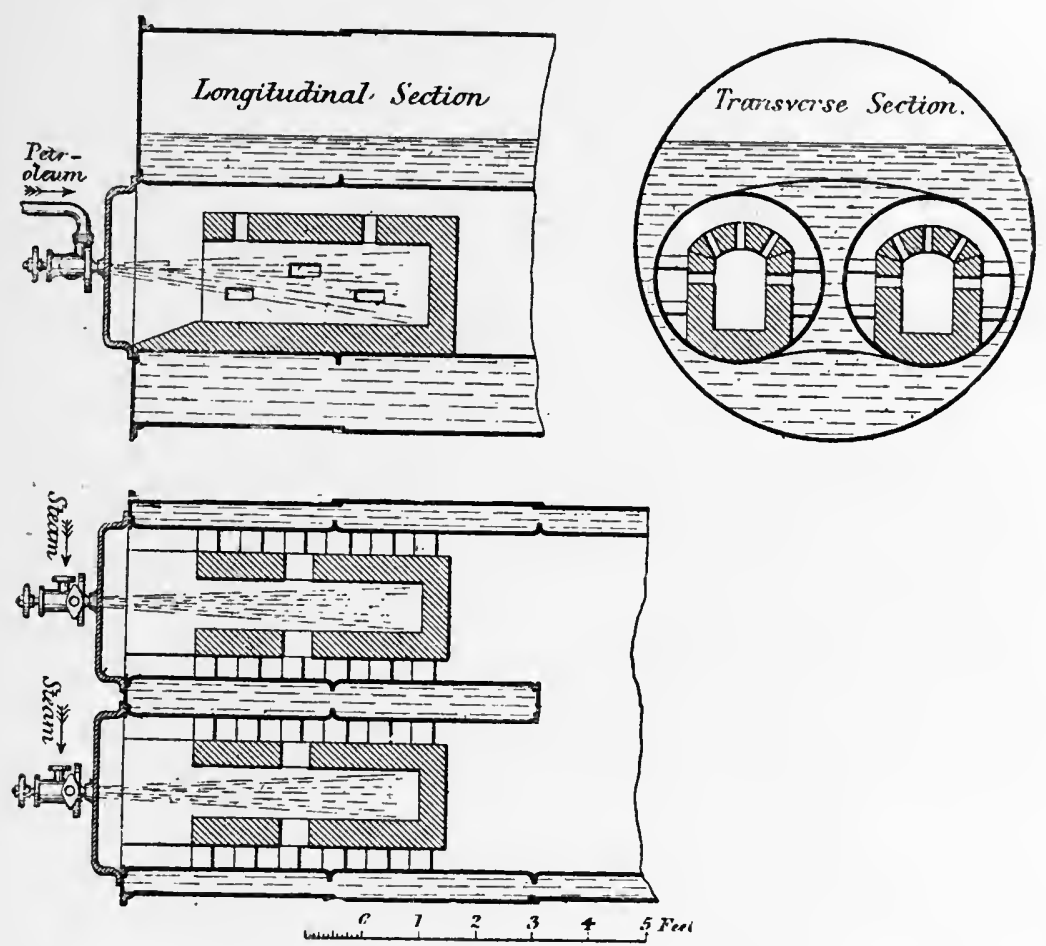

Fig. 45a. Liquid Fuel Furnaces for Two-flue Boiler. Urquhart's System

Fig 45a shows the system adopted by Mr. Urquhart for boilers of Laneashire or Cornish type, the essential brick chamber being fully present. 


\section{Chapter XX}

\section{AMERICAN STATIONARY PRACTICE WITH LIQUID FUEL}

\section{"The Billow System,"}

$\mathrm{T}$ HE fuel oil appliances of the National Supply Company of Chicago consist of pumps and atomizers.

The first installation of fuel oil apparatus made by this Company was in 1886, since which time they claim to have furnished at least 80 per cent. of all the fuel oil equipment in the United States, to have sold more than twelve thousand oil burners to users, and to have designed, installed, and worked the fuel oil plant at the World's Columbian Exposition. This boiler plant consisted of fifty-five water tube boilers, of 25,000 h.p., and the fuel plant required twelve storage tanks, and $5 \cdot 69$ miles of pipe. The oil plant worked without one moment's interruption.

All atomizers are actuated in one or a combination of the following ways-by steam, by air supplied by an air compressor, or from a positive blast blower or fan.

The various methods of combining the atomizing agent with the fuel constitute the distinguishing feature in their construction and economical operation.

If properly designed, the small particles are immediately and perfectly commingled with air and eonsumed. Therefore, an oil burner becomes more efficient and approaches nearer to perfection which will pulverize the greatest amount of oil with the least expenditure of energy.

An atomizer that will vaporize oil at the point of expansion of the agent used for that purpose, and is easily manipulated, properly designed and constructed, is the highest type that can be devised. The differences in construction and operation between the simplest jet burner and the most highly designed and efficient atomizer are solely these distinguishing features.

Atomizers are constructed with various shaped openings, through which the oil vapour is admitted to the furnace. They may be annular, flaring, slotted, semicircular or fan shaped, producing either a long, round, or a broad spreading flame.

Atomizers having annular openings are said to be more economical in steam or air than other forms, as a more intimate association of the oil and the vaporizing agent is afforded.

By actual experiment various atomizers consume from 3 to 15 per cent. of the entirc product of the boiler in vaporizing sufficient oil to develop the capacity of the boiler. This feature, being quite essential, should be looked after with considerable care, as upon it much of the economy of a boiler depends.

The number of atomizers required for each boiler or furnace is direstly proportionate to its size. Of atomizing agents steam is considered the best for boilers, air from a positive blast blower for furnaces where heat of medium intensity is required, 


\section{AMERICAN STATIONARY PRACTICE WITH LIQUID FUEL,}

and air from a compressor for small furnaces. These are opinions not held universally as regards boiler furnaces.

The Billow Atomizer (fig. 47) is designed to cover the features above enumerated, with the object of vaporizing the greatest amount of oil with the least expenditure of energy, and is automatic in its operation within a 5 per cent. steam variation. It is of a form which it is claimed precludes the possibility of choking, clogging, dripping or the wasteful use of steam, air or oil, and is entirely constructed of brass of many forms and for either steam or air. The regulation and adjustment are good. In its design all the points necessary to produce the best results in oil

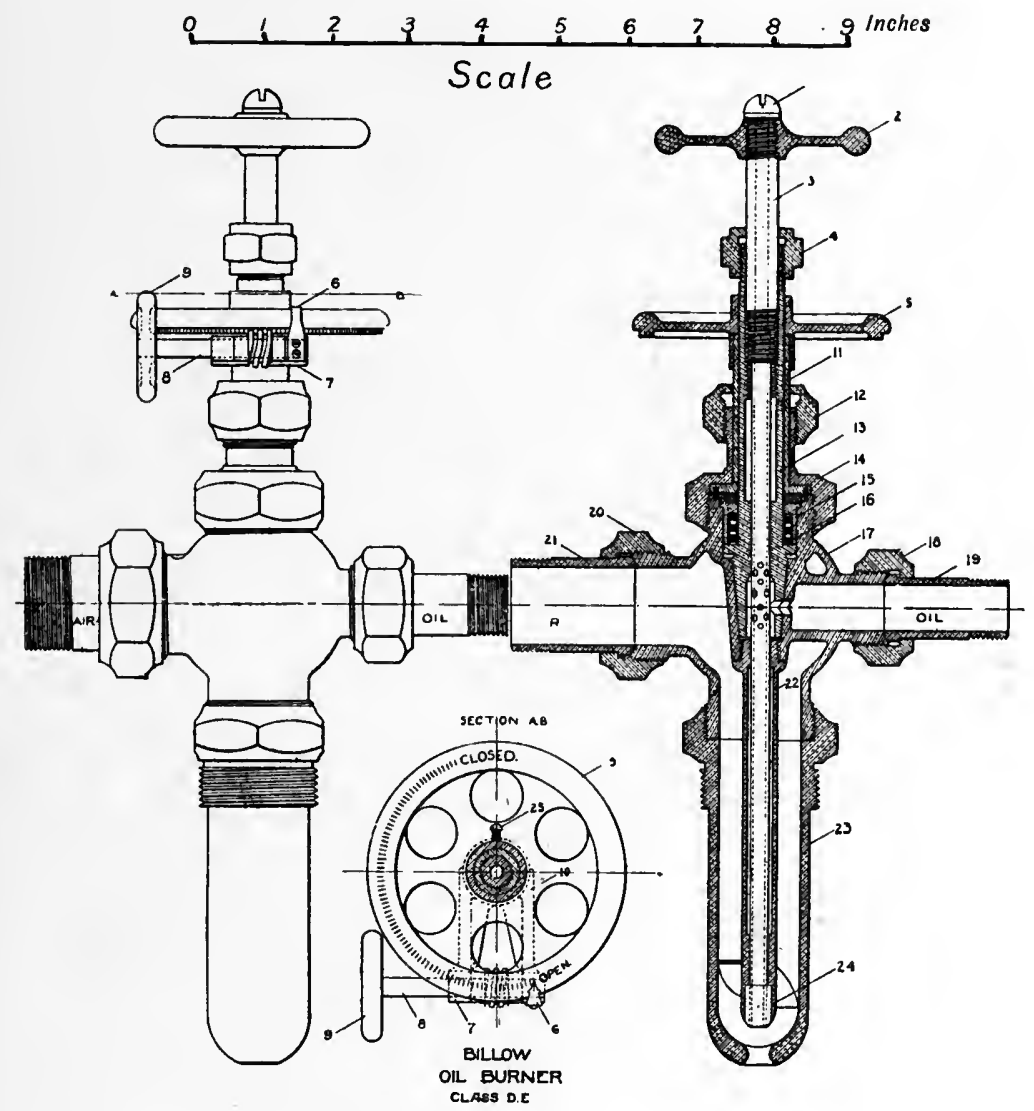

Fig. 47. Atomizer. Billow System. National Supply Co. of Chicago

atomization are carefully observed. It is self contained. The fuel and the atomizing agent are controlled within the burner. It has ground joint union pipe connexions placed on an axis transverse to the body, a good feature, which permits the flame to be directed as desired. It is susceptible of a wide range in adjustment, and will perfectly vaporize a few drops of oil per minute or many gallons per hour. It is constructed with various shaped nozzles or outlets of the retort type, when desired, but these are not recommended on account of their wasteful steam or air consumption. Only in special instances should atomizers other than those with annular openings be employed. 


\section{LIQUID FUEL AND ITS COMBUSTION}

\section{Fuel Oil Pumping Systems.}

In order to produce the highest results with fuel oil, a system for its handling and control between the storage tank and the atomizers is an important faetor. This system must be so designed as properly to heat the oil, free it from mechanical impurities, and deliver it to the atomizer at a eonstant pressure and temperature under the control of the operator. The amount of oil necessary for feeding the atomizers should be automatieally eontrolled, and the system suffieiently flexible to pump the oil to one atomizer or any number within its eapacity without useless expenditure. It should handle all grades of oil fuel equally well.

Residuum, or manufaetured fuel oil, often contains particles of eoke and sand. All grades may have dirt, bits of waste, stieks, floating and extraneous matter whieh disturb the adjustment of the atomizers at the furnace door, necessitating their frequent cleansing. These meehanical impurities also clog the feed lines, necessitating their frequent blowing out. It is the duty of an oil pumping system to provide against the objeetionable elements by filtering as well as removing these accumulations and cleansing the filtering medium without disturbing the continued performanee of the pump.

These are essential features in the successful installation of a fuel oil equipment and the satisfactory action of the atomizer.

Feeding the oil at a temperature nearly approaching the point of distillation insures speedy vaporization, with a resultant flame soft and diffusing, and not sharply impinging upon the boiler surfaces. It is therefore essential, in order to obtain the highest economy, that the pumping system be designed so that the desired heat may be secured, and be also provided with the necessary automatic governing valves to insure uniform delivery to the atomizers under the desired pressure.

To meet this demand the National Supply Co. have designed a number of oil fuel systems covering all the requirements that have come to their notice in this direction. That these pumping systems are successful is attested by the fact that this Company alone has manufactured and plaeed upon the market almost four hundred complete machines.

These systems are considered indispensable in eonnexion with a modern fuel oil non-gravity equipment. They are compact, occupy a minimum floor space, and are so dripped and drained that no oil can reach the floor.

The National Supply Co. claim that any oil fuel produces the best results when heated to a temperature just under its distilling point, and that fuel oil is atomized with less energy when heated to sueh a temperature and delivered to a proper atomizer under a constant pressure.

That when air is used as an atomizing agent, carbonization is not liable to occur at the outlet of the burner in the furnaee because the oil is passed through water heated with exhaust steam in the receiver, and minute quantities of water vapour are carried over with the oil, and this prevents carbonizing.

\section{Double Pumping System.}

These oil pumping systems (fig. 48) consist generally of a battery of two duplex steam pumps, speeially brass fitted for oil, and of a east-iron receiver, tested to two hundred pounds hydrostatic pressure, mounted on a cast iron drip pan and base frame upon which the mechanism is securely fastened. A partition divides the 


\section{AMERICAN STATIONARY}

PRACTICE WITH LIQUID FUEL

receiver into two compartments or chambers. Projecting into the rear chamber and screwed to the partition are tubes with fine gauze heads, accessible through the rear head of the receiver. 'These heads act as a filtering or straining medium, and the compartment is provided with blow-off pipe and valve for removing any sediment of extraneous matter deposited therein.

The forward chamber is usually carried two-thirds full of water, and contains a coil of pipe through which live steam or exhaust steam from the operating pump flows. The coil has suitable controlling valves, permitting the use of steam from either of these sources or both at the same time.

One pump is held in reserve against contingencies or possible accident to the working parts of the other or working pump.

The apparatus is provided with a pump governor, or regulator, actuated by the pressure in the receiver to maintain a constant pressure on the oil in the receiver; a relief valve adjustable in construction and placed be-

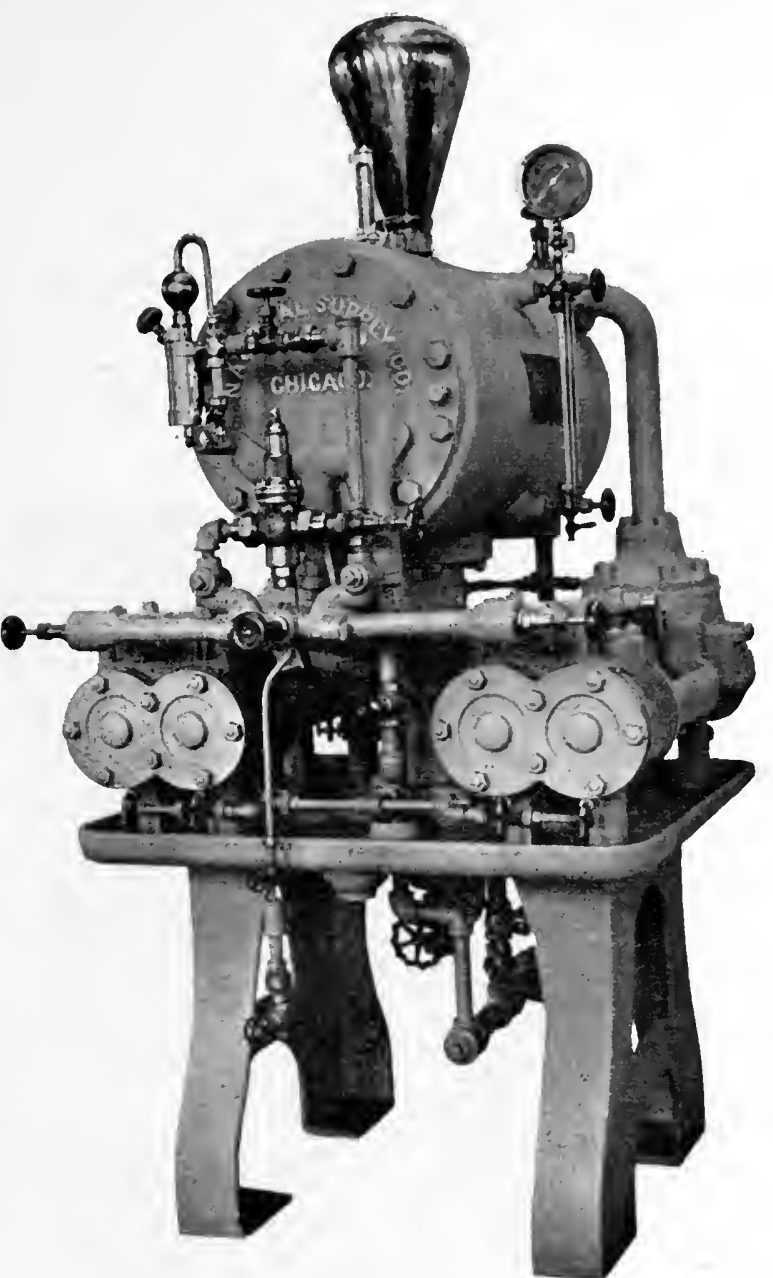

Fig. 48. Double Pumping System. Capactiy, 1 to 5,000 Boiler H.P. National Supply

Co., Chicago tween the suction and the delivery side of the pump through which all oil in excess of the requirements of the atomizer may pass in case of accident to the governor ; a thermometer, steam, oil pressure, and automatically closing sight gauge. The apparatus is designed to pump and deliver any quantity of filtered oil within its capacity under uniform pressure and temperature. All joints are machine faced and metal packed.

In action the oil is discharged through the force chamber of the pumps into the forward chamber. The oil flowing through the hot water becomes heated and passes out through an inner tube to the point of consumption.

All sediment collecting on the tubes or in the rear compartment is blown out through a blow-off pipe without removing the cover.

These pumping systems are made up to sizes of ten to eighteen thousand boiler horse-power.

Thus No. 5 Double, employing two $5 \frac{1}{4}$-in. by $3 \frac{1}{2}$-in. by 5 -in. duplex steam pumps has a capacity of five to fifteen thousand boiler horse-power, or twenty to forty gallons per minute. 


\section{LIQUID FUEL AND ITS COMBUSTION}

No. 4 Double, employing two $4 \frac{1}{2}$-in. by $22_{4}^{3}$-in. by 4 -in. duplex steam pumps, eapacity one to five thousand boiler horse-power, or ten to twenty gallons per minute.

No. 3 Double, employing two 3-in. by 2-in. by 3-in. duplex steam pumps, capable of properly preparing and delivering sufficient oil, when burned in a furnace; to produce from ten to one thousand boiler horse-power, or five to eight gallons per minute.

In attaching fuel oil atomizers to furnace or boiler fronts under certain conditions, it is sometimes necessary to admit all the air for vaporization and combustion in the furnace at the atomizer, for the reasion that at no other point can a sufficient amount of air be induced into the furnace to complete combustion owing to conditions of draught or construction. The device of fig. $48 \mathrm{a}$ answers this purpose by providing

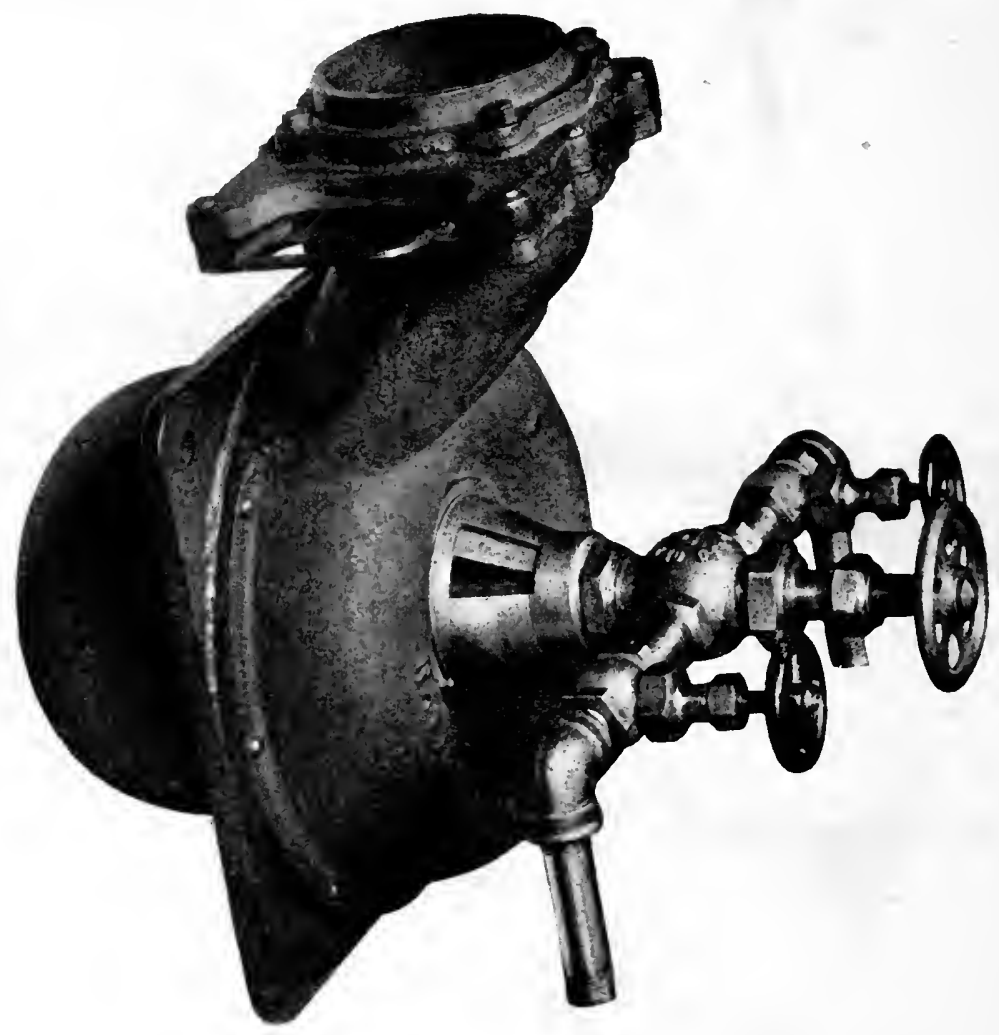

Fig. 48a. Compound Tuyere for Air Admission. National Supply Co., Chicago

the air for combustion irrespective of the atomizing agent used for vaporizing the oil. This air for combustion is intimately mixed with the fuel oil at the point of admission into the furnace. It is intended for boilers where oil is burned as an auxiliary to some other form of fuel, making it impossible to dispense with the grate bars, and is, therefore, very useful in connexion with the burning of bagasse, sawdust and material of like character. It is also the form of construction used aboard steam vessels that employ water tube boilers for steam generation.

The Tuyere or air regulator attached is shown enlarged in fig. $48 \mathrm{~b}$, the outer part being revolvable so as to close the air slots and regulate the amount of air admitted round the atomizer. 'These appliances are the designs of the National 


\section{AMERICAN STATIONARY PRACTICE WITH LIQUID FUEL}

Supply Co., of Chicago, as also is the arrangernent fig. 49 of atomizer tuyere, casting, and internal block of fire-brick which is intended to be placed in a furnace wall or in the fire-front of a boiler. The firebrick has a trumpet-shaped hole through it, and the nozzle of the atomizer enters a short distance only, so that the initial flame is contained within the body of the block.

An example of the National Co.'s system is the fuel oil plant of the Union Loop, Chicago, Illinois. This plant consists of a system for the complete unloading, handling, storing, circulating, controlling and firing of fuel oil, after design prepared by C. O. and E. F. Billow.

The apparatus includes three steel storage tanks, 16, 10, and 8 feet in diameter, and 20 feet high, of a combined capacity of 1,764 bbls., of 42 U.S. gallons each (35 imp. gals.).

Fuel oil is received at the station in tank wagons, and is transferred to the storage tanks, which are placed in the building, by two duplex pumps, having 6-in. steam and $7 \frac{1}{2}$-in. oil cylinders, and a 6-in. stroke. These pumps are specially brass fitted and have 6-in. suction and 5-in. discharge openings.

Provision is made for unloading four $30 \mathrm{bbl}$. tank wagons simultaneously. These tank wagons are attached to oil hydrants, by steel band lined oil unloading hose.

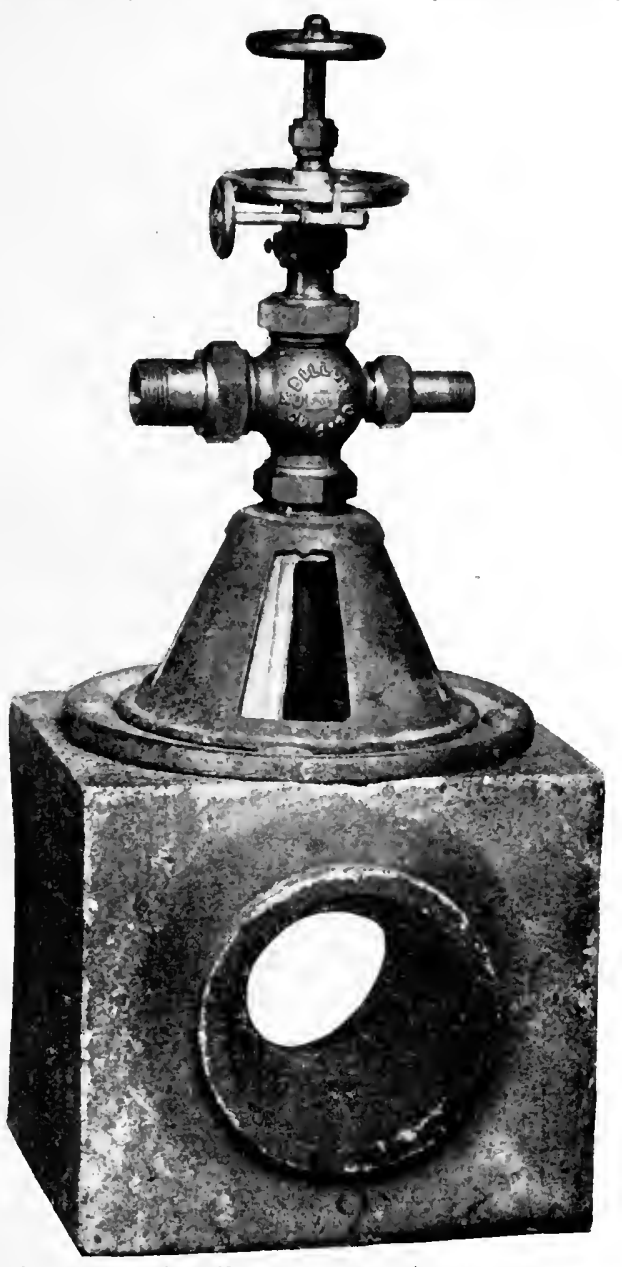

Fig. 48b. Air Regulator, Atomizer and Tuyere Block for Furnace Front. National Supply Co., Chicago

The oil storage tanks are provided with all the necessary flanges for pipe connexions, a 16-in. screw top manhole and cover on the roof, and an 18-in. on the side near the bottom of the tank, floats and indicators which indicate the level of the oil, by finger boards in the tank room and mercury columns in the basement.

From the storage tanks the oil is conveyed to two 4-in. stand pipes, $70 \mathrm{ft}$. in height, joined by a header near the top by means of a duplex pump, having $3 \frac{1}{2}$-in. steam cylinder, $4 \frac{3}{4}$-in. oil cylinder, and a 5 -in. stroke. This pump is also specially fitted for oil, and has a 3 -in. suction and a $2 \frac{1}{2}$-inch discharge.

From the stand pipe header the oil is conveyed to the oil atomizer loop, by two No. 5 oil heating and circulating systems, set upon the boiler room floor. These systems are so erected as automatically to maintain a uniform pressure and temperature, and a constant flow of oil to the oil atomizer. They also purge the oil of all mechanical impurities, and dispose, by condensation, of the gases generated by the manipulation of the oil in transit between the oil storage tank and the atomizer. These circulating systems each consist of a battery of duplex pumps with 


\section{LIQUID FUEL AND ITS COMBUSTION}

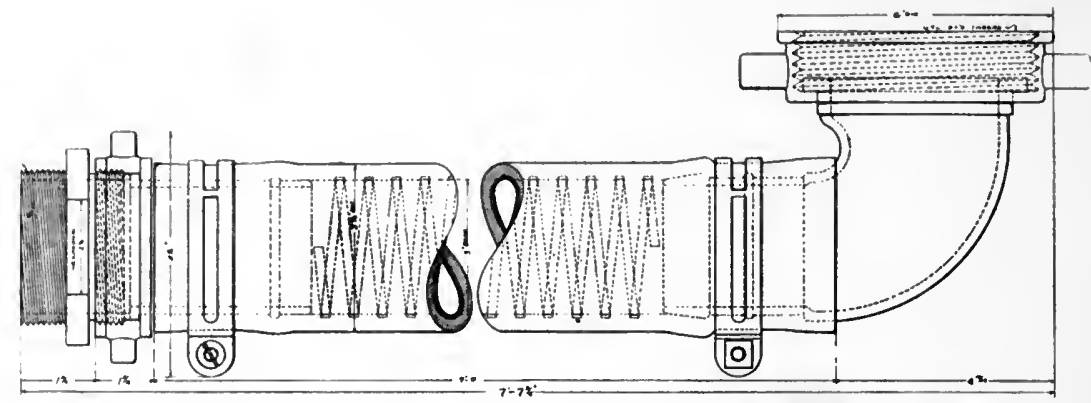

Fig. 48c. Spectal Tank Car 3-inch Hose Connexion. National Supply Co., Chicago

packed pistons having $5 \frac{1}{4}$-in. steam cylinders, $3 \frac{1}{2}$-in. oil cylinders, and a 5 -in. stroke. They have a $2 \frac{1}{2}$-in. suction and a 2-in. discharge. Each pump is provided with a copper air chamber and mounted on a cast iron base and drip pan, construeted to dispose of all leaking of stuffing boxes and glands on the pumps. This base is attached to a cast iron frame, supporting one combined steel receiver, heater and condenser, 24 inches in diameter, and 36 inches high, surmounted by the 7-in. copper air chamber 24 inches high. The receiver has two diaphragms riveted to its shell, and expanded full of tubes (125 1-in. boiler tubes, having their ends caulked and beaded), around which passes the exhaust from the pumps. The receiver also has provision for the introduetion of water, through which the fuel oil flows, under a high pressure, for the purpose of breaking it up into molecules, in order that all foreign substances may be precipitated; the oil passing through the heated tubes becomes thoroughly cleansed, and deposits water and settlings dud to the cleansing process Each receiver is further provided with a brass automatically closed glass gauge, air cocks, pressure gauge for steam and oil, blow-off connections, pressure relief valve and pump governor or steam regulator.

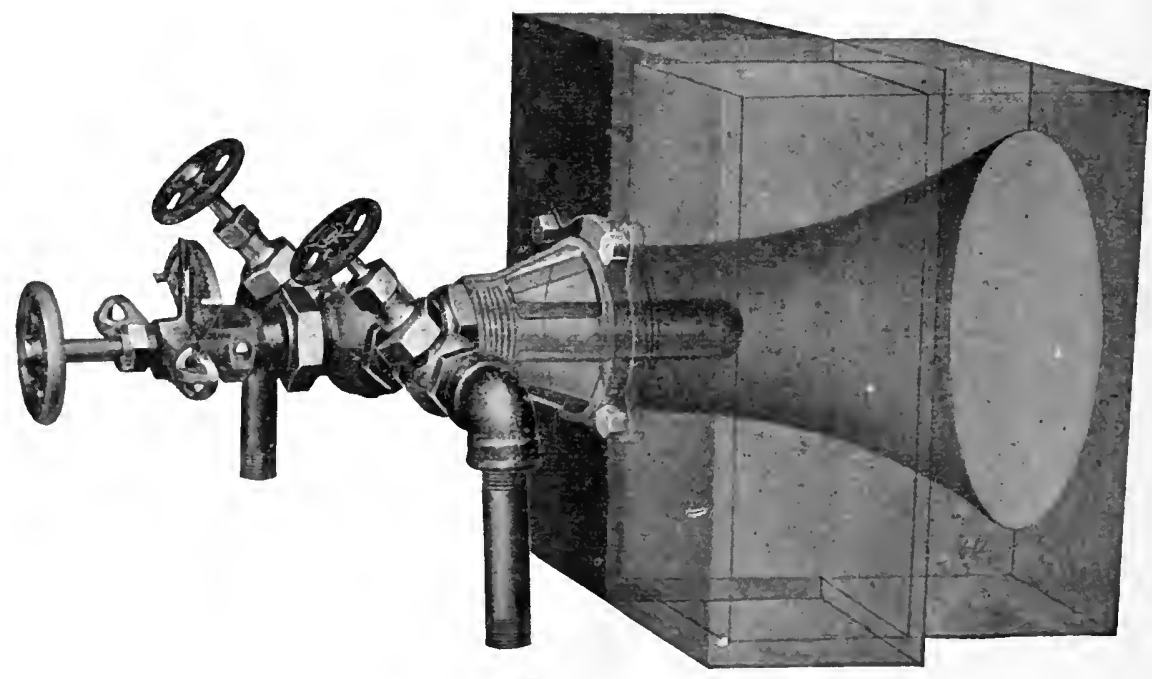

Fig. 49.

The drips from the pumps, receiver, drip pans, and exhaust have catch basin connexions. 


\section{AMERICAN STATIONARY PRACTICE WITH LIQUID FUEL}

The whole circulating system is as nearly automatic in its action as is desirable, and is duplicated throughout to guard against any possible contingencies or accident.

Each circulating system is capable of preparing and properly delivering sufficient fuel oil to the oil atomizers to develop, when burned, 15,000 horsc-power, or the two combined 30,000 boiler horse-power, and each system occupies a floor space of $30 \mathrm{sq}$. $\mathrm{ft}$., and is $8 \mathrm{ft}$. in height.

Four fuel oil atomizers are placed in the combustion chamber of each boiler, or a total of sixty-four oil burners compose the installation. These oil burners receive their oil from a loop, beneath the boiler room floor, which is sectionalized with valves into five distinct headers.

The furnaces are erected upon the grate bars of an Acme stoker, and consist of a series of fire-brick flues for heating and circulating the incoming air, chequer work for distributing flame, and baffle walls for directing same.

The apparatus is so designed that oil at the same uniform pressure and temperature will be delivered to a single oil burner or to the entire battery of sixty-four.

\section{Furnace Construction.}

The National Supply Company rightly say this is a most important feature connected with a fuel oil equipment, and one which is often the least understood and most neglected.

"Too often it happens that complete combustion is impaired not from the lack of air, but on account of the method of its introduction into the furnace, often from such points as to render it ineffective, producing losses as great as 50 per cent. Therefore, for economic reasons, no more air should be supplied than is necessary.

During the early stages of combustion of any fuel the gases of a highly volatile nature distil at a low temperature, rise rapidly, hug the boiler, enter the tubes or flues and pass out through the breeching unconsumed. The combustion chamber should therefore be arranged with fire-brick, so that the incoming air may be heated to the required temperature, the flames retarded, diffused, and distributed, and the velocity impeded. There will be no concentration or localization, and the danger of blistering or burning any part of the boiler is avoided.

The nature of the furnace construction varies according to the type of boiler or furnace. The question may be asked, 'Will an apparatus work if no change is made in the combustion chamber or furnace of a boiler other than that of covering the grate bars?' A furnace so arranged will not average as high economical results as when properly constructed for diffusing the heat and retarding the flow of the gases. Fuel oil appliances can only vaporize the oil ; in the furnace it is consumed. Therefore the statement is not unreasonable that a scientifically arranged combustion chamber with a shovel to feed the oil is preferable to a poorly constructed furnace to which is attached the highest type of atomizing device.

\section{Operating a Fuel Oil Plant,}

The results to be secured from a properly designed fuel oil plant depend wholly upon the amount of intelligence that is exercised in its manipulation. All the mechanism that can be supplied, outside of the furnace, is designed to perform the single function of delivering the oil to the furnace in a finely divided, nebulised condition with as little cost to the operator as possible, and to give insurance against 


\section{LIQUID FUEL AND ITS COMBUSTION}

accidents or possible shut-downs, with ease and facility in manipulation. Other economical results depend wholly upon the draught. This should be regulated by the ash-pit doors, or other proper means. The flame may be increased or diminished at will by the simple opening or closing of a valve, but it is only by experi-

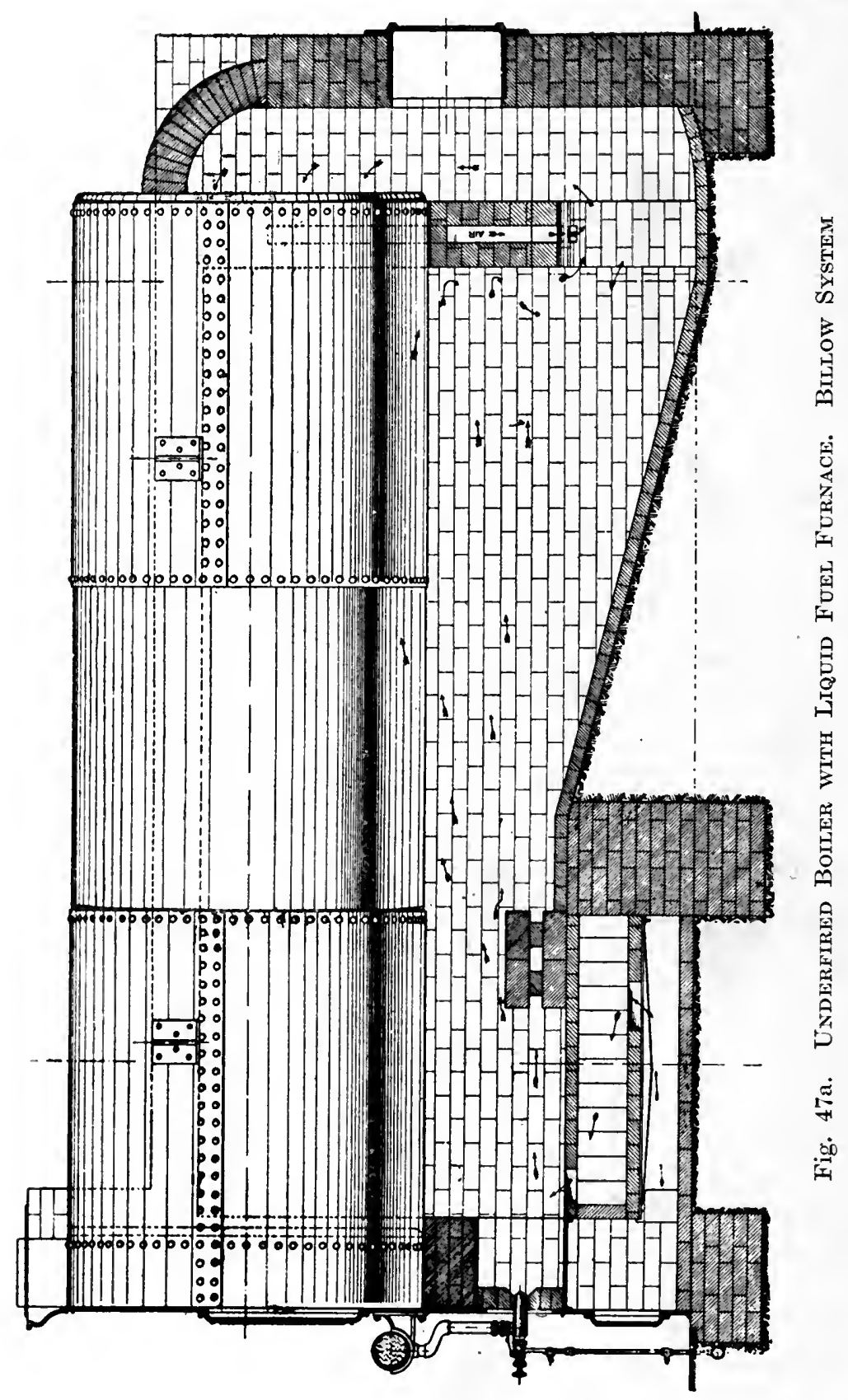

ment or long-eontinued contact with fuel oil that the oil, the atomizing agent, and the air necessary for combustion will be properly combined and the beneficial results of this combination be obtained. The operator should continue the open- 


\section{AMERICAN STATIONARY PRACTICE WITH LIQUID FUEL}

ing and closing of the ashpit doors, or the manipulation of the damper and the increasing or diminishing of the flame until he can produce a fire large or small, without the least indication of smoke. When this condition is attained he will have no more occasion for handling any of the apparatus, provided the elements of combustion are perfectly balanced.

The gases should not pass from the furnace at too high a temperaturc. This can be controlled and regulated largely by the damper. A clear flame consumes less oil than a smoky flame, and has greater efficiency. Smoke is an evidence of imperfect combustion, but the absence of smoke does not necessarily demonstrate or prove that perfect combustion is being attained. Too much steam produces

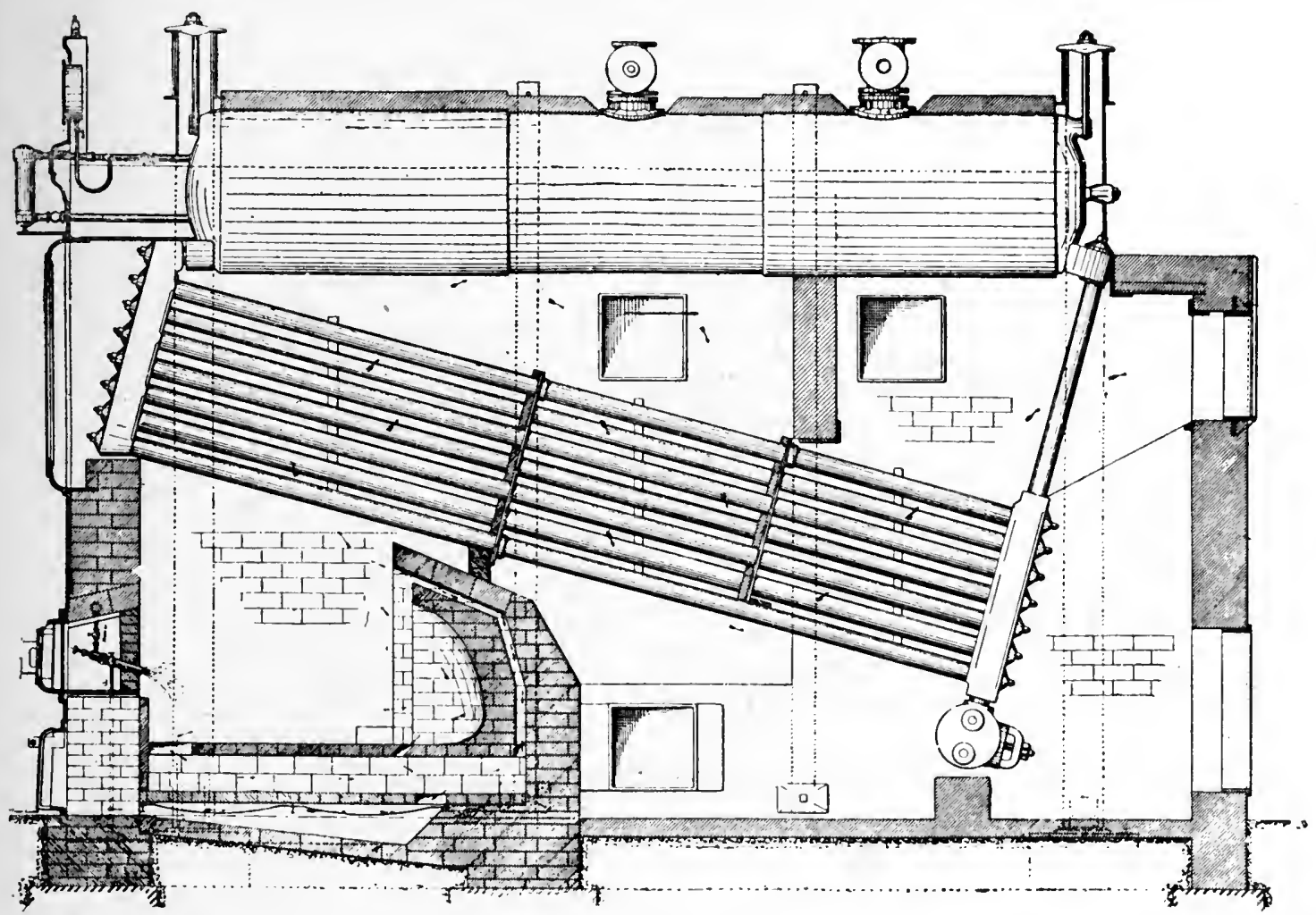

Fig. 47b. Whter Tube Boller. Billow System

a light grey vapour ; too little, a smoky flame ; too great a draught, an intensely vibrating flame accompanied with a roaring noise; too little draught produces a dull red, smoky flame. When the elements are properly united the result is a reddish orange flame.

The temperature of the escaping gases from a boiler will increase as the excess of air becomes greater, provided the same amount of fuel is being burned. This is because the furnace temperature is less, owing to the greater amount of air present, which results in a less rapid transfer of the heat to the boiler, and consequently allows more heat to escape to the chimney.

On the other hand, with a uniform excess of air, if more fuel is burned, the temperature of the escaping gases will increase, owing to the heat produced being greater in proportion to the absorbing capacity of the boiler." 


\section{LIQUID FUEL AND ITS COMBUSTION}

It is only through close application that the theory of oil burning can be fully understood and mastered, and as high an efficieney as 80 per cent. of the theoretical value of the fuel transmitted from the furnace to the boiler. Mr. C. O. Billow, the engineer to the Company, has designed furnaces for many types of boilers. A few are here illustrated. Fig. $47 \mathrm{a}$ is the ordinary Ameriean underfired tubular boiler with the bars replaeed by a fire-briek air casing, through which air flows to the furnace through the "ash-pit" door and comes up under the atomized jet. The furnace widens out laterally from front to rear, the atomizer being placed at the narrow end of this brick,furnace. The grate bars are ten inches lower than usual, and the

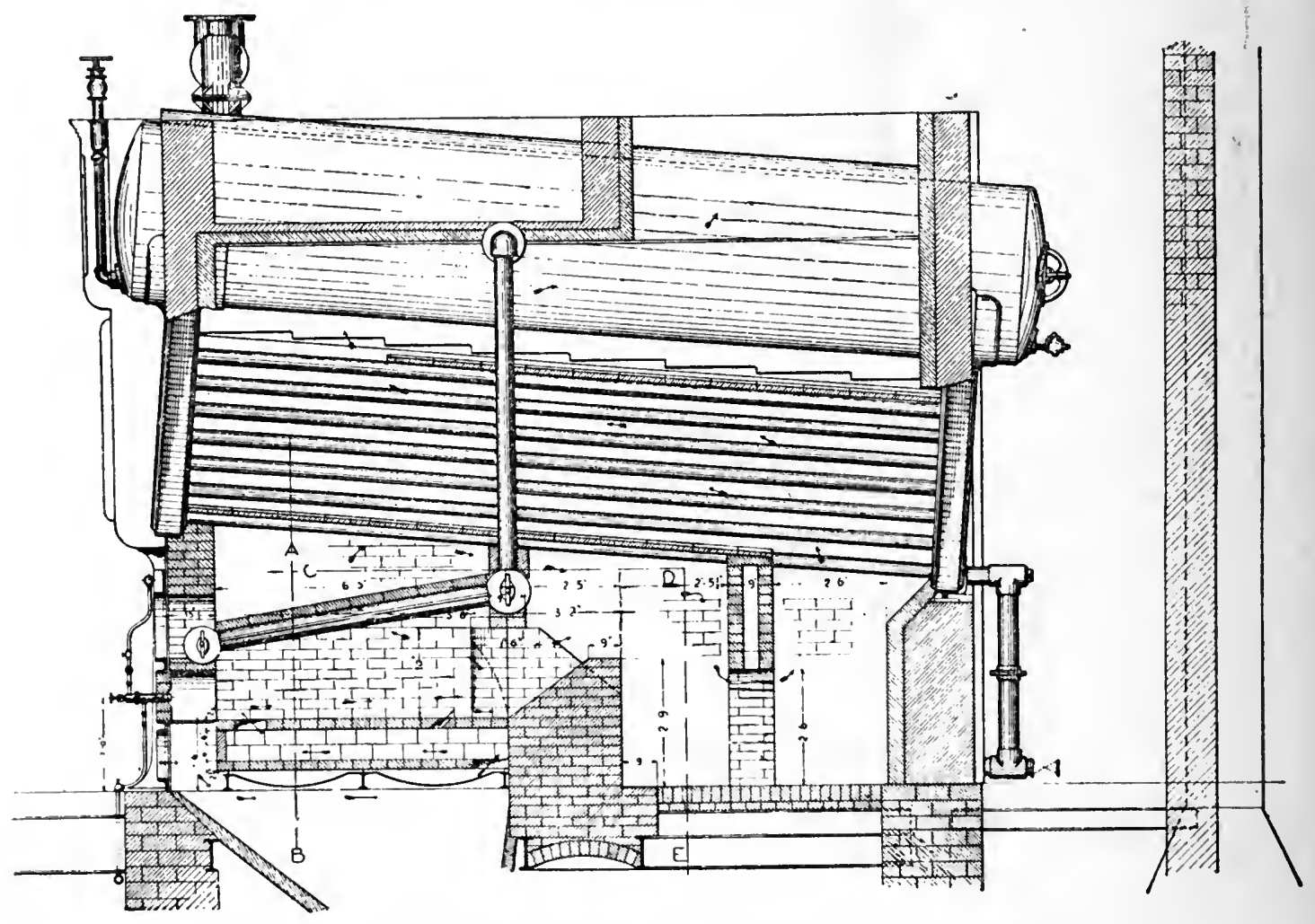

Fig. 47e. 500 1f.P. Heine Boiler with Down Draught Grate. Billow Oil Fuel SYSTEM

air easing of briek occupies this ten-inch space. The ash-pit doors serve to regulate the air admission. The atomized oil is directed upon the ehequer work brick bridge, which breaks up and diffuses the flame throughout the furnace and directs it upon the boiler. A hanging bridge is placed at the extreme end of the combustion chamber. If too little air has been admitted at the front, a further supply is let in through this rear bridge, which also serves further to retard the flow of the hot gases. Either steam or air may be used as the atomizing agent in this furnace, and though air is the more effieient, the cost of the air eompressor detracts from its advantage, but a good eompressor saves steam. Mr. Billow eonsiders that steam atomizing should be done with $3 \cdot 3$ per eent. of the total steam ; that a positive air blast blower will only use 1.36 per cent. of the boiler output, but when air is compressed above 30 pounds absolute, it costs 6 per cent. with ordinary compressors. Hence the im- 


\section{AMERICAN STATIONARY PRACTICE WITH LIQUID FUEL}

portance of well designed compressors. Exactly the same system is carried out in the ordinary water tube boiler (fig. 47b). This furnace is applicable to the many forms of water tube boiler. In this case the same grate cover of fire-brick is $\mathrm{cm}$ ployed, but the bars are lowered considerably to provide room for the concave bridge, which is also split to admit air. The burner points somewhat down so as to strike on the brick floor at about half length, the flames curving round the bridge hollow.

In fig $47 \mathrm{c}$ is the setting arranged for a 500 h.p. Heine boiler, which was provided with the Hawley down draught furnace previous to oil being used. The illustration shows how the Hawley grate has been retained and covered with tiling on the middle section only. In this boiler are five fire doors and six atomizers, the middle door having two, and the others one each. The gases from the side furnaces pass between the bars or tubes of the Hawley grate and join the gases from the central section in the combustion chamber. The illustration shows the central section of the furnace.

It may be added here that for English practice the containers of oil pumping systems of fig. 48 type should be of boiler plate and not of cast iron-a material, the use of which for pressure work, and especially for pressure work with liquid fuel, is considered indefensible, and would probably not be passed as safe by the English Boiler Insurance Companies. 


\section{Chapter XXI}

\section{AMERICAN STATIONARY PRACTICE WITH LIQUID FUEL-(continued).}

\section{The Kirkwood System.}

$\mathrm{T}$ ATE, JONES \& Co., of Pittsburg, make the Kirkwood burner, for which they claim that it can be worked by air or steam, does not clog, is easily cleaned, and is regulated at the point of combustion. A graduated scale for both oil and steam or air is fitted. Oil is pumped through a coil in the exhaust chamber of the oil pump itself, which is in duplicate.

It is claimed that oil with a fire test of $180^{\circ} \mathrm{F}$. to $200^{\circ} \mathrm{F} .\left(82^{\circ} \mathrm{C}\right.$. to $\left.93^{\circ}\right)$ is as safe as coal, which will sometimes ignite spontaneously, that at $250^{\circ}$ to $300^{\circ} \mathrm{F}$. a red hot poker will not ignite oil stirred by it, nor will hot coals do so if thrown into it. This may all be true, but yet does not of course justify other than great care in regard to the dangers inseparable from any self flowing oil.

Steam is considered the best atomizing agent, but this claim is supported by the now exploded error that it assists the fuel value of oil by itself burning after dissociation.

It is correct, however, to call for superheated steam as more effective than less dry steam, and it need not be disputed that there may be a chemical action which promotes the combustion of hydrocarbons in the presence of moisture, as claimed by Professor Dixon; but this must not be confused with the erroneous claim that steam, being split up, acts as fuel and gives out more heat energy than it absorbed in the process of decomposition.

Professor Deniche, of the University of California, who tested oil at the Western Sugar Refinery in San Francisco, where 700 barrels of oil are used daily, states that there are 32 boilers, of which 22 are 6 feet 6 inches diameter by 21 feet long, and have $27 \frac{1}{2}$ square feet of grate surface. Each boiler has 113 three inch tubes, giving 688 square feet of heating surface. The ten other boilers are 6 feet 6 inches in diameter by 26 feet long, have the same grate surface and $962 \frac{1}{2}$ inch tubes, giving a heating surface of 1,098 square feet. The plant is rated at 2,540 horse power, but 4,340 horse power is obtained. There are also three Green economizers, which heat the feed water-two with 432 pipes and one of 360 pipes.

When coal was burned, forced draught was supplied by a 4 by 6 foot Sturtevant blower, driven by $11 \frac{1}{2}$ inch $\times 16$ inch engine.

The oil is received in tank cars containing from 6,000 to 6,500 gallons. The contract price for the oil is $\$ 1.30$ per barrel, delivered (42 gallons per barrel, weighing $301 \cdot 33$ pounds) $=5 \mathrm{~s} .6 \mathrm{~d}$. per $35 \mathrm{imp}$. gallons.

"Seven cars are coupled to pipes along the track and the oil flows by gravity to a centrifugal pump, driven by an electrical motor, which pumps the oil into closed steel storage tanks of 10,000 barrels each. These tanks are surrounded by a con- 


\section{AMERICAN STATIONARY PRACTICE WITH LIQUID FUEI,}

crete dam, the space enclosed containing a little more than the contents of one tank. From these main tanks the oil flows by gravity to a small underground tank near the fire room. A network of fire-brick set on edge is laid directly upon the grate bars, and against this the oil flame is directed. This network can be removed and a coal fire started within twenty minutes, by actual practical trial. When oil was first used it was blown with two or three per cent. of generated steam, but this gave an imperfect flame and set up a vibration. Now eight per cent. is used, and a Bunsen flame is obtained with little vibration."

The fire-room cost of handling the fuel is stated to be less than one-third of that of coal.

When coal was used as fuel, twenty-six firemen were employed ; now twelve are needed.

When coal was used careful tests were made, and from the results obtained there has been prepared the following table, which shows a saving of $\$ 46,012.15$ per year by burning oil. But as it was based on the first test made under poor conditions, since remedied, it is claimed that the minimum saving over coal is $\$ 60,000$. This does not take into account wear and tear on the boilers and general convenience.

Statement of Comparative Value of Oil and Coal.

Based on the First Trial Test. Coal Basis of 1897.

Total bituminous coal received during 1897, tons . . . .

Average evaporation of that coal from and at $212^{\circ} \mathrm{F}$, pounds

Total water evaporated on that basis, pounds

Fire room cost of handling that coal, reckoning 300 days at $\$ 64 \cdot 26$

Cost of coal for this work on basis of present price, 35,347 tons at

$\$ 6.55$ (have paid as high as $\$ 7.25$ this month)

otal cost of evaporating above quantity of water, coal .

Oil, basis of \$1.30 Per Barrel, and 13.9 Pounds Evaporation.

Oil necessary to evaporate above quantity of water, barrels .

Total cost of evaporating above quantity with oil

Saving on year's work by burning oil under the above conditions .

Tate, Jones \& Co. give the following working figures for Beaumont oil-

Specific gravity of Beaumont Oil, $22^{\circ}$ Baume.

One gallon

One barrel

Six barrels

One barrel

Flash point

Fire point

weighs $7 \cdot 66$ pounds.

,

,

, $\quad 322 \mathrm{lb}$.

$" \quad$,

, ,

" 1 ton nearly $(2,000 \mathrm{lb}$. $)$.

,,

contains 42 gallons $=35$ imp. gals.

$200^{\circ} \mathrm{F}$

Theoretical calorific value of Beaumont oil, $1 \mathrm{lb}$. will evaporate $15 \frac{1}{2} \mathrm{lb}$. water.

Calorific value of ordinary Western coal, $1 \mathrm{lb}$. will evaporate $15 \frac{1}{2} \mathrm{lb}$. water.

From which it appears, $48 \frac{1}{2} \mathrm{lb}$. oil will evaporate as much as $100 \mathrm{lb}$. coal.

They also consider that there should be from 6 to 7 per cent. of oxygen in the 


\section{LIQUID FUEL AND ITS COMBUSTION}

furnace gases. As with most American systems, the Kirkwood system embodies a heater and pumps. The heater consists of a steam chamber, the steam chamber containing a pipe coil through which the oil passes before reaching the burner, the coil being heated by the waste steam from the pumps. These pumps are in duplicate, so that one may always be in reserve in case of breakdown. The relief valves in the pressure chamber are designed to keep the oil in it and in the supply lines at a uniform pressure of about 20 pounds or more, an automatic by-pass allowing any surplus oil to return to the storage tanks without rise of temperature.

By applying the oil itself both hot and under pressure it is compelled to be admitted through finer orifices and in a more thin and divided state for atomization.

The oil must not appear visible as a dark stream at the burner tip, but as an almost imperceptible spray.

\section{The Aërated Fuel Process.}

This process is that of the Gilbert and Barker Manufacturing Company of New York, and is simply a system of atomizing by compressed air. The system is used in all manner of industrial arts, the flame being used direct in metal work, glass making, japanning, etc. The apparatus includes an air compressor, oil pump and receiver, storage tank and the burners and necessary pipes.

Compression is to 15 pounds per square inch, a pressure below which it is stated that the fuel is not perfectly atomized.

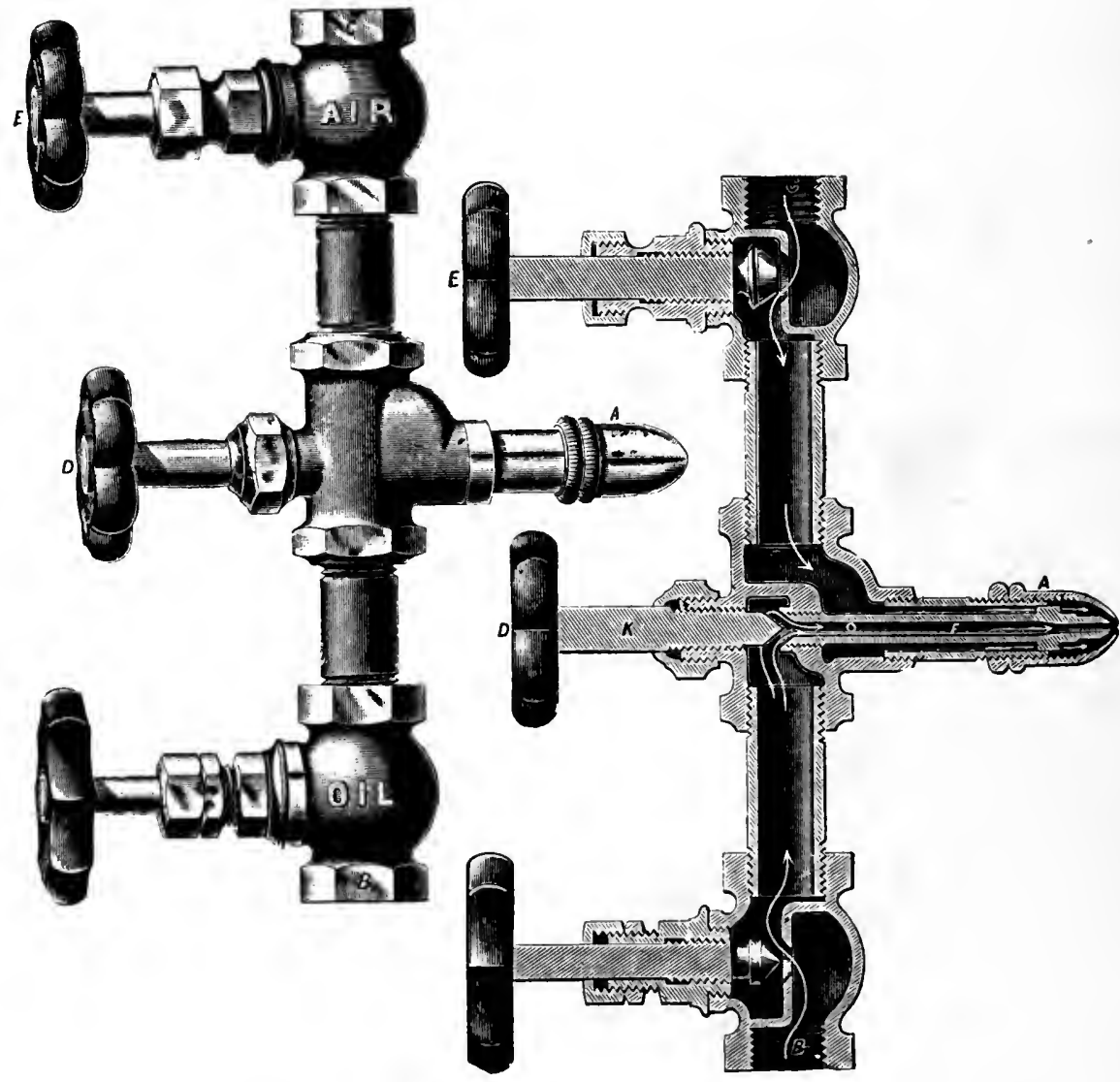

Fig. 50. Atomizer. Aërated Fuel Process 196 


\section{AMERICAN STATIONARY PRACTICE WITH LIQUID FUEL}

The oil pump is itself worked by the air, and serves to keep a full receiver of about 30 gallons capacity ( 25 imperial gallons). The receiver also contains compressed air which forces the oil to the burner (fig. 50), where it meets the air eoming direct from the compressor. Valves regulate the proportions and the air pressure preserves even working conditions, whether two or twenty burners are at work. It is claimed that the combustion is really gaseous, clean and smokeless. The main supply is a buried tank outside the building and away from the burners. The oil pump is automatically regulated by a float, and all apparatus is below the burners, so that no gravity flow can take place. The use of gravity is held by some to be bad practice, and this view will bear argument in its favour. Low pressure air is specially condemned as leading to imperfect atomization and large globules, which burn imperfectly and deposit carbon and injure the fire-brick. From 60 to 120 gallons of oil are claimed to do the work of a ton of coal.

The process is held to be very much superior to any steam atomizing process for metallurgical work.

Low pressure air which throws oil upon the fire-brick unconsumed, causes these to shell off and break, and smoke is made also while carbon is deposited in the furnace.

Applied to metallurgy, to forge furnaces, crucible heating, and other industrial work outside steam raising, the advantages of oil fuel are set out, in regard, not merely to the absence of dirt and dust, but that there is no loss of time through men waiting for fires to burn up. There are no times of good or of bad fires, no uneven heat, but a full flowing flame is maintained with an even continuous degree of heat. Then the economy of oil is largely secured by increased production and better work. Oil has the advantage over gas fuel also, which, though equally good in the furnace, cannot be produced without labour and dust and at a considerable outlay in plant and apparatus. table-

A usual computation of the calorific capacity of various gases is as per following

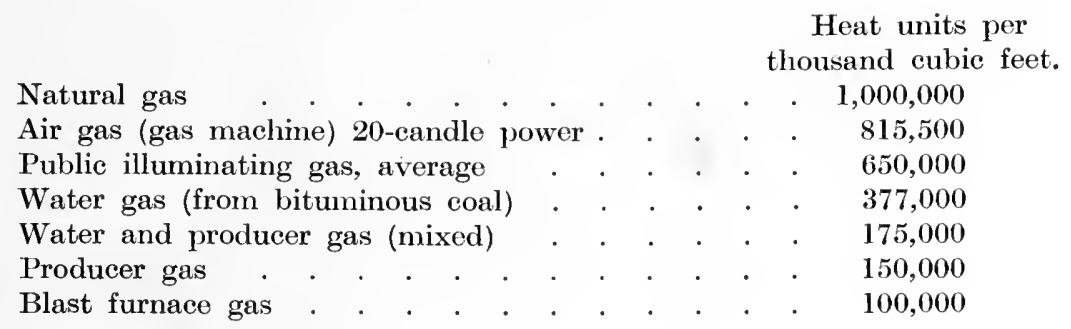

Since a gallon of fuel oil ( 7 pounds) contains 151,000 heat units, the following comparisons may evidently be made. At three cents a gallon (about 1.8d. per English gallon), for instance, the equivalent heat units in oil would be equal to-

Dollars
per thousand
cubic feet.
at $\cdot 1987$
, .1620
,.$\cdot 1291$
,. .0749
,, .0347
, .0298
,, .0200




\section{LIQUID FUEL AND ITS COMBUSTION}

At four cents a gallon (about $\mathbf{2 \cdot 4} d$. per English gallon) the equivalent heat units in oil would equal-

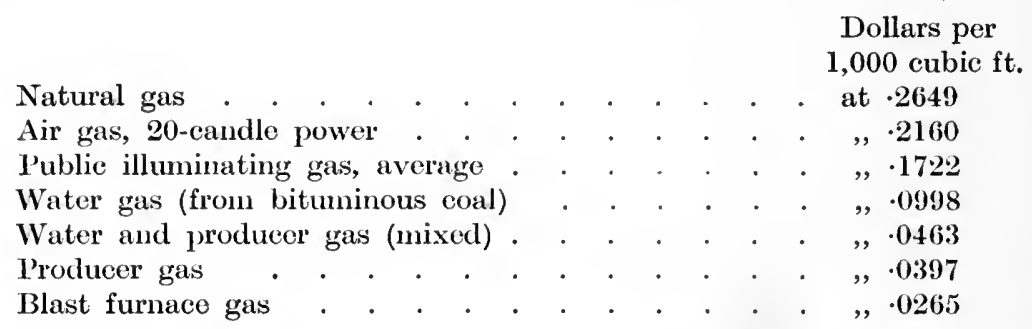

so that when oil will pay to use it may be installed at one-tenth the cost of a gas plant and worked for a fraction of the cost in upkeep and wages.

The Gilbert \& Barker Co. also work the Springfield System, in which air as low as 18 or 24 ounces pressure is employed to atomize oil, which comes forward at forty pounds pressure and is apparently contradictory of the statements above, that low pressure air is not satisfactory. Possibly an explanation is to be found in the oil pressure which, as in the Körting system, should itself do much towards atomizing the oil. 


\section{Chapter XXII}

\section{ENGLISH STATIONARY PRACTICE WITH LIQUID FUEL}

The Kermode System.

$\mathrm{N}$ this system air at low pressure is the atomizing agent, the air being heated in a thick retort pipe, which is carried round the furnace.

Oil is allowed to gravitate from an overhead tank, as very usual in marine work. It flows thence by a $1 \frac{1}{4}$ in. pipe to the furnace front and separates to the two burners by equal branching pipes. Where two burners are supplied off one pipe the branches to each must be symmetrically arranged in order that equal supplies of oil may reach each burner

The illustrations figs. 51, 5la represent one form of the furnace arranged by the Wallsend Slipway Co. for this system, the lower part of the marine furnace being filled with special fire-brick blocks through which air enters the furnace beneath the flame. These blocks are covered with asbestos lumps similar to the ordinary grate of fig. 52, which shows an alternative arrangement including also an oil heating pipe in the furnace in addition to the air heating pipe.

The accompanying table of tests and copy of analysis of Borneo oil are given from results of trials at the Wallsend Company's Works-

Copy of Analysis by Dr. George Tate, F.I.C. F.G.S. November 9, 1899.

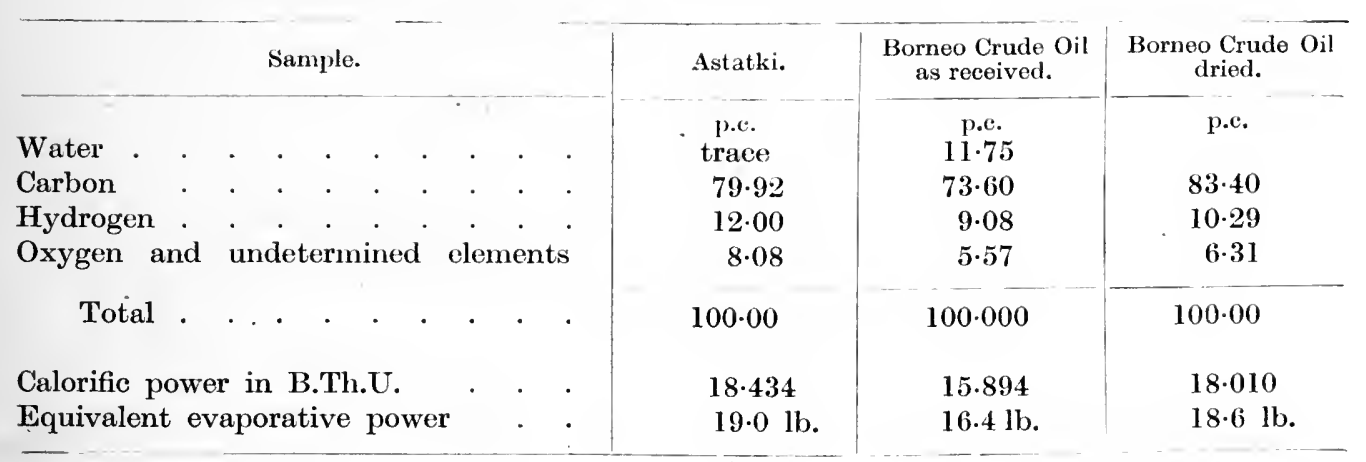




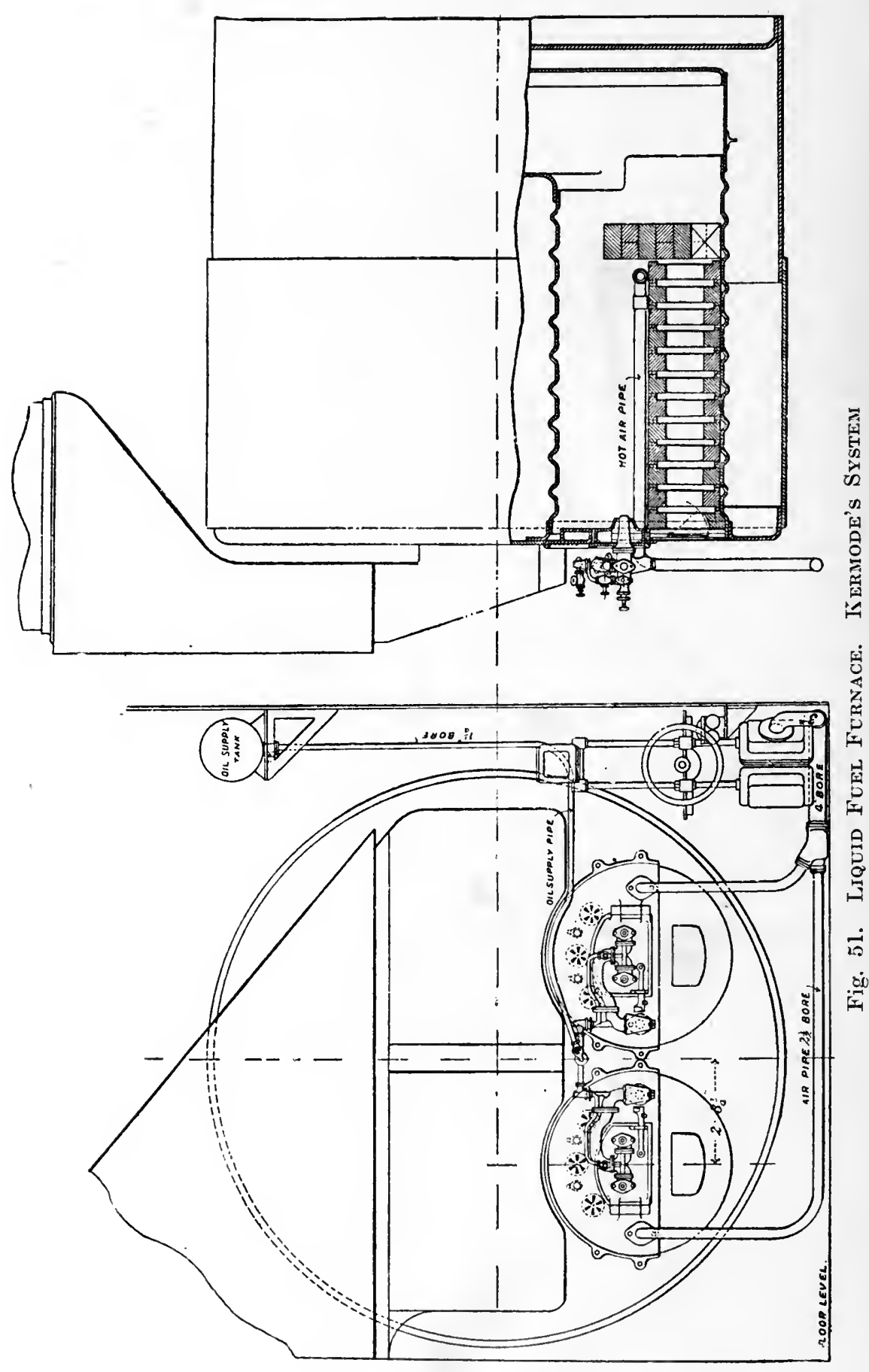



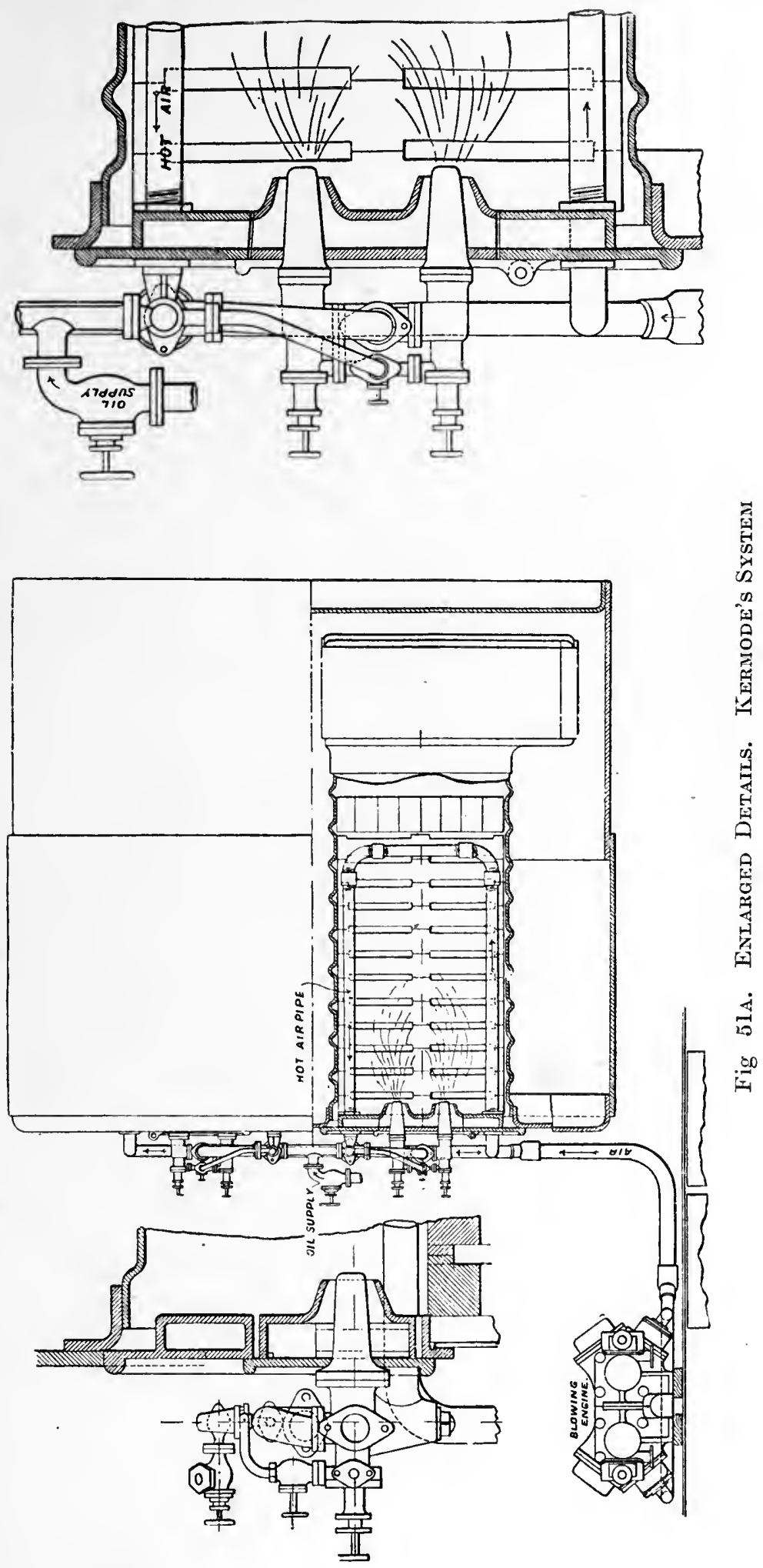


\section{LIQUID` FUEL AND ITS COMBUSTION}
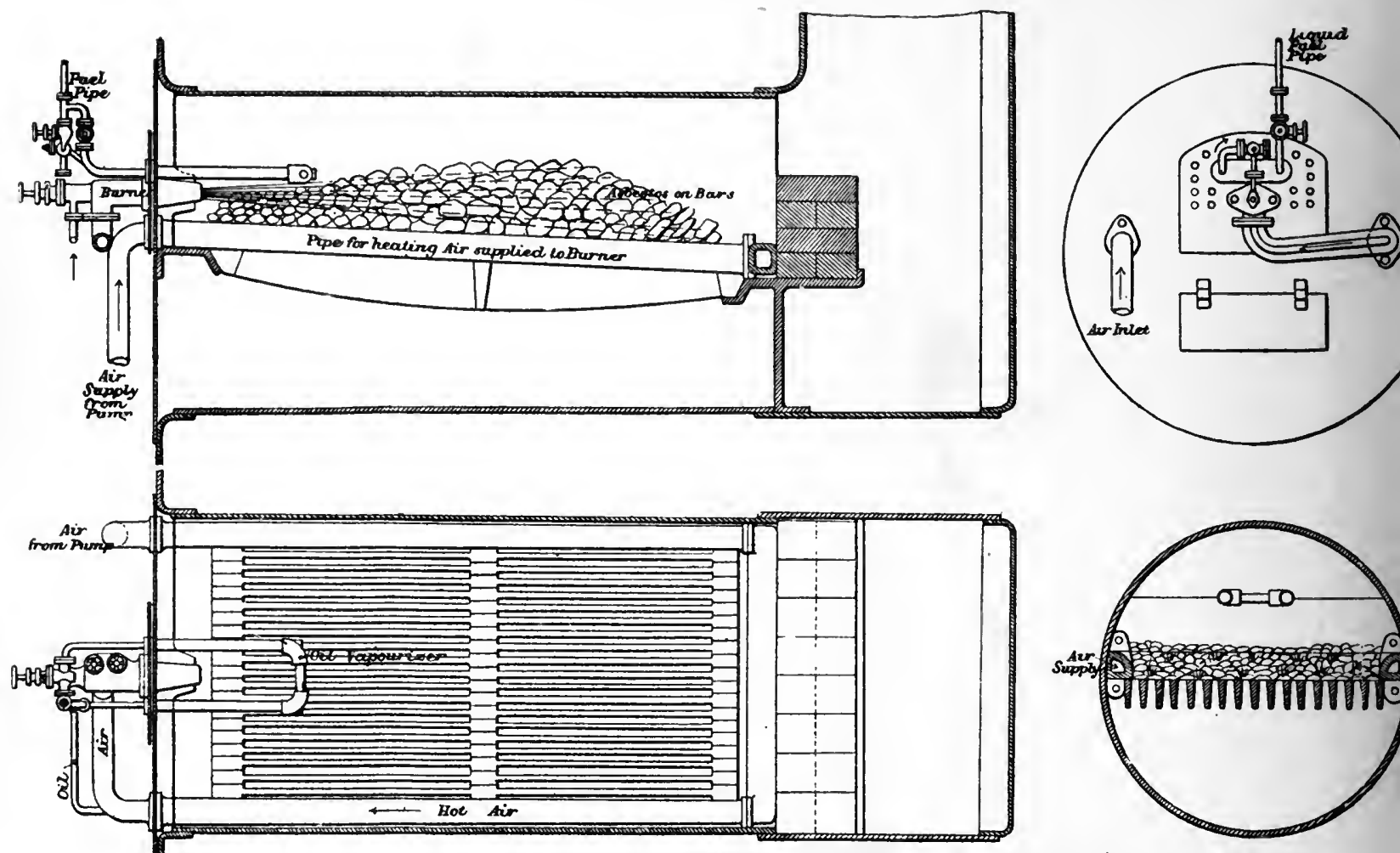

Fig. 52. Liquid Fuel Furnace. Kermode's System. Alternative Arrangement

Date of Trial.

Duration of trial

Class of oil used

Mean pressure on boiler, $1 \mathrm{lb}$.

Total lb. of water evaporated

Pounds evaporated per hour

Pounds of water per pound of oil

Ditto from and at $212^{\circ} \mathrm{F}$.

Mean temperature of feed water deg. Fahr. . . . . . .

Temperature of oil in measuring tank, deg. Fahr.

Total gallons of oil consumed ,, pounds of oil consumed

Gallons consumed in 1 hour

Pounds consumed in 1 hour

Pressure on oil at burner pound.

Specific gravity of oi

Temperature of uptake deg. F.

Smoke at funnel top . . .

Air pressure in burner, pounds

Revolutions of blowing engine

Pounds of oil per sq. ft. of grate.

Pounds of water per sq. ft. of heating surface

\begin{tabular}{|c|c|} 
Sept. 6, 1899. & Sept. 14, 1899. \\
\hline 3 hours & 4 hours
\end{tabular}

Borneo crude Borneo crude

\begin{tabular}{c|c|}
111 & $110 \cdot 5$ \\
24,161 & 35,323 \\
$8053 \cdot 7$ & $8830 \cdot 75$ \\
$11 \cdot 1$ & $10 \cdot 9$ \\
$12 \cdot 9$ & $12 \cdot 75$ \\
& \\
$89^{\circ}$ & $89^{\circ}$ \\
& \\
$68^{\circ}$ & $68^{\circ}$ \\
$225 \cdot 3$ & 337 \\
2174 & 3244 \\
$75 \cdot 1$ & $84 \cdot 2$ \\
$724 \cdot 7$ & 811 \\
$4 \cdot 3$ & $4 \cdot 3$ \\
.965 & .965 \\
$650^{\circ}$ & $665^{\circ}$ \\
\hline
\end{tabular}

Light brown Light brown

\begin{tabular}{c|c}
3.2 & $3 \cdot 2$ \\
310 & 350 \\
$18 \cdot 1$ & $20 \cdot 3$ \\
& \\
4.75 & $5 \cdot 5$
\end{tabular}

Sept. $19,1899$.

2 hours

Borneo crude

First hour. 'Second hour.

$109.8 \quad 110.4$

$9362 \cdot 5 \quad 9511$

$9362 \cdot 5 \quad 9511$

$10 \cdot 93 \quad 10 \cdot 92$

$\begin{array}{ll}12 \cdot 85 & 12 \cdot 84\end{array}$

$83^{\circ} \quad 83^{\circ}$

$67^{\circ} \quad 67^{\circ}$

\begin{tabular}{l|r}
88.8 & 90.2
\end{tabular}

\begin{tabular}{l|r}
$856 \cdot 5$ & $870 \cdot 3$
\end{tabular}

$88 \cdot 8 \quad 90 \cdot 2$

\begin{tabular}{l|l}
856.5 & $870 \cdot 3$
\end{tabular}

\begin{tabular}{l|l}
$4 \cdot 3$ & $4 \cdot 3$
\end{tabular}

$.965 \quad .965$

\begin{tabular}{l|l}
$720^{\circ}$ & $720^{\circ}$
\end{tabular}

Light brown

$$
\begin{array}{r}
3 \\
320 \\
21 \cdot 5 \\
\\
5.5
\end{array}
$$




\section{ENGLISH STATIONARY PRACTICE WITH LIQUID FUEL}

7.5 per cent. of water in the oil is allowed for in the above results. This seems rather excessive.

The boiler had the following dimensions-

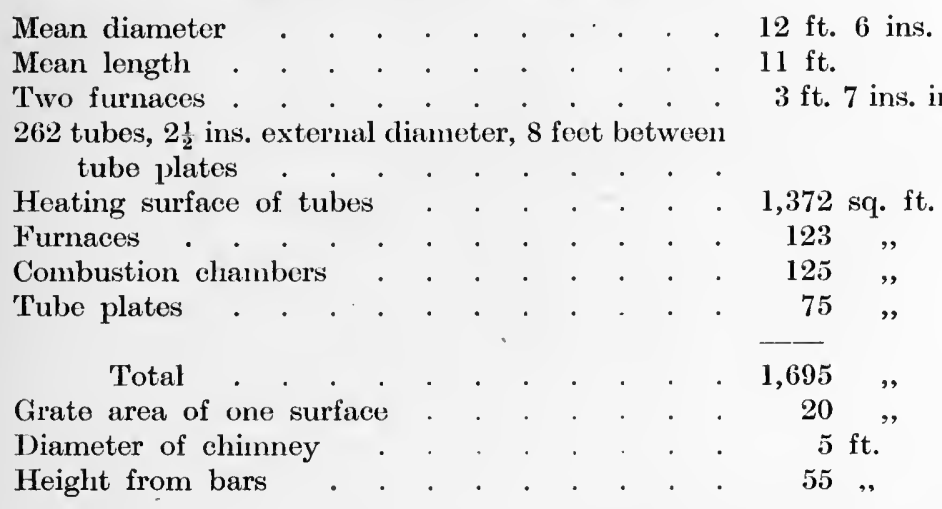

The burners are arranged so as to be readily swung back when coal firing is to be resumed, and there is very little change to the furnace in the system of fig. 52 . Probably the light smoke which is made might be reduced by the use of somewhat more fire-brick in the furnace or combustion chamber.

Tests made at Birkenhead are said to have shown an evaporation as high as 15.5 pounds from and at $212^{\circ} \mathrm{F}$. per pound of Russian astatki and without smoke. Borneo oil is credited by Dr. Tate with less hydrogen than usually is found in petroleum fuels, the average formula apparently being $\mathrm{C}_{7} \mathrm{H}_{10}$. The burner for this system is described under the head of atomizers, fig. 82 .

\section{The Hydroleum Company's System.}

In this system great stress is laid upon the spraying of the oil through a com-

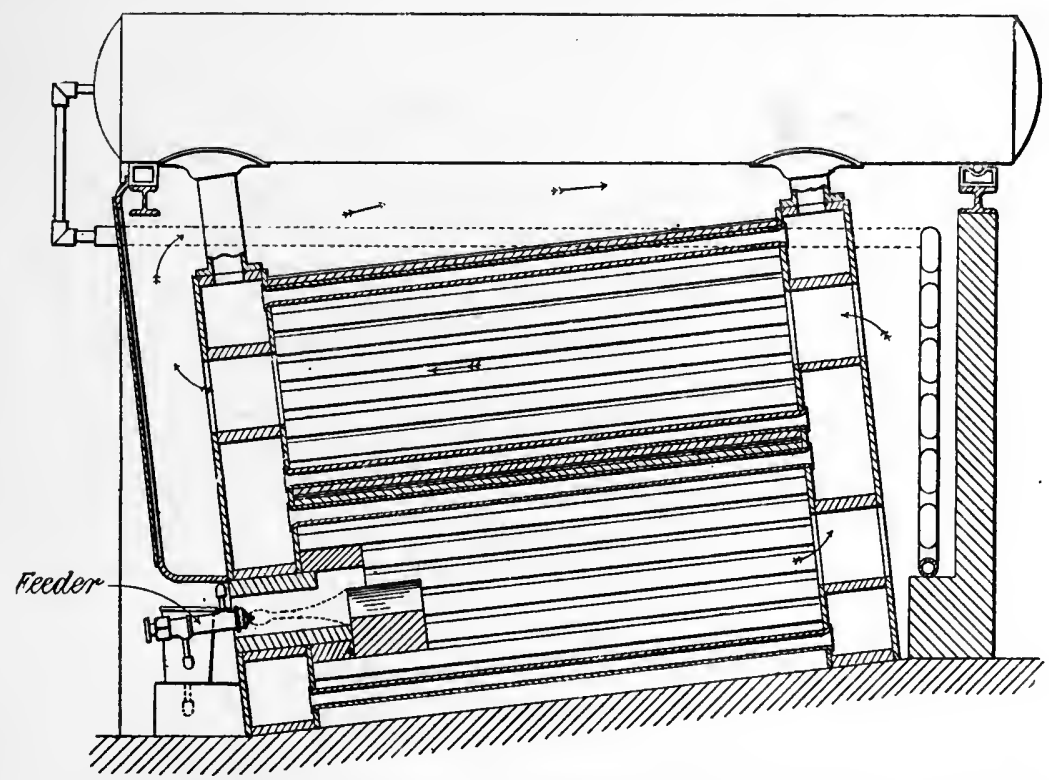

Fig. 53. Special Boiler. "Hydroleum" Liquid fuel System 203 


\section{LIQUID FUEL AND ITS COMBUSTION}

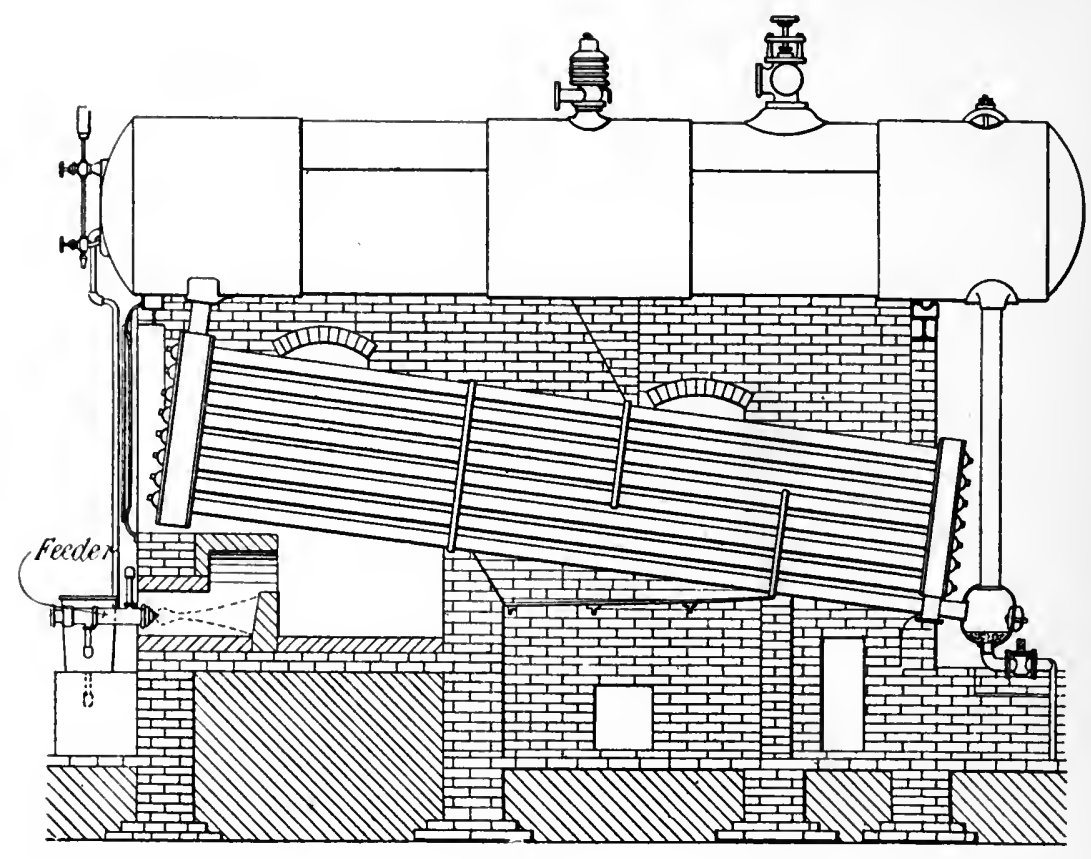

Fig. 53a. Water Tube Boller with Hydroleum Liquid Fuel System

paratively restricted area or passage upon a dash-brick, which, it is elaimed, becomes highly heated and vaporizes the spray. This is shown in fig. 53, which is a form of water tube boiler fitted with the system, and in fig. 53a.

Tested with water gas tar at the works of Messrs. Muirhead \& Co., Elmer's End, Kent. the following results were obtained-

Wate

Duration of test .

Mean temperature of feed water.

Mean pressure on boiler

Pounds of water evaporated
Oil.

Aug. 14, 1901. May 15, 1901.

2 hours

70 Fahr.

$90 \mathrm{lb}$.

2,400

211
9 hours

60 Fahr.

$90 \mathrm{lb}$.

10,100

1,792

Pounds of water evaporated per $\mathrm{lb}$. from and at $212^{\circ} \mathrm{F} . \quad$. $\quad 13 \cdot 47 \quad 16 \cdot 73$

Pounds of water evaporated per $\mathrm{lb}$. from and at $212^{\circ} \mathrm{F} . \quad$. $\quad 13 \cdot 47 \quad 16 \cdot 73$

Priee of tar

Price of coke

N.B.-In making the test the tar was taken as received, no deduction being made for any water it contained.

Comparing these two tests it will be seen that-

To evaporate each pound of water with coke cost

To evaporate each pound of water with water gas tar
$0 \cdot 0172 d$.

$0.0075 d$.

$0 \cdot 0097 d$. per $1 \mathrm{~b}$.

Saving by the systen of oil firing

The burner of this system will be found deseribed under the head of atomizers, but the Hydroleum Company do not profess to atomize. They lay stress upon the use of a dash-brick only about 18 inches in front of the spray nozzle, an intense local heat being developed on the face of the brick. Sufficient air to burn the vaporized oil 
ENGLISH STATIONARY PRACTICE WITH LIQUID FUEL

\begin{tabular}{|c|c|c|c|c|c|c|}
\hline & & 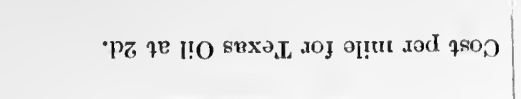 & & & $\begin{array}{l}08 \\
10 \\
\frac{10}{0} \\
0\end{array}$ & \\
\hline & & " & 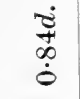 & & & \\
\hline & & . & . & & 离 & \\
\hline & & 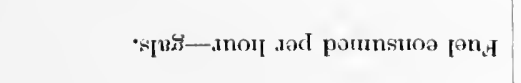 & 总 & $\stackrel{\infty}{\stackrel{\infty}{\rightarrow}}$ & $\stackrel{8}{\dot{\leftrightarrow}}$ & $\stackrel{+}{\stackrel{\leftrightarrow}{-}}$ \\
\hline & & 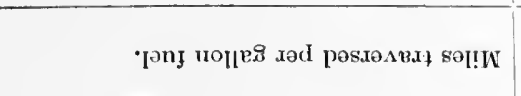 & $\stackrel{\dddot{\Xi}}{ \pm}$ & & $\stackrel{9}{\stackrel{9}{i}}$ & \\
\hline & & 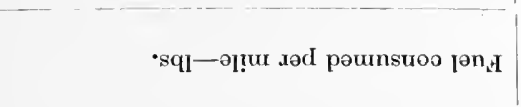 & $\stackrel{\infty}{+}$ & & 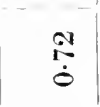 & \\
\hline & & 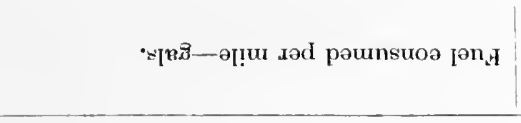 & $\stackrel{5}{\grave{b}}$ & & 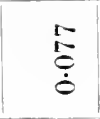 & \\
\hline & & 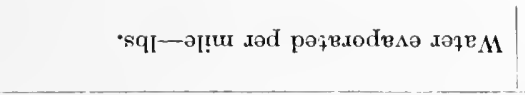 & $\ddot{g}$ & & $\stackrel{\substack{9 \\
i}}{i}$ & \\
\hline & & 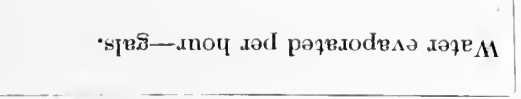 & $\stackrel{\hat{\varphi}}{\dot{S}}$ & $\frac{a}{\dot{\theta}}$ & $\stackrel{8}{\leftrightarrow}$ & $\because$ \\
\hline & & 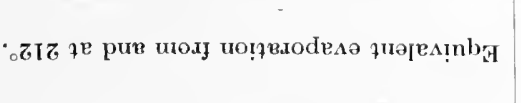 & $\stackrel{\infty}{i g}$ & $\stackrel{\Xi}{=}$ & $\stackrel{\infty}{\stackrel{\infty}{=}}$ & $\stackrel{\stackrel{\leftrightarrow}{\leftrightarrows}}{\doteq}$ \\
\hline & & 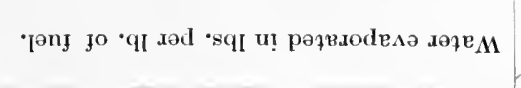 & $\stackrel{9}{\stackrel{9}{i}}$ & $\stackrel{\leftrightarrow}{\dot{b}}$ & $\stackrel{\check{\sigma}}{\check{\sigma}}$ & $\stackrel{\infty}{\rightleftharpoons}$ \\
\hline & & 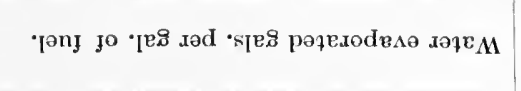 & $\begin{array}{l}\infty \\
\dot{\infty} \\
\dot{\infty}\end{array}$ & $\stackrel{0}{\stackrel{0}{0}}$ & 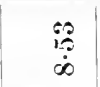 & $\overrightarrow{\dot{s}}$ \\
\hline & & $\cdot{ }^{\mathrm{sq}} \mathrm{I}-$ pəuunsuoo $_{\text {Iөn }}$ & $\vec{i}$ & 9 & 莣 & $\stackrel{+}{G}$ \\
\hline & & $\mathrm{s}_{\mathrm{S} \text { [в }}$ & ڤִ & 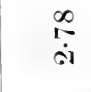 & $\stackrel{\Re}{\mathscr{H}}$ & 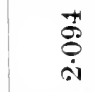 \\
\hline & & : & $\dot{\leftrightarrow}$ & $\stackrel{\substack{0 \\
\stackrel{\infty}{\infty}}}{\sim}$ & 量 & 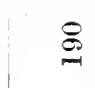 \\
\hline 客 & & 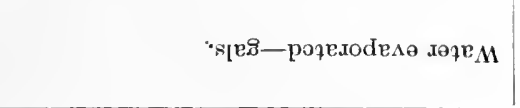 & $\stackrel{\dot{m}}{\dot{m}}$ & 党 & 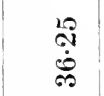 & $\stackrel{\rho}{\dot{g}}$ \\
\hline & & 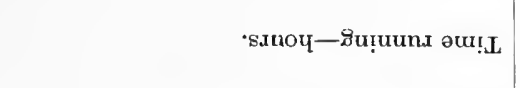 & 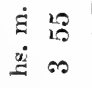 & $\begin{array}{ll}0 \\
\mathrm{a}\end{array}$ & $\begin{array}{l}0 \\
*\end{array}$ & $\begin{array}{ll}0 \\
\text { a }\end{array}$ \\
\hline & & 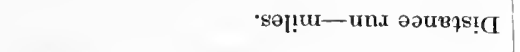 & i⿱口 & & 임 & \\
\hline & & & 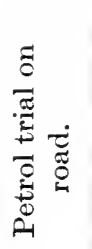 & 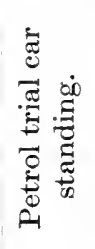 & 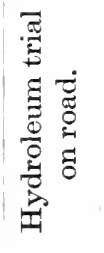 & 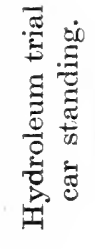 \\
\hline
\end{tabular}




\section{LIQUID FUEL AND ITS COMBUSTION}

is induced through the openings provided round the spray nozzle. The sprayer is made in three sizes, having capacities of 1,3 , and 10 to 12 gallons of oil per hour, and the oil is induced to flow by the inductive action of the steam annulus. The feed tank is kept at a level of half an ineh below the nozzle by means of a ball float valve. From 14.5 to 15 pounds of water are stated to be evaporated from and at $212^{\circ} \mathrm{F}$. per pound of oil, the expense of steam being 5 per cent. of the evaporation.

The Hydroleum system has been applied to steam motor cars, and Mr. W. Beaumont found that, per gallon of Texas oil, the Hydroleum burner evaporated 8.81 gallons of water from $48^{\circ} \mathrm{F}$. against 7.71 pounds evaporated by a petrol burner. The figures of the tests are here given. It must be noted, of course, that a gallon of oil contains 32 per cent. more weight than a gallon of petrol. The final result, however, is greatly in favour of the cheap heavy oil, as might be anticipated. With oil
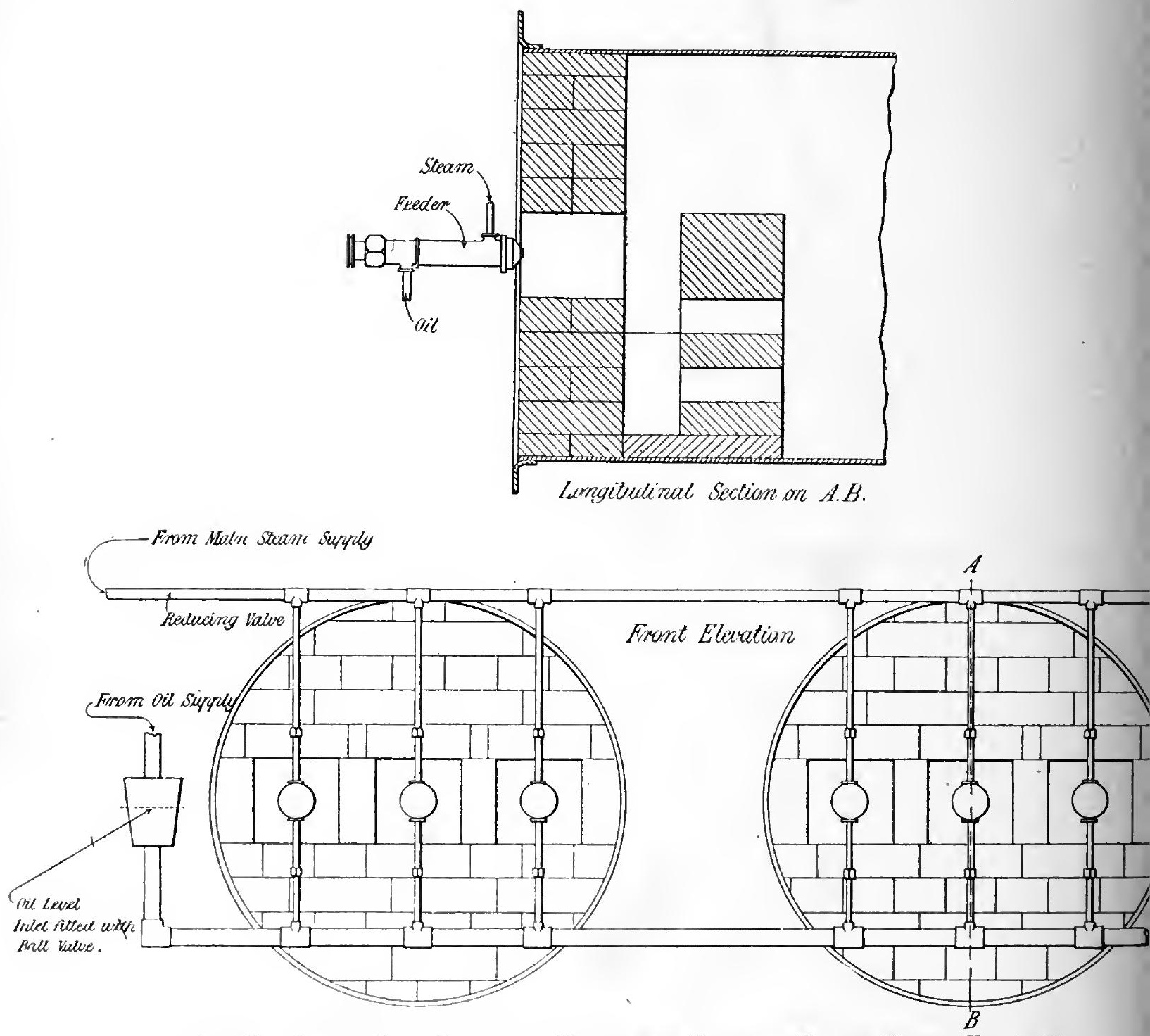

Fig. 53b. Jiquin Fuei, Burning. Hydroleum System. Marine Boiler Furnaces 206 


\section{ENGLISH STATIONARY PRACTICE WITH LIQUID FUEL}

fuel, in fact, a steam car was run at an expense for fuel under $\frac{1}{6}$ of a penny per mile, where more expensive petrol spirit costs five or six times as much.

Though not claimed as an atomizing system, the Author considers that the effects of the Hydroleum burner sufficiently resemble atomizing for this burner to be held up as an example of the success of the system.

Experience shows that for a burner capable of burning 10 gallons per hour there should be an opening for air round the atomizer of $8^{\prime \prime} \times 8^{\prime \prime}$, which, after deducting the cross section of the atomizer itself leaves sixty square inches of air opening for ten gallons per hour. Worked out on the basis of $15 \mathrm{lbs}$. of air per $\mathrm{lb}$. of oil fuel and 13 cubic feet per lb. the velocity per second of the air stream is only 13 feet. Agallon of fuel is taken as $10 \mathrm{lb}$., which is about correct for tar. The amount of fuel fed is simply regulated by the amount of steam used, and this draws in more or less air as required by the fuel, and very little regulation of the air inlets is required. The Hydroleum Company, to reduce noise, place a trunk casing round each burner with opening downwards. This gives very effectual silencing. If desired, these air trunks may be all coupled to a common air main brought from outside the building. As seen by the Author, burning oil gas tar of Sp. Gr. 1.04 the system was smokeless and very silent. The tar was being burned in a Lancashire boiler. In fig. $53 \mathrm{~b}$ is shown the application of the Hydroleum system to circular furnaces of Lancashire or marine type, each burner having its air opening surrounding it. The air trunks are not shown in the figure. The Hydroleum atomizer will be found described and illustrated in the chapter on atomizers. 


\section{Chapter XXIII}

\section{THE COMBUSTION OF VAPORIZED LIQUIDS}

\section{The Clarkson and Capel Burner}

$I^{1}$ $\mathrm{N}$ this burner system the liquid employed is preferably the cheaper and commoner qualities of lamp oil. The burner shown fig. 55 is one that is fitted to floating fire engines. It is capable of burning 40 gallons of oil per hour and of developing up to 200 h.p. The No. 5 size will burn 20 gallons per hour.

In each of these burners there is a gas ring to give the necessary initial heat to vaporize the oil. The gas jets heat the coils to which the oil is fed, and the vapour passes from the coil to the rear of the long casting, which it enters through a small orifice controlled by a needle point. Air is admitted by a door at the back end of the casting and the mixed vapour and air are thoroughly mixed in the pipe and issue round the lip of the mushroom valve, where ignition takes place and a large flaring flame is formed of great intensity, the heat from which eontinues to vaporize the oil in the coil, and the process is continuous. The oil is under pressure in the supply tank, the pressure being easily generated by an air pump. The pressure forces the oil through the system, and when, in vaporized form, this reaches the jet nozzle, it issues with a high velocity and induces a large flow of air through the valve. The needle of the jet nozzle is worked by the same controlling lever as regulates the cap of the burner. In the course of this lever, which is of compound order, is a maximum and minimum stop that can be regulated to prevent excessive opening or entire extinguishing of the flame. The hand wheel, in fig. 55, of the large burner, shows how this is effected.

Fig. 56 is the automobile pattern and its initial heating device is a spirit trough containing a coil of nickel wire. Petrol or alcohol can be employed for this initial heating. The burner is placed in the cylindrical base of the boiler; the case bottom is perforated for air admission and provided with a door for inspection. The air door of the burner trunk is shown open on the first notch of its catch.

In fig. 57 is shown the open tank system, the main oil tank not being under pressure. From this it is pumped to the pressure tank into which air is also pumped, and thence is fed to the burners. Any excess of oil pumped in, escapes by way of a relief valve to the main tank. A pressure gauge is fitted to show the pressure of the oil.

The application to a small boat boiler is shown in fig. 58, and shows that no structural change is made in the boiler, the burner tube or trunk coming in under the mud ring, and air admission being otherwise through the ash-pit. The fire bars are removed. Fig. 59 is a diagram of the small vessel itself. 


\section{THE COMBUSTION OF VAPORIZED LIQUIDS}

A system of preliminary heating by means of paraffin is shown in fig. 54 . Here a series of asbestos wicks are provided with an air draught by a small

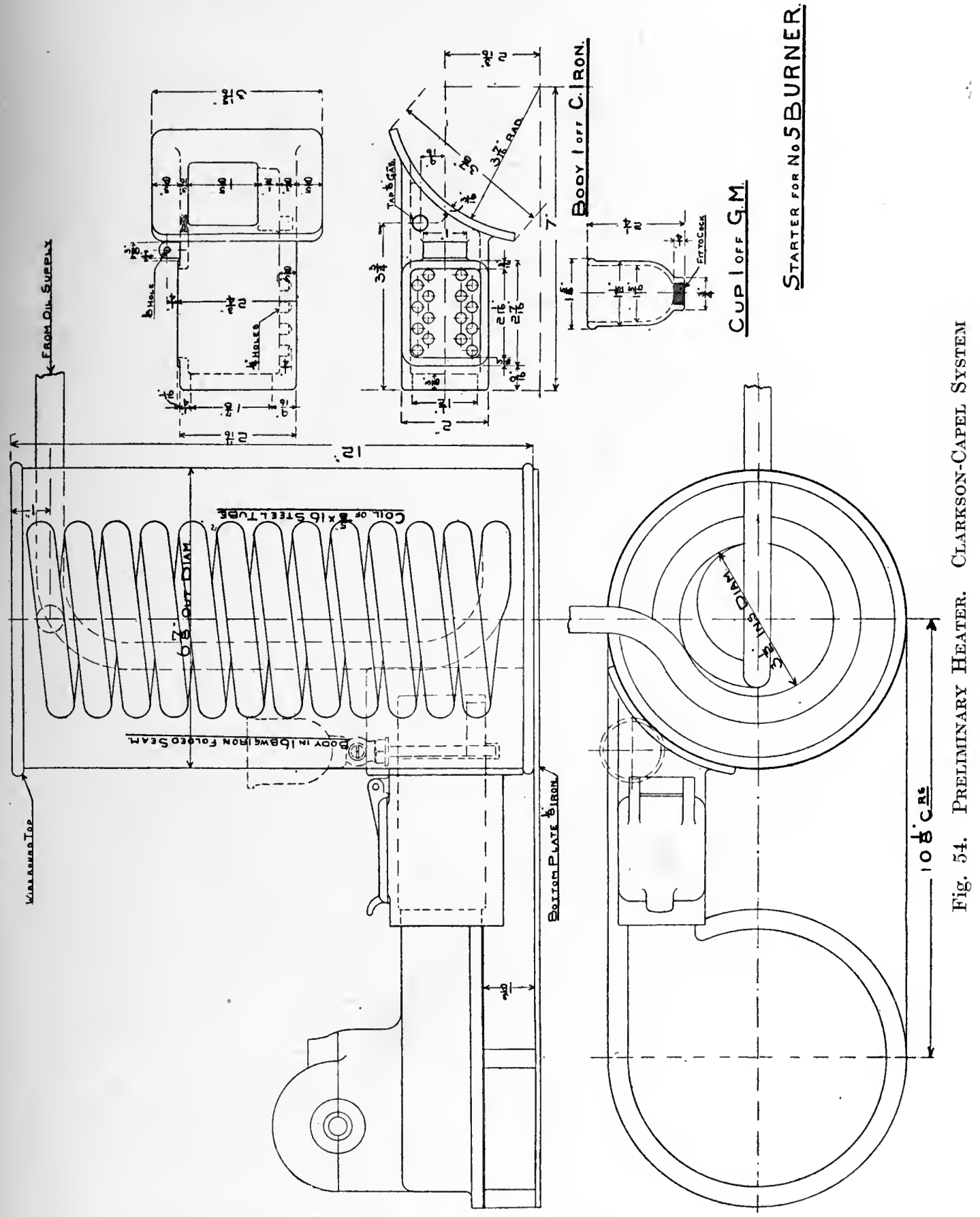

fan and fed with a limited quantity of paraffin from a small cup, the main supply of oil being heated in the $\frac{5}{8}$ inch coil. After the cupful of paraffin is finished the flame of the main burner will be burning and will provide heat 


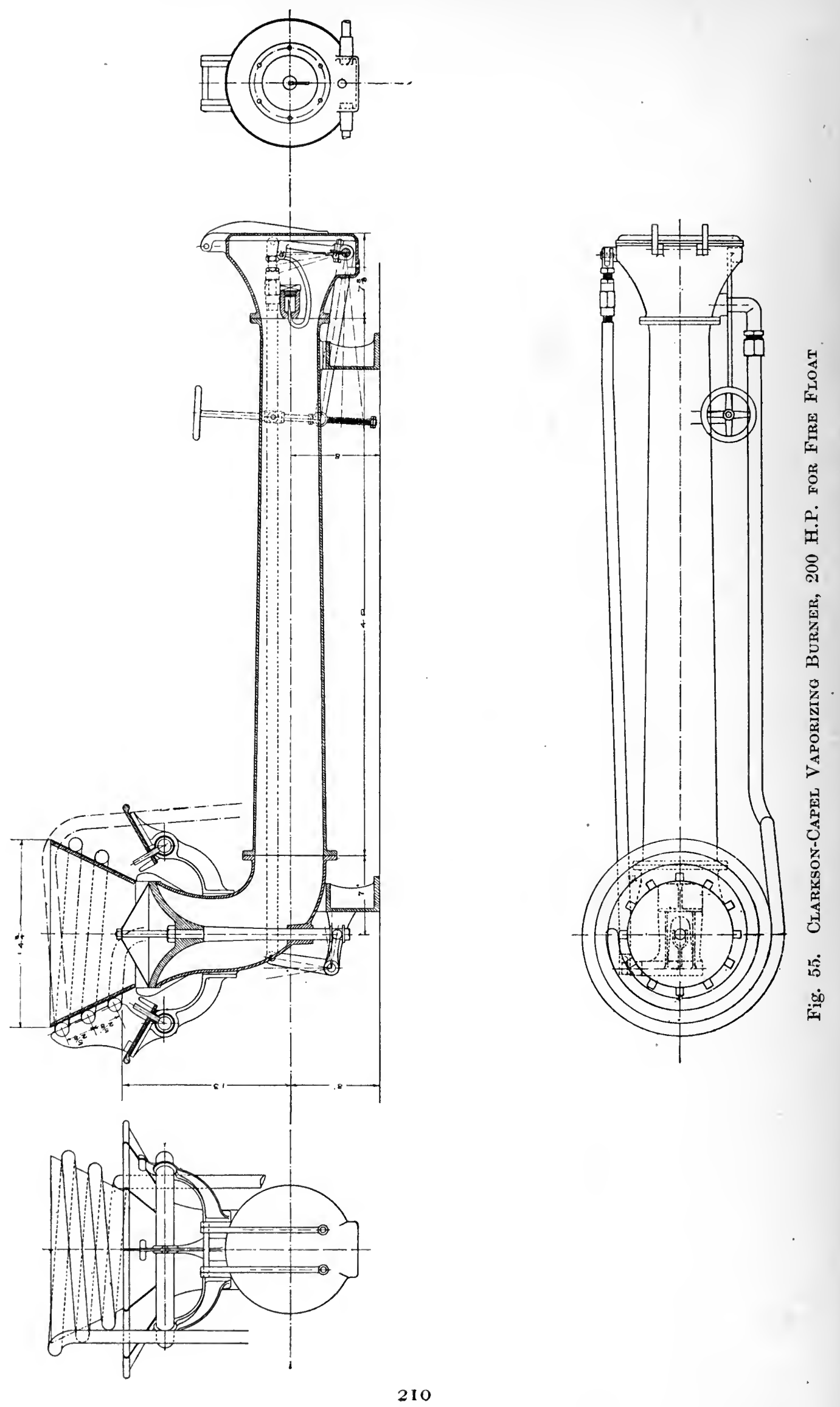




\section{THE COMBUSTION OF VAPORIZED LIQUIDS}

for further vaporization.

For use in automobiles, small steam boats, the cheap forms of lamp oil are commercially practicable, though they would be too expensive for ordinary continuous industrial steam raising purposes. For other reasons these same oils commend themselves particularly for the purposes of fire engines and fire floats. Here the use of expensive fuel in even considerable quantity for a few hours is warranted by the extraordinary nature of the service, namely, the extinguishment of a fire that may be consuming valuable buildings and their contents. Even the lighter petrols are used for steam raising purposes in certain forms of steam cars, the petrol being sprayed upon a hot cast iron plate through which fine jets of air are introduced and the heat is utilised to raise steam in coil boilers of the flash type into which water is injected to provide the steam for instant use by the engine.

In the Clarkson system one pound of oil can be counted upon to give an evaporation of 10 pounds of water from $80^{\circ} \mathrm{C}$., to steam at 200 pounds, or an equivalent evaporation from $212^{\circ} \mathrm{F}$. of nearly 11 pounds. The oil receptacle is usually worked at a pressure of 40 pounds, and the cheaper grades of Russian oil are perhaps the most suitable, such as Rocklight, Lustre, etc.

As stated elsewhere, the calorific capacity of all the petroleum products is prac-

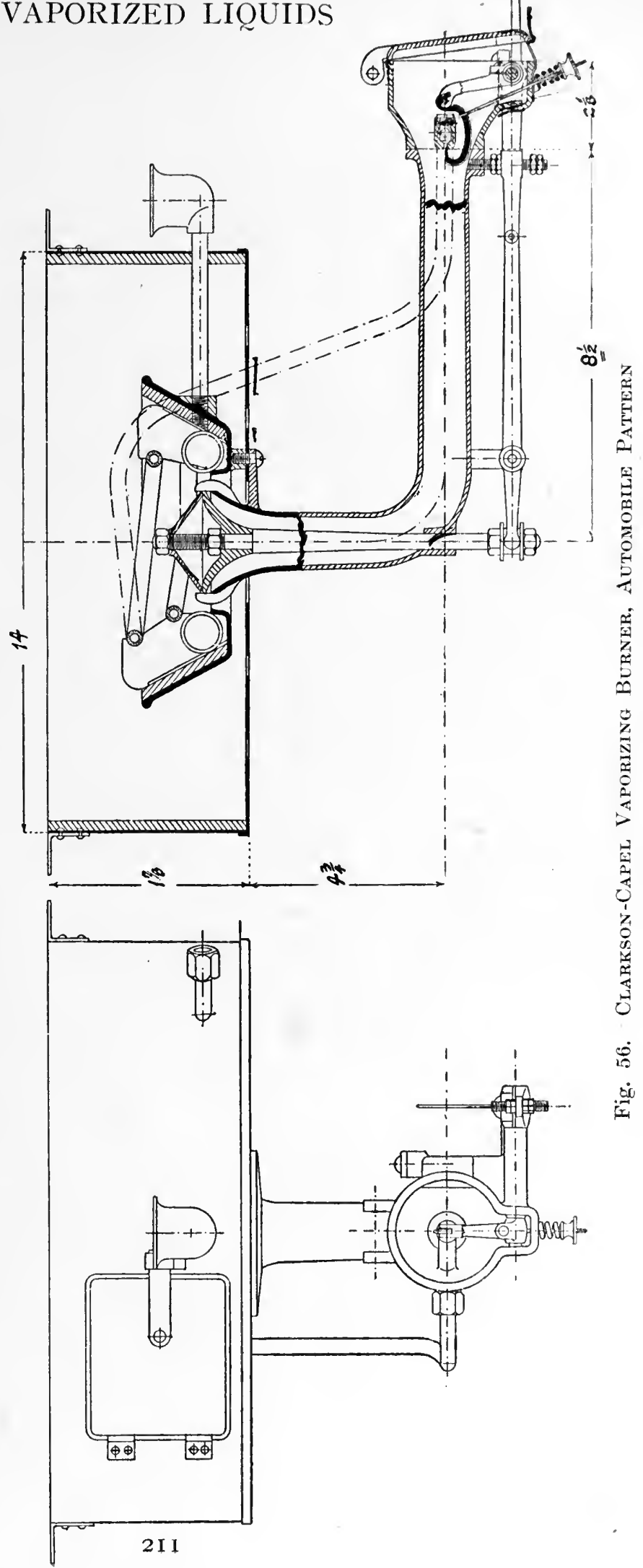




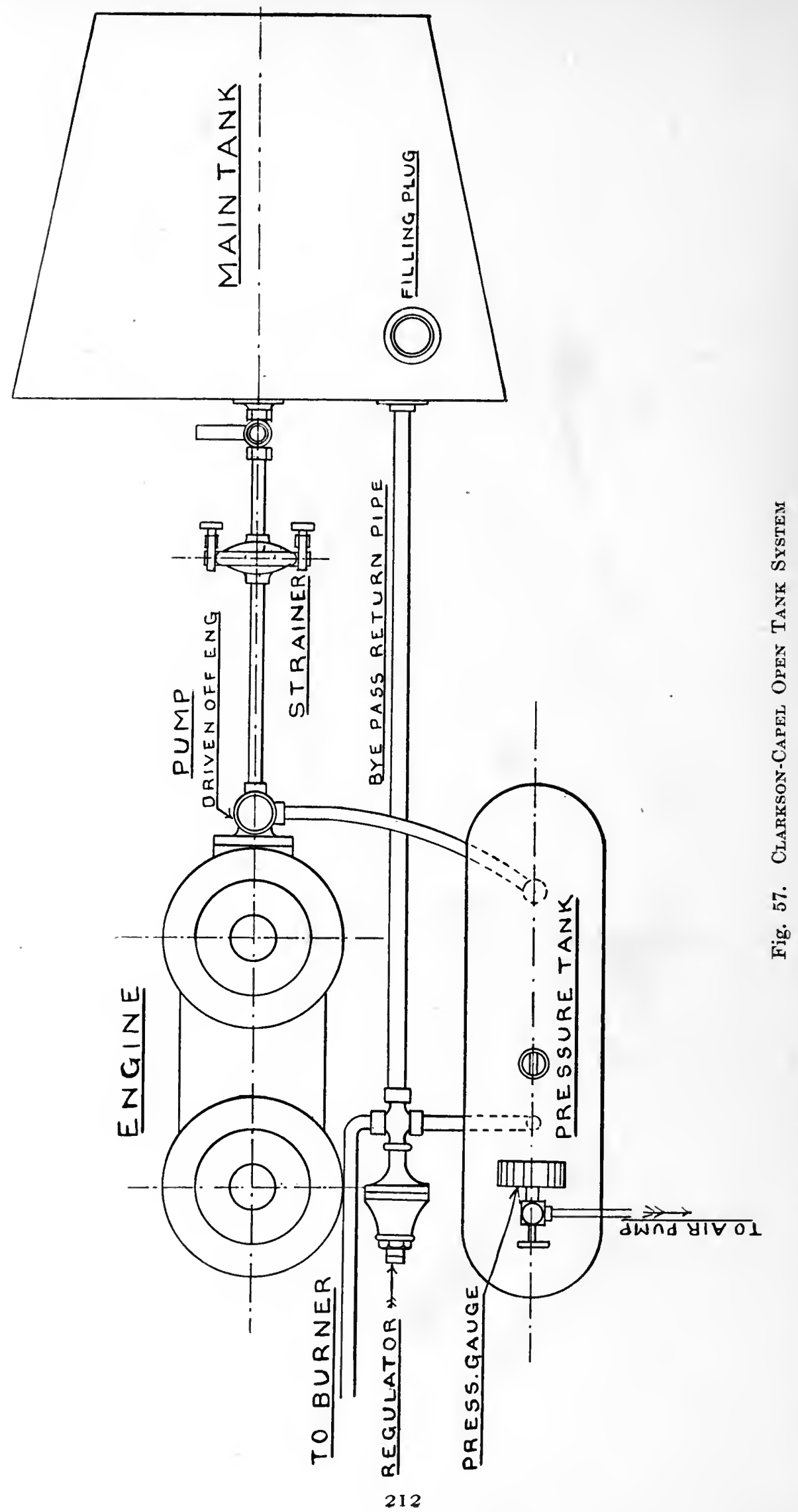



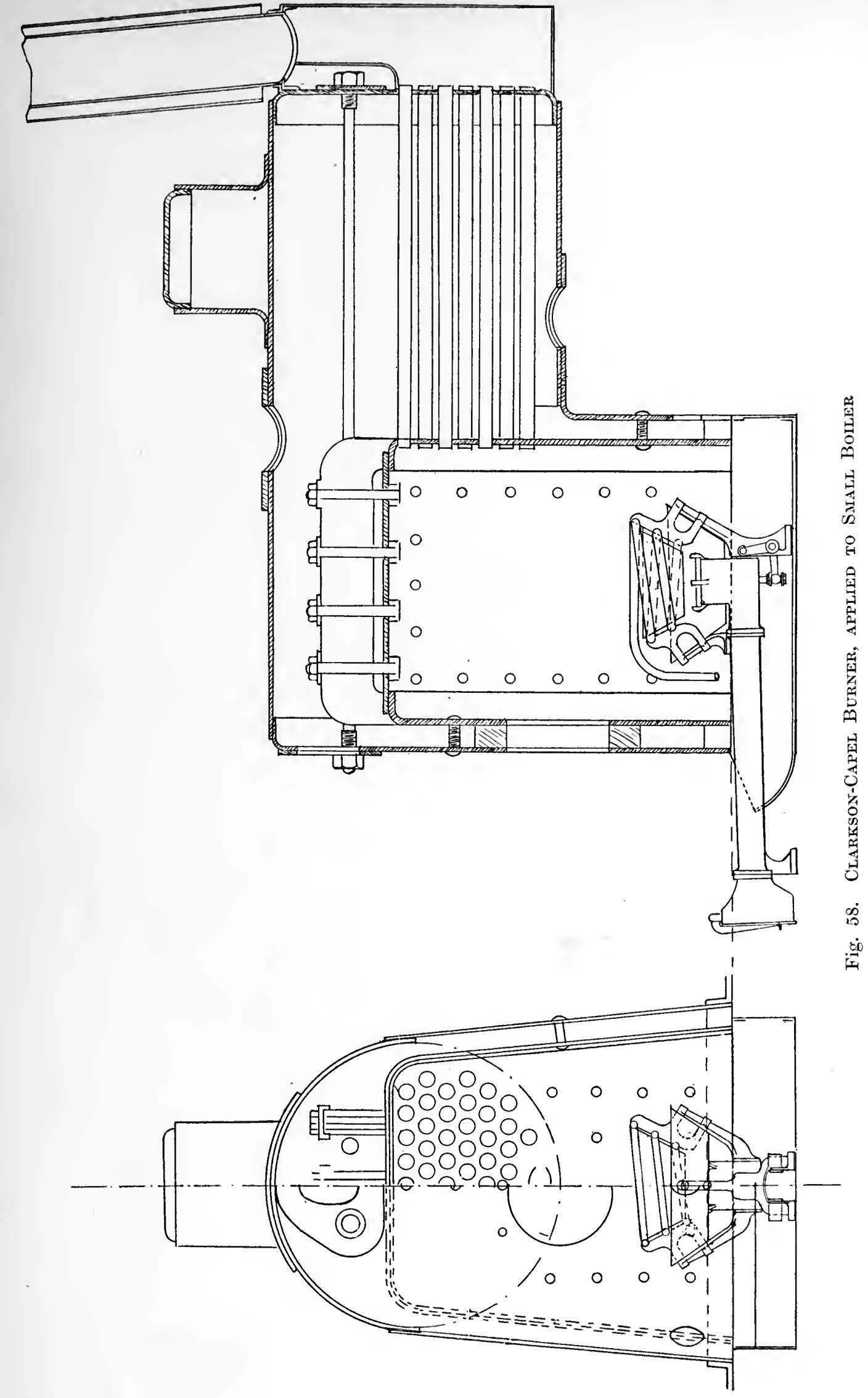


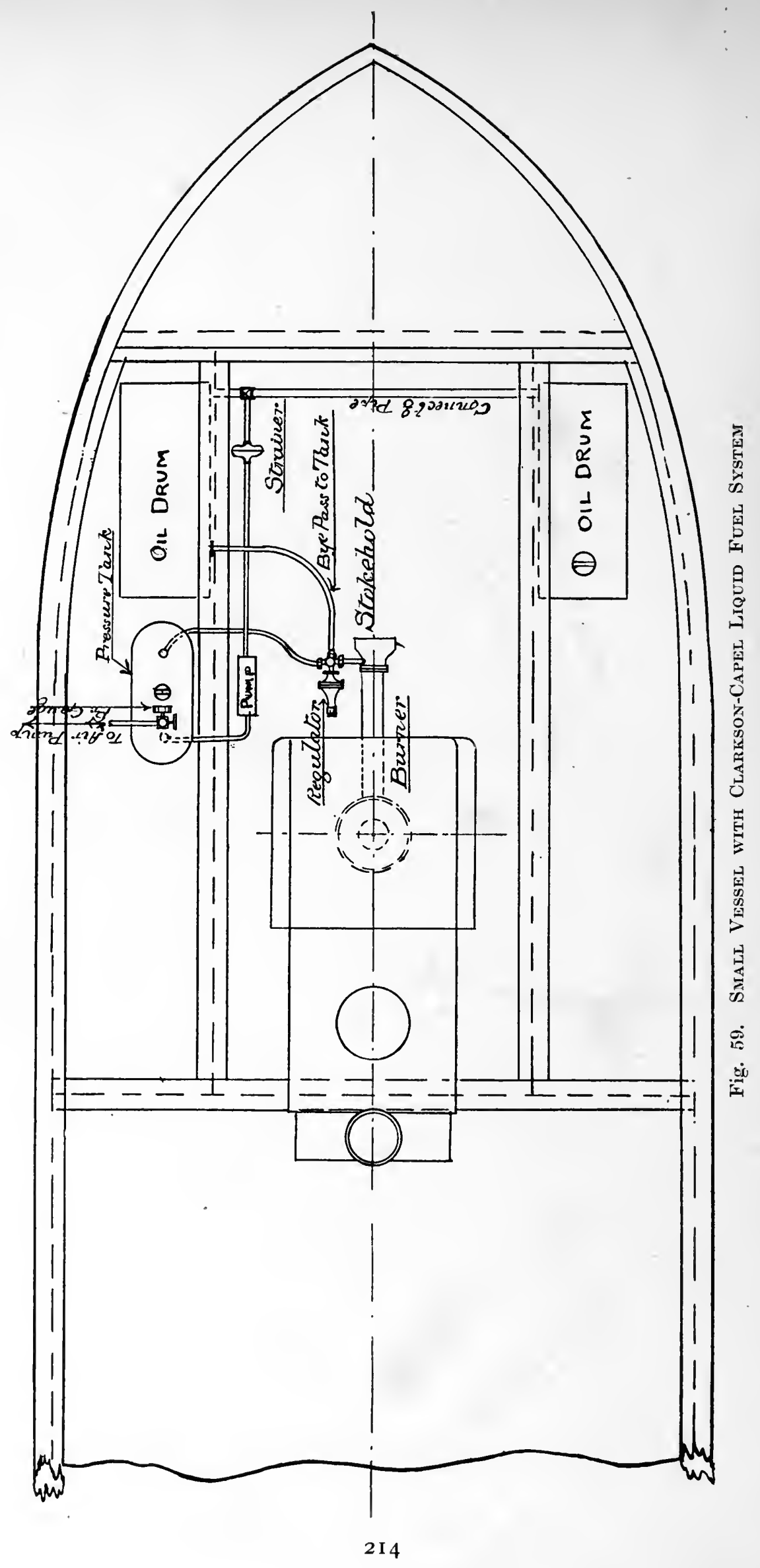




\section{THE COMBUSTION OF VAPORIZED LIQUIDS}

tically identical, the lighter oils being most powerful beeause they contain the highest percentage of hydrogen, but the difference is immaterial. The evaporative efficiency of the small boilers of cars and eanoes, is less than that of large boilers simply because it is not desirable to load up a ear with too great a weight of heating surface.

In fig. 60 is shown the starting device employed on automobile cars, a pad fed with a drop feed of oil being ignited by a match and giving preliminary heat to the burner.

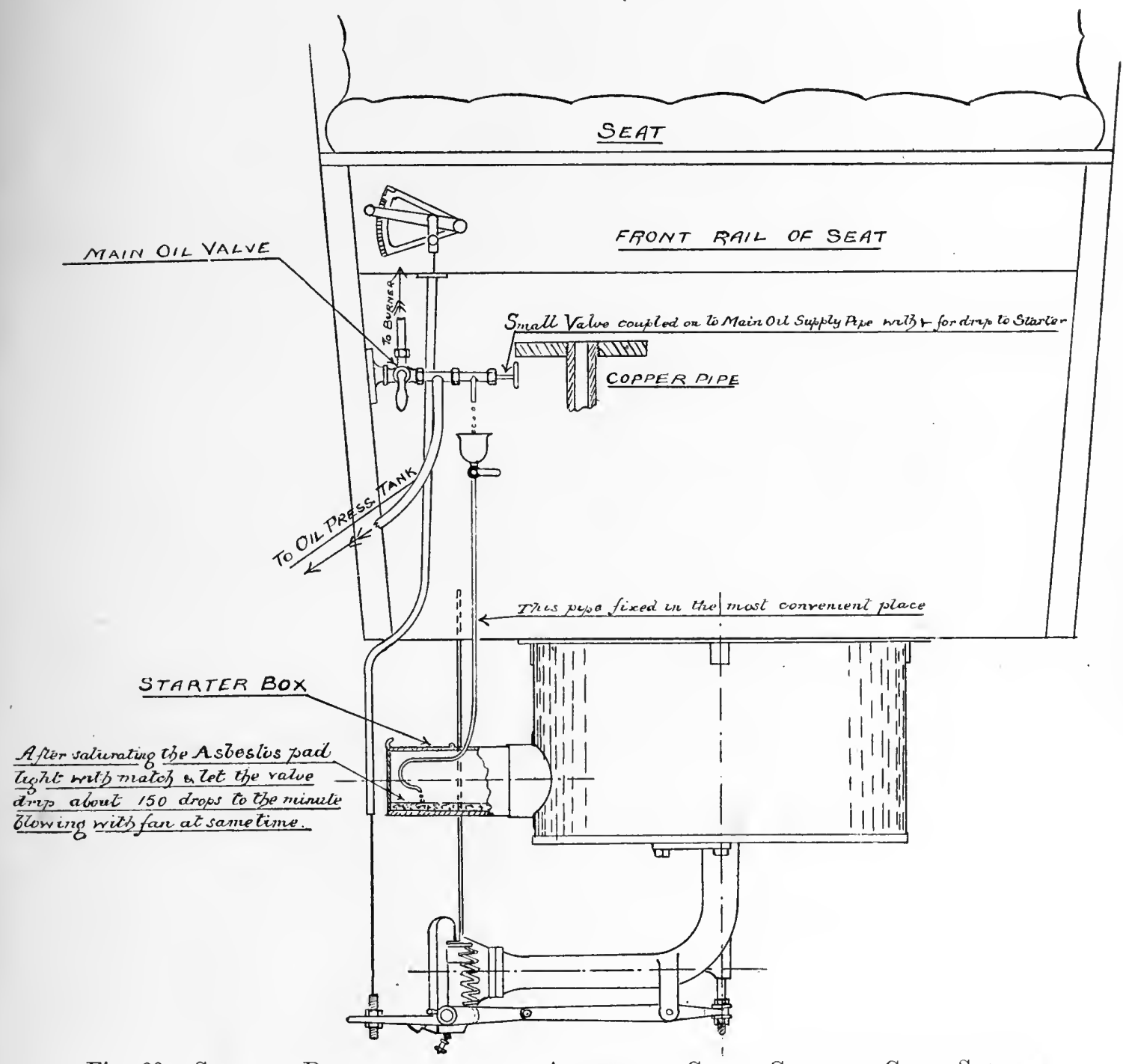

Fig. 60. Starting Device employed on Automobile Cars. Clarkson-Capel System 


\section{Chapter XXIV.}

\section{COMPARISON OF AIR AND STEAM ATOMIZATION}

The Ellis and Eaves System.

$\mathrm{N}$ this system the atomizing is done by steam, and heated air is supplied to the furnaces, the draught being fan induced. The air is heated in tubular heaters having two-thirds of the boiler heating surface, and placed over the boiler in the
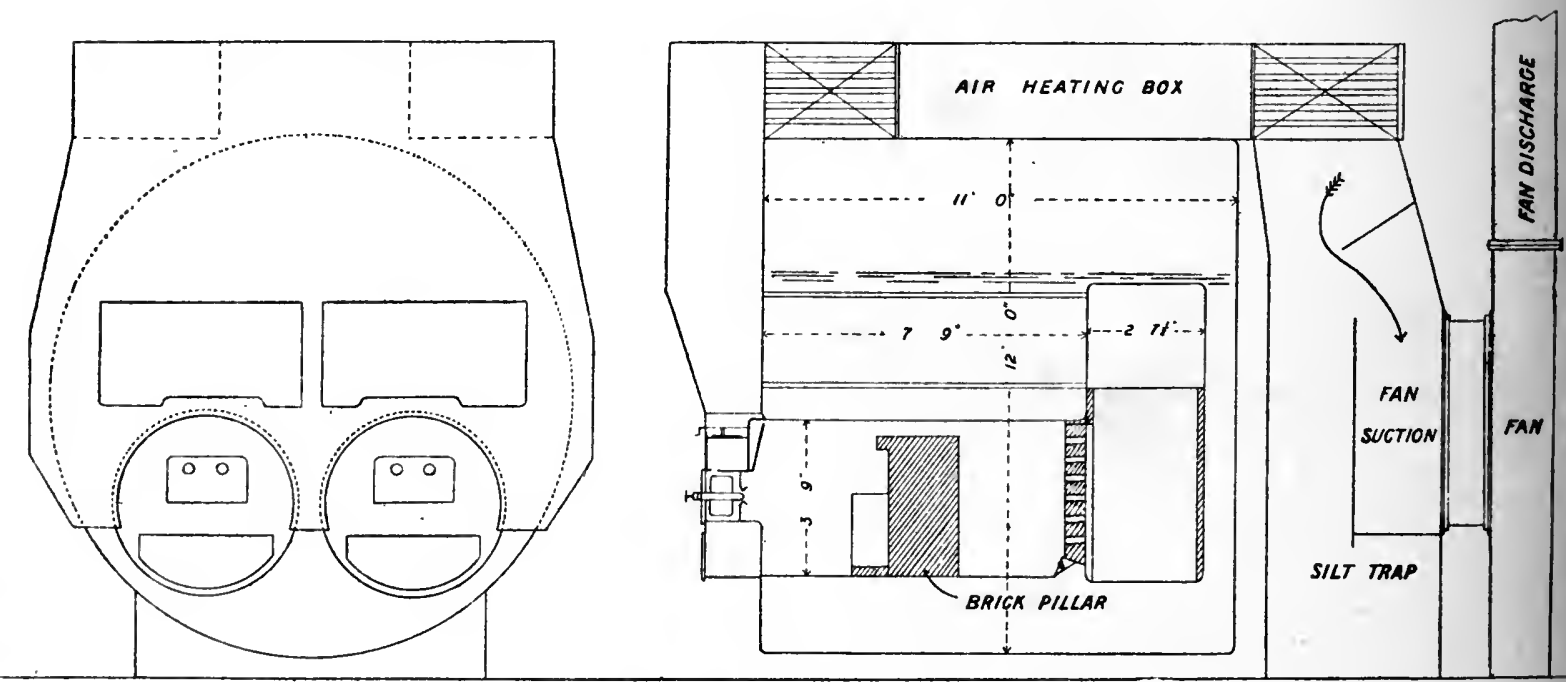

Fig. 61. Ellis and Eaves System, Marine Boller Arrangement, for Heating Air

course of the gases to the fan, as shown in fig. 61 ; the admission of air to the furnaces being, as in fig. 62 , round the outside of the atomizer.

Tests were also made with air as the atomizing agent. The air pressure was 20 pounds per square inch, and the results are given below. A subsequent test with air at 35 pounds pressure showed 11,108 pounds of water per hour from and 


\section{COMPARISON OF AIR AND STEAM ATOMIZATION}

at $212^{\circ} \mathrm{F}$. and $15 \cdot 49$ pounds per pound of oil. This is somewhat less than air at the more moderate pressure of 20 pounds. The atomizing air was not heated, and had a temperature of $80^{\circ} \mathrm{F}$. only, or it might have given better results.

The difference between steam and air atomizing seems to be practically nil.

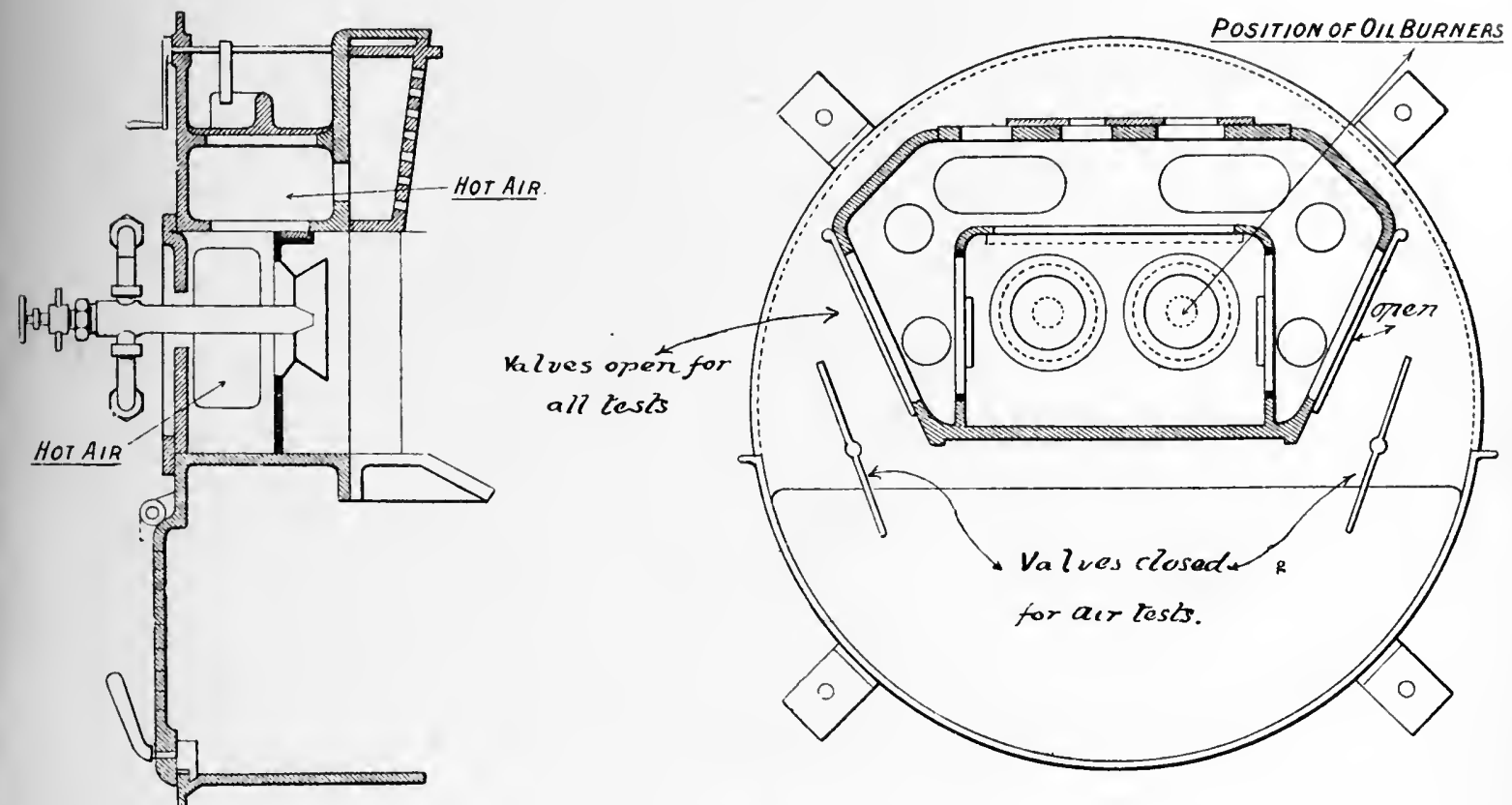

Fig. 62. Ellis and Eaves Systeme, Furnace Door Arrangement

It remains simply to compare the amount of steam used direct with that used in eompressing the air.

The analysis of the flue gases showed a mean result of 11.2 per cent. of $\mathrm{CO}_{2}$ and 10 per cent. of oxygen in the left hand furnace and 14.1 per cent. of $\mathrm{CO}_{2}$ and 8.4 of oxygen in the right hand furnace, the mean of both being $\mathrm{CO}_{2}=12 \cdot 6$, $0=9 \cdot 6, \mathrm{CO}=0$.

The tests made with this system of induced draught and oil fuel burning of six hours duration, were a suceess, but the question was raised whether the system could be worked for a lengthened period without giving trouble through deposits of soot and unconsumed oil becoming ignited in the air heater and casings.

A continuous test of 120 hours was made, careful observations being taken of the temperatures, evaporation, etc., during that time.

Particulars of boiler, which were the same as in the previous tests-

$12 \mathrm{ft}$. mean diameter by $11 \mathrm{ft}$. mean length, fitted with two Purves furnaces of 3 ft. 9 in. inside diameter.

148 Servé tubes, $3 \frac{3}{4}$ in. outside diameter by $7 \mathrm{ft} .9 \mathrm{in}$. long and retarders.

Heating surface, 1,200 sq. ft. Grate surface (for coal burning) 43 sq. feet.

Ratio of H.S. to G.S. 28 to 1. 


\section{LIQUID FUEL AND ITS COMBUSTION}

Fitted with the Ellis and Eaves system of induced draught. Surface in air heating tubes, $800 \mathrm{sq}$. ft.

Diameter of Fan wheel, $7 \mathrm{ft} .6 \mathrm{in}$.

The boiler feed supply was taken from two tanks, each of 800 gallons and two oil supply tanks for burners, having a capacity of about 900 gallons each were provided. These tanks were not fitted with heating coils, the oil being fed to burners at $75^{\circ} \mathrm{F}$.

The steam to the burners was supplied at 70 pounds per square inch. Texas oil was used, closed flash point 185, calorific value 18400 B.Th.U. Sp. gr. 0.915.

Smoke was only visible for a few seconds when changing over the oil tanks about every eight hours. Heated air was provided; the difference in right and left hand temperatures of air entering the fires being due to the fact that the right hand air heating box and air casings are protected from the weather by a wall, and also that the air entering these is at a higher temperature, due to radiation from the fan discharge.

The test was started on Monday, December 15, 1902, at eleven a.m., the boiler being cleaned before starting, and was continued night and day till eleven a.m. on Saturday, December 20, the installation working without a hitch during the whole of that time. Burners required cleaning occasionally, but this was carried out one at a time, and only occupied a few minutes. Hot air was admitted to the furnaces, the greater portion of this only being admitted round about the burners through vena-contracta nozzles.

At the end of the trial the boiler, air heater casings, etc., were opened up and examined by representatives of the Wallsend Slipway Co. and the International Mercantile Marine Co., and were found to be perfectly clean and in good order, there being no indication whatever of flaming in the casings. From the foregoing and a perusal of the following tables, to the use of heated air the perfected combustion of the oil may be attributed, no smoke is formed and there is no deposit of inflammable oil or soot on the tubes or casings to take fire.

From the table on page 221 the advantages of air heating are shown up clearly. Air which enters the heater at about $54^{\circ} \mathrm{F}$. leaves it at about $284^{\circ} \mathrm{F}$., having taken up $230^{\circ}$ of temperature all of which is absorbed from the furnace gases, which are reduced from about $760^{\circ} \mathrm{F}$. to $520^{\circ} \mathrm{F}$. more or less. They lose the $230^{\circ}$ gained by the air, and this alone represents a very considerable economy, something like 33 per cent. of the otherwise waste heat passing up the chininey. The fan efficiency is also increased. Assuming that the furnace temperature is $2,800^{\circ} \mathrm{F}$. the heating of the air by the waste gases would appear to represent an economy of fuel of 8 to 10 per cent., apart from the higher boiler efficiency due to increased temperature head. bustion.

Air heating is thus advantageous both in economy and more perfect com- 


\section{COMPARISON OF AIR AND STEAM ATOMIZATION}

Steam Atomization.

\begin{tabular}{|c|c|c|c|c|c|c|c|c|c|c|c|c|c|}
\hline \multirow{2}{*}{ Time. } & \multirow{2}{*}{$\begin{array}{c}\text { Steam } \\
\text { Pres- } \\
\text { sure. }\end{array}$} & \multirow{2}{*}{\begin{tabular}{|c|} 
Fan \\
Revo. \\
lutions
\end{tabular}} & \multirow{2}{*}{$\begin{array}{c}\text { Vacu- } \\
\text { um } \\
\text { at Fan } \\
\text { Suc- } \\
\text { tion. }\end{array}$} & \multirow{2}{*}{$\begin{array}{c}\text { Vac- } \\
\text { uum } \\
\text { at } \\
\text { Fur- } \\
\text { nace. }\end{array}$} & \multirow{2}{*}{$\begin{array}{l}\text { Tem. } \\
\text { per- } \\
\text { ature } \\
\text { of Air } \\
\text { eftering } \\
\text { Heater. }\end{array}$} & \multicolumn{2}{|c|}{$\begin{array}{c}\text { Heated Air } \\
\text { entering Fires. }\end{array}$} & \multirow{2}{*}{$\begin{array}{c}\text { Escaping } \\
\text { Gases } \\
\text { entering } \\
\text { Air } \\
\text { Heater. }\end{array}$} & \multirow{2}{*}{$\begin{array}{c}\text { Escaping } \\
\text { Gases } \\
\text { at } \\
\text { Fan } \\
\text { Suction. }\end{array}$} & \multirow{2}{*}{$\begin{array}{c}\text { Foed } \\
\text { Water } \\
\text { Tem- } \\
\text { per- } \\
\text { ature. }\end{array}$} & \multicolumn{2}{|c|}{$\mid \begin{array}{c}\text { WaterTime } \\
\text { talken to } \\
\text { empty } \\
\text { Tanks. }\end{array}$} & \multirow{2}{*}{$\begin{array}{l}\text { Oil. } \\
\text { Gals. }\end{array}$} \\
\hline & & & & & & Left. & Right. & & & & $\begin{array}{c}\text { Tank } \\
1 . \\
\text { Mins. }\end{array}$ & $\mid \begin{array}{c}\text { Tank } \\
2 . \\
\text { Mins. }\end{array}$ & \\
\hline 10.0 & 145 & 305 & $24^{\prime \prime}$ & $\frac{3}{4}$ & $75^{\circ} \mathrm{F}$ & $235^{\circ} \mathrm{F}$ & $300^{\circ} \mathrm{F}$. & $700^{\circ} \mathrm{F}$. & $475^{\circ} \mathrm{F}$ & $60^{\circ} \mathrm{F}$. & 46 & & \\
\hline 10.30 & 135 & 309 & $21_{4}^{\prime \prime}$ & $\frac{3 " 1}{4}$ & $75^{\circ}$ & $235^{\circ}$ & $290^{\circ}$ & $700^{\circ}$ & $475^{\circ}$ & $60^{\circ}$ & & 49 & $82 \frac{1}{2}$ \\
\hline 11.0 & 140 & 308 & $2 \frac{1}{4}^{\prime \prime}$ & $\frac{3^{\prime \prime}}{4}$ & $75^{\circ}$ & $232^{\circ}$ & $285^{\circ}$ & $695^{\circ}$ & $470^{\circ}$ & $55^{\circ}$ & & & \\
\hline 11.30 & 135 & 305 & $21^{\prime \prime}$ & $\frac{3}{4}$ & $75^{\circ}$ & $230^{\circ}$ & $285^{\circ}$ & $695^{\circ}$ & $470^{\circ}$ & $58^{\circ}$ & 55 & & 80 \\
\hline $12 \cdot 0$ & 140 & 300 & $21^{\prime \prime}$ & $\frac{3}{4}$ & $75^{\circ}$ & $227^{\circ}$ & $275^{\circ}$ & $675^{\circ}$ & $455^{\circ}$ & $58^{\circ}$ & & & \\
\hline 12.30 & 137 & 299 & $2 x_{4}^{\prime \prime}$ & $\frac{3}{4}$ & $75^{\circ}$ & $233^{\circ}$ & $275^{\circ}$ & $700^{\circ}$ & $460^{\circ}$ & $58^{\circ}$ & & 41 & $81 \frac{1}{4}$ \\
\hline 1.0 & 140 & 308 & $21^{\prime \prime}$ & $3^{\prime \prime}$ & $75^{\circ}$ & $242^{\circ}$ & $295^{\circ}$ & $715^{\circ}$ & $485^{\circ}$ & $58^{\circ}$ & 39 & & \\
\hline 1.30 & 130 & 302 & $21^{\prime \prime}$ & $\frac{3}{4}{ }^{\prime \prime}$ & $75^{\circ}$ & $247^{\circ}$ & $305^{\circ}$ & $710^{\circ}$ & $490^{\circ}$ & $58^{\circ}$ & & 40 & 100 \\
\hline 2.0 & 150 & 305 & $2 \mathbf{1}^{\prime \prime}$ & $\frac{3}{4}$ & $75^{\circ}$ & $248^{\circ}$ & $308^{\circ}$ & $715^{\circ}$ & $490^{\circ}$ & $58^{\circ}$ & & & \\
\hline 2.30 & 145 & 305 & $21^{\prime \prime}$ & $\frac{3}{4}$ & $75^{\circ}$ & $248^{\circ}$ & $305^{\circ}$ & $715^{\circ}$ & $485^{\circ}$ & $58^{\circ}$ & 40 & & $93 \frac{3}{4}$ \\
\hline 3.0 & 140 & 312 & $21^{\prime \prime}$ & $\frac{3}{4}$ & $75^{\circ}$ & $245^{\circ}$ & $295^{\circ}$ & $705^{\circ}$ & $475^{\circ}$ & $58^{\circ}$ & & 42 & \\
\hline 3.30 & 140 & 310 & $21^{\prime \prime}$ & $\frac{3}{4} "$ & $75^{\circ}$ & $245^{\circ}$ & $290^{\circ}$ & $705^{\circ}$ & $485^{\circ}$ & $58^{\circ}$ & $\begin{array}{l}135 \mathrm{gal} \\
\text { of last }\end{array}$ & als.out & $82 \frac{1}{2}$ \\
\hline 4.0 & 145 & 309 & $21_{4}^{\prime \prime}$ & $\frac{3}{4} "$ & $75^{\circ}$ & $246^{\circ}$ & $295^{\circ}$ & $710^{\circ}$ & $505^{\circ}$ & $58^{\circ}$ & $\begin{array}{r}\text { Tot } \\
6535\end{array}$ & & $\begin{array}{l}\text { Total } \\
530\end{array}$ \\
\hline
\end{tabular}

Water evap. per hour.

Actual observed conditions.

Equivalent weight of water evap per hour, assuming feed at, $110^{\circ} \mathrm{Fah}$. to steam at $180 \mathrm{lbs}$.

\begin{tabular}{|c|c|c|}
\hline $\begin{array}{l}10891 \\
\text { lbs. }\end{array}$ & $\begin{array}{l}\text { Water evap. per lb. of Oil. } \\
\text { Actual observed conditions. }\end{array}$ & $\begin{array}{l}13 \cdot 4 \\
\text { lbs. }\end{array}$ \\
\hline $\begin{array}{l}11340 \\
\text { lbs. }\end{array}$ & $\begin{array}{l}\text { Water evap. per lb. of Oil, } \\
\text { assuming feed at } 110^{\circ} \text { Fal., } \\
\text { to steam at } 180 \mathrm{lbs} \text {. }\end{array}$ & $\begin{array}{l}13 \cdot 9 \\
\text { lbs. }\end{array}$ \\
\hline $\begin{array}{l}13145 \\
\text { lbs. }\end{array}$ & $\begin{array}{l}\text { Water evap. per lb. of Oil } \\
\text { from and at } 212^{\circ} \text { Fah. }\end{array}$ & $\begin{array}{l}16 \cdot 1 \\
\text { lbs. }\end{array}$ \\
\hline $\begin{array}{c}9 \\
\text { lbs. }\end{array}$ & $\begin{array}{l}\text { Water evap. per sq. ft. H.S. } \\
\text { from and at } 212^{\circ} \text { Fah. }\end{array}$ & $\begin{array}{l}10 \cdot 9 \\
\text { lbs. }\end{array}$ \\
\hline $\begin{array}{l}19 \cdot 14 \\
\text { lbs. }\end{array}$ & Efficiency of Boiler. & $84 \%$ \\
\hline
\end{tabular}




\section{LIQUID FUEL AND ITS COMBUSTION}

The steam tests were of 6 hours' duration, that with air of 4 hours'.

Air Atomization.

\begin{tabular}{|c|c|c|c|c|c|c|c|c|c|c|c|c|c|}
\hline \multirow{2}{*}{ Time. } & \multirow{2}{*}{$\begin{array}{l}\text { Steam } \\
\text { Pres- } \\
\text { sure. }\end{array}$} & \multirow{2}{*}{$\begin{array}{c}\text { Fan } \\
\text { Revo- } \\
\text { lutions } \\
\text { per } \\
\text { min- } \\
\text { ute. }\end{array}$} & \multirow{2}{*}{$\begin{array}{l}\text { Vincu- } \\
\text { um at } \\
\text { Fan } \\
\text { Suc. } \\
\text { tion. }\end{array}$} & \multirow{2}{*}{$\begin{array}{l}\text { Vac- } \\
\text { uum } \\
\text { at } \\
\text { Fur- } \\
\text { nace. }\end{array}$} & \multirow{2}{*}{$\begin{array}{c}\text { Tem- } \\
\text { per- } \\
\text { ature } \\
\text { of Air } \\
\text { entering } \\
\text { Air } \\
\text { Heater. }\end{array}$} & \multicolumn{2}{|c|}{$\begin{array}{c}\text { Heated Air } \\
\text { entering Fires. }\end{array}$} & \multirow{2}{*}{$\begin{array}{c}\text { Escaping } \\
\text { Gases } \\
\text { entering } \\
\text { Air } \\
\text { Heator. }\end{array}$} & \multirow{2}{*}{$\begin{array}{l}\text { Escaping } \\
\text { Gases } \\
\text { at } \\
\text { Fan } \\
\text { Suction. }\end{array}$} & \multirow{2}{*}{$\begin{array}{c}\text { Feed } \\
\text { Water } \\
\text { Tem- } \\
\text { per. } \\
\text { ature. }\end{array}$} & \multicolumn{2}{|c|}{$\begin{array}{c}\text { Water'ime } \\
\text { taken to } \\
\text { empty } \\
\text { Tanks. }\end{array}$} & \multirow{2}{*}{$\begin{array}{l}\text { Oil. } \\
\text { Gals. }\end{array}$} \\
\hline & & & & & & Left. & Right. & & & & $\begin{array}{c}\text { Tank } \\
\text { M. } \\
\text { Mins. }\end{array}$ & $\begin{array}{c}\text { Tank } \\
2 . \\
\text { Mins. }\end{array}$ & \\
\hline 10.30 & 130 & 297 & $2 \frac{1}{2}^{\prime \prime}$ & $1 \frac{1}{8}^{\prime \prime}$ & $74^{\circ} \mathrm{F}$. & $220^{\circ} \mathrm{F}$ & $225^{\circ} \mathrm{F}$ & $600^{\circ} \mathrm{F}$ & $360^{\circ} \mathrm{F}$. & $50^{\circ} \mathrm{F}$. & 52 & & \\
\hline 11.0 & 130 & 297 & $2 \frac{1}{2}^{\prime \prime}$ & $11^{\prime \prime}$ & $74^{\circ}$ & $216^{\circ}$ & $245^{\circ}$ & $630^{\circ}$ & $400^{\circ}$ & $50^{\circ}$ & & 47 & 68.4 \\
\hline 11.30 & 130 & 300 & $2 \frac{1}{2}$ & $1 \frac{1}{8}$ & $74^{\circ}$ & $225^{\circ}$ & $250^{\circ}$ & $630^{\circ}$ & $410^{\circ}$ & $50^{\circ}$ & & & \\
\hline 12.0 & 130 & 300 & $2 \frac{1}{2}{ }^{\prime \prime}$ & $11^{\prime \prime}$ & $74^{\circ}$ & $225^{\circ}$ & $250^{\circ}$ & $630^{\circ}$ & $410^{\circ}$ & $50^{\circ}$ & 45 & & 99.28 \\
\hline 12.30 & 130 & 298 & $2 \frac{1}{2}^{\prime \prime}$ & $11^{\prime \prime}$ & $74^{\circ}$ & $223^{\circ}$ & $250^{\circ}$ & $630^{\circ}$ & $410^{\circ}$ & $50^{\circ}$ & & & \\
\hline 1.0 & 140 & 298 & $2 \frac{1}{2}$ & $1 \frac{1}{8} "$ & $74^{\circ}$ & $223^{\circ}$ & $250^{\circ}$ & $630^{\circ}$ & $410^{\circ}$ & $50^{\circ}$ & & 45 & 86.04 \\
\hline 1.30 & 140 & 298 & $2 \frac{1}{2}^{\prime \prime}$ & $11^{\prime \prime \prime}$ & $74^{\circ}$ & $225^{\circ}$ & $250^{\circ}$ & $630^{\circ}$ & $410^{\circ}$ & $50^{\circ}$ & & & \\
\hline 2.0 & 140 & 298 & $2 \frac{1}{2}$ & $1 \frac{1}{8} "$ & $74^{\circ}$ & $225^{\circ}$ & $250^{\circ}$ & $630^{\circ}$ & $410^{\circ}$ & $50^{\circ}$ & 46 & & $83 \cdot 83$ \\
\hline \multirow[t]{2}{*}{2.30} & 135 & 298 & $2 \frac{1}{2}^{\prime \prime}$ & $1 \frac{1}{8}^{\prime \prime}$ & $74^{\circ}$ & $225^{\circ}$ & $250^{\circ}$ & $630^{\circ}$ & $410^{\circ}$ & $50^{\circ}$ & \multirow{2}{*}{\multicolumn{2}{|c|}{$\begin{array}{c}90 \text { gallons } \\
\text { taken from } \\
\text { last tank. } \\
\text { Total } \\
4,090 \text { gals. }\end{array}$}} & \\
\hline & & & & & & & & & & & & & $\begin{array}{l}\text { Total } \\
337.55\end{array}$ \\
\hline
\end{tabular}

\begin{tabular}{|c|c|c|c|}
\hline $\begin{array}{l}\text { Water evap. per hour } \\
\text { Actual observed conditions. }\end{array}$ & $\begin{array}{l}10,225 \\
\text { lbs. }\end{array}$ & $\begin{array}{l}\text { Water evap. per lb. of Oil. } \\
\text { Aetual observed conditions. }\end{array}$ & $\begin{array}{l}13 \cdot 24 \\
\text { lbs. }\end{array}$ \\
\hline $\begin{array}{l}\text { Equivalent weight of water } \\
\text { evap. per hour, assuming feed at } \\
110^{\circ} \text { Fah. and steam at } 180^{\circ} \text { Fah. }\end{array}$ & $\begin{array}{l}10,710 \\
\text { lbs. }\end{array}$ & $\begin{array}{l}\text { Water evap. per lb. of Oil, } \\
\text { assuming feed at } 110^{\circ} \text { Fah. } \\
\text { and steam at } 180 \mathrm{lbs} \text {. }\end{array}$ & $\begin{array}{l}13 \cdot 8 \\
1 b s .\end{array}$ \\
\hline $\begin{array}{l}\text { Water evap. per hour } \\
\text { from and at } 212^{\circ} \text { Fah. }\end{array}$ & $\begin{array}{l}12,413 \\
\text { lbs. }\end{array}$ & $\begin{array}{l}\text { Water evap. per Ib. of Oil } \\
\text { from and at } 212^{\circ} \text { Fah. }\end{array}$ & $\begin{array}{r}16 \cdot 07 \\
\text { lbs. }\end{array}$ \\
\hline $\begin{array}{l}\text { Theoretical total heat value } \\
\text { of Oil in Ibs. of water from } \\
\text { and at } 212^{\circ} \text { Fah. }\end{array}$ & $\begin{array}{l}19 \cdot 14 \\
\text { lbs. }\end{array}$ & Effieieney of Boiler. & $84 \%$ \\
\hline
\end{tabular}




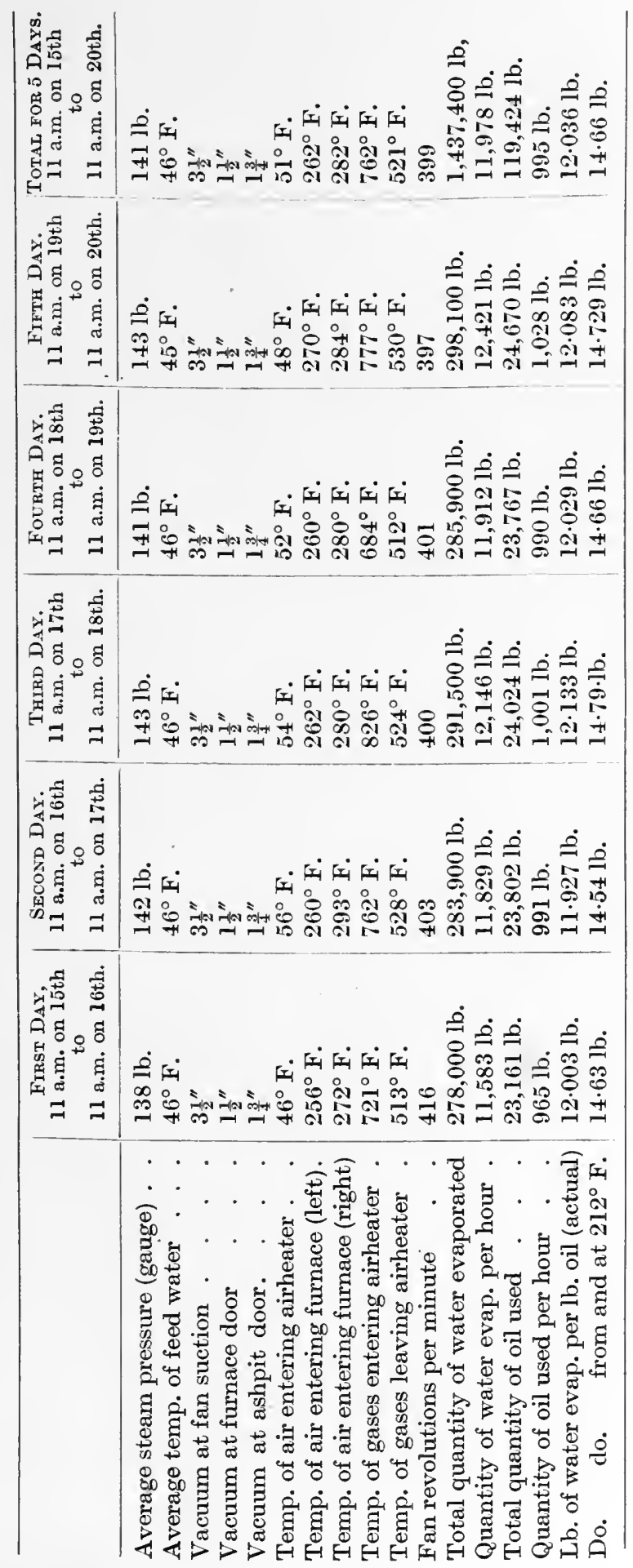




\section{Chapter XXV}

\section{THE STORAGE AND DISTRIBUTION OF LIQUID FUEL}

$I^{\mathrm{N}}$ $\mathrm{N}$ carrying or storing oil, it is necessary to provide for its expansion, and it is also necessary to provide a safeguard against the rupture of the storage tanks unless these are below ground level. Provision must also be made for the escape of any gas or vapour generated from the oil and against danger from leakage.

The tanks used for oil storage have a diameter of from 40 to 70 feet. Some are as large as 90 feet, and the largest will hold over one million gallons, or 3,300 gallons per inch of depth. In order to prevent danger, should a tank fail, it ought to be surrounded by a moat capable of holding the contents of the tank. Botl crude oil and the refined products are now carried in specially constructed tank steamers, some of which will carry as much as 8,500 tons of oil.

At Liverpool these steamers are discharged through an 8-inch pipe into vertical tanks of 2,000 and 3,000 tons capacity. The carrying space in the steamers is formed by riveted bulkheads across the ship, the skin of the ship itself forming sides to the tanks, the screw shaft being laid in a tunnel. Refined oil possesses such penetrative properties that the riveting of such tanks must be carefully done, and the rivet spacing is closer than in ordinary work. The tanks ought to be full of oil, and they must not be too large, a bulkhead being placed at intervals not wider than 24 feet. These bulkheads must be stiff enough to stand the unsupported pressure of the liquid upon one side only, together with such extra stress as may be caused by the movement of the vessel. The specific gravity of petroleum varies considerably, but an approximate rule to cover all cases of oil pressure is $\mathrm{P}=0.40 \mathrm{H}$, where $P$ is the pounds pressure per square inch and $H$ is the depth in feet below the top level of the oil, which may of course be some distance up the expansion tanks.

It is not considered safe to store Texas crude oil nearer to boilers than 500 feet, and in ease of a spouting well all fires within 500 feet are extinguished.

Mr. Schoen writes to Insurance Engineering on the subject of safe storage and the system of piping, and an abstract of this is given in Appendix 1, with some further abstracts in Appendix 2 on individual installations of oil. It is particularly to be noted that where oil is used so very freely as fuel the proposal is to lead it to the different establishments by pipes in preference to carting it through the streets in tanks.

Pipes for this purpose ought to be of wrought iron or steel, carefully threaded and fitted together with sound and carefully threaded sockets. Pipe joints may be made in three ways (a) The pipes are screwed tapering and the sockets ought to be 


\section{THE STORAGE AND DISTRIBUTION OF LIQUID FUEL}

threaded similarly from each end by a tapering tap, so that a tight joint may be secured; (b) Back nuts may be employed to reinforce the sockets by aid of an interposed fibrous ring; $(c)$ The pipe ends may be truly faced off exactly at right angles to the axis of the threading, a compressible, but thin, washer of soft metal or fibre being interposed between the ends of the abutting pipes. Such pipes meet together in the sockets like artesian drive pipes.

Ordinary pipes, if found to leak after being put together, should be carefully caulked round the ends of the sockets. Before screwing together the pipes ought to be painted with some cement not soluble in petroleum. Litharge and glycerine is recommended. The precautions to be generally observed in the use of oil are well set out in Appendix 3, which contains the latest requirements of the American Board of Underwriters, and may be studied with advantage. Many of the precautions with regard to oil arise from the fact that, being lighter than water, it may be carried up and down a tidal river and spread a general conflagration. Being liquid, it will travel by gravity to long distances from a ruptured tank or broken or leaking joint. Where, to avoid these dangers, oil is stored in buried vaults, there is danger of the accumulation of vapours of an explosive nature, and ventilation is required to carry these away, and the outlet of a ventilating shaft should be well exposed and out of any danger, such as the throwing of a lighted match from some point above. Where ventilation does not take place freely, it might be necessary to use some positive means of drawing out the air from a tank chamber or to assist the action of the ventilating trunk by a warm water pipe within it and a swivelling cowl head.

In order to deal with the 58 liquid fuel locomotives of the Great Eastern Railway, there is provided a series of underground tanks of a capacity in the aggregate of 50,000 gallons. These are filled direct from the travelling tanks of the railway (fig. 63).

From these underground tanks a small rotary pump lifts the oil to six cylindrical tanks elevated 20 feet above rail level, and of a total capacity of 42,000 gallons.

Outlet pipes controlled by valves, operated from a gallery above, conduet the oil to cranes similar to an ordinary water crane. Only four men are employed, three for day work, pumping oil, receiving fresh supplies, and delivering to locomotives, and one at night to attend to delivery only.

A main line engine will take in 600 gallons of oil in four or five minutes.

Electric lighting is employed, with portable lamps for the cranes or filling arms.

At the country depots oil is stored underground only, and in air tight tanks, which are caused to supply the filling arms by pumping air into the tanks above the oil, the air brake pump of the locomotive itself doing this work.

The tanks of the tender are filled through a fine gauze strainer protected by a perforated cylinder, so that everything in the shape of an obstruction is filtered out, and the gauze also serves to prevent ignition of any possible vapour in the tank, acting to prevent this on the well known principle of the miner's safety lamp. This precaution is more necessary where crude oils are used than for the higher flash point residues.

On the Grazi and Tsaritzin Railway Mr. Urquhart, in his $1884^{1}$ paper gave the length of line worked with petroleum as from Tsaritzin to Burnack, 291 miles, and a total of 423 miles, including the Volga-Don branch. There is a main reservoir

1 Proceedings of the Institution of Mechanical Engineers, 1884. 
है่

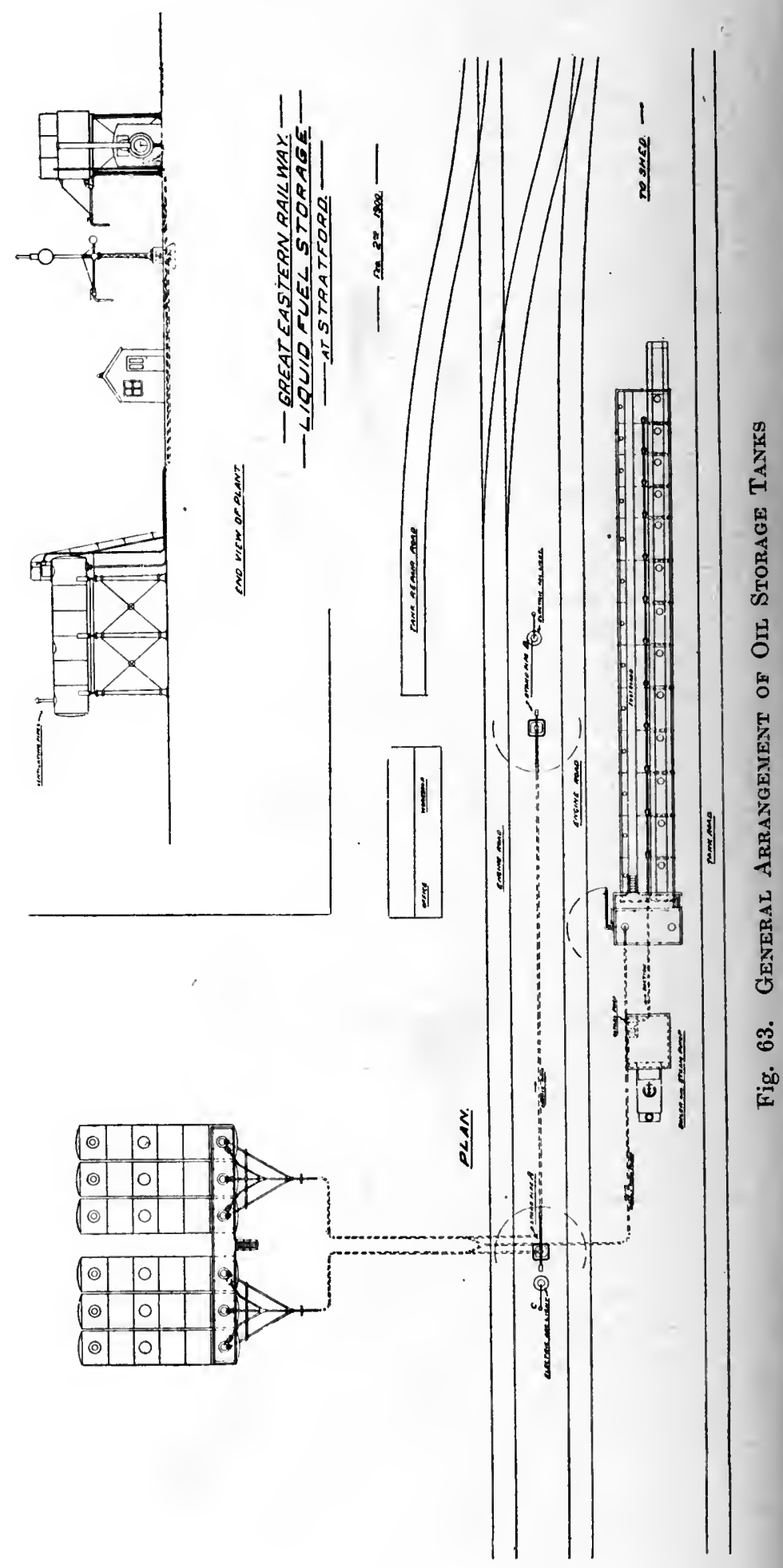




\section{THE STORAGE AND DISTRIBUTION OF LIQUID FUEL}

for petroleum at each of the four engine sheds, namely, Tsaritzin, Archeda, Filonoff, and Borisoglebsk. Each reservoir is 66 feet internal diamcter and 24 feet high, and, when full, holds about 2,050 tons. The method of eharging the reservoir, which stands a good way from the line and at a convenient distance from all dwelling houses and buildings, is as follows-

On a siding specially prepared for the purpose are placed 10 eistern cars full of oil, the capacity of each being about 10 tons. From each of these ears a connection is made by a flexible india-rubber pipe to one of the ten standpipes, which project one foot above the ground line. Parallel with the rails is laid a main pipe, with which the ten standpipes are all connected, thus forming one general suction main. About the middle of the length of the main, which is laid underground and

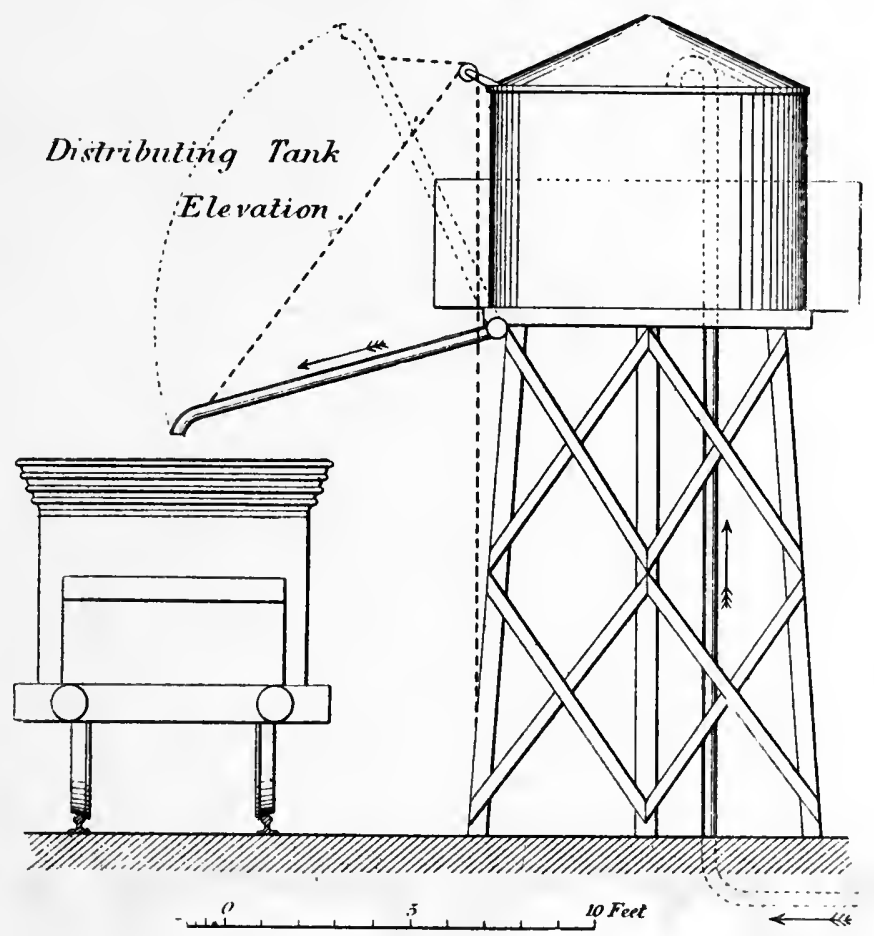

Fig. 64. Distributing Tank for Oil Fuel. Grazi and Tsaritzin Railway

eovered with sawdust or other non-conducting material, is fixed a steam pump. As soon as the ten connexions are made with the eistern ears, the pump is set to work, and in about one hour the whole of the ears are discharged into the main reservoir, the time depending of course upon the eapacity of the pump. The pipes are all wrought iron, lap welded, 5 inch socketed.

At each shed there is also an elevated tank (fig. 64) $8 \frac{1}{2}$ feet diameter by 6 feet deep, built of $\frac{1}{4} \mathrm{in}$. plate, to serve as a distributing tank to the locomotives. Their area is calculated, and a divided scale shows exactly how many poods ${ }^{1}$ of oil have been drawn out, the amount being correeted for temperature at intervals of $8^{\circ} \mathrm{R} .=$ $18^{\circ} \mathrm{F} .=10^{\circ} \mathrm{C}$, the scale ranging from $24^{\circ} \mathrm{R}$. to $-24^{\circ} \mathrm{R} .=86^{\circ} \mathrm{F}$. to $-22^{\circ} \mathrm{F}$, the quantity and temperature being entered in the driver's book. The heaviest refuse

11 pood =36.114 English pounds $=40$ pounds Russian. 62.0257 poods $=1$ ton. 


\section{LIQUID FUEL AND ITS COMBUSTION}

has a specific gravity of 0.921 at $0^{\circ} \mathrm{C} .=32^{\circ} \mathrm{F}$., so that 39 eubic feet measure one ton, or 57.4 pounds $=1$ cubic foot. Lighter refuse has a speeific gravity of 0.889 $=40 \frac{1}{2}$ eubic feet per ton, or $55 \frac{1}{2}$ pounds per cubic foot.

The engineer-in-charge at each station is provided with a hydrometer and thermometer to deal with the ten different grades of liquid, each grade having its own peculiar sp. gr. and co-efficient of expansion. Table XXVIII. gives useful information on this subject.

\section{The Thwaite Storage Tanks.}

An ingenious storage tank devised by Mr. B. H. Thwaite is shown in fig. 65 .

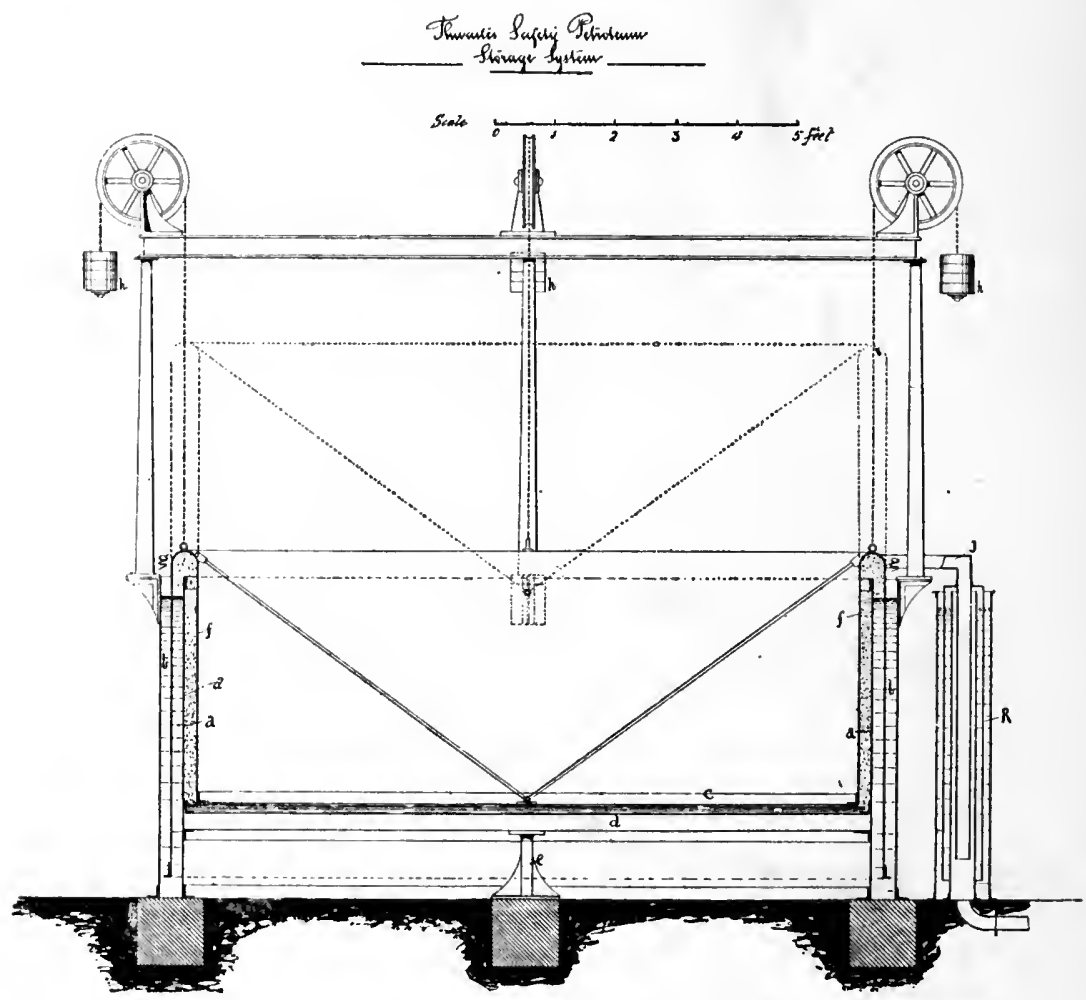

Fig. 65. Storage Tank for Orl Fuel. Thwaite's System

It is in form very like a gas holder with sides $a, a$, and bottom supported on girders d. The rising bell, however, is of inverted form, the roof coming down as shown at $c$ into elose proximity to the bottom of the holder. The bell is nearly balanced by the usual weights, $h, h$. The outer ease of the bell dips into a water seal $b$; the inner case $f$, with the roof $c$, forms the inner bell, which occupies the whole interior of the tank when in the position shown. As oil is pumped into the tank this bell rises, being already nearly balanced. Thus there is no space for vapour to aceumulate in the tank, and the bell is always filled with liquid. To prevent aceumulation of water in the inner bell a light cover ought to be provided, $k$. The full position of the bell is shown by the dotted lines. By this holder the interior of a tank is sealed off from the atmosphere. A telescoping filling pipe, $j$, rises and falls with the holder in a similarly water-sealed valve chamber, $R$, the oil being entered and 


\section{THE STORAGE AND DISTRIBUTION OF LIQUID FUEL}

withdrawn from the highest point, $g$, of the bell. Any vapour that may accumulate must always be first drawn off before oil can flow. If desired, a vent pipe with gauze protected overflow may rise from the joint $g$, but if a vent pipe is used, it is especially important that the holder should not be fully balaneed by the weights $h, h$, or the vent would perhaps draw in air. It should contain a non-reflux valve at its upper end.

\section{Oil Pumps.}

Any pump which will pump water will pump oil. So long as an oil is free from

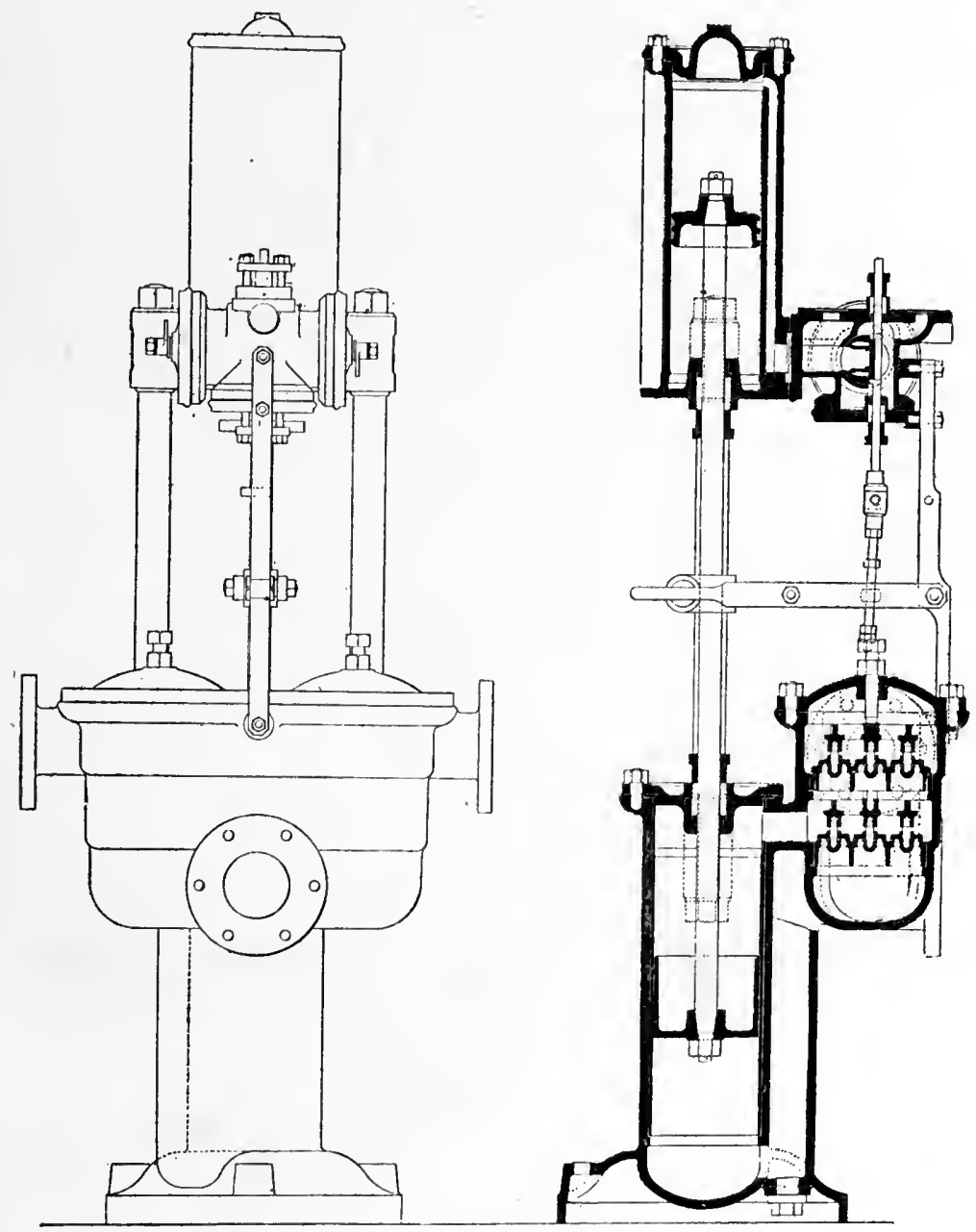

Fig. 70. Weir's Oir. PuMP

the more volatile hydrocarbons, it ean be lifted by suction from a depth greater than is possible with water, in inverse ratio to its specific gravity. By weight also a pump will throw less oil than water, but it should throw an equal volume.

For rapidly transferring large bodies of oil from a ship to a storage tank, the centrifugal pump is very convenient. There are also numerous other rotary pumps of the positive propulsion type similar to the Roots' Blower.

Valves of india-rubber must of course be avoided, and only such substances 


\section{LIQUID FUEL AND ITS COMBUSTION}

employed as will resist the solvent action of the oil. Metal valves should prove most generally durable and efficient. Simplicity and reliability are the characteristics desired in a pump. For bunker filling especially the pump must be of ample capacity, so that a ship may not be long detained when calling for fuel in port.

An example of a bunkering pump is the Weir Patent Pump for oil pumping as shown in fig. 70. This is of the direct double-acting type. The valve gear is positive, i.e., the stcam valve can never be in such a position that the pump will not start immediately after the steam is turned on. The valve arrangements also ensure constant length of stroke and certainty of action.

The steam valve consists of a " $\mathrm{D}$ " slide valve with a small auxiliary valve working on the back. These are the only moving parts proper in the steam chest, so that there is little opportunity for wear and no delicate adjustments to get out of order.

The oil end is of special design fitted with Weir group valves, which provide a large area with only a small lift, thus ensuring easy working and little wear and tear. For this duty the valves are of the flat disc type.

The pump is specially economical in steam consumption, and is simple and with all its parts easily accessible. The front elevation shows that there is a separate valve chamber for each end of the pump cylinder, the valves being grouped on the valve plate round a central valve. With long pump buckets there should be no need to use rings. The bucket simply requires to be turned a good but free fit in its barrel and grooved with square edged grooves $\frac{1}{4}^{\prime \prime}$ wide $\times \frac{3}{32}$ " deep, spaced about $5^{\prime \prime}$ centres. This plan is very effectual with water, and should be perfect for oil of the consistency of fuel oil. 


\section{Chapter XXVI}

\section{FLUE GAS ANALYSIS}

$\mathrm{T}$

THE analysis of flue gases is undertaken for the purpose of showing the perfection of the combustion and the excess of air employed.

Considering that about 9 per cent. more coal is consumed if the percentage of $\mathrm{CO}_{2}$ is 8 per cent. instead of 13 per cent., the waste of coal will amount to 900 tons a year in 10,000 tons burned.

In practice, about 1.3 times the theoretical quantity of air is required to effect perfect combustion. If this proportion is exceeded, the fuel required to heat the excess of air to the temperature of the flues is wasted, and whilst the percentage of carbonic acid under perfect conditions should be about 15 per cent., the theoretical maximum of 21 per cent. cannot, of course, be attained; it will be very considerably below this figure, if a great volume of air is allowed to rush through the furnace.

These figures refer to coal fed furnaces.

How much coal is wasted, if the percentage of carbonic acid gas falls to a low level, may be seen at a glance from the following table-

\begin{tabular}{l|r|r|r|r|r|r|r|r|r|r|r|r|r|r}
\hline $\begin{array}{l}\text { Percentage of } \mathrm{CO}_{2} \\
\text { Loss of fuel in per cent. } \\
\text { against the theoreti- } \\
\text { cally lowest possible }\end{array}$ & 2 & 3 & 4 & 5 & 6 & 7 & 8 & 9 & 10 & 11 & 12 & 13 & 14 & 15 \\
quantity & 90 & 60 & 45 & 36 & 30 & 26 & 23 & 20 & 18 & 16 & 15 & 14 & 13 & 12 \\
\hline
\end{tabular}

It is not possible to tell from the appearance of the fire in the furnace the percentage of $\mathrm{CO}_{2}$.

As one pound of carbon requires a minimum of $11 \frac{1}{2}$ pounds of air for perfect combustion, it will produce $12 \frac{1}{2}$ pounds of total furnace gas, and of this $3 \frac{2}{3}$ pounds will be $\mathrm{CO}_{2}$ : that is, fully 29 per cent. by weight or nearly 21 per cent. by volume. For anthracite coal free from hydrogen the excess of air can be calculated from the percentage of $\mathrm{CO}_{2}$ in the flue gas.

For fuels containing hydrogen, the analysis being done cold, the steam which is produced by the hydrogen is therefore not measured, this steam is less in volume than the nitrogen of the air which supplied oxygen to burn the hydrogen. The percentage of $\mathrm{CO}_{2}$ in the flue gas thus appears smaller with the more hydrogenous fuels than it does with the less hydrogenous fuel. But in every case the actual percentage can be calculated, and, once known, all subsequent records can be compared with the calculated datum line. 


\section{LIQUID FUEL AND ITS COMBUSTION}

A fuel containing hydrogen to the extent of one per cent. demands 55.9 litres of oxygen per kilo. of coal, or 0.9 cubic foot per pound, to satisfy the hydrogen.

The following tabular numbers give the volume of oxygen per kilo. and per pound of coal for various percentages of hydrogen.

\begin{tabular}{|c|c|c|c|c|c|c|c|c|c|c|}
\hline$\%$ & & & & & Litres per & Kilo. & & & & Cubit ft. per lb. \\
\hline 1 & . & . & . & . & . $\quad 55.9$ & 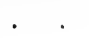 & . & & . & . $\quad 0.9$ \\
\hline 2 & . & . & . & . & $112 \cdot 0$ & . & . & . & . & $1 \cdot 8$ \\
\hline 3 . & . & . & & . & $168 \cdot 0$ & . & . & . & . & $2 \cdot 7$ \\
\hline 4 & . & . & . & . & $223 \cdot 0$ & . & . & . & . & $3 \cdot 6$ \\
\hline 5 & . & . & . & . & $279 \cdot 0$ & . & . & . & . & $4 \cdot 5$ \\
\hline 6 & . & . & . & . & $336 \cdot 0$ & . & . & . & . & $5 \cdot 4$ \\
\hline 7 & . & . & . & . & $391 \cdot 0$ & . & . & . & . & $6 \cdot 3$ \\
\hline 8 & $\because$ & . & . & . & $446 \cdot 0$ & . & . & . & . & $7 \cdot 2$ \\
\hline 9 & . & . & . & . & $504 \cdot 0$ & . & . & . & . & $8 \cdot 1$ \\
\hline 10 & . & . & . & . & $559 \cdot 0$ & . & . & . & . & $9 \cdot 0$ \\
\hline 11 & . & . & . & . & $615 \cdot 0$ & . & . & . & . & $9 \cdot 9$ \\
\hline 12 & . & . & . & . & $672 \cdot 0$ & . & . & . & . & $10 \cdot 8$ \\
\hline 13 & . & . & . & . & $727 \cdot 0$ & . & . & . & . & $11 \cdot 7$ \\
\hline 14 & . & . & $\therefore$ & . & $782 \cdot 0$ & . & . & . & . & $12 \cdot 6$ \\
\hline 15 & & . & . & . & $837 \cdot 0$ & . & . & . & . & $13 \cdot 5$ \\
\hline 16 &.$\quad$. & . . &. & . & . 892.0 &. & . & & . &.$\quad 14 \cdot 4$ \\
\hline
\end{tabular}

In calculating the volume of dry gas from analysis, any hydrocarbon gas is calculated as though it were simply carbon vapour of a weight of 1.072 grams per litre.

At $0^{\circ} \mathrm{C}$. and $760 \mathrm{~mm}$. pressure,

$\begin{array}{rrr} & \text { Molecular weight } \\ 1 \text { litre of } \mathrm{CO}_{2}=1.966 \text { gram }=44 . \\ 1 \quad, \text {, } \mathrm{CO}=1.251 \quad, \quad=28 . \\ 1 \quad, \text { "C vapour }=1.072 \quad,=12 .\end{array}$

Each volume of $\mathrm{CO}_{2}$ contains $\frac{3}{11}$ of its weight of carbon, or $1.966 \times \frac{3}{11}=0.536$ grams per litre. Similarly, the proportion of carbon in carbonic oxide is $\frac{3}{7}$ of the weight, or $1.251 \times \frac{3}{7}=0.536$ grams per litre, the weight of carbon vapour being 1.072 grams per litre.

Thus the total weight of carbon is $\mathrm{C}=0.536\left(v+v^{\prime}\right)+1.072 v^{\prime \prime}$ where $v, v^{\prime}$ and $v^{\prime \prime}$ are the volumes of $\mathrm{CO}_{2}, \mathrm{CO}$, and carbon vapour in litres per each cubic metre or per 1,000 volumes of flue gas.

For British units the formula becomes $\mathrm{C}=0.0335\left(v+v^{\prime}\right)+0.06693 v^{\prime \prime}$ where $v, v^{\prime}$ and $v^{\prime \prime}$ are the volumes in cubic feet per thousand feet of flue gas.

Kent's formula for the weight of dry gas per pound of carbon is

$$
\mathrm{W}=\frac{11, \mathrm{CO}_{2}+8 \mathrm{O}+7(\mathrm{O}+\mathrm{N})}{3\left(\mathrm{CO}_{2}+\mathrm{CO}\right)}
$$

Having found this weight of dry gas from the analysis of the furnace gases, there must be added the proportion necessary for the steam produced. This will measure 9 by weight for each unit weight of hydrogen, and, the density of steam being 9 , the relative volume may be found or it may be taken from the above table.

By formula the total volume of gases thus becomes

$$
\mathrm{V}=\frac{\mathrm{C}}{0.536\left(v+v^{\prime}\right)+1 \cdot 072 v^{\prime \prime}}+55 \cdot 9 \mathrm{H}+\mathrm{A},
$$

where $\mathrm{H}$ is the percentage of hydrogen in the fuel and $\mathrm{A}$ is the combined volume of nitrogen and excess of air. 


\section{FLUE GAS ANALYSIS}

In British measures the formula becomes

$$
\mathrm{V}=\frac{\mathrm{C}}{0.0335\left(v+v^{\prime}\right)+0.06693 v^{\prime \prime}}+0.9 \mathrm{H}+\mathrm{A}
$$

Though a volume of nearly 21 per cent. of $\mathrm{CO}_{2}$ would be obtained from pure carbon burned with the chemical minimum of air, this minimum is excceded in practice, and a percentage of 12 of $\mathrm{CO}_{2}$ is considered good with coal. As seen under the head of Combustion, the amount must be still less with liquid fuel unless this is burned to better effect, as it should be.

\section{The Orsat-Lunge Apparatus.}

This apparatus, fig. 66, as made by Messrs. 'Townson and Mercer, is one of the most convenient for the practical analysis of furnace gases.

It consists of a burette marked to contain 100 c.cnl. above the zero mark and graduated to 40 cubic centimetres in fifths. The upper end of the tube is connected to a small-bore glass tube, to the other end of which is connected the vessel containing the gas to be sampled.

From this tube are four branches connecting to bottles below, and these are connected at their bases to four other bottles of equal capacity or a little larger.

The front bottles are filled with small glass tubes in order to provide a large area of wetted surface. In the first bottle is placed a solution of caustic potash or caustic soda, which is absorbent of carbonic acid, $\mathrm{CO}_{2}$. The second bottle is filled either with a solution of pyrogallic acid in caustic potash or soda, or of yellow phosphorus in small rods, or of fragments of phosphorus, and is intended to absorb oxygen. The third bottle contains cuprous chloride and hydrochloric acid, which absorbs carbonic oxide, $\mathrm{CO}$. The fourth bottle contains water, and receives the gas after the first three absorptions have been effected, and in its passage to this bottle the gas passes through a heated tube containing palladium asbestos, by which any hydrogen or hydrocarbons are burned to water and to carbon dioxide.

At the base of the measuring burette is a con-

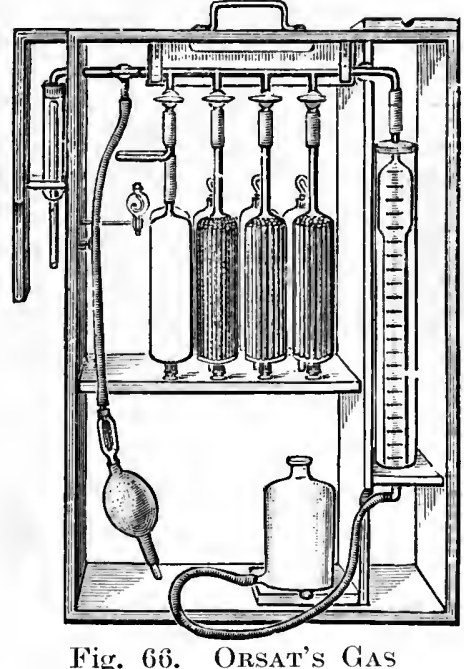

Fig. 66. Orsat's Gas

Analysis Apparatus nexion to a gravity bottle, by raising which the burette can be filled with water, the cocks above the pipettes being closed. ${ }^{1} \quad$ To work the apparatus the burette is filled by raising the gravity bottle and filling the burette with water to the top. On lowering the bottle the water runs back to the bottle and draws in a supply of gas to about $104 \mathrm{c.cm}$. The level of the water in the gravity bottle is then made to coincide with the zero mark of the burette and the surplus gas is discharged by the top cock.

There are now exactly 100 c.cm. in the burette. The cock to the first pipette

1 Previous to taking in a sample of gas the solutions in the absorption bottles are drawn up to the containing mark on the connecting tube, by the aid of the gravity bottle, and the coek closed. 


\section{LIQUID FUEL AND ITS COMBUSTION}

is then opened and the gas is forced over into this by raising the gravity bottle. This fills the burette with water, which must not be allowed to go so far as the cock of the pipette. The contents of the pipette are forced out into the rear bottle, and after allowing time for the $\mathrm{CO}_{2}$ to be absorbed by the potash solution on the wetted tubes, the gravity bottle is lowered until the absorbing solution again reaches its containing mark; then the cock is closed, the water level adjusted to that in the burette, and the percentage of gas absorbed is read directly off the scale. This process should be repeated until no further absorption takes place, the reading remaining the same. Closing the cock of the first pipette, that of the second is now opened and the process repeated to find the absorption of oxygen, and so on with the third.

Finally the decrease of volume due to the combustion of the hydrogen is found, the product of course going to water.

The $\mathrm{CO}_{2}$ formed in this last operation is exactly equal to the volume of the oxygen absorbed by it, and this is determined by means of the first pipette. Before the hydrocarbons can be burned it is of course necessary to provide oxygen. As the oxygen has already been absorbed which was contained in the original 100 c.cm., it is necessary to add a further supply after the first three gases have been absorbed, therefore a supply of air is drawn into the burette by means of the gravity bottle, and the volume in the burette is again carefully adjusted to $100 \mathrm{c.cm}$. The mixed gas is then passed over through the heated palladium asbestos tube, and the hydrocarbon or hydrogen gas is oxidised. When normal temperature has been regained, the volume in the burette is noted. The amount which has disappeared represents hydrogen, for each two volumes of which one volume of oxygen has disappeared also, so that the reduction in volume is twothirds hydrogen and one-third oxygen.

To correct the volume of gas to normal temperature and pressure-

Then

$$
\begin{aligned}
& V_{0}=\text { volume at } O^{\circ} \mathrm{C} \text {. and } 760 \mathrm{~mm} \text {. of mercury column. } \\
& V=, \quad \text { pressure } P \text {. }
\end{aligned}
$$

$$
V_{0}=V P \div 760 \text {. }
$$

To correct for temperature-

Gases expand $\frac{1}{2} \frac{1}{7}$ of their volume at $U^{\circ} C_{\text {: }}$ for each degree $C$.

Then

$$
V_{0}=\text { Vol. at } O^{\circ} C \text {. } V=\text { vol. at } t^{\circ} C \text {. }
$$

$$
V_{0}=V \frac{273}{273+t^{\circ}}
$$

For combined temperature and pressure corrections.

$$
V_{0}=\frac{V \times 273 \times(P-f)}{\left(273+t^{\circ}\right) \times 760}
$$

Where $f=$ tension of aqueous vapour of damp gas at $t^{\circ} C$. when completely moisture saturated (See table XII)-

$$
\begin{gathered}
V=\text { Volume at } P \text { and } t^{\circ} \text { saturated. } \\
V_{\circ}=, \quad \text { dry at } 760 \mathrm{~mm} \text {. and } O^{\circ} \mathrm{C} . \\
\qquad V=\frac{V_{5,}(273+t) \times 760}{273(P-f)} \\
232
\end{gathered}
$$




\section{FLUE GAS ANALYSIS}

\section{Absorbing Solutions.}

For $\mathrm{CO}_{2}, 16$ grams of potassium hydrate $=\mathrm{KHO}$ in $100 \mathrm{c.cm}$. of water.

For Oxygen, 20 grams pyrogallic acid $+100 \mathrm{c.cm}$. of water will absorb the oxygen of 100 c.c. of air.

For $\mathrm{C}_{2} \mathrm{H}_{4}, \mathrm{H}_{2} \mathrm{~S}_{2} \mathrm{O}_{7}$ or bromine water, 1 c.c. of $\mathrm{Br}$. water will absorb 2 c.c. of $\mathrm{C}_{2} \mathrm{H}_{4}$.

For Carbonic Oxide, CO, Cuprous Chloride 15 grams in 100 c.c. of $\mathrm{H} . \mathrm{Cl}$ (1.19 sp. gr.); 1 c.c will absorb 20 c.c. of CO.

Tables XIII and XIV will be found useful to gas analysts.

When analysing producer or blast furnace gas suspected of having an appreciable percentage of hydrocarbon gas, it is advisable, after having measured off the contraction of volume due to passing the gaseous mixture through the palladium asbestos, to pass the remaining gas into the $\mathrm{CO}_{2}$ absorption tube, and measure the further contraction of volume. Should there be a measurable contraction of volume due to $\mathrm{CO}_{2}$, then this may be for general purposes calculated as due to marsh gas, $\mathrm{CH}_{4}$, having been present (this is only approximate, as probably there was a mixture of various hydrocarbons), in which case the volume of $\mathrm{CO}_{2}$ would be the same as the volume of $\mathrm{CH}_{4}$.

The results of analysis may be stated thus-

Volume of gas employed, 100 c.c.

I. Passed into $\mathrm{CO}_{2}$ absorption tube.

Reduction of volume $=\mathrm{CO}_{2} \%$.

II. Passed into O absorption tube.

Reduction of volume-reduction of volume due to $\mathrm{CO}_{2}=\mathrm{O} \%$.

III. Passed into CO absorption tube.

Reduction of volume - reduction due to $\mathrm{CO}_{2}$ and $\mathrm{O}=\mathrm{CO} \%$.

IV. Volume in burette made up to 100 c.c. by drawing in air, after having cleared the tubes by aspiration.

V. Heat palladium asbestos tube and slowly pass the gas over into the absorption bottle containing water, and back again into the burette.

Measure the amount of contraction of volume.

VI. Pass the remaining gas into $\mathrm{CO}_{2}$ absorption tube and note further contraction of volume. If the hydrocarbons present be taken as marsh gas $\mathrm{CH}_{4}$, then the volume of $\mathrm{CO}_{2}$ will be the same, and will represent the volume of $\mathrm{CH}_{4} \%$.

This is obtained by subtracting the contraction due to combustion in asbestos tube from the total contraction of volume found.

VII. From the contraction due to combustion subtract the volume of $\mathrm{CH}_{4}$ found, then twothirds of the remainder will give the hydrogen $\%$.

VIII. The nitrogen present is the difference between the gases as found in percentage and the total of 100 .

The combustion of hydrogen and marsh gas may be represented thus-

$$
\begin{array}{ll}
2 \mathrm{H}+\mathrm{O} & =\mathrm{H}_{2} \mathrm{O} \\
2 \text { vols. }+1 \text { vol. } & =2 \text { vols. } \\
\mathrm{CH}_{4}+4 \mathrm{O} & =\mathrm{CO}_{2}+2 \mathrm{H}_{2} \mathrm{O} \\
2 \text { vols. }+4 \text { vols. }= & =2 \text { vols. }+4 \text { vols. }
\end{array}
$$

Where there is much hydrogen in the gas it may be necessary to add oxygen instead of air, or to start with an originally smaller volume of gas. With flue gas this is never necessary, of course. The burette is simply filled to the 100 c.c. mark after the first absorptions. The small tube which contains the thread of palladium asbestos is gently heated with a small flame. The gravity bottle is raised and the 


\section{LIQUID FUEL AND ITS COMBUSTION}

gas passed over into the fourth pipettc and back again to the burette. One end of the palladium asbestos will become red hot during this operation if sufficient hydrogen is present. The burette must then be read and the operation repeated until no further contraction of volume is observed. Usually no contraction occurs after the first passage. Two-thirds of the contraction is calculated as hydrogen. Ethylene gas will be absorbed by the cuprous chloride, and oxygen to be absorbed by the phosphorus requires the phosphorus not to be colder than $20^{\circ} \mathrm{C}$. or $15^{\circ}$ at least $=68^{\circ} \mathrm{F}$. or $59^{\circ} \mathrm{F}$.

The subject of gas analysis is too complex to receive full treatment here, and can only be studied in a special treatise. In determining chimney gases, as a rule it will be sufficient to ascertain the percentage of $\mathrm{CO}_{2}$ alone, so that the excess of air present may be approximated rapidly.

\section{The "Ados" Recorder of Carbon Dioxide.}

This instrument (figs. 67 and 68), is devised to give a continuous record of the percentage of $\mathrm{CO}_{2}$ in the flue gases, and its action is based on the property of caustic potash of absorbing $\mathrm{CO}_{2}$, whereas all the other constituents of flue gas are unaffected.

The apparatus consists of motor, gas pumps and analysing and recording apparatus.

A quantity of the flue gas is pumped through the recorder ; part of it is bottled up, measured, and passed through a solution of caustic potash, which absorbs all the $\mathrm{CO}_{2}$ gas ; the quantity of gas absorbed, which represents the percentage of $\mathrm{CO}_{2}$ gas, is determined and recorded on a diagram by means of vertical lines.

This process is repeated about every five minutes. 'The tops of the various lines form a curve which shows a fluctuation of the percentage of $\mathrm{CO}_{2}$ in the flue gases during the time the recorder has been working.

It is advisable to have one recorder for each furnace. Where it is, however, desired to test several furnaces by one recorder only, this may be connected with each furnace by a system of tubes, and the furnace to be tested is switched on.

If the recorder constantly or frequently shows a very low percentage of $\mathrm{CO}_{2}$, indicating that fuel is being wasted, the cause will be either due to carelessness or want of skill on the part of the stoker, who may allow an excessive quantity of air to enter the furnace, or it may be traced to the excessive size of the furnace, or to cracks in the brickwork of the flues. As soon as such defects are made good the recorder will show a higher percentage of $\mathrm{CO}_{2}$, and thus it serves the purpose of detecting such constructional defects and of controlling automatic stokers.

The motor (fig. 67), consists of a tank and bell and fittings, the interior of the bell being connected with the chimney by means of a tube.

The draught in the chimney creates a vacuum under the bell, which is pressed into the tank by atmospheric pressure. Air is then admitted into the bell by the automatic action of a valve, and the bell rises again.

This motion is utilized to raise and lower a bottle $F$ filled with glycerine, and to drive a pair of special pumps $P$ which force the flue gases from the chimney through the analysing and recording apparatus.

So long as there is any draught in the chimney, the motor will work without supervision. 


\section{FLUE GAS ANALYSIS}

The gas pumps consist of two cylinders (fig. 67), which dip into oil tanks and rise and fall alternately, drawing flue gases from the chimney, and forcing them through the recorder.

The analysing and recording apparatus (fig. 68), consists of a glass tube which serves as a measure to enclose 100 cubic centimetres of gas; of a bottle containing a solution of caustic potash which absorbs the $\mathrm{CO}_{2}$ gas, and of a pen which records the percentage of $\mathrm{CO}_{2}$ gas ascertained.

The bottle $F$, filled with a mixture of glycerine and water, is raised and lowered by the action of the motor.

In the lowest position the glycerine mixture will touch the mark $m_{1}$; in the highest position, the glycerine touches the mark $m_{2}$; the cubic contents of the tube between $O$ and $m_{2}$ is 100 cubic centimetres.

When the glycerine touches $m_{1}$ the gases which enter through tube $S_{3}$ will pass through the passage $G_{1}$ and eventually through the

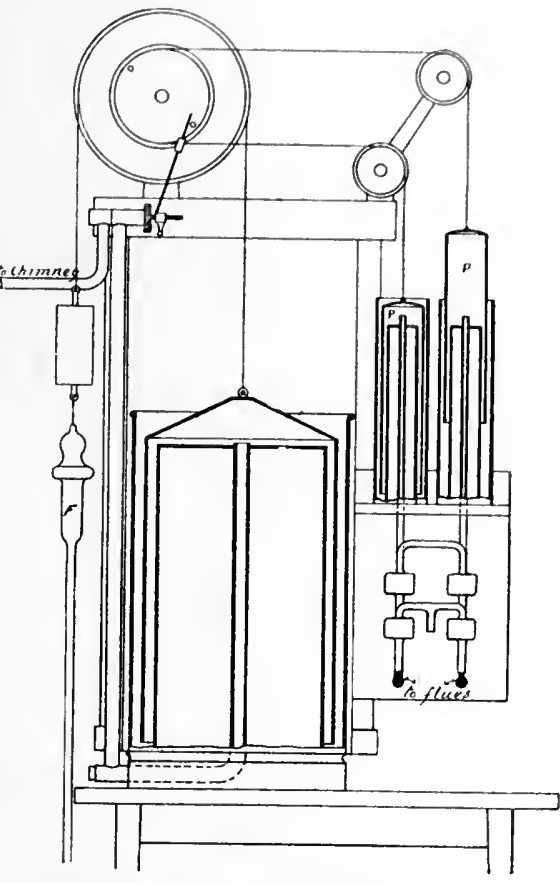

Fig. 67. "Ados" $\mathrm{CO}_{2}$ Recorder Motor and Pumps tube $S_{4}$ into the open air.

When the bottle is raised, the glycerine rises and shuts off the passage $G_{1}$; the moment the glycerine reaches the mark $\mathrm{O}, 100$ cubic centimetres are enclosed.

The gases will then of course be unable to pass out through the tube $G_{1}$, but they will pass through the tube $S_{2}$ into the open, after overcoming the resistance offered by the glycerine in the bottle $S$.

When the bottle rises still further, the glycerine is forced into the tube $G$ and presses the $100 \mathrm{cb}, \mathrm{cm}$ through the tube $S_{5}$ into a bottle $A$ filled with a solution of caustic potash which absorbs the $\mathrm{CO}_{2}$ gas contained in the above volume of flue gases.

The non-absorbed volume of gas replaces an equal volume of caustic solution. The solution is forced up the tube $R_{2}$ into the globe $a_{1}$ and shuts off the tube $R_{3}$. By rising in $a_{2}$ it presses the air from this vessel through a tube $S_{6}$ into the bell $T$, which rises and raises the lever $R$.

It is evident that the bell $T$ will rise the higher, the less $\mathrm{CO}_{2}$ gas has been absorbed in bottle $A$.

The lever $R$ moves a pen $F$, which makes a vertical stroke on the diagram. The higher the bell rises, i.e. the less $\mathrm{CO}_{2}$ gas been absorbed, the longer will be the stroke of the pen.

The moment the bottle $F$ has reached its highest position its downward motion commences, the glycerine goes back to $m_{1}$, the gas shut off in bottle $A$ recedes into the tube $G_{1}$ and is forced into the open air through the tube $S_{4}$ by the action of the pumps.

As the pumps deliver about twenty times the volume of gas required for an analysis the same gas is never analysed over again.

The above process is repeated every 5 to 10 minutes, according to the rapidity 


\section{LIQUID FUEL AND ITS COMBUSTION}

with which the motor works; each analysis is recorded by the stroke of the pen on the diagram, and the work of the furnace is thereby automatically recorded.

It is necessary to change the diagram paper every day, to wind up the clock and point the pen to correct time ; and to keep the pen filled and ascertain whether the liquids in the pump-valves, bottles and tubes are touching their marks, the caustic potash solution touching the mark $M_{3}$ in the bottle $A$ when the glycerine in the tube $G_{1}$ is at the mark $m_{2}$.

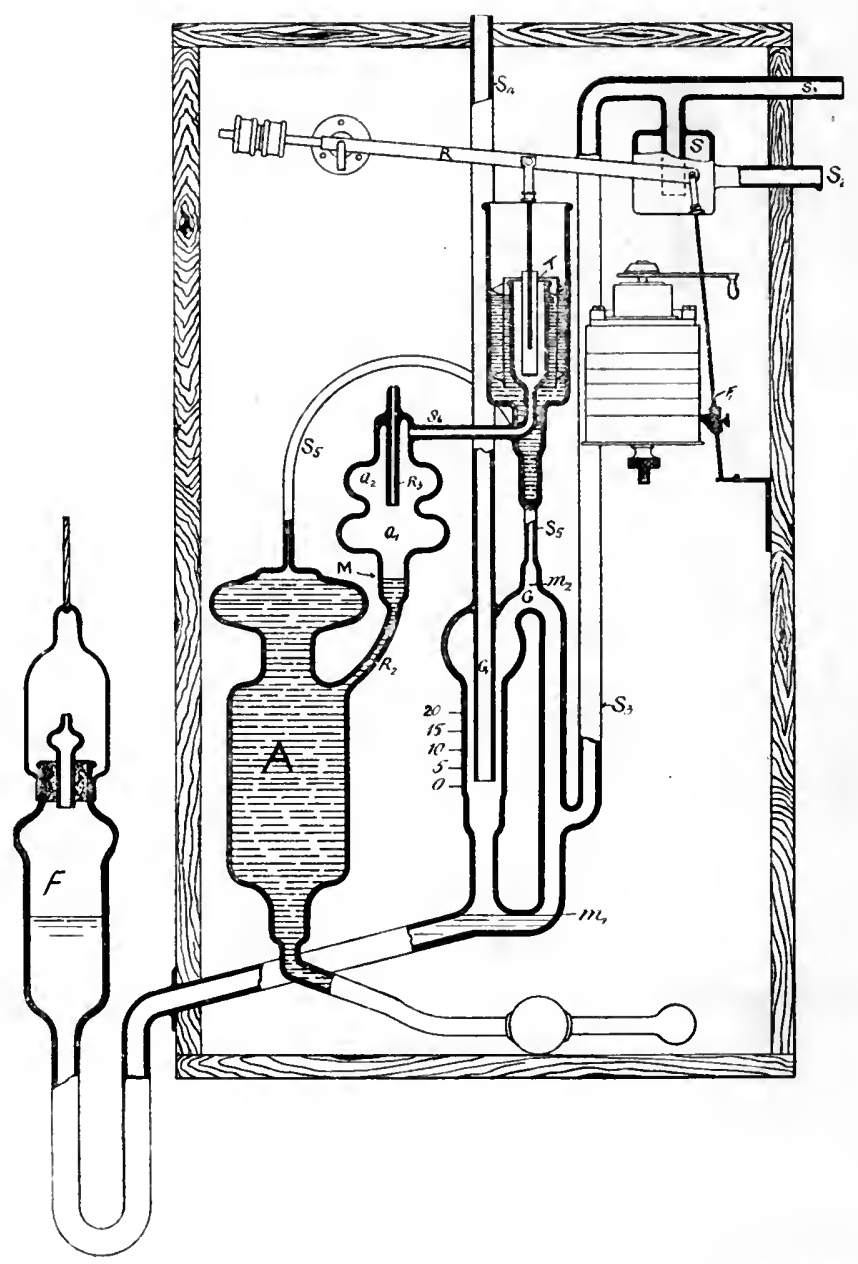

Fig. 68. "Ados" $\mathrm{CO}_{2}$ Recorder, Analyser and Recorder Portion

The potash solution is mixed to a specific gravity of 1.27 ; the glycerine is mixed with twice its bulk of water.

The gas from the flues should be drawn through some filtering material to remove the dust. Wood wool is recommended and will last two or three months without changing.

The bottle $F$, when at its highest point, is filled to drive the glyeerine in the tube $G_{1}$ up to the mark $m_{2}$.

The pen when at rest must point to line 20 of the diagram.

The gas suction pipe is to be eleaned every 3 or 4 weeks. 


\section{FLUE GAS ANALYSIS}

Any air bubbles showing in the water in the syphon $S$ when the apparatus is working, indicate that the suction pipe is blocked and wants cleaning.

\section{Recipe for Making the Caustic Potash Solution.}

Take 395 parts by weight of caustic potash.

, 875 , , distilled water.

1270 parts by weight of caustic potash solution of $1.27 \mathrm{sp}$. gr.

It will be noted when carefully following out the action of the recorder that some of the gas is allowed to escape before it reaches the bell $T$. This is designedly done, the volume escaping being a fixed quantity and the final volume measured

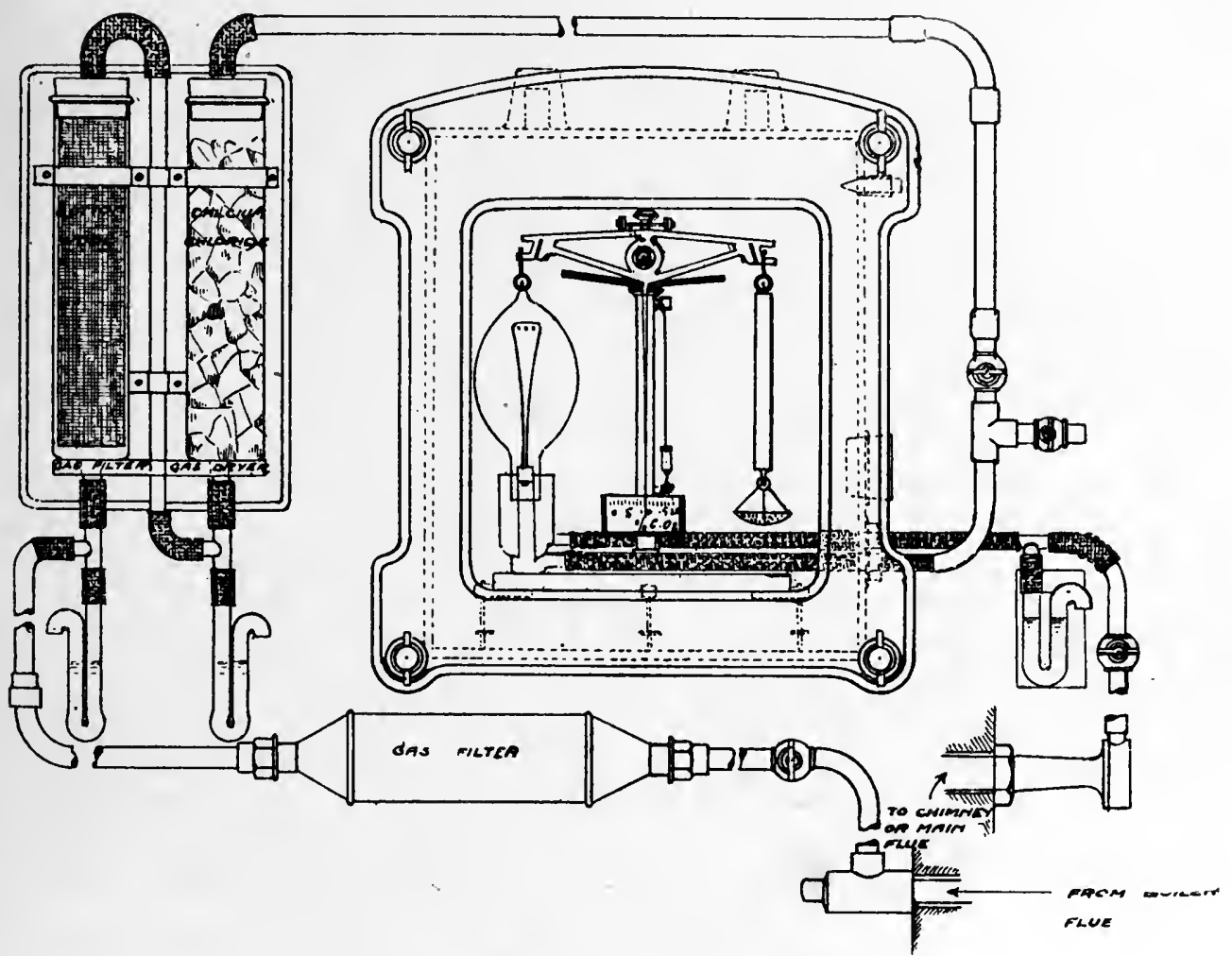

Fig. 69 Arndt's Econometer

being simply a remainder. By these means the bell $T$ is kept small and light and the chance of error is reduced and the whole instrument kept smaller.

\section{The Econometer of Arndt.}

An instrument known as Arndt's Econometer (fig. 69) will show at any moment the amount of $\mathrm{CO}_{2}$ present in the flue gas.

It consists of a chemical balance, one end carrying a scale pan while on the other end is a bottle through which is continually drawn a stream of the flue gas which is first filtered through wood wool and cotton wool and dried by passing through a bottle of calcium chloride. The proportion of $\mathrm{CO}_{2}$ is shown by the finger on the scale at the base of the balance central pillar. 


\section{LIQUID FUEL AND ITS COMBUSTION}

The proportions of the instrument are such that the reading is given in percentage of dry gas.

For ordinary average coal, the following table shows the loss of heat and fuel with from 2 to 15 per cent. $\mathrm{CO}_{2}$ in the combustion gases.

The proportion of air actually used to the theoretical amount required is in the case of coal (according to Bunte) $18 \cdot 9$, being the amount per cent. of carbonic $\mathrm{K}$

acid in gases.

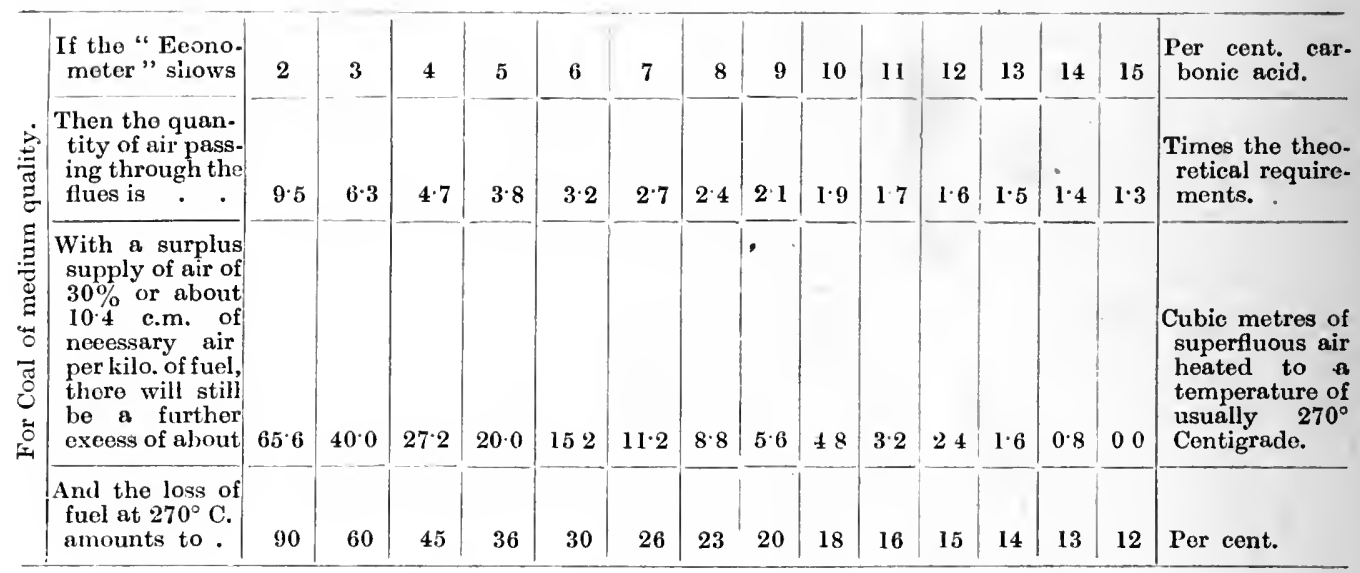

One kilogramme of anthracite coal of medium quality requires theoretically about 8 cubic metres of air or 127 cubic feet per pound.

If, for example, in the case of a steam boiler using a medium quality of anthracite the "Econometer" shows an average of only 3 per cent. $\mathrm{CO}_{2}$ (a case often happening in practice) then the volume of air used for the combustion of a kilogramme of coal and the almost equal volume of gaseous smoke is about $8 \times 6 \cdot 3=$ 50.4 cubic metres reduced to the temperature of $0^{\circ}$ Centigrade.

If the air passes to the grate at a temperature of $20^{\circ} \mathrm{C}$. and the gases leave the boiler at $270^{\circ} \mathrm{C}$, the difference of temperature amounts to $250^{\circ} \mathrm{C}$., and the heat carried away by the chimney gases (which on the average for each degree Centigrade per cubic metre, require 0.32 of a heat unit) amounts to $50.4 \times 250 \times 0.32=4032$ units.

Further, if the anthracite coal used has an actual heat value of 7,000 units, the loss of heat or fuel loss can be calculated at about

$$
\frac{4032 \times 100}{7,000}=58 \text { per cent. }
$$

If with the same firing and a larger quantity of air the amount of carbonic acid falls to 2 per cent., the loss amounts at once to $8 \times 9.5 \times 250 \times 0.32=6,080$ heat units, or about

$$
\frac{6080 \times 100}{7,000}=87 \text { per cent. of the coal. }
$$

The loss of heat, as calculated from the amount of carbonic acid, may be variously caused. Usually the grate is not the right size for perfcct combustion; it is generally too large. If by properly regulating the draught, thickness of fire, etc., 


\section{FLUE GAS ANALYSIS}

until the "Econometer" shows the desired percentage of $\mathrm{CO}_{2}$, there is excessive production of steam, it may be taken for granted that the grate should be shortened or otherwise reduced in area.

A very usual loss of fuel is made if the fire burns into holes, so permitting the air to pass through without combustion; this will at once be shown by the "Econometer."

By comparing the amount of carbonic acid at the entrance and exit of the boiler flues, which can easily be done by fixing the apparatus at the corresponding places, it can be discovered if any defects exist in the brickwork admitting air and causing loss of heat and fuel.

The "Econometer," like the "Ados," is simply an automatic means of showing approximately what is found by the first absorption pipette of the Orsat apparatus. The action of the instrument is as follows--Being set level by means of base screws, the balance is adjusted to zero under ordinary atmospheric conditions. The funnel inside the gas vessel is connected to the flues whence it is desired to draw the gas to be sampled.

The base vessel is connected to the chimney, or it may have a connexion to the vacuum system of a steam engine. This draws air from the mouth of the bottle, and the whole instrument being in a closed case, the only inlet is that from the flue. The flask is thus always full of gas containing an average of $\mathrm{CO}_{2}$ taken over the time occupied in passing one flask volume through the apparatus. According to the percentage of $\mathrm{CO}_{2}$ present in the gas so will the index finger of the balance point on the scale. In order that the air in the case may also represent the true atmosphere and not become vitiated by a possible admixture of flue gases, there may be also a small opening into the case suitably fitted with a wool filter so that the air in the case may be continually changed. This opening must be, of course, much less than the other two pipes so that the gas suction may not be seriously impaired. 


\section{Chapter XXVII}

\section{COMPRESSED AIR AND AIR COMPRESSORS}

$7 \mathrm{HE}$ use of air as the atomizing agent has been unpopular merely because steam is more readily obtained, and where the loss of fresh water in the form of steam is not a serious matter, it is claimed that steam is a cheaper agent than air, which must be compressed by steam power to begin with. But steam is not a supporter of combustion, and air is ; and there is a tendency to-day to employ air where possible, and to use it hot. Air being so nearly a perfect gas, the whole work of compressing it is practically converted into heat, and the temperature of the compressed air is raised. In the compression of air to 60 pounds per square inch or more it is usual to compress in two stages, cooling both cylinders by means of a water jacket, and cooling the air between the two stages by means of a tubular

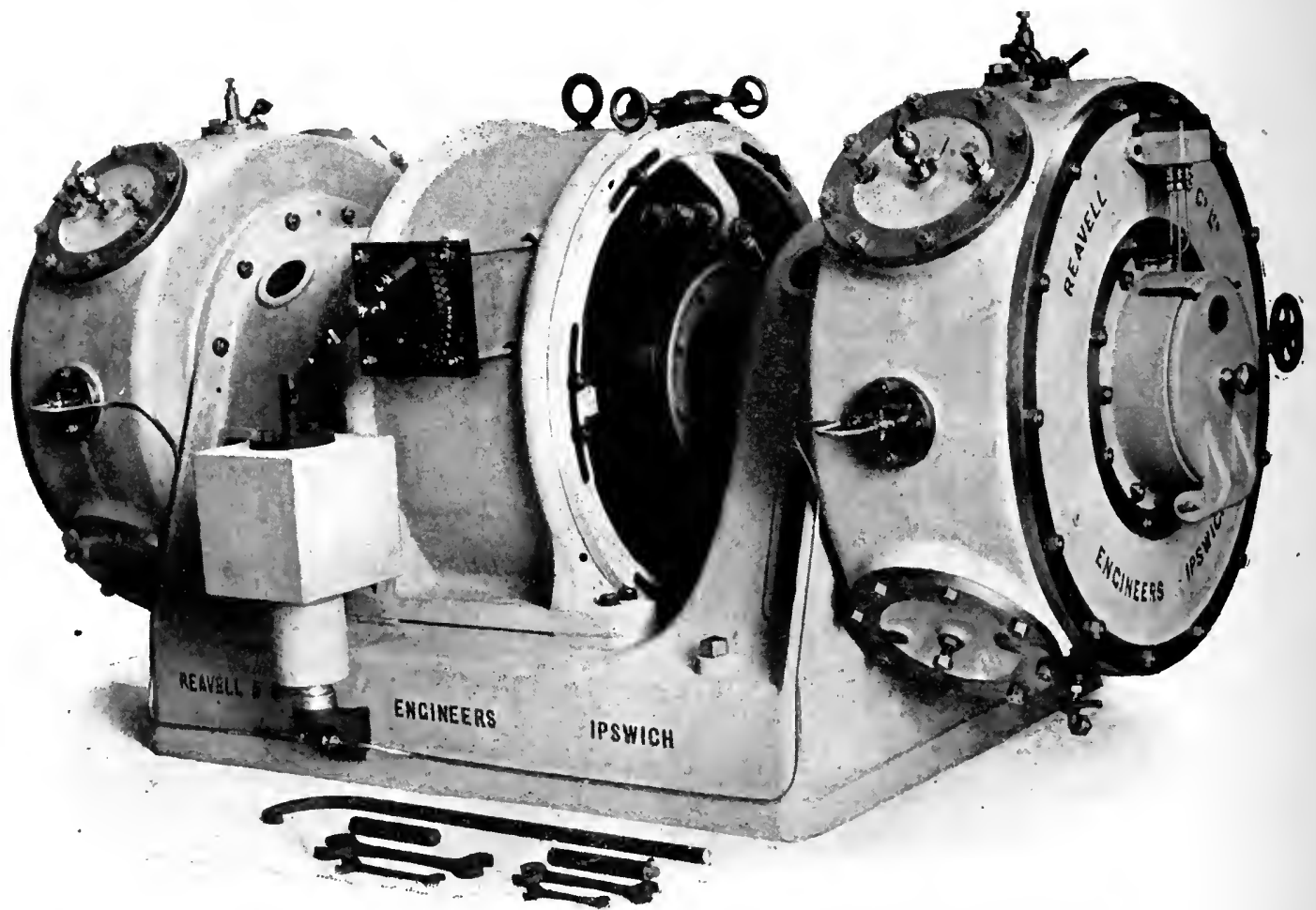

Fig. 71. Reavelu Double Quadruplex Electrically Driven Two Stage Air COMPRESSOR 


\section{COMPRESSED AIR AND AIR COMPRESSORS}

receiver or a sufficient area of exposed tubes. But in fuel atomizing a pressure of 15 pounds by gauge is held by some to be ample, and generally it is not necessary to use air at the same high pressure as steam. This is probably due to the greater efficiency of this high pressure steam which can be employed in less volume. But this does not apply to air which must of necessity be introduced into the furnace and is required for the proper combustion of the fuel. As a rule, air compressors are somewhat long and awkward machines, and, especially on shipboard, they are not easily housed. A modern compressor of an entirely different type is that of fig. 71-72, which is made by Messrs. Reavell and Co. In this machine there are
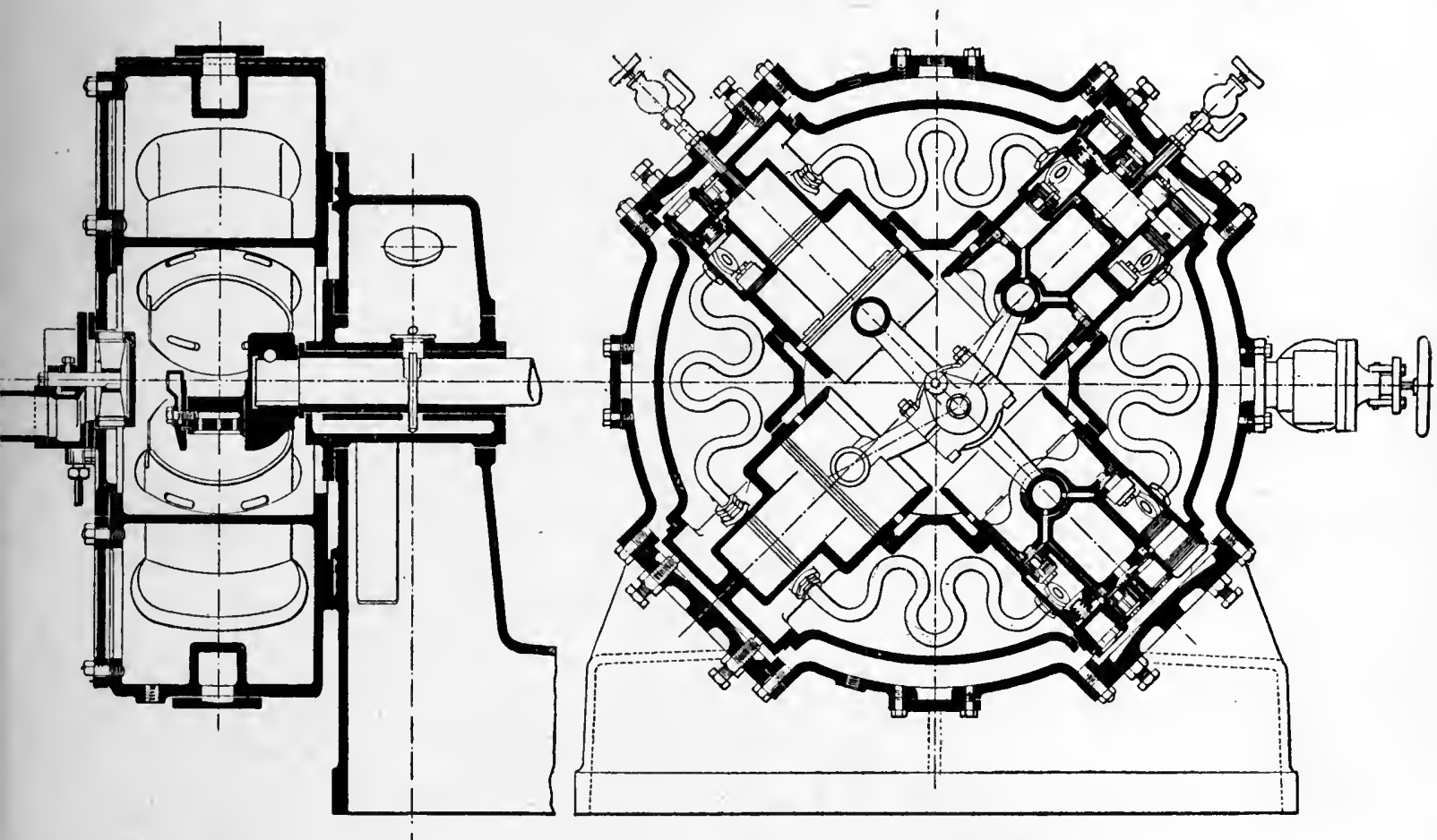

Fig. 72. Section of Reavell Two Stage Quadruplex Air Compressor

four cylinders set round a circular framing tank. The pistons of the four cylinders are driven by short rods off one crank-pin, and the crank shaft is most conveniently driven by a direct connected electrical motor, the armature of which is keyed upon the shaft, which carries a crank at each end and drives a double compressor. Thus one combination has eight cylinders and eight maximum torque points per revolution, so that it will run steadily without fly-wheel. For oil atomizing it is not necessary to employ a two-stage compressor. The heat of compression is not great for the first moderate stage of 15 to 30 pounds, and after the air leaves the compressor it should be heated on its way to the atomizer. This is usually effected by means of pipes in the flues of the stationary boiler or in the smoke box of the locomotive, as in fig. 26.

The curve of isothermal compression of a perfect gas is the hyperbola, the equation to the curve being such that $\mathrm{Pv}=$ constant.

Thus two cubic feet at 40 pounds absolute pressure become one cubic foot at 80 pounds, but the temperature remains constant. 


\section{LIQUID FUEL AND ITS COMBUSTION}

When air is compressed adiabatically, or without loss or gain of heat, its curve has the equation-

$$
\frac{\mathrm{P}}{p}=\left(\frac{\mathrm{V}}{v}\right)^{1: 403}
$$

$\mathrm{P}$ being the pressure corresponding to the small volume $v$, and $\mathrm{V}$ the volume at small pressure $\mathrm{p}$.

Assuming the volume $\mathrm{v}=1$ we have-

$$
\frac{\mathrm{P}}{p}=\frac{\mathrm{V}^{1^{*}+08}}{\mathrm{l}} \text { or } \mathrm{P}=p \mathrm{~V}^{1^{4} 408}
$$

Thus air at pressure $\mathrm{p}=15$ is compressed to $\mathrm{P}=90$.

Then $\frac{P}{p}=6$ and the relative volumes before and after compression are for $v=1$.

The log. of 6 is 0.77815

$$
\frac{\mathrm{V}^{1 \cdot 408}}{\mathrm{l}}=\frac{\mathrm{P}}{p}=6
$$

and $0.77815 \div 1 \cdot 408=0.55266$, which is the log. of $3 \cdot 57=\mathrm{V}$.

Thus in place of an original 6 vols. of air, only 3.57 will be needed to give a final volume of 1 , owing to the increased volume due to temperature rise. For a moderate compression of 2 only we shall have $V^{1 \cdot 408}=2$. The log. of 2 is $0 \cdot 30103$ and $0 \cdot 30103 \div 1 \cdot 408=0 \cdot 2138$, which is the log. of $1 \cdot 636$, this being the number of eompressions necessary to give a double pressure instead of two compressions, had the temperature been kept down or $\mathrm{V}=\mathbf{l} \cdot 636$

The heat generated in compressing a gas from a pressure of $p$ to a pressure of $p_{1}$ is-

$$
\mathrm{H}=\frac{53 \cdot 15 \mathrm{~T}_{0}}{\gamma-1}\left[\left(\frac{p_{1}}{p}\right)^{\frac{\gamma-1}{\gamma}}-1\right]
$$

where $\gamma$, according to Rankine, is $1.408 ; p$ and $p_{1}$ are the initial and final pressures in atmospheres and $\mathrm{H}=$ foot pounds, $\mathrm{T}_{0}$ being the absolute temperature whence the heat units per pound of air compressed will be $\mathrm{H} \div 772$, and the temperature

$\frac{\mathrm{H}}{772 \times 0.237} ; 0.237$ being the specific heat of air.

The work done in compressing and delivering one pound of air is thus, in footpounds-

$$
\mathrm{W}=53 \cdot 15 \mathrm{~T}_{0} \frac{1 \cdot 408}{0 \cdot 408}\left\{\left(\frac{p_{1}}{p}\right)^{\frac{0 \cdot 408}{1 \cdot 408}}-1\right\}
$$

whence can be found the power required for compression. The efficiency overall from motor switch-board should not be taken above 70 per cent. when designing a motor for the purpose. The overall efficiency of a first-class air compressor is said to exceed 70 per cent. with its electric motor, but ordinary compressors cannot be ealculated above 50 per cent.

As free air wcighs one pound for each cubic 13 feet at ordinary temperatures, 


\section{COMPRESSED AIR AND AIR COMPRESSORS}

the size of compressor required for any weight of air is easily calculated from the speed and piston displacement.

In a water-cooled compressor the index of the curve of compression of a good compressor may be safely taken at $\gamma=1.2$ in place of 1.408 , as in adiabatic compression.

The subject of air compression is one of such importance in respect of liquid fuel combustion as to justify full explanation of the peculiar action of a perfect gas.

Air is so nearly a perfect gas that there is very little internal work done upon it when it is compressed. All the work appears as heat. In fig. 75 this action is shown diagrammatically. A volume of air $a b$ at the pressure $b n$ of one atmosphere, if compressed to several atmospheres so slowly that it loses all the heat of compression at once, will occupy a volume $c d$ at the pressure $a c$.

The area $a b n i$ will be exactly equal to the area $a c d m$; in other words, the product of pressure and volume is constant.

If compressed quickly, without loss of heat, the curve $n k$ will be described

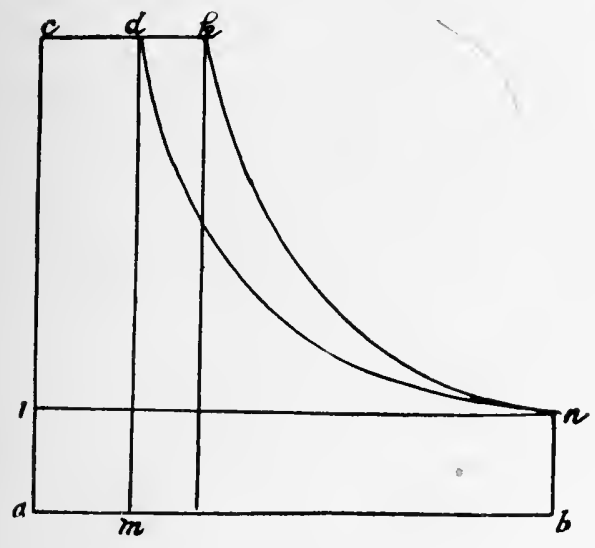

Fig. 75 .

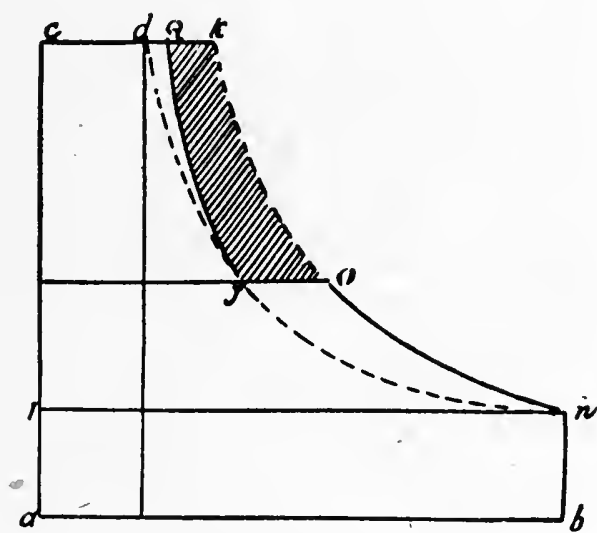

Fig. 76 .

and the volume of the compressed air will be $c k$. The rectangle $d a$ is equal to the rectangle $a n$ for $d$ and $n$ are points in the isothermal curve $n d$. Consequently the rectangles $d i$ and $m n$ must be equal and $n k c i$ is equal to $m b n k d$, or, in words, the mechanical work of adiabatic compression is equal to the work done in compression and delivery.

If, in place of single-stage compression, the double-stage system be adopted, the principle of intermediate cooling can be employed. Thus, in fig. 76 compression is first carried to the point $o$; the compressed air is cooled in the receiver to the point $j$, and arrives at the ultimate pressure $a c$ with a volume very little greater than $c d$. The diagram is less in area than fig. 75 by the area $j o k q$, and this represents energy economized during compression.

These same principles and arguments may be applied to the use of air in two stages in place of one. Thus, the compressed air may be made to run a pump the exhaust from which is carried to a hoisting engine or other motor.

When compressing air the heat of compression is dissipated to the atmosphere, and when the air is used again in a two-stage expansion it is reheated between the stages by absorption of heat from the atmosphere, which thus serves the part of a 


\section{LIQUID FUEL AND ITS COMBUSTION}

general equalizer, absorbing heat from compressed air and giving it out again to expanding air.

In the use of compressed air two systems of regulation are employed by Messrs. Reavell. Where the compressed air is in constant use at an approximately steady pressure, the compressor must not stand still, but must run constantly at varying speeds. To secure this end, there is a field-regulating rheostat connected to a pressure cylinder, the piston of which is balanced by a weight. This apparatus can be arranged to take up its extreme positions with a range of, say, five to ten pounds of air pressure. At one end the motor runs at full speed; at the other end it runs down to half speed.

There is, of course, a maximum pressure beyond which a compressor cannot work. This upper limit is governed by the clearance of the compressor pistons, and is one argument in favour of two- or three-stage compression. With no clearance in the compression cylinder, there is no limit of pressure short of the strength of the machine. With clearance in front of the piston, the clearance space is always filled with air at the reservoir pressure, and it expands as the piston retreats and reduces the volume of new air drawn in on the suction stroke. Thus, with a clearance of one-sixth the cylinder capacity, the maximum pressure possible is six atmospheres. In a two-stage machine clearance can seriously affect only the first cylinder. In ordinary machines with large clearances it is a usual practice to inject water into the cylinders to assist in cooling the air and to fill up clearance spaces, but this is not desirable for purposes of atomizing. Obviously, therefore, the effect of clearance will be to reduce the efficiency of a compressor. Hence the fallacy of running tests from an initial of one atmosphere, instead of at the steady final pressure thoughout.

The following figures were obtained by the writer at a test of a two-stage Reavell compressor made for work in a tube railway. One end alone was tested in order that the longest possible time might be taken in filling the reservoir-

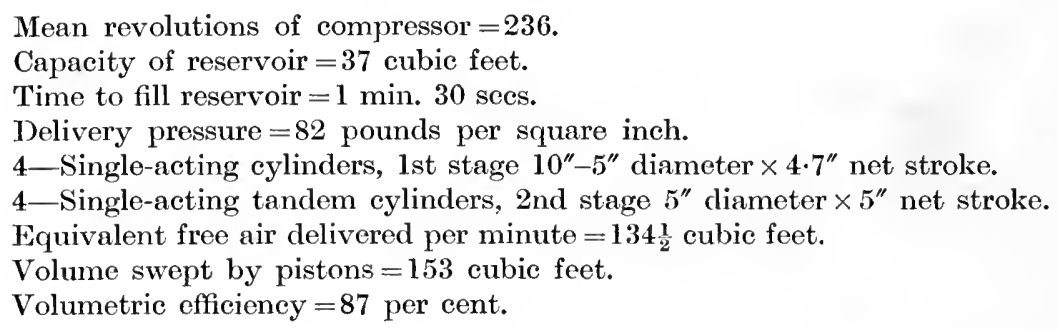

In making this test the reservoir was filled to 82 pounds pressure through a throttle-valve from an auxiliary vessel in which the pressure was maintained at 82 pounds all through the run. The volumetric efficiency was found to be 87 per cent., on the basis of one atmosphere being 15 pounds per square inch. The actual output is, therefore, a trifle better than 134.5 cubic feet.

The cylinder ratio was 4 to 1 ; but as the first stage of compression takes place between the 10-inch and 5 -inch pistons, the true ratio is 3 to 1 .

In a second test, the throttle-valve was wide open and the compressor delivered into an initial pressure of one atmosphere, the total volume of the reservoir being increased by the volume of the auxiliary reservoir. Yet the efficiency was only 90.75 per cent., a small increase above the previous result. The effect on the 


\section{COMPRESSED AIR AND AIR COMPRESSORS}

apparent efficiency of the adoption of 15 pounds as one atmosphere is to give a less result by $2 \frac{1}{2}$ per cent., but each test is equally affected.

Mean revolutions of compressor $=240$ per minute.

Capacity (total) of reservoir and connexions $=37+2 \cdot 975=39.975$ cubic feet.

Time to fill reservoir $=1$ min. 35 secs.

Delivery pressure $=82$ pounds per square inch.

Equivalent free air delivered per minute $=141$ eubic feet.

Volume swept by pistons $=155$ cubic feet.

Volumetric efficiency $=90.75$ per eent.

The importance of small clearance is thus made manifest and the advantage of two-stage compression is undoubted for pressures above about four atmospheres.

It is stated by Lieutenant Winchell (see Appendix III, p. 317) that tests made on various atomizers show that each pound of water evaporated from and at $212^{\circ} \mathrm{F}$. requires one cubic foot of free air compressed to $20 \mathrm{lb}$. gauge pressure $=35 \mathrm{lb}$. absolute. Assuming that $1 \mathrm{lb}$. of oil will evaporate $13 \mathrm{lb}$. of water, and that 13 cubic feet of air are equivalent to $1 \mathrm{lb}$., the figures represent $1 \mathrm{lb}$. of air to atomize $1 \mathrm{lb}$. of oil. How much power, then, will be required to atomize the fuel for 1,000 h.p., using, say, $16 \mathrm{lb}$. of steam per h.p. hour, with an evaporation, say, of $14 \mathrm{lb}$ : per pound of oil ? Here $1,000 \times \frac{16}{14}=1,143 \mathrm{lb}$. of oil per hour, or $1,143 \mathrm{lb}$. of air. This is $19 \mathrm{lb}$. of air per minute, to compress which, according to equation (2) adiabatically from a temperature of $62^{\circ} \mathrm{F}=522^{\circ}$ absol., will require per pound of air-

$$
\begin{gathered}
{\left[\frac{53.15 \times 522 \times 1408}{408} \times\left\{\left(\frac{35}{15}\right)^{0.29}-1\right\}\right] \div 33000} \\
=\frac{95745 \times 0.286}{33000}=0.8384 \text { h.p. }
\end{gathered}
$$

per pound of air compressed to $20 \mathrm{lb}$. gauge pressure per minute. At 70 per cent. efficiency, this becomes $1.2 \mathrm{~h} . \mathrm{p}$. nearly, or a total of $22.8 \mathrm{~h} . \mathrm{p}$. for the total engine power of 1,000 , which is less than $2 \frac{1}{3}$ per cent. of the total power; whereas steam atomizing requires 3 to 5 per cent. of the total power of a boiler. The citation of the air per pound of evaporation is hardly a correct niethod, but not much is yet known of this part of the subject, and meantime one pound of air, or 13 cubic feet of free air, should be provided per pound of oil ; and probably with the cooling effect allowed for, one brake horse-power will compress one pound of air to 20 pounds gauge pressure. The figures thus confirm M. Bertin's original idcas, as given below.

The above calculation is for adiabatic compression.

Per kilogram of air per minute the power expended in air compression will be nearly 50 h.p.

To spray one kilo. of oil requires 28.6 cubic fect of free air, or 812.0 litres. As it is usual to order air compressors by their capacity in cubic feet of free air, the amount of one unit weight per unit of oil works out at 13 cubic feet per l.p. hour, more or less, according to the efficiency of steam engine and boilers, or from 20 to 25 cubic feet per minute per 100 h.p. From this the size of air compressor can be calculated.

Thus an eight cylinder air compressor will have, say, a total useful piston stroke equal to 3 feet per revolution. At 240 revolutions per minute, this repre- 


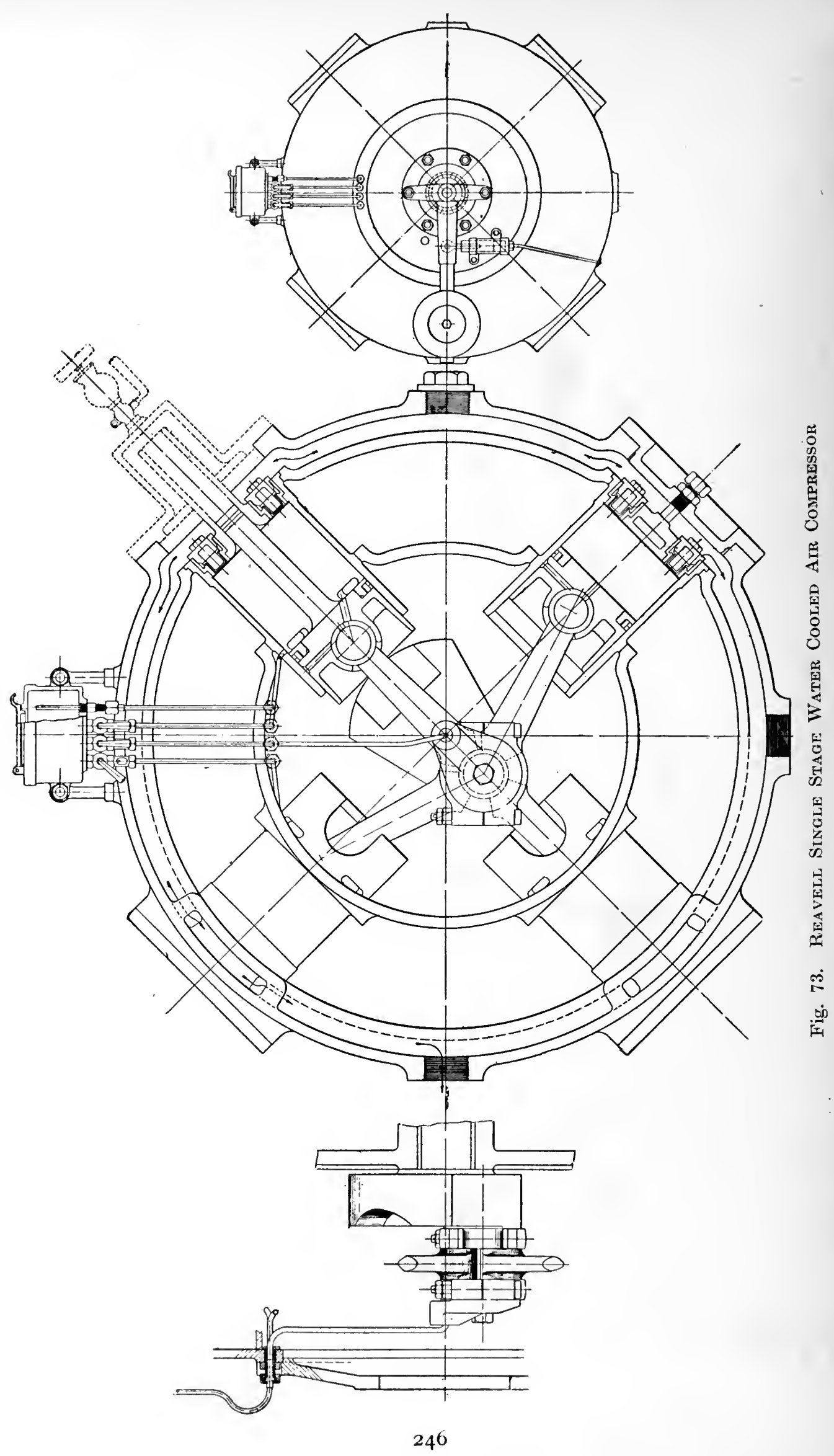




\section{COMPRESSED AIR AND AIR COMPRESSORS}

sents 720 linear feet. With 10 inch diameter pistons the capacity is thus about 390 cubic feet per minute, less, say, 10 per cent. for slip or 350 cubic feet, which

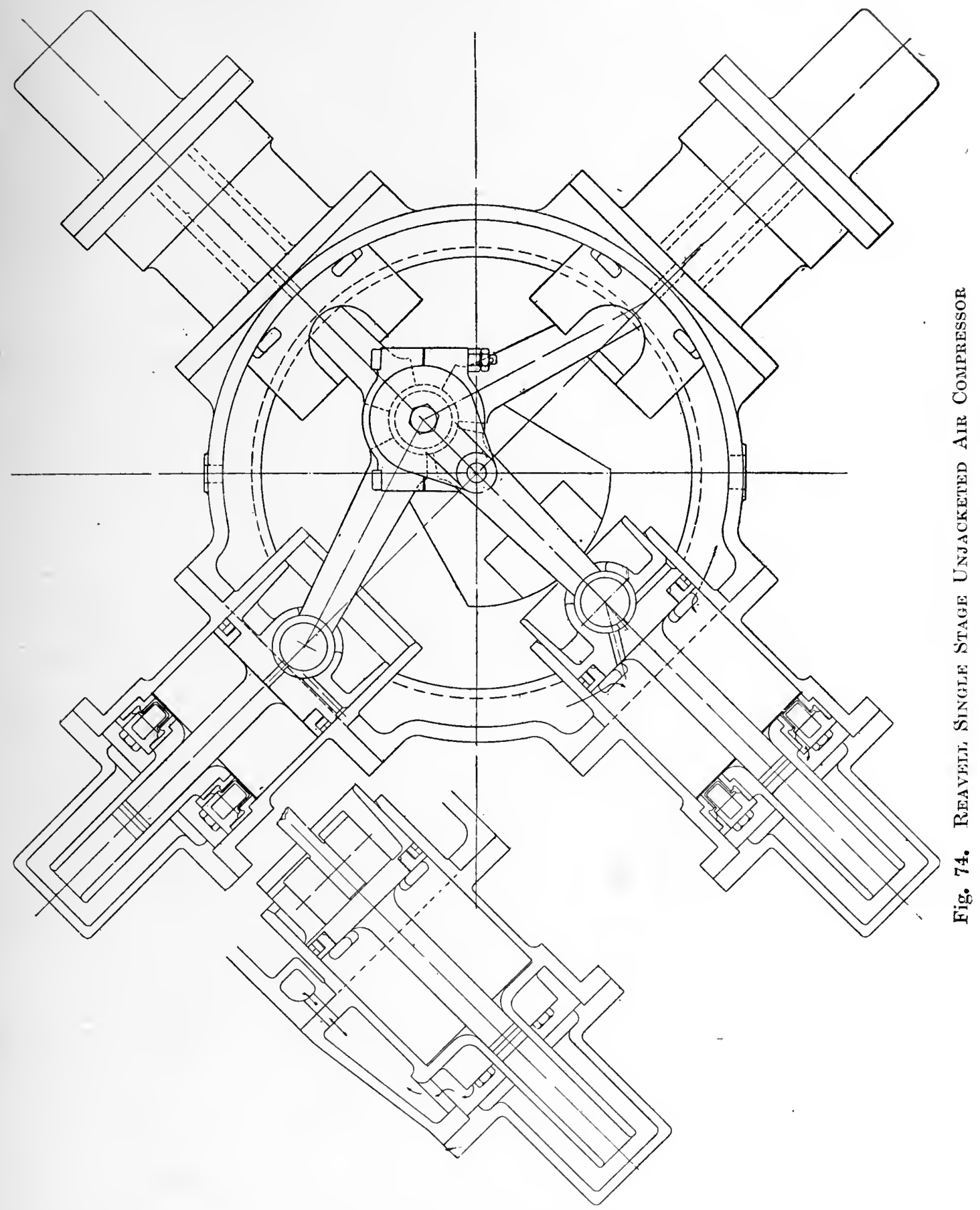

should supply about 1,400 to 1,700 h.p. of burners in a fairly economical plant. An allowance of ten per cent. for slip is enough in these compressors for 80 pounds compression, and is therefore more than ample for ordinary low pressure work. 


\section{LIQUID FUEL AND ITS COMBUSTION}

The Reavell compressor lends itself very readily to direct electric driving, as per fig. 71 , which shows a double two-stage machine driven off one central motor. These compressors require no fly-wheel, the torque all round the circle being so even that the armature provides sufficient fly-wheel energy. In fig. 73 is shown the simple stage machine with water casing, the same machine without casing being shown in fig. 74. Cooling is not important at low air pressure, and as the air is always heated by compression and is wanted hot at the atomizers, it is perhaps doubtful economy to cool during compression to moderate pressures. In fig. 72 the section of the two-stage compressor of fig. 71 is given. The illustrations are, to a large extent, self-explanatory. It may be remarked that in all compressors the delivery valves are alike, and the requisite valve area is given by varying the numbers of the valves, which are self-contained gun metal fittings with light steel cup valves. The air cylinders are supplied with air through the cross head-pin, and finally filled up to the full atmospheric pressure by the uncovering of ring ports by the piston. Automatic regulating devices are fitted to maintain the air pressure constant in the case of electric driving by rheostatic control actuated by the air receiver pressure.

M. Bertin, of the French Navy, states that a good compressor will not use half the steam that is used where steam atomizing is employed, for steam will compress more than its own weight of air up to its own pressure ; and it can hardly be doubted that for naval and marine purposes generally the use of air for atomizing must eventually become general.

In the foregoing calculations the compression of the air has been assumed to be adiabatic. This is not strictly correct even in uncooled cylinders, and some distance from correctness in cooled cylinders, but any error is on the right side, and it is better to proportion the air compressors on an adiabatic basis, so that there may be a fair allowance of power.

As already stated, where the index of the adiabatic curve is $\gamma=1 \cdot 4$, and that of the isothermal curve is $\gamma=1 \cdot 0$, practical work may be done at values of $\gamma=1 \cdot 2$. Expanding air becomes so very cold that between the compressor and the atomizer air should be heated as hot as possible, in order to counteract the chilling effect.

For compound compressors, which so far hardly come into the sphere of liquid fuel work, the power required to compress up to an absolute pressure of 2,4 or 6 atmospheres is as follows, compared with adiabatic compression in a single-stage machine-

\begin{tabular}{c|c|c}
\hline $\begin{array}{c}\text { Pressure in Atmo- } \\
\text { spheres. Absolute. }\end{array}$ & $\begin{array}{c}\text { Ratio of Power. } \\
\mathrm{W}_{\mathbf{2}}: \mathrm{W}_{\mathbf{1}}\end{array}$ & $\begin{array}{c}\text { Probable Ratio } \\
\text { in practice. }\end{array}$ \\
\hline 2 & .951 & .975 \\
4 & .901 & .950 \\
6 & .871 & .935 \\
\hline
\end{tabular}

Even in single-stage compression the actual power required in a cooled machine will probably be about midway between the figures for adiabatic and twostage intercooled work. See column 3 above.

As explained elsewhere, the economy of cooling is doubtful ; though if there are suitable means of heating the air, it is expensive to heat it by expending power upon it.

In the following table is given the horse-power necessary to compress one pound of air to 2, 4 and 6 atmospheres pressure absolute from the ordinary tem- 


\section{COMPRESSED AIR AND AIR COMPRESSORS}

perature of $60^{\circ} \mathrm{F} .=15 \cdot 5^{\circ} \mathrm{C}$. The figures are for adiabatic compression of one pound per minute-

\begin{tabular}{c|c|c|c}
\hline Absolute Almospheres. & Horse Power. & Actual h.-p. of driving motor. & Gauge l'ressure. \\
\cline { 2 - 3 } 2 & 0.645 & 0.860 & $14 \cdot 7 \mathrm{lb}$. \\
4 & 1.433 & 1.911 & $44 \cdot 1$, \\
6 & 1.972 & $2 \cdot 629$ & 73.5, \\
\hline
\end{tabular}

The difference between adiabatic and isothermal compression is of no serious account up to $30 \mathrm{lb}$, , or even to $45 \mathrm{lb}$. The volumetric efficiencies of good compressors at these low pressures may be safely taken at 90 per cent. of the piston displacement. The efficiency of the machine being, say, 75 per cent. overall from engine to compressor, the indicated horse-power actually required will be found by adding one-third to the figures in column 2 , whence is found column 3 .

Apparently, therefore, air for atomizing may be compressed by one horsepower to the extent of about 60 pounds weight per hour. Now, one horse-power in a good steam engine will consume, say, $16 \mathrm{lb}$. of steam per hour, or, say, $20 \mathrm{lb}$. per electrical horse-power hour, so that under favourable circumstances $1 \mathrm{lb}$. of steam should compress $3 \mathrm{lb}$. of air; and air should, apparently, be the better agent to employ, quite apart from the advantage at sea of not wasting fresh water. Further experiment is, however, required to afford reliable and fuller figures before a hard and fast ruling can be even attempted. The Author's own opinion is in favour of air heated to a considerable temperature and more or less charged with moisture to assist in preventing fouling of the atomizers.

\section{Flow of Air.}

Mr. D. K. Clarke gives the velocity of air flowing from any pressure $P$ into any other lower pressure of not more than $\frac{5}{8}$ of $P$ as 880 feet per second.

Actual experiments upon orifices having a length greater than their diameter give about 750 feet per second.

The following results were obtained-

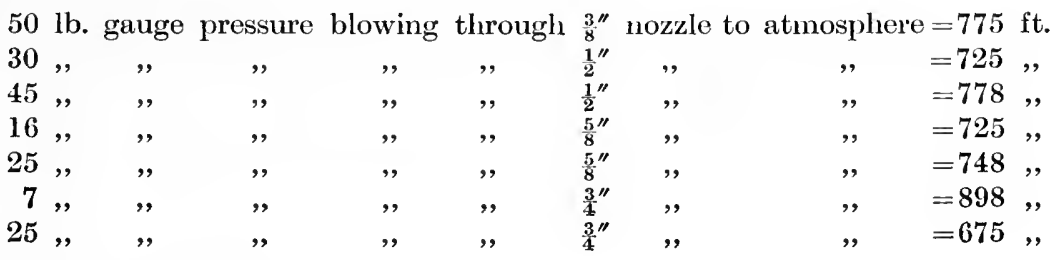

The last two results were doubtful.

It will be safe to count upon a velocity of 750 feet in making calculations as to the weight of air which will pass an orifice. The above velocities are calculated, of course, on the air at the higher pressure. The weight of air is proportional to the absolute pressure, twice as much air escaping at $35 \mathrm{lb}$. gauge pressure as at $10 \mathrm{lb}$., that is to say at $50 \mathrm{lb}$., and $25 \mathrm{lb}$. absolute.

On the relative economy of air or steam for atomizing, Professor Williston says unquestionably that air at 2 to 5 or even 10 pounds per square inch is more economical than steam, so far as the spraying is concerned. At higher pressures there is a doubt as to economy, for the cost of compression increases so rapidly with the pressure, and yet the atomizing capacity of the air does not increase at the same 


\section{LIQUID FUEL AND ITS COMBUSTION}

rate. Thus in the U.S. Navy tests already referred to (Chapter XVII) the most economical results were found with air pressures of only one or two pounds. All atomizers will not work at this pressure. At these low pressures, however, less than two per cent. of the steam generated would compress the air. At an air pressure of four or five pounds, four per cent. of the total steam was required to compress the air. Obviously, where atomizers will act satisfactorily, it will be advantageous to use much air at a low pressure in order that the combustion may be improved, for air must enter the furnace, and in air atomization there is not the risk of fire extinguishment that there is with steam.

\section{Small Duplex Compressor.}

A small duplex compressor, electrically driven, on the Reavell system, is shown in fig. 77. The capacity is 18 cubic feet of free air per minute, compressed if required

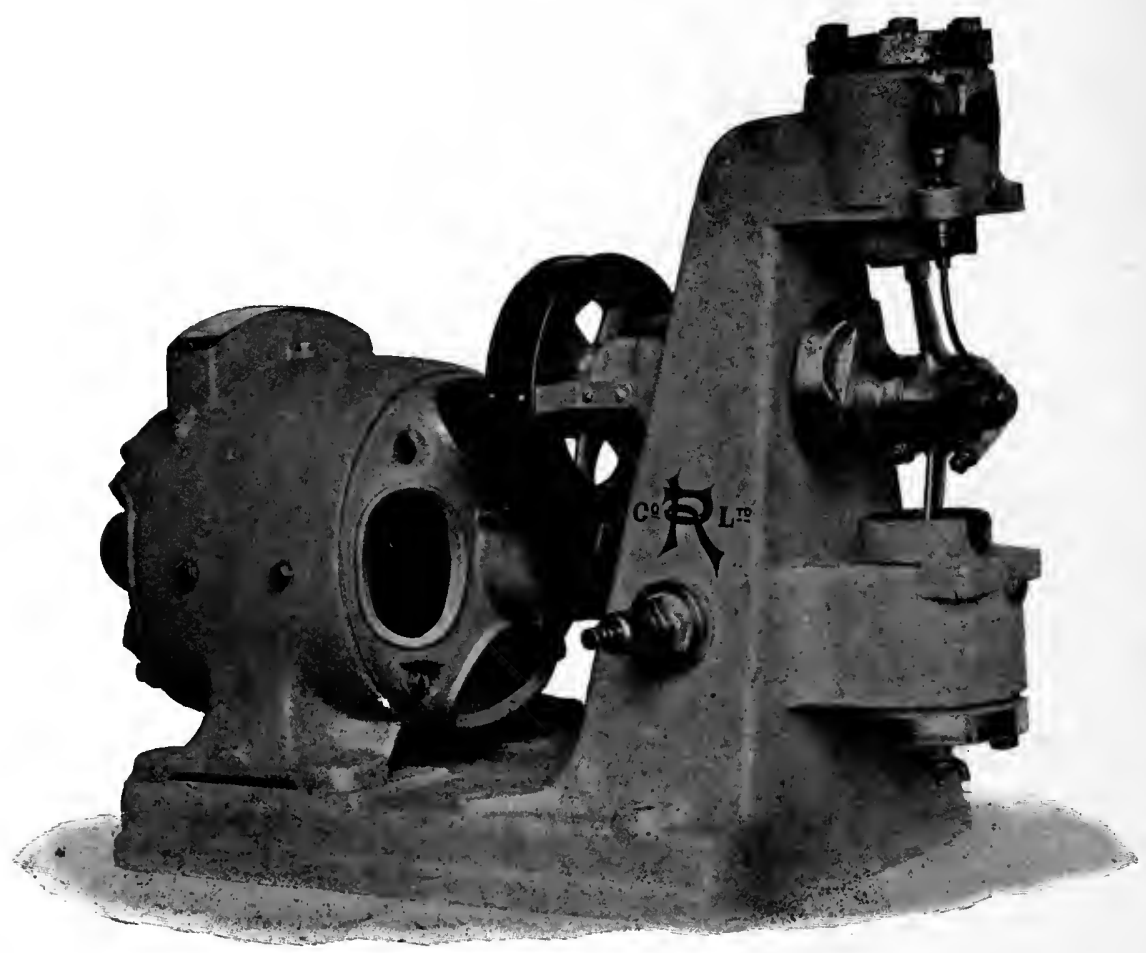

Fig. 77. Electrically Driven Duplex Compressor. Reavell System

to 30 pounds pressure. The compressor runs at 400 revolutions per minute, and is driven by a $1 \frac{1}{2}$ to 2 h.p. motor at 1,200 revolutions, geared down by 3 to 1 raw hide pinion and cut cast-iron spur wheel. The space occupied is $30^{\prime \prime} \times 18^{\prime \prime} \times 30^{\prime \prime}$ high. The capacity of the compressor should be such as to produce 1,000 to 1,200 pounds of steam per hour, according to the evaporative efficiency secured. 


\section{Chapter XXVIII}

\section{CALORIMETRY AND DRAUGHT}

\section{Calorimetry.}

W

HILE the calorific value of a fuel may be calculated approximately by the Dulong formula from its chemical composition, for more exact figures the value is found by experiment. For this purpose an apparatus called a calorimeter is employed. It consists of a closed vessel in which a small weight of the fuel can be burned by means of a supply of oxygen. The heat developed by the combustion is found by calculation from the rise of temperature of the apparatus and its water contents and the known specific heat of the apparatus.

There are many forms of calorimeter. Two only will be here described, namely the Thompson and the Berthelot-Mahler.

The first is a comparatively simple instrument and is shown in fig. 78. It consists of a graduated water vessel holding a definite weight or volume of water of, say, 2,000 c.c. or 2 kilograms, and of an inverted glass bell which contains a platinum crucible, this latter holding the fuel to be tested. A bottle of oxygen completes the outfit, the gas being led by suitable pipes to the interior of the crucible. Between the bell and the outer casing the annular space is provided with four or five discs of fine gauze through which the gaseous products of combustion must rise, and to which and the water encircling them, they give up their heat by bubbling from the bell up through the water and through the gauze discs and escape as cold as the water they have passed through.

Oxygen is fed down the bell from its upper part where the supply is admitted, and there is a special central rod by which the burning fuel is kept stirred. A delicate thermometer is placed inside the instrument, and another one is placed outside in the air. Coal or other solid fuel is pulverized. Liquid fuel may be mixed with powdered pumice stone.

The instrument is set level on a stand by means of two self-contained levels, and the container is filled to the 2,000 c.c. mark.

The crucible is supported on the base of the bell glass at such a height that its upper lip is above the level to which the water can rise in the bell when immersed. The outer casing of the crucible is fireclay. Oxygen is supplied through the tube $i$ in which is the stirrer $j$.

A weight of five grammes of fuel is placed in the crucible and a bit of lighted wax vesta is dropped in with it. Oxygen is then turned gently on and the bell lowered to the bottom of the container. Combustion is rapid, and the gas produced bubbles through the water and gauze diaphragms. When combustion is complete 


\section{LIQUID FUEL AND ITS COMBUSTION}

the tube $n$ is opened to the air, and water rises in the bell and cools the crucible. The bell is raised and lowered several times to equalize the temperature, and the thermometer is read and its rise noted. The instrument is evaluated for its specific
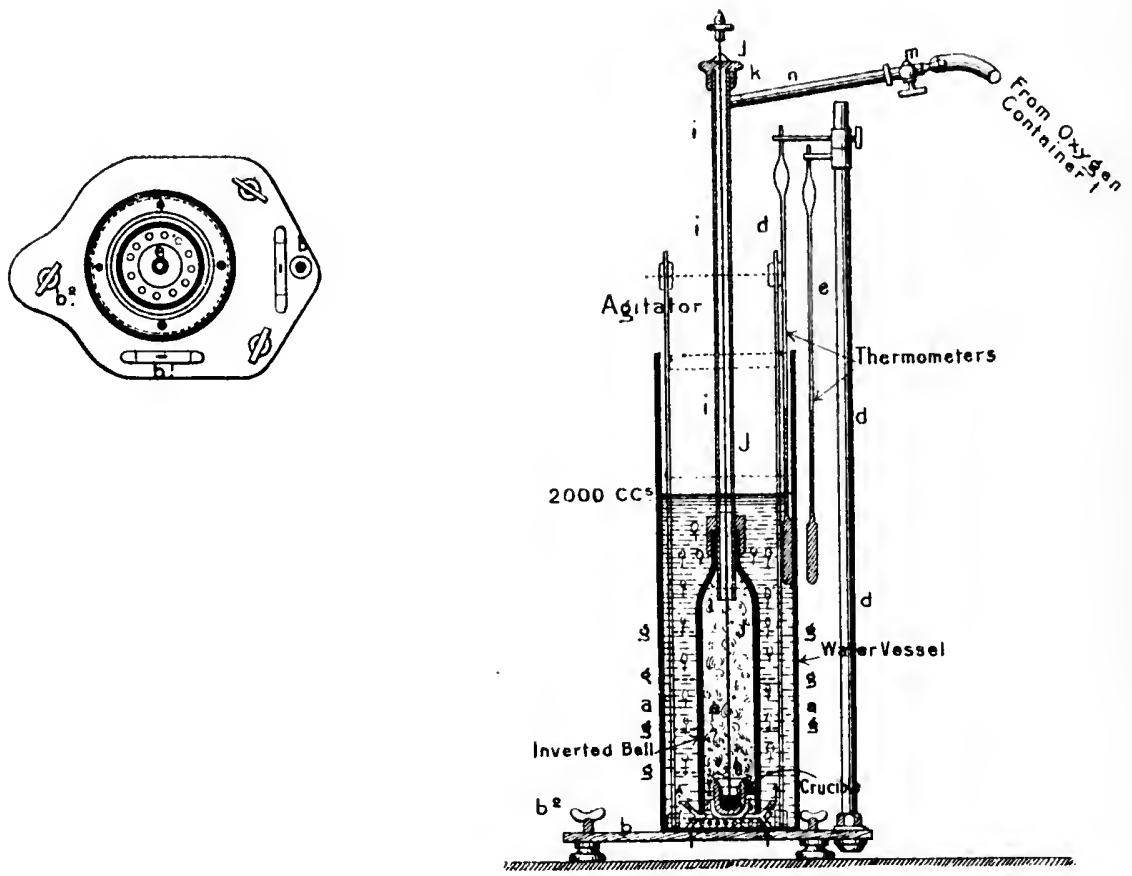

Fig. 78. Thompson's Calorimeter

equivalence of water by pouring into the empty instrument 2,000 grams of water raised $15^{\circ} \mathrm{C}$. above the temperature of the atmosphere. The lowering of the temperature of the water is noted, and the water equivalence is calculated by taking half the difference of temperature.

Thus if the water poured in has a temperature of $35^{\circ} \mathrm{C}$. and the atmosphere or laboratory temperature is $30^{\circ} \mathrm{C}$. and the final water temperature is $34 \cdot 5^{\circ}$, the water equivalent will be

$$
\frac{2,000(35-34 \cdot 5)}{35-30}=400
$$

This number of grams is to be added to the weight of water used in each determination, so that the equivalent total water in this case will be 2,400 c.c. This figure must be determined once for all for each instrument.

Then assuming that the test of a 4-gram sample of fuel gave a rise of $4^{\circ} \mathrm{C}$. we have $\frac{4^{\circ} \times 2,400}{4 \text { grams }}=2,400$ calories or the calorific value per gram or per kilogram in little and great calories respectively. Mr. Thwaite, to whom I am indebted for information on calorimeters, states that sixteen determinations did not vary more 


\section{CALORIMETRY AND DRAUGHT}

than an average of 0.75 per cent. Liquid fuel is absorbed in asbestos or pumice stone and burns freely, these substances promoting the contact of the oxygen.
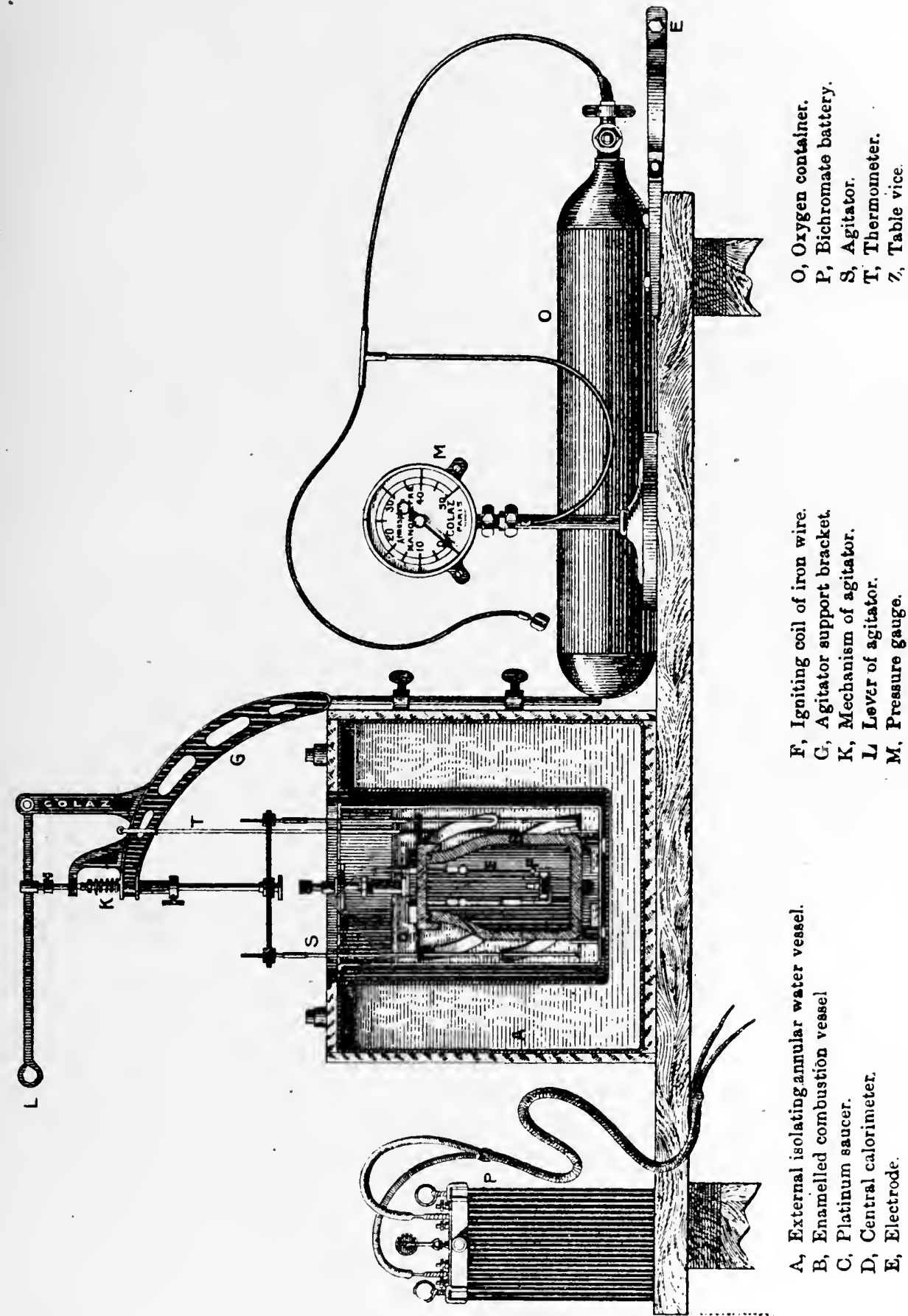

这

范总

눈

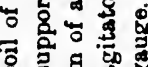

更

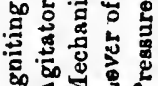

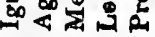

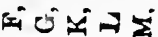

离

ษ

可

疍

总욯

.

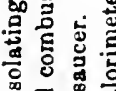

क्ष हैं

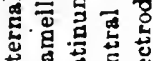

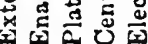

<

A more elaborate and accurate instrument is the Mahler modification of the Berthelot bomb (fig. 79). Combustion takes place in a steel bomb $B$ with a tightly 


\section{LIQUID FUEL AND ITS COMBUSTION}

screwed cover. It is made of mild steel of a tenacity of $55 \mathrm{kilos}$. per $\mathrm{mm}^{2}{ }^{2}$ and 22 per cent. elongation. The shell is $8 \mathrm{~mm}$. thick and its capacity 654 c.c. It is nickel-plated outside and enamelled inside.

The top cover is traversed by a well-insulated electrode for ignition and a valve to admit oxygen. Ignition is effected by a little bit of spiral iron wire which is heated by the electric current.

A helicoidal agitator is worked by the lever $L$. A small bichromate battery of 2 amps. $\times 12$ volts provides ignition.

Two thermometers and a gauge to show 150 atmospheres are provided. A bottle of oxygen containing 1,200 litres (free) at 120 atmospheres suffices for 100 tests.

The fuel being placed in the crucible and the bomb screwed up with the ignition details in place, oxygen is admitted till 25 atmospheres are recorded on the gauge, when the oxygen is shut off. The fuel is not too finely pulverized and oxygen is admitted very gently. The bomb is now immersed, the water agitated and the temperature carefully noted every minute for five minutes before ignition. Ignition being now effected, the temperature is noted half a minute after and one minute after, and then at intervals until it shows signs of going back. Readings are then made for five minutes, the agitator working all the time. Correction for loss of heat during test is thus found by Newton's law of cooling.

1. After maximum temperature has been read the descent of temperature represents the loss of heat from the calorimeter before the attainment of the maximum, and for one minute on the condition that during this minute the mean temperature does not vary more than $1^{\circ} \mathrm{C}$. from maximum.

2. If the difference is over $1^{\circ} \mathrm{C}$. and under $2^{\circ} \mathrm{C}$. the law of descent of temperature at the maximum moment diminished by 0.005 gives the correction.

After completing observations, the bomb is washed out to recover asidulous liquor formed during combustion. The hydric-nitrate $\left(\mathrm{N}_{2} \mathrm{O}_{5} \mathrm{H}_{2} \mathrm{O}\right)$ is tested for acid.

The definition of the thermic value of the fuel is now determined as follows-

$\Delta=$ difference for corrected temperature.

$W=$ weight of water.

$W^{\prime}=$ water equivalent of apparatus.

$n=$ weight of hydric nitrate found.

$f=$ weight of iron ignition spiral.

$0 \cdot 23$ = heat of formation of $1 \mathrm{gr}$. of dilute nitric acid.

$\mathbf{1 \cdot 6}=$ heat of eombustion of $1 \mathrm{gr}$. of iron.

$x=$ calorific power of combustible.

Then $x=\Delta\left(W+W^{\prime}\right)-(0 \cdot 23 n+1 \cdot 6 f)$

Any $\mathrm{SO}_{3}$ may be usually neglected, but if neccssary to allow for it, 2 grams of fuel should be used under a pressure of 30 atmospheres.

The formation of $\mathrm{SO}_{3} \mathrm{H}_{2} \mathrm{O}$ disengages 0.73 calories per gram.

The following temperatures were noted in a particular test of oil-

During Combustion.

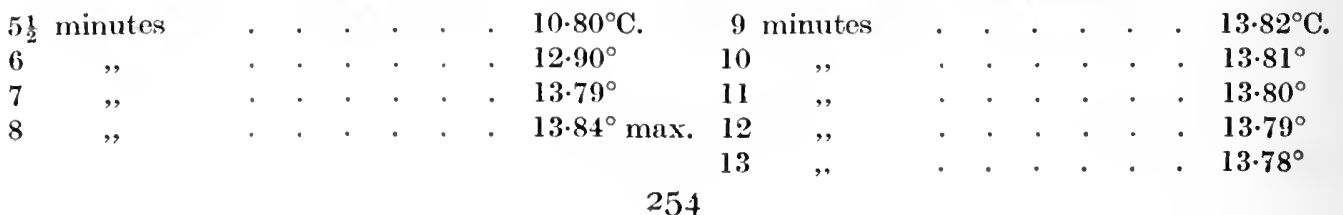




\title{
CALORIMETRY AND DRAUGHT
}

\author{
Prejiminary Period. \\ Then $\Delta=\frac{13 \cdot 84-13 \cdot 78}{5}=0 \cdot 012$
}

The temperature variation has been $13 \cdot 84-10 \cdot 25=3 \cdot 59^{\circ} \mathrm{C}$. The corrections are as follows-

Start at $10 \cdot 23^{\circ} \mathrm{C}$.

1 minute $10 \cdot 23^{\circ}$.
2 minutes $10 \cdot 24^{\circ} \mathrm{C}$.

$3 \quad, \quad 10 \cdot 24^{\circ}$.
4 minutes $10 \cdot 25^{\circ} \mathrm{C}$.

$5 \quad, \quad 10 \cdot 25^{\circ}$.

During the two minutes $7-8$ and $6-7$ the thermic loss has been $0.012 \times 2=0.024^{\circ}$ for maximum cooling. In the half minute $5 \frac{1}{2}-6$ the loss has been $(0 \cdot 012-0 \cdot 005)$ $\frac{1}{2}=0.0035$, and during the half-minute $5-5 \frac{1}{2}$ a gain of

$$
\frac{10 \cdot 25-10 \cdot 23}{5} \times \frac{1}{2}=0.004 \times \frac{1}{2}=0.0020
$$

whence the relative loss in the minute $5-6$ will be $0.0035-0.0020=0.0015^{\circ}$.

Thus during the experiment the thermic loss is $0.024+0.0015=0.0255$ to be added to $3 \cdot 59^{\circ}=3 \cdot 615^{\circ}$. Consequently the heat value absorbed by the instrument and water is where $W=2200$ and $W_{1}=481$ grams, the weight of water and the equivalence of the instrument.

$$
(2,200+481) \times 3 \cdot 615=9 \cdot 69181 \text { calories }
$$

from which, say, 0.13 grams of nitric acid formed will require $0.13 \times 0.23=0.0299$ calories to be subtracted, and for the iron spiral of 0.025 grams a further subtraction of $0.025 \times 1 \cdot 6=0.04$.

The final result is $9 \cdot 6918-(0 \cdot 0299+0 \cdot 0400)=9 \cdot 6219$ cals. or $9,621 \cdot 9$ per kilogram of oil $=17,319 \cdot 4$ B.Th.U.

Mahler's original paper, from which these figures were taken, was read before the Société d'Encouragement de Paris in June, 1892.

The water equivalent of $W^{\prime}$ of a calorimeter may be determined by burning in it 1 gram of naphthalene of well known value, first, say, with 2,300 grams of water and then 2,100 grams. of water with 0.8 grams. of naphthalene, the discrepancy from the known value of naphthalene being obviously the instrumental effect.

\section{Calorimetric Values by Berthelot-Mahler Calorimeter.}

\begin{tabular}{|c|c|c|c|c|c|}
\hline Character of Combustible. & Carbon. & Hydrogen. & Oxygen. & Nitrogen. & Calorific Value. \\
\hline $\begin{array}{c}\text { Heavy oil from American petro- } \\
\text { loum } .\end{array}$ & $86 \cdot 894$ & $13 \cdot 107$ & & & $10,912 \cdot 7$ \\
\hline Refined American petrolcum . & $85 \cdot 491$ & $14 \cdot 216$ & & $0 \cdot 203$ & $11,045 \cdot 7$ \\
\hline Treble refined American petroleum & $80 \cdot 583$ & $15 \cdot 101$ & & $4 \cdot 316$ & 11,086 \\
\hline Crude American oil . . . . & $83 \cdot 012$ & $13 \cdot 389$ & & $3 \cdot 099$ & $11,09 \cdot 1 \cdot 1$ \\
\hline Heavy Baku oil . . . . . & $86 \cdot 700$ & $12 \cdot 944$ & & 一 & $11,804 \cdot 6$ \\
\hline Novorossisk petroleum, Caucasian & $84 \cdot 906$ & 11.636 & & $9 \cdot 458$ & 10,328 \\
\hline Tar from hydraulic main . . & $89 \cdot 910$ & $4 \cdot 945$ & $5 \cdot 145$ & 一 & $8 \cdot 9428$ \\
\hline Tar from cooler . . . & $87 \cdot 222$ & 5.499 & $6 \cdot 279$ & 一 & $8 \cdot 8310$ \\
\hline Tar from condenser & $85 \cdot 183$ & 5.599 & $9 \cdot 218$ & 一 & $8 \cdot 5384$ \\
\hline
\end{tabular}

Elementary Analysis. 


\section{LIQUID FUEL AND ITS COMBUSTION}

\section{Draught.}

The draught due to a chimney arises from the difference of pressure of two columns of gas of the height between the grate surface and the chimney-top. The column inside the chimney is hot because of the furnace through which it has passed. That outside the chimney has the temperature of the outer atmosphere. At a temperature of $300^{\circ} \mathrm{C} .\left(572^{\circ} \mathrm{F}\right.$.) the inner column is just about double the absolute temperature of the outer column, so that the relative density is one-half.

The velocity of flow of a gas under any head is $v=\sqrt{2 g h}$ where $v$ is the velocity in feet per second, $h$ is the head in feet and $2 g=64.4$ or 2 gravity.

Expressed in metres values of $v$ and $h$ we have $v=\sqrt{2 g h}$ where $g=\mathbf{9} \cdot \mathbf{8 1}$.

Assuming that at ordinary temperatures 13 cubic feet of air weigh one pound, the atmospheric pressure of 2,115 pounds per square foot represents a column 27,495 feet in height, which would flow into a vacuum at a velocity of approximately $8 \sqrt{27,495}=1,321$ feet per second.

The pressure to produce draught, however, is only measured by inches of water pressure. If a chimney has an internal absolute temperature double that of the external atmosphere, it will contain only one pound of gas for each 26 feet of a column of gas 1 foot square, or, what is the same thing, the external column is halfbalanced only. Thus if $H$ be the height of the chimney $H \div(2 \times 13)$ will give the pressure per square foot, producing draught. Thus a chimney of 104 feet will give an acting pressure of 4 pounds. As 1 inch of water gives a pressure of 0.036 pounds per square inch, the draught pressure of the above chimney would be

$$
\frac{4}{144 \times \cdot 036}=1 \cdot 3 \text { inches nearly }
$$

Having found the pressure, the air column equivalent to this must be found. Water weighs 62.4 pounds per cubic foot. Air weighs 0.077 pounds, whence the equivalent air column in feet per inch of water column will be found

$$
\frac{62.4}{12 \times 0.077}=67 \text { feet }
$$

The velocity of flow is then $8 \sqrt{67 \mathrm{H}}$ or fully $64 \sqrt{H}$ where $H$ is the pressure in inches shown by the actual water gauge. In coal-fired furnaces the reading of the draught gauge is much greater at the chimney base than in the flues, for the friction of the flues exerts considerable resistance. The simplest form of water gauge is a bent glass tube of $U$ form, one end being open to the atmosphere, the other connected by a piece of indiarubber tubing to a piece of pipe which enters the flues at the point where the draught intensity is sought.

It is convenient to remember that where the velocity of flow due to head in feet is $v=\sqrt{2 g h}$, that due to a pressure as shown in inches of water is almost exactly $v=2 g \sqrt{H}$. All these figures can only be approximate, because they will vary with the temperature. They are sufficiently accurate to base designs upon in respect of providing sufficient openings for air to burn the oil.

The following table of velocities of air for a fow pressures in inches of water will be useful- 


\section{CALORIMETRY AND DRAUGHT}

\begin{tabular}{c|c|c}
\hline \multirow{2}{*}{$\begin{array}{c}\text { Pressure in } \\
\text { inches of water. }\end{array}$} & Velocity of air in feet. \\
\cline { 3 - 3 } $0 \cdot 1$ & $20 \cdot 7$ & Per minute. \\
\hline $0 \cdot 2$ & $29 \cdot 3$ & 1243 \\
$0 \cdot 3$ & $35 \cdot 8$ & 1758 \\
$0 \cdot 4$ & $41 \cdot 4$ & 2150 \\
$0 \cdot 5$ & $46 \cdot 3$ & 2485 \\
$0 \cdot 6$ & $50 \cdot 7$ & 2778 \\
$0 \cdot 7$ & $54 \cdot 8$ & 3043 \\
$0 \cdot 8$ & $58 \cdot 5$ & 3287 \\
$0 \cdot 9$ & $62 \cdot 1$ & 3513 \\
$1 \cdot 0$ & $65 \cdot 4$ & 3726 \\
$2 \cdot 0$ & $92 \cdot 4$ & 3927 \\
\hline
\end{tabular}

An ordinary $U$ gauge is not capable of being finely read. It possesses a capillarity which is difficult to allow for and will not serve for accurate work. A better gauge consists of a glass-fronted box in two divisions partly filled with water (fig. 80). A hook gauge, reading on a scale, permits the water level in one division to be determined to 0.01 inch easily.

A very sensitive gauge (fig. 81 ) consists of a $U$ tube with a drum at the top of each leg. Half the height is filled with water and alcohol. A stop-cock at the bottom of the $U$ is then closed and the upper parts are filled with olive oil to the middle of the top drums, which intercommunicate by a cross tube. The oil has a specific gravity of 1 to 2 per cent. less than the alcohol mixture. One tube is open to the air, the other to the pressure to be gauged. The lines of contact of the oil and spirit move up and down in the two tubes respectively, and they move through a distance as many times as the difference of specific gravity of the two liquids. Thus for

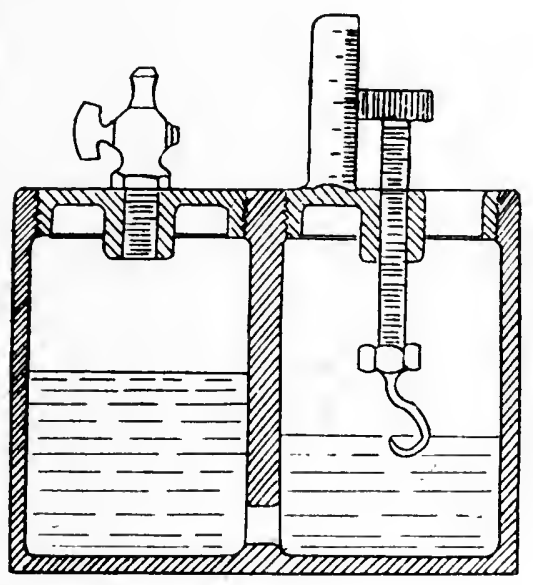

Fig. 80 . 2 per cent. difference the reading is fifty times greater than that of a plain water tube. The two tubes are about 30 inches long, to provide length for reading, and there are two scales to read, respectively the up and down travel of the point of liquid contact. In Hoadley's design of this gauge he used tubes $0 \cdot 4^{\prime \prime}$ diameter and drums at the top of each $4 \cdot 25^{\prime \prime}$ diameter with glass fronts. The large area of these drums prevents any great variation in their level for quite a large range of movement in the tubes.

In coal firing, about three-fourths of the draught is swallowed up by grate and fuel friction, and much of the remainder in the flues and chimney itself. With oil firing alone and no grate friction there is usually ample velocity of the inflowing air. The chimney, in fact, ceases to possess so much importance, but must be large enough in area to carry off the waste gases.

The weight of a cubic foot of air at $0^{\circ} \mathrm{C} .=32^{\circ} \mathrm{F}$. being $0.08 \mathrm{lb}$, that at any other temperature will be

$$
\frac{0.08 \times 273}{273+t^{\circ}} \text { where } t^{\circ} \text { is expressed in degrees Centigrade }
$$




\section{LIQUID FUEL AND ITS COMBUSTION}

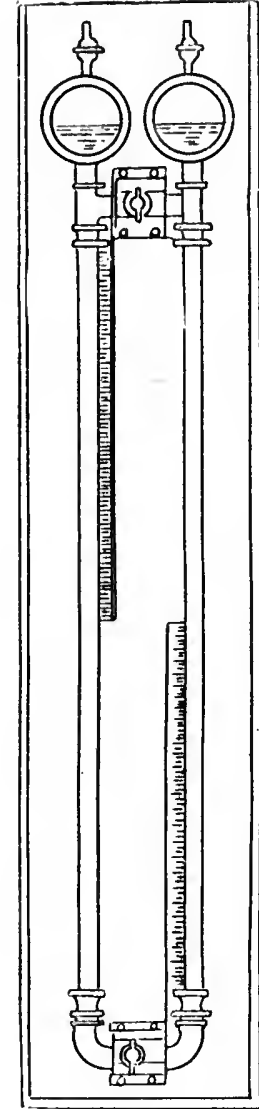

Fig. 81 . and $\frac{0.08 \times 491}{t^{\circ}+459}$ where $t^{\circ}$ is in degrees Fahrenheit.

By these formulx may be calculated the weight of air inside and outside a chimney. The difference of the two is the pressure to produce draught per foot of chimney height.

Calling $D$ and $d$ the greater and less densities the equivalent height of a column for any chimney of height $=h \mathrm{ft}$. will be $L=h\left(\frac{D-d}{D}\right)$ and the velocity of flow per second will be

$v=\sqrt{ } 2 g L$ where $L$ is the equivalent column in feet.

In all the foregoing the specific gravity of furnace gas is assumed equal to that of air of the same temperature, the steam balancing the carbonic acid more or less closely.

Seeing that draught is of less importance with liquid fuel, it is permissible to reduce the furnace products to a lower temperature if facilities can be had for doing this. The smaller excess of air with which perfect combustion can be secured is a factor in rendering more efficient the heating surfaces of the boiler, and reduced flue gas temperatures are a natural consequence of liquid fuel.

A chimney must be large enough to pass all the products of a furnace at a certain given velocity of flow. The calculation of chimney area is thus simple. Assuming the velocity of flow of gas to be 30 feet per second, it is simply necessary to divide the volume of gas produced per second by 30 . The result is the area in square feet of the chimney. To find the volume of gas produced per second, the coal consumption per second is first found as follows in pounds-

$P=\frac{W \times 2,240}{H \times 3,600}$ where $W$ is the daily coal consumption in tons

and $H$ the daily hours. Then $P \times 20=$ pounds of gas $=G$. At ordinary temperatures one pound of gas measures 13 cubic feet very closely. At the chimney temperature it will measure 20 to 25 feet. Let 22 be assumed : then $G \times 22 \div 30$ will give the area of the chimney inside $=A$. The chimney will measure, if square, $\sqrt{A}$, on each side, or, if round, its diameter will be $D=1.128 \sqrt{A}$. Chimneys for liquid fuel are similarly calculated from the weight of fuel burned, and the ratio of $\boldsymbol{P}$ to $G$ will still be $1: 20$, for though a pound of oil uses up more air than a pound of coal, the excess supplied will be less, and in each case the furnace gases will weigh about twenty times the fuel burned.

When coal is burned it rests upon a grate surface, the bars of which and the fuel resting upon and obstructing the spaces offer great resistance to the inflow of air. A fan or a chimney is necessary to draw in the air which is necessary to burn the coal.

With oil it is quite different. Air is either blown in with the oil or induced through free openings by the action of the steam or air atomizer, and a very small draught will draw in enough air for perfect combustion, and it is usually considered necessary rather to check the flow of the gases through the flues, only sufficient draught being required to remove the products of combustion as formed. Chimneys of small altitude will do this, for they do not require to overcome any grate or fuel- 


\section{CALORIMETRY AND DRAUGHT}

bed resistance. In locomotives, for example, the steam-jet may be considerably reduced in the chimney, and on the Great Eastern Railway of England the MacAllan variable blast-pipe is enlarged from 5 inches with coal to $5_{4}^{3}$ inches diameter with oil to the reduction of the back pressure on the pistons and economy of steam in consequence. In foreign locomotive practice it is usual to employ caps over the chimney-top in order to save the loss of heat when running down grade or standing idle. Mr. Urquhart continued to use this cap with his oil-fired engines, and though it presents an odd appearance to English eyes, the cap has advantages. Applied to stationary work it is represented ordinarily by a damper at the chimney-base, and is thus recognized as good, but it is not used in locomotive work. It affords, however, a ready means of regulating the fires, and cannot quite be replaced by the ash-pit damper, which is heavier to work and is by no means always so tight-shutting as it should be.

A very usual remedy for a bad draught in coal-fired furnaces is a steam jet. This is very effective in moving the gases forward to a poor chimney, which then appears able to deal with them. In oil-firing this aid to draught is inevitably present in the atomizer, which really replaces the need for a certain chimney or fan effect. The area for chimneys must not be calculated from the horse-power to be developed at a station. The actual fuel consumption should be worked from. The fuel per horse-power hour will vary according to the load-factor and other conditions, and large stations will use less fuel per horse-power hour than will small stations with smaller load-factors. Each case must stand by itself. A very small draught will give a velocity of 30 feet per second. The resistance to draught is chiefly the fuel on the grate and the long flues, especially if narrow, and the economizer.

Ordinary rules for chimneys provide for areas that will reduce the velocity of flow to much less than the foregoing 30 feet per second, but it is doubtful if such large areas are necessary with liquid fuel, and it is certain that a chimney hitherto used for solid fuel will serve well when a change is made to liquid fuel. Experience so far is lacking on the question of chimney practice for liquid fuel work, but the subject may be approached from the standpoint above, viz., that with liquid fuel not only is the resistance of the fuel on the grate eliminated but there is added a propelling force in the atomizer which, if applied to a poor draught in a coal-burning furnace, would render such draught good and sufficient. Bearing these points in mind, the ordinary treatises on draught may be studied with advantage as regards the effect of height upon velocity of flow. But the ordinary rules otherwise have very little application to liquid fuel conditions. 


\section{Chapter XXIX \\ THE ATOZIZING OF LIQUID FUEL}

OINCE liquid fuel of the heavy varieties cannot be burned except by the system $\infty$ of atomizing, the burner, injector, sprayer or atomizer, as it is variously termed, is an important detail in any oil burning system.

The object aimed at is the pulverizing of the liquid fuel, so that, mixed with air in the act of pulverization, and supplied with any further amount of air that may be necessary, the liquid atoms may burn like vapour. The spray must not be so directed that an intense blow-pipe flame impinges severely upon any small area of furnace plate.

It is sought to fill the furnace with a full soft voluminous flame which shall envelope the whole interior of the furnace. Given a sufficiently long space in front of the burner, a spray jet directed straight ahead and gradually coning out would doubtless produce a satisfactory effect, but the space between the point of the burner and that part of the cone of flame which first touched the furnace plate would be of little use as heating surface. What should be aimed at is such a burner and spray device as will produce a certain disrupture and outward expanding effect, so as at once to spread the oil to a considerable extent normally to the axis of the burner as well as parallel ; to give a sort of balloon effect, so that, in a locomotive boiler for example, there shall be flame well to the back of the box as well as forward under the arch. Various forms of atomizers will be found illustrated here or elsewhere, including-

The Holden (figs. 21, 24 and 27).

The Baldwin (fig. 37).

The Urquhart (fig. 45).

The Oil City Boiler Works Co. (figs. 9 and 13, Appendix 3).

The Hayes (fig. 11, Appendix 3).

The Grundell-Tucker (fig. 5, Appendix 2).

The Hydroleum Co. (fig. 81).

The Swensson (fig. 86).
The Guyot (fig. 89).

The Rusden and Eeles (figs. 7 and 81a).

The Billow (fig. 47).

The Williams (fig. 102).

The Aerated Fuel Co. (fig. 50).

The F. M. Reed (fig. 14, Appendix 3).

Kermode's Burner (fig. 82).

Orde's (fig. 10).

Körting's (figs. 19, 19a).

The Holden Atomizer.

The Holden Injector (figs. 21, 27, 24) consists of a gun-metal casing with oil, air and steam inlets. Air comes in at the back, preferably hot, and is delivered at the point where the oil eseapes to the inner nozzle. Steam comes between the oil and air, and the mixed jet escapes forward and slightly laterally by two orifices. A further air supply is directed upon the spray by a ring of several fine jets of steam. 


\section{THE ATOMIZING OF LIQUID FUEL}

The atomized fuel is directed along the plane of the fire when the fire-bars are retained, as this gives the best action. Mr. Holden does not confine himself to the use of steam as an atomizing agent, but recognizes that air may be preferable for chemical reasons. Two burners deal with about six pounds of oil each per mile, or, say, 240 pounds per hour.

Rusden and Eeles.

In this burner (fig. 7 and fig. 81a), steam eseapes by a central annular jet, and

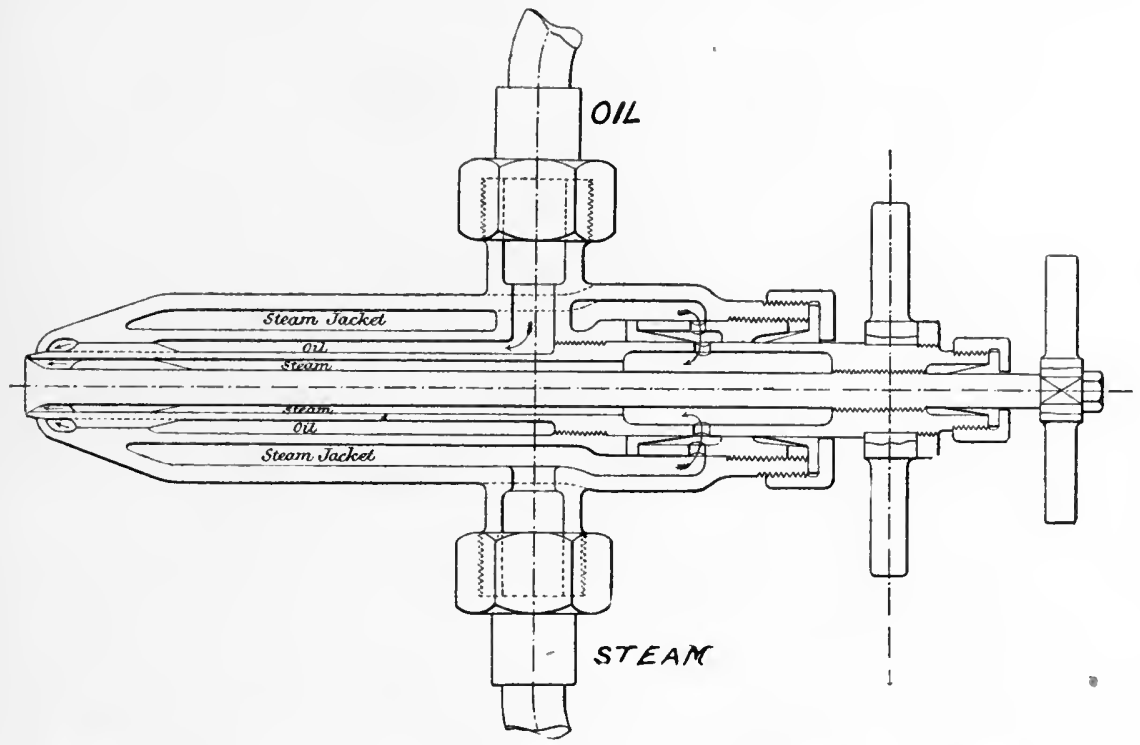

Fig. 81a. Atomizer. Rusden-Eeles

is directed outwards on a fine annular jet of oil, which is heated also by a steam jacket. This disposition gives a balloon flame. The burner is largely used in marine work.

\section{The Urquhart.}

This burner (fig. 45), one of the earliest of the successful atomizers, employs central steam, external air, and an annular oil jet between the two, the expansion of the steam atomizing the oil into the air and mixing the two.

For tyre heating, Mr. Urquhart used the arrangement of fig. 112a, the oil simply dropping into a jet of air under pressure, which induces also a supply of air round the oil supply.

\section{The Baldwin Company's Burner (fig. 37).}

The burner is very simple, being simply a broad thin jet of steam which is directed upon oil eseaping from a parallel passage. It could not well be simpler, but it is elaimed to aet well, and there appears no reason to doubt this.

\section{The Aerated Fuel Company's Burner.}

This is of the central air jet type, as shown in fig. 50 .

The Oil City Boiler Company's Burner.

Fig. 9, Appendix 3, shows this Company's air spray burner, air being admitted 


\section{LIQUID FUEL AND ITS COMBUSTION}

outside a central oil jet and directed inwards upon the oil which escapes at the centre. This burner was used in the tests of the Bureau of Steam Engineering, Nos. 1 to 8 . These burners were arranged in pairs, so that they inclined towards each other, and produced impinging flames. Each burner dealt with about 140 pounds of oil per hour. The same company supplied the steam actuated burner (fig. 13, Appendix 3), the oil being here admitted by a cone or needle valve, and steam being admitted outside. Both these burners appear to have given satisfaction, and in both it was found that the best results followed on the highest oil pressure, which in tests $10,11,12$, was 20,30 , and 45 pounds per square inch respectively. High steam pressure was also condueive to efficieney, but more steam was used. It appears to be thought also that higher air pressure would be an improvement in the ease of air burners.

\section{The F. M. Reed Burner.}

Fig. 14, Appendix 3, is a combined air and steam burner, not recommended as economieal in steam. Here the provision for air is very large, and in no way resembles the small air passage of the Holden burner, and it would appear as though the ring jets of the Holden burner were more effieient than the air bulbs of this burner.

\section{The Grundell-Tucker Burner.}

This, as used in the ss. Mariposa trials, Appendix 2, is given in fig. 5 of Appendix 2, the mixed oil and air being gyrated by special blades and ballooned out. Air was used at $40 \mathrm{lb}$. pressure and heated. The oil enters the air stream through several small holes drilled normal to the air jet. Twenty-four burners appear to deal with 3,000 to 3,400 pounds of oil per hour, or 125 to 140 pounds per hour each.

What apparently is necessary to good operation is an air pressure not under $15 \mathrm{lb}$. by gauge, while even better results will accompany higher pressures. High pressure of the oil also appears good, probably beeause of the self-atomizing tendency of the oil as it escapes through the fine openings necessary where the pressure is considerable.

\section{The Hayes Burner.}

Fig. 11 of Appendix 3 was not found to be a success, probably because the long pipe nozzle destroyed the atomizing effeet. Atomizing, to be a suecess, apparently requires to be performed close to the point of eseape into the furnace.

Fig. $81 \mathrm{~b}$ shows the nozzle of the Hydroleum Company's burner. Oil is een-

$$
\text { The Hydroloum sistem }
$$

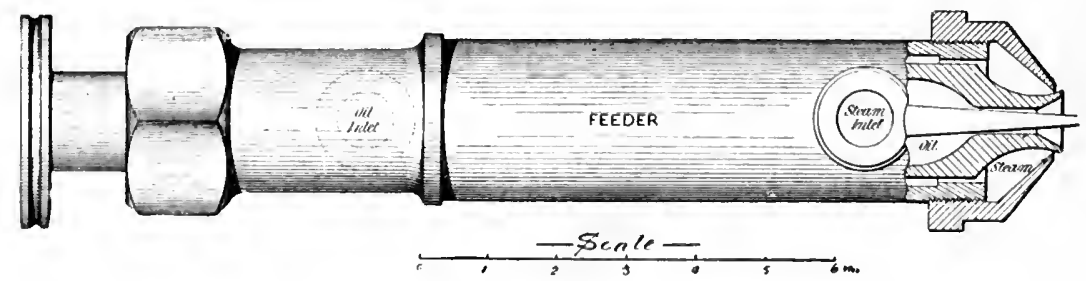

Fig. $81 b$.

trally regulated by a needle, and issues from a mouthpieee flared out externally 262 


\section{LIQUID FUEL AND ITS COMBUSTION}

the oil of a large steamship, as a simple caleulation will show. With a horse-power of 5,000 there may be used 5,000 pounds of oil per hour, or, say, 600 gallons per

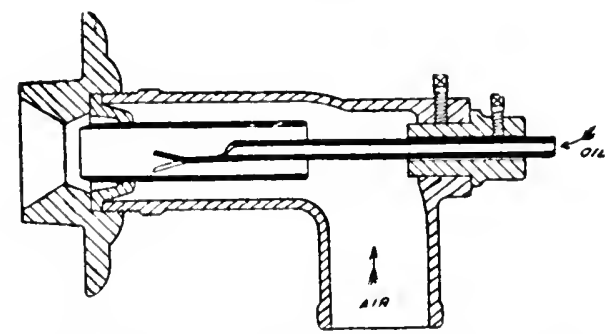

Fig. 84. Atourzer for Rivet Furnace

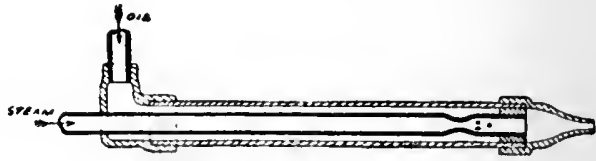

Fig. 85 .

hour $=10$ gallons per minute, which would fill a three-inch pipe 400 inches long. Thus a three-inch oil pump with a six-inch stroke, if run at sixty-seven strokes per minute, or, say, thirty-four revolutions, would feed oil for 5,000 horse-power, and
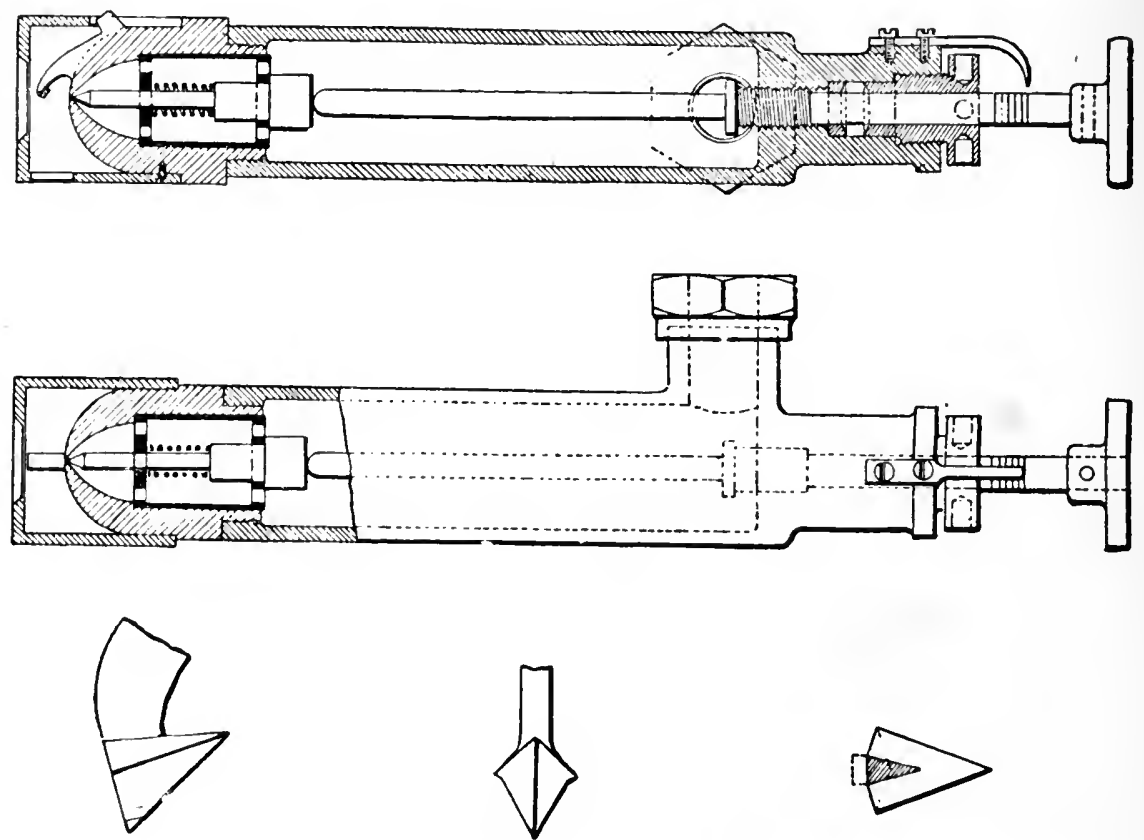

Fig. 86. Swensson Atomizer

two or three smaller pumps would in practice be employed in any ship. The oil pumps are thus very insignificant in size, and this fact will no doubt help to popularize the self-spraying atomizers if they prove satisfactory under ordinary conditions. Of course, the oil will not spray unless heated suffieiently to be limpid and easily flowing. If too viscous it will spray in strings, and not burn as thoroughly as it should.

\section{The Symon-House Burner.}

This is one of the vaporizing burners which use the paraffine or kerosine grades of oil, a cellular reservoir above the flames serving as the vaporizer through which the oil travels in a long cirenitous course, passing down the pipe to a turned-up 


\section{THE ATOMIZING OF LIQUID FUEL}

jet below, this being regulated by a needle, and surrounded by a cone which conducts air to the flame. Preliminary heating by a lamp of petrol or alcohol is necessary. This burner is used by the Liquid Fuel Engineering Company for small launch boilers, and is shown in fig. 87 .

It is claimed that in small work the use of atomizing produces too intense a heat, and that vaporized petroleum is better. Steam can be raised to a 100 pounds pressure in twelve or fifteen minutes, and by means of the igniter above the vaporizer the fire will relight after several minutes if put out by a sudden jar or a gust of wind. The igniter

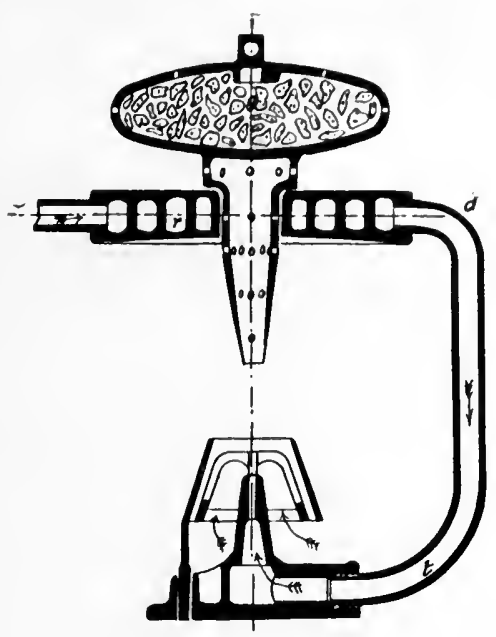
consists of a hollow disc full of broken firebrick.

In the French navy the Guyot burner has been generally used. This is shown in fig. 88, the oil entering centrally and being impinged upon by an annular jet of air or steam directed upon it round the cone, which can be- 2 regulated for supply. The oil is also regulated by a valve. The atomizing nozzle should not project as in fig. 89 , but should be kept short, as in fig. 90.

\section{The Atomizing Agent.}

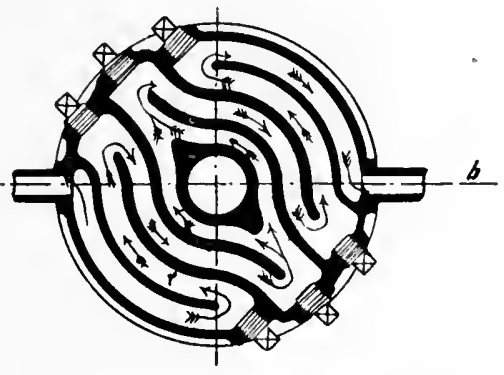

Fig. 87. Symon-House Burner AND VAPORIZER

Though in the early French trials of 1887 as much as 1.2 pounds of steam was used per pound of oil, the quantity was gradually reduced until, in 1893, less than half a pound of steam was used in the Godard boiler, says M. Bertin, and in $1895 \mathrm{M}$. Guyot got down to as low as $0 \cdot 25$, results which also have been obtained in the Italian Navy. Indeed, on a Schichau torpedo boat as low as 0.102 is claimed.

Compressed air, said M. Bertin some years ago, has some theoretical advantages, because a given weight of steam will compress up to its own pressure a weight of air superior to itself, and the pulverizing effect of a jet depends on the energy of the jet rather than upon its volume. Probably the resistance of the maehine overbalances any theoretical advantage, but at sea the loss of fresh water, where a steam atomizer is employed, must amount to about 5 per cent. of the total steam generated. M. Bertin, however, said that a good air compressor will not use half the steam necessary where this is used direct. When starting from the cold boiler, auxiliary means must be employed to get steam in one boiler at least. The compressed air for this boiler may not inaptly be raised by a small compressor driven from a storage battery, or by a small petroleum engine, or even by hand. Steam atomizing is also open to the objection that should priming occur the fires may be extinguished, and where the steam comes over wet, as it may do from a priming boiler, it is quite common for burners to be extinguished, and the red-hot brickwork fails to ignite the oil, and it is necessary to do this by means of a flaming toreh. 


\section{LIQUID FUEL AND ITS COMBUSTION}

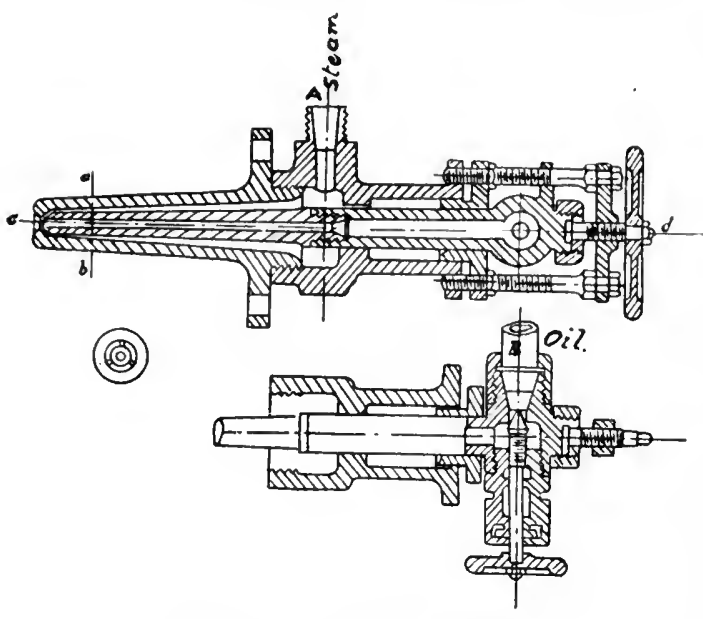

Fig. 88. GuYot Atomizer

Steam should therefore be superheated, both to render it dry and to improve its general action.

In $1885 \mathrm{M}$. D'Allest found in l'Aude that atomizing by steam used up 15 per cent. of the total steam produced. A little later, at Cherbourg, the Torpedo-boat 22 used as little as $1.2 \mathrm{k}$, and the Buffle only $0.75 \mathrm{k}$. , per kilo. of oil pulverized, until finally the results as detailed above were secured, though actual facts are not easy to obtain, and tests require to be undertaken with a special boiler to supply atomizing steam. With this results of 0.5 and 0.7 are frequently obtained, and have gone below $0 \cdot 3$. Such a figure as this is to be eonsidered very good indeed. To save fresh water at sea is so much to be desired that could compressed air be substituted for steam it should be. M. Bertin, formerly favourable to air as more economical, saw reason to change his views. Air was necessary at much higher pressure than

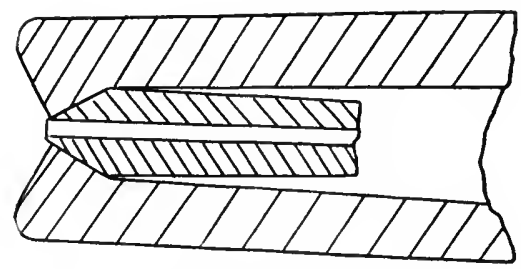

Fig. 89. Nozzle of Guyot Atomizer. INCORRECT ForM

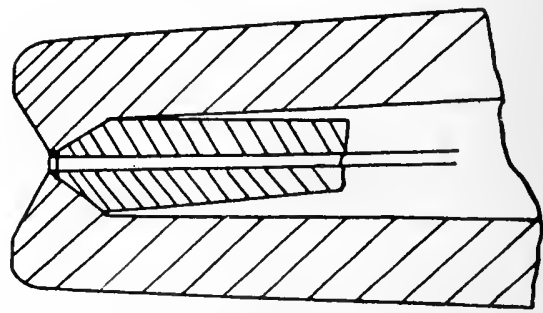

Fig. 90. NozzLe of GuYot Atomizer. Correct Form

that required for forced draught. It is affirmed that $1.4 \mathrm{k}$. of steam at $6 \mathrm{k}$. pressure must be expended to eompress 1 kilo. of air to $1.5 \mathrm{k}$., and more air must be expended to pulverize each unit of oil as compared with steam. Thus Torpedo-boat 60 at Cherbourg expended $0.6 \mathrm{k}$. to $0.8 \mathrm{k}$. of air in place of $0.4 \mathrm{k}$. of steam.

During a test at Indretinot less than $0.5 \mathrm{k}$. of air was expended. In brief, with ordinary apparatus to obtain $2 \mathrm{k}$. of air, which is needed to do the work of $1 \mathrm{k}$. of steam used direct, one must use $3 \mathrm{k}$. of steam in the compression engine.

The difficulty is that compression is slow in an ordinary machine, and steam eannot be used at all economically, for the air attains its highest pressure when the steam is ready to exhaust, and a heavy flywheel is necessary to help the expanded steam. Hence the benefit of such a machine as that of fig. 71, wherein the torque is even all round the cirele, and no flywheel is needed. M. Bertin is further most sympathetic to-day on the physical and chemical advantages of steam, which, he affirms, secures the Ragosine effect as utilized in the distillation of petroleum without eracking, owing to a certain solvent aetion of steam on petrolcum which is yet little understood. 


\section{THE ATOMIZING OF LIQUID FUEL}

The particular form of the Guyot atomizer (fig. 88) is that of Torpedo boat No. 22, the furnace of which is shown in fig. 91, the boiler bcing of return tube type.

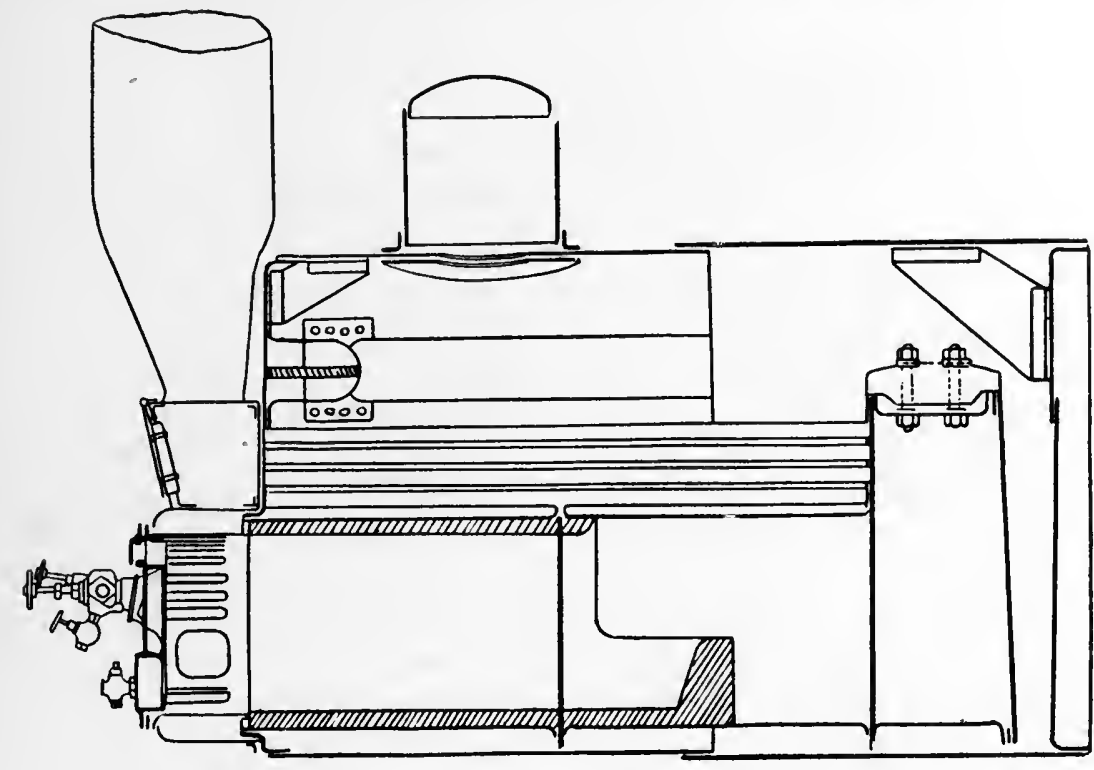

Fig. 91. Boller of French Torpedo-boat No. 22

M. Bertin finds from French experience that though regulation of an oil atomizer is most delicately effected by means of the central needle of the feed water injector, yet a valve is a less delicate detail, and many atomizers have no contral moving cone, but are regulated solely by valves.

It is necessary when atomizing that the steam should flow at a certain speed. If too rapid, the flame is extinguished; if too slow, there is incomplete pulverization, and the oil escapes in drops too large to burn well.

Hence the steam orifice must be regulated to suit the boiler pressure.

The opening for oil should not be less than $1 \mathrm{~mm} .=\frac{1}{25}$ inch. If too large the oil flows in too great a quantity. It is, of course, essential that both steam or air and oil shall be capable of regulation when at work, and also that the interior of the atomizer should be readily removed while at work, so that the orifices can be cleared quickly, and the whole replaced immediately.

After numerous experiments with atomizers producing both thin flat jets, and thin annular or cylindrical jets, M. d'Allest devised the atomizer of fig. 92, for which is claimed the best results in regularity of effect and steady working. It is very simple in form, and can be rapidly dismounted for cleaning. It consists of an outer case containing an inner cone and spindle; a steam inlet at the side $N$ admits steam to the casing. The whole is attached to a conical mouthpiece.

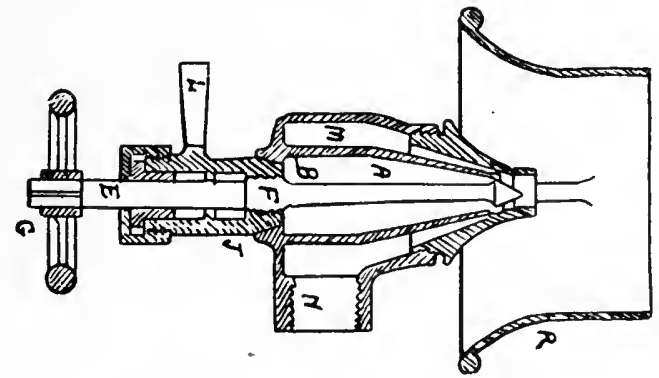

Fig. 92. D'Aluest Atomizer 


\section{LIQUID FUEL AND ITS COMBUSTION}
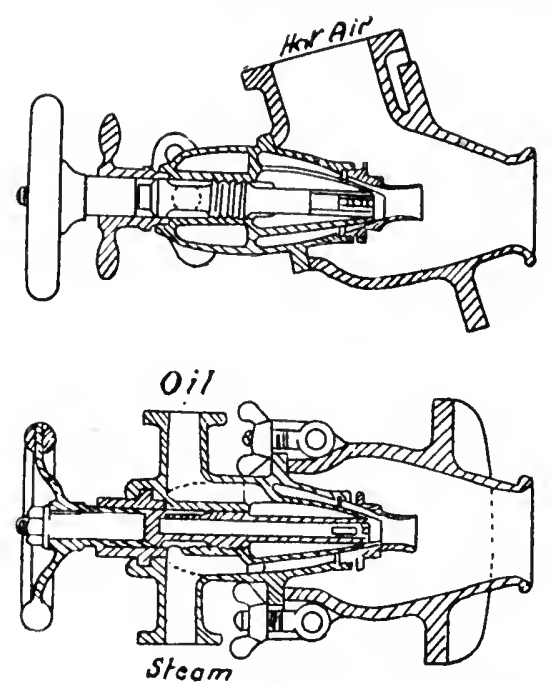

Fig. 93. D'Allest Double Atonizer
Steam is regulated by a valve, and escapes round the two cones, while oil comes round the central spindle.

Air is induced through the surrounding opening $R$.

The cone can be screwed upon the nose of the case for partial adjustment of the steam, which is further regulated by a valve in the steam pipe. M. d'Allest places these vaporizers, if necessary, in couples in one furnace, connecting them to the same oil pipe to the number of three, or even four.

Each burner will dispose of from 10 to 80 kilos. $=22$ to 176 pounds of oil per hour. Two burners, using each 80 kilos. of oil, will evaporate 13 kilos. of water per kilo. of oil, or say 2,080

litres per hour $=4,576$ gallons. Allowing 30 litres per square metre of heating surface; about 6 pounds per square foot; these two burners should serve a boiler of 70 square metres of heating surface or 753 square feet.

In a torpedo boat, however, the desired evaporation exceeds this amount per square metre. With this in view, M. d'Allest has designed a double atomizer, in which oil is admitted round the eentral tube in an annular jet. Steam comes outside this, and hot air is induced round the whole, the heating being effected by a tube in the chimney. 'This apparatus (fig. 93) will burn as much as 400 kilos. $=880$ pounds of oil per hour without a trace of smoke.

It was tried in l'Aude, one of the ships of the Compagnie Frassinet. A weight of 120 kilos. of oil per hour $=264$ pounds produced 170 horsepower, the evaporation being $14 \cdot 1$ units of water per unit of oil, but the French Navy considered 12 units as the maximum that should be calculated upon.

M. d'Allest has also devised an atomizer for working with air compressed to two or three kilos. $=28$ to 42 pounds per square inch. The Guyot small tube boiler arranged for liquid fucl, is shown in fig. 94 .

\section{Fvardofski System.}

This system applied to locomotives consists in the placing of an atomizer in each wall of the furnace

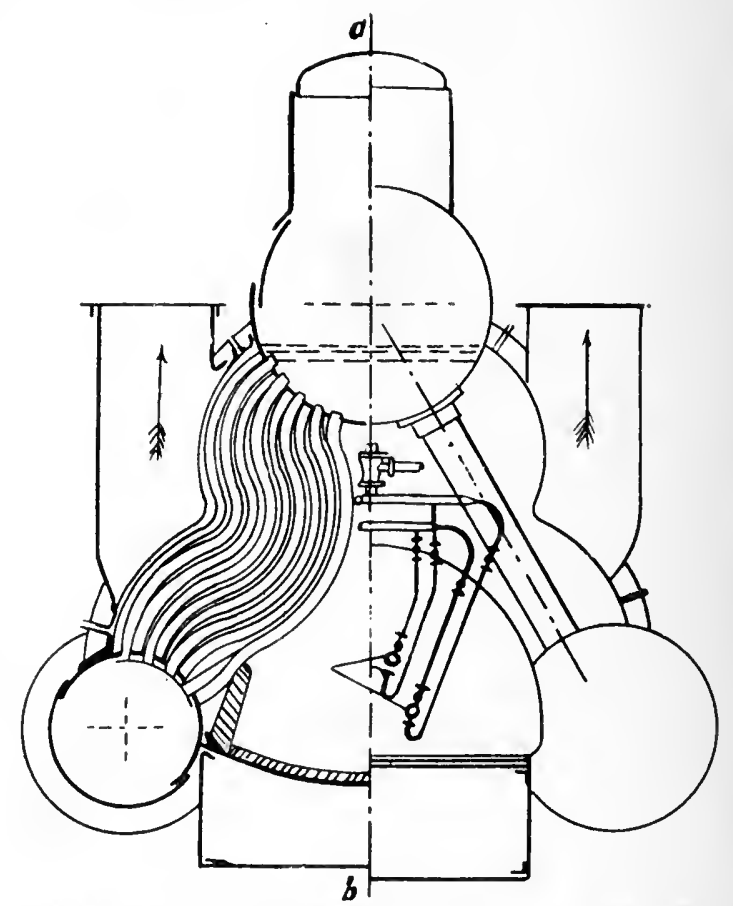

Fig. 94. Guyot Shata Tupf Boiler with - L Liquid Fued Arrangements 208 


\section{THE ATOMIZING OF LIQUID FUEL}

(fig. 95) two and two exactly opposite, the jets meeting centrally and promoting mixture. The grate is covered with firebricks, between which air enters.

Though a special pulverizer was used (fig. 96), it would appear that any atomizer could be arranged on this system.

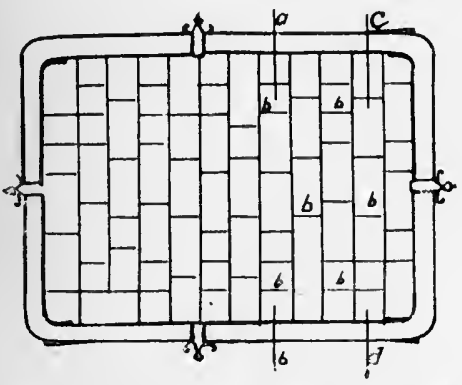

Fig. 95. Fvardofski System Locomotive Firebox

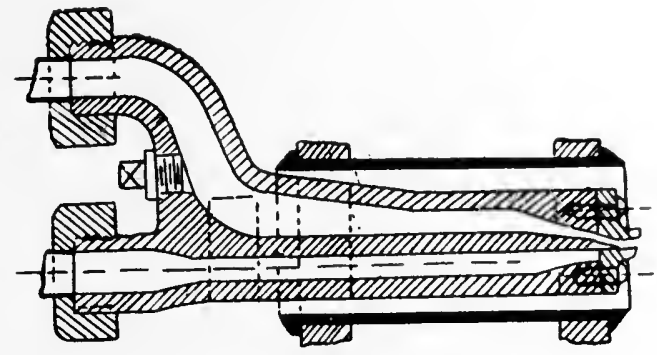

Fig. 96. Fvardofski Amonizer

The speeial atomizer consists of two simple passages for steam and oil uniting at a special nozzle plate, and regulated by means of valves on each supply pipe. The orifice is flat and wide, the flame being fan-shaped.

The Brandt burner eonsisted of a eireular box (fig. 97), with a tapered slot all round it nearly elosed by the edge of a dise. Steam eseaped under the dise and oil above it. The burner was set in the middle of the firebox and gave a large hollow flame, but it had the disadvantage of being inaceessible when at work, and the flame was easily extinguished, as by the slipping of the wheels of a loeomotive, the sudden pull of the blast extinguishing the flame and ehilling the box.

The atomizer of Vetillard Seherding (fig. 98), employed on the Chemin de fer de l'Est of France,

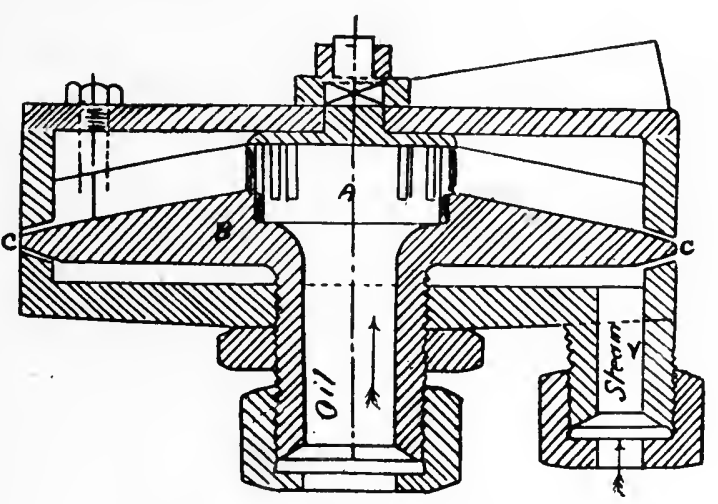

Fig. 97. Brandt Atomizer eonsists of a primary injeetor, with an annular steam jet and central oil passage. The mixed jet passes to the secondary cone, through which it induees an inner supply of air, and finally; at the entrance to the furnace, air is indueed outside the whole, and the mixed jet is considered to be of correet proportion for perfect combustion. The express eompound engines on this railway are furnished with two of these burners, each of a eapacity of 100 kilos. $=220$ pounds of oil per hour. The atomizers, two per boiler, are similarly arranged to those on the Great Eastern of England for eoal burning in eonjunetion with oil.

The Soliani burner (fig. 99) is of simple form, resembling the scent spray.

The Artemeff burner (fig. 100) is an old form with a curved face, round which oil is atomized in a flat wide-spreading sheet of flame, steam eoming below the dise and oil above it, and regulation being by cocks on the steam and oil pipes.

The Bereznef burner (fig. 101), like the Brandt, has the disadvantage of being 269 


\section{LIQUID FUEL AND ITS COMBUSTION}

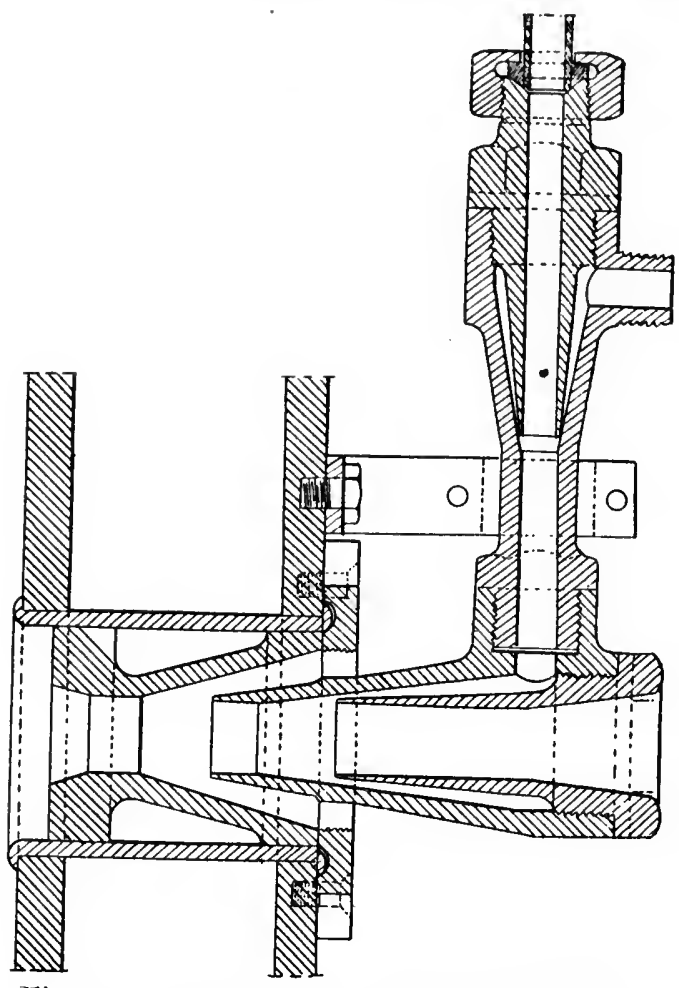

Fig. 98. Atomizer Vetillard-Scherding surrounded by flame, exposed to high temperature, and not to be got at while at work. Tests made with this burner may be found on page 11 .

The Williams atomizer (fig. 102) is that which was used by Prof. Denton, and referred to in Chapter V. under the head of "Texas Oil Efficiency." It consists of the usual body and of an annular steam nozzle. Across the steam jet drops the oil from a tube above, regulated by a cock, the flow of steam being regulated by the central cone and screwed spindle.

In the atomizer of the Compagnie Russe Standart the oil jet is central and annular (fig. 103), steam issuing round the oil cone.

Some atomizers direct their sprays divergently, others, as the Chaukoff (fig. 104), have convergent jets. This atomizer, like the Urquhart and some others, is often surrounded by an air inlet tube, and the action of the jet is to entrain air. The Guyot atomizer is not unlike the Chaukoff, except that the oil in the Guyot instrument arrives centrally.

The Nobel, Lenz and others, in place of annular jets, throw out flat jets, but these atomizers appear to involve more complication of make and mechanism without any corresponding advantages.

There are numerous other forms, some complex, others crude, but to enumerate all would occupy great space, and serve no good purpose. Those illustrated will show the general trend of practice and what has been done, the chief point being apparently that the annular form of jet is preferable and conduces to best mixtures.

The difficulty with burners which vaporize has been the deposit of carbon. This will occur even with kerosene, the carbon being a pulverulent coke. The difficulty was got over by Soliani Burner M. Serpollet by means of easily replaced burners. Heavy oils can then be burned. Too high a heat seems to be the cause of carbon deposit, the oil being "cracked" exactly as in a highly heated still. At present not much is being done in vaporizers, at least for large powers, the atomizer becoming more general.

On the question of pre-heating, the French Naval tests are in accord with others as to the advantage of this.

Long recognized as an advantage to heat to $80^{\circ} \mathrm{C} .=176^{\circ} \mathrm{F}$., it is to-day established that Mazout may well be heated to $132^{\circ} \mathrm{C} .=269 \cdot 6^{\circ} \mathrm{F}$. 


\section{THE ATOMIZING OF LIQUID FUEL}

At this temperature the fucl gives off a certain amount of vapour, which raises the pressure in the burner, helps the velocity of the jet, and ignites promptly at

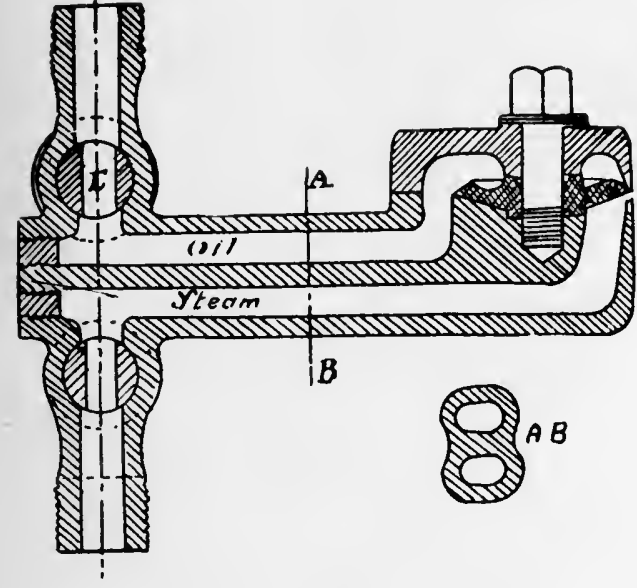

Fig. 100. Artemeff Atomizer

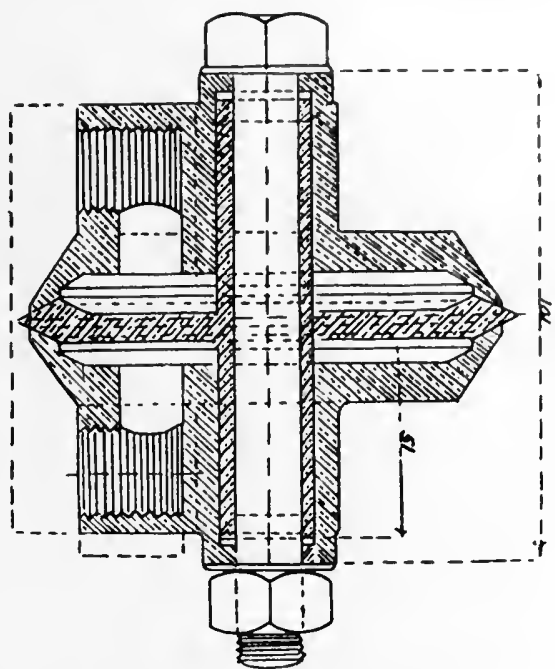

Fig. 101. Bereznef Atomizen

the nozzle, and assists the combustion of the whole. Heating the oil raises the efficiency of the combustion, cuts short the flame, and increases the effect of the heating surface.

It is not desirable to generate too much vapour at the orifice of the atomizers, or no air can get access to the jet, and combustion cannot occur. Air admixture is, of course, absolutely necessary, and when atomizing is done with compressed air this is a mere fraction of the total air required. The air itself is best heated, especially if this can be done by recuperation of otherwise wasted heat.

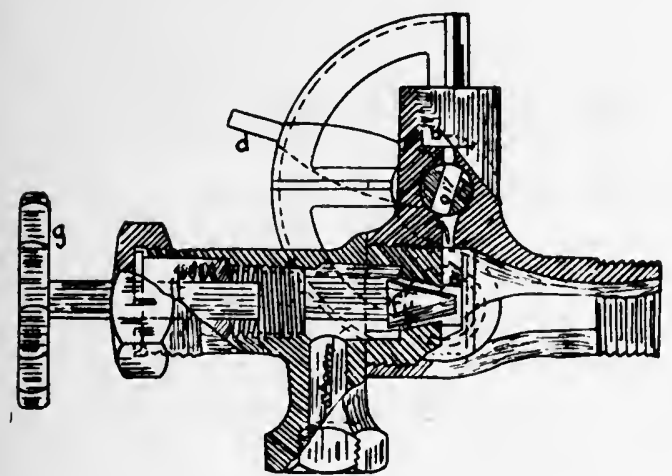

Fig. 102. Williams' Atomizer

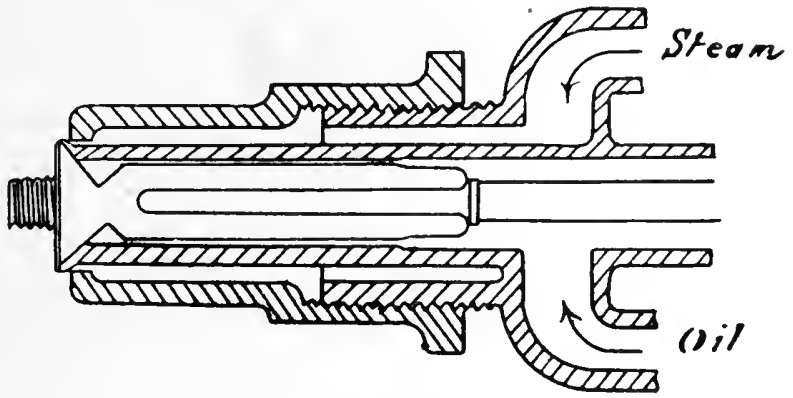

Fig. 103. Atomizer, Standart

The object of an atomizer is to fill the furnace with flame, and the furnace must avoid contact with the flame pending complete combustion. The accomplishment of these various ends has brought about the many forms of atomizers already described. All of them bear a strong family resemblance. In Russia there appears a tendency to employ flat jets, such as given by the Artemeff and 


\section{LIQUID FUEL AND ITS COMBUSTION}

similar burners. Hence also the various forms of furnace with their refractory linings of firebrick, as in the figure 105 annexed, which represents a boiler made

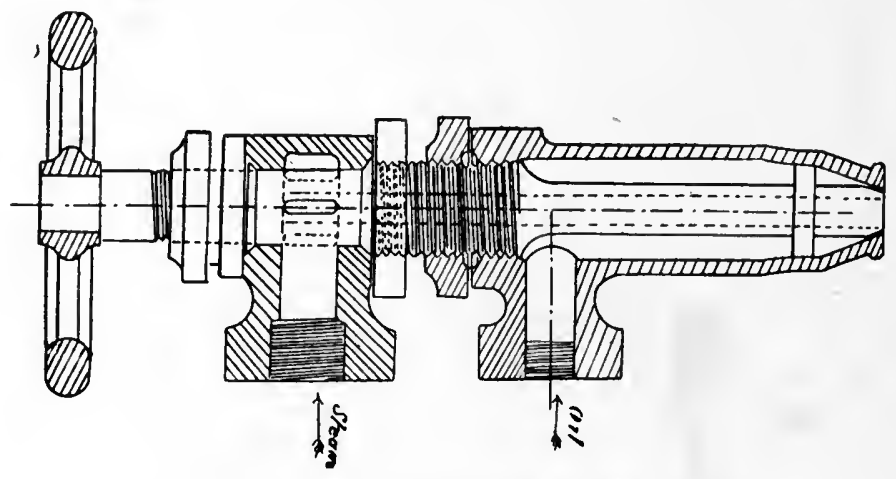

Fig. 104. Chaukoff Atomizer

at Cherbourg in 1893, and bears a general resemblance to the much older forms devised by Urquhart. In this boiler the atomizers are placed as shown in the side walls of the furnace.

Railway practice in America tends to the use of flat jets. On the Southern Pacific Railway a simple atomizer, which allows the oil to fall from an orifice over the front of a flat steam jet, has this jet $3 \frac{1}{2}$ inches wide. The petroleum escapes at an orifiee half an inch high and of the length of three inches, the steam opening being about $0.8 \mathrm{~mm}$. high, or $\frac{1}{32}$ inch. The width of the jet of steam is $3 \frac{1}{2}$ inehes, extending $\frac{1}{4}$ inch at each end below the flow of oil, so that no oil eseapes unatomized. The flat pulverizers are stated by M. Bertin to be suitable for boilers of the Belleville or Nielausse type, in which the flames rise direetly from the grate

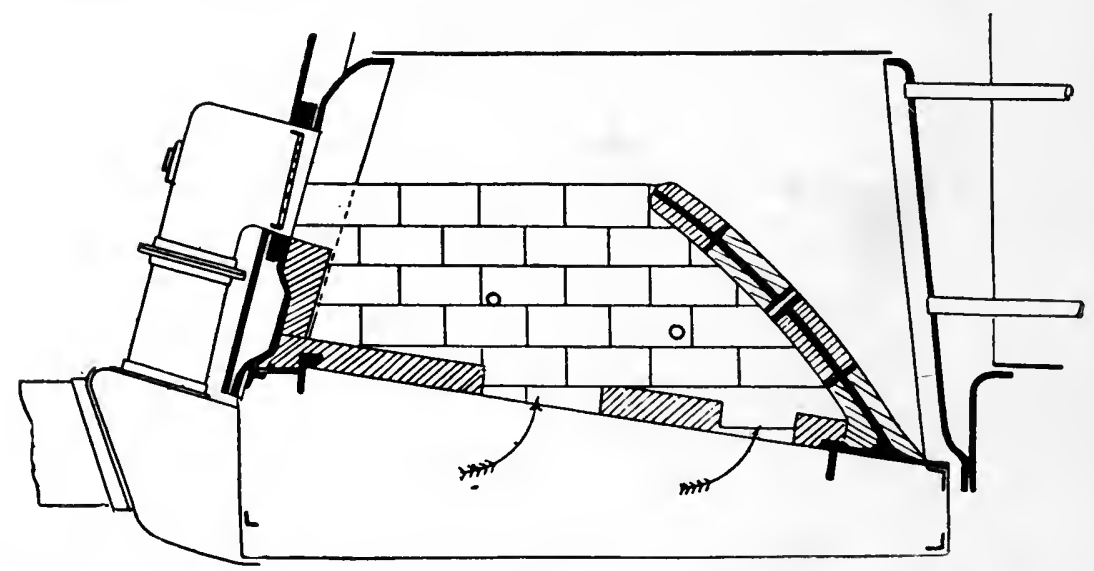

Fig. 105. Loconotive Type Boiler Tested at Cherbourg with Liquid Fuel

to the water tubes. The broad flat flame probably burns over a wide area, and does not enter between the pipes so rapidly as if it were a less wide spreading jet.

Should a pulverized jet encounter a cold boiler plate at a temperature of $400^{\circ}$ to $500^{\circ} \mathrm{C} .=752^{\circ}$ to $932^{\circ} \mathrm{F}$, the oil will eondense on the plate and not again ignite.

In the boiler of Torpcdo-boat No. 22 (fig. 91) the furnace is fitted with an air advance ehamber in which oil is atomized and meets air streams admitted radially. 


\section{THE ATOMIZING OF LIQUID FUEL}

The furnace is brick-lined, with a low striking bridge. In this boiler $11.6 \mathrm{k}$. and $10.8 \mathrm{k}$. of water have been evaporated per kilo. of oil with a draught of 20 to $30 \mathrm{~mm}$. (1 inch mean) of water. At heavier draughts of 95 to $110 \mathrm{~mm}$. water gauge (or a mean of four inches), only $9.45 \mathrm{k}$. and $8.5 \mathrm{k}$. were evaporated. A similar boiler, with the air arriving parallel with the jet, however, evaporated $13.25 \mathrm{k}$. of water, which shows the difference due to arrangements.

M. Guyot's boiler of the Du Temple type, with four atomizers, showed from $12.5 \mathrm{k}$. to $11.3 \mathrm{k}$. evaporation, with draughts of 8 and of $45 \mathrm{~mm}$. of water $\left(\frac{5}{16}\right.$ and $1 \frac{3}{4}$ inches). The above results are given by M. Bertin from $16^{\circ} \mathrm{C} .=61^{\circ} \mathrm{F}$. at 12 kilos. of pressure. See Table XLVI.

It may be stated finally that, taking a review of all atomizers, the more suecessful are those which atomize the oil right at the nozzle or point of exit. This class appears least liable to choke with dirt or to permit of the oil beeoming earbonized within the body of the atomizer.

\section{Combined Atomizing and Vaporizing System.}

\section{Thwaite's System of Oil Firing.}

The system of boiler firing proposed by Mr. B. N. Thwaite is based on a recognition of the fact that oil firing is often accompanied by an excessive use of air. He proposes to use the air or a portion of it twiee. For this purpose he employs a double apparatus containing an oil atomizer with its own supply of atomizing air or steam, and an inspirator whieh draws hot gas from the flues of the boiler through a pipe and delivers it about the atomizing nozzle, thus heating up the oil and supplying air for combustion and at the same time diluting the air supply with neutral or burned gas and redueing the intensity of the combustion by producing what is known as a softer flame of larger volume. Heating the air supply by direct admixture of flue gases has not previously been attempted, and there is no practical installation by which to judge of the result, but the invention possesses merits prima facie, and offers a cheap means of heating the air supply and the oil atoms. Mr. Thwaite terms his system the Reeuperative system, and justifies it on the ground that the excess of air passed through a furnaee is so great that the waste gases eonsist largely of oxygen. He also aims partieularly at producing the soft flame at a temperature less local, and therefore less severe on the furnace apparatus and surroundings. 


\section{Chapter XXX}

\section{THE APPLICATION OF LIQUID FUEL TO METALLURGY}

T IQUID fuel lends itself particularly well to the operations of metallurgy, especi$\mathcal{L}$ ally of a small nature, or, perhaps, the smallness of the operations thus far carried on are due merely to novelty. In metallurgical work it would appear that air is on the whole the more suitable atomizing agent. In the sequel will be found a few examples of what has thus far been accomplished. In America furnaces of

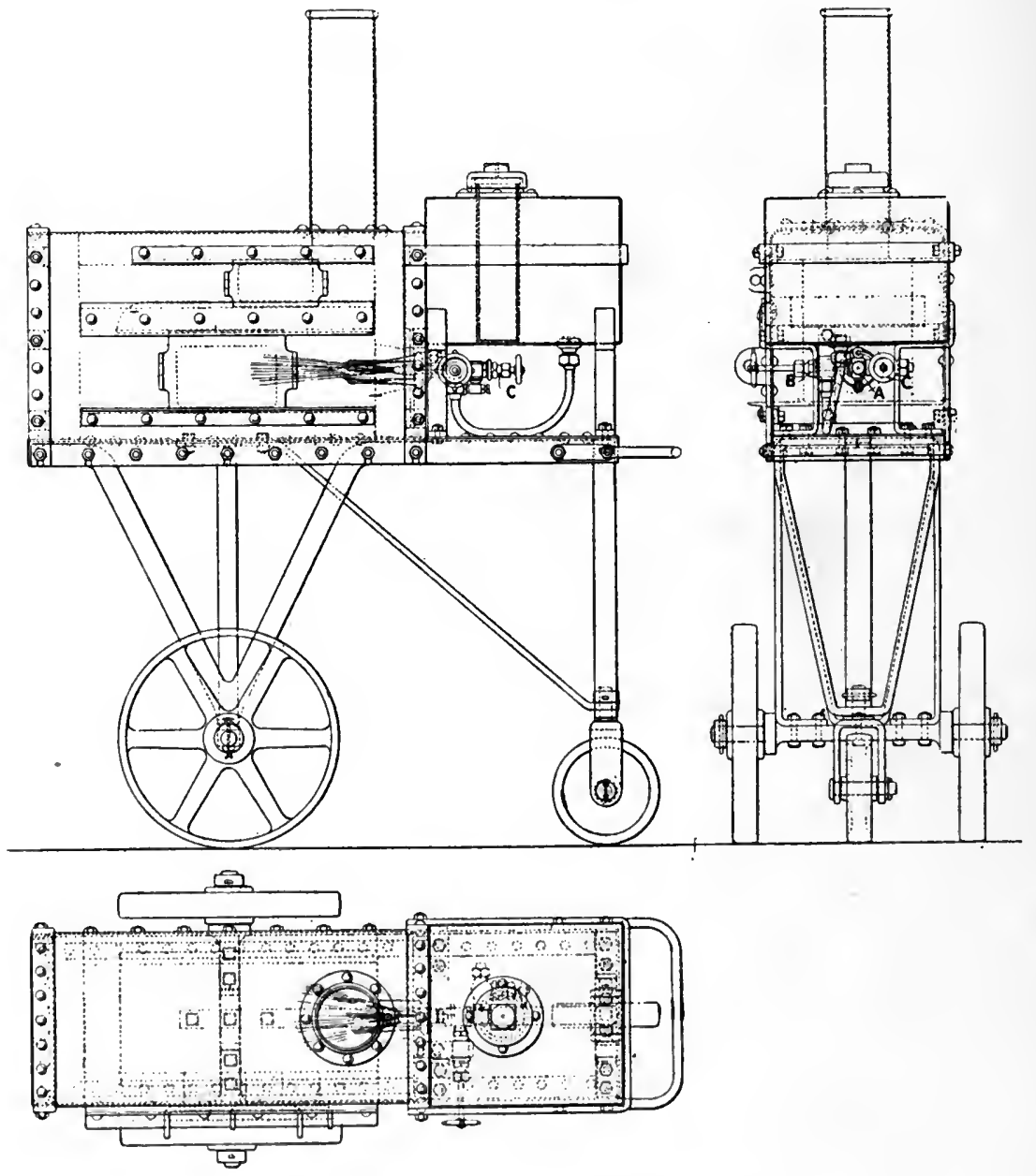

Fig. 106. Portable Rivet Furnace 


\section{THE APPLICATION OF LIQUID FUEL TO METALLURGY}

large size for heating boiler-plates and for other purposes of considerable bulk have been built by the Roekwell Company. The extension of liquid fuel in this direction finds, of eourse, a powerful rival in produeer gas made from cheap coke fuel, and, within limits, fully equal to oil, being eapable of equal uniformity of temperatures, equality of heats and eeonomy, though, perhaps, for many purposes not eapable of such high temperatures as oil, exeept in the ease of the more powerful water gases, which are made at some saerifice of fuel.

\section{Rivet Furnace.}

A rivet furnace with a Holden Atomizer is shown in fig. 106, the furnace being portable for more eonvenient use and carrying its own oil tanks. A connexion is made between the valve $C$ and the steam or eompressed air pipe.

Rivets are fed in at the top door where they are exposed first to the waste heat. They are moved down to the full heat below as required and removed through the lower door.

The furnace is started with a little flaming oily waste, and oil is fed more and more as needed during the heating up of the briekwork lining, the air valve $G$ being regulated until smokeless combustion results. One hundred $\frac{3}{4}$ inch rivets per hour ean easily be heated at an expense of $1 \frac{1}{2}$ gallons of oil.

\section{Oil Fired Brass Crucible Furnace.}

In fig. 107 is shown an arrangement of furnaee for four brass-melting erueibles.
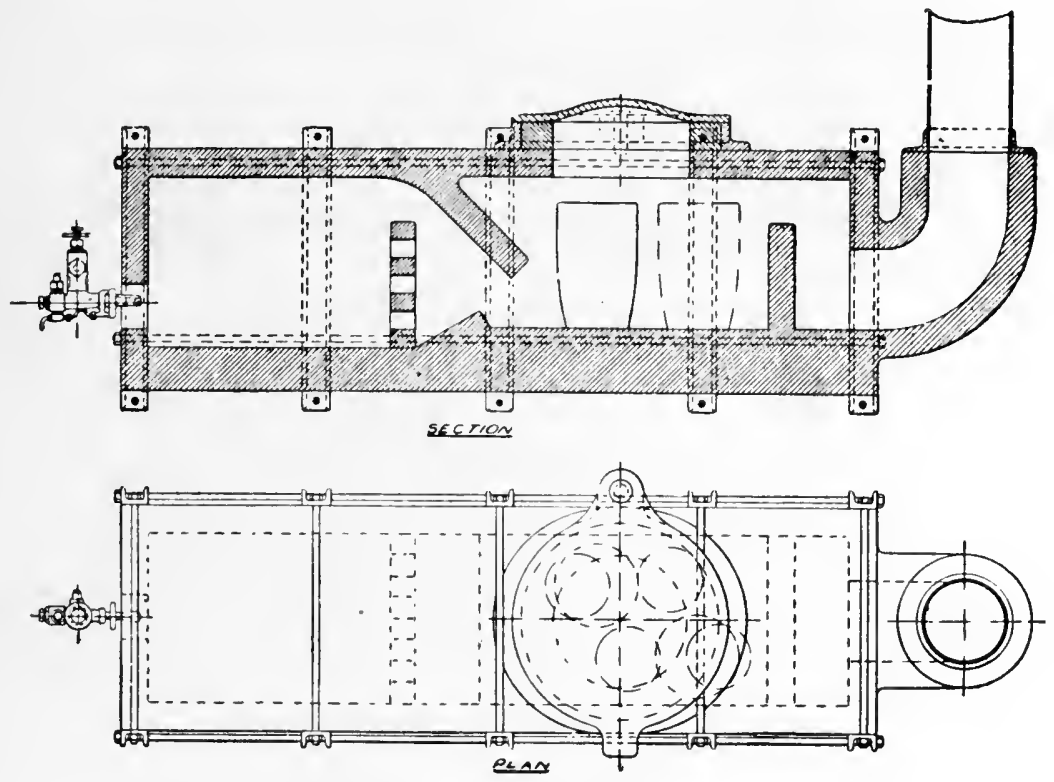

Fig. 107. Furnace for Four Crucibles

With this furnace 112 pounds of brass ean be melted in one hour at an expense of three gallons of oil. The furnace being small, less heat is thrown away in getting the lining hot, and small charges can be melted at irregular intervals without so much expense as is ineurred where large bodies of brickwork must be heated up. 


\section{LIQUID FUEL AND ITS COMBUSTION}

Assaying Furnace.-The Bickford Burner Co., of Camborne, make the apparatus shown in fig. 108. This small furnace can be got to work in less than half a minute,

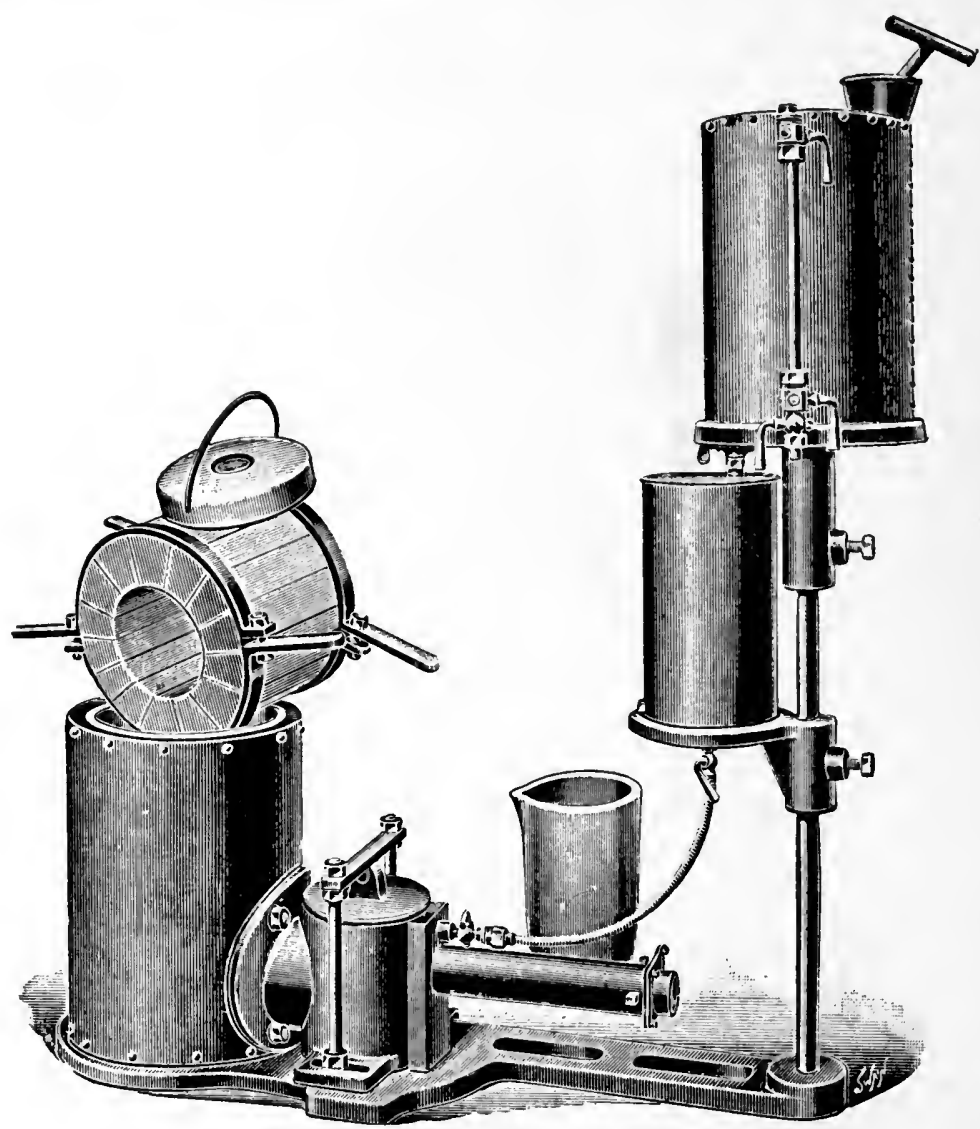

Fig. 108. Furnace of Bickford Burner Co.

and within half an hour a weight of 40 pounds of brass can be melted at an expense of half a gallon of oil.

The fan-blast necessary is 2 inches of water column or more for small work; 5 to 8 inches for general work, and 8 to 12 inches for fine brass and cast iron.

In a large foundry using this apparatus the comparative cost of coke and oil for melting 40 pounds of brass is given as under-

\section{Соке}

1. cwt. oven coke at $1 s .3 d$. . . . 3.75

$3 \frac{1}{2}$ per cent. waste of brass. . . 8.4

Crucible (20 charges per crucible, 5s.) 3
Fuel Oil

$\frac{3}{4}$ gallon oil at $2 \frac{1}{2} d$. (bouglit in small quantities) . . . . . 2

$1 \frac{1}{2}$ per cent. waste of brass . $3 \cdot 6$ Crucible (30 charges per crucible, 5s.) . . . . . . . 2

15.5

d.

2

$3 \cdot 6$

showing a saving of over 50 per cent., exclusive of any advantages of labour and saving or cleanliness.

The action of the furnace and its arrangement is shown in fig. 109. Oil is stored 


\section{THE APPLICATION OF LIQUID FUEL TO METALLURGY}

in the air-tight reservoir $(W)$, flows through the cock $(T)$, into the filter tank $(N)$, containing the filter $(O)$. When the oil level in $N$ reaches the end of the pipe $(T)$, the flow from $W$ stops (as when a bottle of water is inverted in a tumbler). The level of the oil in $N$ then remains constant. From $N$ the oil flows through the tube $(N)$ and the stopcocks $(M M)$ to the oil spout, and thence round the air nozzle $(I)$ through a slot, by the air issuing from which it is blown to the bottom of the combustion chamber $(K)$. The resulting flame is blown through the hole $(F)$ into the furnace $(D)$, around the crucible $(E)$, and up through the warming cylinder $(B)$, warming the overlapping charge $(X)$. Air is supplied through the valve $(L)$. That part of the charge $(X)$ in the warming cylinder is the first to melt.

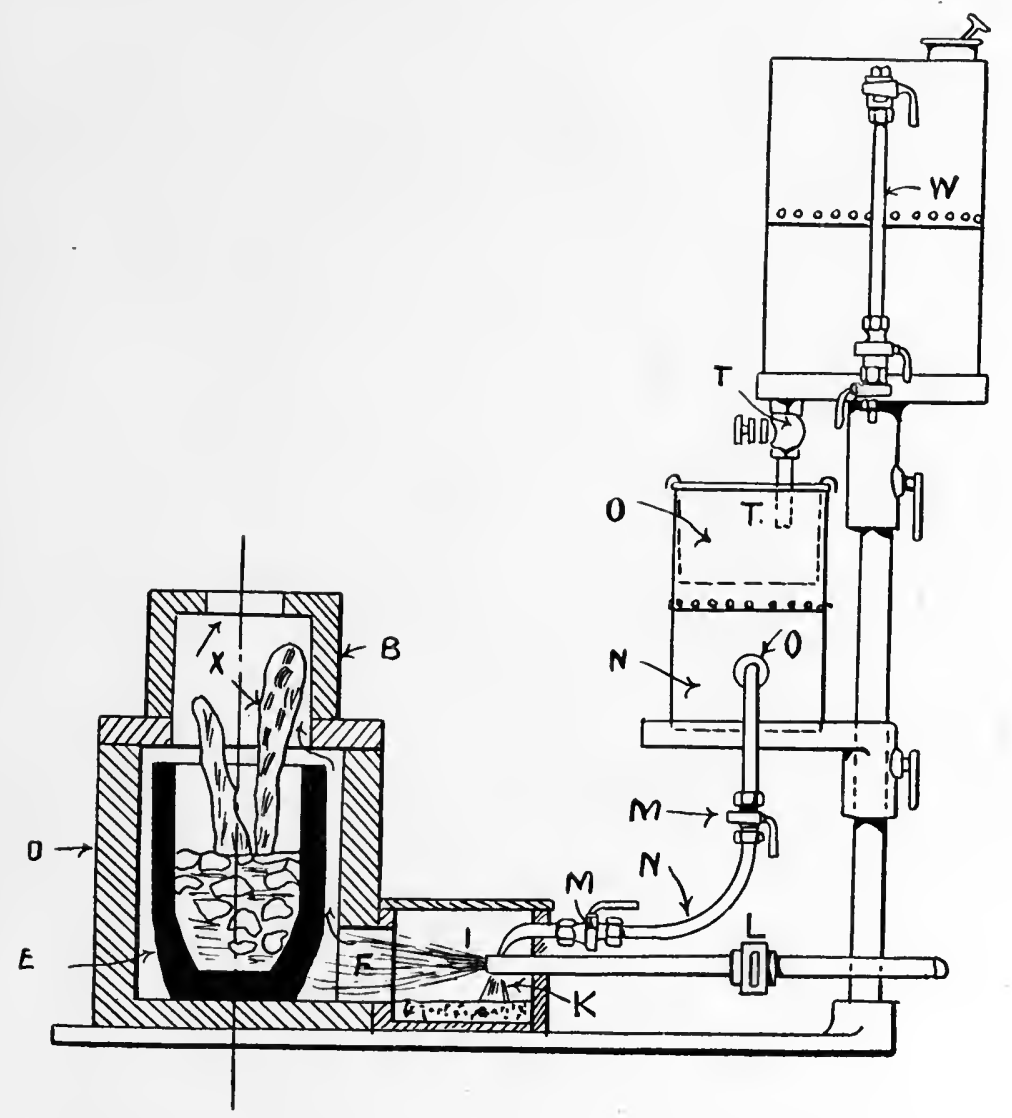

Fig. 109. Section of Furnace of Bickford Burner Co.

Usually one ton of brass will require 40 gallons (Impl.) of oil, where not less than 80 pounds at once are melted.

Iron requires twice the time and fuel of brass, and about 15 inches of air-blast and not less than 10 inches for ordinary cast iron. Mild steel requires 25 inches of blast.

Tube-welding furnaces will turn out 50 to 80 heats per hour, when oil fired, and the work done is clean.

Generally in all metallurgical furnaces a clean heat is secured, as well as uniform temperature. This makes liquid fuel a most suitable fuel for glass furnaces, glazing and japanning work, and all work where dust is to be avoided. 


\section{LIQUID FUEL AND ITS COMBUSTION}

The Schwartz Melting and Refining Furnace.

This furnace (fig. 110), is similar in appearance to a small Bessemer converter.
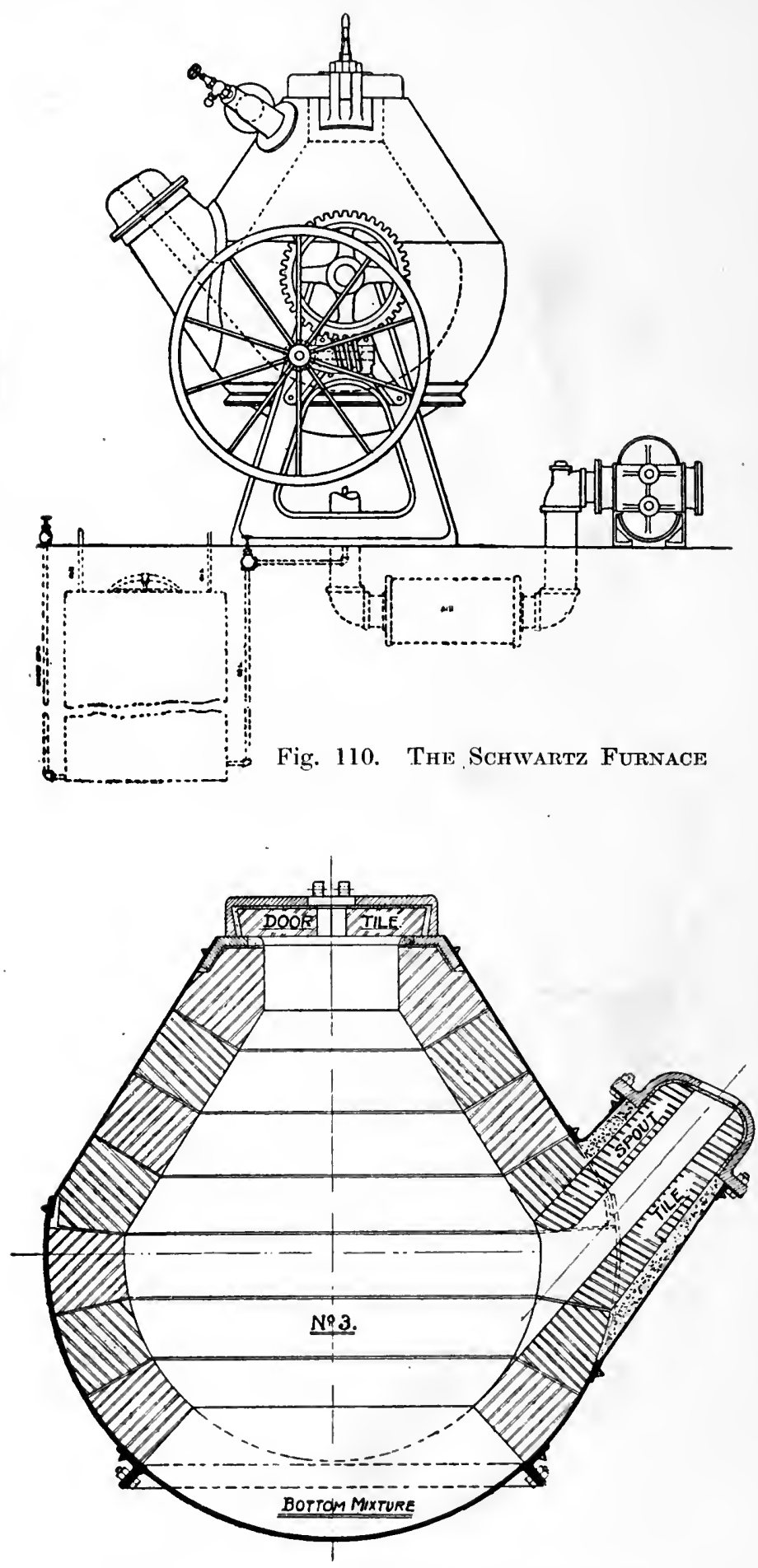

Fig. 111. Section of Schwartz Furnace 278 


\section{THE APPLICATION OF LIQUID FUEL TO METALLURGY}

A section is given in fig. 111. The fuel is injected at the upper portion, and the flames play on the charge, and the gases escape at the pouring spout. When melted, the charge can be well mixed, to give regularity, by rocking the furnace to and fro, and the finished product is then poured.

Annexed are given the results of tests made in December, 1901, with this furnace, and endorsed by the Mechanical Department of the Chicago, Rock Island and Pacific Railway Company-

Test started with furnace cold at . . . . 7.25 a.m.

The furnace was hot at . . . . . . . . 8.11

Time consumed in heating furnace . . . 46 minutes.

\begin{tabular}{|c|c|c|c|c|c|c|c|c|c|}
\hline $\begin{array}{l}\text { Heat } \\
\text { No. }\end{array}$ & Charge. & & lbs. & $\begin{array}{l}\text { Time of } \\
\text { charging. }\end{array}$ & $\begin{array}{l}\text { Time } \\
\text { to melt. }\end{array}$ & Time poured. & $\begin{array}{l}\text { Amount } \\
\text { charged. }\end{array}$ & $\begin{array}{l}\text { Amount } \\
\text { received. }\end{array}$ & Shrinkage. \\
\hline 1 & $\begin{array}{l}\text { New Copper } \\
\text { Zinc } \cdot \\
\text { Lead } \cdot \\
\text { Block Tin. }\end{array}$ & $\begin{array}{l}\dot{ } \cdot \\
\dot{ } \\
\dot{ }\end{array}$ & $\begin{array}{c}201 \\
21 \frac{1}{2} \\
7 \\
5 \frac{1}{2}\end{array}$ & $\begin{array}{l}8 \cdot 15 \\
9 \cdot 08\end{array}$ & $\begin{array}{c}\min . \\
53\end{array}$ & $9 \cdot 10-9 \cdot 16$ & $\begin{array}{l}\text { lbs. } \\
235\end{array}$ & $\begin{array}{l}\text { lbs. } \\
227\end{array}$ & $3.40 \%$ \\
\hline 2 & $\begin{array}{l}\text { New Copper } \\
\text { Block 'Tin . } \\
\text { Lead . . }\end{array}$ & . & $\begin{array}{r}300 \\
32 \\
24\end{array}$ & $\begin{array}{r}9 \cdot 10 \\
10 \cdot 10\end{array}$ & 60 & $10 \cdot 17-10 \cdot 29$ & 356 & 353 & $0 \cdot 84 \%$ \\
\hline 3 & $\begin{array}{l}\text { Light Scrap } \\
\text { Copper. } \\
\text { Old Brasses } \\
\text { Brass Borings. } \\
\text { Lead . }\end{array}$ & $\begin{array}{l}\dot{ } \\
\dot{ } \\
\dot{ } \\
.\end{array}$ & $\begin{array}{r}130 \\
220 \\
100 \\
10\end{array}$ & $\begin{array}{l}10 \cdot 30 \\
11 \cdot 0 \\
11 \cdot 20 \\
11 \cdot 32\end{array}$ & 58 & $11 \cdot 33-11 \cdot 39$ & 460 & $449 \frac{1}{2}$ & $2 \cdot 28 \%$ \\
\hline 4 & $\begin{array}{l}\text { Light Scrap } \\
\text { Copper. } \\
\text { Old Brasses } \\
\text { Brass Borings } \\
\text { Lead . }\end{array}$ & $\begin{array}{l}. \\
. \\
. \\
.\end{array}$ & $\begin{array}{c}159 \frac{1}{2} \\
190 \frac{1}{2} \\
100 \\
10\end{array}$ & $\begin{array}{l}11 \cdot 40 \\
12 \cdot 12 \\
12 \cdot 34 \\
12 \cdot 58\end{array}$ & 72 & $11 \cdot 59-12 \cdot 6$ & 460 & $443 \frac{1}{2}$ & $3 \cdot 58 \%$ \\
\hline 5 & $\begin{array}{l}\text { New Copper } \\
\text { Block 'Tin } \\
\text { Lead . . }\end{array}$ & $\begin{array}{l}\cdot \\
. \\
.\end{array}$ & $\begin{array}{r}300 \\
32 \\
24\end{array}$ & $\begin{array}{l}1 \cdot 42 \\
2 \cdot 41\end{array}$ & 56 & $2 \cdot 43-2 \cdot 56$ & 356 & 349 & $1.96 \%$ \\
\hline 6 & $\begin{array}{l}\text { New Copper } \\
\text { Zinc } . \\
\text { Lead } \cdot \\
\text { Block Tin. }\end{array}$ & $\begin{array}{l}\cdot \\
\cdot \\
\cdot\end{array}$ & $\begin{array}{r}271 \frac{1}{2} \\
30 \frac{1}{2} \\
10 \frac{1}{2} \\
9\end{array}$ & $\begin{array}{l}2.57 \\
3 \cdot 53\end{array}$ & 56 & $3 \cdot 54-4 \cdot 05$ & $321 \frac{1}{2}$ & $315 \frac{2}{3}$ & $1.78 \%$ \\
\hline 7 & $\begin{array}{l}\text { Old Brasses } \\
\text { I sead }\end{array}$ & . & $\begin{array}{r}500 \\
10\end{array}$ & $\begin{array}{r}4 \cdot 08 \\
4 \cdot 53\end{array}$ & 48 & $4 \cdot 57-5 \cdot 13$ & 510 & 500 & $1 \cdot 96 \%$ \\
\hline
\end{tabular}

Total amount charged

Total amount received Shrinkage
$2,698 \frac{1}{2} \mathrm{lb}$.

$2,637 \frac{3}{4} \mathrm{lb}$.

$603 \mathrm{lb}$. or $2.25 \%$ 


\section{LIQUID FUEL AND ITS COMBUSTION}

Oil Consumption.

Total amount used

Amount used in heating surface

Amount used in melting

Amount per huncired pounds of metal melted.

From Heats Nos. 1, 2, 5, and 6, sample test bars were poured and drillings analyzed. Test bars were not poured from the other three heats on account of scrap having been used in the mixtures. The analyses of the test bars are as follows :-

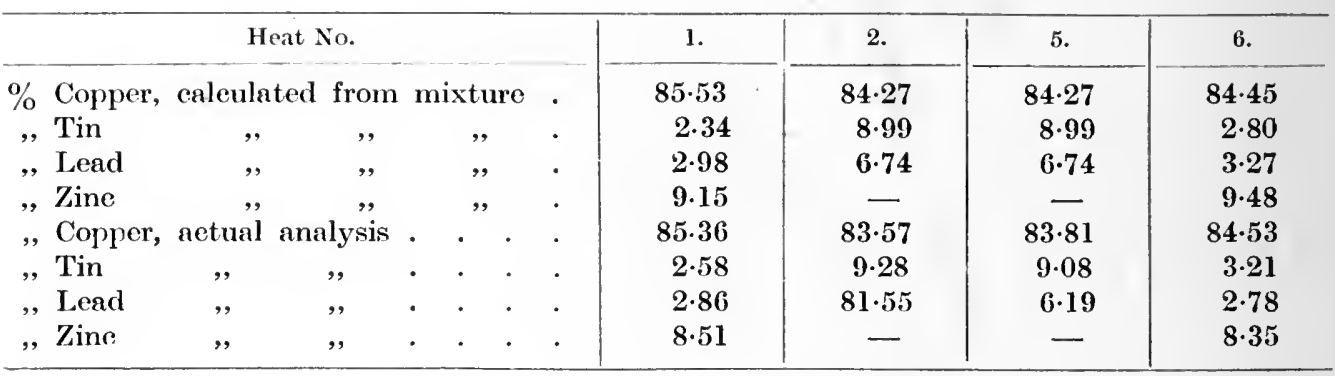

Ordinary or crude oil can be used for fuel, and a brick liner is said to endure 300 heats.

The dimensions and capacities of furnaces are given below-

\begin{tabular}{c|c|c|c|c}
\hline Number. & Capacity per hour. & Size O.D. & Weight. & Lining. \\
\cline { 2 - 4 } 1 & $400 \mathrm{lb}$. & $42 \mathrm{inch}$ & 3650 \\
2 & $1000 \mathrm{lb}$. & $60 \mathrm{ineh}$ & 10400 & 6 inch \\
\hline
\end{tabular}

No. I Furnace. Space required, $15 \mathrm{ft}$. square Floor space, $8 \mathrm{ft}$. square.
No. 2 Furnace. Space required, $20 \mathrm{ft}$. square. Floor space $10 \mathrm{ft}$. square.

One of the economies of this furnace is that it saves the cost of crucibles.

The furnace is lined with fireclay blocks or tiles, the bottom being pugged in from a mixture of crushed quartz, pure washed silica, sand, and best fireclay in equal proportions mixed and rammed in place sufficiently damp to hold well.

The furnace requires to be slowly dried by a wood fire and then to be glazed by heat before use. It is started in the usual way with shavings or oily waste, and when alight and regulated the cap is replaced and the furnace is heated ready to charge.

It is well to tilt the furnace slightly from time to time during each heat. This saves the lining. Oil should be heated to about $100^{\circ} \mathrm{F}$. for best results, and its pressure should not exceed 20 pounds, the air pressure being 16 to 20 ounces, or as low as 12 to 14 ounces for yellow brass, or when much borings are used. It is best to melt copper or heavy scrap before adding the lighter metals. Borings should also be added after the heavy metal is melted, zinc and lead may often be added in the ladle from ten to fifteen minutes before pouring. Little loss is then made.

The Atlantic Brass Company, of Jersey City, N.S., give the following results of working a furnace- 


\section{THE APPLICATION OF LIQUID FUEL TO METALLURGY}

450 lb. metal.

First Heat

$77 \%$ scrap copper.

$10 \%$ tin.

$13 \%$ lead.

Melted in 30 minutes. Result, $445 \mathrm{lb}$.

Making fine grade of brass.

Loss $44_{4}^{1} \mathrm{lb}$.

\section{SECOND Heat}

100 lb. copper.

$66 \frac{1}{2} \mathrm{lb}$. copper wire, ete.

216 lb. composition.

66 lb. lead.

448 $\frac{1}{2}$ lb. Result, $444 \frac{1}{2} \mathrm{lb}$.

Loss $4 \mathrm{lb}$.

Oil may either be supplied by pump or by air pressure on the oil surface in a elosed supply tank.

\section{Application of Liquid Fuel to Tyre Heating.}

The employment of liquid fuel to the heating of tyres was carried out by Mr. Urquhart in the shops of the Grazi and Tsaritzin Railway in 1884 or earlier.

Fire for healing Tyres.

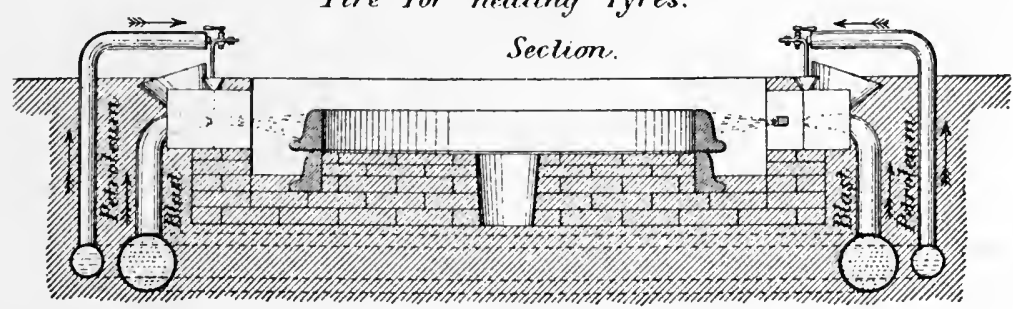

Plan.

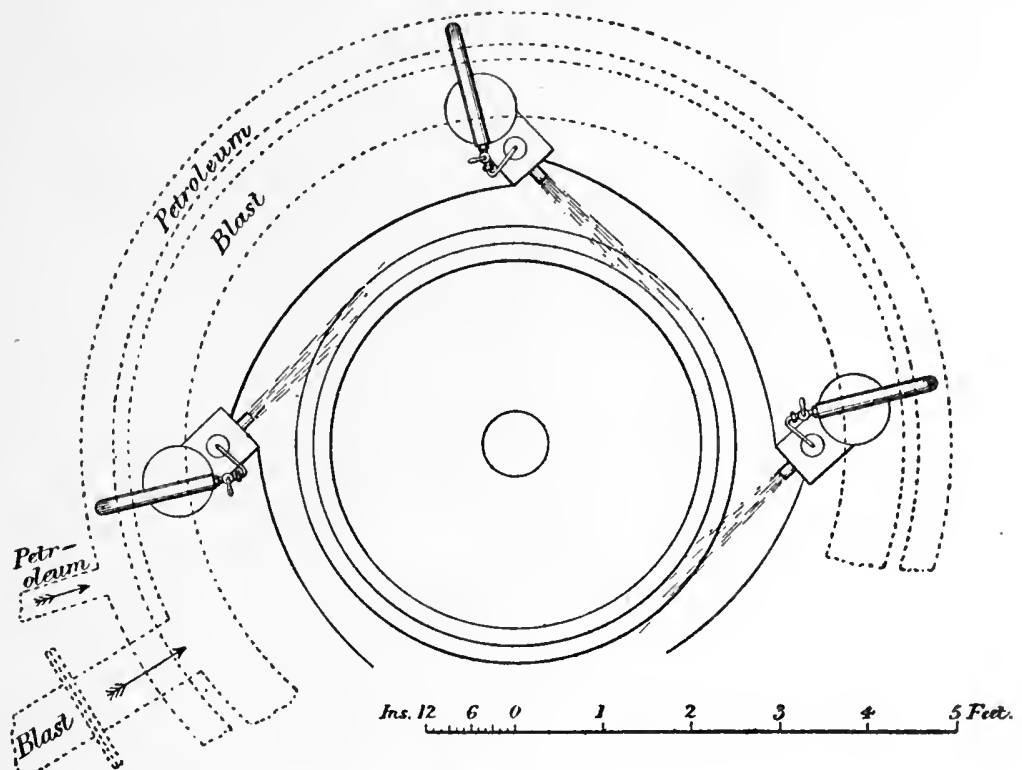

Fig. 112.

28 I 


\section{LIQUID FUEL AND ITS COMBUSTION}

The spraying agent is cold air supplied by a Roots blower, and the cost is only onethird that of bituminous coal, while the amount of work per day can be increased by 25 per cent. Four sprayers are used, which blow tangentially, as shown in fig. 112,

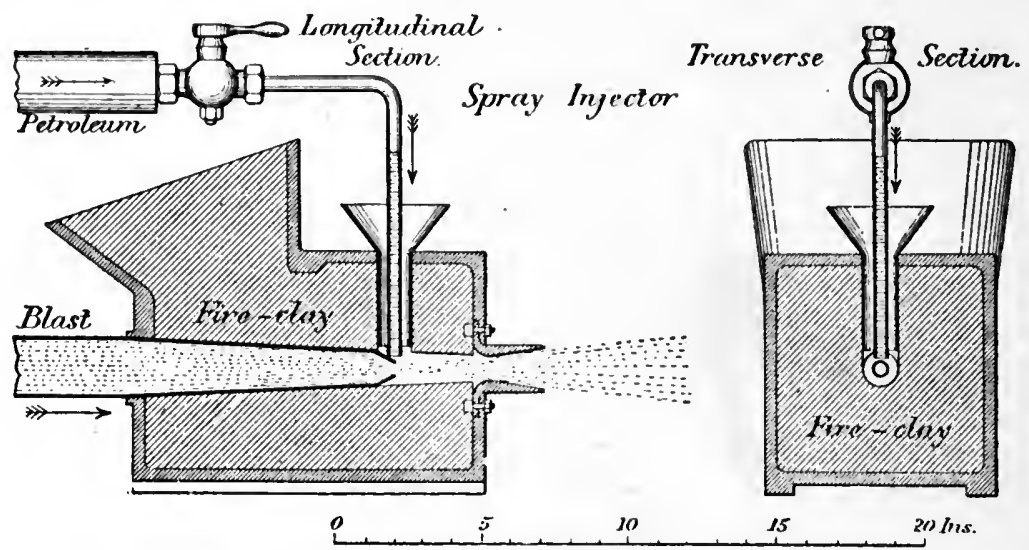

Fig. 112a. Spray Injector for Tyre Furnace, Enlarged

and give a flame circulating round the tyre. The arrangement rather suggests that a cover, to be lifted by a light crane, would produce an economy in time and fuel. The principles of liquid fuel heating for other purposes are embodied in this tyre furnace, namely, the placing of an object to be heated in an oven of firebrick, and arranging the burners to direct their flame in such a way as not to produce local heating, but to spread the flame as evenly as possible over the whole surface of the object to be heated.

\section{Forge Fire.}

A simple form of forge fire is shown in fig. 113. A casing of plate is filled

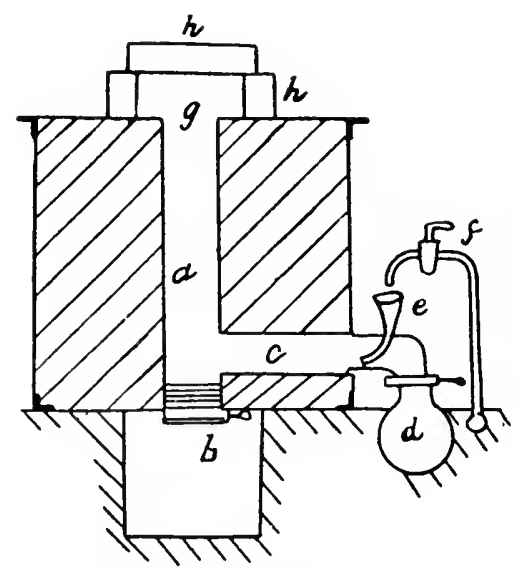

Fig. 113. Forae Fire with fire-brick, leaving a central passage with a lateral opening $c$ about two inches diameter, into which an air blast enters from an air main $d$. Oil is supplied at $e$ from a pipe $f$ and flame issues at $g$. The central passage $a$ has a diameter of three to four inches. Iron up to four inches can be heated in this furnace.

The lower opening of the passage $a$ is closed by a door protected by fireclay. Through this, dirt and oxide can be cleared into the pit below. Fire-bricks $h$ are built above the flame, and can be melted by the intense heat developed; the flame will rise 10 feet above the uneovered opening.

The general form of a larger furnace is that of fig. 114. Here the oil enters at one end into a chamber $a$, and passes through the heating chamber construeted with an arch, and with a fire-brick bed $4 \frac{1}{2}$ inches thick, the whole carried on a plate bed or frame, and held together with angle irons as usual. The ehamber $a$ is double, and is called the generator. It is pierced with 


\section{THE APPLICATION OF LIQUID FUEL TO METALLURGY}

a round sight hole and a hole for the atomizer, which consists of an air tube and an oil tube with a funnel and a sight feed as in the last example. A hole is provided through which to light the oil when starting up the furnace, and there is a narrow inclined passage to the furnace proper. This furnace is in trough form, covered with an arched roof supported on loose bricks, and it is filled on

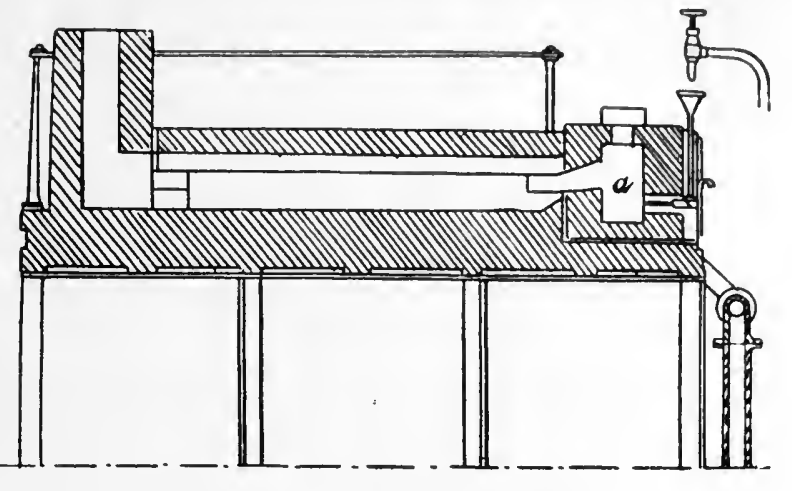

Fig. 114. Large Furnace the bed with broken bricks to facilitate contact of the flame with the article to be heated.

Lighting up is done with flaming waste or shavings, and the air is regulated to the oil, the opening of the passage from the generator to the furnace being higher than the atomizer. The fire becomes white when the generator has become hot, and regulation then ceases. Good results are got with two inches of air pressure in the pipes, and about $1 \frac{1}{4}$ inches in the generator. About 40 pounds of oil per hour will be consumed.

Six smiths will use an ordinary furnace. Two of them will work objects of some size, and not be in the way of the others.

Larger objects require double furnaces with a central chimney, two fire beds, and two generators.

Brick or Lime Kilns. In one form of kiln the brickwork of the kiln contains three to five basins, kept full of oil by means of pipes. Air for combustion is brought in by slots between the basins.

Copper also, and other metals, may be melted in crucibles.

In one works, at Chemnitz, a malleable cast iron is made in crucibles heated by oil, the vapour of which is mixed with hot air before entering the combustion chamber in which the crucibles stand two and two.

In other apparatus oil falls drop by drop or in fine streams; the vapour, brought into contact with air, burns freely and gives a high temperature. This class of apparatus is successfully employed for re-heating and brazing or welding, but the oil must be gasefied in a particular space before the flame is applied to its work.

Atomizers may also be used for metallurgical furnace work, actuated preferably by air. In the recuperative Siemens-Martin furnace the depth of the air chambers and of the gas chambers placed directly under the bottom should not be too great, because the vapour of oil contains less carbonic oxide than does coal gas, and is liable to condense if left too long in the state of gas, and form tars and coke.

Across the front wall of the recuperator is fixed a thick iron plate with an opening through which passes a hollow fitting of iron with the oil tube.

Oil is supplied by the tube, and spreads over the fitting of iron previously heated. It gasefies and at once passes to the furnace by two passages, air coming in by three other openings.

The iron vaporizer is heated by an atomizer. In a puddling furnace on 


\section{LIQUID FUEL AND ITS COMBUSTION}

this principle were produced in twenty-four hours five to six tons of iron. The loss was seven to eight per cent., and the consumption of oil 550 pounds per ton of finished metal, which represented an economy of 80 per cent. as compared with coal.

The Körting atomizer (fig. 19) is much used in Siemens-Martin furnaces, oil being pumped at 75 to $105 \mathrm{lbs}$. pressure into an accumulator, whence it passes by a pipe to the atomizer, which plays directly into a heating chamber whence issue the heated vapours to the furnace, where they mix with air introduced by slits below the opening for the vapour. With a furnace of 10 to 15 tons capacity, the consumption of oil is 20 per cent. of the weight of metal. Other simple furnaces have the oil introduced by five air-worked atomizers, two at each end and one in the middle of the furnace. The atomizers are water jacketed for protection. Oil greatly simplifies the work of attendance, the highest heats are obtained, and the fire can be extinguished any time and fuel saved. Furnaces are as durable as gas heated furnaces and have as high an output.

\section{Copper Smelting.}

In the Caucasus at Kedabeg and Kalakent the melting of ores roasted in the heap for the produetion of copper matte is done in reverberatory furnaces heated by oil, as also is the refining of crude copper. The furnace for ore smelting consists of a working chamber with a quartzose floor, and covered with a very flat vault or arch. Two steam atomizers and two air tuyeres are placed symmetrically at the back of the furnace, the air and petroleum obliquely towards the front. The two oil jets, in flames, having crossed the circular furnace nearly diametrically, recurve in semicireles and escape by a flue opening close to the injection openings. The flames aet by reverberation. A furnace will pass 40 tons of ore of 7 per cent. quality in 24 hours, with one skilled man and three labourers. 


\section{Chapter XXXI}

\section{EXAMPLES OF LIQUID FUEL CARRIERS BY RAIL AND SEA}

\section{Oil Carriage by Rail.}

$T$ is of great importance that the carriage of oil by rail should be conducted only in such vehicles as are safe in case of the most severe accidents occurring to the train of which they form a part.

The form now considered best is that of figs. 115 and 116, for which I am indebted to Messrs. Renshaw \& Co., Limited, of Stoke-on-Trent. They show an all steel railway tank wagon having a capacity of 2,800 gallons of oil at a specific gravity of $\cdot 82$, being one of ninety built for the Shell Transport Company.

The shell plates are made in one length, $\frac{5}{16}$ inch thick and the dished ends are $\frac{3}{8}$ inch thick.

The manhole is provided with a screwed cover, thereby forming an air-tight joint. The outlet has a plug valve worked by a handwheel at the top of the tank inside the manhole, and to the stool in which this valve rests is connected a wrought iron branch tee piece giving two outlets, one on either side of the wagon. These have each a $2 \frac{1}{2}$ inch gun metal sluice valve, and the end of the pipe is covered by a gun metal cap to protect the screw to which hose coupling may be attached for discharging the oil.

A wagon throughout must be of high-class workmanship, the whole of the riveting being done by hydraulic and pneumatic machinery, and the tanks must be tested to 20 pounds per square inch pressure, and must be absolutely water-tight before being passed.

The steel underframe should be of exceptional strength, a special feature in the wagon illustrated being the method by which the sole bars are joined to the head stocks, both by flanging of the bars and by cover plates.

The axle-boxes have open sliding fronts to allow easy access to the grease chambers, and altogether an oil wagon must be strongly and soundly built.

The oil tank is attached by four side brackets to the framing, and is also supported at each end against the headstock by blocks of timber.

There is a longitudinal stay plate between the two dished ends and a pair of diaphragm or swash plates to distribute surging stresses throughout the whole tank structure.

Made of tough steel plate of boiler quality, such a tank should bear a good deal of rough usage or collision without failure. 


\section{LIQUID FUEL AND ITS COMBUSTION}

In Fig. 117 is illustrated the oil carrying steamer, Newyork, built by the Palmer's Shipbuilding and Iron Company, Ltd., of Jarrow-on-Tyne. In this elass of vessel all the seams and butts of the shell plating, deeks, and bulkheads

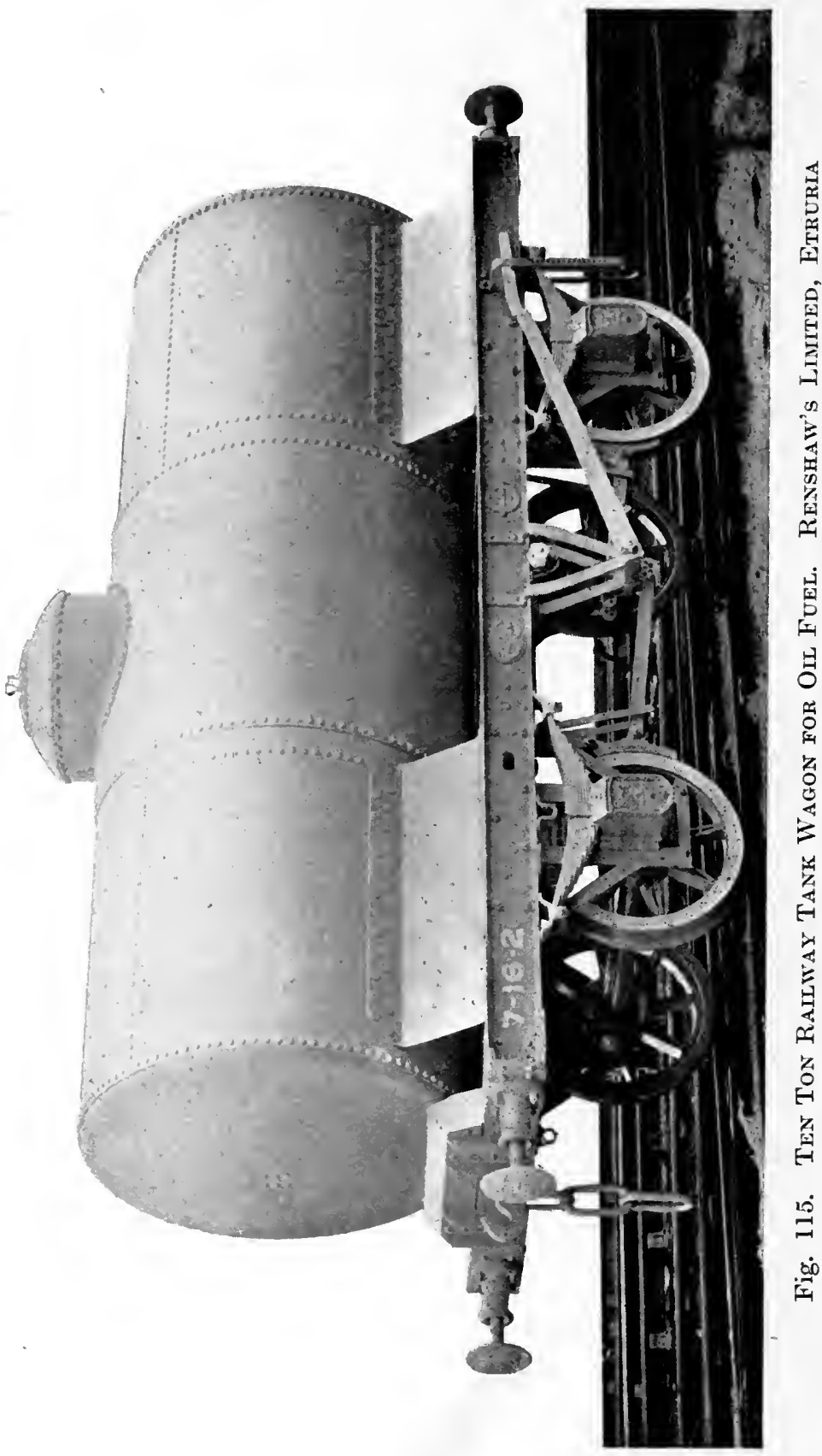

are riveted, and the rivets are spaced, for oil tightness, $3 \frac{1}{2}$ diameters centre to centre, instead of 4 diameters as required for water-tight work. Special care is also taken to avoid as far as possible any rivet passing through more than two 
EXAMPLES OF LIQUID FUEL CARRIERS BY RAIL AND SEA

thicknesses of plating. It will be obscrved that the vessel is divided into eight
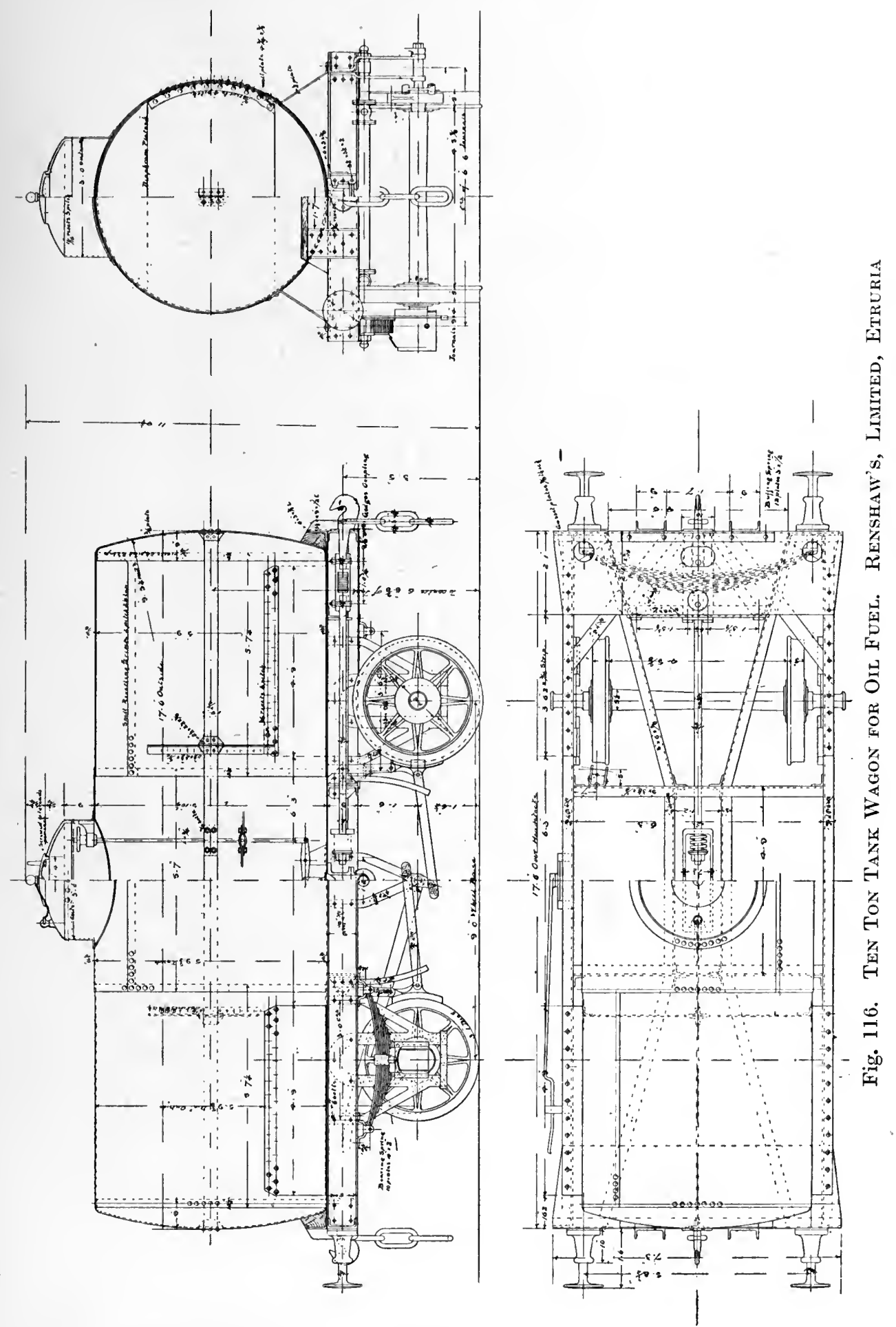

pairs of oil tanks with expansion trunks. for each pair. There is a cofferdam at 287 


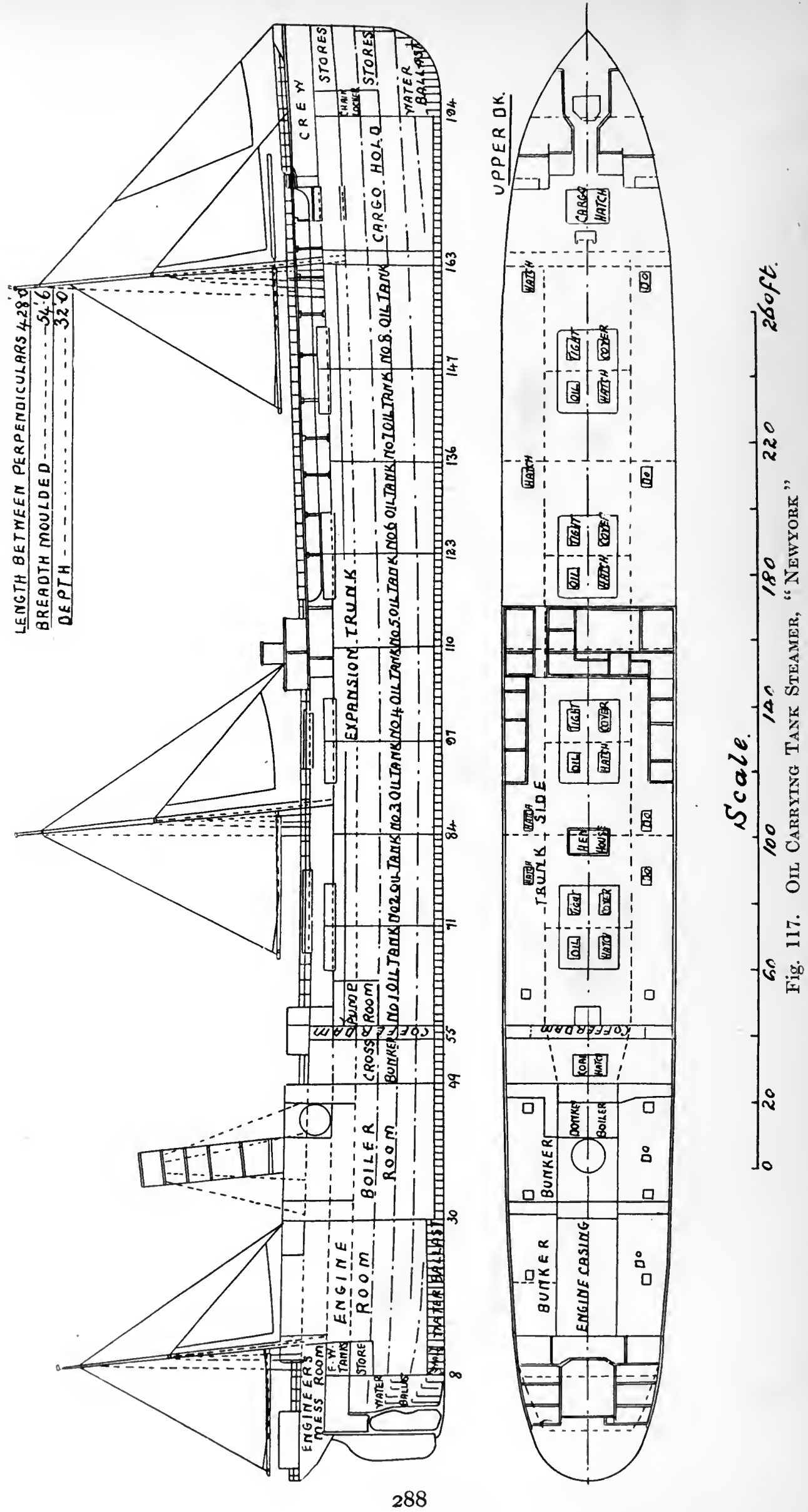




\section{EXAMPLES OF LIQUID FUEL CARRIERS BY RAIL AND SEA}

the back of No. 1 tank, separating it from the power department. A small hold for miscellaneous eargo is placed forward by No. 8 tank, from which it is separated by a cofferdam. The oil tanks are divided along the centre line of the vessel by an oil-tight bulkhead, so that there are really sixteen oil cargo tanks. The length of the Newyork is 428 feet between perpendiculars, the breadth 54 feet 6 inches, and the depth 32 feet. The water ballast tanks extend the full length of the ship below the oil tanks. Coal bunkers are provided on each side of the engine and boiler compartments, and also forward of the boilers, between the boiler eompartment and the after cofferdam.

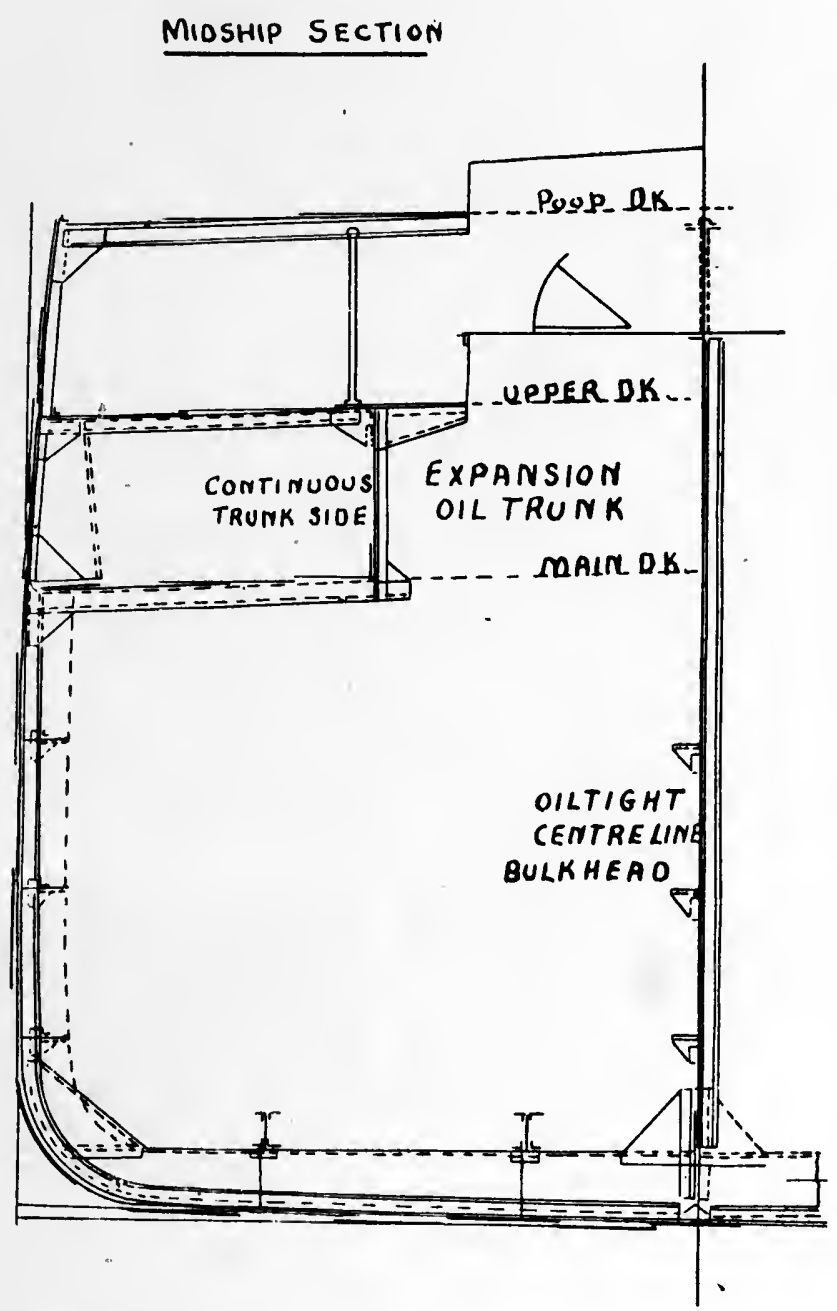

Fig. 117a. Enlarged Cross Section of Oil Tank-Steamer, "Newyork" 


\section{Chapter XXXII}

\section{Ringelmann's Smoke Chart.}

7 HIS chart (fig. 118) is very useful as a means of comparing smoke. The chart should be ruled in squares of about eight inches, and hung about 50 feet

No. $\mathbf{t}$.

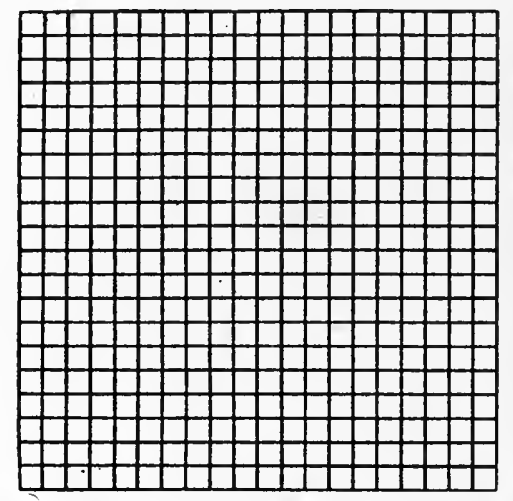

Ligbe Gray Smoke.

No 3 .

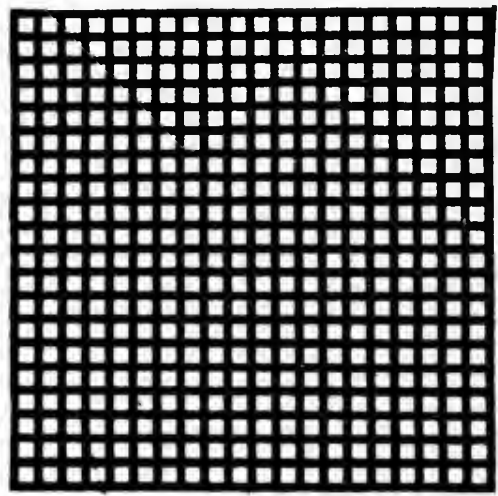

Very Dark Grey Swoke.

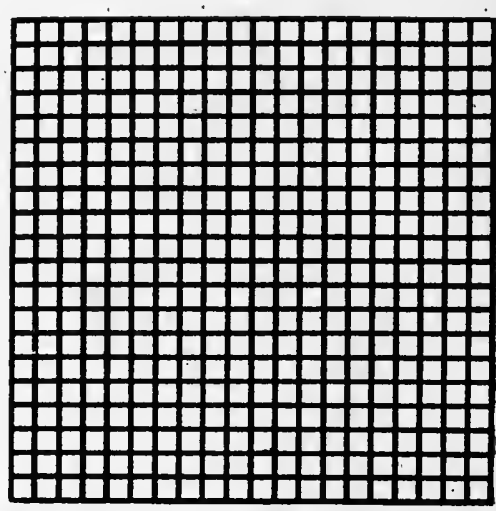

Darker Gray Smoke.

No. 4.

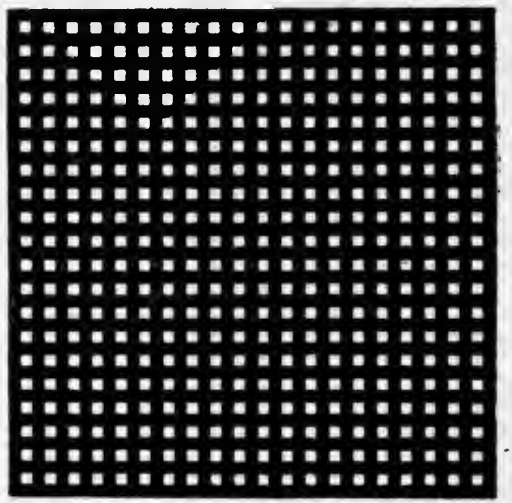

Mlack Suote

Fig. 118. Ringelmane's Smoke Chart. No. 0-All White. No. 5-All Black

from the observer, at which distance each square assumes a uniform tint all over, the rulings being indistinguishable. There are six cards in a set, No. 0 being all white and No. 5 all black. 


\section{RINGELMANN'S SMOKE CHART}

The proportion of the lines is as follows-

No. 1. Black lines $1 \mathrm{~mm}$. thick, spaces $9 \mathrm{~mm}$. wide

No. $2 . \quad$ " " $2.3 \mathrm{~mm}$. , , $7.7,$, ,

No. 3. " " $\quad 3 \cdot 7, \quad, \quad, 6 \cdot 3, \quad$,

No. 4. " , $\quad 5.5 \quad, \quad, \quad, \quad 4.5, \quad$,

The illustrations are redueed from a larger size, and the proportion of black and white is of course preserved.

\section{APPENDIX TO CHAPTER XXXI}

Aceording to Lloyd's Register for the year 1902, there were 195 steamers and 19 sailing ships engaged in the earrying trade of petroleum in bulk. The largest steamers were the s.s. Tuscarora of 3,925 net tonnage, built in 1898 for the AngloAmeriean Oil Co., and the s.s. Pinna, of 4,100 net tons, built in 1901 for the Shell Co. There were building and now launehed the s.s. Pecten and Spandilus, of 7,300 gross tons, for the Shell Co.

The largest sailing ship was the Quevilly, of 1,710 net tons, owned by a Rouen firm. This ship was built in Rouen by Laporte et Cie.

There were also 77 steamships fitted for burning liquid fuel, and nearly all included in the oil earrying class above named. 

Part III APPENDICES 



\title{
APPENDIX No. I
}

\section{EXTRACT FROM REPORT OF THE CHIEF OF BUREAU OF STEAM ENGINEER- ING, RELATING TO COMPARATIVE TESTS OF COAL AND OIL MADE UNDER A WATER-TUBE BOILER OF THE HOHENSTEIN DESIGN, ALSO OFFICIAL REPORT OF THE STEAMSHIP MARIPOSA BURNING LIQUID FUEL}

\author{
The Problem of the Water-Tube Boiler-The Hohenstein Boiler Trials (Coal Tests).
}

$\mathrm{T}^{\mathrm{H}}$ HE experience of the United States Navy with the boilers of the torpedo boats and torpedo-boat destroyers ought to afford some startling evidence as to the manner in whieh incompetent or untrained men ean impair or destroy the efficieney of these steam generators. The agitation of Great Britain over the navy-boiler question ought also to convince naval administrators that the boiler problem is the naval problem of the hour.

In view of the British experience with the Belleville boiler, it is not surprising that the general public of that Empire regard the Boiler Commission, now in session, as the most important board appointed by the Admiralty during the past ten years. The membership of this board comprises distinguished experts within and without the naval service. This board has been in session nearly two years investigating the question as to which type of marine boiler is most suitable for use in the navy as the one of approved design. The Admiralty regard the solution of this problem as of vital importance to the effieiency of the British fleet, for it has been discovered, after installing over a million and a quarter of horse-power of boilers of particular design, that a doubt has arisen as to whether or not this particular form of boiler should have been settled upon as the approved type for the naval service. A series of evaporative and endurance tests have been made, and the more earefully the question is investigated the more important does it appear in relation to the operation of a modern navy.

The work of the British Boiler Commission will have a very important influence upon naval construction, sinee it will cause thoughtful experts to give more attention to the design, construction, installation, and operation of the boiler. One must have experienee in the operation of a modern marine boiler to appreciate the intelligence, skill, and care that must be devoted to keeping it in a state of efficiency. The boilers are the lungs of a vessel, although this fact is not generally understood. It was not many years ago when a naval officer of high rank spoke of the boilers as "the stean tanks in the bottom of the ship," it being probably his impression that these tanks could be tapped like a gasometer, and it was the fault of the fireman if the boiler output was not suffieient at all times.

The boiler problem has been unsolved. Without taking into consideration the question of personnel, the value of the warships of the different naval Powers can be measured by the effieieney and endurance of the steam generator installed in the vessel. This fact may not be appreeiated in its fullness at the present time, but the experience of the coming five years with the ships nearing completion will conclusively show that in future naval conflicts the question of victory may be quite as mueh dependent upon the battle of the boilers as the contest between the guns.

With a deep appreciation of the necessity of soon settling upon an approved type of marine boiler for the battleships and armoured cruisers of the United States Navy, the 


\section{LIQUID FUEL AND ITS COMBUSTION}

Bureau has invited competition among designers. It believes, however, that, if possible, a boiler of American design should be adopted, and that this marine boiler should be a development of one in general use on shore. By seeking a design that is familiar to thousands of firemen on shore, an important military advantage would be secured, since in time of emergency there conld thus be recruited for the naval service water tenders and firemen who had operated almost similar steam generators, and would therefore require but little training to familiarize themselves with the duty on board ship. While the navy can and ought to do some efficient work in training firemen, it would be very advantageous to the service if the enlisted force in the stokeholds could have considerable preliminary training with boilers of nearly like design to the one in most extensive use as the approved type for the navy.

There is now being built, for the battleships in course of construction, water-tube boilers of three distinct types. Practically four-sevenths of this boiler power will be of the Babcock \& Wilcox design, two-sevenths of the Niclausse, and one-seventl of the Thornycroft. These types include the best of representative groups of water-tube boilers, and a sufficient installation of each kind will be secured to test the efficiency and endurance of the several designs.

About two years ago the Bureau was informed that another American boiler firm, with considerable financial backing, desired to enter the field of marine-boiler construction. In keeping with the Bureau's policy of inviting competition, encouragement was therefore given the Oil City Boiler Works to design and build a marine boiler and turn it over to the Bureau for test as to its evaporative efficiency and endurance, and they placed at the disposal of the Bureau a boiler of the Hohenstein design, installed in an air-tight steel house, approximating to one of the fire rooms of the cruiser Denver. All the limitations and difficultics that were met with in the installation of the boilers of the cruiser Denver were therefore designedly encountered in the installation of the experimental plant.

Information has been secured in regard to the best means of baffling the gases, thus increasing the evaporative efficiency as well as permitting the boiler to be forced for emergency purposes. Particular care has also been given by the Board to the investigation of the circulation of the water, for probably the key to the boiler problem is the question of circulation.

While only scventeen official tests were made with coal as fuel, there were a great many unofficial experiments. Between the several official tests the experts of the Oil City Boiler Works conferred with the Bureau, and therefore each test represents the result of study and experiment. An examination of the data will conclusively show that in many respects the completeness and character of the tests have never been surpassed.

The first six tests were run by a picked crew of firemen who had experience in torpedoboat work. It was believed that these men by training and experience were particularly well fitted to operate the boiler when under severe forced-draught conditions. An experience of a few weeks with this force showed that new methods in firing had to be employed in efficiently operating water-tube boilers, and that the best means of securing efficient work was to have skill and intelligence from those in charge of the fire room and implicit obedience upon the part of the subordinates. The remaining eleven tests were thus made by firemen living in the city, not one of whom had ever before worked a boiler under forceddraught conditions. The second set of firemen implicitly obeyed orders, and it was therefore possible for the Board to have its instructions carried out. A uniform pressure of steam was maintained, as well as a regularity in firing that was productive of good results.

The data secured can be regarded as reliable, for checks and counter-checks were used, so that the Burean could be placed in possession of information that could be relied upon as to completeness and accuracy. As this same boiler is being used to carry on the extended series of tests to determine the value of liquid fuel for naval purposes, it is proposed to duplicate every one of the coal tests with oil as a combustible. The comparative information thus obtained ought to afford valuable data as to the relative value of the two combustibles. 


\section{APPENDIX}

In view of the present condition of this experimental boiler after eighteen months of use with both coal and oil as a combustible, considering the results secured, and by reason of the following report submitted by the Board which conducted the series of tests, the Bureau has no hesitation in regarding the boiler as the equal in efficiency and endurance of any used in a foreign battleship.

\section{Report of Board on Hohenstein Boiler Trials.}

Navy Department,

Bureau of Steam Engineering,

July 1, 1902.

SiR,--The Board appointed to conduct an extended series of tests to determine the

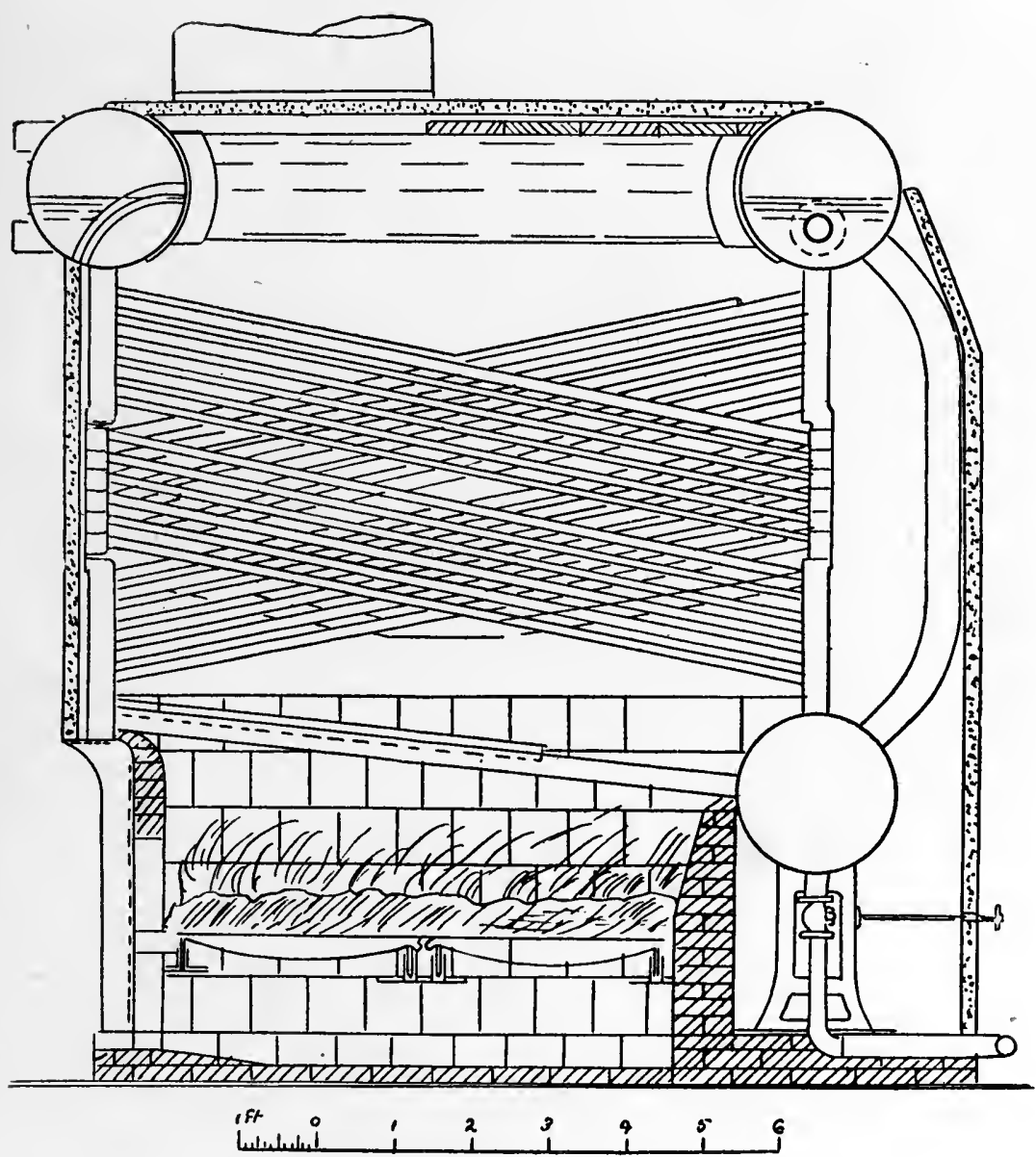

Fig. 1.-Arrangement of Hohenstein Experimental Boller for Coal Burning Tests

efficiency and adaptability of the Hohenstein marine boiler for naval purposes submits the following report-

The boiler was built by the Oil City Boiler Works, of Oil City, Pa., in conformity with the Bureau specifications for the cruiser Denver and class. The limitations as to weight, height, and floor space in regard to the Denver's steam gencrators were therefore taken into account in the construction of this boiler. A noteworthy feature of the boiler is the 


\section{LIQUID FUEL AND ITS COMBUSTION}

arrangement of the tubes in pairs in such a way that each tube is free to expand independently of other tubes, thus effectually preventing longitudinal stresses. Fig. 1 shows a longitudinal section of the boiler. The entire downflow takes place within tubes which are located in a comparatively cool place, while there is invariably an upward trend to the current in all tubes and headers exposed to the hot gases. It is therefore highly probable that there are no reverse currents at any part of the water eireuit, and the cross-section areas of tubes and headers are equitably apportioned with a corresponding degree of certainty. The feed water is introduced at the top of the down-take tubes, which is obviously the best possible place as regards influence on the circulation; at the same time the head due to the velocity of the feed water is conserved by means of injector nozzles pointing in the direction of flow.

The following are the more important dimensions-

\section{Boiler Data.}

Drums at water-surface level: One front drum, 24 inches diameter (inside one rear drum, 24 inches diameter; four connecting drums, 16 inches diameter.

One lower rear mud drum, 24 inches diameter.

Tube-heating surface: Three hundred and eighty-four 2-inch tubes 9 feet long; sixteen 4 -inch tubes 7 feet long.

Fifteen down-take tubes 5 inches diameter.

Floor space occupied, 9 feet wide $\times 10$ teet $11 \frac{1}{4}$ inches deep.

Height above floor line, 12 feet $\frac{3}{4}$ inch.

Height over all, 2 feet 63 inches.

Heating surface: 2,174 square feet for tests No. 1 to No. 6, inclusive ; 2,130 square feet for tests No. 7 to No. 17 inclusive. Per cent water-heating surface, 100.

Grate surface : 50.14 square feet, 6 fect 4 inches long, 7 feet 11 inches wide.

Ratio of heating surface to grate surface: 43.4 to 1 for tests No. 1 to No. 6 , inclusive; 42.5 to 1 for tests No. 7 to No. 17 , inclusive.

Volume of water at steaming level, 142 cubic fect.

Volume of stean space, 50 cubic fect.

Area of steam liberating surface, 75 square fect.

Weight of water at steaming level and 275 pounds pressure, 7,559 pounds.

Weight of boiler and fittings, excluding uptake and smoke pipe: Without water, 46,568 pounds ; with water, 54,127 pounds. Without water per square foot of heating surface, $21 \cdot 4$ pounds for tests No. 1 to No. 6 inclusive; 21.8 pounds for tests No. 7 to No. 17, inclusive. With water per square foot of heating surface, 24.9 pounds for tests No. 1 to No. 6, inchisive; 25.4 pounds for tests No. 7 to No. 17, inclusive. With water, per square foot of grate surface, 1,080 pounds.

Height of furnace, 2 feet 5 inches.

Volume of furnace above bars, $121 \cdot 14$ cubic feet.

Width of air spaces between grate bars: Five-eighths inch for tests No. 1 to No. 11, inclusive ; threefourths inch for tests No. 12 to No. 17, inchusive.

Ratio of grate area to area of air space : $1 \frac{1}{8}: \frac{5}{8}=1: 0.555$ for tests No. 1 to No. 11, inclusive; $11: 3-1: 0.60$ for tests No. 12 to No. 17, inclusive.

Height of smoke pipe above grate, 70 feet.

Area of smoke pipe, $8 \cdot 73$ square feet.

Ratio of smoke-pipe area to grate area, 1:5.75.

Number of fire doors, 3.

The steel structure was built espeeially for these tests and has the following dimensions -Floor space, 16 feet by 24 feet; height, 14 feet. The strueture was air-tight, had an airlock for entrance and exit during foreed draught trials, and seven windows that could be opened during natural draught trials. Figure 3 shows the ground plan. The auxiliary machinery, together with facilities for making observations, were, so far as possible, placed in an adjoining lean-to wooden structure. The auxiliaries consisted of a Davidson suction pump, two weighing tanks, one feed tank, a Snow high-pressure feed pump, a small upright boiler with independent feed pump, and a direct-connected blowing engine and fan. The fan had an impeller 72 inches in diameter and a discharge duet 20 inches by 42 inches, which led to the fire room and terminated in a box placed so as to direct the air current toward the ceiling. The pipe eonnexions were such that steam for the auxiliaries eould be taken either from the small upright boiler or from the main boiler. The bottom blow valve was blanked, but in plain sight, so that leakage from that source would be particularly observed. 


\section{APPENDIX}

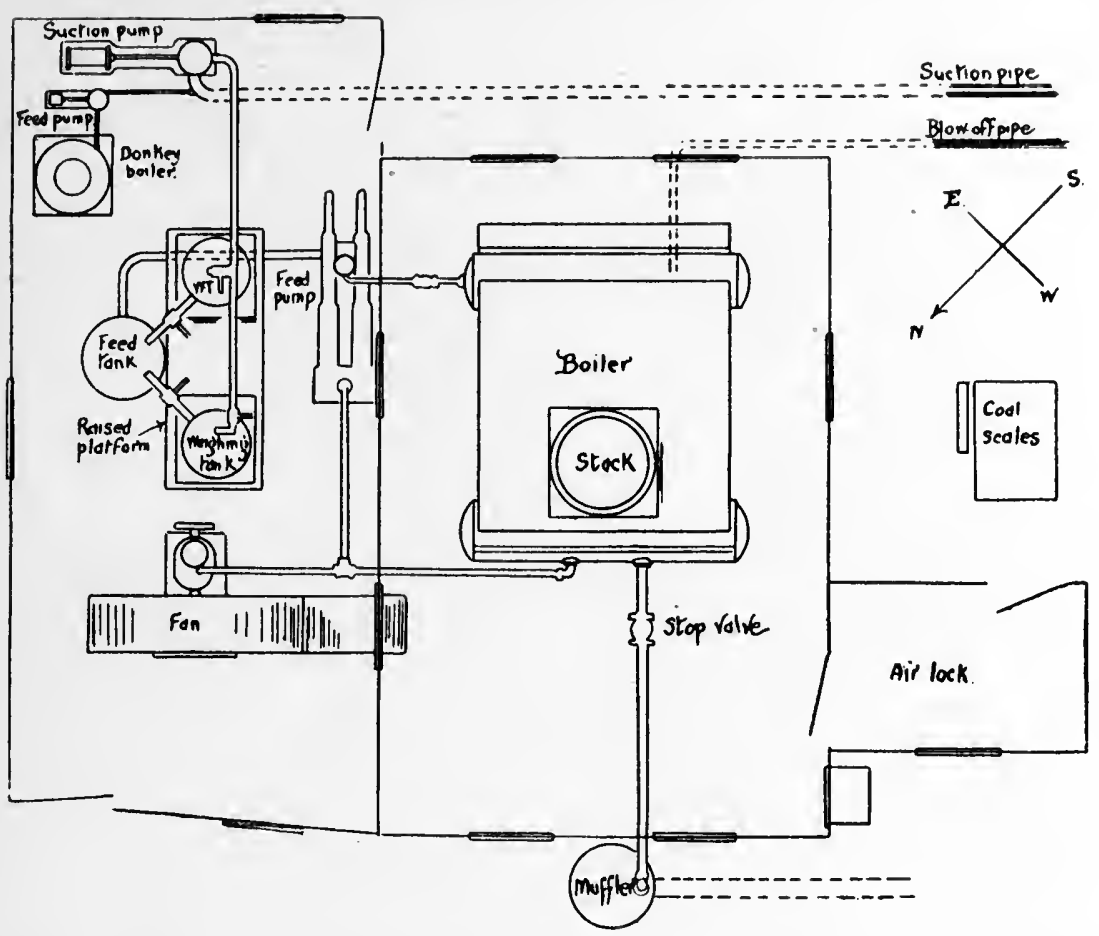

Fig. 3.-Arrangement of Hohenstein Experimental Boiler Plant for Coal Burning Tests.

The feed water was weighed in two tanks, each of 1,000 pounds capacity, resting on 1,500-pound tested scales, on a platform above the feed tank. The weight of each tank was taken when filled, and the water was then allowed to flow into the feed tank as needed. As soon as the weighing tank was emptied the weight was again taken and the time noted. The feed tank was provided with a graduated water-level gauge. The height of water by this gauge was noted at the moment of beginning the test, and at the end of each hour it was again brought to the same level. The feed tank had a steam coil for heating the water, wide variations in the temperature of which were easily avoided by keeping the water level fairly constant. In most of the forced-draught trials the weighing tanks had to be filled, weighed, and emptied with such rapidity, owing to their insufficient size, that the above method of catching the weight at the end of each hour could not be used. The weighing tanks were accordingly each fitted with a water-level gauge graduated to 5 pounds, by the aid of which the weight within 5 pounds could be caught at any moment without interfering with the rapid manipulation of the tanks. The temperature of the feed water was taken at an elbow of the feed pipe between the pump and the boiler.

The several air-pressure gauges and two steam gauges were placed near each other on the wall of the steel structure, on the opposite or fire-room side of which the necessary pipe connexions were made.

The steam was blown off into the atmosphere, the pressure being controlled by a hand-operated stop valve.

The coal was weighed in cans or bags, the method being to adjust each can or bag to a uniform weight of 220 pounds, or 130 pounds while on the scales, and then keep tally of the number passed into the fire room. Beginning with the seventh test, the coal account was balanced at the end of each hour by estimating and deducting the weight of coal lying at the moment on the fire-room floor. 


\section{LIQUID FUEL AND ITS COMBUSTION}

The ashes and refuse were weighed in sheet-metal cans as they accumulated, and the weight of sweepings from tubes and bafles was ascertained for each test on the day following the test.

A sample of coal for analysis and for the determination of moisture by weighing and drying was taken from a box which had been gradually filled during the test by specimens taken from each ean or bag as weighed.

The following table gives the results of analyses of samples of each lot of coal, made by the chemist at the New York Navy-yard--

Analyses of Fuel.

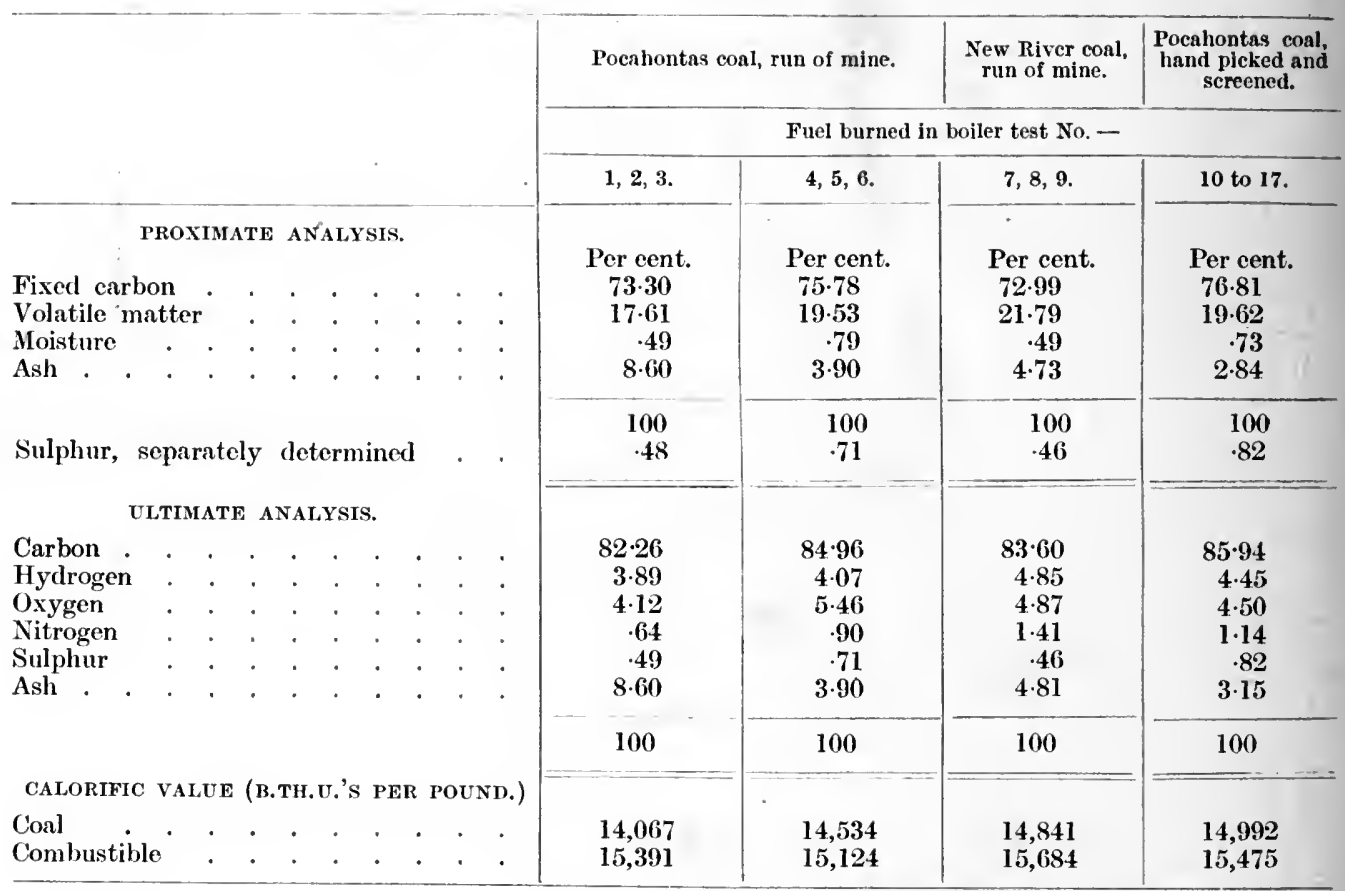

The quality of the steam was determined by means of a Barrus throttling calorimeter, which drew steam from the main steam pipe at a point 8 inches from the boiler. The sampling nozzle consisted of a half-inch pipe reaching nearly across the steam pipe on a horizontal diameter and having four rows of perforations (top, bottom, and sides) extending the length of the diameter of the inside of the steam pipe, save for one half-inch at each end. An extra calorimeter was fitted and readings were taken from both.

The temperatures at the base of the stack and the samples of flue gas were taken above the roof at a point about 5 feet from the nearest heating surface of the boiler, measured along the path of flow of the gases. In the natural draught trials the temperatures were taken with a mereury-nitrogen pyrometer, and attempts were made to do the same in the forced-draught trials. Momentary flaming in the stack, however, caused so many breakages of glass bulbs that reliance had finally to be placed on a Brown quick-reading pyrometer, the readings of which were, however, ehecked as well as could be by the melting points of zinc, aluminium, and copper.

The samples of flue gas were drawn by means of an aspirator improvised from two half-gallon bottles. The sampling tube was one-half inch diameter and extended to the centre of the stack, the inner end being nearly closed and the sides being perforated with one-eighth-ineh holes spaced 4 inches apart. 


\section{APPENDIX}

The aspirator, charged with gas, was carried to a neighbouring building, where the sample was analyzed by the aid of an Orsat apparatus.

The following determination was made of the actual wcight of water contained in the boiler at a temperature of $56^{\circ} \mathrm{F}$. and at different gauge-glass readings, the correct steaming level being at 1 inch-

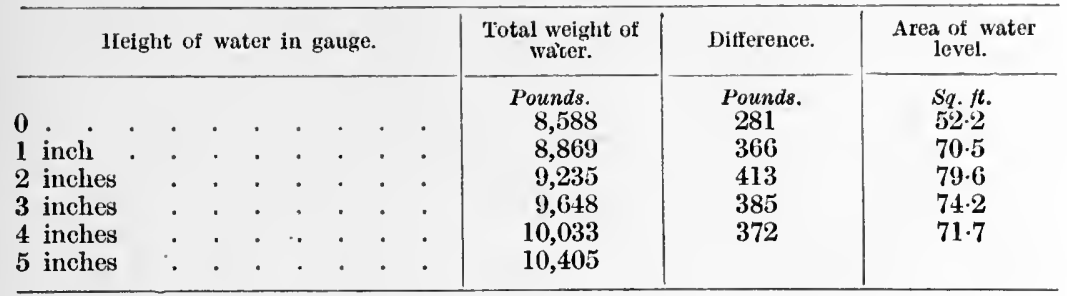

The feed water was always muddy, and especially so for the fourteenth and subsequent tests. The water was drawn from the Potomac River through a suction pipe that ran out to the end of a dock. When about to start the fourteenth test, a long reach of the suction pipe was found frozen solid. To avoid postponing the test the pipe was quickly rearranged so as to draw from a point farther in, where the water was only 3 or 4 feet deep and very muddy.

The last test was to have been of three and one-half hours' duration, but it was brought to a sudden close at 1.02 p.m. by the failure of the feed water. The outflowing tide had exposed the end of the suction pipe, but before this became known the furnace doors were thrown open and the fires hauled. It was several minutes before the blowing engine was stopped, so that, in the meantime, the tubes were exposed to the blast of cold air from the 4 inches of air pressure. There was no appearance of leakage at this or any at other time during the seventeen trials. In this connexion the construction of the plugs in the headers opposite the tube ends is worthy of special remark. These plugs are of composition. There

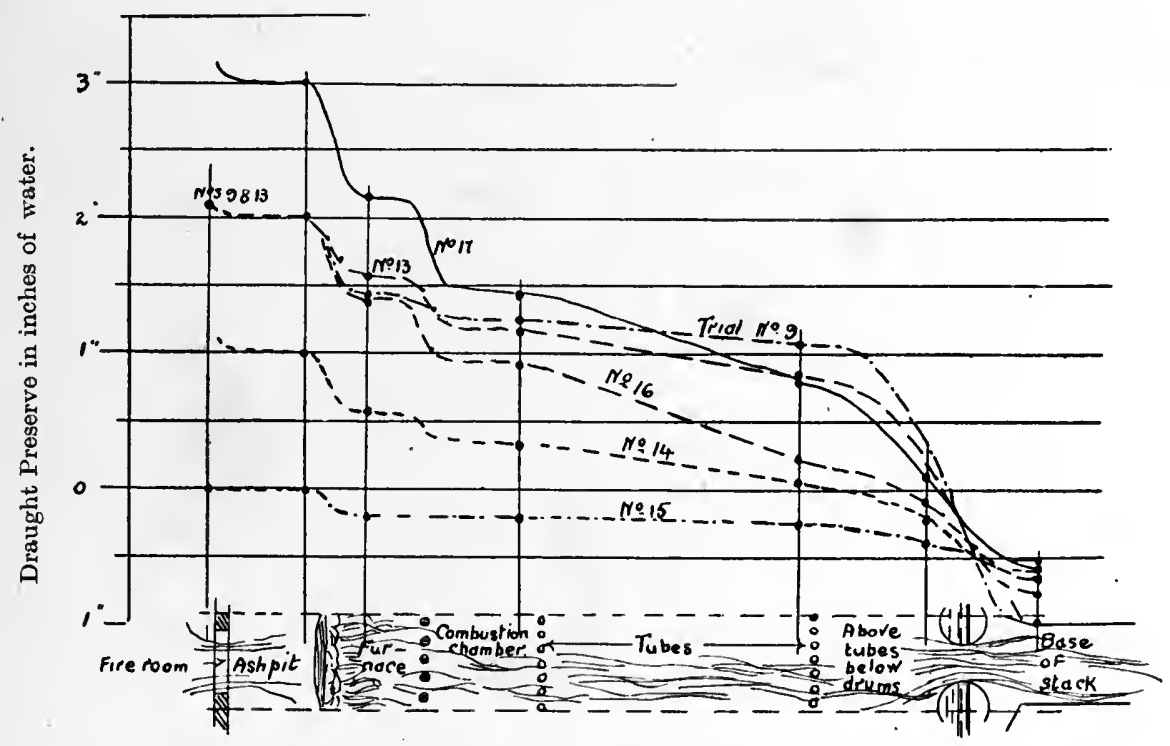

Abscissas are roughly proportional to measurements along the path of gases.

Fig. 4.-Curves showing Variation of Air Pressure within the Boiler during certain Coal Burning Trials. Spots indicate points where measurements were made. 


\section{LIQUID FUEL AND ITS COMBUSTION}

arc two sizes, 23 inches and $4 \frac{1}{2}$ inehes in diameter with, respectively, $11 \frac{1}{2}$ threads and 8 threads per inch. The material of the plugs, together with the use of a graphite lubricant on the threads, makes it possible to remove and replace them without difficulty after any length of service. Also, by virtue of the greater expansion coefficient of composition as compared with steel, the plugs are tighter at steaming pressure than at ordinary temperature $\left(70^{\circ} \mathrm{F}\right.$.) by 0.0026 inch and $0.0049 \mathrm{inch}$, respectively, for the 23 -inch and $4 \frac{1}{2}$-inch sizes.

Part of these plugs were made with tapering threads such as are inserted in the ordinary screwed pipe joints and depend for tightness on the threads alone. The joints thus formed were tight, but the plugs could be removed only with great difficulty. The others had parallel threads and a narrow flange at the end. A "McKim" gasket, consisting of a copper ring fitted with suitable packing material, was used under the flange to make a tight joint. The plugs thus fitted were tight and could be easily removed or replaced when desired. The same gasket could be used for an indefinite time. A good graphite lubricant was used on all the threads of all the plugs.

By varying the connexions of the draught gauges during the early trials it was found that the draught was seriously interfered with by the resistance of the uptake.

The uptake was accordingly increased in size for the later trials, with the result that the boiler showed a greater capacity, the fireroom temperature was much lower, and there was no further trouble, as there had been previously, with the burning of grate bars. The variation of draught pressure within the boiler, together with the improvement that resulted from the change just alluded to, is shown diagrammatically in fig. 4.

In the accompanying tables of the individual trials the " pounds of air per pound of carbon " is calculated by the approximate formula-

$$
\frac{11 \cdot 55\left(\mathrm{CO}_{2}+\mathrm{O}+\frac{1}{2} \mathrm{CO}\right)}{\mathrm{CO}_{2}+\mathrm{CO}}
$$

which takes no account of the air consumed in burning hydrogen. In the table of summaries the weight of dry gas per pound of carbon is calculated by the accurate formula as there given.

The amount of smoke is designated in a rather crude manner by a scale in which 0 stands for no smoke and 5 stands for very thick smoke.

The first six tests were run by a crew of firemen experienced in torpedo-boat work, but the remaining 11 tests were made by firemen picked up around the wharves, not one of whom had ever before fired a boiler under forced draft conditions.

Careful examination of the boiler after each of the tests showed no distortion of the tubes, nor any damage to the boiler.

The notes that are recorded in connexion with the several tests will show the severe work to which the boiler has been exposed. Under these several trials the boiler shows no indication of injury whatever. Not a leak has developed and not a tube has been bent. The tubes have frequently been examined, and they are clear of mud, showing that a good circulation has been maintained.

The casing of the boiler has not proved satisfactory, the lining not being able to stand the effect of strong forced draught. This has been probably due to the use of improper non-conducting material. This defect is one which can be easily remedied by a more liberal use of fire tile or fire-brick.

The front drum is only 24 inches in diameter. Although this boiler is so baffled that it has given reasonably dry steam, and the design of the boiler is such that there is a much greater water surface in the drums, and at least an equal weight of water to that used in other water-tube boilers, yet the Board considers that for marine work, where the ship will roll and pitch, and thus cause the water level to vary, the front drum should be increased to about 42 inches in diameter.

With an improved casing and a larger front drum for the boiler, the series of experi- 


\section{APPENDIX}

ments conducted indicate that this boiler is a satisfactory steam generator for the naval service. The Board therefore recommends that the Hohenstein boiler be given a place on the very limited list of straight-tube water-tube boilers of Ameriean design that have been found suitable for naval purposes.

\section{(Signed),}

Join R. EDwards, Lieutenant-Commander, U.S. Navy.

Wythe M. Parks, Lieutenant-Commander, U.S. Navy.

Frank H. BaIley, Lieutenant-Commander, U.S. Navy.

Rear-Admiral Georae W. Melvinue, U.S. Navy, Chief of Bureau of Steam

Engineering. 


\section{LIQUID FUEL AND ITS COMBUSTION}

Summary of Seventeen T'ests of Hohenstein

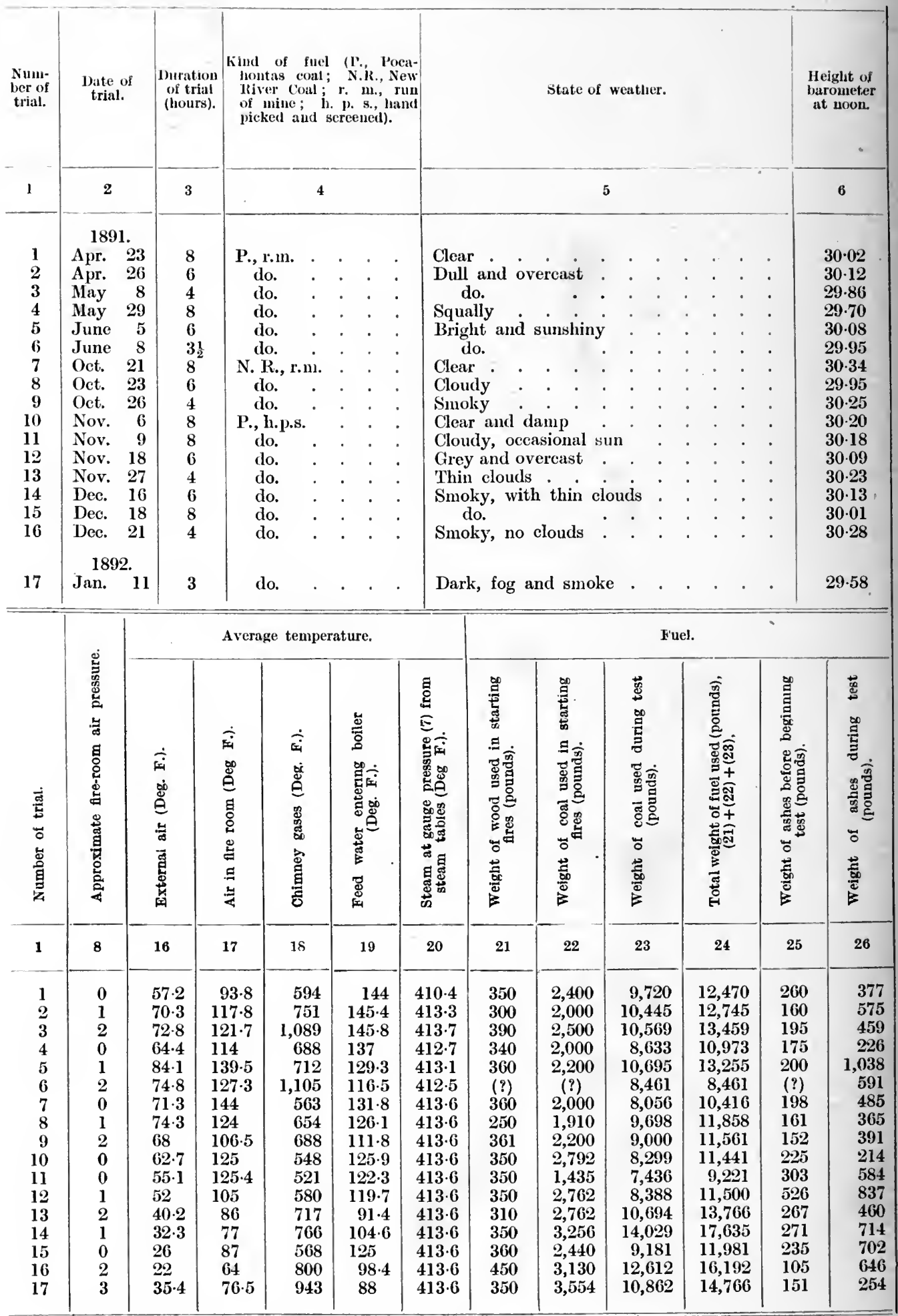




\section{APPENDIX}

Marine Water-tube Boiler, burning coal.

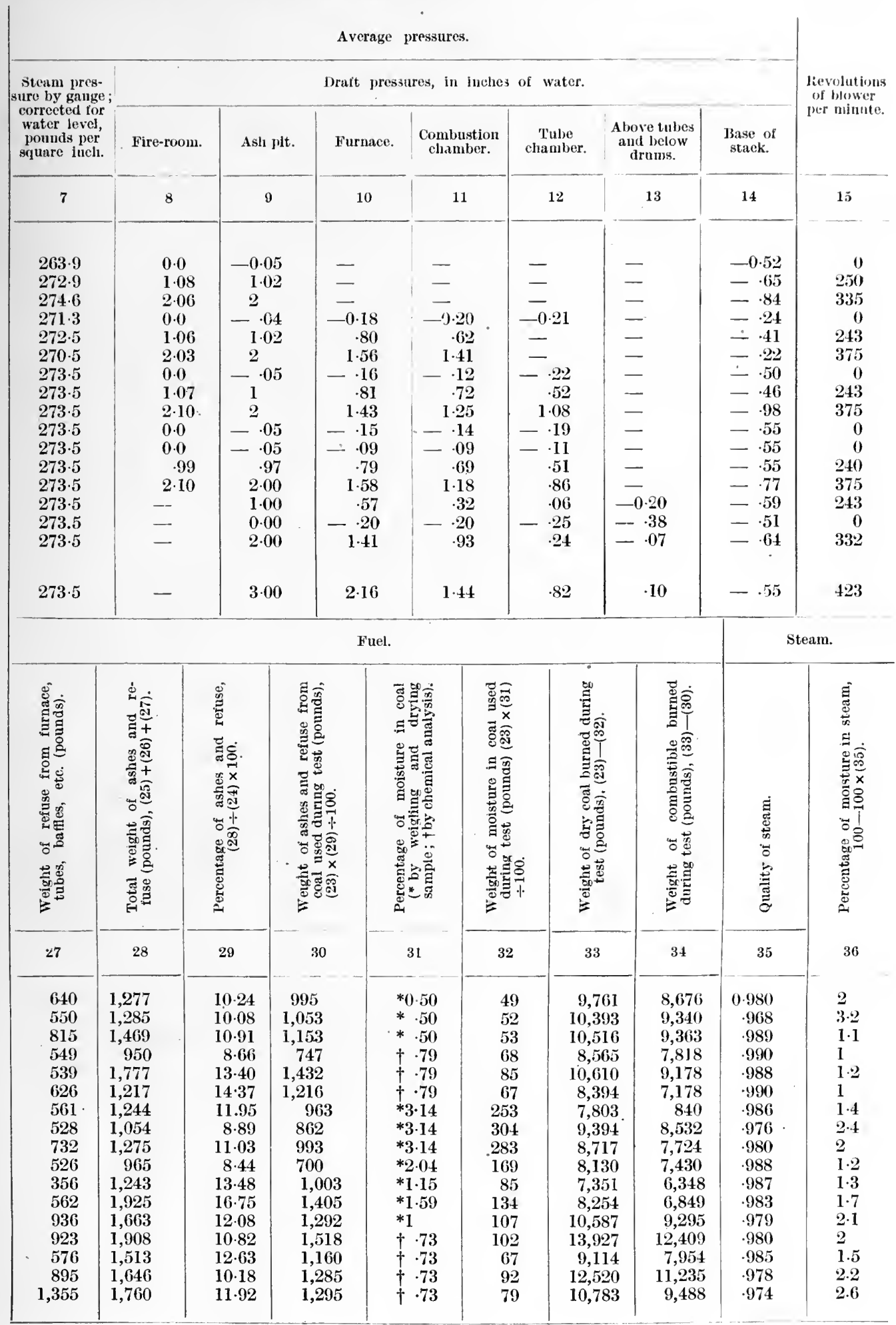




\section{LIQUID FUEL AND ITS COMBUSTION}

Summary of Seventeen Tests of Hohenstein

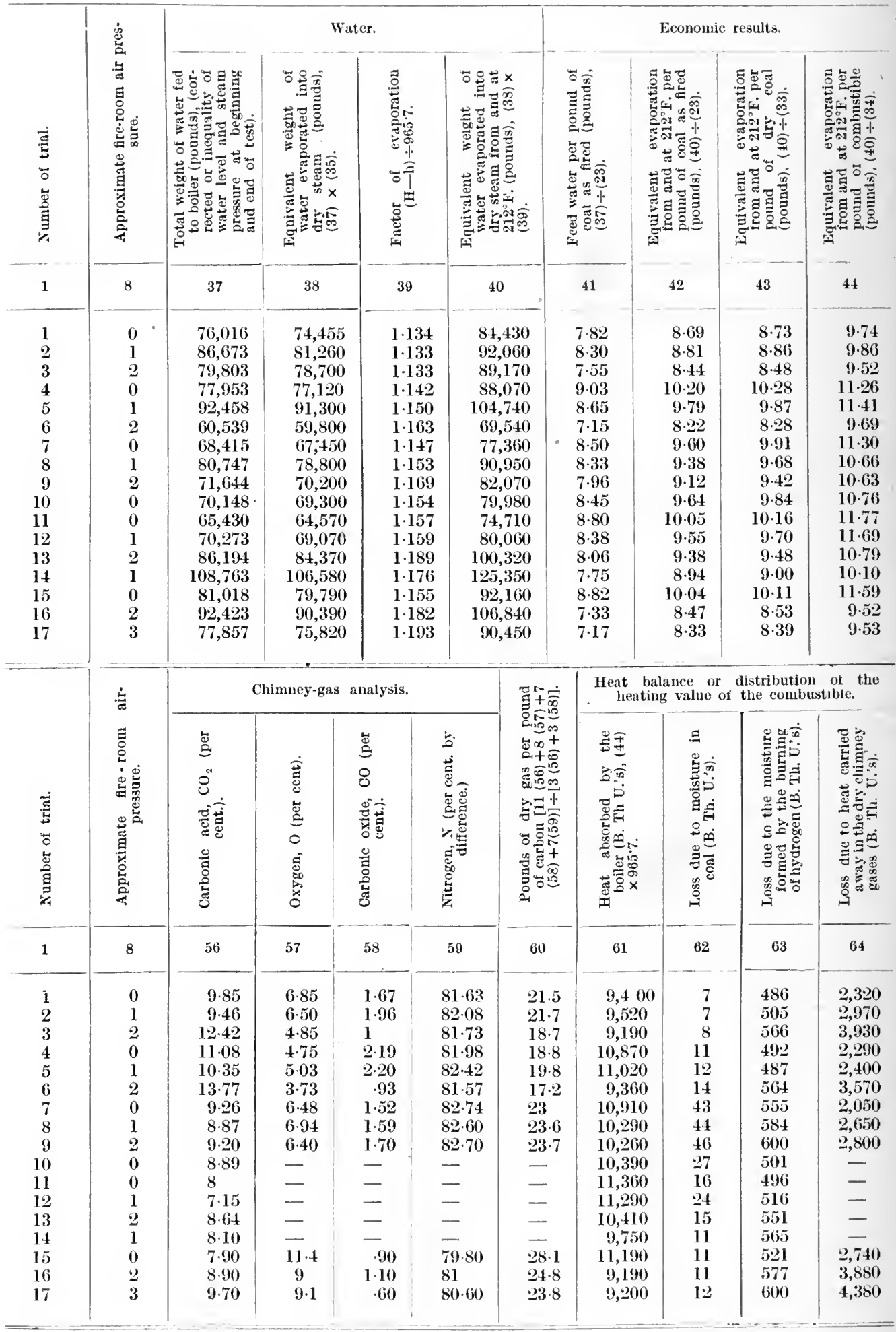




\section{APPENDIX}

Marine Boiler, December 2I, I90I.-Continued.

\begin{tabular}{|c|c|c|c|c|c|c|c|c|c|c|}
\hline \multicolumn{6}{|c|}{ Fuel per hour. } & \multicolumn{5}{|c|}{ Water per hour. } \\
\hline 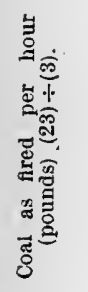 & 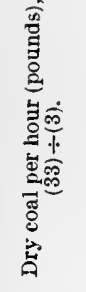 & 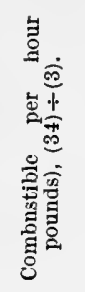 & 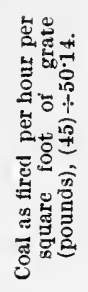 & 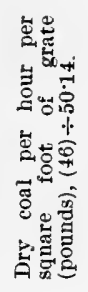 & 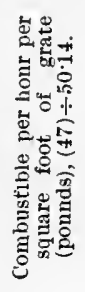 & 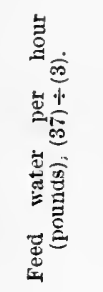 & 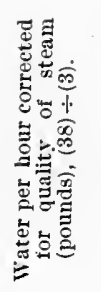 & 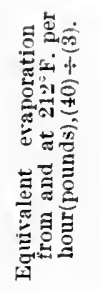 & 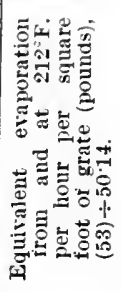 & 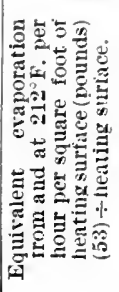 \\
\hline 45 & 46 & 47 & 48 & 49 & 50 & 51 & 52 & 53 & 54 & 55 \\
\hline 1,215 & 1,209 & 1,085 & $24 \cdot 2$ & $24 \cdot 1$ & $21 \cdot 6$ & 9,502 & 9,307 & 10,554 & 210 & $4 \cdot 85$ \\
\hline 1,741 & 1,732 & 1,557 & 34.7 & $34 \cdot 5$ & 31 & 14,446 & 13,543 & 15,343 & 306 & $7 \cdot 05$ \\
\hline 2,642 & 2,629 & 2,341 & $52 \cdot 6$ & $52 \cdot 4$ & $46 \cdot 7$ & $19,95 \mathrm{I}$ & 19,675 & 22,292 & 445 & $10 \cdot 25$ \\
\hline 1,079 & 1,071 & 977 & $21 \cdot 5$ & $21 \cdot 3$ & $19 \cdot 5$ & 9,744 & 9,640 & 11,009 & 219 & $5 \cdot 06$ \\
\hline 1,782 & 1,769 & 1,530 & $35 \cdot 5$ & $35 \cdot 2$ & 30.5 & 15,410 & 15,180 & 17,457 & 348 & $8 \cdot 03$ \\
\hline 2,417 & 2,398 & 2,051 & $48 \cdot 2$ & $47 \cdot 8$ & $40 \cdot 8$ & 17,297 & 17,086 & 19,869 & 396 & $9 \cdot 14$ \\
\hline 1,007 & 975 & 855 & $20 \cdot 1$ & $19 \cdot 4$ & 17 & 8,552 & 8,431 & 9,670 & 193 & 4.53 \\
\hline 1,616 & 1,566 & 1,422 & $32 \cdot 2$ & $31 \cdot 2$ & $28 \cdot 3$ & 13,458 & 13,133 & 15,158 & 302 & $7 \cdot 11$ \\
\hline 2,250 & 2,179 & 1,931 & $44 \cdot 8$ & $43 \cdot 4$ & $38 \cdot 4$ & 17,911 & 17,554 & 20,518 & 411 & $9 \cdot 64$ \\
\hline 1,037 & 1,016 & 929 & $20 \cdot 7$ & $20 \cdot 2$ & $18 \cdot 5$ & 8,769 & 8,663 & 9,998 & 199 & $4 \cdot 69$ \\
\hline 930 & 919 & 794 & $18 \cdot 5$ & $18 \cdot 3$ & $15 \cdot 8$ & 8,179 & 8,071 & 9,339 & 186 & $4 \cdot 38$ \\
\hline 1,398 & 1,376 & 1,142 & $27 \cdot 8$ & $27 \cdot 4$ & $22 \cdot 7$ & 11,712 & 11,512 & 13,343 & 266 & $6 \cdot 26$ \\
\hline 2,674 & 2,647 & 2,324 & $53 \cdot 4$ & $52 \cdot 8$ & $46 \cdot 2$ & 21,549 & 21,092 & 25,080 & 500 & $11 \cdot 77$ \\
\hline 2,338 & 2,321 & 2,068 & $46 \cdot 6$ & $46 \cdot 3$ & $41 \cdot 2$ & 18,127 & 17,763 & 20,892 & 417 & $9 \cdot 81$ \\
\hline 1,148 & 1,139 & 994 & $22 \cdot 9$ & $22 \cdot 7$ & $19 \cdot 8$ & 10,127 & 9,974 & 11,520 & 229 & $5 \cdot 40$ \\
\hline 3,153 & 3,130 & 2,809 & $62 \cdot 9$ & $62 \cdot 4$ & 56 & 23,106 & 22,598 & 26,710 & 533 & 12.54 \\
\hline 3,621 & 3,594 & 3,163 & $72 \cdot 2$ & $71 \cdot 7$ & $63 \cdot 1$ & 25,952 & 25,273 & 30,150 & 602 & $14 \cdot 15$ \\
\hline
\end{tabular}

\begin{tabular}{|c|c|c|c|c|c|c|c|c|c|c|}
\hline \multicolumn{9}{|c|}{ Heat balance or distribution of the heating value of the combustible. } & \multicolumn{2}{|c|}{ Efficiency. } \\
\hline 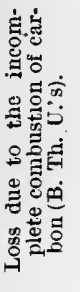 & 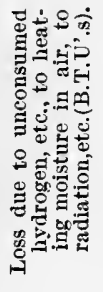 & 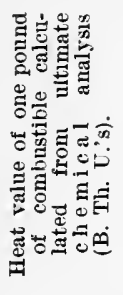 & 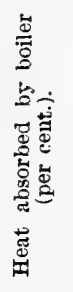 & 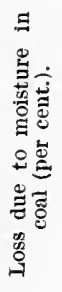 & 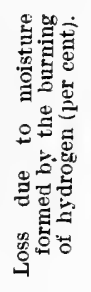 & 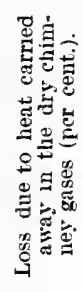 & 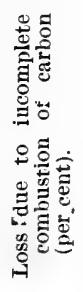 & 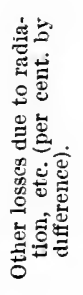 & 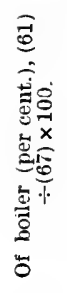 & 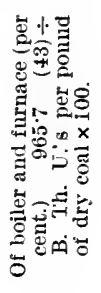 \\
\hline 65 & 66 & 67 & 68 & 69 & 70 & 71 & 72 & 73 & 74 & 75 \\
\hline 1,325 & 1,853 & 15,391 & 61 & $0 \cdot 1$ & $3 \cdot 2$ & $15 \cdot 1$ & $8 \cdot 6$ & 12 & 61 & 60 \\
\hline 1,571 & 818 & 15,391 & $61 \cdot 8$ & $\cdot 1$ & $3 \cdot 3$ & $19 \cdot 3$ & $10 \cdot 2$ & $5 \cdot 3$ & $61 \cdot 8$ & $60 \cdot 8$ \\
\hline 682 & 1,015 & 15,391 & $59: 7$ & $\cdot \mathbf{1}$ & $3 \cdot 7$ & $25 \cdot 5$ & $4 \cdot 4$ & $6 \cdot 6$ & $59 \cdot 7$ & $58 \cdot 2$ \\
\hline 1,388 & 73 & 15,124 & $71 \cdot 8$ & $\cdot 1$ & $3 \cdot 3$ & $15 \cdot 1$ & $9 \cdot 2$ & $\cdot 5$ & $71 \cdot 8$ & $68 \cdot 3$ \\
\hline 1,569 & -364 & 15,124 & $72 \cdot 8$ & 1 & $3 \cdot 2$ & $15 \cdot 9$ & $10 \cdot 4$ & $-2 \cdot 4$ & $72 \cdot 8$ & $65 \cdot 6$ \\
\hline 567 & 1,049 & 15,124 & 62 & .1 & $3 \cdot 7$ & $23 \cdot 6$ & $3 \cdot 7$ & $6 \cdot 9$ & 61.9 & 55 \\
\hline 1,265 & 861 & 15,684 & $69 \cdot 5$ & $\cdot 3$ & $3 \cdot 5$ & $13 \cdot 1$ & $8 \cdot 1$ & $5 \cdot 5$ & $69 \cdot 6$ & $64 \cdot 4$ \\
\hline 1,362 & 754 & 15,684 & $65 \cdot 6$ & 3 & $3 \cdot 7$ & $16 \cdot 9$ & $8 \cdot 7$ & $4 \cdot 8$ & $65 \cdot 6$ & 63 \\
\hline 1,398 & 580 & 15,684 & $65 \cdot 5$ & $\cdot 3$ & $3 \cdot 8$ & $17 \cdot 8$ & 8.9 & 3.7 & $65 \cdot 4$ & $61 \cdot 3$ \\
\hline - & - & 15,475 & $67 \cdot 1$ & - & $3 \cdot 2$ & - & - & - & $67 \cdot 1$ & $63 \cdot 3$ \\
\hline - & - & 15,475 & $73 \cdot 4$ & - & $3 \cdot 2$ & 一 & - & - & $73 \cdot 4$ & $65 \cdot 4$ \\
\hline - & - & 15,475 & $72 \cdot 9$ & - & $3 \cdot 3$ & - & - & - & 73 & $62 \cdot 4$ \\
\hline- & - & 15,475 & $67 \cdot 2$ & - & $3 \cdot 6$ & - & - & - & $67 \cdot 2$ & 61 \\
\hline- & - & 15,475 & 63 & - & $3 \cdot 7$ & 一 & - & - & 63 & $57 \cdot 9$ \\
\hline 908 & 105 & 15,475 & $72 \cdot 2$ & $\cdot 1$ & $3 \cdot 4$ & $17 \cdot 7$ & $5 \cdot 9$ & $\cdot 7$ & $72 \cdot 3$ & 65 \\
\hline 989 & 828 & 15,475 & $59 \cdot 4$ & $\cdot 1$ & $3 \cdot 7$ & $25 \cdot 1$ & $6 \cdot 4$ & $5 \cdot 3$ & $59 \cdot 4$ & $54 \cdot 9$ \\
\hline 519 & 764 & 15,475 & $59 \cdot 4$ & $\cdot 1$ & $3 \cdot 9$ & $28 \cdot 3$ & $3 \cdot 4$ & 4.9 & $59 \cdot 4$ & 54 \\
\hline
\end{tabular}




\section{LIQUID FUEL AND ITS COMBUSTION}

\section{Liquid Fuel for Naval Purposes.}

The use of erude oil as a combustible for marine purposes lias probably increased to a greater extent during the past two years than during the previous century. This has been due to several eauses. The character of the oil lately discovered throughout the world is particularly applieable for use as a fuel. The oil fields are likewise near tide water, and therefore it is possible to construct pipe lines to the sea and deliver the product on board the tank steamers at comparatively slight cost. There is also good rcason for believing that the wells are not likely to be soon exhausted and that an ample supply can be assured for an increased demand of the future.

It is evident that there is a very strong desire and purpose upon the part of many shipowners to substitute oil for coal. The thermal, mechanical, and conmercial advantages that would result from a change are so well known that it is unnecessary to recount them. Nearly every reason that can be advanced for using oil as a fuel in the mercantile marinc is also applieable to the Navy. In the case of warships, however, there are also military benefits to be secured that are as important as the commercial and mechanical advantages.

Any fuel installation which will obviate the snoke nuisance, reduce the complement in the fire room, extend the steaming radius of the war vessels, and permit maximum speed to be obtained at shorter notice, inereases the efficiency and value of the fighting ship.

The numerous experiments that have been made by several naval powers during the past forty years in the attempt to use oil as a fuel show how important this question is regarded by military experts. It is now plain why success was not attained. There was too much effort exerted to burn oil in the same manner as coal. It is now realized that the oil should be atomized (it is impossible completely to gasefy it) before ignition, and that the length of the furnace, the volume of the combustion chamber, and the calorimetric area are factors which must be considered. In fact, it is highly probable that it may be found advisable to design a special boiler for burning oil.

As more time, talent, and money are now being devoted to the solution of the problem, the hope of securing success has been greatly strengthened. Many unreliable statements have been published as to the success secured, but careful investigation shows that they were inspired by interested parties. It can be well understood that it is exceedingly difficult to secure reliable data at the present time. The several shipowners, manufacturers, and inventors are not inclined to tell of their disappointments, reverses, or failures. Those who have attained success as a result of experiment and experience do not feel called upon to give the world information that has been obtained at considerable cost and trouble.

In view, therefore, of the trifling amount of reliable data extant, the Bureau has projected an extended series of tests to determine the value of liquid fuel for naval purposes. These experiments commenced a few months ago. Taking into consideration the inevitable delay that must result from the installation of various burners, and recognizing the fact that competitors expect and should be permitted to make preliminary trials, it can be stated that the experiments have been conducted with considerable rapidity. It takes about one week to instal a new burner, make preliminary tests, and conduct two official trials.

It is expected that each competitor will carefully study the detailed drawings furnished him of the experimental plant, and therefore be prepared to fit his appliance-and be ready for a preliminary trial in two days from the time the plant is placed at his disposal.

The problem of using liquid fuel for naval purposes is quite distinct from the problem of its use in the mercantile marine, although the conditions on passenger and freight ships approximate very closely in some respects to service requirements. For ships of war the problem can therefore be solved only by the Department making its own tests and experiments. The performances, however, of the merchant ships having oil-fuel installations have been earefully observed. The owners of the steamers J. M. Guffey, Paraguay, City of Everett, and Mariposa, having permitted the Bureau to report upon the oil-fuel 308 


\section{APPENDIX}

installations of those vessels, a careful and extended investigation as to the character of each of their plants has been made.

The more this question is investigated the more intricate seems the problem of successfully installing an oil-fuel appliance on board a battle ship. It ought to be successfully used on the torpedo boats, as well as upon auxiliary naval vessels that steam between regular ports. For the army transport service it might prove very desirable, since a supply of oil could be maintained at the several calling ports. In regard to the installation on the large-powered battle ships and armoured cruisers, there are three distinct features which must be considered, viz : the mechanical, the commercial, and the structural. Regarded from two of these viewpoints, it seems as if it would be some time before "coaling ship " ceases to be an evolution upon the war vessel. While both the naval and mercantile vessels traverse the ocean, there is a wide difference in their construction as well as in the nature of the duty performed, and this must be taken into account in designing the motive plant.

In the investigation of the subject of using liquid fuel for naval purposes, it will be necessary to give due weight to the various features that will influence, if not determine the solution of the problem. The question, therefore, comprises the following divisions :-

First. The engineering or mechanical feature.

This relates to the efficient and economical burning of oil, and to the possibilities of increasing the consumption at short notice, so that maximum power can be readily and easily obtained. From the time the mechanical experts realized that the efficient, economical, and rapid burning of liquid fuel was greatly dependent upon the success secured in atomizing the oil, there was rapid development. It was only a few years ago when the oil was simply thrown into the furnace by means of an injector. When that method was used the evaporation was dependent to a great extent upon the amount of incandescent surface that could be secured to ignite the fuel. It has only been within the last three years that the exceeding importance of atomizing the oil has been recognized. ${ }^{1}$

It may therefore be affirmed that the efficiency of the burner is simply proportionate to its power to atomize the oil and then to burn these minute particles of oil into a mixture of combustible gas and fine particles of carbon, so that complete combustion, as well as ability to force the consumption of the oil, can be secured. There are many burners which can atomize the oil quite satisfactorily, and, as constant and progressive improvement is being made in this direction, the engineering and mechanical problem is nearing solution. The heating of the oil, as well as the heating of the air required for combustion, must be provided for, and extended experiments should be made to determine the simplest and the cheapest methods of attaining these objects.

The necessity for heating the air requisite for combustion should be impressed upon all contemplating the use of liquid fuel as a combustible. It would be best to force the passage of this air over heated surfaces either by forced or induced draft, but as this might involve considerable expenditure for installation, it is possible that simpler means might be effectual. The Bureau hopes before these experiments are concluded to make a special series of tests showing the evaporative efficiency secured when admitting the air to the furnace at different degrees of temperature.

The mechanical method of introducing the oil was so inefficient in the past that even experts were not able to burn the amount of oil desired. It has always been possible to burn some oil and to seeure nearly the full thermal efficiency of the combustible. The great difficulty in the past was due to the fact that no one seemed to know how to burn enough oil and yet have it under control. There is therefore no record that, previous to two years ago, any boiler ever evaporated the amount of water with oil as a combustible that was secured under forced-draught conditions with coal as a fuel. Stated in another way, the boiler could not be forced with oil to the same extent as with coal. The experiments conducted by the liquid fuel board have shown that it is now possible to force the combustion of oil, and that the greatest evaporation per square foot of heating surface secured

1 This is not true of English practice, which has atomized for many ycars with the best results.-AUTHOR. 


\section{LIQUID FUEL AND ITS COMBUSTION}

with coal can be greatly exceeded by an oil-fuel installation of modern design where provision has been made for atomizing the combustible and heating the air and oil. Continued experiments should therefore be conducted under Government supervision.

Second. The commercial feature.

This relates to the question of cost and supply. It may be regarded as a certainty that, except where unusual conditions prevail, the eost of oil for marine purposes will generally be greater than that of coal. The cost is even now less for vessels departing from the Gulf and California sea ports, but the rule will hold elsewhere. While the question of eost should be of secondary importance in military matters, it must be taken into eonsideration in industrial matters. It is the expense of transportation that now prevents the oil from being a cheap eombustible for marine purposes, but this disadvantage ought to be soon removerl. While it may be put on the tank steamer very eheaply at ports like Point Sabine, its commereial value will be determined by the cost of delivery at commereial and maritime centres. This feature of the problem is beyond the ability of the Navy to control, but it must be regarded as an important phase of the subjeet.

In considering the matter of cost, the fact should be remembered, however, that but compraratively few tank steamers are earrying oil between Point Sabine and the North Atlantic seaports. The expense of fitting up these vessels has been very heavy, due to the fact that unexpeeted diffieulties developed in the cost of making the installations. This has compelled the owners of the oil steamers to charge comparatively high prices for transportation of the fuel. It ean certainly be expected that when a large fleet of vessels are used for earrying oil and when terminal storage facilities are provided, there will be a material deerease in the price of oil in the leading cities on the coast. This is a very important commercial phase of the question, and should be carefully considered in determining the probable relative value of the two combustibles in the early future.

It is undoubtedly a fact that the transportation eharges per mile for oil at the present time are excessive compared with the freightage for coal, and this incongruity of expense aceount against oil cannot continue much longer.

As regards the question of supply, it may be more expensive if not difficult to transport and to store oil than coal. The fumes of all petroleum compounds have great searehing qualities, and therefore extreme precaution will have to be taken to guard the storage tanks. If it be true that for military purposes it is best in time of war to keep all reserve fuel afloat, then liquid fuel is at a disadvantage in this respect. The mining and railroad companies have invested so heavily in the coal industry, and the transportation facilities have been so perfected, that it is now possible quickly to deliver a eargo of coal at any point in the world. There has been, likewise, a development in the method of loading and unloading cargoes of coal. Since it will require progressive development to perfect the transportation and the storage of oil, and as the world's supply is still an unknown quantity, it will be some time before there may be a reserve supply of oil at the principal seaports.

It must also be remembered, when considering the problem of supply, that the naval vessel must be kept in readiness for orders to proceed at any time to any port within her steaming radius. The merehant vessel steams between regular seaports, where it would not be difficult to induce merchants to keep a supply of oil as soon as there is a regular and eonstant demand for it. The question of supply for battle ships and cruisers may therefore not only be a commercial affair, but prove to be a military problem, since the oil requirements of naval vessel for service conditions might only be met by the Government establishing oil-fuel stations. The military aspeet of the question may prove to be a serious problem, sinee it not only necessitates heavy expenditures, but it may involve the greater question as to the wisdom of maintaining a complete chain of fuel stations between country and colony.

Third. While the engineer may be most interested in the mechanical features and the shipowners in the commercial aspect, the eonstruetor will meet with diffieulties in solving the structural problem relating to the installation of oil fuel on board ship. 


\section{APPENDIX}

The struetural feature of the battle ship may prove a serious detriment to the installation of an oil-fuel applianee. The problem of storing oil on board war ships which possess proteetive decks is mueh more complex than the problem of its storage in vessels of the merchant marine. Everything on board the battleship is subordinated to making the vessel a gun platform. There are many more compartments in the war vessel than in the merehant ship.

In all probability the great bulk of the oil in the war ship would have to be kept in the double bottoms. As the petroleum vapours are quite heavy, it may be a diffieult matter to free these compartments of explosive gases, especially when the eompartments are partly empty. By reason of the great number of eleetrical applianees in use on board the war ship, thousands of sparks are likely to be caused, any one of which might eause an explosion and set the oil fuel on fire. Our limited experienee with submarine boats may give us an object lesson as to the liability of hydrocarbon gases to explode.

In the merchant service the oil is often stored in expansion tanks or trunks whieh rise to the height of the deck, and on some of the vessels there is a cofferdam around these tanks so that any leakage of oil can be quickly discovered. It is also a comparatively easy matter to free such tanks of any dangerous gases that may accumulate. Inspection of the tanks at all times ean also be readily aecomplished.

In view, therefore, of the more diffieult conditions under which the oil will have to be carried in the naval service, the struetural features are eertain to have an important bearing upon the question as to whether or not an oil installation is possible in large ships of war.

The Bureau is not inclined to be pessimistie in regard to the suecessful solution of the problem. It believes that it is expedient frankly to state the difficulties that are likely to be encountered, so that every means can be considered for overeoming them.

The Bureau has no hesitation, however, in declaring that in view of the results already secured by the liquid-fuel board, an installation should be effected without delay on at least a third of the torpedo boats and destroyers. The junior officers of the service are very much interested in the matter, and if several boats are equipped entirely with oil-fuel appliances, a spirited and keen but friendly rivalry will be ereated which will result in a material inerease in the efficieney of the torpedo-boat flotilla. Such an installation would also permit a competition to be established between the boats using eoal and those using oil, and this would be another incentive to eause systematic and eareful study of the subject upon the part of all conneeted with the torpedo fleet.

The data which have been secured by the liquid-fuel board will be exceedingly appreciated in maritime and industrial circles. A eareful analysis of these data will show how complete they are and how earefully they have been collected. Although the experiments have only been in progress for a short time, practically every engineering principle that enters into the oil-fuel question has been touehed upon by the board. The tests have been of sueh a diversified nature, and so many deductions can be made, that other experimenters will now be enabled to ascertain in what direction research should be carried on to secure further definite information.

The completeness and character of the experimental plant has probably never been surpassed, and it is due to this faet that the data collected will eommand attention in the engineering world.

While the information secured may not hasten the introduetion of oil as a fuel in armoured eruisers and battle ships, it will materially inerease oil-fuel installation in ships of the merchant marine and in shore establishments.

It is the engineering or mechanical feature which is of eommanding importance in the industrial or mereantile marine world. The structural disadvantages which are so serious as regards naval development will only be encountered in a less degree in ships of the mercantile marine.

The structural disadvantages that may prove so serious in the Navy will not be 


\section{LIQUID FUEL AND ITS COMBUSTION}

encountered in the installation of liquid fuel appliances in shore establishments. The insuring of a reserve supply of the fuel ought also to be a less serious problem for industrial plants. It should therefore be understood that the naval problem is distinct unto itself, and that while the experiments so far conducted show that an installation on a battle ship is a scrious question, the tests also prove that for manufacturing purposes crude petroleun is in many respects an incomparable fuel.

The data collected during the official oil tests should be compared with the results secured under the same boiler when coal was used. The evaporation efficiency, as well as the ability to force the boiler with two kinds of fuel, can thus be compared and the engineering advance that has been made of late can best be appreciated. It will be mainly by reason of the fact that this comparative data is obtainable that important conclusions can be drawn from the information already secured.

The Bureau submits a copy of the report of Lieut. Ward P. Winchell as to the performance of the steamer Mariposa when using oil exclusively under her boilers in making the round trip between San Trancisco and Tahiti. .

The Bureau also submits a copy of the preliminary report of the liquid-fuel board. (Appendix No. 3). 


\section{Appendix No. 2}

The Voyage of s.s. "Mariposa," using an oil-fuel Installation exclusively under her Boilers.

The following is a description of the steamer Mariposa, of the Oceanic Steamship Company, as fitted for oil-fuel burning, with an account of the preliminary trial trips of the vessel as witnesssed by Commander H. N. Stevenson, United States Navy ; also the report of Lieut. Ward P. Winchell, U.S. Navy, who officially represented the Department on the round trip of the steamer between San Francisco and Tahiti.

The Mariposa is a single-screw iron steamer, built at the yard of William Cramp \& Sons, Philadelphia, Pa., in 1883. She has just had new engines and boilers installed by the Risdon Iron Works, San Francisco, Cal. The oil-burning plant has just been installed by the same company.

This vessel has been employed in the Pacific trade, and is now running to Tahiti from San Francisco, making the round-trip voyaga of 7,320 knots each month.

\section{Description of the "Mariposa."}

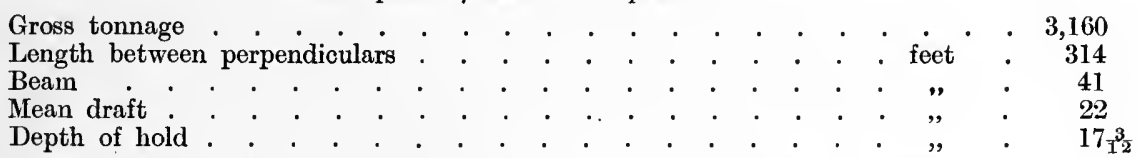

There is a single bottom with four watertight athwartship bulkheads, and two masts, square rigged on the foremast.

The total crew was formerly 81 , but since the change from coal to oil, 16 men have been taken out of the engineer's force, reducing the crew to 65 men and making the engineer's force for oil burning 20 men, as follows : 1 chief engineer, 3 assistant engineers, 3 oilers, 1 electrician, 1 attendant for ice machine, 1 attendant for air compressor, 3 water tenders, 6 firemen, 1 storekeeper ; total; 20.

\section{THE ENGINES AND BOILERS.}

There is one triple-expansion engine of the inverted direct-acting type, with cylinders 29 inches, 47 inches, and 78 inches by 51 -inch stroke, designed for 2,500 indicated horsepower, fitted with piston valves on the high pressure and intermediate pressure, and slide valves on the low-pressure cylinders, all driven by link motion. The condenser is part of the back framing. The cylinders are not jacketed.

The air, feed, and bilge pumps, of which there are two sets, are driven from the forward and after crossheads. The centrifugal circulating pump is driven by a separate engine. The 4-bladed propeller is. 16 feet 6 inches diameter and has a pitch of 23 feet.

There are three cylindrical tank boilers placed fore and aft in the line of the ship- 


\section{LIQUID FUEL AND ITS COMBUSTION}

two are double ended 15 feet 3 inches diameter by 17 fect 3 inches long,and one single ended, 14 feet diameter by 9 fcet 9 inches long, the latter placed amidships forward of and worked from the forward firc room. Each double-ended boiler has six corrugated furnaces; the double-ended boilers have a common combustion chamber for opposite furnaees. while the single-ended one has a eommon combustion ehamber for its three furnaces. There is one smokestack for all the boilers. The combustion chambers of the double-ended boilers have a brick bridge wall, and the back sheet of the single-ended one is covered with firebrick. The decision to use oil in place of coal was not made until the changes in engines and boilers were well under way, and it was decided to put the ship on the route to Tahiti. The steam pressure is $\mathbf{1 8 0}$ pounds. There is one auxiliary boiler, two-furnace return-tube type, in upper fire-room hatch, and fitted to burn coal only.

\section{TIIE OIL TANKS.}

These were constructed out of the old coal-bunker space forward of the boilers, and as the steamer is intended to carry oil for the round trip of about 7,320 miles some additional space had to be taken from the fore hold. They are arranged as follows: Just forward of the boiler space a solid water-tight bulkhead, well braced, was built from the berth deck to the single bottom of the ship, extending to the single skin of the ship, from side to side ; 4 feet, or two frame spaces, forward of this was also built another similar solid bulkhead, which formed the after ends of the oil tanks ; 48 feet farther forward another similar solid bulkhead was built to form the forward ends of the oil tanks, and 4 feet forward of this another solid bulkhead. The spaces of 4 feet at each end of the tanks being a cofferdam space to catch any oil from leakage or accident, these cofferdam spaces can be filled with water if necessary. The tank space is divided into six tanks by a middle bulkhead and two side partitions. Splash plates to break the impact of rolling are placed in each tank, a small opening at the top allowing any accumulation of gas to pass off to ventilating trunk. Small openings at the bottom allow free communication for the oil. Along the top of the tanks is provided an expansion head or trunk, being $4 \frac{1}{2}$ feet high and $4 \frac{1}{2}$ feet wide. Over each a ventilating trunk connecting with the top of cach tank extends up to about 5 feet above the hurricane deck. The cofferdam spaces are ventilated by tubes reaching to the upper deck, fitted with cowls, one tube reaching to near the bottom to carry off any heavy gas that might accumulate there. From the upper deck the sounding pipes to each tank are reached. There are no pipes in or through the tanks except those connected with the oil service. 'The total capacity of the tanks, exclusive of expansion trunk, is 6,338 barrels of oil-about 905.43 tons. One barrel of oil equals 42 gallons of 231 cubic inches or 35 Imperial gallons.

To fill the tanks, on the port side outside the ship a 6 -inch hose connexion is fitted ; from this a pipe leads to the forward fire room where the tank oil pump is placed. This pump, horizontal duplex, steam eylinders, 9 inches, oil cylinders $8 \frac{1}{2}$ inches, stroke 10 inches, can be used to draw its supply from the pipe and deliver into each of the tanks, or by using by-passes, which are provided, the oil barge alongside can fill all the tanks; an overflow pipe from each tank, carried at height of the deck above them, leads to an overflow outside the ship near the supply-hose coupling.

There are two service or settling tanks placed in pockets formed on either side of the single-ended boiler. They are reached by doors from the forward fire room; each of these tanks holds about twelve hours' supply. They are filled by the oil-tank pump and have overflows back to the main tanks, ventilating tubes lead from near the bottom of the pockets in which they are placed to the smoke stack.

Each service tank is provided with glass gauges, by means of which the amount used every hour or watch can be easily measured.

Each settling tank has two suction pipes, one at bottom to draw off water if necessary, the other at a height of about two feet for the oil supply to the service pumps. All the Tanks are provided with manholes to reach the interior. 


\section{APPENDIX}

THE OIL-SERVICE PUMPS.

The oil-service pumps, of which there are two, horizontal duplex, steam eylinders 6 inches, oil cylinders 4 inches, and stroke of 6 inches, one being large enough to supply all the burners, are placed in the forward fire room on either side. They draw their supply from the settling or receiving tank through removable strainers so placed that they can be easily changed for cleaning, and discharge into the bottom of the small heating tank near them where the oil is heated by a steam coil to not more than $150^{\circ} \mathrm{F}$., and thence by a pipe to the burners. The air from the compressors, under a pressure limited to 40 pounds, discharges into the top of the heater tank on its way to the burners, so that the oil and the air go to the burners under the same pressure. The heater tank is provided with glass gauges, also a float to work a telltale and automatic control of oil-supply pump.

\section{THE AIR COMPRESSOR.}

The air compressor is placed in a pocket off the upper engine-room platform, and consists of duplicate steam and air cylinders connected to a crank shaft carrying a fly wheel turning between the cylinders. Either set is large enough to supply all the air necessary. The air compressor is horizontal, double acting, duplex. Air cylinders 22 inches, steam cylinders 12 inches, diameter, by 18-inch stroke for all cylinders. Capacity equals 1,000 cubic feet of free air per minute compressed up to 30 pounds at 120 revolutions per minute. Air is used at the heat of compression, or as heated by the air heater.

\section{THE ATOMIZER.}

The atomizer, shown in fig. 5, consists of a hollow plunger for the oil, screwed into a pipe through which the air passes. The outlet for the oil is through a series of small

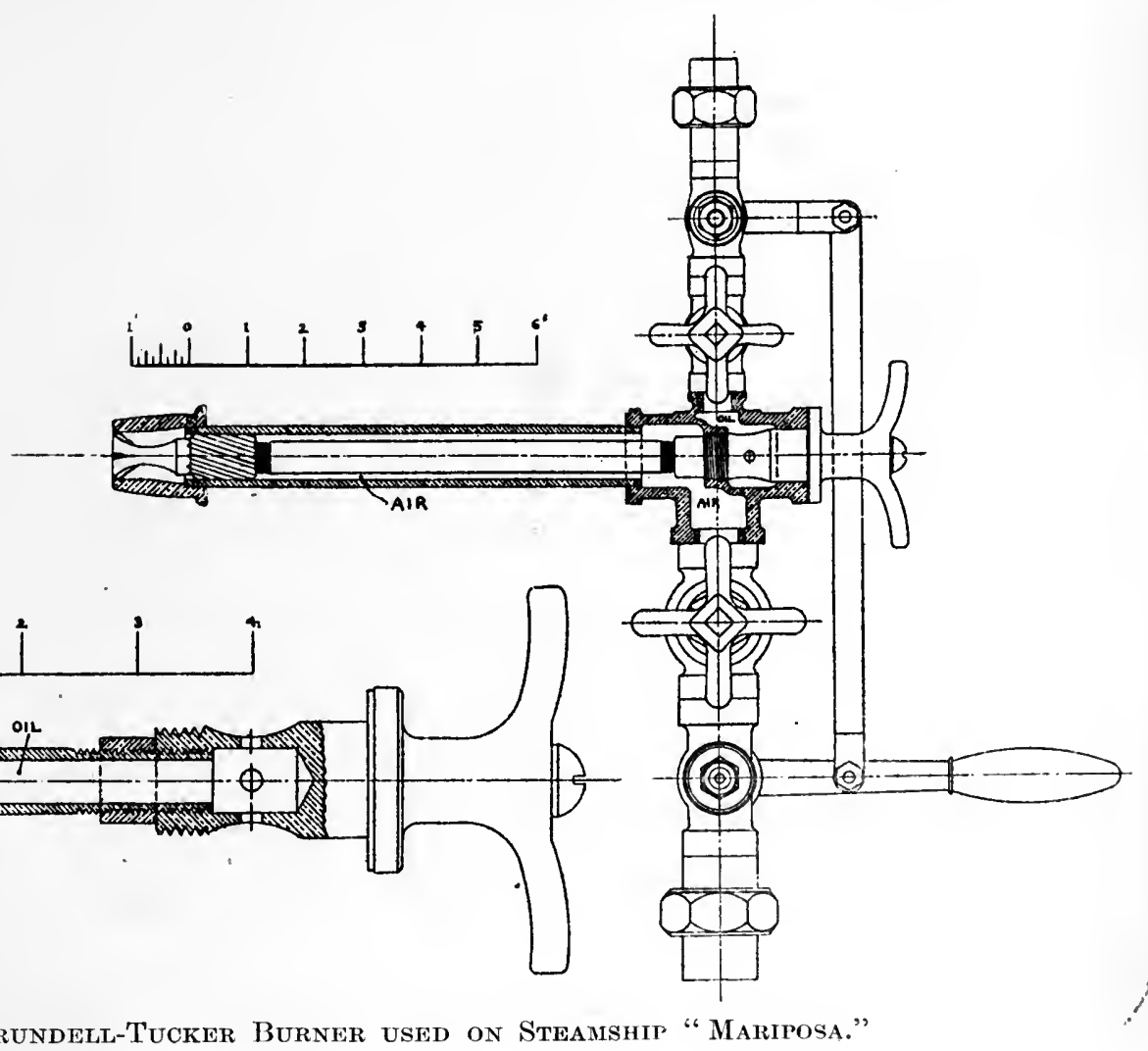

Fig. 5.-The Grundell-Tucker Burner used on Steamship "Mariposa." 


\section{LIQUID FUEL AND ITS COMBUSTION}

holes at right angles to the central hole, the air meets the oil through spiral directors and is sprayed into a rose shape by the expanded end of the atomizer.

The air and oil pipes have globe valves to regulate the supply of either, also plug cocks connected together to a handle by means of which each burner can be shut off immediatcly, in ease of necessity, a slow-down bell, or other eause. The air-supply pipe is also connected to the steam line so that steam can be quickly substituted for air, if desired. The length of the oil plunger is adjustable, to give the best form to the roseshaped flame. Two burners are fitted to each furnace.

\section{THE AIR HEATER.}

A part of each furnace front is a hollow iron easting through which the air passes on its way to the atomizers and becomes heated. The chamber surrounding the burner is lined with a crucible lead (sic) lining, a by-pass to the burners is provided for use in case of accident to the heater. The lower part of the furnace front is a door on hinges that can be fastened open at any desired degree to give air for combustion. There are also two louvres in the door for the same purpose. Near the front of the furnace inside the door is placed a brick wall made to deflect upwards the inward current of air to meet the rose-shaped flame from the burners. There is ample space over the brick wall for a man to enter the furnace through the ash-pit door. The double furnace combustion ehambers have a brick bridge wall reaching above the top of the furnaces, and in the singleended boiler the eommon combustion chamber has the back sheet covered with fire brick to protect it.

\section{THE TRIAL TRIPS.}

Two trial trips with the vessel under way were made on July 5 and 11 , the vessel being under way about eight hours each day, running from the vessel's dock to the Farallone Islands and return, and were made for the purpose of ascertaining if the oil apparatus, the new engines and boilers, were in good working condition. On the first run the boilers primed badly, owing to the construction dirt not having been thoroughly eleaned out. Before the second run they were eleaned and worked well on this run.

It was impossible to obtain any data other than observation of the working of the oil apparatus.

Very few of the fire-room force had any experience with oil burners on steamers, and one object was to give the force practical experience. When properly regulated the burners gave no smoke, but that they were not properly regulated is shown by the fact that more or less smoke was visible most of the time, and at times dense black. Owing to lack of the telltale and regulating device of the small heating tank the pump tender once allowed this tank to fill up and the oil to flow over into the air pipe and flood the burners. As soon as this was discovered every burner was immediately shut off by means of the lever connecting to the plug eocks on the oil and air supply pipes at the burners.

The atomizer tubes were unserewed, and on some of them, where the oil had eaked, considerable force had to be applied to pull them out. New, clean atomizers were screwed in, and as soon as the oil-heater tank could be brought to the proper oil level the burners were started again. Some steam pressure was lost during this delay, but the engines did not stop nor slow down very much; some of the burners were started in a few minutes and all of them in not over fifteen minutes. The value of being able to shut off the oil and air quiekly and elean or substitute other atomizers was shown by this mishap. The burners made considerable roaring noise, and the air pressure was, in order to clean the burners from dirt, earried at about twice the intended pressure, owing to the lack of the strainers, which allowed dirty oil to ehoke them, and they had to be taken out frequently for eleaning. By shutting off with the lever the regulating valves were left in adjustment for starting the fire again provided it was right before. The new fire is started by a toreh inserted into the plug hole around the burner. 


\section{APPENDIX}

On the second run the strainers and regulating deviee for the heater tank had been completed. The oil apparatus was handled with greater ease and uniformity, and less smoke was noticeable. For intervals of an hour or more scareely any or none would be observed. On the run in from the Farallones the engine was speeded up to 74 to 77 turns, and an average speed of $14 \frac{1}{4}$ knots was obtained. The steam pressure was uniformly maintained at the point desired without difficulty, and the oil-burning apparatus gave no trouble whatever and worked well.

The oil used on both runs was from the Kern River distriet, near Bakersfield, Cal.

The following data were observed :-

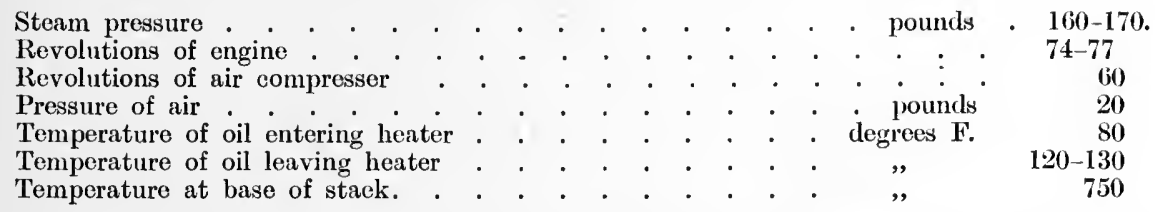

It is to be regretted that the nature of the trials did not permit of obtaining a greater amount of data beyond observing the apparatus in use.

The chemist at the New York yard submitted the following report upon the sample of the Kern River district oil sent him for analysis-

The sample is practically free from low boiling naphtha, as on distillation only a small percentage passed over below $150^{\circ} \mathrm{C}$, and less than 10 per eent. below $225^{\circ} \mathrm{C}$. A boiling point above $360^{\circ} \mathrm{C}$. was reached before the seeond 10 per cent. was collected.

It shows on ultimate analysis the following eomposition-

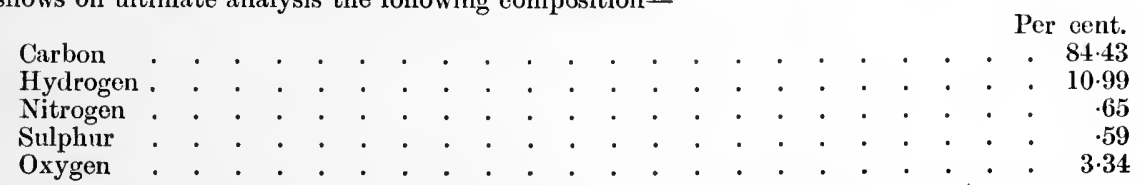

This gives a ealorifie value, by Dulong's formula, of $18,806 \mathrm{~B}$.Th.U. The specific gravity at $60^{\circ} \mathrm{F}$. is 0.962 . Flash point, $228^{\circ} \mathrm{F}$. Fire point, $258^{\circ} \mathrm{F}$. Vaporization point, $178^{\circ} \mathrm{F}$. Loss for six hours at $212^{\circ} \mathrm{F}$. 12.01 per eent.

\section{Report of Lieut. Ward Winchell on the Voyage of the "Mariposa."}

$$
\text { August 15, } 1902 .
$$

I took passage on the Oceanic Steamship Company's steamer Mariposa, leaving San Francisco at. 10 a.m. on July 15, 1902, for the round trip to Tahiti.

In aecordance with the instructions of the Bureau, I took two sets of indicator eards each day, making forty-five sets in all, the data of which were worked up.

There have been no tests to determine the evaporative efficiency of the two main double-ended boilers used on the run, and the chief engineer was unable to improvise apparatus by which the feed water could be determined with accuracy.

The amount of oil is of much importance; the tanks hold barely enough to make the round trip, and but one day's supply of coal is aboard. The oil was measured first by the amount pumped into the two settling tanks, as shown in inches on the scale back of the gauge glasses on the tanks; secondly, this amount was checked by the number of inches used out of eaeh tank for each wateh ; thirdly, and most accurate as dealing with large quantities and small errors, by sounding the tanks from time to time and comparing the amounts taken out with the expenditures in the log. The latter method gave a correction which was applied to the daily $\log$, inereasing the daily expenditure slightly, as summed up by inches in the settling tank.

The most careful inspection at Tahiti failed to show any bad effect of the flame upon the boilers. No leaks nor defeets developed anywhere about them, and there was no diffieulty at any time in feeding them. As I was ordered to the Boston immediately on my arrival at San Franciseo, I lost the opportunity of again inspecting the boilers, but 


\section{LIQUID FUEL AND ITS COMBUSTION}

no defeets showed from the outside. At Tahiti the tubes were swept by tube scrapers, and back connexions, uptakes, ash pans, and furnaces were cleaned. All the ref use from these various places barcly filled two ash buckets.

This refuse, mainly soot, was the result not only of the twelve days' run to Tahiti, but also of the three preliminary trials by the contractors. The first one, a four-hour trial of engines and boilers, was made with Comax coal, and the other two were free runs at sea, of about eight hours' duration each, burning oil. The tubes had never been cleaned previous to arrival at Tahiti. It is the intention hereafter to make the round trip of twenty-four days' steaming without swceping tubes.

There are no precautions other than those usually taken on board ship to guard against fire or explosion. All spaces to which oil has access are well ventilated by both inlet and outlet ducts. The oil is a thick, dark fluid, like molasses, and in the open air burns slowly, giving off much smoke. It gives off volatile gases which form explosive mixtures with air, tanks empty or nearly so being more dangerous than full ones in this respect. The ship is electrically lighted, but in addition an open hand lamp is burning in the fire room all the time to light the burners; the firemen smoke on watch, and the oil is treated no more tenderly than if it were coal.

Of the six firemen, three were relieved from watch the second day out, leaving but one mian on a watch to fire twelve furnaces in two different fire rooms separated by the length of the double-ended boilers. The water tender did not touch the burners except in emergency, his duty being to tend water, fill settling tanks, and record height of oil in them, record temperatures of oil at settling tank and in heater of fire room and of superheated air, take reading of lower pyrometer where the two uptakes meet, and run oil pump supplying oil to the settling tanks and small oil pump supplying oil to the oil heater.

As a coal burner the Mariposa formerly had the following engineer force : one chief engineer, three assistant engineers, three oilers, twelve firemen, twelve coal passers, three water tenders, one messenger, one storekeeper; total, thirty-six.

A reduction of sixteen men in the fire-room force is effected by oil burning. At sea she needs now but three firemen, but carried six. This would reduce the force by ninetecn mon.

Temperatures of fire rooms seem to be about what one would expect in coal burning, but the temperatures of the uptake and smoke-pipe gases run high, the maximum being $925^{\circ} \mathrm{F}$., which shows an undue loss of heat here. The temperature of the oil in the settling tanks ranged between $68^{\circ}$ and $100^{\circ} \mathrm{F}$. on the trip out, and between $90^{\circ}$ and $108^{\circ} \mathrm{F}$. on the trip back.

The oil auxiliaries comprise one large oil pump, two small oil pumps, two oil heaters, one air compressor, and four strainers.

There is a steam-pipe connexion to blow out the oil strainers, and another one to blow out the oil burners when clogged.

On August 3 the air compressor needed overhauling, and steam atomizing was kept up for two and one-half hours until the compressor was again working. During this time the evaporator supplied enough feed water to use twenty burners; the engines were not stopped while shifting from steam to air atomizing, and averaged $67 \cdot 8$ turns for the two and one-half hours. They had before been making seventy turns. During the four days in port at Tahiti the forward main single end three-furnace boiler was used, atomizing with steam. Generally two burners in the middle furnace gave ample steam to run the following auxiliaries, all exhausting into the atmosphere, the boiler being fed with fresh water from the dock: Ice machine, dynamo, flushing pump, feed injector, two eargo winches, small portable steam pump, and steam for cooking, bath tubs, ete.

At first two firemen and a water tender were on wateh at a time, each fireman having one fire room of six furnaces or twelve burners. The men had but little experience, combustion was poor, much smoke was made, much oil burned, and poor speed attained. To locate the responsibility for bad adjustment of burner valves, but one fireman was 


\section{APPENDIX}

put on at a time to attend twelve furnaces (twenty-four burners). This made an im provement in the eombustion.

The top of the funnel cannot be seen from either fire room, and while the fireman can tell by the appearance of the flame as shown in the sight-hole, or even by the roar of the burner, when the combustion is perfect, in designing a boiler room for liquid fuel the ventilators should be so arranged that a view of the top of the smoke pipe can be had from each fire room.

The work of the fireman would be even easier than it is and better results attained if the oil and air pressure and the heated temperature of the oil were kenstant. The apparatus then, once properly adjusted, would need very little change. To get these results is a mere matter of detail easily arranged. If the temperature of the oil rises it feeds more freely, and a readjustment is necessary, and the same conditions hold with regard to the pressure.

In addition to the independent oil and air supply valves, the burners are fitted with an air plug cock and an oil plug cock eonnected to one lever, which then eontrols both air and oil supply, enabling the operator to shut them both off at once in emergency. At first when steam went up too high and a burner was shut down this lever was used; but shutting off the air thus gave the air eompressor less work, and as its governor is not sensitive the air pressure inereased, making a readjustment of all oil and air supply valves necessary, with consequent snoke. Later on, when it was desirable to shut down a burner, the oil alone was shut off by the independent feed valve on the burner, and the untouched. air valve kept the air compressor's work more nearly constant; then when the burner was again required, the oil valve was opened and immediately lighted from the flame of the adjacent burner.

In starting fires with everything eold, steam is raised on the auxiliary boiler, which burns eoal, and the air compressor, oil pumps, and oil heater are started. The oil is lighted by inserting oil-soaked rags in the air space surrounding the burner and touching a lamp to them, or an arrangement like a gas lighter may be used.

Sometimes when the air pressure is too high, or insufficient oil is feeding, the flame flickers and may go out. If the oil is kept feeding under these eonditions, on relighting there is a small explosion of the gases in the furnaee, with a momentary back draft through the peep-holes and ash pans.

When shut down July 19, for two and one-half hours, plugging condenser tubes, one burner at each end of each boiler (four burners in all), furnished steam to run all auxiliaries, including feed pump, bilge pump, air compressor, ice machine, dynamo, and flushing pump, all of whieh were exhausting into the atmosphere.

Generally two burners in the middle furnace gave ample steam to run the following auxiliaries, all exhausting into the atmosphere, with boiler fed from fresh water on the dock: Iee machine, dynamo, flushing pump, feed injector, two cargo winches, and smäll portable steam pump.

In the Grundell-Tucker burner (see fig. 5) the oil, heated by a steam coil under boiler pressure, throttled down, passes through the inside pipe and is thrown out radially through the series of small holes. The air, first heated by compression up to twenty pounds, is further heated to a temperature of about $350^{\circ} \mathrm{F}$. in the air chamber surrounding the burner, and called the air superheater. Air ean be used at the temperature at which it leaves the compressor, and was so used on the trip down until July 17, when the superheaters were connected up. This air under the pressure of about twenty pounds surrounds the oil pipe in the burner and passes axially along the pipe until near the end, where it is given a whirling motion through small helical passages arranged like the rifling of a gun. It crosses axially and whirling through the fine oil streams spurting radially from the end of the burner, breaking up the oil into fine spray, the drops of which can be seen before they ignite. A further air supply (cold) is admitted through the hinged door of the ash pan, and is direeted up across the path of the flame and heated also by a curved fire-brick wall built in the ash pan elose to the front. 


\section{LIQUID FUEL AND ITS COMBUSTION}

This ash-pan door is not moved mueh, but the regulation of the air supply is by the valve control of the air and oil in the burner. The flame should be a steady, full, white or yellowish white one, filling the furnace.

The principal difficulties encountered were in the regulation of the supply of oil to the heater's by the pump, and the consequent variation of the temperature of the heated oil and the freedom of flow through the burners. An automatic submerged float, arranged like a steam trap and fitted in the oil heater to control the throttle of the pump, failed to give good automatic results, and the supply of oil was regulated by hand. If the oil is heated with too much (above $150^{\circ} \mathrm{F}$.) some of the volatile gases are given off and mingle with the air pressing on top of the oil in the heater, thence passing with the air into the air superheaters, and burners, the result being that on one occasion a heater got red hot from this cause.

Another difficulty was due to the choking of the strainers by foreign matter and impurities in the oil, shutting off the supply of oil, and on one occasion, August 10, putting out all the fires. Just previous to the fires going out, and while the usual air supply was on, and an insufficient amount of oil being fed, a dense white smoke like steam arose from the funnel.

This strainer difficulty will be solved by fitting the strainers in pairs, so that a clean one ean always be switched in while the choked one is being cleaned.

Generally the revolutions of the engines did not vary much during the day, and in ealculating the horse-power for each day's average revolutions, when the eards for that day differed much, that set was selected whose revolutions were near the average for the day with the indicated horse-power, assumed to vary as the cube of the revolutions. If the two sets of eards for the day had the same number of revolutions their average indicated horse-power was used as a basis to compute the day's horse-power as before.

It will be noted that the log accompanying this report is kept from noon to noon. This was done as the patent log was inaccurate, and the speed of the ship was got from noon positions as given by sights.

It will be noted that speed was much higher on the return trip than on the outgoing, which is ascribed partly to the better combustion as the firemen got experience, partly to the overhauling of the bearings at Tahiti by the force on board, and mostly to the increased oil consumption allowed after the run down had proved that there was plenty of oil for the return trip, which was a matter of some doubt before, the ship being provided with coal for twenty-four hours to cover possible emergency.

Full power was not developed in the two boilers used, as schedule time was easily exceeded with from two to four burners shut off, though it would not appear, from the tabulated results, that the indicated horse-power would equal what can be got by a good system of forced draft. This burner, however, works well with the Howden system of forced draft, as seen on the tank steamer George Loomis.

It must be remembered that the tabulated ealeulations are all based on the indicated horse-power of the main engines only, as it was considered better to use only data actually obtained, and afterwards estimated data, such as indicated horse-power of auxiliaries, eould be supplied without vitiating the observed data and results. No eards eould be taken from any of the auxiliaries, but careful estimates give the following results-

\begin{tabular}{|c|c|c|c|c|c|c|c|c|c|c|c|}
\hline \multirow{2}{*}{\multicolumn{3}{|c|}{ Air compressor, at 60 revolutions per minute }} & & & & & & & & & I.H.P. \\
\hline & & & & & & & & & & & 110 \\
\hline $\begin{array}{l}\text { Auxntary teed pump } \\
\text { Dynamos }\end{array}$ & and two oll & pumps, one & in & & & & & $t$ use & & & \\
\hline $\begin{array}{l}\text { Dynamos } \\
\text { Iee machine }\end{array}$ & . & . & . & & . & . & . & . & & & 30 \\
\hline $\begin{array}{l}\text { Iee machine } \cdot \\
\text { Circulating pump }\end{array}$ & . & & & & - & . & $\cdot$ & . & & & 7 \\
\hline Circulating pump & $\cdot \cdot$ & . & & & • & . & . & & & & 5 \\
\hline Flushing pump & $\cdot \quad \cdot \quad \cdot \quad \cdot$ & $\cdot \therefore \cdot$ & & & 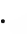 & . & . & . & & & 2 \\
\hline Baths, steam tables, & evaporator, & cooking, etc. & & & & - & - & . & & & 11 \\
\hline 'Total & . & . & . & . & & • & . & . & & & 195 \\
\hline
\end{tabular}

The steering engine is not used except near port. 


\section{APPENDIX}

The size of air eompressor was based on the assumption that it requires one cubie foot of free air for every pound of water evaporated from and at $212^{\circ} \mathrm{F}$., as shown by tests of various oil burners at Western Sugar Refinery, San Franciseo.

The weights of oil auxiliaries are as follows-

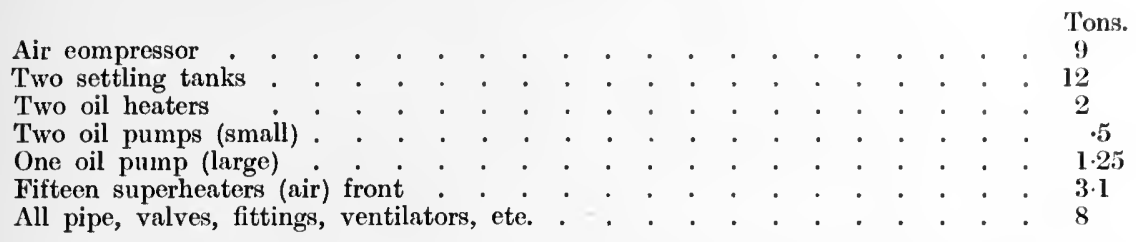

It should be remembered that the boilers were designed for coal burning; that the oil-burning plant was fitted in a hurry, the machinists not leaving the ship until the gong rang for people to go ashore; that the firemen were without experience in oil burning, and that most of the automatic gear did not work properly.

With the air pressure constant; with the oil heated at constant temperature near $140^{\circ} \mathrm{F}$.; with oil strainers arranged in pairs, so that one is always efficient, and with experienee in firing, the results in economy of oil should be much better on the next trip ; and the fireman's work, already very easy, will approach supervising automatic regulation. The fireman does not need strength nor previous training with coal. He should have a good eye, good ear, some common sense, and a desire to learn a new and easy trade.

(Signed) WARD Winchell, Lieutenant, United States Navy.

Chief of Bureau of Steam Engineering,

Navy Department, Washington, D.C. 


\section{LIQUID FUEL AND ITS COMBUSTION}

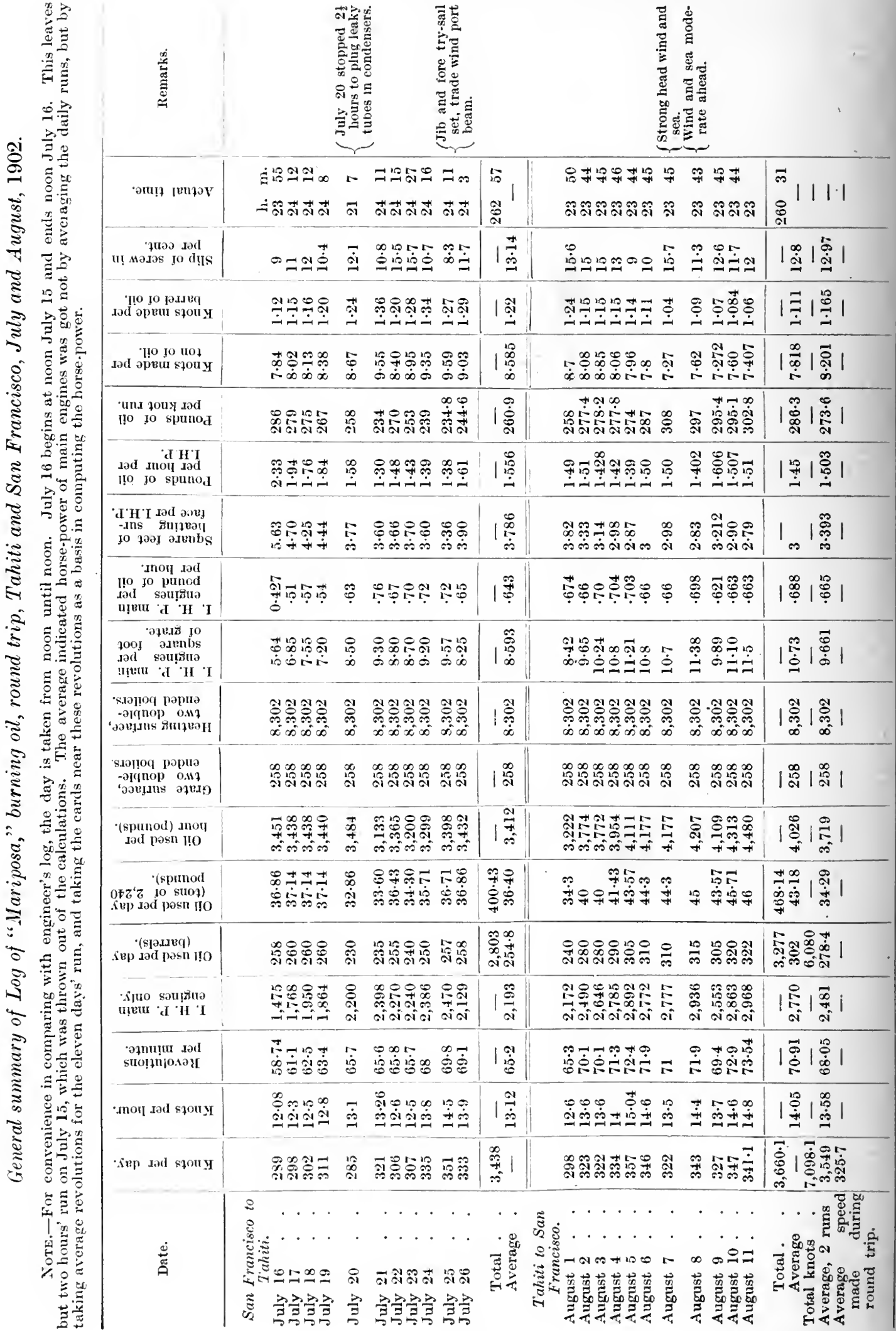




\section{APPENDIX}

Note.-The Bureau has also received the following summary of the second voyage of the steamship Mariposa on the round trip between San Franciseo and Taliti. These data show that the oil eonsumption on the second voyage was eonsiderably less than that on the first, due to two eauses: Improvements in detail of the oil-fuel installation, and increased skill and intelligence upon the part of the engine-room force.

The Oecidental Steamship Company is fitting an oil-fuel installation on the sister ship Alemeda, and it ean be expected that when a spirited rivalry is created between the crews of the Alameda and Mariposa, even better results ean be anticipated.

\section{O.S.S. "Mariposa," voyage No. 2, from San Francisco to Tahiti, 1902.}

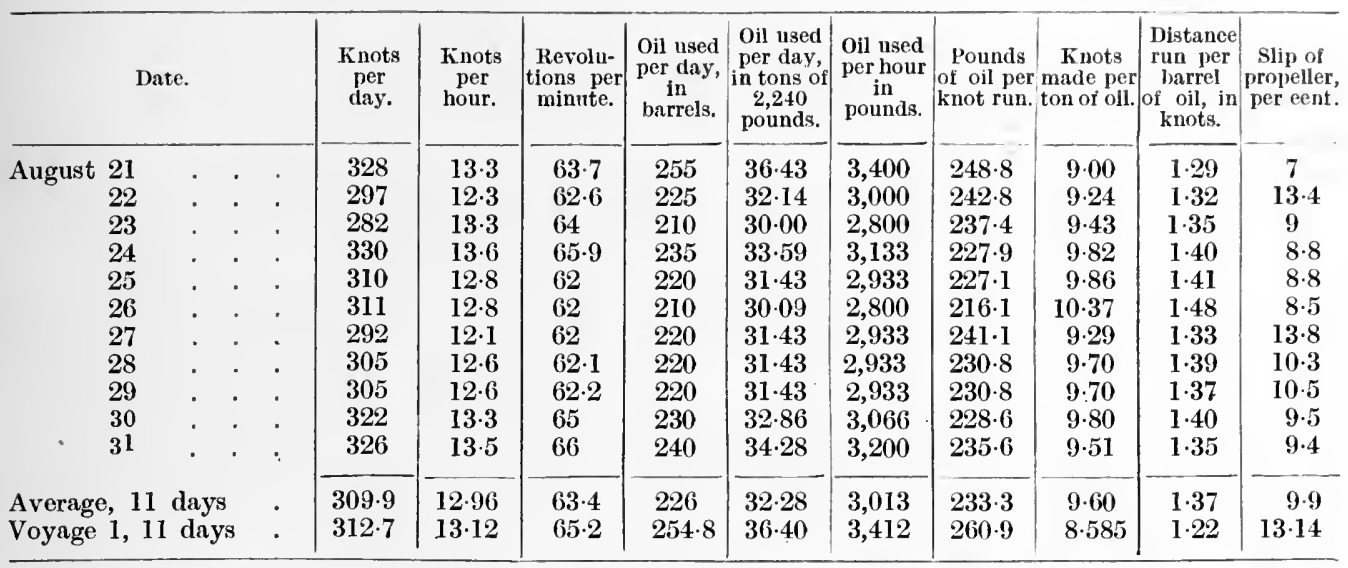

Average temperature of uptake, $548^{\circ}$; average temperature of superheaters, $360^{\circ}$; average temperature of eold oil, $91^{\circ}$.

O.S.S. "Mariposa," voyage No. 2, from Tahiti to San Francisco, 1902.

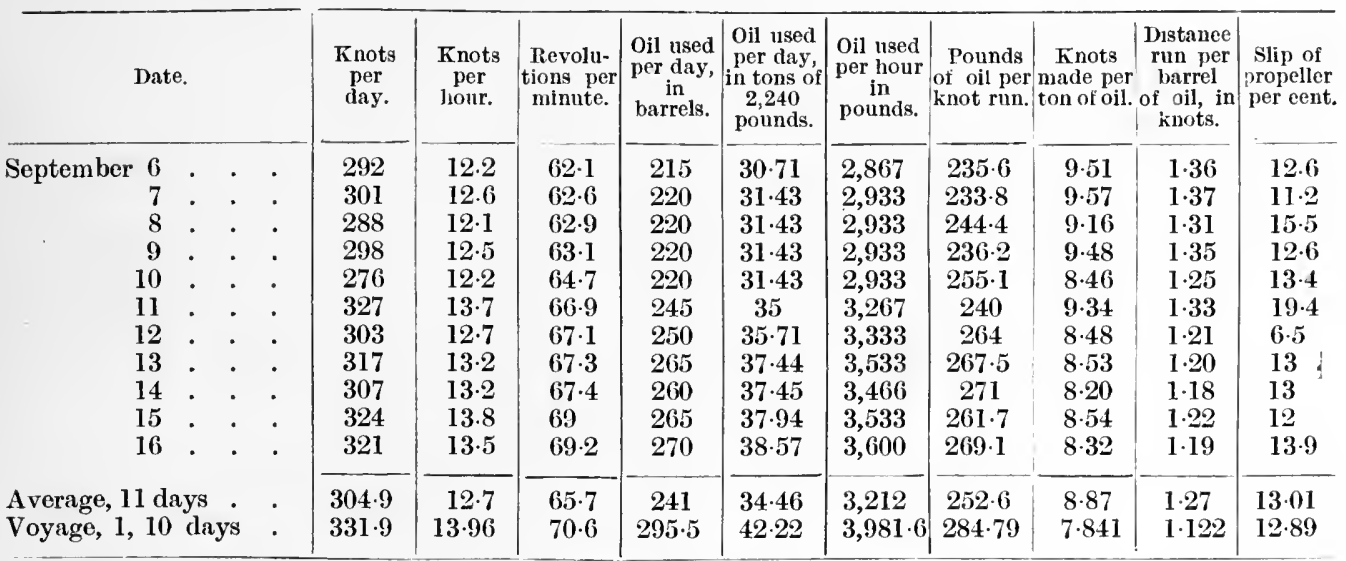

Average temperature of uptake, $546^{\circ}$; average temperature of superheaters, $360^{\circ}$; average temperature of cold oil, $90^{\circ}$. 


\title{
Appendix No. 3
}

\section{EXTRACT FROM REPORT OF BOARD ON TESTS OF LIQUID FUEL FOR NAVAL PURPOSES.}

\author{
Department of the Navy, \\ Bureau of Steam Engineering, \\ Washington, D.C., October 1, 1902.
}

SIR,-- The board appointed to conduct an extended series of tests to determine the value of liquid fuel for naval purposes submits the following preliminary report-

The board is of the opinion that the best interests of the Navy will be subserved by making public at this time the data and information collected during the fourteen official experiments that have been conducted.

Upon investigation the board finds that much of the data published is very reliable, particularly upon the most important features of the problem. As an illustration, it has been asserted that the boilers of some merchant vessels only consume, for sustained sea work, 1 pound of oil to develop 1 horse-power. When it comes to checking this information by the consumption from the storage tanks it will be found that a much larger quantity is used.

It is directly within the sphere of the Navy Department to conduct an extended series of experiments that will be of great value to the shipbuilding and manufacturing interests, even if the Navy does not receive an immediate return.

The naval problem is a quite complieated one, and an extended series of experiments to determine the value of liquid fuel for ships of war should be conducted for at least a year. The board reeognizes the fact that the commercial phase of the liquid-fuel question as regards the Navy is quite different from what it is in the merchant marine, and that it will be much more diffieult to ensure an adequate supply for ships of war than for merchant vessels. It will also tax the ability of the naval constructor to solve the construction problem involved in installing oil-fuel appliances on board the battle ship, sinee it will not be possible to find such satisfactory storage compartments in the fighting ship as in the freighter.

\section{Engineering Features of the Oil-Fuel Problem.}

It is the engineering or mechanical feature of the problem that the board is concentrating its energies upon. Therefore the board proposes to try to solve some of the following problems in eonnexion with the subject-..

1. The relative advantages of air and steam as an atomizing agent for liquid fuel. The question of supply of fresh water is very important in the Navy, and therefore the use of steam should be obviated, if possible. On the other hand, the air compressors are quite heavy and take up considerable room. As air compressors, however, are used for many purposes on board ship, it might be possible to have a central plant for all purposes. It is also important to know to what extent it will be necessary to superheat the steam in ease it is used as the atomizing agent. 


\section{APPENDIX}

2. There is a wide divergence of opinion as to the pressures at which oil, steam, and air should be delivered to the burners. Progressive tests may afford valuable information upon this point.

3. The design of the steam generator. As the experimental boiler now in use by the liquid-fuel board is of the water-tube type, it will be possible to extend the length of the furnace and make other changes which will give important information as to whether or not it would be advisable to design a special form of marine boiler for oil-fuel installation.

4. The simplest and most economical means of heating the air and the oil. In view of the result of the present experiments and of the information obtained from outside sources, there is no doubt but that the air should be heated; and it would seem that, particularly in a water-tube boiler, such heating could be effected in a simple and cheap nianner by utilizing the heat radiated to the ash-pit.

5. The value or necessity of an air receiver when compressed air is used as the atomizing medium. Can the pulsations of the compressor be reduced or minimized by installing such an intermediate receiver between the compressor and the burner?

6. Experiments could be made concerning the baffling of the gases, for the tests already conducted show that the calorimeter area can be somewhat reduced when using oil.

7. The relative value of leading types of burners. Particularly is it necessary to know whether a simple burner should be installed and provision made for heating the air, or whether an appliance should be installed which partially gasefies the oil before ignition. There are on file in this Bureau over 2,000 drawings and specifications pertaining to the use of liquid fuel,and it is said that new patents are being issued at the rate of about 30 a week. In view of such widespread interest in the subject, the board deems it important to test representative types of the various classes of burners.

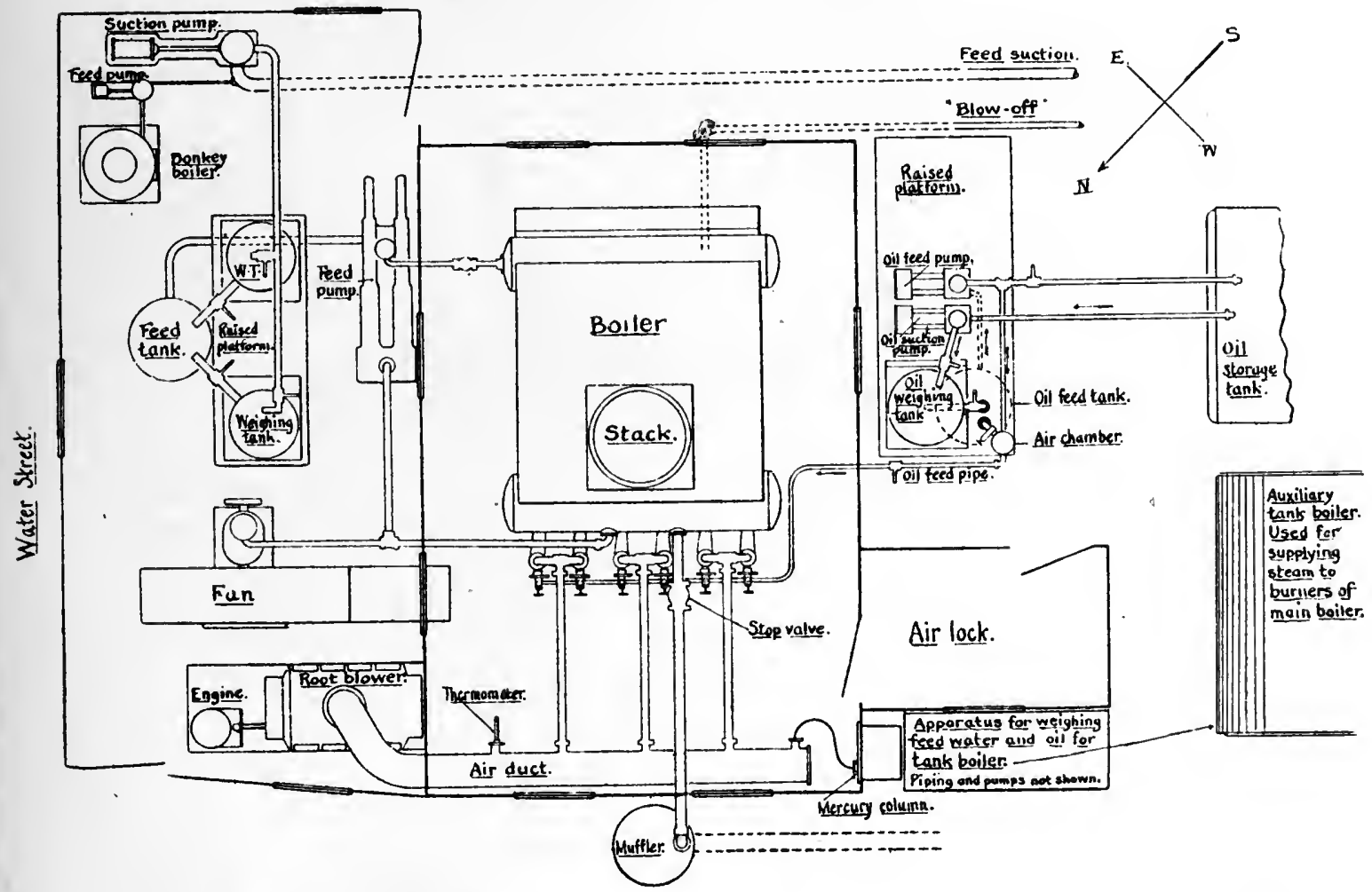

Fig. 6.-Arrangement of Hohenstein Experimental Boiler Plant for Liquid Fuel Tests. 


\section{LIQUID FUEL AND ITS COMBUSTION}

8. The problem as to whether the oil could be consumed under all conditions without producing smoke. In the naval service this is an important question. As there is also a tendency to compel manufacturers to take means to prevent smoke issuing from the stacks of their plants, the question also coneerns the general public.

\section{Opportunities Possessed by the Board for securing Trustworthy Data.}

The board considers it but just to acknowledge that through the generosity of the Oil City Boiler Works the Bureau of Steam Engineering has had placed at its disposal

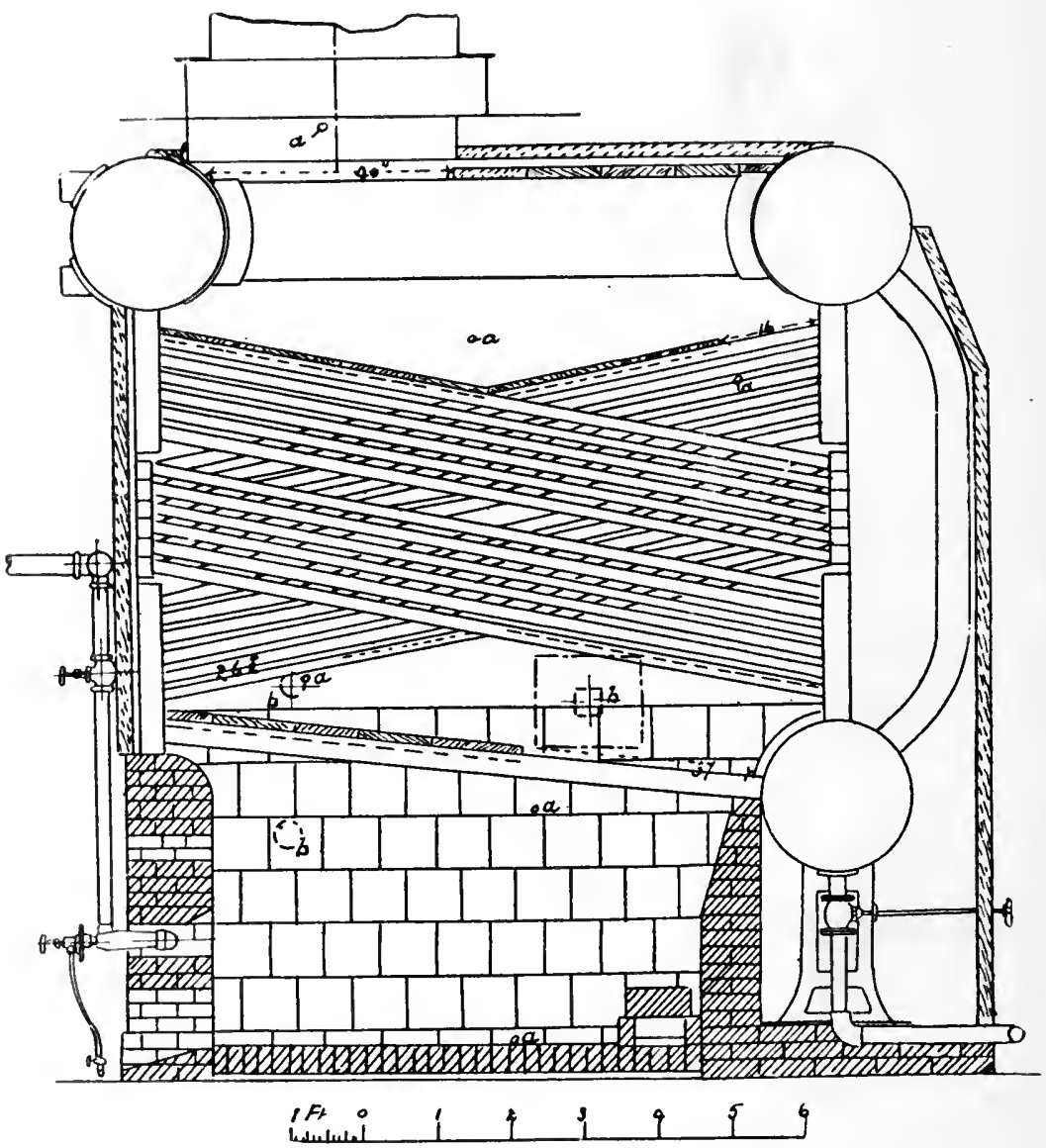

Fig. 8.-Arrangenent of Hohenstein Experimental Boller for Liquid Fuel Tests. $a$, Draught Gauge Connection ; $b$, Mica Windows.

without cost for rental a thoroughly equipped experimental plant. The experimental boiler is of the Hohenstein design, and it is the same boiler that was used by the Navy Department in conducting the extended series of tests that were made with coal at various rates of combustion. The value of the data collected during the liquid-fuel experiments can only be appreciated in its fullness by comparing the various tables with those secured during similar tests when coal was used as a combustible.

\section{General Description of the Plant.}

Fig. 6 is a ground plan of the plant. Fig. 8 shows a longitudinal section of the boiler with the oil burners in place. Fig. 9 shows the construction of an air burner of the Oil City 


\section{APPENDIX}
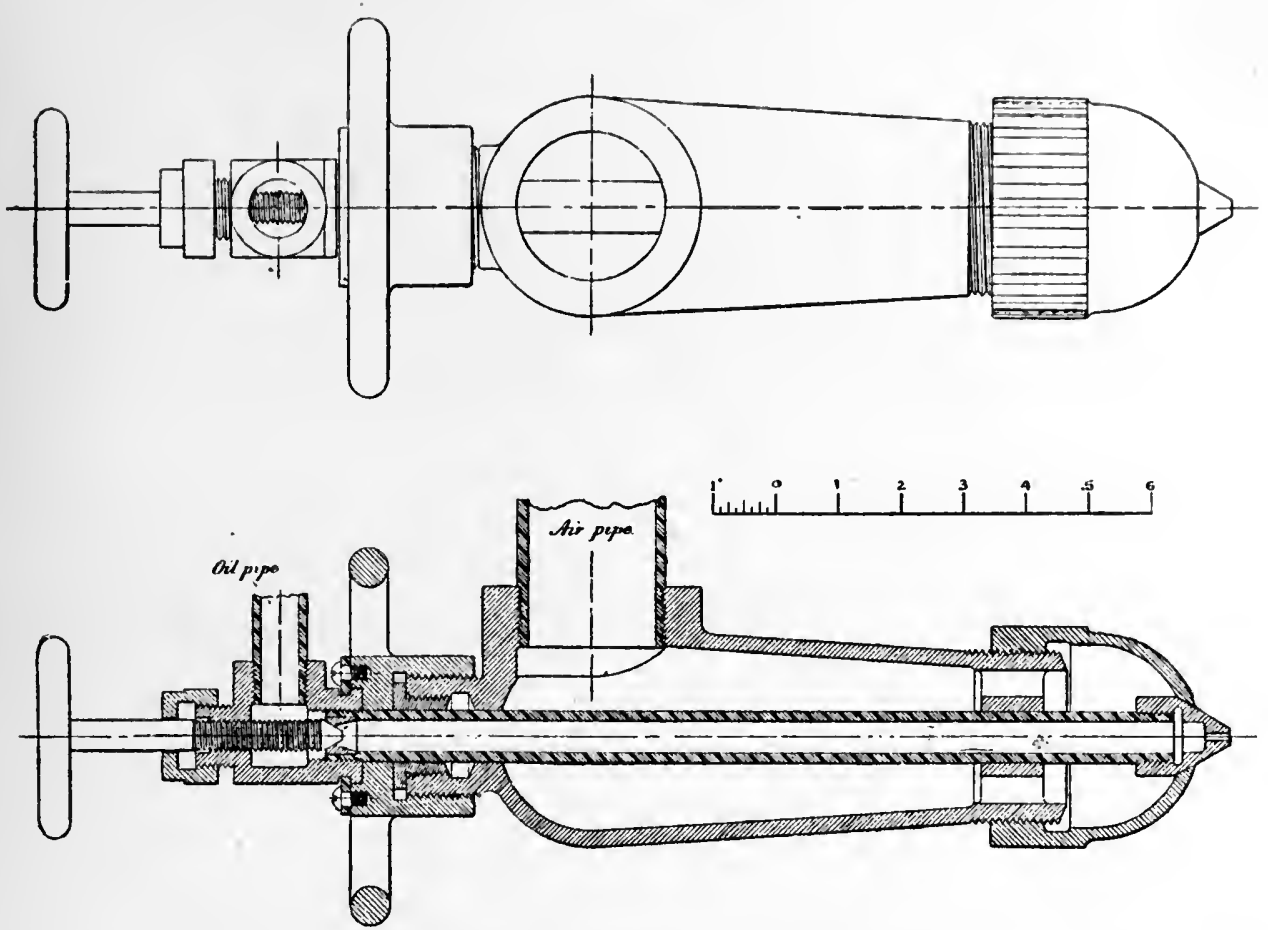

Fig. 9.-The Oil City Boiler Works Burner used in tests Nos. 1 to 8 inclusive.

Boiler Works design. This burner was used during the seven general tests that were conducted to show, among other things, whether or not it would be possible to secure a greater evaporative efficiency from the boiler with oil than was secured with coal. Six of these burners, spaced 18 inches apart, were ranged across the front of the furnace, there being a separate opening in the furnace wall for each burner. Considering the burners as arranged in pairs, those of each pair were inclined toward each other at an angle such that their flame impinged near the transverse centre line of the furnace.

The arrangements for weighing the feed water were substantially the same as during the coal-burning tests. The facilities for securing forced draft were likewise the same.

\section{Uniform Quality of Oil used during Experiments.}

The oil was secured from the Standard Oil Company. The product of different localities will be tested, for the evaporative efficiencies of each field should be ascertained.

\section{Method of Weighing Oil Used.}

From the storage tank the oil was pumped, as desired, into a weighing tank, from which it flowed by gravity into the oil-feed tank. From this reservoir the oil was pumped into a pipe leading to the burners, constancy of the pressure being secured by an air chamber and a relief valve. An overflow pipe led from relief valve back to the feed tank. The weighing and feed tanks were fitted with gauge glasses graduated to 5 pounds, by the aid of which the exact weight of oil was secured at the end of each hour, the same as with the feed water.

The air for atomizing the oil is supplied by a Root blower driven by a direct connected engine. This blower delivered 8 cubic feet of free air per revolution, at pressures ranging from 0.78 pound to $4 \cdot 68$ pounds per square inch. The air pressure was measured by a mercury column, the location of which was such that it gave substantially the same pressure as at the discharge of the blower. The temperature of the compressed air was taken 


\section{LIQUID FUEL AND ITS COMBUSTION}

near the same point. A Rand air compressor has been bought and will be installed, enabling higher pressures of air to be used.

The process of getting up steam in the main boiler was somewhat slow, as dependence had to be placed on a small auxiliary boiler for driving the Root blower until sufficient steam pressure could be secured for that purpose from the main boiler. The auxiliary boiler was only equal to the task of supplying the air to two burners.

The oil used was from the Beaumont, Tex., field. It is said to have been subjeeted to an inexpensive treatment which removed the sulphur and some of the more volatile hydrocarbons. The board believed that it would be best to use an oil that had been thus treated until some positive information could be secured as to whether or not it was advisable to attempt to use crude oil.

\section{Chemical Composition of the Oil used during Tests compared with the Crude Product.}

The character of the oil used during the official tests can be best appreciated by comparing it with the average grade of the crude product. The changes wrought by the refining process ean thus be clearly seen by comparing the analyses of the crude Beaumont product and that used in the experiments.

Analysis of Beaumont Crude Oil.

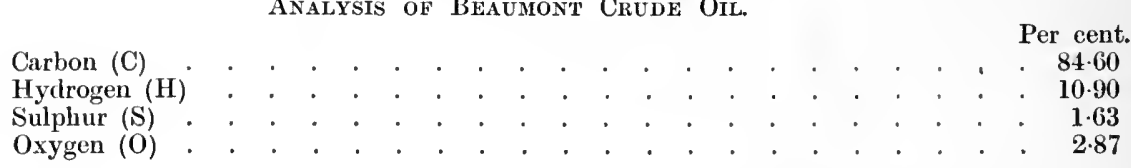

The amount of sulphur in different samples of the crude Beaumont oil varies from 2 to 3 per cent.

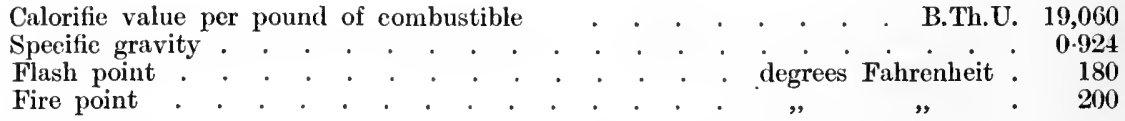

On distillation at atmospheric pressure to $524^{\circ} \mathrm{F}$. it was found that the-

First 10 per cent. passed over below

Degrees Fahrenheit.

Seeond 10 per cent. passed over between . . . . . . . . . . 428 and 485

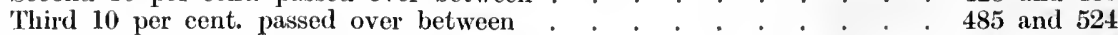

Fourth 10 per cent. passed over between. . . . . . . . . . 524 and 554

Analysis of Oil used by Liquid Fuel Board as determined by the Chemist of the Navy Yard, New York.

On distillation at atmospheric pressure to $680^{\circ} \mathrm{F}$. it was found that with the oil used during the tests-

First 10 per cent. passed over between

Degrees Falırenheit.

216 and 482

Second 10 per cent. passed over between . . . . . . . . . . . 482 and 523

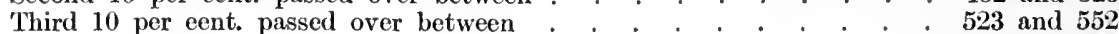

Fourth 10 per eent. passed over between . . . . . . . . . . 552 and 680

This oil showed on analysis to be composed of the following constituents-.

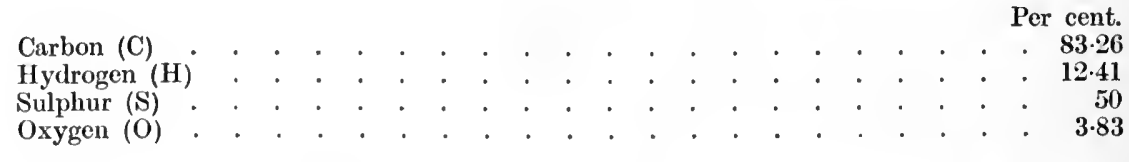

The sulphur was determined by oxidation with fuming nitric acid in an open capsule. 


\section{APPENDIX}

Speeific gravity at $60^{\circ} \mathrm{F}$.

Flash point

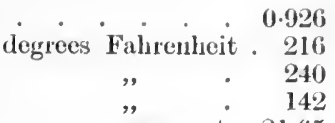

Fire point

Vaporization point

Loss for six hours at $212^{\circ} \mathrm{F}$.

per cent. $21 \cdot 65$

The calorific value of the combustible, calculated on the analysis of the United States Chemist by Dulong's formula, viz.--

$$
\begin{aligned}
\text { B.Th.U. } & =14500 \quad \mathrm{C}+62100 \quad\left(\mathrm{H}-\frac{0}{8}\right) \\
& =19481
\end{aligned}
$$

These analyses show that nearly all the sulphur was removed from the crude petroleum.

It will probably be best to continue using a uniform grade of oil for some time, so that comparisons can be made of the burners as well as the efficiency and advantages of the various methods of atomizing the combustible.

\section{Conditions between the Combustion Chamber and Smokestack.}

The temperatures in the base of the stack were remarkably free from the rapid fluctuations that characterized the coal-burning trials. There was no flaming in the stack except during the last two hours of the eighth test, and even then the fluctuations of temperature were absent. This was a test where everything was forced to the utmost, and therefore unusual conditions prevailed. The stack temperatures were noted by a Tagliabue mercury-nitrogen thermometer. It was used without mishap throughout the series of trials. Advantage was taken of the constancy of the stack temperature to check the readings of a Brown quick-reading pyrometer. The pyrometer was afterwards used in the furnace and elsewhere to record temperatures that were not excessive. For temperatures higher than $1,600^{\circ} \mathrm{F}$. a platinum-rhodium electric pyrometer was used. The measurements secured with this instrument show a maximum furnace temperature of $2,200^{\circ} \mathrm{F}$. for both natural and forced draft conditions.

The draft pressures were measured at the same points as in the series of coal-burning tests, and the average readings are shown diagramatically in fig. 10.

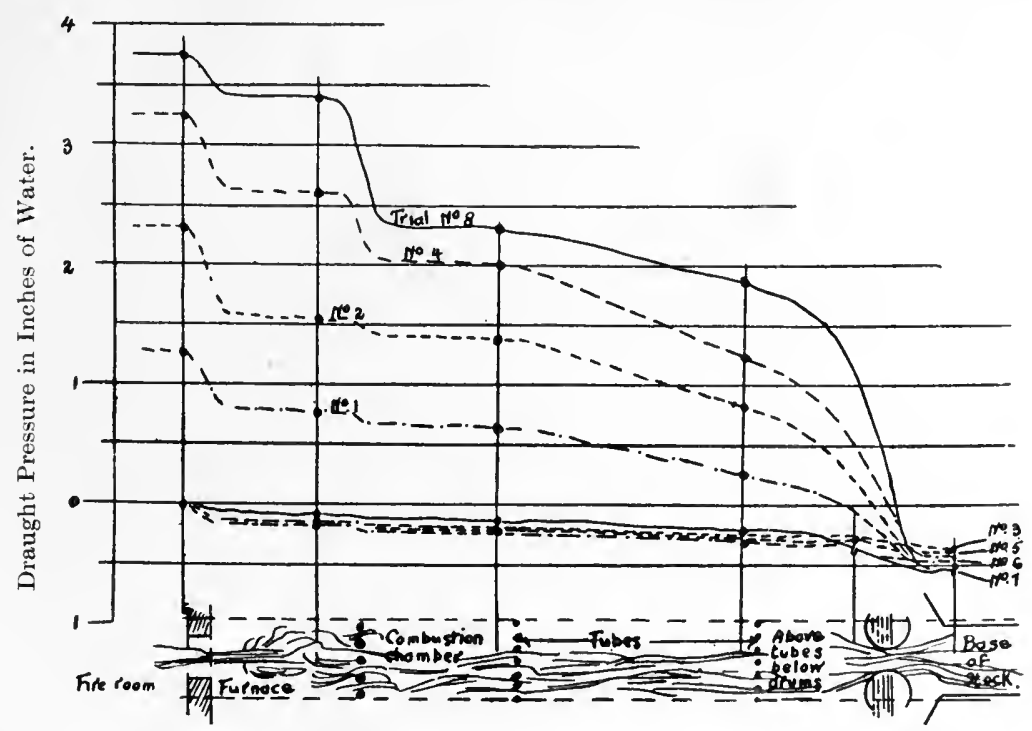

Abscissas are roughly proportional to measurements along the path of gases.

Fig. 10.-Curves showing Variation of AIR Prissure Within the Boller during certain Trials.

Spots indicate points where measurements were made. 


\section{LIQUID FUEL AND ITS COMBUSTION}

As an aid to the proper regulation of the supply of oil and air to the burners, a mirror was so placed that the man in charge of the fire room could quickly note the colour of the gases that issued from the top of the stack. The board considered it of great importance that those operating an oil-fuel installation should possess some device whereby the condition of affairs at the top of the stack can be immediately ascertained.

After considerable study and discussion, it was decided that it would be best to give each burner an excess of oil, and this would be shown by the smoke issuing from the stack. Then there was a gradual reduction of the quantity of oil until just a faint trace of smoke could be noticed.

Provision was made for introducing extra air at the sides of the furnace. Holes were cut 8 inches by $1 \frac{1}{2}$ inches through the side walls, on a level with the furnace floor and close to its back wall. A flue was built of loose fire-brick across the furnace floor. thus connecting the two openings. The roof of the flue had openings between the bricks, thus permitting extra air to be introduced where the combustion was most intense. This extra air supply was cut off during the natural draught and maximum forced-draught trials. The aggregate area of all openings for the admission of atmospheric air into the furnaee is given in the detailed report of each trial.

\section{Character of the Information desired.}

Before attempting to test the relative merits of individual burners, the board sought general information along the following lines-

The evaporative efficiency of oil as compared with coal under like conditions.

The degree to which the eombustion of oil could be forced with both steam and air as atomizers when using both natural and forced draught.

The ability of a hydrocarbon burner to work under forced dranght eonditions.

The liability of the boiler to injury when using oil under foreed draught conditions.

The amount of steam or air requisite for atomizing purposes.

The degree of pressure whieh should be applied when steam or air was used as the atomizing medium.

The effect of preheating the air neeessary for combustion.

The time required to train men to operate the burners.

The best means of reducing the noise eaused by the numerous but minute explosions within the furnace.

The attitude of the firemen as regards operating an oil installation.

\section{Experimental Plant thoroughly overhauled before commencing Liquid Fuel Tests.}

The experimental plant was not turned over to the Bureau of Steam Engineering for experimental purposes in connexion with the liquid fuel tests until the Oil City Boiler Works was assured that the Congress would make a special appropriation for this purpose. The Naval Appropriation Bill having become a law July 3, 1902, the board was then informed that the plant was at its disposal.

The test of June 27, 1902, having been a very severe one, and the casing of the boiler having been considerably warped, it was deemed necessary thoroughly to overhaul the plant before commencing the extended series of tests projeeted. The boiler was opened, cleaned, and thoroughly examined. The baffling bricks were renewed where necessary. As these bricks were of particular shape, some time elapsed before new ones eould be secured. The easing was repaired, and an asbestos lining was put underneath the firebricks of the furnace floor. All auxiliary machinery about the experimental plant was overhauled and put in order. The cylindrical-tank boiler received from the Navy Yard, New York, was covered with a non-conducting material. The neeessary platforms for holding the scales and tanks for weighing the oil and water required for this extra boiler were installed in place. The request was also made that several warrant machinists and the erew of a small naval vessel be detailed for duty in connexion with the tests. 


\section{APPENDIX}

\section{Endurance Test of 116 Hours.}

The board particularly deemed it expedient to make an endurance test of the plant. (See Table 6.) A test of this nature was therefore conducted for a continuous period of 116 hours. The torpedo boat Gwin was ordered from the Naval Academy, and the torpedo boat Rodgers from Norfolk, to assist in the experiments. The day wateh of eight hours was conducted by a regular erew of employees of the Oil City Boiler Works, although all the data during this period were taken by observers from the draughting-room staff of the Bureau of Steam Engineering. The crew of the Gwin operated the boiler and auxiliaries during half the night, the crew of the Rodgers taking the other night watch during the entire test. The data during the night were taken by the leading petty officers of the two torpedo boats, the commissioned and warrant officers in charge of the respective watches checking and verifying the data. The character of the data collected during the night, compared with that secured during the day, shows the efficiency of the crews of the torpedo boats even as compared with the highly trained force of draughtsmen in the Bureau of Steam Engineering.

The test was conducted under the general supervision of the Oil Fuel Board. The following four commissioned officers had entire charge of the crews and observers during successive watches: Lieut. A. M. Procter, United States Navy; Lieut. G. S. Lincoln, United States Navy; Lieut. William R. White, United States Navy ; Ensign John Halligan, junr., United States Navy. These officers not only supervised the work of the entire watch, but checked and counter-checked the data.

Four warrant machinists, Messrs. Steele, Johnson, Schreiber, and Rowe, were detailed to assist the commissioned officers. These warrant officers were placed in charge of the fire room.

After a preliminary run the test was commenced at noon on August 4.

The oil burners during the endurance test were so regulated that they consumed about 830 pounds of oil per hour. Although the data were only recorded at hourly intervals throughout the test, there were unofficial readings and checks made between the hours, thus insuring uniformity in the performance of the boiler.

The smoke issuing from the stack was quite light and uniform in colour. From the records of ten observations made during the day watches, it appears that the maximum variation was from 0 to 1 by Ringelmann's charts, the average colour throughout the day being 0.4 .

Temperatures taken with a platinum-rhodium pyrometer showed $1,980^{\circ} \mathrm{F}$. near the middle of the furnace. At the receiving end of the combustion chamber the temperature was $1,900^{\circ} \mathrm{F}$.

Toward the end of the test the water in the boiler became very muddy. It should be stated that during the entire endurance trial the boiler was fed with Potomac River water that had not been filtered. It might also be stated that during the past eighteen months the experimental boiler has been subjected to just this kind of work. The notes appended to the coal and oil tests will show in detail the treatment the boiler reccived. Occasionally the gauge-glass connexions would get clogged with mud, and toward the end of the endurance test it was necessary to blow steam through them every half hour.

Two pieces of carbon were removed from the vicinity of the second burner from the left : one piece on August 7 and the other on August 9. Each piece was about 64 cubic inches, and was caused by the burner being so placed as to permit the flame to impinge on the brickwork of the front furnace wall.

\section{The Hayes Hydrocarbon Burner.}

The construction of this burner is shown in fig. 11 and the manner of its installation in fig. 12. Part of the air supply is introduced at the sides of the furnace near the back wall. It then passes through heating pipes $A A$ to the pipe $B$, the latter extending across the furnace just inside the front wall. 


\section{LIQUID FUEL AND ITS COMBUSTION}

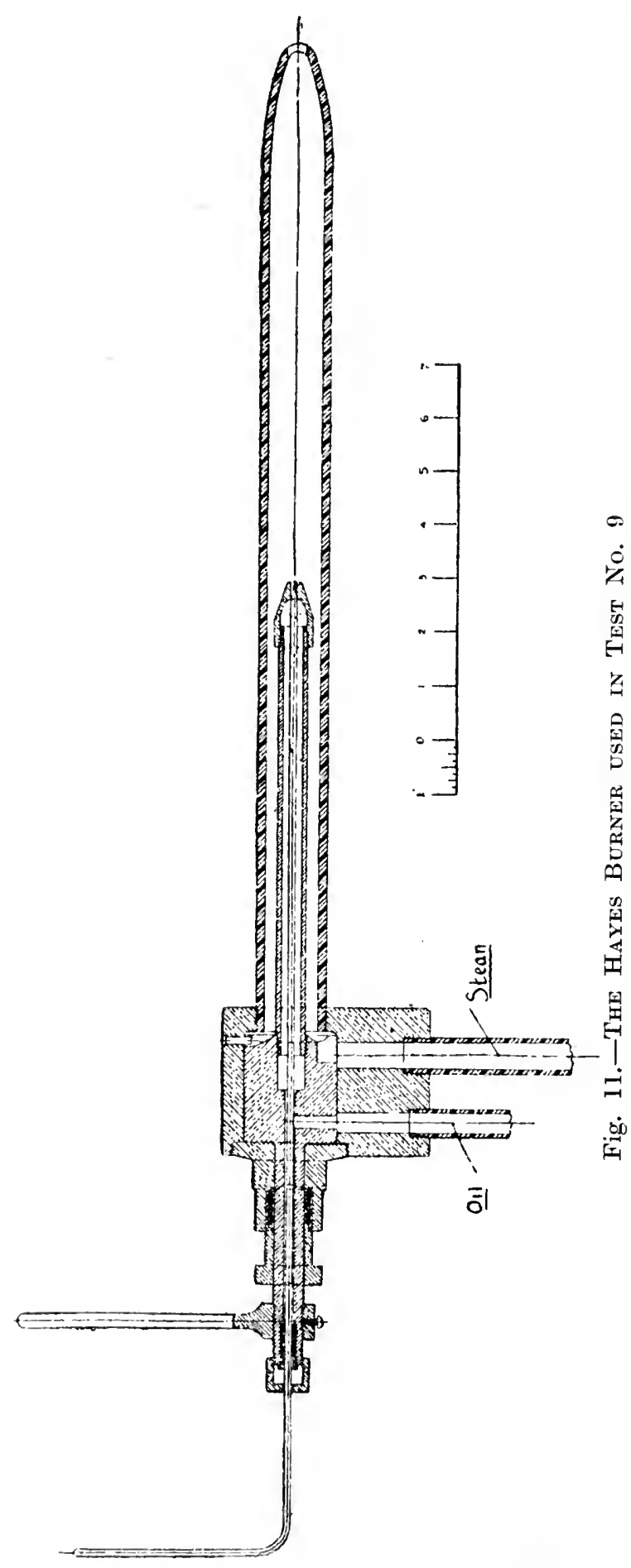

The burners project diametrically through the pipe $B$, and it is contended that the hot air in this pipe will cause the oil to be completely gasefied before it escapes from the burner orifices. There is no doubt but that the heating of the air is a direct benefit. Careful and extended experiments will have to be made to show whether this heating could best be effected as in the Howden system of forced draught, or by a simple arrangement of pipes which receive the direct heat of the furnace. The experience of simply heating the pipes during these tests would rather tend to show that this arrangement would not have much endurance. The edges of the holes in the pipe $B$ were found somewhat burned upon completion of the official test. If such impairment could occur after the pipe had been in actual service about twenty hours, it is probable that very little endurance can be expected of such an installation under forced draught conditions.

Two preliminary tests were made. Some representatives of the company owning the burner were present during these trials, and suggestions were sought of these men, who were supposed to have expert knowledge of that particular appliance. At no time were they able to secure from the boiler an actual evaporation of 11 pounds of water. During the first experimental trial, on September 10, it was manifest that the bulk of the combustion was above the tubes and in the uptake and stack. In consequence of this loss of heat, and before the second unofficial trial was attempted, the draught opening above the tubes was reduced in the proportion of 16 to 101. This caused a noticeable improvement. It should be stated that it required ten days for the company to prepare for the first preliminary trial. Their experts had been furnished blue prints showing in detail the character of the experimental plant, also the position and arrangement of the baffle plates in the experimental boiler. Representatives of the com- 


\section{APPENDIX}

pany had also been permitted to witness some of the previous tests. The experience with this company has now caused the Liquid Fuel Board to compel every inventor to make arrangements whereby he can install his appliance within three days.

Steam for the burners was supplied from an independent boiler at a uniform pressure of 90 pounds. Dur. ing the unofficial trials the steam was not superheated, the inventor having previously maintained that he could use exhaust steam and attain the object desired. It might also be incidentally stated that the claim was made that one single burner would consume all the oil that would be required for even forceddraught purposes.

Oil was supplied to the six burners during the unofficial tests at a uniform pressure of 80 pounds. Be-

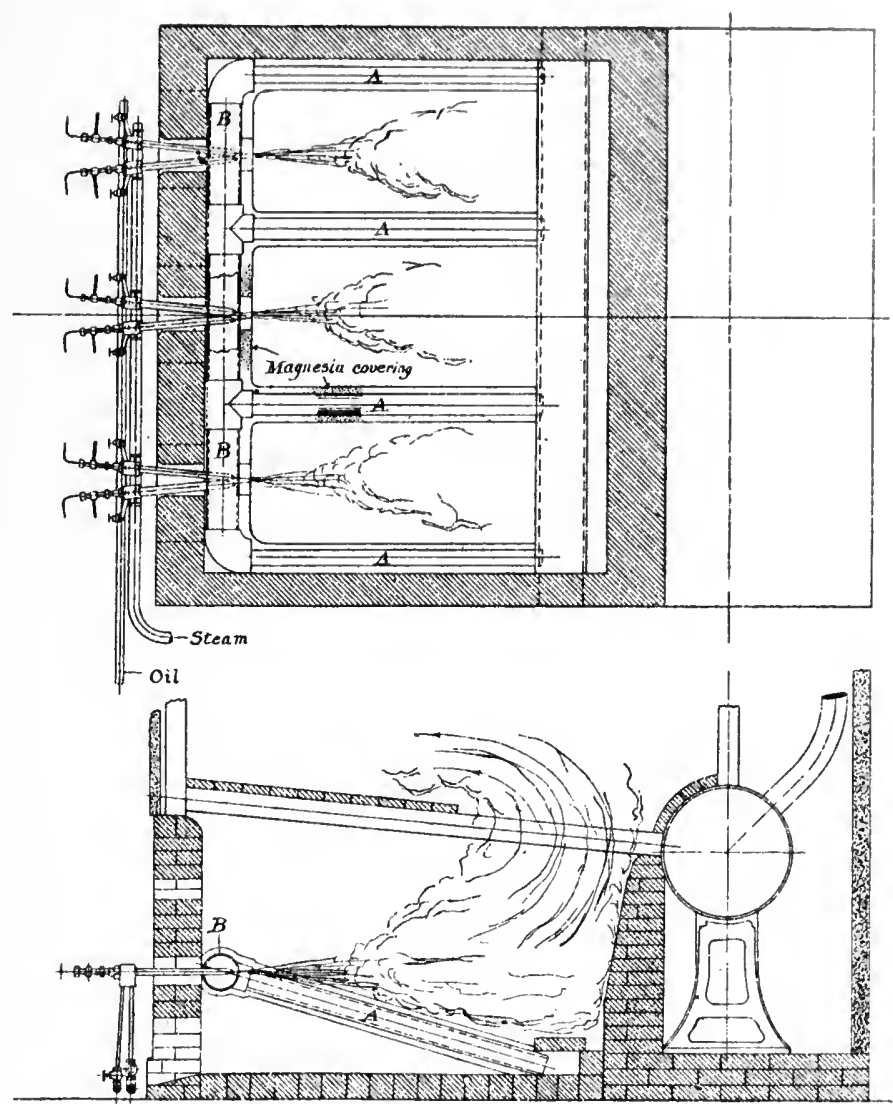

Fig. 12.-Installation of Hayes Burner Tests No. 9

sides the air introduced through the heating tubes, some additional air was admitted through what were formerly the ash-pit openings. The aggregate area of these ash-pit openings was about 60 square inches.

During the official trial (test No. 9), which continued for six hours, the steam for the burners was superheated. There was fitted, in the opening above the tubes and below the steam drum of the main boiler, 44 feet of $1 \frac{1}{2}$ inch pipe. This pipe was in the form of three return bends. Steam from the cylindrical tank boilers was led through this pipe and thence to the burners.

The leading experts of the company did not attend this official trial. The mechanics who installed the burners, however, operated these appliances under the direction of the warrant machinists. The board was informed that it was these mechanics who operated the burners during an official test that had been made at an electric-light station in the city, where it was claimed that there had been evaporated 18 pounds of water per pound of combustible. It is needless to say that no such results were secured under the experimental boiler.

\section{Progressive Tests with Burners using Steam for Atomizing.}

These tests were made September 19, 20, and 22. One of the special purposes of conducting these trials was to ascertain the exact amount of steam that would be required for atomizing the oil. Every possible ehcek was used to secure trustworthy data. All during the trials there were searches for leaks, but none were discovered.

The board was desirous of ascertaining just how much steam was required for atomizing, and therefore a separate boiler was installed for generating steam for this purpose. It 


\section{LIQUID FUEL AND ITS COMBUSTION}

is a cylindrical return-tube boiler with two plain cylindrical furnaces. This boiler is piped to furnish steam for the oil burners, and has no other steam pipe leading from it. The opening from the safety valve was blanked. This boiler is fitted with two oil burners of Oil City Boiler Works' design in each furnace, these burners using air for atomizing pur-

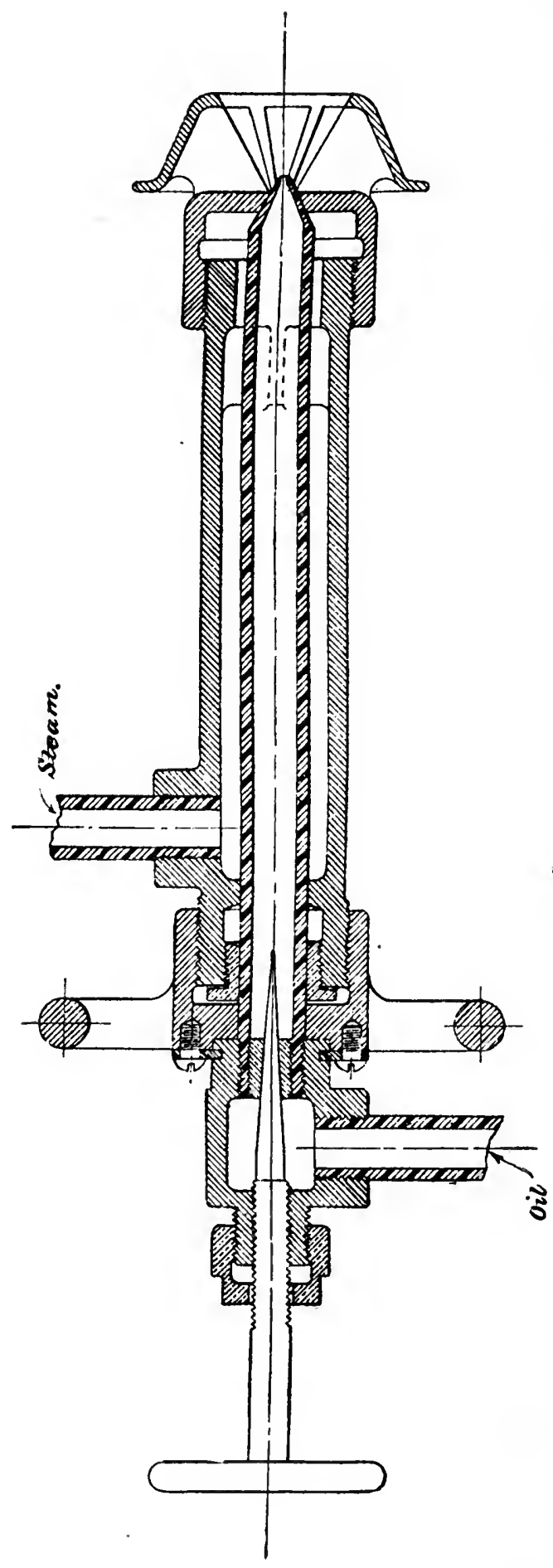

poses. After steam was raised one burner in one furnace was found sufficient to keep the steam pressure uniform.

This boiler was in thorough order and tight at 100 pounds pressure. During the oil burning test great care was taken to

-7 keep both the water level and \& the steam pressures in this boiler - f uniform. The water used was 4 carefully weighed in a separate - $\approx$ weighing apparatus, in exactly

- 0 the same manner as the water supplied to the experimental - 7 The pressure for atomizing I - at which the oil was forced to the burner, was increased each - 省 day. It was found that the ? higher the pressure the greater - - - evaporated. The efficiency was also slightly greater as higher - 5 pressures were used. The percentage of steam required for -1 atomizing the oil, however, also slightly increased as higher pres. sures were used.

During these tests deflectors were placed in the ash-pan openings, so as to cause the air to be drawn up near the burners, thus effecting combustion nearer the front of the furnace. The average percentage required for atomizing purposes was about $4 \frac{1}{2}$ per cent. of the entire evaporation. The atomizer is shown in fig. 13.

In these three tests the side burners were directed toward the centre of the furnace more than heretofore, in order to reduce the amount of heat absorbed by the side walls. The amount so absorbed was judged of by the condition of glow immediately after extinguishing 


\section{APPENDIX}

the burners. This glow of the side walls, and also of the back and bridge walls, generally showed a more intense combustion on the right side of the furnace than on the left. The fact that the steam and oil connexions to the burners were also at the right side of the furnace front suggests the desirability of proportioning the piping, both as to size and location, so as to get substantially equal pressure at all burners.

Before making further tests the front wall of the furnace was rebuilt with ferruled openings 8 inches in diameter for the burners. Ample latitude was thus allowed for the angular setting of the burners, and there was also opportunity for trying the effect of admitting air round the burners.

An accident to the engine of the fan blower prevented the continuance of these trials with different pressures of forced draught. It should be ascertained just how much steam is required for atomizing purposes when the boiler is forced to its utmost.

The board deems it important, when opportunity will permit, to make an extended series of tests with steam as the atomizing agent. Fresh water can be secured in unlimited quantities at nearly all naval stations, and it might not be a difficult matter to make arrangements whereby the torpedo boats and destroyers could be furnished with an ample supply in specially constructed tanks, thus obviating the risk of being compelled to feed salt water into the boilers.

Even. if compressed air should be used on the torpedo boats as the atomizing agent, an accident might happen to the compressor plant which would compel the temporary use of steam. There is therefore an urgent necessity to secure reliable data upon the subject of how much steam is required for spraying purposes under various conditions of natural and forced draught

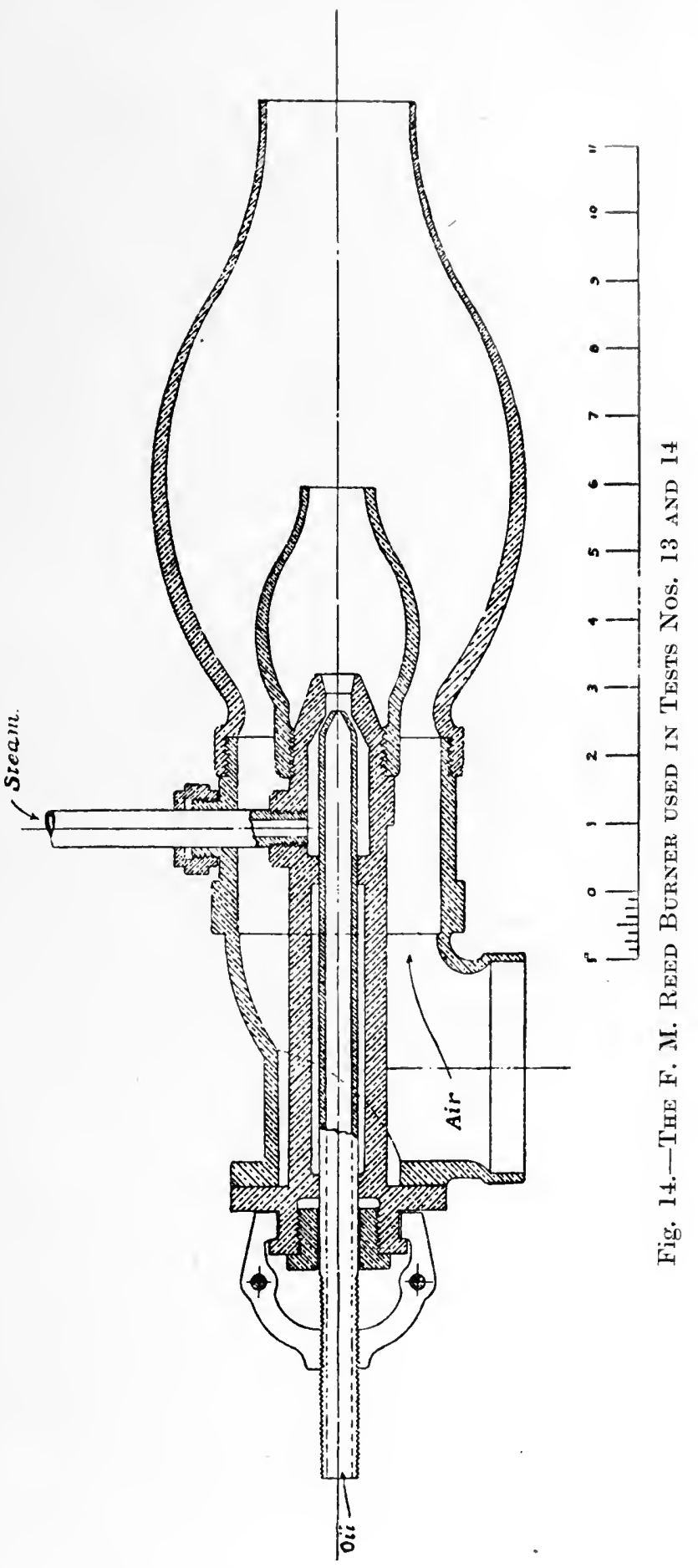




\section{LIQUID FUEL AND ITS COMBUSTION}

\section{The F. M. Reed Combined Air and Steam Burner.}

One preliminary and two official tests were made with this burner, whose construction is shown in fig. 14. The "from and at" evaporation during the first official experiment fell short of the best yet attained in these trials (test No. 3) by only about one-half of 1 per cent. On the other hand, the amount of steam consumed in spraying the oil was excessive, being about 1 pound of steam per pound of oil, or several times as much as in test No. 3 . Apart from any question of furnace efficiency, the board considers that the combined use of both air and steam in the burners is undesirable. ${ }^{1}$ Such an installation involves unnecessary expense and complication, and requires much more skill and attention in the adjustment and manipulation of the burners.

The board gave particular attention to watching the operation of this burner, since it is desirous of securing definite information upon the subject as to whether or not it was advantageous to use a combination of both air and steam as the atomizing agent. The inventor personally operated the burner, and every effort was made to reduce the amount of air and stcam used for spraying purposes.

It is by a process of eliminating undesirable classes of burners that the best form can be secured, and therefore the board has no hesitation in stating that further experimentation with the combined air and steam burner should not be made.

\section{Thermal Efficiency not Increased by the Use of Steam.}

There is quite a widespread misconception regarding the part that the steam which is used for atomizing purposes plays in effecting combustion. It is supposed by many that after atomizing the oil the steam is decomposed and that the hydrogen and carbon are again united, thus producing heat and adding to the heat value of the fuel. While it may be true that the presence of steam may change the character and sequence of the chemical reaction, and result in the production of a higher temperature at some part of the flame, such an advantage will be offset by lower temperatures elsewhere between the grate and the base of the stack. All steam that enters the furnace will, if combustion is complete, pass up the stack as steam, also carrying with it a certain quantity of waste heat. The amount of this waste heat will depend upon the amount of steam and its temperature at entrance of the furnace. The quantity of available heat, measured in thermal units, is undoubtedly diminished by the introduction of steam. In an efficient boiler it is quantity of heat rather than intensity that is wanted. For many manufacturing purposes intensity of heat may be of primary importance, but in a marine steam generator a local intense heat is objectionable on other grounds than those of economy, viz., its liability to cause leaky tubes and seams from the unequal expansion of heating surfaces.

\section{Information Already Obtained.}

It is believed that expert engineers will be able to make important deductions from the trustworthy data that have been so carefully collected. The tables should be carefully studied in connexion with the information secured during the coal tests, and the board enjoins that the two reports be studied together.

The following information has undoubtedly been secured-

(a) That oil can be burned in a very uniform manner.

(b) That the evaporative efficiency of nearly every kind of oil per pound of combustible is probably the same. While the crude oil may be rich in liydrocarbons, it also contains sulphur, so that, after refining, the distilled oil has probably the same calorific value as the crude product.

This does not agreo with other experience, as for example that of the Great Eastern Railway, England. -Autnon. 


\section{APPENDIX}

(c) That a marine steam generator can be forced to even as high a degree with oil as with coal.

(d) That up to the present time no ill effects have been shown upon the boiler.

(e) That the firemen are disposed to favour oil, and therefore no impediment will be met in this respect.

(f) That the air requisite for combustion should be heated if possible before entering the furnace. Such action undoubtedly assists the gasefication of the oil product.

(g) That the oil should be heated so that it could be atomized more readily.

(h) That when using steam higher pressures are undoubtedly more advantageous than lower pressures for atomizing the oil.

(i) That under heavy forced-draught conditions, and particularly when steam is used, the board has not yet found it possible to prevent smoke from issuing from the stack, although all connected with the tests made special efforts to secure complete combustion. Particularly for naval purposes is it desirable that the smoke nuisance be eradicated in order that the presence of a war ship might not be detected from this cause. As there has been a tendency of late years to force the boilers of industrial plants, the inability to prevent the smoke nuisance under forced-draught conditions may have an important influence upon the increased use of liquid fuel. ${ }^{1}$

(j) That the consumption of liquid fuel can not probably be forced to as great an extent with steam as the atomizing agent as when compressed air is used for this purpose. This is probably due to the fact that the air used for atomizing purposes, after entering the furnace, supplies oxygen for the combustible, while in the case of steam the rarefied vapour simply displaces air that is needed to complete combustion.

(k) That the efficiency of oil fuel plants will be greatly dependent upon the general character of the installation of auxiliaries and fittings, and therefore the work should only be entrusted to those who have given careful study to the matter, and who have had extended experience in burning the crude product. The form of the burner will play a very small part in increasing the use of crude petroleum. The method and character of the installation will count for much, but where burners are simple in design and are constructed in accordance with scientific principles, there will be very little difference in their efficiency. Consumers should principally look out that they do not purchase appliances that have been untried and have been designed by persons who have had but limited experience in operating oil devices.

\section{Necessity of Permilting Unofficial or Preliminary Trials.}

Between the several official tests there are invariably conducted a number of unofficial trials, and by reason of this experimentation valuable suggestions are received. Those who have received permission to instal their appliance find that it is quite a different matter to apply it to a boiler that is capable of developing 2,000 horse-power from what it was to instal it on some boiler that supplied steam to a small vessel or mediumsized manufacturing plant.

Up to the present time no firm has been able to tell the board the best manner in which their device should be operated. In fact, the details of installation of every burner yet tested are quite different when completed from that projected at the beginning of the test. The two or three days that are given to experimental trials invariably furnish surprises to the inventor. Probably no better illustration could be given of the lack of definite knowledge in regard to the correct way of operating burners than has been shown during these experiments. The experience of the board in this particular respect shows the necessity of having some disinterested experts conduct an extended series of tests to determine the guiding principles which should be followed in the burning of liquid fuel. There has been sufficient evidence already produced to prove that in all probability special

1 The Hohenstein boiler does not appear specially favourable for smokelessness.-Author. 


\section{LIQUID FUEL AND ITS COMBUSTION}

forms of burner will be required for different types of boilers. It can hardly be expected that a burner which could do efficient and economical work in some small steam generator would be equally applicable to the largest steam generators of the marine type.

In noting the evaporative efficieney seeured, it should be remembered that the experimental boiler was designed for actual Navy conditions, and that the limitations prescribed by the Department as to height, weight, and floor space were of a severe nature. There is not only considerable radiation from the boiler, but the proportion of heating to grate surface is not as large as in land boilers. Taking these facts into consideration, the results are exceedingly satisfactory. The engineering world is looking for comparative results from the series of tests that are now being eonducted, and trustworthy information in this respect will be furnished.

\section{An Oil Installation should be fitted to Boilers of several Torpedo Boats.}

The information and data already secured warrants the immediate installation of oil fuel appliances on two torpedo boats and two torpedo-boat destroyers, to test the adaptability for use with water-tube boilers of bent-tube type. The installation eould be effected on boats of similar charaeter, so that an earnest but friendly rivalry would be ereated between the crews of the several vessels. There will come development and success by boldly equipping several boats with different types of installation. The morale of the torpedo-boat flotilla ean be strengthened in no better way than by experimenting along this line.

In all probability but one or two of the bent-tube types of boilers fitted in our torpedo boats or destroyers will burn oil efficiently, unless extensive baffling is resorted to in the furnaces so as to direct the products of combustion among the tubes. Extended tests should be made with torpedo boats, to find out the best means of securing effective baffling, and some junior officers of the line should accompany the Liquid Fuel Board on inspection trips.

\section{An Efficient Experimental Crew Secured.}

The experience of the past two months has undoubtedly eaused the crew of the torpedo boat Rodgers to be well trained in the handling and operating of oil fuel devices. This crew has been so well drilled and has been so receptive for information that they ean now quickly tell whether the burners are effieiently or properly regulated. By noting the character and length of the flame, the eolour of the escaping gases from the chimney, the eondition of affairs in the furnaee and combustion chamber as observed through the sight holes, the roar of the air as eombustion takes place, and the appearance of the bridge wall, they can quiekly adjust the several valves and seeure the best possible results. The efficiency of the crew in this respect has been due in great part to the zeal, intelligence, and ability of the commanding officer of the boat, Ensign John Halligan, junr.

\section{The Experiments should be Conducted Entirely by Persons within the Navy.}

The board desires to state that these experiments can not be conducted to the best interest of the service without the aid of a Navy crew of firemen and observers. It is essential that the board should be able to eall upon such erew for either day or night work. While most of the offieial tests are only of eight hours' duration, it requires several hours properly to warm up the boiler and get things in good running shape. Then it requires one or two hours after the completion of the test to secure the plant and guard against fire.

A civilian crew will only work eight hours, and then at stated intervals. They demand extra compensation for overtime, and it is no easy matter to get them to stand up to forced-draught eonditions, partieularly when the higher air pressures are used. A crew of firemen that is changed from day to day, and who are apprehensive of their personal 


\section{APPENDIX}

safety when forced-draught trials are made, can not be interested in the work. The experiences of the Oil City Boiler Works for over a year in the conduct of the coal experiments show excessive trouble, annoyance, expense, and delay, arising from attempting to use such employees in experimental research.

The experimental crew must be under military control and discipline, and this can only be secured by having some regular vessel of the Navy, regularly in commission, assigned to duty in connexion with the experimental board.

(Signed)

JoIn R. EDwards, Lieutenant-Commander, U.S. Navy.

WYThe M. Parks,

Lieutenant-Commander, U.S. Navy.

Frank H. Bailey,

Lieutenant-Commander, U.S. Navy.

The Chief of the Bureau of Steam Engineering. 


\section{LIQUID FUEL AND ITS COMBUSTION}

Summary of tests of Hohenstein marine

\begin{tabular}{|c|c|c|c|c|c|c|}
\hline $\begin{array}{l}\text { Nunl- } \\
\text { ber of } \\
\text { trial. }\end{array}$ & $\begin{array}{c}\text { Date of trial } \\
1902 .\end{array}$ & $\begin{array}{l}\text { Duration } \\
\text { of triz) } \\
\text { (hours). }\end{array}$ & Find of fuel. & Oil burner used. & State of weather. & $\begin{array}{l}\text { Helght of of } \\
\text { barometer } \\
\text { at noon. }\end{array}$ \\
\hline 1 & 2 & 3 & 4. & 5 & 6 & 7 \\
\hline 1 & June 11 & 6 & Beaumont oil & O. C. B. W. (air) & Bright sunny day & 30.02 \\
\hline 2 & June 12 & 4 & & do. & do. & 30 \\
\hline 3 & June 26 & 8 & do. & do. & do. & $29 \cdot 70$ \\
\hline 4 & June 27 & 3 & do. & do. & Bright sun, few elouds & $29 \cdot 94$ \\
\hline 5 & Aug. 2 & 5 & do. & do. & Bright sunny day. & $30 \cdot 13$ \\
\hline 6 & Aug. 4-9 & 116 & do. & do. & (See $\log$ ) & 29.89 \\
\hline 7 & Ang. 15 & 6 & do. & do. & Thin fleecy elouds. & $30 \cdot 10$ \\
\hline 8 & Aug. 20 & 3 & do. & & $\begin{array}{l}\text { Smoky } \\
\text { clouds. }\end{array}$ & $30 \cdot 08$ \\
\hline 9 & Sept. 12 & 6 & do. & Hayes (steam) . & Partly eloudy . . & $30 \cdot 16$ \\
\hline 10 & Sept. 19 & 8 & do. & O. C. B. W. (stcam) & Thin clouds & $30 \cdot 20$ \\
\hline 11 & Sept. 20 & 8 & do. & do. & do. & $30 \cdot 18$ \\
\hline 12 & Sept. 22 & 8 & do. & & Partly cloudy. & 30.05 \\
\hline 13 & Scpt. 13 & 8 & do. & Reed (air and steam) & Fair. & 29.92 \\
\hline 14 & Sept. 29 & 8 & do. & & Clear & 29.96 \\
\hline
\end{tabular}

Summary of tests of Hohenstein marine

\begin{tabular}{|c|c|c|c|c|c|c|c|c|c|c|c|}
\hline \multirow[b]{2}{*}{ 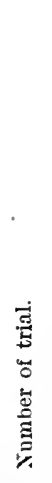 } & \multirow[b]{2}{*}{ 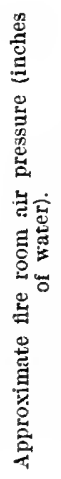 } & \multicolumn{2}{|c|}{ Oil. } & \multicolumn{2}{|c|}{ Steam. } & \multicolumn{4}{|c|}{ Water. } & \multicolumn{2}{|c|}{$\begin{array}{l}\text { Economic } \\
\text { results. }\end{array}$} \\
\hline & & 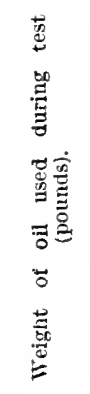 & 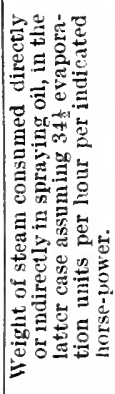 & 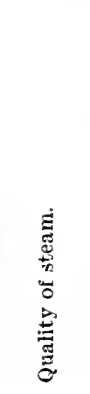 & 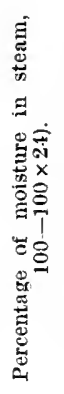 & 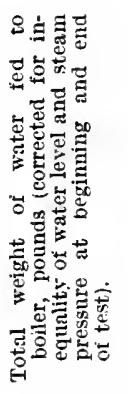 & 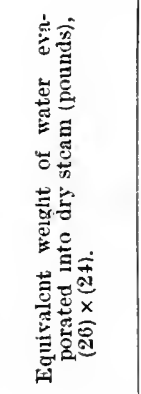 & 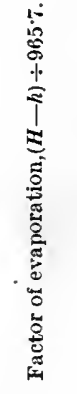 & 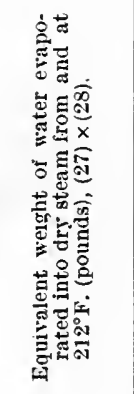 & 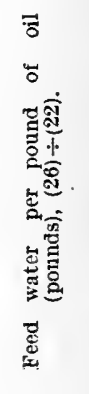 & 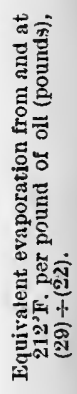 \\
\hline 1 & 10 & 22 & 23 & 24 & 25 & 26 & 27 & 28 & 29 & 30 & 31 \\
\hline 1 & $1 \cdot 3$ & 10,584 & 2,820 & 0.983 & 1.7 & 117,976 & 115,960 & $1 \cdot 159$ & 134,400 & $11 \cdot 15$ & 12.70 \\
\hline 2 & $2 \cdot 3$ & 9,180 & 3,770 & .980 & 2 & 96,928 & 94,980 & $1 \cdot 177$ & 111,800 & $10 \cdot 56$ & $12 \cdot 18$ \\
\hline 3 & 0 & 6,122 & 827 & $\cdot 984$ & $1 \cdot 6$ & 78,0 & 76,740 & $1 \cdot 151$ & 88,330 & $12 \cdot 74$ & $14 \cdot 43$ \\
\hline 4 & $3 \cdot 3$ & 8,60 & 2,550 & .981 & 1.9 & 88,0 & 86,915 & $1 \cdot 161$ & 100,900 & $10 \cdot 30$ & $11 \cdot 73$ \\
\hline 5 & 0 & 4,668 & 1,153 & .986 & $1 \cdot 4$ & 58,529 & 57,700 & $1 \cdot 151$ & 66,380 & 12.54 & 14.22 \\
\hline 6 & 0 & 96,517 & 18,240 & .985 & $1 \cdot 5$ & $1,192,482$ & $1,174,500$ & $1 \cdot 160$ & $1,363,000$ & $12 \cdot 36$ & $14 \cdot 12$ \\
\hline 7 & 0 & 9,089 & 7,800 & .995 & $\cdot 5$ & 104,631 & 104,100 & $1 \cdot 16$ & 120,780 & $11 \cdot 5$ & $13 \cdot 29$ \\
\hline 8 & $3 \cdot 75$ & 9,909 & 3,950 & .988 & 1.2 & 92,99 & 91,870 & $1 \cdot 16$ & 106,690 & & $10 \cdot 77$ \\
\hline !) & 0 & 3,600 & 2,524 & .991 & $\cdot 9$ & 43,7 & 43,367 & $1 \cdot 15$ & 50,000 & $12 \cdot 16$ & $13 \cdot 89$ \\
\hline 10) & 0 & 7,30 & 3,412 & .995 & 5 & 85,7 & 85,350 & $1 \cdot 16$ & 99,1 & $11 \cdot($ & $13 \cdot 47$ \\
\hline 11 & 0 & 8,257 & 4,252 & .994 & .6 & 96,469 & 95,880 & $1 \cdot 160$ & 111,190 & 11 . & $13 \cdot 45$ \\
\hline 12 & 0 & 8,974 & 5,305 & .995 & $\cdot 5$ & 105,547 & 105,020 & $1 \cdot 160$ & 121,840 & $11{ }^{\circ}$ & $13 \cdot 58$ \\
\hline 13 & 0 & 7,692 & 8,166 & 996 & $\cdot 4$ & & 95,310 & 1.158 & 110,370 & $12 \cdot 43$ & $14 \cdot 35$ \\
\hline 14 & 0 & 9,216 & 6,838 & .998 & 2 & 112,115 & 111,890 & $1 \cdot 159$ & 129,570 & $12 \cdot 17$ & 14.06 \\
\hline
\end{tabular}




\section{APPENDIX}

water-tube boiler burning oil.

\begin{tabular}{|c|c|c|c|c|c|c|c|c|c|c|c|c|c|}
\hline & & & rage $\mathrm{pr}$ & sures. & & & & & Avera & ge temp & rature (De & g. F.). & \\
\hline & & & raft pre & ure in in & hes of wa & & & & & & & & \\
\hline 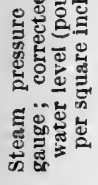 & 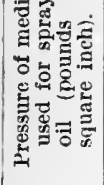 & 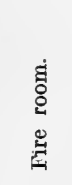 & 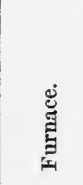 & 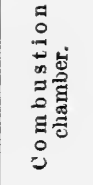 & 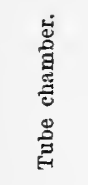 & 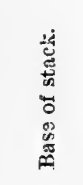 & 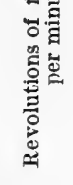 & 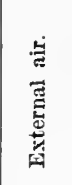 & 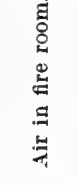 & 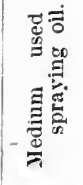 & 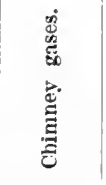 & 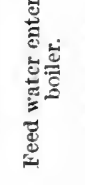 & 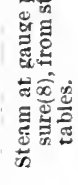 \\
\hline 8 & 9 & 10 & 11 & 12 & 13 & 14 & 15 & 16 & 17 & 18 & 19 & 20 & 21 \\
\hline $273 \cdot 5$ & $3 \cdot 20$ & 1.27 & 0.78 & $0 \cdot 642$ & 0.25 & $-0 \cdot 49$ & 327 & $85 \cdot 4$ & 121 & (?) & $704 \cdot 6$ & $120 \cdot 7$ & $413 \cdot 7$ \\
\hline 273.5 & & $2 \cdot$ & & I & & -.50 & 423 & 86 & $121 \cdot 5$ & $(?)$ & 779 & $103 \cdot 2$ & 413.7 \\
\hline $273 \cdot 5$ & .78 & 0 & - & -19 & -.25 & -.35 & 0 & $7 !$ & 106 & 1025 & $503 \cdot 6$ & 128.5 & $413 \cdot 7$ \\
\hline $273 \cdot 5$ & $3 \cdot 37$ & $3 \cdot 25$ & $2 \cdot 60$ & 2.02 & 1.25 & -.41 & 483 & 8 & 108 & 12 & 854 & 119 & $413 \cdot 7$ \\
\hline $273 \cdot 5$ & 1.41 & 0 & -.15 & -20 & $-\cdot 28$ & -.40 & 0 & 8 & 112 & 120 & 55 & 129 & 413 \\
\hline $271 \cdot 5$ & & 0 & -.17 & -.23 & $-\cdot 30$ & -.46 & 0 & 79 & 112 & 113.5 & 585 & $119 \cdot 4$ & 413 \\
\hline $272 \cdot 5$ & $4 \cdot 66$ & 0 & -09 & $-\cdot 13$ & -.21 & -.54 & 0 & $77 \cdot 6$ & 120 & 16 & 74 & $119 \cdot 7$ & 413.4 \\
\hline 276 & $4 \cdot 68$ & 3.75 & $3 \cdot 40$ & $2 \cdot 30$ & $1 \cdot 86$ & -.53 & 506 & 82 & 115 & 136 & 1,017 & 119 & $414 \cdot 5$ \\
\hline $273 \cdot 5$ & 32 & 0 & -.20 & -20 & -.20 & $-\cdot 38$ & 0 & 75 & 98 & (?) & 449 & 127 & \\
\hline $273 \cdot 1$ & & 0 & -.20 & -.20 & $-\cdot 28$ & -.60 & 0 & 69 & 98 & $444 \cdot 4$ & 59 & $118 \cdot 3$ & $413 \cdot 6$ \\
\hline $273 \cdot 7$ & $61 \cdot 4$ & 0 & -.14 & -.20 & $-\cdot 28$ & -.53 & 0 & 77 & 106 & $408 \cdot 2$ & 628 & $120 \cdot 2$ & $413 \cdot 8$ \\
\hline $274 \cdot 2$ & 91 & 0 & -.14 & -.16 & -.21 & -.53 & 0 & 77 & 103 & 401 & 66 & 119 & 414.0 \\
\hline 276.7 & 92 & 0 & $-\cdot 15$ & -.15 & -.20 & -.45 & 0 & $80 \cdot 4$ & $99 \cdot 4$ & 375 & 57 & 121 & 414.8 \\
\hline $277 \cdot 4$ & 89 & 0 & -.097 & -10 & $-\cdot 20$ & -.50 & 0 & $85 \cdot 4$ & $111 \cdot 5$ & 416 & 645 & $120 \cdot 8$ & 415.0 \\
\hline
\end{tabular}

water-tube boiler burning oil.

\begin{tabular}{|c|c|c|c|c|c|c|c|c|c|c|c|}
\hline \multicolumn{3}{|c|}{ Economic results. } & \multicolumn{4}{|c|}{ Fuel per hour. } & \multicolumn{5}{|c|}{ Water per hour. } \\
\hline 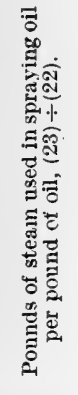 & 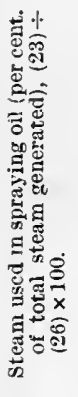 & 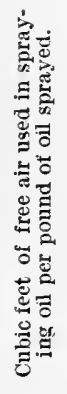 & 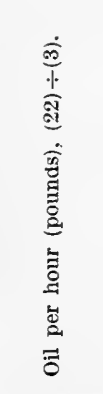 & 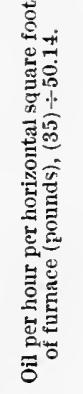 & 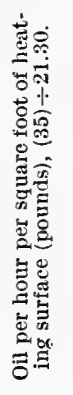 & 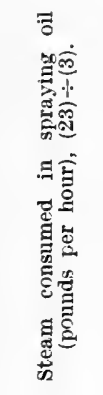 & 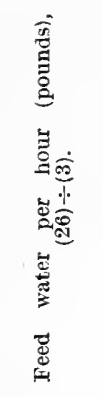 & 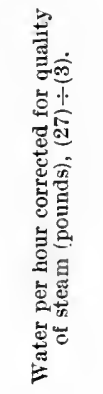 & 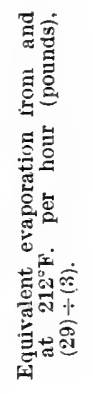 & 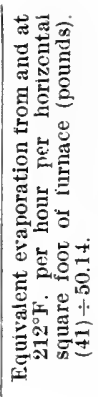 & 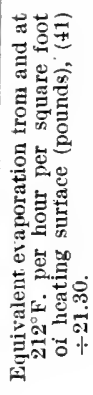 \\
\hline 32 & 33 & 34 & 35 & 36 & 37 & 38 & 39 & 40 & 41 & 42 & 43 \\
\hline $0 \cdot 303$ & $2 \cdot 39$ & $34 \cdot 3$ & 1,764 & $35 \cdot 15$ & 0.83 & 535 & 19,663 & 19,327 & 22,400 & 447 & $10 \cdot 5$ \\
\hline .474 & $3 \cdot 89$ & $37 \cdot 4$ & 2,295 & $45 \cdot 8$ & 1.08 & 1,088 & 24,232 & 23,745 & 27,975 & 558 & $13 \cdot 1$ \\
\hline$\cdot 153$ & 1.06 & $62 \cdot 8$ & 765 & $15 \cdot 25$ & $\cdot 36$ & $117 \cdot 5$ & 9,750 & 9,593 & 11,041 & 220 & $5 \cdot 18$ \\
\hline .337 & $2 \cdot 88$ & $36 \cdot 7$ & 2,867 & $57 \cdot 2$ & 1.35 & 967 & 29,535 & 28,972 & 33,633 & 671 & $15 \cdot 8$ \\
\hline$\cdot 280$ & 1.97 & 70 & $933 \cdot 6$ & $18 \cdot 6$ & $\cdot 44$ & 262 & 11,706 & 11,540 & 13,276 & 265 & $6 \cdot 23$ \\
\hline .216 & $1 \cdot 53$ & $55 \cdot 4$ & 832 & $16 \cdot 6$ & .39 & $179 \cdot 5$ & 10,280 & 10,125 & 11,750 & 234 & $5 \cdot 52$ \\
\hline .990 & $7 \cdot 45$ & $78 \cdot 3$ & 1,515 & $30 \cdot 2$ & .71 & 1,501 & 17,447 & 17,360 & 20,137 & 402 & $9 \cdot 45$ \\
\hline .458 & $4 \cdot 25$ & 36 & 3,303 & $65 \cdot 9$ & 1.55 & 1,511 & 31,001 & 30,629 & 35,560 & 709 & $16 \cdot 7$ \\
\hline .701 & $5 \cdot 77$ & 0 & 600 & $11 \cdot 97$ & .28 & 421 & & 7,228 & 8,333 & 166 & 3.91 \\
\hline .464 & $3 \cdot 98$ & 0 & 920 & $18 \cdot 34$ & .43 & 427 & 10,724 & 10,669 & 12,396 & 247 & $5 \cdot 82$ \\
\hline .515 & $4 \cdot 41$ & 0 & 1,032 & $20 \cdot 57$ & .48 & 532 & 12,057 & 11,985 & 13,899 & 277 & $6 \cdot 52$ \\
\hline .591 & $5 \cdot 03$ & 0 & 1,122 & $22 \cdot 35$ & .53 & 663 & 13,193 & 13,128 & 15,230 & 303 & $7 \cdot 15$ \\
\hline 1.062 & $8 \cdot 54$ & $81 \cdot 4$ & 962 & $19 \cdot 15$ & .45 & 1,021 & & 11,914 & 13,796 & 275 & $6 \cdot 48$ \\
\hline .742 & 6.09 & 78 & 1,152 & 22.95 & 54 & 855 & 14,014 & 13,986 & 16,196 & 323 & $7 \cdot 60$ \\
\hline
\end{tabular}




\section{LIQUID FUEL AND ITS COMBUSTION}

Summary of test of Hohenstein marine water-tube boiler burning oil.

\begin{tabular}{|c|c|c|c|c|c|c|c|c|c|c|c|}
\hline \multirow[b]{3}{*}{ D. } & \multirow{3}{*}{ 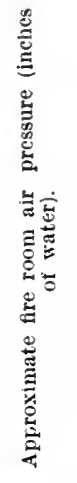 } & \multicolumn{4}{|c|}{ Chimney gas analysis. } & \multirow{3}{*}{ 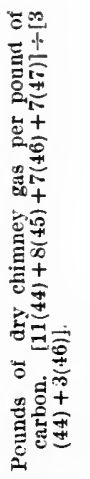 } & \multirow{3}{*}{ 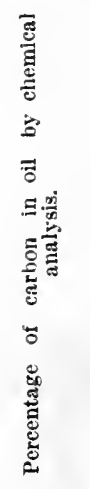 } & \multirow{3}{*}{ 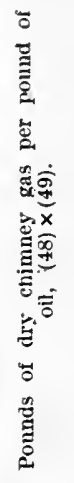 } & \multirow{2}{*}{\multicolumn{3}{|c|}{$\begin{array}{c}\begin{array}{c}\text { Heat balance, or distribution of } \\
\text { the heattag value of the oil. }\end{array} \\
\text { In Britsh thermal units. }\end{array}$}} \\
\hline & & \multirow[b]{2}{*}{ 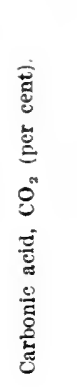 } & \multirow[b]{2}{*}{ 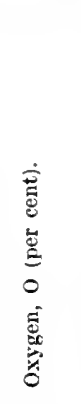 } & \multirow[b]{2}{*}{ 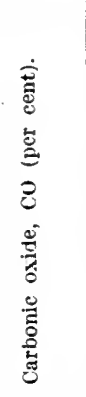 } & \multirow[b]{2}{*}{ 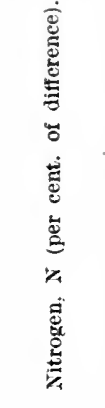 } & & & & & & \\
\hline & & & & & & & & & 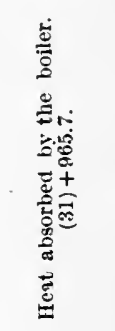 & 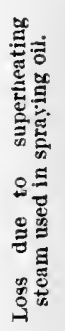 & 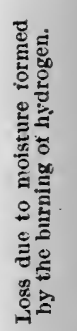 \\
\hline 1 & 10 & 44 & 45 & 46 & 47 & 48 & 49 & 50 & 51 & 52 & 53 \\
\hline 1 & $1 \cdot 3$ & 6.97 & 8.77 & $1 \cdot 50$ & $82 \cdot 76$ & 28.99 & $83 \cdot 26$ & $24 \cdot 1$ & 12,250 & 0 & \\
\hline 2 & $2 \cdot 3$ & 6.96 & 9.20 & 1.20 & $82 \cdot 64$ & $30 \cdot 11$ & $83 \cdot 26$ & $25 \cdot 1$ & 11,7 & 0 & 1,4 \\
\hline 3 & 0 & 7.24 & $10 \cdot 2$ & .425 & $82 \cdot 135$ & $32 \cdot 15$ & $83 \cdot 2$ & 26 & 13,9 & 0 & \\
\hline 4 & $3 \cdot 3$ & 7.50 & 10.4 & $\cdot 3$ & & $31 \cdot 64$ & $83 \cdot 2$ & 26 & 11,3 & 0 & 1,5 \\
\hline 5 & 0 & 7.70 & 10 & $\cdot 13$ & $82 \cdot 17$ & $31 \cdot 54$ & $83 \cdot 26$ & 26 & 13,7 & 0 & \\
\hline 6 & 0 & $7 \cdot 68$ & $10 \cdot 25$ & .06 & & 31.91 & $83 \cdot 2$ & 26 & 13,6 & 0 & \\
\hline 7 & 0 & $10 \cdot 1$ & $6 \cdot 64$ & .275 & $82 \cdot 985$ & 24 & $83 \cdot 2$ & 20 & 12,8 & 0 & 1,4 \\
\hline 8 & $3 \cdot 75$ & 7.87 & 9 & .22 & $82 \cdot 25$ & $30 \cdot 54$ & $83 \cdot 2$ & 25 & 10, & 0 & 1,620 \\
\hline 9 & 0 & & $13 \cdot 0$ & .27 & & $42 \cdot 47$ & $83 \cdot 2$ & 35 & 13,4 & 58 & 1,366 \\
\hline 10 & 0 & & $11 \cdot 05$ & .013 & & $35 \cdot 16$ & $83 \cdot 26$ & 29 & 13,0 & 77 & 1,445 \\
\hline 11 & 0 & $7 \cdot 47$ & $10 \cdot 66$ & .086 & $81 \cdot 78$ & $32 \cdot 64$ & $83 \cdot 26$ & 27 & 12,9 & 79 & 1,458 \\
\hline 12 & 0 & 8.44 & $9 \cdot 29$ & .014 & $82 \cdot 26$ & $29 \cdot 29$ & $83 \cdot 2$ & 24 & 13,1 & 93 & 1,470 \\
\hline 13 & 0 & $\begin{array}{l}8 \cdot 70 \\
8.53\end{array}$ & $9 \cdot 85$ & .075 & $82 \cdot 37$ & $31 \cdot 70$ & $83 \cdot 26$ & $26 \cdot 4$ & 13,857 & 125 & 1,481 \\
\hline 14 & 0 & $8 \cdot 53$ & $9 \cdot 04$ & .05 & $82 \cdot 38$ & 28.85 & $83 \cdot 26$ & 24 & 13,578 & 112 & 1,465 \\
\hline
\end{tabular}

Heat balance, or distribution of the heating value of the oil.

II British thermal units.

\begin{tabular}{|c|c|c|c|c|c|c|c|}
\hline 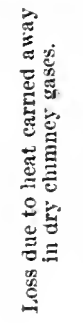 & 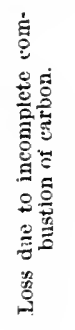 & 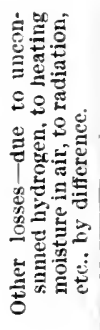 & 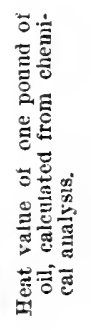 & 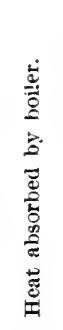 & 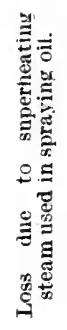 & 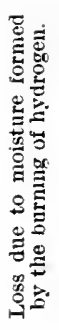 & 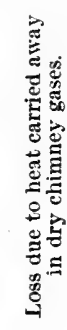 \\
\hline 54 & 55 & 56 & 57 & 58 & 59 & 60 & 61 \\
\hline 3,375 & 1,495 & 921 & 19,481 & 62.8 & 0 & $7 \cdot 4$ & $17 \cdot 3$ \\
\hline 3,925 & 1,242 & 1,074 & 19,481 & $60 \cdot 3$ & 0 & $7 \cdot 6$ & $20 \cdot 1$ \\
\hline 2,565 & 469 & 1,167 & 19,481 & 71.5 & 0 & 6.9 & $13 \cdot 2$ \\
\hline 4,720 & 320 & 1,575 & 19,481 & $58 \cdot 1$ & 0 & $7 \cdot 9$ & $24 \cdot 2$ \\
\hline 2,800 & 141 & 1,450 & 19,481 & $70 \cdot 4$ & 0 & 7 & $14 \cdot 4$ \\
\hline 3,020 & 60 & 1,385 & 19,481 & $69 \cdot 9$ & 0 & $7 \cdot 1$ & 15.5 \\
\hline 2,945 & 224 & 2,012 & 19,481 & $65 \cdot 8$ & 0 & 7.5 & $15 \cdot 1$ \\
\hline 5,480 & 230 & 1,751 & 19,481 & $53 \cdot 4$ & 0 & $8 \cdot 3$ & $28 \cdot 1$ \\
\hline 2,990 & 395 & 1,259 & 19,481 & 68.9 & $\cdot 3$ & 6.9 & $15 \cdot 4$ \\
\hline 3,500 & 16 & 1,435 & 19,481 & $66 \cdot 7$ & .4 & $7 \cdot 4$ & 18 \\
\hline 3,410 & 97 & 1,448 & 19,481 & $66 \cdot 7$ & .4 & $7 \cdot 5$ & $17 \cdot 5$ \\
\hline 3,270 & 14 & 1,511 & 19,481 & $67 \cdot 3$ & .5 & 7 76 & $16 \cdot 8$ \\
\hline 3,000 & 82 & 986 & 19,481 & $71 \cdot 1$ & 6 & $7 \cdot 4$ & $15 \cdot 4$ \\
\hline 3,070 & 49 & 1,207 & 19,481 & $69 \cdot 7$ & 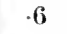 & $7 \cdot 5$ & $15 \cdot 7$ \\
\hline
\end{tabular}

Efficiency.

alue of the oil.

\begin{tabular}{|c|c|c|c|c|}
\hline 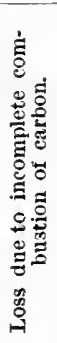 & 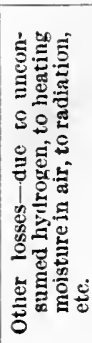 & 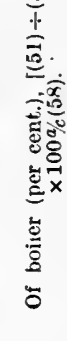 & 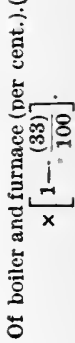 & 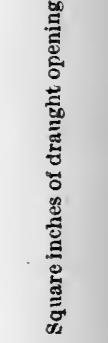 \\
\hline 62 & 63 & 64 & 65 & 66 \\
\hline $7 \cdot 7$ & 4.8 & $62 \cdot 8$ & $61 \cdot 3$ & 666 \\
\hline $6 \cdot 4$ & $5 \cdot 6$ & $60 \cdot 3$ & 58 & 666 \\
\hline $2 \cdot 4$ & 6 & 71.5 & $70 \cdot 7$ & 124 \\
\hline $1 \cdot 7$ & $8 \cdot 1$ & $58 \cdot 1$ & $56 \cdot 4$ & 666 \\
\hline .7 & $7 \cdot 5$ & $70 \cdot 4$ & 69 & 275 \\
\hline 3 & $7 \cdot 2$ & 69.9 & $68 \cdot 8$ & 348 \\
\hline $1 \cdot 2$ & $10 \cdot 4$ & $65 \cdot 8$ & 60.9 & 642 \\
\hline $1 \cdot 2$ & 9 & $53 \cdot 4$ & $51 \cdot 1$ & 642 \\
\hline 2 & 6.5 & 68.9 & $64 \cdot 9$ & 180 \\
\hline$\cdot 1$ & $7 \cdot 4$ & $66 \cdot 7$ & $64 \cdot 1$ & 500 \\
\hline$\cdot 5$ & $7 \cdot 4$ & $66 \cdot 7$ & $63 \cdot 8$ & 500 \\
\hline$\cdot 1$ & $7 \cdot 7$ & $67 \cdot 3$ & 63.9 & 500 \\
\hline .4 & $5 \cdot 1$ & $71 \cdot 1$ & 65 & 165 \\
\hline$\cdot 3$ & $6 \cdot 2$ & $69 \cdot 7$ & $65 \cdot 4$ & $664-408$ \\
\hline
\end{tabular}




\title{
Appendix No. 4
}

\section{LLOYD'S REGISTER OF BRITISH AND FOREIGN SHIPPING}

\author{
Rules for the Burning and Carrying of Liquid Fuel
}

The following rules for steel vessels have been approved:-

1. In vessels fitted for burning liquid fuel, the record "Fitted for Liquid Fuel" will be made in the Register Book.

2. The compartments for carrying oil fuel must be strengthened efficiently to withstand the pressure of the oil when only partly filled and in a seaway. They must be tested by a head of water extending to the highest point of the filling pipes or 12 feet above the load line, or 12 feet above the highest point of the compartment, whichever of these is the greater.

3. If peak tanks or other deep tanks are used for carrying liquid fuel, the riveting of these should be as required in the case of vessels carrying in bulk. The strengthening of these compartments must be to the Committee's satisfaction.

4. Each compartment must be fitted with an air-pipe, to be always open, discharging above the upper deck.

5. Efficient means must be provided by wells and sparring or lining to prevent any leakage from any of the oil compartments from coming into contact with cargo or into the ordinary engine-room bilges.

6. If double bottoms under holds are used for carrying liquid fuel, the ceiling must be laid on transverse battens, leaving at least two inches air space between the ceiling and tank top and permitting free drainage from the tank top into the limbers.

7. The pumping arrangements of the oil-fuel compartments and their wells must be absolutely distinct from those of other parts of the vessels and must be submitted for approval.

If it is intended to sometimes carry oil and sometimes water ballast in the various compartments of the double bottom the valves controlling the connexion between these compartments and the ballast donkey pump, and also those controlling the suctions of the special oil pump, must be so arranged that the suctions for each separate compartment cannot be connected at the same time to both pumps.

8. No wood fittings or bearers are to be fitted in the stokehold spaces.

9. Where oil-fuel compartments are at the sides of, or above, or below the boilers, special insulation is to be fitted where necessary to protect them from the heat from the boilers, their smoke boxes, casings, etc.

10. If the fuel is sprayed by steam, means are to be provided to make up for the fresh water used for this purpose.

11. If the oil fuel is heated by a steam coil the condensed water should not be taken directly to the condenser, but should be led into a tank or an open funnel mouth, and thence led to the hot well or feed tank.

12. The above arrangements are applicable only to the case of oil fuel; the flash point of which, as determined by Abel's close test, does not fall below $150^{\circ}$ Fahrenheit.

NoTE.-The foregoing alterations and amendments also apply to the Rules for Iron Vessels.

By order of the Committee,

A. G. DRYHURST,

71, Fenchurch Street, E.C.

Secretary. December 18th, 1902. 


\section{Appendix No. 5}

\section{RULES AND PERMITS OF VARIOUS AMERICAN BOARDS OF FIRE UNDERWRITERS}

N.B.-For use in Cities, or where it is impracticable to place the supply tank fifty feet or more from the building.

\section{CRUDE PETROLEUM FUEL PERMIT}

In consideration of the following conditions, it being warranted by the assured that the apparatus shall be maintained as conditioned below during the life of this policy, permission is hereby granted to use Crude Petroleum for fuel.

\section{CONDITIONS}

(a)-Supply tank to be substantially eonstructed of three-sixteenths ineh, or heavier iron, and equipped with indicator and man-hole;

(b) - To be under ground, and

(c)-Below the lowest point at which the oil is burned ;

(d) - To be enclosed in a briek vault of substantial construction ;

(e) - To be located OUTSIDE all buildings ; and

(j) Entirely free from the FOUNDATION of any building;

(g)-Filling pipe to be perfectly elosed, except when used in filling; (h) - A vent pipe, not less than ONE and ONEHALF INCH diameter, to be attached to tank ;

(i)-To extend at least FIVE FEET HIGHER than adjacent buildings ;

(j) - Top to be made weather proof ;

(k)-Oil to be conveyed DIRECTLY from SUPPLY TANK to FURNACE by an approved duplieate system of AUTOMATIC PUMPS

(l)-All connexions to be made perfectly tight, with well-fitted joints.

(m) - The feeding of oil by gravity pressure, whether through a stand-pipe or otherwise, is strictly prohibited.

(n)-Where storage tank for holding reserve supply of fuel oil is situated so that top of tank is above the level of the atomizers at furnace, it is prohibited to connect same with supply tank by any nipes whatever.

This form attaches to, and is hereby made a part of Poliey No. ..................

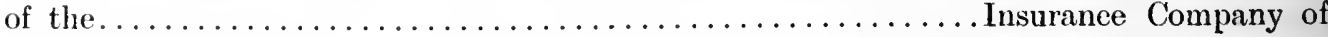

UNDERWRITERS' AGENCY OF LOUISIANA,

NEW ORLEANS, I.A.

Agent.

N.B.-For use in the County, or where it is practicable to place the supply tank fifty feet or more from the building.

\section{CRUDE PETROLEUM FUEL PERMIT}

In consideration of the following conditions, it being warranted by the assured that the apparatus shall be maintained as conditioned below during the life of this policy, permission is hercby granted to use Crude Petroleum for Fuel. 


\section{APPENDIX}

\section{CONDITIONS.}

(a)-Supply tank to bo substantially constructed of three-sixteenths inch, or heavier iron, and equipped with indicator and man-hole; (b)-To be under ground, and

(c)-Below the lowest point at which the oil is burned;

(d) - To be fifty feet or more from any building ;

(e)-Filling pipe to be perfectly closed, except when used in filling;
(f)-A vent pipe, not less than ONE and ONE-HALF INCH diameter to be attached to tank:

(g)-To extend at least FIVE FEE'C ABOVE the ground ;

(h) - Top to be made weather proof;

(i)-Oil to be conveyed DIRECTLY from SUPPLY TANK to FURNACE by an approved duplieate system of AUTONATIC PUMPS;

(j)-All connexions to be made perfectly tight, with well-fitted joints.

(k)-The feeding of oil by gravity pressure, whether through a stand-pipe or otherwise, is strictly prohibited.

$(l)$-Where storage tank for holding reserve supply of fuel oil is situated so that top of tank is above the level of the atomizers at furnace, it is prohibited to connect same with supply tank by any pipes whatever.

This form attaches to, and is hereby made a part of Policy No...................

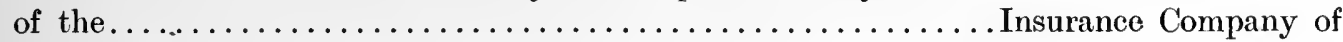

UNDER WRITERS' AGENCY OF LOUISIANA,

NEW ORLEANS, L.A.

Agent.

No. 1-Texas Form.

\section{PERMIT TO USE CRUDE PETROLEUM FOR FUEL IN STEAM PLANTS}

Permission is granted to use Crude Petroleum, or earth oil, for fuel for generating steam on the premises described in this policy under the following conditions only, the strict observance of which is hereby warranted by the assured, otherwise this entire policy shall be null and void :

(1) The tank for storage of oil supply shall be of boiler iron, or No. 18 galvanized iron or steel, having proper ventilation at top, and shall be located not less than 50 feet from the risk described, if wholly underground, or 100 feet if wholly or in part above ground, in which latter case tank shall be enclosed by a substantial brick or stone wall, or earth embankment, of sufficient capacity to hold contents of tank in event the oil is released from any cause; and in every case tank shall be so placed that the highest point in said oil supply shall be lower than the furnace where such oil is to be burned or converted for burning.

(2) Where the oil supply does not exceed 50 gallons, tank shall be underground, or encased above ground in a brick vault with 8 -inch walls, having proper ventilation at top, and in every case located outside of building described; tank to be so placed that top of tank shall be lower than the furnace where such oil is to be burned or converted for burning.

(3) The conveying of oil to furnace shall be by artificial pressure or suction, whether by pump, vacuum or other means that will accomplish the purpose. This expressly prohibits the feeding of oil by gravity pressure, or by other means from a storage supply higher than the furnace; provided, that oil may be fed to burners at furnace, under a maximum pressure of eight pounds to the square inch, from an iron stand-pipe-having a maximum capacity of five gallons-located at storage tank, and supplied from storage tank by pump while oil is being conveyed to furnace. Stand-pipe shall have an overflow pipe (with capacity equal to discharge of pump) to storage tank, and shut-off cock where supply-pipe leaves stand-pipe for furnace.

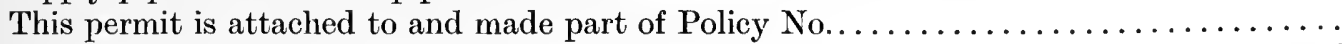

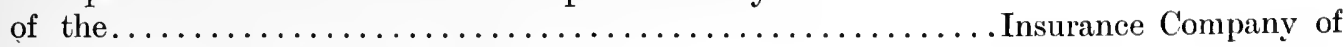




\title{
LIQUID FUEL AND ITS COMBUSTION
}

\author{
No. 2-Chicago Form-Amended.
}

\section{RULES GOVERNING THE USE OF CRUDE PETROLEUM FOR FUEL}

Permission is granted to use Crude Petroleum, or earth oil, for fuel for generating steam on the premises described in this policy under the following eonditions only, the strict observance of which is hereby warranted by the assured, otherwise this entire policy shall be null and void :-

\section{VAULT}

Vault to be located so that the oil it contains can buru out without enclangering property.

Location of vault to be left to the approval of an authorized inspector. Distance from any property to be regulated by the size of tanks.

Vault to be underground, built of brick or conerete, sides and ends to be at least 16 inches thick and to be made praetieally water-tight with hydrau. lic cement; bottom to be dished toward centre and inelined to one end, so as to drain all overflow or seepage to that end, said incline to be towards the end from which the tank is to be tapped; top to be supported with heavy iron "I" beams, with arehes of solid brick or conerete sprung from one beam to its neighbours.

Vault to be aceessible by one or more large manholes, which, when not in use, are to be kept securely locked, key to be held by some responsible party.

A trough must run from one end of the vault to the other, directly under each tank, and in the same direction as the tank or tanks.

The vault shall be air-tight as near as possible.

A siphon or pump to be arranged so as to carry out any seepage or leakage from the vault, and discharge same upon the ground.

\section{TANK}

Tank to be of substantial eonstruction, say : boiler iron or steel at least $\frac{3}{1}$ of an ineh in thickness, rivets to be not less than $\frac{3}{8}$ of an inch in dia. meter and not over $1 \frac{1}{4}$ inehes apart between centres; the entire onter surface of tank to have two good coats of coal tar or mineral paint before the tank is placed in position.

Size and number of tanks to be left to the Underwriters' organization having jurisdiction.

When tank is set, the bottom of the tank must be three inches above the floor of the vault, and must be in saddles of masonry not less than 8 inches in thickness, built from the floor of the vault, and laid in hydraulic cement, with an opening through eentre for drainage.
The filling pipe, telltale or indicator, pump supply connexion, steam connexion and ventilating pipe, where they connect with tank, must be made petroleum-tight by the use of litharge and glycerine cement. Man-hole should be at least $16^{\prime \prime}$ in diameter with a vapour-proof screw top, contact surfaces to be faced.

Flanges to make tank $\frac{3}{4}$ of an inch in thickness to be riveted so as to furnish a satisfactory joint where pipe connexions are made.

Filling pipe connexion must have gas-tight valve which must be kept elosed and locked unless the tank is being filled. Each tank must have a ventilating pipe at least $1 \frac{1}{2}$ inches in diameter, so arranged that the outlet be weather-proof and project into the air at least 10 feet, so that all the gases that form in the tank will be constantly discharged.

Tank must have indicator to show at all times height of oil in tank.

All pipes leading from the tank to the furnaces or place of burning must incline toward the tank, and must be so constructed that the feed-pipe from pump to burners shall be entirely below burners.

\section{PUMPING SYSTEM}

All systems of delivering fuel to furnaces should be so arranged that oil will be fed automatically to the atomizers in such quantities as may be required for burning-oil to be freed from mechanical impurities and from the time it leaves the tank until it escapes to the furnace the oil is not to be exposed to the atmosphere-this is intended to prohibit the feeding of oil by gravity pressure whether through a stand-pipe or by any other method.

All systems shall have twin pumps, so that each one can be used independently of the other.

All pipes between tank and furnace within the building shall be placed within a box with movable top, so as to be easily aceessible.

The oil and steam pipes, if any, between the supply tank and oil pumps shall parallel each other and be placed in the same box.

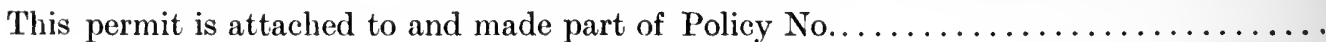

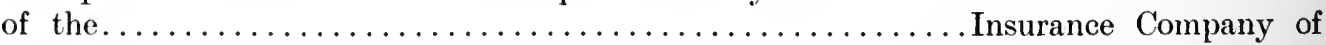




\section{APPENDIX \\ BOARD OF FIRE UNDERWRITERS, OF THE PACIFIC \\ OfFice OF District " $\mathrm{C}$ " \\ Los Angeises, Chl.}

Before any permit for the use of crude petroleum for fuel will be granted, an inspection of the premises must be made by a surveyor of the Board of Underwriters, and his report must show that all the conditions hereinafter named shall have been complied with.

No policy will be issued to cover on or in premises in which petroleum for fuel is used unless such permit is endorsed thereon, and additional premium charged at the rate of onequarter of one per cent. on the sum issued.

(A plant installed strictly in accordance with these specifications and under the immediate supervision of the Board Surveyor will not entail the one-quarter of one per cent. additional charge.)

After a plant has been approved by the Board Surveyor, any changes in its arrangements without due notice, inspection and approval of same will invalidate former certificates.

Permission granted for the use of petroleum for fuel must be in the following words. (See form of permit and conditions below).

\section{Form of Permit to be Attached to Policy.}

In consideration of the following conditions, it being warranted by the assured that the apparatus shall be maintained as conditioned below during the life of this policy, permission is hereby granted to use crude petroleum for fuel.

\section{CONDITIONS.}

(a)-Storage tank to be constructed of twosixteenth inch or heavier iron ;

(b) - To be not less than four feet underground, and

(c)-At least two feet below the lowest point at which the oil is burned;

(d)-Surrounded on all sides by at least two feet of earth or masonry;

(e)-To be located outside all buildings, and

(f)-Not within five feet of the foundation of any building;

(y)-Filling pipe to be perfectly closed, except when used in filling:

(h)-A vent pipe not less than $\frac{3}{4}$ inch diameter to be attached to tank;

(i)-To extend at least 10 feet higher than adjacent buildings;
(j)-To be covered at the top with copper gauze;

(k)-Petroleum to be forced directly from storage tank to furnace by an improved pump;

(l)-All connexions to be made perfectly tight with well-fitted joints ;

(m)-All pipes, connexions, and pumps to be capable of resisting a pressure of $300 \mathrm{lb}$. per square inch ;

(n)-Storage tank to be connected with the boiler by a steam pipe with shut-off cock;

(o)-Feed and overflow pipes not to exceed $2^{\prime \prime}$ in diameter ;

$(p)$-To be run in such a manner that they will drain into the storage tank;

$(q)$-Drain pipes to be not less than 1-4" in diameter ;

$(r)$-Overflow and drain pipes to be free trom all check, spring or shut-off valves. 


\section{Appendix No. 6}

\section{EXTRACT FROM REPORT OF MR. SCHOEN ON OIL STORAGE}

In Beaumont the point I was most struck with was the general difference in the opinions given by various experts. In most instances $I$ found their opinions very greatly biassed by that particular class of industry they represented, although their statements were made in perfect honesty. In many of the opinions obtained the statement of one man of acknowledged standing was entirely opposite to that of another standing equally as high as a man of experienee and judgement, and it was rather a diffieult matter to arrive at the true eonclusion to be derived from this mass of conflicting evidence. For instanee, one engineer considered an oil-tank fire a matter of small moment, and one which he would not hesitate to put out by means of going on top of the tank with wet blankets or other paraphernalia and smothering it, while another stated that no man with good sense would attempt such a thing and that he would not go near a tank under such circumstanees, but would shoot a hole, by means of a cannon kept for the purpose, through the base of the tank, and allow the oil to eseape into the surrounding reservoir and burn itself out there.

Mr. MeDowell, the general manager of the Guffey Oil Company, places great reliance on the reservoir [or Moat] built around the tanks. He is a man of wide experience, and states that one of the greatest dangers from this oil is that, when burning in a tank, it beeomes heated through and through and boils up like a yeast and is seattered over everything near, and that, without the reservoir walls, property is endangered within a large area adjoining the tank itself; but if the oil is allowed to run out and burn in a reservoir having a depth of say 4 feet, this boiling will not oceur and the oil will burn itself quietly out without doing further damage. The only vital point on whieh Mr. MeDowell differed from the engineers' eommittee was the 500 feet requirement as to location of tanks near the water front, as he thought that distance excessive, and that eircumstances should determine the loeation. The practice of his eompany was to leave a distance of 300 feet from outside to outside of tanks, each tank being properly surrounded by its own levee.

Mr. Brown, of the Lone Star and Creseent Oil Company, did not think the 500 feet space excessive; he was separating his tanks from each other 400 feet from outside to outside, and surrounding each tank with suitable levees [Moats].

Mr. McFadden, of the Byrd Syndicate of London, was inelined to think the hazard slight, and the 500-foot distance excessive. There were other opinions, unnecessary to mention here, but none convineed the writer that there is any reason for changing the 500 -foot space requirement.

I made flash-tests of the oil with an Eimer \& Amend elosed test apparatus. The flash varied a good deal, aeeording to the well from which the oil was taken. One test of oil taken from a well and not opened until tested, showed a flash of 122 degrees F., while another sample flashed at 91 degrees $F$., which was at the ordinary temperature, without any fire being applied ; and with the fire applied flashed freely and frequentlyafter passing 97 degrees $F$., the burning point being reached at 135 degrees $F$. 


\section{APPENDIX}

On the subject of pipe lines the engineers at Beaumont agreed that they should be constructed of wrought iron of standard oil pipe line thickness and dimensions, joints to be threaded not less than eight to the inch (11 threads per inch is English practice) and the line constructed to maintain a pressure of at least 1,200 pounds to the square inch, a maximum pressure being allowed of say 300 pounds to the square inch-in other words, allowing a factor of safety of four.

Pipes to be laid underground at such depth as to be unaffected by either heat or cold and the equipment arranged to be drained back to the main tank and empty itself when not in actual operation, such draining back to be through siphoning or pumps. The connexions with the individual tanks for supplying boiler equipments not to be permanent, but in every instance to be connected up through double valves and a lose break joint. This hose to be removed as soon as the small supply tank has been filled. The idea is to have a regular time for filling these tanks and the attendant connected with the pipe line company to go to each tank separately, connect up his hose length, open the valve on the pipe line side and the one on the tank side, meter the oil passing into the smaller tank, and when the proper volume has been supplied, shut off both the beforementioned valves and remove the section of hose. This avoids either hydrostatic or hydraulic pressure.

At all times when the equipment is in service and the pipe line attendant not present, there should be a blind cap for each end of the pipes where broken, the pipe from the pipe line to the hose connexion to be arranged to drain back and a vent pipe connected thereto, equipped with convenient hand valve in order that aecumulating gases may be allowed to escape. Several pipe line breaks had occurred, due to the accumulation and expansion. of these gases, and, therefore, at proper intervals, vent pipes should be installed.

Desulphurizing was being carried on by means of which the flash point of the oil is raised before it is sent out as a fuel. This is a very important part of the process, as otherwise the oil is liable to vary in flash from that of gasoline up to such point as may have been reached through the volatilization of the lighter oils and drawing off of the gases, which is, of course, largely dependent on the temperature to which it has been subjected, and to what extent the oil has been handled and stored.

The desulphurizing process is in itself a simple one and merely consists in driving off the more highly volatile oils in the shape of gases by means of a steam coil in the tank containing the oil. It would seem that the German Admiralty requirement is 188 degrees F., the British Admiralty 270 degrees F., and the Lloyds 160 degrees F. Some of the German Admiralty oil was being obtained at the time of my visit, and no trouble whatever was found in obtaining the flash test of 188 degrees demanded.

As a further important reason for desulphurizing this oil and raising the flash test. it has been found that the gases given off from the low flash oil attack the metals with which they come in contact, forming sulphides. Thus, it was found that sulphide of iron, sulphide of copper and sulphide of zine had been formed, according to whether the gases came in contact with iron or brass. Some of the oil men in the field had experienced considerable trouble from this chemical action occurring, the metal principally affected being that above the ordinary level of the oil, it being the part most in contact with the gases. 


\section{Appendix No. 7}

\section{EXTRACTS FROM REPORT BY MR. SCHOEN ON INSTALLATIONS OF FUEL OIL}

Accidents sometimes arise from failure to keep open the main damper connected with the boiler equipment. The result of this had been an aceumulation of gases in the fire box, followed by explosions which had varied in the damage done from blowing a few bricks out of the stack to blowing off the brickwork of the firebox and sides of the boiler. In every instance it had resulted through carelessness and the damper being allowed to fall shut or partially so. The necessary draught can be regulated through the doors at the front of the furnace, and the writer thinks that it would be best to require either the removal of the damper altogether or else that it should be strapped open permanently.

The questions of burners or jets is one so broad in its scope that after investigating a large number of these the writer feels that it would be inadvisable to make any recommendations or comments regarding them. Almost every engineer either using or installing the apparatus has a different idea as to the burner, and who is right and who is wrong must be left to time to determine.

Of eourse, it was found that the opinions of the various men using this apparatus varied according to the equipment they had in service and their individual ideas. Some felt that a standpipe was necessary to insure an even, steady feed; others eonsidered it quite unnecessary. Some thought a pop valve desirable for regulating the oil pressure on the burners; others thought this unnecessary and that the regulation should be at the pumps. Some considered steam heat necessary both in the tanks and in the base of the pump in order to bring up the oil more readily, others thought this heat unnecessary and that better service would be obtained through drawing the oil in at ordinary temperatures; consequently I thought the wisest way of dealing with these matters would be to go to the oil equipment manufacturers themselves and discuss every phase of the situation with them, which was done in New Orleans, as will be stated further on in this report.

At Dallas I met with the members of the Fuel Oil Committee of the Texas Fire Prevention Association, and diseussed the question of wood and also of cement tanks for holding this oil. The chairman felt that such tanks should be permitted, but the writer did not agree with him for reasons that will be indicated later on.

On the question of location of individual supply tanks under sidewalks the committee did not feel that there were sufficient reasons to justify the underwriters in refusing to permit equipments to be installed in this manner, and they also recommended that overground tanks be permitted where the ground space and conditions justified this being done. In other details they pretty well agreed with the Engineers' Committee as to method of installing equipments. 


\section{APPENDIX}

In New Orleans the matter of individual equipments was fully discussed with concerns contracting for this class of equipment.

The general idea seemed to be that a small standpipe of say not exceeding 10 gallons capacity should be permitted, in order to bring about an even and steady feed to the burners.

It was thought that a steam coil leading into the tank was quite unnecessary, and, in fact, objectionable, for, although the oil was heated and would therefore flow more readily in cold weather, at the same time the heat would be sufficient to drive off gases which might prove troublesome. The manufacturers seemed to think this coil unnecessary in connexion with the class of oil being used. They all recommended, however, that a free steam pipe be run into the tank for the purpose of extinguishing fire in case of accident.

I found the oil pressure varying from 15 pounds as the lowest to 80 pounds as the highest of the different equipments. The manufacturers agreed that a maximum limit of 60 pounds would be ample for any equipment, this pressure to be controlled, not by a pop valve, or arrangement on the oil pipe, but through the medium of a steam valve most of which valves are operated by means of a spring and disc. The reason for the pressure limit is that the apparatus is not ordinarily built to withstand excessive strain.

All were agreed as to the necessity for a duplicate system of pumps. There was no exception to this whatever

Most of them felt that tanks having a maximum capacity of 12,000 gallons would be quite satisfactory, the capacity mentioned being on account of the capacity of the largest tank cars which I understand will be made as large as 12,000 gallons.

They did not feel that vaults were in any way necessary in connexion with the construction of these tanks, but were strongly in favour as a whole of insisting on properly constructed steel or iron tanks built of not less than $\frac{3}{16}$-inch metal. A maximum diameter of 8 feet was recommended, or 10 feet at the outside, this being in the interest of strength.

As to burners, the Rockwell Company laid great stress on having a combustion chamber at the point where the steam and oil jet enters the firebox.

Of course, the necessity for checkerwork for thoroughly dividing up and consuming the gases goes without saying.

The question of burners, though thoroughly investigated, admits of little comment. Some of them are arranged to mix the oil with the steam as they leave the jet, others have a mixing chamber just before issuing from the jet to the furnace. I am inclined to think that in this latter type of burner the method of bringing the steam and oil together accounts for the extra high pressure used at the pump for forcing the oil through the opening, the explanation lying in the fact that the back steam pressure at the end of the burner has to be overcome by the oil.

With the increase in horse power required by the boiler there is generally an increase in the number of burners, and limiting one burner to say 75 horse power, met with the approval of most. Some objection was made on account of one form of burner, which, instead of sending out steam and oil as a jet, spreads it out in the shape of a fan ; I understand this has been found suitable for over 200 horse-power, and calorimeter measurements have proven the results entirely satisfactory.

My reason for wishing to limit the number of horse power to a burner was to prevent throttling, as far as possible. With a single burner, as the demand on the plant decreases, it is customary to throttle the fuel at the burner, and when too closely throttled, the fire has been known to go out while the gas continued to accumulate under the boiler, causing an explosion when re-ignited. If two or more burners are used, the burners will be shut off at one time, and thus throttling to any very great extent is avoided. This point is mentioned in the report as being desirable, but possibly not practicable at the present time.

At each point visited I made a flash test of oil procured from plants in actual operation. 


\section{LIQUID FUEL AND ITS COMBUSTION}

That is, a bottle was dropped into the tanks supplying the boilers, and the oil taken was actually as used. The results were as follows :-

\begin{tabular}{|c|c|c|c|c|c|c|c|c|c|c|c|c|c|c|}
\hline & & & & & & & & & & & & & $\begin{array}{c}\text { Flash Point. } \\
\text { Degrees F. }\end{array}$ & $\begin{array}{l}\text { Burning Point. } \\
\text { Degrees F. }\end{array}$ \\
\hline Galveston & . & . & - & . & . & . & . & . & . & . & & & . $\quad 120$ & \\
\hline Houston . & . & . & . & . & . & . & . & . & . & . & . & . & 105 & 158 \\
\hline Dallas . & . & . & . & . & . & . & . & . & . & . & . & . & 96 & 140 \\
\hline Dallas . & . & . & . & . & . & . & . & . & . & . & . & . & 87 & $\ldots$ \\
\hline New Orleans & & . & . & . & . & . & . & . & . & . & . & . & 118 & $\ldots$ \\
\hline Beanmont & . & . & . & . & . & . & . & . & . & . & . & . & 122 & $\ldots$ \\
\hline Beaumont & . & . & . & . & . & . & . & . & . & . & . & . & 91 & 128 \\
\hline
\end{tabular}

It would seem that a properly constructed and operated pipe line or system would be an ideal method of supplying the individual installations with oil. Such an arrangement should prevent possible spilling and loss of oil in the streets and avoid the necessity for large storage on the premises, do away with tank cars standing about the premises, and with variouss other possible dangers and annoyances that would be incident to the usual method of supplying the oil ; and while every restriction should be imposed tending to the careful installation and equipment of these lines to prevent possible breakage and waste of oil in the streets, if this is done the advantages.accruing would appear to overbalance the disadvantages of such installations.

Outside of its being readily changed into gas, a dangerous feature of oil over coal is its liquid state. A large volume of it, if not properly safeguarded, and cut off carefully from other than its own proper limits, would be liable, in case of accident, to flow over a large area, carrying destruction with it, and especially if on water and flowing past the waterfront of a town. The ordinary fire fighting apparatus is worse than useless in such emergencies and the hazard faced is conflagration rather than individual losses. Therefore it behoves the underwriters and municipalities to see that all proper precautions are taken where large storage tanks are erected, for by taking these precautions, every possibility of danger may be removed.

The extent to which this ideal fuel will be used depends, of course, on the extent of the oil fields, and the prices to consumers. At the present time oil is being sold at Spindle Top as low as 3 cents per barrel, though the prices generally range from 10 cents to 20 cents per barrel.

According to Professor Denton, of Stevens' Institute of 'Technology, coal at $\$ 3$ per ton would be the equivalent of oil at from 58 cents to 85 cents per barrel, depending on the grades of coal to which reference is had.

With these prices before us and having in mind the cleanliness and convenience of handling, absence of smoke, etc., it is probable that, unless some unforeseen difficulties arise, such as the decrease in yield at the fields, this fuel will become a factor in the commercial prosperity of this country, and it is the part of wisdom to provide proper requirements for safeguarding its use, in the beginning. 


\section{Appendix No. 8}

\section{RULES AND REQUIREMENTS OF THE NATIONAL BOARD OF FIRE UNDER- WRITERS FOR REGULATING THE HAZARD OF THE STORAGE AND USE OF FUEL OIL, AND FOR THE CONSTRUCTION AND INSTALLATION OF OIL BURNING EQUIPMENTS, AS RECOMMENDED BY ITS COMMITTEE OF CONSULTING ENGINEERS, EDITION OF 1902}

Fuel oil is a term applied to oils having numerous variations as regards source of origin, composition, manufacture and flash point. The latter chiefly interests the fire underwriters and governs the hazard. The objectionable and volatile gases should first be driven off from the oil, and this chief danger thereby removed. These rules therefore relate to such a safeguarded oil having a minimum flash test of $160^{\circ} \mathrm{F}$.

\section{Class A}

Large Supply or Storage Tanks for F'uel or Crude Oil.

\section{Capacity}

Shall have a capacity not exceeding 37,500 barrels; 42 gallons * to the barrel; or $1,575,000$ gallons. [1,312,500 imp. gals. $]$

Shall not exceed 30 feet.

\section{Height}

\section{Material}

Shall be strongly built of steel or iron plates, properly riveted together having a factor of safety of at least 4 , and properly braced inside.

\section{Top}

Shall be provided with an air and water-tight top having a non-inflammable upper surface, which shall be properly vented through a pipe not less than 6 inches in diameter. This vent pipe to be provided with a copper screen.

\section{Location}

a. Shall be so located as to leave a clear space of not less than 500 feet between it and any burnable property, other than oil tanks, and shall be at the lowest point available.

$b$. Tank shall be located at least 500 feet back from the water front. (High water.)

c. When near a stream without tide, tank shall be located down stream from the town.

d. On tide-water, tank shall be located well away from the shipping districts.

\section{Distance Between Tanks}

The minimum distance between tanks shall be at least 300 feet.

* The American gallon of $8 \frac{1}{3} \mathrm{lb}$. of water. The English or Imperial gallon-10 lb. of water. 


\section{LIQUID FUEL AND ITS COMBUSTION}

\section{Embankment}

a. Each tank shall be surrounded by an embankment having a height of not less than 4 feet, nor more than 6 feet.

b. 'To be firmly and compactly built of good earth, from which stones, vegetable matter, etc., have been removed. To have a crown of not less than 3 feet and a slope of at least 2 to 1 on both sides.

c. To bo provided with properly built steps where it is necessary to pass over the embankment.

d. Reservoirs thus formed to have a capacity of at least one and one-half times that of the tank surrounded.

\section{Steam Pipe}

a. Each tank shall be equipped with an independent steam pipe for use in case of fire, the outlet of which shall be inside the tank, above the surface of the oil.

Nork. - This pipe to be of ample eapaeity, but never smaller than $\frac{1}{2}$ inch.

b. Stean to be supplied from the boilers used in connexion with the pump or from other boilers conveniently located.

\section{Pumps}

Pumps used in eonnexion with the supply and discharge of the tank shall be located outside the reservoir walls and at such a point that they will be accessible at all times, even if the oil in the tank or reservoir should be on fire.

\section{Pipe Connexions}

a. All oil conveying pipes to be laid underground, but under no circumstances shall they break through the reservoir walls.

The above rule does not apply to pipes passing under the reservoir wall and laid well below the surface of the ground.

b. Separate pipes shall be used for discharging oil from and supplying oil to the tank.

\section{Controlling Valves}

a. There shall be a gate valve located at the tank in each oil conveying pipe. In case two or more tanks are cross-connected these shall be a gate valve at each tank in each cross-connexion.

b. There shall be a gate valve in the discharge and suction pipes near the pumps, and a cheek valve in the discharge pipe located underground.

\section{Plans and Specifications}

A complete set of plans and specifications of proposed installation shall be submitted to the underwriters having jurisdiction before beginning construction.

\section{Class B}

\section{Individual Oil-Burning Equipments. For other than Household Purposes}

Apparatus using oil for fuel, however safeguarded, introduces a distinct increase in hazard which should be recognized by underwriters.

Where used the following rules should be rigidly observed. $160^{\circ} \mathrm{F}$.

All oil used for fuel purposes under these rules shall show a flash test of not less than

\section{Tank Capacity}

a. No single tank shall have a capacity in excess of 300 barrels ; 42 gallons to the barrel, or 12,600 gallons. $[10,500$ imp. gals. $]$

b. Where the supply is taken from tank ears, two tanks shall be installed, each tank to have a capacity equal to that of the tank ear from which it is filled, but never in excess of 300 barrels. 'Tank cars not to remain on the premises except when filling supply tank.

A tank sliould be shut off from the system while it is being filled and the pumps sup. 


\section{APPENDIX}

plied from the second tank. The above rule provides sufficient capacity for this arrangement. See Rule $27 b$.

c. Where the supply is taken from tank wagon, a single tank having a capacity not exceeding 300 barrcls may be used.

\section{Location}

a. Tanks to be located outside of the building, undergrotind, at least 2 feet below the surface, at least 30 feet removed from all buildings, and the top of the tank to be below the level of the lowest pipe in the building used in connexion with the apparatus.

$b$. When owners prefer to put the tank in a vault (which would increase the danger of a mixture of gas with air in a confined space and be liable to result in explosion by ignition from lightning or otherwise) and the same is permitted by underwriters having jusrisdiction, the tank shall be enclosed in a properly constructed vault and shall be connected to moist ground to carry off lightning.

The following general rules of safety should be complied with in the construction vaults for this purpose ; vault to be underground, at least 30 feet removed from buildings, built of brick or concrete, sides and ends to be at least 16 inches thick, to be made practically water-right; bottom to be of concrete, dished toward the centre and inclined to the opposite end from which the tank is tapped ; top to be supported with heavy "I" beams with arches of brick or concrete.

A trough to run from one end of the tank to the other, directly under each tank, and in the same direction as the tank or tanks. A siplion or pump to be arranged so as to carry out any seepage or leakage, suction to be from a cesspool at lowest end. Vault to be accessible through one or more man-holes, which, when not in use, are to be kept securely closed and locked. Vault to be well ventilated and no open lights to be used.

c. When permitted by the underwriters having jurisdiction, tank may be located above ground subject to the following conditions : It shall be located at least 200 feet from burnable property ; at the lowest point available ; shall have a capacity not exceeding 1,500 barrels; top of tank shall be located below the level of the lowest pipe used in connexion with the apparatus. It shall otherwise comply with the rules for large supply tanks. See Rules 2, 3, 4 and 7 to 12 inclusive.

\section{Materials}

Tanks shall be built of iron or steel, having a thickness not less than $\frac{3}{8}$-inch for tanks buried in earth and $\frac{1}{4}$-inch for above ground and vault tanks. To be sufficiently strong to support the weight of the earth under which it is buried, and to withstand corrosion and the most severe strains to which it is liable to be subjected in practice with a factor of safety of at least 4. The shell of the tank to be properly reinforced where pipe connexions are made.

\section{Coating}

Tanks shall be painted on the outside with a heavy coat of tar or other suitable material impervious to the corrosive action of moisture and mineral salts contained in the earth.

\section{Vent Pipe}

Each tank shall be equipped with a vent pipe not less than 2 inches in diameter attached to the top of tank and extending at least 10 feet above the ground. Vent pipe to be provided with a weather-proof top.

\section{Indicator}

Each tank shall be equipped with a device indicating the level of the oil, installed in suitable iron piping extending within 2 inches of the bottom of the tank.

\section{Man Head}

Shall be of metal, oil and gas-tight and securely bolted in position, to be kept tightly closed except when cleaning or repairing the tank. 


\section{LIQUID FUEL AND ITS COMBUSTION}

\section{Filling-Pipe}

Shall have a screw eap which shall be kept in place and tightly closed except when tank is being filled.

\section{Hose for Filling}

Filling shall be through a seetion of hose suitable for the purpose, which shall be detached from the filling pipe when not in service.

Flexible metallie hose is recommended.

\section{Oil Feed}

a. Oil to be fed from supply tank to the burners by an approved duplicate system of oil pumps. Pumps to be equipped with a pressure gauge for oil, and shall be so arranged that either pump can be cut entirely out of service while the other is in use.

b. System shall be so arranged that the oil pressure cannot at any time exceed 60 pounds. This is to be accomplished by the automatic control of the pumps and an automatic spring relief valve in the oil system. The relief valve to be arranged to return the surplus oil back to the supply tank.

\section{Gauge Glasses}

Gauge glasses, the breaking of which would allow the eseape of oil, are prohibited,

\section{Receivers or Accumulators}

a. If used, they must safely withstand a hydrostatie pressure test of 250 pounds per square inch, maintained for 5 minutes. They shall be equipped with a thermometer, proper oil strainers, and so arranged that the oil will automatically drain baek to the supply tank immediately upon elosing down the pump.

$b$. The eapacity of the oil ehamber shall not exeed 10 gallons.

\section{Stand Pipes}

a. If used, their eapacity shall not exeed 10 gallons.

b. To be substantially eonstructed in every respeet, equipped with an overflow and so arranged that the oil will automatieally drain back to the supply tank immediately upon closing down the pump.

\section{Piping}

a. Standard wrought-iron pipe to be used, the same to be earefully protected against mechanieal injury. Fittings to be of heavy east iron.

The pipe eonnexions to burners, particularly to forge shops, are often subject to breakage, and should be installed so as to avoid injury.

Where flexible connexions to burners are essential, metallic hose must be used.

$b$. All pipes leading from the supply tank shall be so laid that they will drain back to it, and all piping in connexion with the apparatus to be so arranged that it can be drained back to the supply tank.

Where practicable, the latter should be arranged to operate in connexion with the automatie drain from the aecumulator or stand pipe. See Rules $24 a$ and $25 b$.

c. Openings for pipes through outside walls shall be seeurely cemented and made oil-tight.

d. Fill and vent pipes leading to the surface of the ground sliall be boxed or jacketed to prevent loosening or breakage of comexions by frost.

e. Overflow and return pipes to be at least one size larger than the supply pipe.

1. All eomexions to be perfectly tight with well-fitted joints. Threaded joints to be made with litharge and glycerine cement. Flanges, when used, to be faced and packed with copper gaskets.

g. The entire system of piping must safely withstand a test of at least 200 pounds to the square inch.

\section{Shut-off Valves}

a. A valve for cutting off the oil supply in case of aceident shall be installed where 356 


\section{APPENDIX}

readily accessible, and as near as practicable to the point where the supply pipe leaves the tank.

b. When the oil supply is taken from two tanks the necessary valves and connexions shall be installed for shutting off either tank while the other is being filled.

\section{Cluss C}

\section{Oil Conveyors or Carriers}

28. Steamers, Etc

a. Steamers, barges or vessels loading or discharging oil, whether having same in bulk or otherwise, shall not load or discharge at wharves other than those used by the oil company, and such wharves shall be well isolated from all burnable property or wharfage.

$b$. There shall be a gate valve immediately at the point in the pipe line where connexion is made with the hose leading to the ship, for the purpose of shutting off the oil, and there shall be another gate valve in this line of pipe, at a distance of at least 10 feet back from the wharf, where it will be readily accessible for the purpose of shutting the oil off in the event of failure on the part of the valve first mentioned.

c. A tight connexion shall be made with the hose length at the wharf by means of a carefully threaded coupling, to prevent leakage and accumulation of oil around the piers.

d. Lights.-No fire or open lights to be allowed on the vessel while at the wharf.

\section{Class D}

\section{Apparatus for Cooking and Heating}

The use of oil as fuel for domestic purposes is regarded from an insurance view-point as much more hazardous than the use of ordinary fuel, such as coal, wood and coke.

Wherever equipments are installed the following general precautions should be observed-

All oil used for fuel under these rules shall show a flash test of not less than $160^{\circ} \mathrm{F}$.

\section{Storage Tank.}

$a$. Shall be located at least 30 feet removed from all buildings, underground where possible, and below the level of the lowest pipe in the building used in connexion with the apparatus.

$b$. If impracticable to bury the supply tank, the same may be installed in a noncombustible building or vault (for danger of gas accumulation and ignition at vault see Class $b$, Rule 14, Sec. $b$ ) 30 feet removed from all buildings, properly ventilated, preferably from the bottom, always remembering that it must be below the level of the lowest pipe in the building used in connexion with the apparatus.

c. To be constructed of iron or steel having a thickness not less than $\frac{3}{8}$-inch for tanks buried in earth and $\frac{1}{4}$-inch for above ground and vault tanks, securely riveted together or pressed into form. Tanks should be galvanized, or painted with rust proof paint.

d. To be provided with a fill pipe and a vent pipe.

\section{Auxiliary Supply Tank}

a. Shall, if inside the building, not exceed 1 gallon in capacity, and if outside the building not exceed 5 gallons in capacity, except by special consent of the underwriters having jurisdiction.

b. Shall be located at least 10 feet from the burners.

c. Shall be provided with an overflow connexion draining to the storage tank and a vent pipe leading outside the building, the latter to have a weatherproof hood.

$d$. To be constructed of brass, copper or iron, well put together and of sufficient strength to withstand any usage to which it may be subjected in practice. Joints not to rely entirely on solder.

e. An oil pump to. be used in filling the auxiliary from the storage tank. 


\section{LIQUID FUEL AND ITS COMBUSTION}

\section{Piping}

a. None but standard wrought iron or brass pipe to be used.

b. Connexions to outside tank shall not be located near nor placed in the same trench with other piping. oil-tight.

c. Openings for pipes through outside walls shall be securely cemented and made

l. Piping to be run as direct as possible and joints to be made as specified in Rule $26 f$.

e. Piping for oil feed and overflow from auxiliary supply tank shall be installed with a good piteh so the oil will drain back to the storage tank.

t. Fill and vent pipes leading to the surface of the ground shall be boxed or jacketed to prevent loosening or breakage of eonnexions by frost.

g. A shut-off valve to be provided in the supply pipe near the burners and another close to the auxiliary supply tank.

\section{Installation of Burners}

a. Overflow.-Burner shall be installed with overflow attachment so arranged that any surplus oil will drain from the burner through a pipe, by gravity, into a reservoir having eapacity not less than that of the auxiliary tank, and to be supplied with a similar vent.

b. Draught.-The damper in the smoke pipe shall be permanently fixed wide open, and any regulation of the draught accomplished through the dampers in front.

\section{Instruction Card}

A earl giving complete instructions in regard to the eare and operation of the system to be permanently placed in the vieinity of the apparatus.

\section{Construction of Burners, General Precautions}

Owing to the apparently undeveloped condition of burners and appliances designed to use oil for fuel, no detailed specifications covering safeguards in their construction can be given at this time.

a. The size of the orifice through which the oil is supplied to the burners should be limited to furnish only sufficient oil for the maximum burning conditions when the controlling valves are wide open.

$b$. Burners containing ehambers which allow the dangerous aecumulation of gases are prohibited.

c. Burners containing oil conveying pipes or parts subject to intense heat or subject to stoppage from earbonization are prohibited.

d. Burners should be so designed that they can be easily cleaned and so arranged as not to allow leakage of oil under any conditions. 


\section{Part IV}

T A BLES 



\section{TAB}

THE PROPERTIES OF

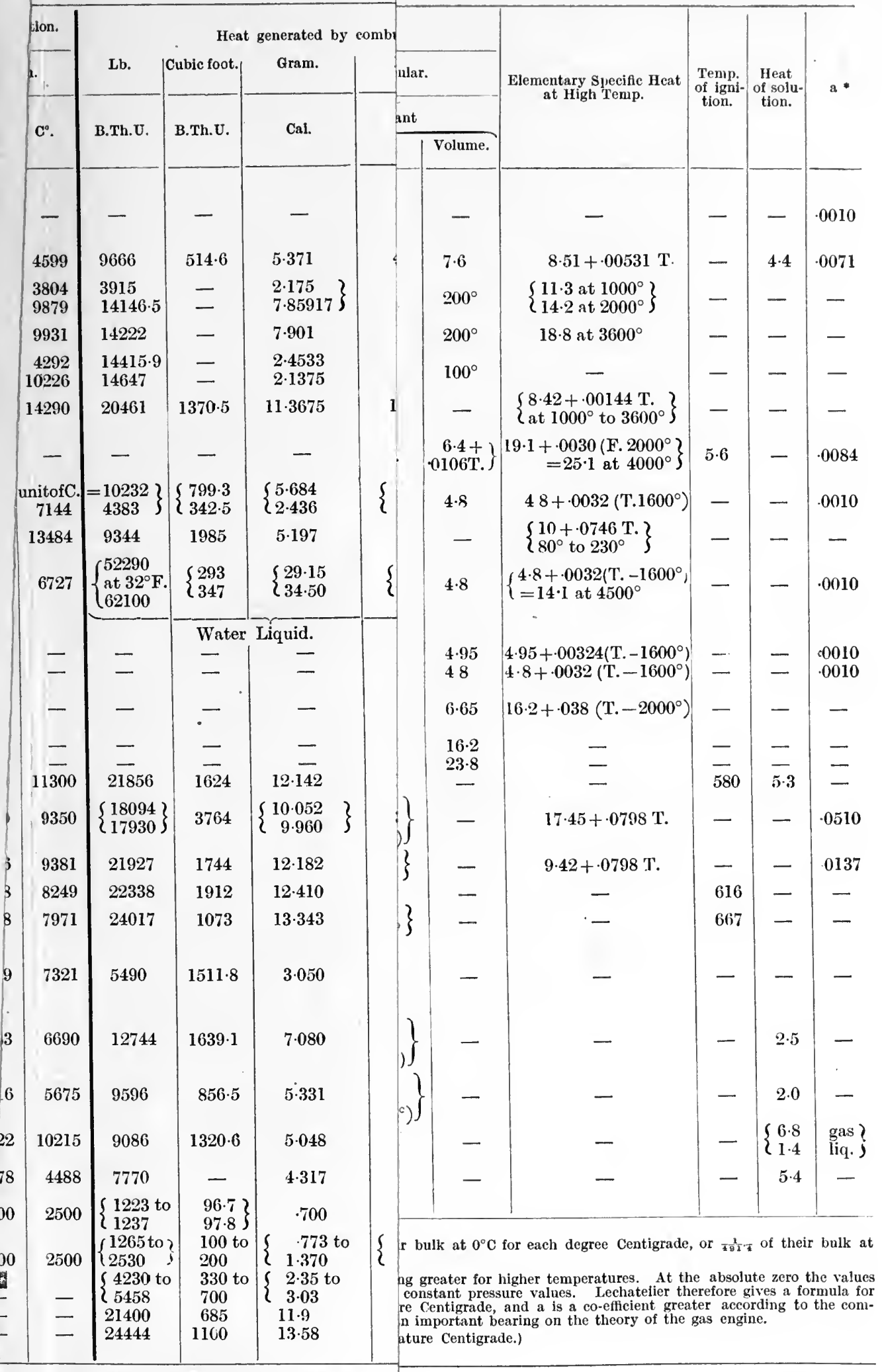



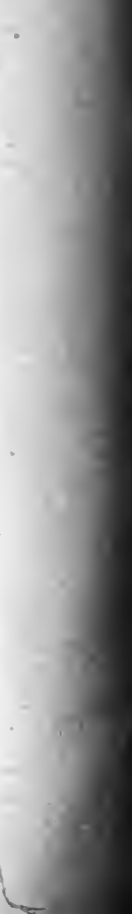
TABLE I. Composition of Crude Oils.

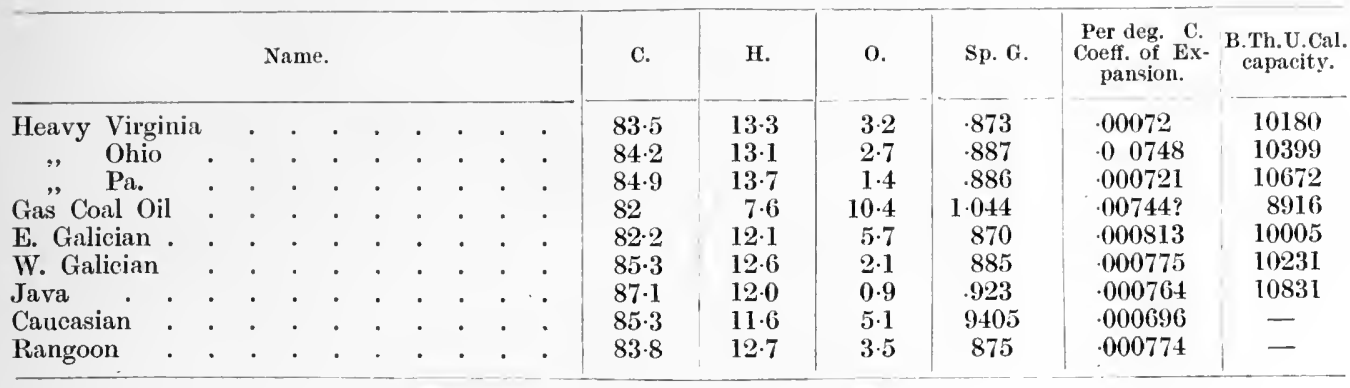

TABLE II. Calorific Capacity of Liquid Fuel Oils.

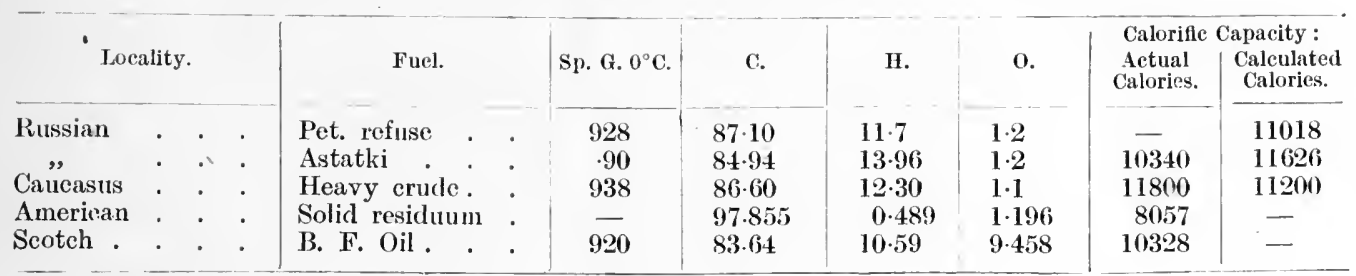

TABLE III. Coefficient of Expansion of Crude Oils.

\begin{tabular}{|c|c|c|c|c|c|c|c|c|c|c|}
\hline & & & & & & & & & Sp. Gr. $\times 1,000$. & $\begin{array}{l}\text { Coefflcient of } \\
\text { Expansion of Crude } \\
\text { Oil } \times 1,000,000 . \\
\text { Dr. Engler. }\end{array}$ \\
\hline Pelina & · & - & $\cdot$ & $\cdot$ & · & • & $\cdot \quad \cdot$ & $\cdot$ & 816 & 840 \\
\hline Canada & $\cdot$ & - & - & - & $\cdot$ & · & - & $\cdot$ & 828 & 843 \\
\hline Alsace & - & . & . &. & . & . & - & . & 829 & 843 \\
\hline Virginia & - & . $\quad$. & - & . & - & . & - & .. & 841 & 839 \\
\hline Alsace & $\cdot$ & $\cdot \quad \cdot$ & - & . & - & · & - & . & 861 & 858 \\
\hline Wallachia & & $\therefore \quad$ & . & . & . & . & . & . & 862 & 808 \\
\hline E. Galicia & & $\cdot \quad \cdot$ & . & $\cdot$ & · & $\cdot$ & - & . & 870 & 813 \\
\hline Rangoon & $\cdot$ & - $\quad$. & . & - & . & . & $\cdot$ & . $\quad$. & 875 & 774 \\
\hline Caucasus & & $\cdot \quad \cdot$ & . & - & · & $\cdot$ & $\cdot$ & .. & 882 & 817 \\
\hline W. Galicia & & $\cdot \quad \cdot$ & - & - & $\cdot$ & $\cdot$ & · & . & 885 & 775 \\
\hline Ohio . & - & . $\quad$. & . & - & & - & · & - : & 887 & 748 \\
\hline Baku . & $\therefore$ & - $\quad$; & . & - & $\cdot$ & $\cdot$ & . & - . & 850 & 784 \\
\hline Hanover ( & $(\mathrm{Od}$ & lesse) & . & - & . & . & - & . $\quad$. & 892 & 772 \\
\hline Pechelbron & $n n$ & • & - & - & $\cdot$ & . & $\cdot$ & $\cdot \quad \cdot$ & 892 & 792 \\
\hline Wallachia & & & - & - & $\cdot$ & - & $\cdot$ & $\cdot \quad \cdot$ & 901 & 748 \\
\hline Hanover ( & $(\mathrm{Ob}$ & erg) & - & - & $\cdot$ & - & $\cdot \quad \cdot$ & $\cdot \quad \cdot$ & 944 & 662 \\
\hline Hanover ( & (Wi & lesse) & - & • & $\cdot$ & - & $\cdot \quad \cdot$ & . $\quad \cdot$ & 955 & 647 \\
\hline
\end{tabular}

Heavy viscous oils 0.0007 to 00.00072 between $20^{\circ}$ and $78^{\circ} \mathrm{C} .=68^{\circ}$ to $172 \cdot 4^{\circ} \mathrm{F}$. containing Paraffin and solid below $20^{\circ}=.00075$ to $\cdot 00081$. 


\section{LIQUID FUEL AND ITS COMBUSTION}

Table IV. Calorific Power of Crude Oil.

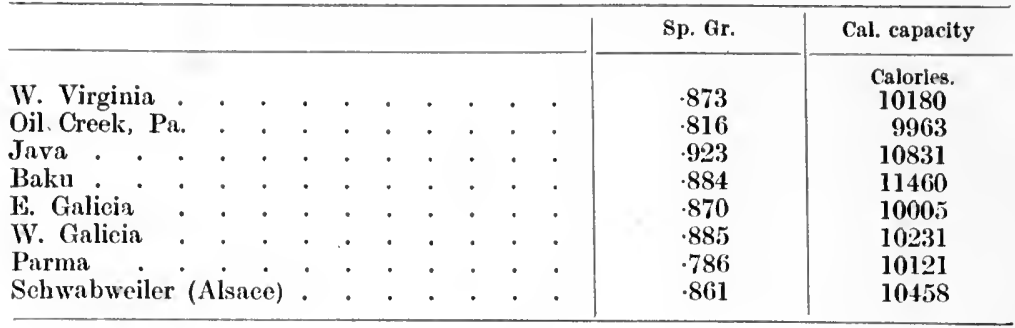

Table VI. Temperature.

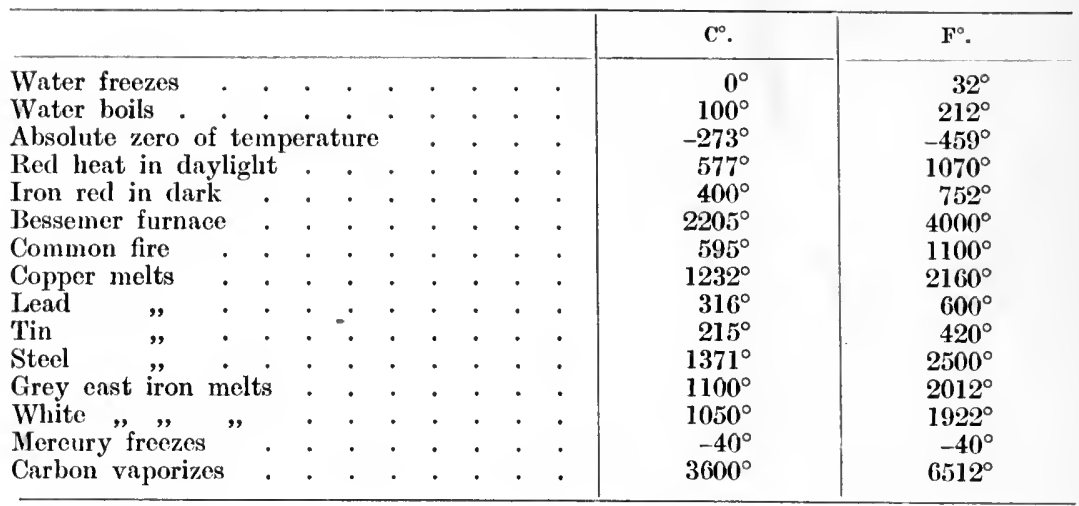

Table VII. Specific Heats of Solids.

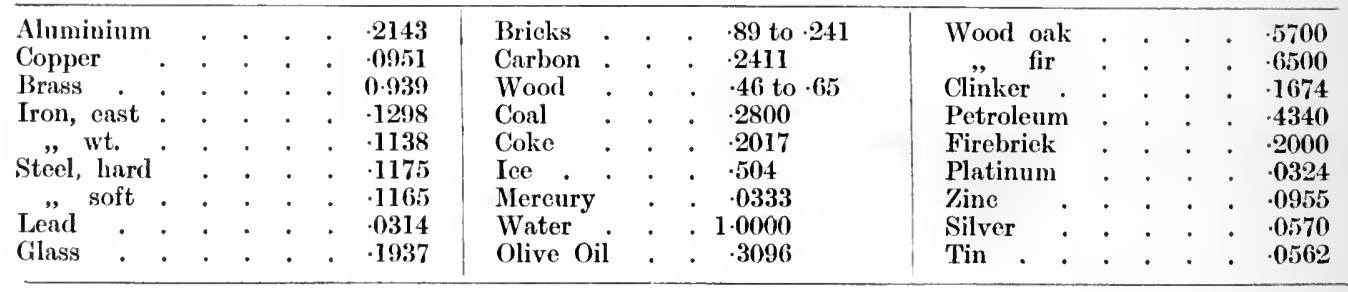

TABle VIII. Specific Heats of Gases.

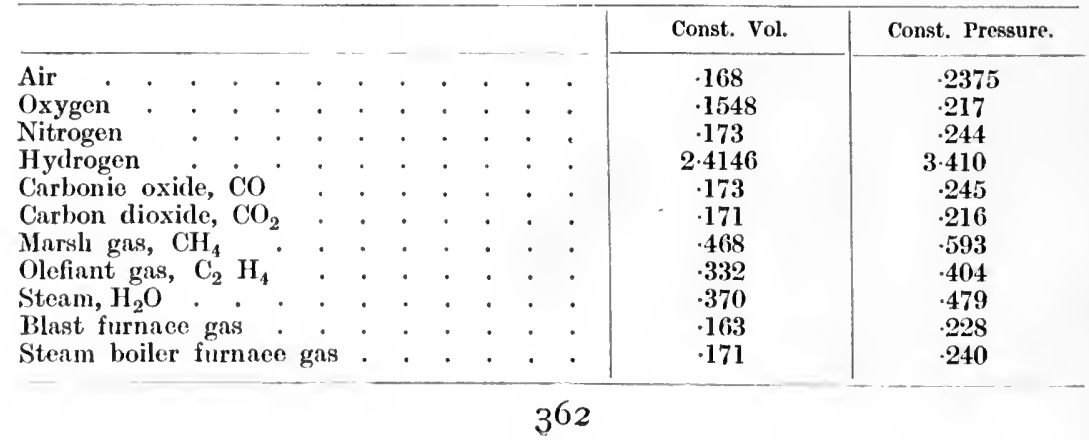




\section{APPENDIX}

TaBLE X. Equivalents.

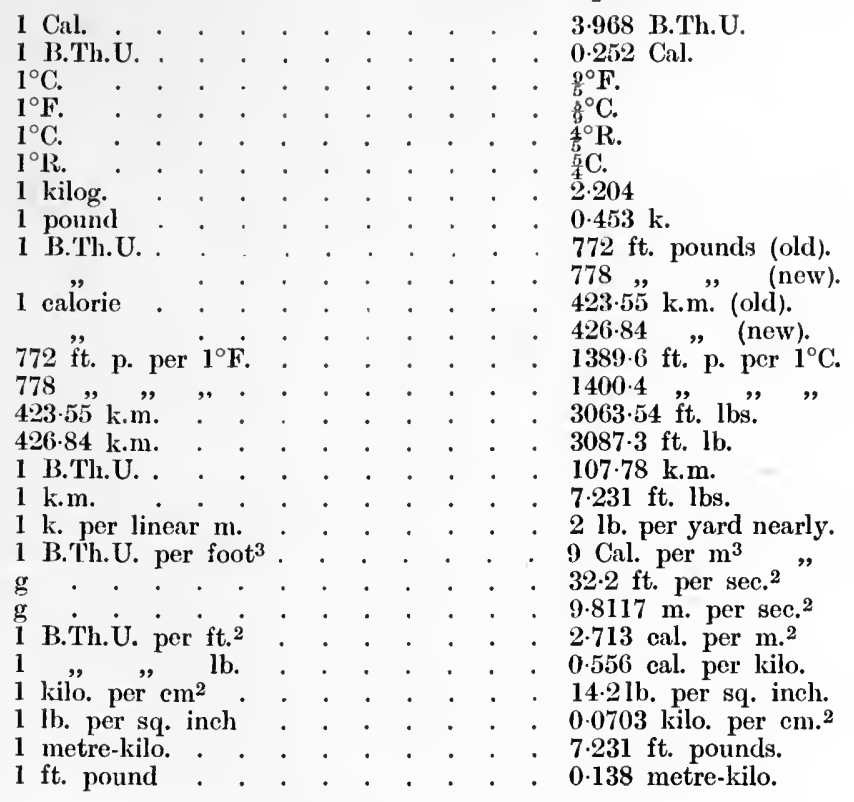

TABLE XI. Properties of Carbon Calorifically.

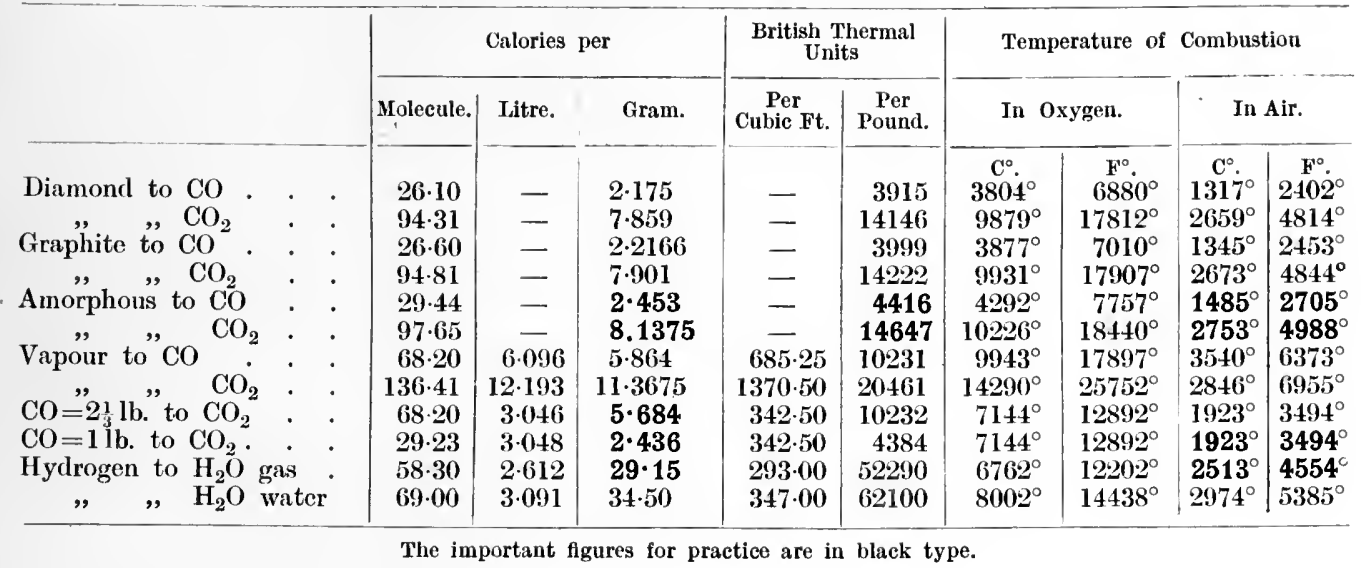

TABLE XII.

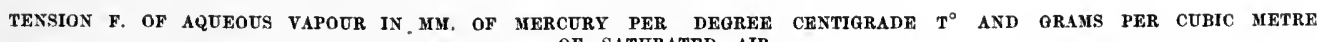
OF SATURATED AIR.

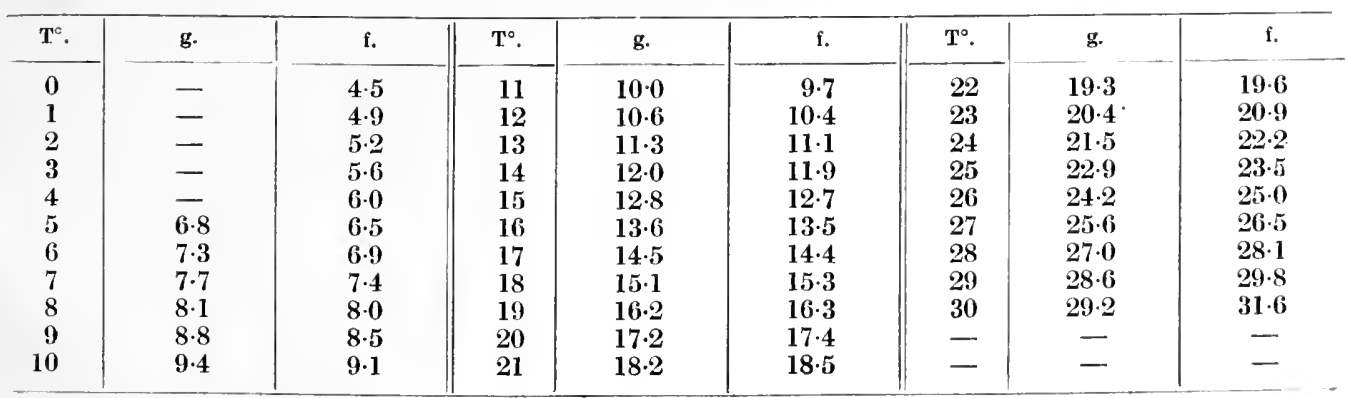




\section{LIQUID FUEL AND ITS COMBUSTION}

\section{TABLE XIII.}

VOLS. OF GAS BEFORE AND AFTER COMBUSTION AND ABSORPTION.

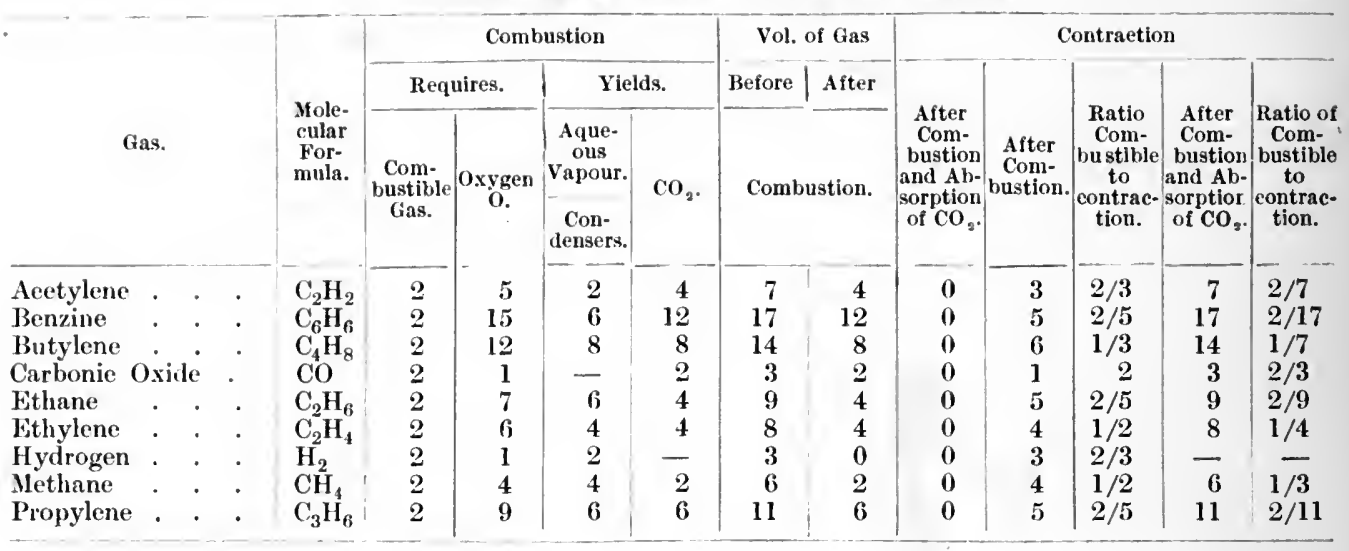

TABle XIV.

Calculated gas DENSITIES AND WeIOHTS PER LITRE.

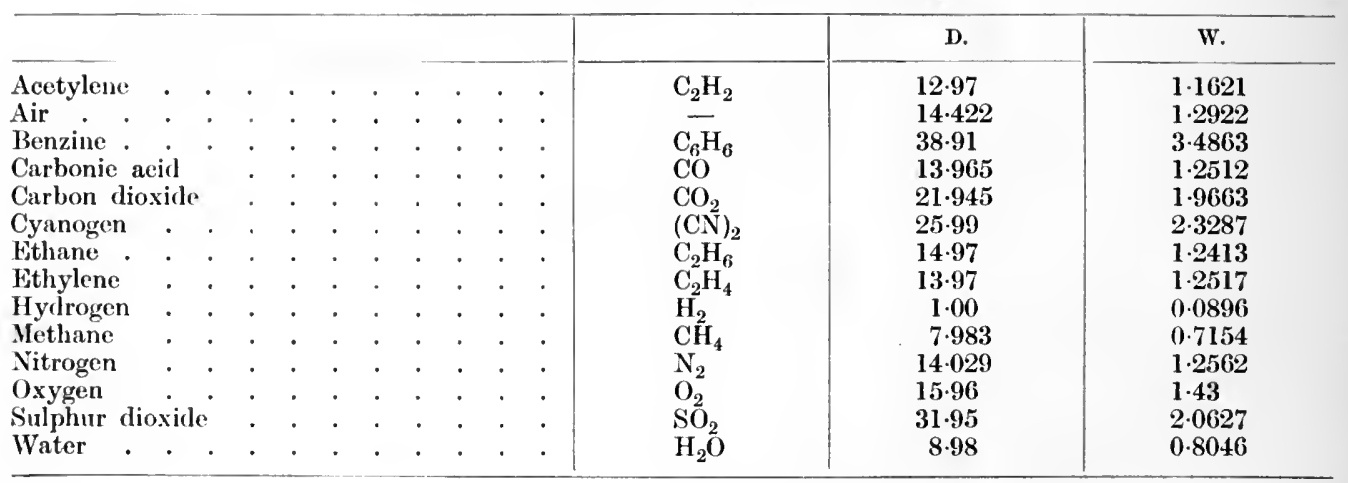

TABLE XV.

RELATIVE VALUE OF COAL AND OIL, FUEL ACCOUNT RELATIVE VALUE OF COAL AND OIL, ALL ASCERALONE CONSIDERED.

Oil per Barrel at
$\$ 0 \cdot 20$
$0 \cdot 30$
$0 \cdot 40$
$0 \cdot 50$
$0 \cdot 60$
$0 \cdot 70$
$0 \cdot 80$
$0 \cdot 90$
$1 \cdot 00$
$1 \cdot 10$
$1 \cdot 20$
$1 \cdot 30$
$1 \cdot 40$
$1 \cdot 50$
$1 \cdot 60$
$1 \cdot 70$
$1 \cdot 80$
$1 \cdot 90$
$2 \cdot 00$

Coal per Ton at
$80 \cdot 74$
$1 \cdot 12$
$1 \cdot 49$
$1 \cdot 86$
$2 \cdot 24$
$2 \cdot 61$
$2 \cdot 98$
$3 \cdot 35$
$\mathbf{3} \cdot 73$
$4 \cdot 10$
$4 \cdot 47$
$4 \cdot 85$
$5 \cdot 22$
$5 \cdot 59$
$\mathbf{5} \cdot 97$
$6 \cdot 34$
$6 \cdot 71$
$7 \cdot 08$
$\mathbf{7} \cdot 45$

TAIVED FCONOYITS COYSIDERED. Coal per Ton at

$\$ 0 \cdot 65$

$0 \cdot 98$

$1 \cdot 30$

$1 \cdot 63$

$1 \cdot 96$

$2 \cdot 28$

$2 \cdot 61$

2.93

$3 \cdot 26$

3.59

$3 \cdot 91$

$4 \cdot 24$

$4 \cdot 56$

489

5.22

$5 \cdot 54$

$5 \cdot 87$

$6 \cdot 19$

1 dollar $=48$ pence approximately.

$6 \cdot 52$ 


\section{APPENDIX}

TABLE XVI. Russian and Pennsylvanian Oils.

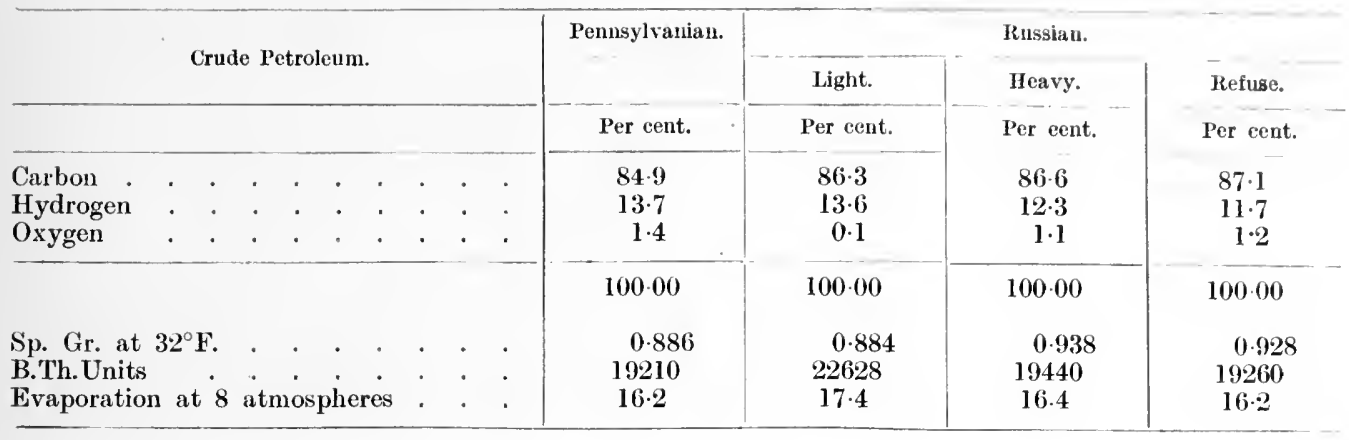

Table XVII. Petroleum Refuse. Comparative Trials, with Petroleum, Anthracite, Bituminous Coal and Wood, between Archeda and Tsaritzin on Grazi and T'saritzin Railway in Winter ime.

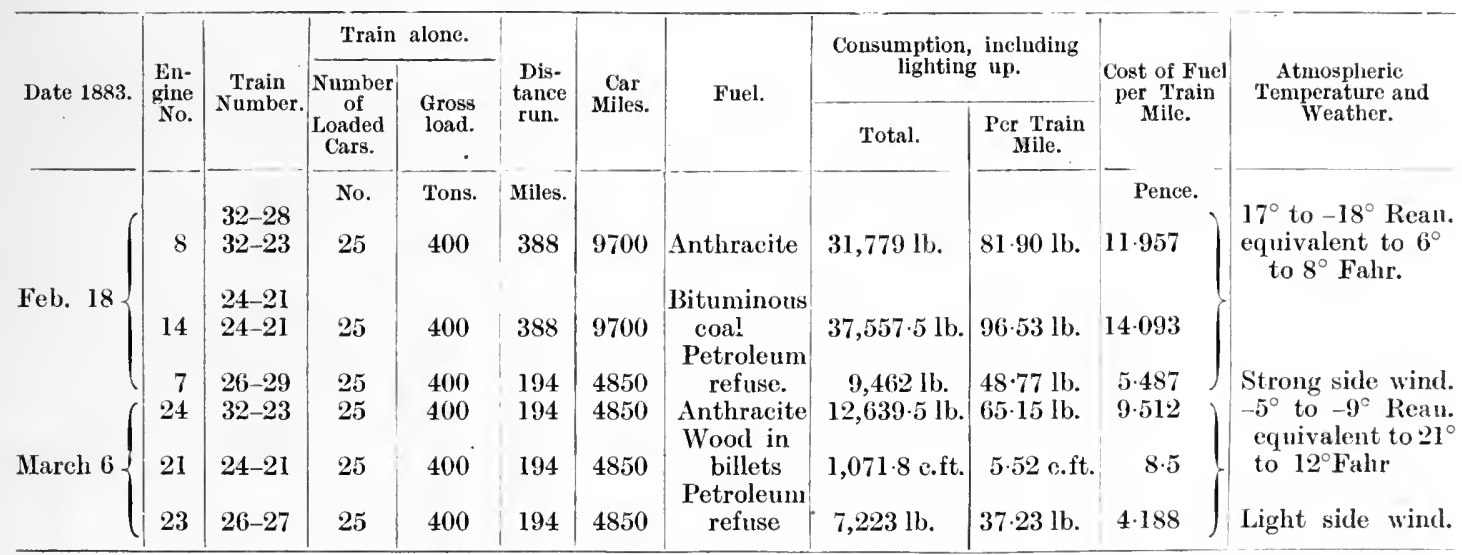

Prices of Fuel.-Petroleum refuse, 21s. per ton; anthracite and bituminous eoal, 27s. 3d. per ton; wood, in billets, 42s. per cubie sajene $=343$ eubic ft. ; equivalent to $1.47 \mathrm{~d}$. per cubic foot.

Dimensions of Locomotives.-Cylinders, $18 \mathrm{in.} \mathrm{diameter} \mathrm{and} 24 \mathrm{in.}$ stroke; wheels, $4 \mathrm{ft} .3 \mathrm{in}$. diameter; total lieating surface, 1,243 sq. ft. ; total adhesion weight, 36 tons; boiler pressure; 8 to $9 \mathrm{~atm}$. 
LIQUID FUEL AND ITS COMBUSTION

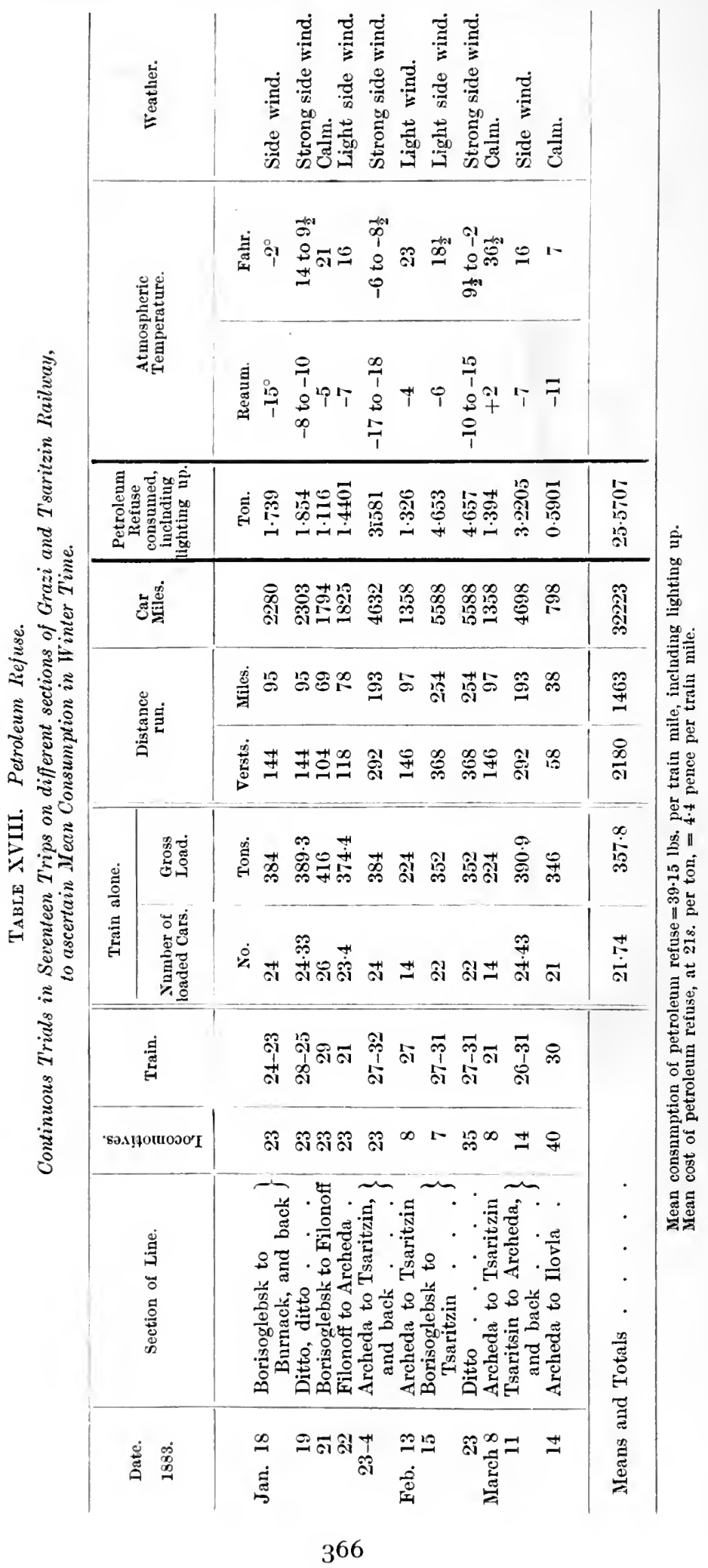




\section{APPENDIX}

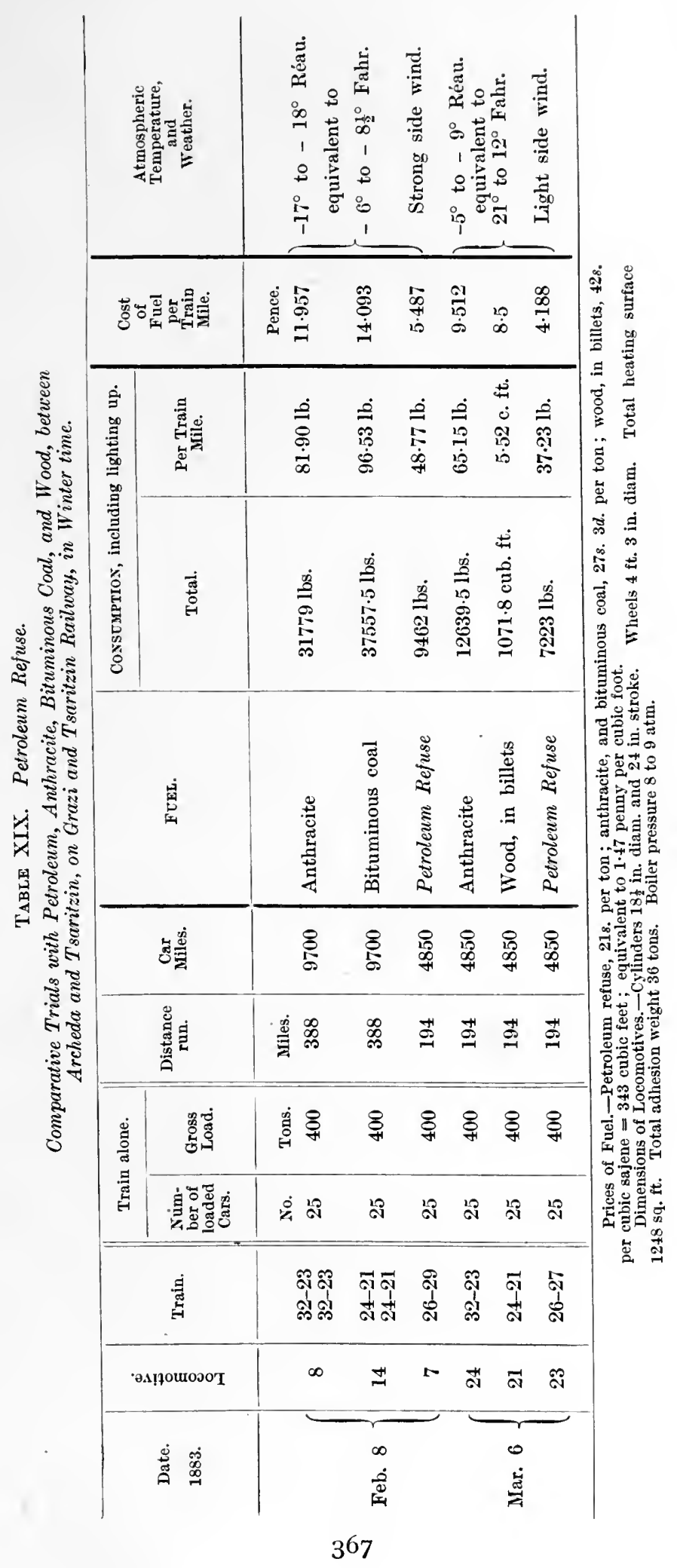




\section{LIQUID FUEL AND ITS COMBUSTION}

'TABLe XX. Pctroleum Refuse.

Continuous Trials in Ninctecn Trips batween Archcda and Tsaritzin, on Grazi. and Tsaritzin Railway, to ascertain Mean Consumption in Summer time.

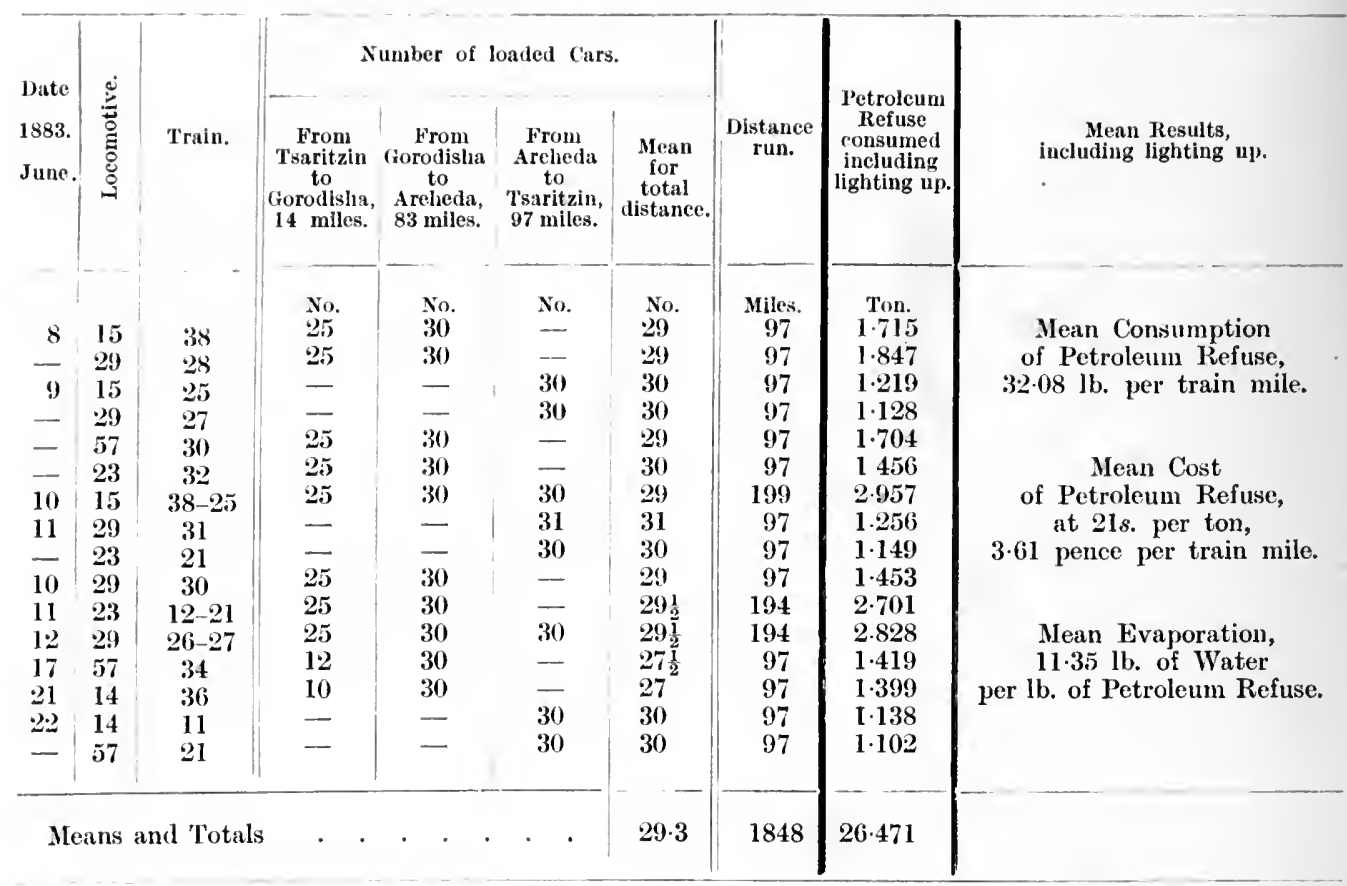

'Table XXI. Pelroleum Refuse.

Comparative Trials with Petroleum, Anthracite, and Bituminous Coal, between Archeda and Tsaritzin, on Grazi and Tsaritzin Railway, in Summer time.

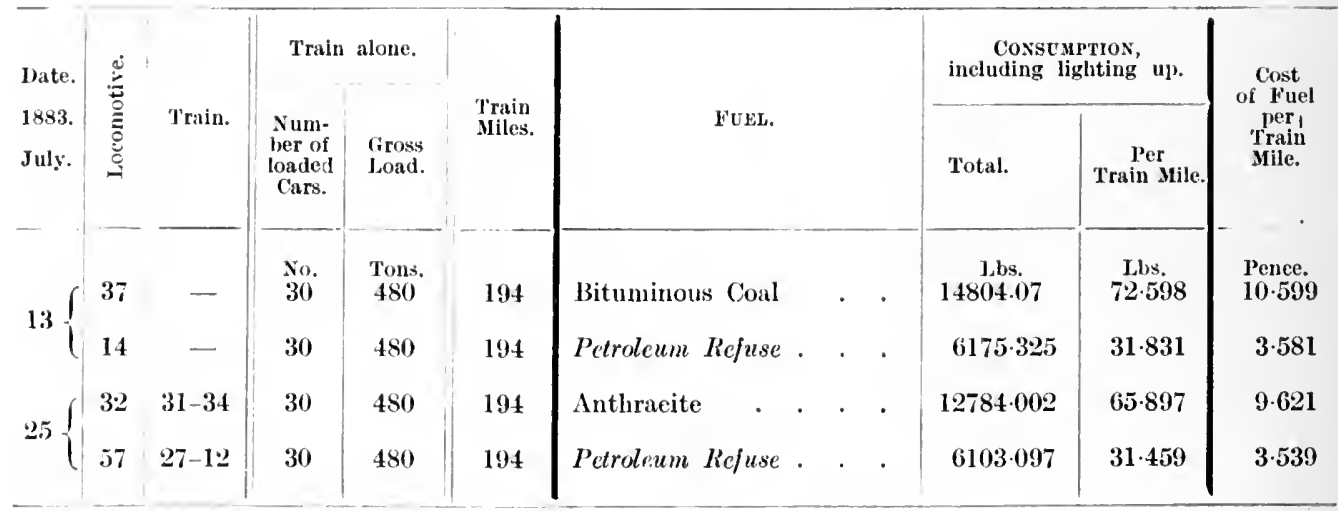

P'rices of Fuel.-Petroleum Refuse, 218. per ton. Anthracite, and Bituminous Coal, 27s. 3 d. per ton. 


\section{APPENDIX}

Table XXII. Petroleum Refuse.

Comparative Trials with Petroleum and Anthracite, between Grazi and Borisoglcbsh on Grazi and 'T'saritzin Railway.

\begin{tabular}{|c|c|c|c|c|c|c|c|c|c|c|c|c|}
\hline \multirow{2}{*}{$\begin{array}{l}\text { Date. } \\
1884 . \\
\text { May. }\end{array}$} & \multirow{2}{*}{ 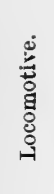 } & \multirow[b]{2}{*}{ Train. } & \multicolumn{2}{|c|}{ Train alone. } & \multicolumn{2}{|c|}{ Distance run. } & \multirow[b]{2}{*}{ FUEL. } & \multicolumn{4}{|c|}{$\begin{array}{l}\text { Consumptros. } \\
\text { including ligliting up. }\end{array}$} & \multirow[b]{2}{*}{ Weatlier. } \\
\hline & & & $\begin{array}{l}\text { Mean } \\
\text { Num- } \\
\text { ber of } \\
\text { Car- } \\
\text { riages. }\end{array}$ & $\begin{array}{l}\text { Gross } \\
\text { Load. }\end{array}$ & $\begin{array}{l}\text { Train } \\
\text { Miles. }\end{array}$ & $\begin{array}{c}\text { Car- } \\
\text { riage } \\
\text { Miles. }\end{array}$ & & Total. & $\begin{array}{l}\text { Per } \\
\text { Train } \\
\text { Mile. }\end{array}$ & $\begin{array}{c}\text { Per } \\
\text { Carriage } \\
\text { Mile. }\end{array}$ & $\begin{array}{l}\text { Mean } \\
\text { per } \\
\text { Carriage } \\
\text { Iile. }\end{array}$ & \\
\hline $6-7$ & 109 & $4-3$ & $\begin{array}{l}\text { No. } \\
15\end{array}$ & $\begin{array}{l}\text { Tous. } \\
240\end{array}$ & 264 & 3960 & Anthracite & $\begin{array}{l}\mathrm{Lb} . \\
11560 \cdot 5\end{array}$ & $\begin{array}{c}\text { Lb. } \\
43 \cdot 79\end{array}$ & $\begin{array}{r}\text { Lb. } \\
2.92\end{array}$ & Lb. & \\
\hline $8-9$ & 109 & $4-3$ & 13 & 208 & 264 & 3432 & Anthracite & 11379 & $43 \cdot 101$ & $3 \cdot 316$ & & \\
\hline $7-8$ & 116 & $4-3$ & 13 & 208 & 264 & 3432 & Petroleum Refuse & 6720 & 25.45 & 1.957 & & \\
\hline $9-15$ & 116 & $4-3$ & $12 \frac{1}{2}$ & 200 & 264 & 3300 & Petroleum Refuse & $6632 \cdot 5$ & $25 \cdot 124$ & $2 \cdot 01$ & & \\
\hline
\end{tabular}

Dimensions of Passenger Locomotives (Borsig's).-Cylinders, 17 in ins. diam. and 22 ins. stroke.

Driving wheels, four coupled, $5 \mathrm{ft}$. 3 ins. diam Total weight, 32 tons. Adhesion weight, 25 tons. Boiler pressure, $8 \frac{1}{2}$ atm.

Carriages, six-wheeled, each 16 tons mean gross weight. Speed, 24 to 26 miles per hour. Maximum gradient, 1 in 125.

TABle XXIII. Petroleum Refuse.

Comparative Trials with Petroleum, Anthracite, and Bituminous Coal, between Borisoglebsk and Filonoff on Grazi and T'saritzin Railway.

\begin{tabular}{|c|c|c|c|c|c|c|c|c|c|c|c|c|}
\hline \multirow{2}{*}{$\begin{array}{l}\text { Date. } \\
1884 . \\
\text { May. }\end{array}$} & \multirow{2}{*}{ 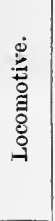 } & \multirow{2}{*}{ Train. } & \multicolumn{2}{|c|}{ Train alone. } & \multicolumn{2}{|c|}{ Distance ritn. } & \multirow[b]{2}{*}{ FUEL. } & \multicolumn{4}{|c|}{$\begin{array}{l}\text { CONSUMPPTION. } \\
\text { inchuding lighting up. }\end{array}$} & \multirow[b]{2}{*}{ Weather. } \\
\hline & & & 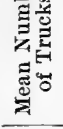 & $\begin{array}{l}\text { Gross } \\
\text { Load. }\end{array}$ & $\begin{array}{l}\text { Train } \\
\text { Miles. }\end{array}$ & $\begin{array}{l}\text { Truck } \\
\text { Miles. }\end{array}$ & & Total. & $\begin{array}{c}\text { Per } \\
\text { Train } \\
\text { Mile. }\end{array}$ & $\begin{array}{c}\text { Per } \\
\text { Truek } \\
\text { Mile. }\end{array}$ & $\begin{array}{l}\text { Mean } \\
\text { per } \\
\text { Truck } \\
\text { Mile. }\end{array}$ & \\
\hline $20-21$ & 147 & $31-28$ & $\begin{array}{l}\text { No. } \\
43\end{array}$ & $\begin{array}{l}\text { Tons. } \\
688\end{array}$ & $136 \frac{1}{2}$ & 5870 & Anthracite & $\begin{array}{l}\text { Lb. } \\
9063\end{array}$ & $\begin{array}{l}\text { Lb. } \\
66 \cdot 40\end{array}$ & $\begin{array}{l}\text { Lb. } \\
1.544\end{array}$ & & Wind favour- \\
\hline $21-22$ & 147 & $21-30$ & 35 & 560 & $136 \frac{1}{2}$ & 4778 & Anthracite & $10841 \cdot 5$ & $79 \cdot 43$ & $2 \cdot 27$ & & $\begin{array}{l}\text { Strong side } \\
\text { wind. }\end{array}$ \\
\hline $23-24$ & 147 & $31-30$ & 38 & 608 & $136 \frac{1}{2}$ & 5187 & Bituminous Coal & 12638 & $92 \cdot 60$ & $2 \cdot 436$ & $2 \cdot 436$ & Calm. \\
\hline $20-21$ & 141 & $26-27$ & 45 & 720 & $136 \frac{1}{2}$ & 6143 & Petroleum Refuse & 6274 & $45 \cdot 90$ & 1.02 & & $\begin{array}{l}\text { strong side } \\
\text { wind. }\end{array}$ \\
\hline $\begin{array}{l}22-23 \\
23-24\end{array}$ & $\begin{array}{l}139 \\
138\end{array}$ & $\begin{array}{l}27-28 \\
21-30\end{array}$ & $\begin{array}{l}41 \\
42\end{array}$ & $\begin{array}{l}656 \\
672\end{array}$ & $\begin{array}{l}136 \frac{1}{2} \\
136 \frac{1}{2}\end{array}$ & $\begin{array}{l}5597 \\
5733\end{array}$ & $\begin{array}{l}\text { Petroleum Refuse } \\
\text { Petroleum Refuse }\end{array}$ & $\begin{array}{l}5524 \\
6151\end{array}$ & $\begin{array}{l}40 \cdot 46 \\
45 \cdot 06\end{array}$ & $\begin{array}{l}0.9868 \\
1.0728\end{array}$ & 1.046 & $\begin{array}{l}\text { Calm. } \\
\text { Callus. }\end{array}$ \\
\hline 26 & 137 & $25-34$ & 45 & 720 & $136 \frac{1}{2}$ & 6143 & Pelroleum Refuse & 6787 & $49 \cdot 72$ & $1 \cdot 105$ & & $\begin{array}{l}\text { Strong sicle } \\
\text { wind. }\end{array}$ \\
\hline
\end{tabular}

Dimensions of Goods Locomotives.-Cylinders, $19 \frac{3}{4}$ ins. diam. and 25 ins. stroke. Wheels, eight coupled, $3 \mathrm{ft}$. $11 \frac{1}{4} \mathrm{ins}$, diam .

Total heating surface, $1938 \mathrm{sq}$. ft. Total adhesion weight, 46 tons. Tractive force, $18045 \mathrm{lb} .=8 \cdot 056$ tous. Boiler pressure. 9 atm. Trucks each 16 tons gross weight. Speed, 14 miles per lour. Maximum gradient, 1 in 125. 


\title{
LIQUID FUEL AND ITS COMBUSTION
}

\author{
TABLE XXIV.
}

Cost of Allerations for Paruleum Firing in Six-whed and Eight-whcel Conpled Goods Locomotives on the Crazi and T'siritzin Railway of 5 /cet gauge.

SPRAY INJECTOR AND CONNECTIONS.

Spray injector

Inlicator to injector

(ias pipe, 2 inehes diancte

Copper pipe, 2 inches dituleter

(ats pipe 3 inch dianeter, 2:3 lb.

Worm and other copper pipes, $61 \mathrm{lb}$.

Wire netting for strainers

Irou fittings, various, $45 \mathrm{lb}$

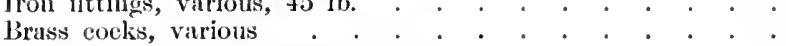

Glastic hose with brass end-sockets

Brass nouthpiece on injector, $7 \mathrm{lb}$.

Stean valve, 3 inch

Two triple connections for steam pipes, $7 \mathrm{lb}$

Workmanship

Total cost of Engine fittings
Fire-briclis from Glenboig Works, 350 and 400, at 20s. per 100 . Fire-clay, two barrels $=400 \mathrm{Ib}$.

Bricklayer's wages

Total cost of Brickwork

TENDER.

Iron plate, 3-16tlis inch thick with angle-irons. . . . . Workmanship

T'otal cost of T'ender alterutions

Total cost of Engine and Tender alterations

Six-wheel and Eight-wheel Engines.

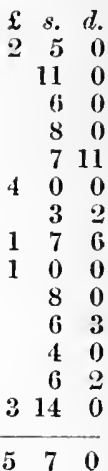

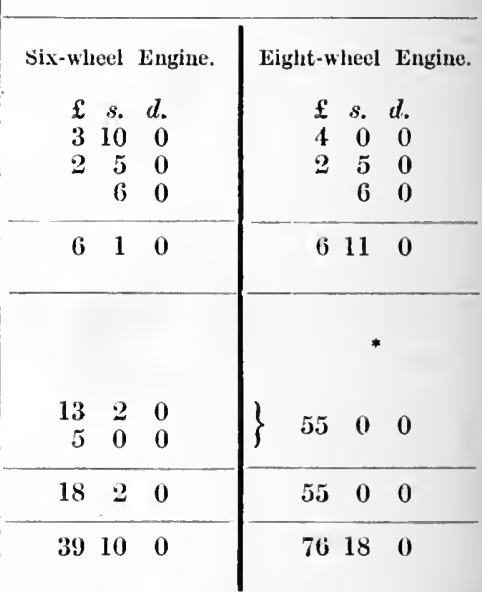

* The eight-wheel engine las a separate tank added on the top of the tender, thereby inereasing the eost so mueh above that in the six-wheel engine. 


\section{APPENDIX}

\section{TABLE XXV.}

Cost of Fuel, and of Engine and Tender Repairs,

per 1000 Axle-miles of trucks, wagons or carriages (not locomotices) on the Grazi and Tsaritzin Railuay, during thirteen years, 1876 to 1888.

\begin{tabular}{|c|c|c|c|c|c|c|c|c|c|c|c|c|c|}
\hline $\begin{array}{c}\text { Per } 1000 \\
\text { Axle miles of } \\
\text { trueks, wagons } \\
\text { or carriages (not } \\
\text { locomotives). }\end{array}$ & & & & $\begin{array}{l}\text { COAL } \\
\text { alone. }\end{array}$ & & & & $\begin{array}{c}\text { Petro- } \\
\text { leuul } \\
\text { Refuse, } \\
15 \% . \\
\text { Coal, } \\
85 \%\end{array}$ & $\begin{array}{c}\text { Petro- } \\
\text { leuni } \\
\text { lefuse, } \\
62 \% \text {. } \\
\text { Coal } \\
38 \% .\end{array}$ & \multicolumn{4}{|c|}{$\begin{array}{l}\text { Petroleum } \\
\text { REFuse } \\
\text { alone. }\end{array}$} \\
\hline $\left.\begin{array}{l}\text { Year } \\
\text { Cost of Fuel, } \\
\text { Shillings } \\
\text { Repairs of } \\
\text { Engines \& } \\
\text { Tendlers } \\
\text { Shillings }\end{array}\right\}$ & $\begin{array}{r}1876 . \\
18.7\end{array}$ & $\begin{array}{r}1877 . \\
16.5\end{array}$ & $\begin{array}{l}1878 . \\
15 \cdot 9\end{array}$ & $\begin{array}{r}1879 . \\
17 \cdot 2\end{array}$ & $\begin{array}{r}1880 . \\
18.9\end{array}$ & $\begin{array}{r}1881 . \\
18 \cdot 4\end{array}$ & $\begin{array}{r}1882 . \\
17 \cdot 1\end{array}$ & $\begin{array}{r}1883 . \\
16.5\end{array}$ & $\begin{array}{r}1884 . \\
13 \cdot 1\end{array}$ & $\begin{array}{c}1885 . \\
9 \cdot 9\end{array}$ & $\begin{array}{c}1886 . \\
9 \cdot 0 \\
+\end{array}$ & $\begin{array}{c}1887 . \\
8.033 \\
\dagger \\
2.265\end{array}$ & $\begin{array}{l}1888 \\
8.087\end{array}$ \\
\hline
\end{tabular}

\$ During 1879 and 1880 the expenses of Repairs were somewhat increased by the amalgamation of the Volga-Don line with the main line, the rolling stock of the former being in bad condition.

* The considerable cost of Repairs in 1885 was due to ehange of fire-boxes damaged or worn by coal firing. For 1887 the cost of Repairs is even less than for 1886, as no fire-boxes are now being renewed.

+ The mean cost of Petroleum Refuse per ton on the railway was $27 s$. $3 d$. for 1886 , and for 1887 was 268 . $6 \frac{1}{2} d$. , which mainly accounts for the reduction in 1887 in cost per 1000 axle miles. The mean cost on the railway includes all expenses of pumping, storage, and transport; and depreciation of pumps, tanks, and pipes; and also administration.

I The cost of Repairs in 1888 ineluded that of altering four engines to the compound system. 


\section{LIQUID FUEL AND ITS COMBUSTION}

'l'aBre XXVI. (continued on opposite page).

Working Cost of Locomotive Department, per 1000 Axle miles of truchs, wagons or carriages (not locomotives), on the Grazi and T'saritzin Railway, during thirteen years, 1876 to 1888.

\begin{tabular}{|c|c|c|c|c|c|c|}
\hline & Items of Cost. & $\begin{array}{c}1876 . \\
*\end{array}$ & 1877. & $\begin{array}{ll}1878 . \\
*\end{array}$ & $\begin{array}{c}1879 . \\
*\end{array}$ & 1880 \\
\hline 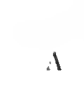 & $\left\{\begin{array}{c}\text { Salaries of loco. supt. and as- } \\
\text { sistants and office management }\end{array}\right\}$ & $\begin{array}{c}\text { Shillings. } \\
0.516\end{array}$ & $\begin{array}{l}\text { Shillings. } \\
0.503\end{array}$ & $\begin{array}{c}\text { Shillings. } \\
0 \cdot 441\end{array}$ & $\begin{array}{c}\text { Shillings. } \\
0 \cdot 360\end{array}$ & $\begin{array}{c}\text { Shillings. } \\
0 \cdot 431\end{array}$ \\
\hline B & $\left\{\begin{array}{c}\text { Wages and premiums to engine- } \\
\text { men, including shed foremen } \\
\text { and men. }\end{array}\right\}$ & $7 \cdot 248$ & $5 \cdot 826$ & $5 \cdot 654$ & $6 \cdot 151$ & $6 \cdot 277$ \\
\hline (: & $\left\{\begin{array}{c}\text { Fuel for engines, engine-sheds } \\
\text { and drivers' rooms, including } \\
\text { management }\end{array}\right\}$ & 19.081 & 16.901 & $16 \cdot 341$ & 17.509 & $19 \cdot 137$ \\
\hline 1) & $\left\{\begin{array}{c}\text { Lubrieation of Engines and all } \\
\text { Rolling Stock and machinery }\end{array}\right\}$ & $1 \cdot 886$ & $1 \cdot 291$ & $1 \cdot 245$ & $1 \cdot 417$ & $1 \cdot 380$ \\
\hline $\mathrm{l}:$ & Water and pumping . . . & $1 \cdot 844$ & $1 \cdot 590$ & $1 \cdot 377$ & $1 \cdot 440$ & 1.630 \\
\hline Ii & $\left\{\begin{array}{c}\text { Repairing shops, management } \\
\text { and wages }\end{array}\right\}$ & 1.981 & 1.622 & $1 \cdot 739$ & $2 \cdot 119$ & $2 \cdot 386$ \\
\hline (i & Cleaning of rolling stock & 0.575 & $0 \cdot 431$ & 0.434 & $0 \cdot 519$ & $0 \cdot 491$ \\
\hline II & $\left\{\begin{array}{c}\text { Renewals and repairs of en- } \\
\text { gines and tenders } \\
.\end{array}\right.$ & $6 \cdot 493$ & $4 \cdot 526$ & $3 \cdot 298$ & $5 \cdot 312$ & $7 \cdot 538$ \\
\hline$J$ & $\left\{\begin{array}{c}\text { Renewals and repairs of car- } \\
\text { riage and wagon stock }\end{array}\right\}$ & $8 \cdot 236$ & 6.698 & $7 \cdot 318$ & $9 \cdot 956$ & $9 \cdot 446$ \\
\hline K & $\left\{\begin{array}{c}\text { Total cost per } 1000 \text { axle miles } \\
\text { in shillings } \\
\cdot\end{array}\right.$ & 47.860 & $39 \cdot 388$ & $37 \cdot 847$ & $44 \cdot 789$ & 48.716 \\
\hline \multicolumn{2}{|c|}{$\begin{array}{c}\text { Total axle-miles of trucks, wagons or } \\
\text { earriages }\end{array}$} & $48,406,497$ & $563,20,237$ & $71,889,982$ & $71,958,659$ & $74,413,099$ \\
\hline \multicolumn{2}{|c|}{ Total working cost in pounds } & $£ 115,621$ & $£ 111,255$ & $£ 135,941$ & $\mathfrak{1} 160,969$ & $£ 181,020$ \\
\hline
\end{tabular}




\section{APPENDIX}

(continued from preceding prge) Tarte XXVI.

Working Cost of Locomotive Department, per 1000 Axle miles of trucks, wagons or carriages (not locomotives), on the Grazi and Tsaritzin Railway, during thirteen years, 1876 to 1888.

\begin{tabular}{|c|c|c|c|c|c|c|c|c|}
\hline & $\begin{array}{c}1881 \\
*\end{array}$ & $\begin{array}{c}1882 \\
*\end{array}$ & $\begin{array}{c}1883 \\
\dagger\end{array}$ & $\begin{array}{c}1884 \\
\dagger\end{array}$ & $\begin{array}{c}1885 \\
\S\end{array}$ & $\begin{array}{c}1886 \\
\S\end{array}$ & $\begin{array}{c}1887 \\
\S\end{array}$ & $\begin{array}{c}1888 \\
\S\end{array}$ \\
\hline A & $\begin{array}{c}\text { Shillings. } \\
0.465\end{array}$ & $\begin{array}{c}\text { Shillings. } \\
0.422\end{array}$ & $\begin{array}{c}\text { Shillings. } \\
0409\end{array}$ & $\begin{array}{c}\text { Shillings. } \\
0.386\end{array}$ & $\begin{array}{c}\text { Shillings. } \\
0.403\end{array}$ & $\begin{array}{c}\text { Shillings. } \\
0.525\end{array}$ & $\begin{array}{c}\text { Shillings. } \\
0.483\end{array}$ & $\begin{array}{c}\text { Shillings. } \\
0.453\end{array}$ \\
\hline $\mathrm{B}$ & $5 \cdot 493$ & $5 \cdot 433$ & $5 \cdot 232$ & $5 \cdot 068$ & $4 \cdot 627$ & $4 \cdot 790$ & $4 \cdot 499$ & $4 \cdot 318$ \\
\hline C & 18.570 & $17 \cdot 125$ & $16 \cdot 626$ & $13 \cdot 174$ & $10 \cdot 067$ & $9 \cdot 084$ & $8 \cdot 335$ & $8 \cdot 486$ \\
\hline D) & $1 \cdot 217$ & $1 \cdot 191$ & $1 \cdot 167$ & 1.083 & 0.845 & 0.702 & $0 \cdot 664$ & $0 \cdot 634$ \\
\hline $\mathrm{E}$ & $1 \cdot 209$ & $1 \cdot 244$ & $1 \cdot 184$ & $1 \cdot 292$ & $1 \cdot 063$ & $1 \cdot 040$ & 0.875 & 0.755 \\
\hline $\mathbf{F}$ & $1 \cdot 629$ & $1 \cdot 644$ & $1 \cdot 792$ & $1 \cdot 507$ & $1 \cdot 639$ & $1 \cdot 736$ & $1 \cdot 479$ & 1.479 \\
\hline G & $0 \cdot 405$ & 0.392 & 0.265 & $\mathbf{0} \cdot \mathbf{3} 68$ & $0 \cdot 234$ & $0 \cdot 369$ & $0 \cdot 302$ & $0 \cdot 332$ \\
\hline HI & $5 \cdot 291$ & 4.727 & $4 \cdot 838$ & $4 \cdot 514$ & $4 \cdot 081$ & $2 \cdot 682$ & $2 \cdot 265$ & $2 \cdot 446$ \\
\hline $\boldsymbol{J}$ & $8 \cdot 188$ & $6 \cdot 955$ & $6 \cdot 664$ & $5 \cdot 197$ & $4 \cdot 383$ & $3 \cdot 941$ & $3 \cdot 443$ & $3 \cdot 231$ \\
\hline $\mathrm{K}$ & $42 \cdot 467$ & $39 \cdot 133$ & $38 \cdot 177$ & $32 \cdot 619$ & $27 \cdot 342$ & $24 \cdot 869$ & $22 \cdot 345$ & $22 \cdot 134$ \\
\hline Axle miles. & $88,151,537$ & $97,927,740$ & $113,579,960$ & $124,461,939$ & $126,569,995$ & $118,900,533$ & $136,420,000$ & $136,909,500$ \\
\hline Cost & $£ 186,981$ & $£ 191,442$ & $£ 216,473$ & $\mathfrak{£} 202,774$ & $£ 173,118$ & $£ 147,732$ & $\mathfrak{f 1 5 2 , 2 7 8}$ & $£ 151,0129$ \\
\hline
\end{tabular}

* In 1876-82 Coal alone was used in the locomotives.

$\$$ In 1885-88 Petroleum Refuse alone.

† In 1883 Petroleum Refuse 15 per cent. and Coal 85 per cent.

† In 1885-88 Petroleum Refuse alone"was used in the locomotives 
LIQUID, FUEL AND ITS COMBUSTION

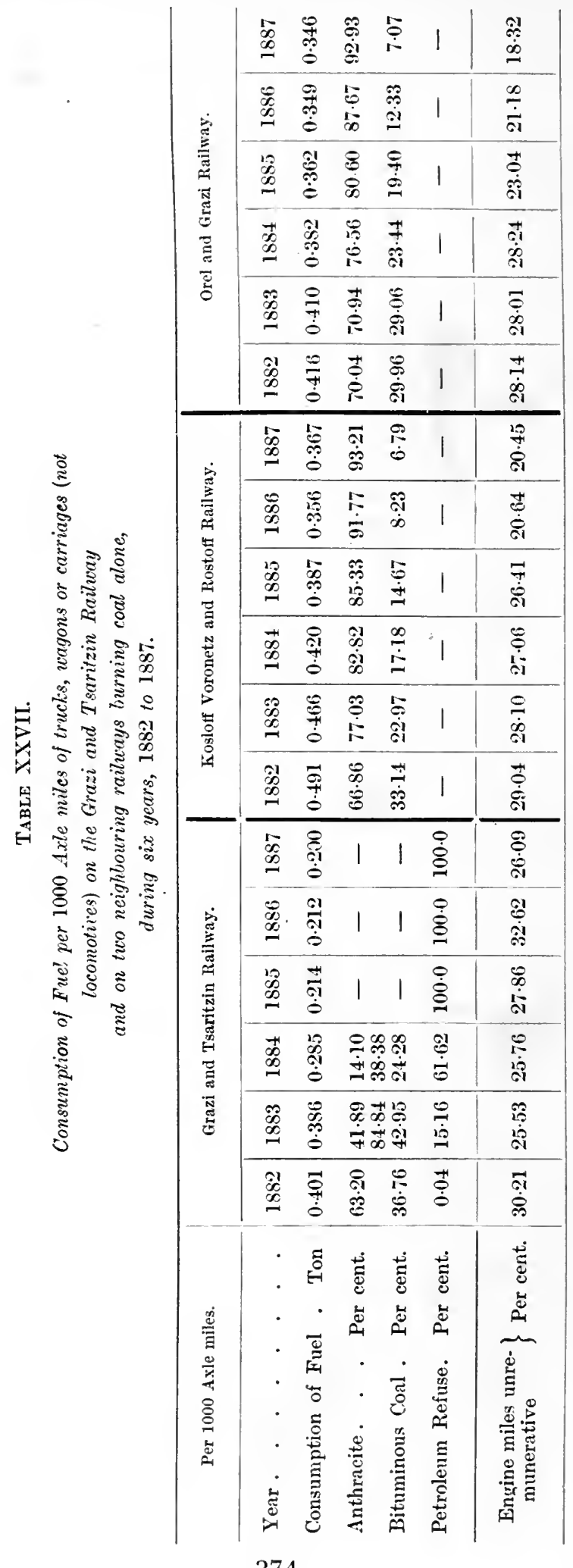




\section{APPENDIX}

Tabia XXVIII. Petroleum Refuse.

Specific aravity and Weight per cubic loot, at various temperatures. Water $=1.0000$ specific gravity, at $171^{\circ}$ Cent. $=632^{\circ}$ Fahr.

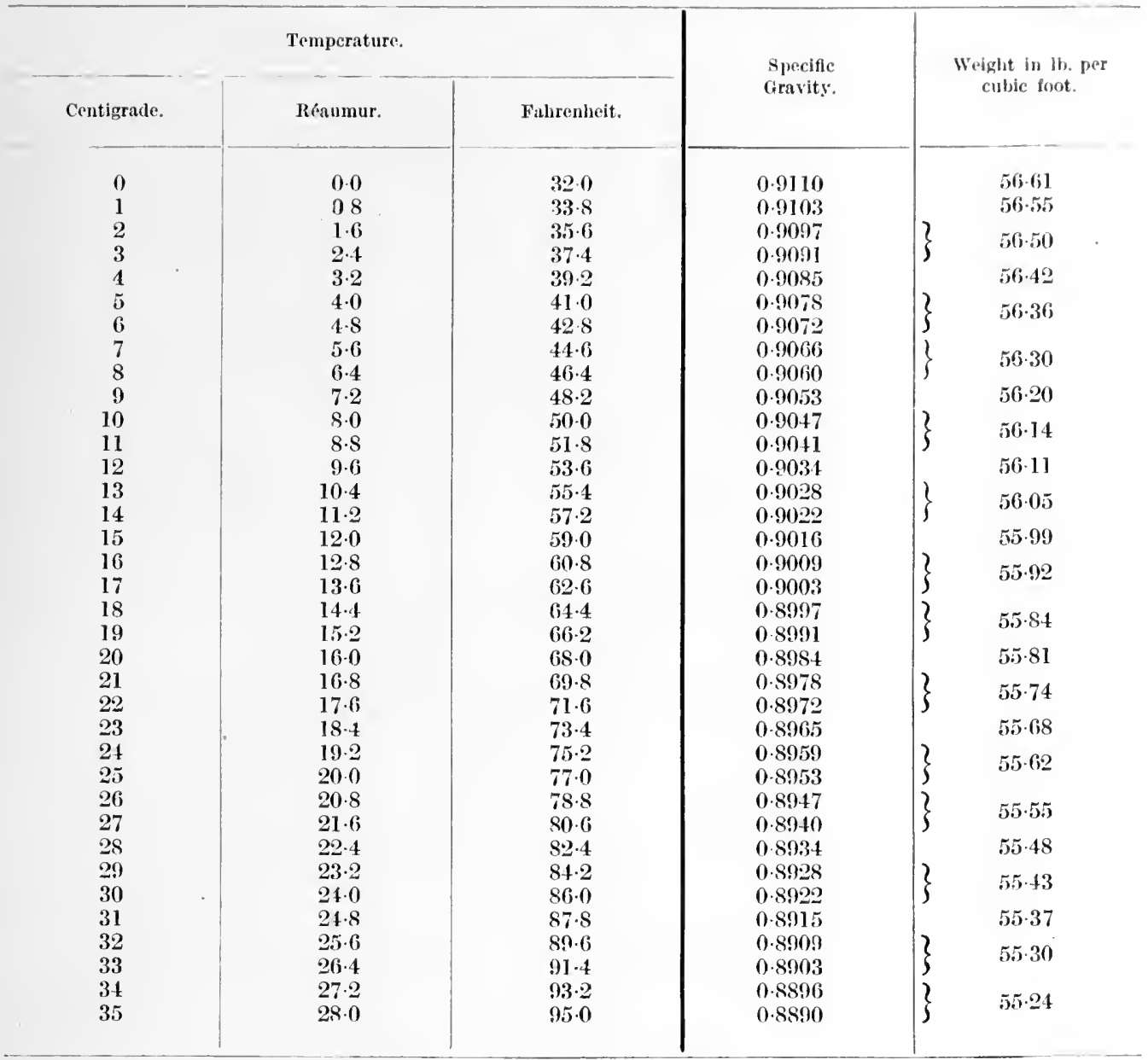

TABl. XXIX. Cost of Evaporating $1000 \mathrm{lb}$. Water.

Fuel-Coal.

National Supply Co.'s Table No. 1.

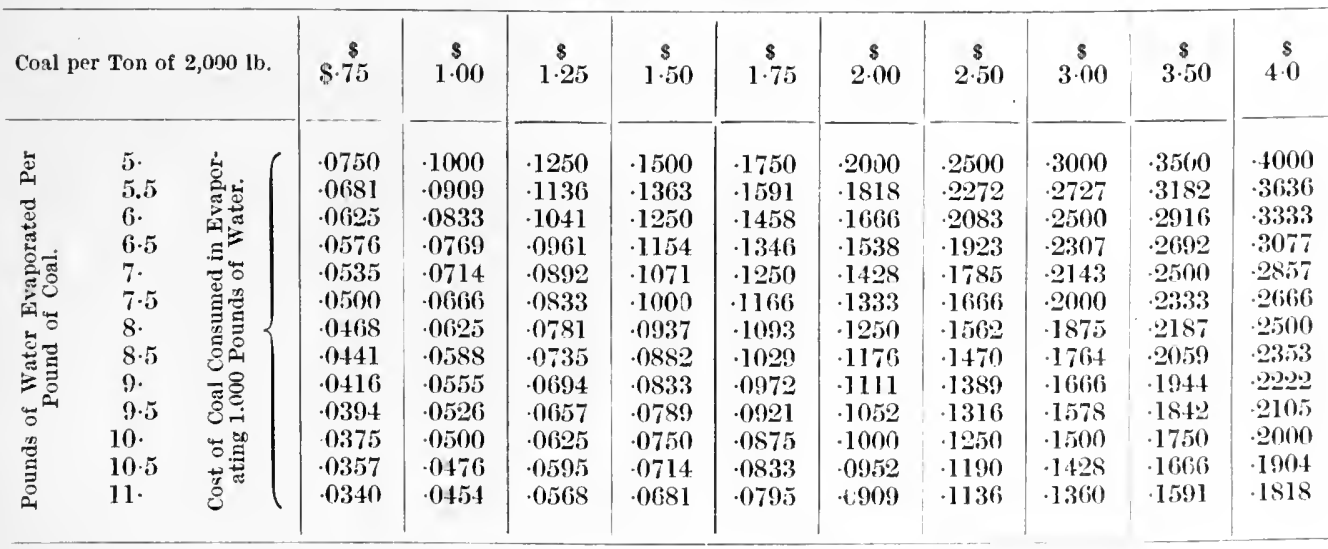

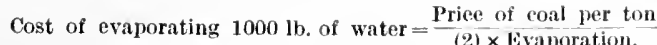

1 dollar $=4 s, 1 d$. To reduce dollars per ton $(2000 \mathrm{lb}$.) to shillings per ton $(2240 \mathrm{lb}$. $)$, multiply by $4-5$. 


\section{LIQUID FUEL AND ITS COMBUSTION}

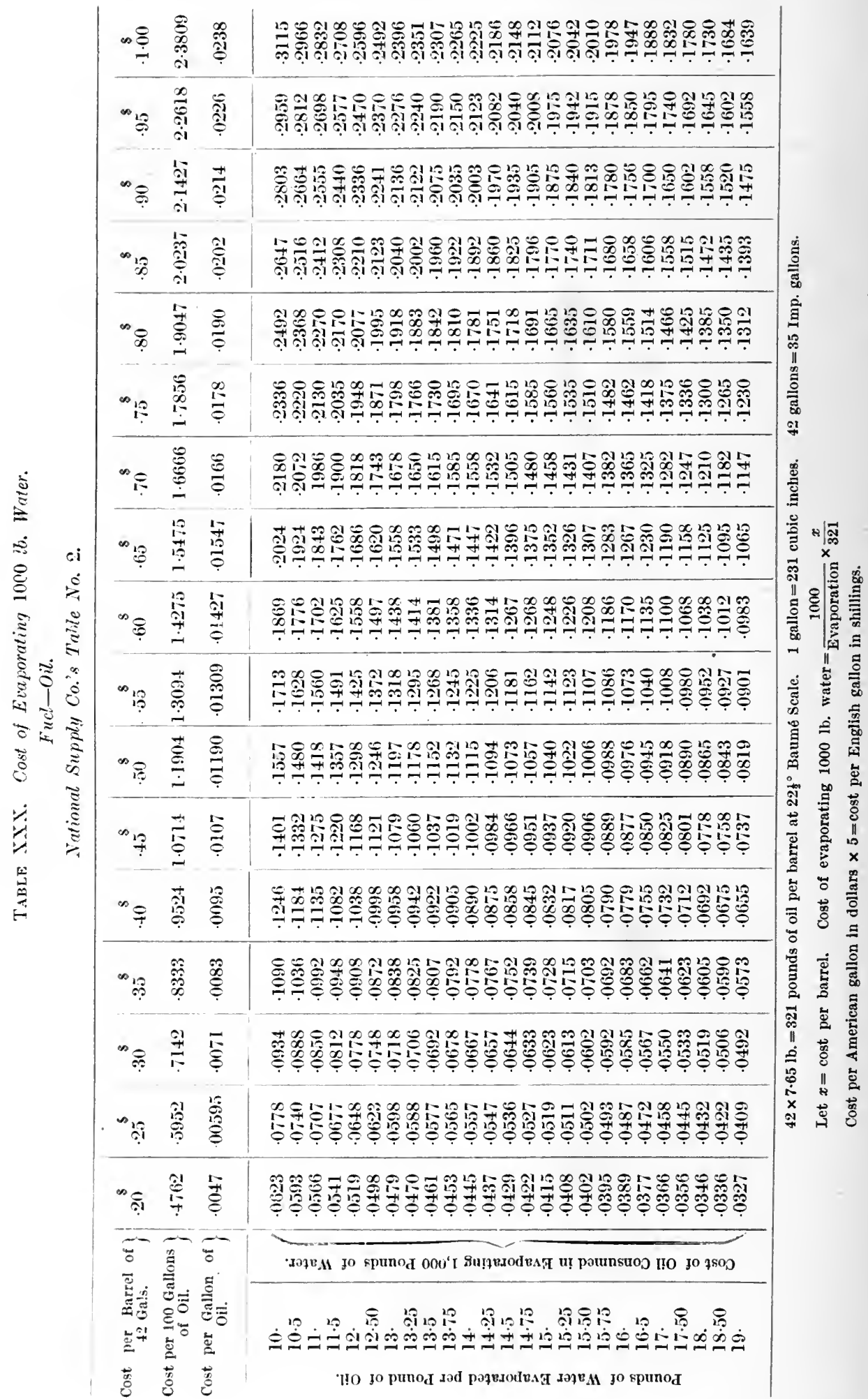


APPENDIX

Table XXXI. Conversion Table for Degrees Baumé.

\begin{tabular}{|c|c|c|c|c|c|}
\hline Degrees Baumé. & Degrees Sp. Gr. & $\begin{array}{l}\text { Lb. in } 1 \text { gal. } \\
\text { (American). }\end{array}$ & Degrees Baumé. & Degrees Sp. Gr. & $\begin{array}{l}\text { Lb. in } 1 \text { Gal. } \\
\text { (American). }\end{array}$ \\
\hline 10 & 1.0000 & $8 \cdot 33$ & 43 & $\cdot 8092$ & $6 \cdot 74$ \\
\hline 11 & .9929 & $8 \cdot 27$ & 44 & $\cdot 8045$ & 6.70 \\
\hline 12 & .9859 & $8 \cdot 21$ & 45 & $\cdot 8000$ & 6.66 \\
\hline 13 & .9790 & $8 \cdot 16$ & 46 & .7954 & $6 \cdot 63$ \\
\hline 14 & .8722 & $8 \cdot 10$ & 47 & $\cdot 7909$ & 6.59 \\
\hline 15 & .0655 & $8 \cdot 04$ & 48 & .7865 & 6.55 \\
\hline 16 & $\cdot 9589$ & 7.99 & 49 & $\cdot 7821$ & 6.52 \\
\hline 17 & .9523 & $7 \cdot 93$ & 50 & $\cdot 7777$ & $6 \cdot 48$ \\
\hline 18 & .9459 & $7 \cdot 88$ & $5 \mathrm{I}$ & $\cdot 7734$ & $6 \cdot 44$ \\
\hline 19 & .9395 & $7 \cdot 83$ & 52 & $\cdot 7692$ & $6 \cdot 41$ \\
\hline 20 & .9333 & $7 \cdot 78$ & 53 & .7650 & $6 \cdot 37$ \\
\hline 21 & .9271 & $7 \cdot 72$ & 54 & .7608 & $6 \cdot 34$ \\
\hline 22 & .9210 & $7 \cdot 67$ & 55 & $\cdot 7567$ & $6 \cdot 30$ \\
\hline 23 & .9150 & $7 \cdot 62$ & 56 & $\cdot 7526$ & $6 \cdot 27$ \\
\hline 24 & .9090 & $7 \cdot 57$ & 57 & .7486 & 6.24 \\
\hline 25 & .9032 & $7 \cdot 53$ & 58 & $\cdot 7446$ & $6 \cdot 20$ \\
\hline 26 & $\cdot 8974$ & $7 \cdot 48$ & 59 & .7407 & $6 \cdot 17$ \\
\hline 27 & $\cdot 8917$ & $7 \cdot 43$ & 60 & $\cdot 7368$ & $6 \cdot 14$ \\
\hline 28 & $\cdot 8860$ & $7 \cdot 38$ & 61 & .7329 & $6 \cdot 11$ \\
\hline 29 & $\cdot 8805$ & $7 \cdot 34$ & 62 & .7290 & $6 \cdot 07$ \\
\hline 30 & -8750 & $7 \cdot 29$ & 63 & $\cdot 7253$ & 6.04 \\
\hline 31 & .8695 & $7 \cdot 24$ & 61 & .7216 & $6 \cdot 01$ \\
\hline 32 & $\cdot 8641$ & $7 \cdot 20$ & 65 & $\cdot 7179$ & $5 \cdot 98$ \\
\hline 33 & $\cdot 8588$ & $7 \cdot 15$ & 66 & $\cdot 7142$ & 5.95 \\
\hline 34 & $\cdot 8536$ & $7 \cdot 11$ & 67 & $\cdot 7106$ & $5 \cdot 92$ \\
\hline 35 & $\cdot 8484$ & $7 \cdot 07$ & 68 & .7070 & $5 \cdot 89$ \\
\hline 36 & $\cdot 8433$ & 7.03 & 69 & $\cdot 7035$ & $5 \cdot 86$ \\
\hline 37 & .8383 & 6.98 & 70. & .7000 & $5 \cdot 83$ \\
\hline 38 & $\cdot 8333$ & 6.94 & 75 & 6829 & $5 \cdot 69$ \\
\hline 39 & $\cdot 8284$ & 6.90 & 80 & 6666 & 5.55 \\
\hline 40 & $\cdot 8235$ & $6 \cdot 86$ & 85 & .6511 & $5 \cdot 42$ \\
\hline 41 & .8187 & 6.82 & 90 & $\cdot 6363$ & $5 \cdot 30$ \\
\hline 42 & .8139 & $6 \cdot 78$ & 95 & .6222 & $5 \cdot 18$ \\
\hline
\end{tabular}

The Sp. Gr. $\times 10=$ weight in pounds per Imperial gallon.

TABLE XXXII. Quantity of Air required for perfect combustion of Fucls.

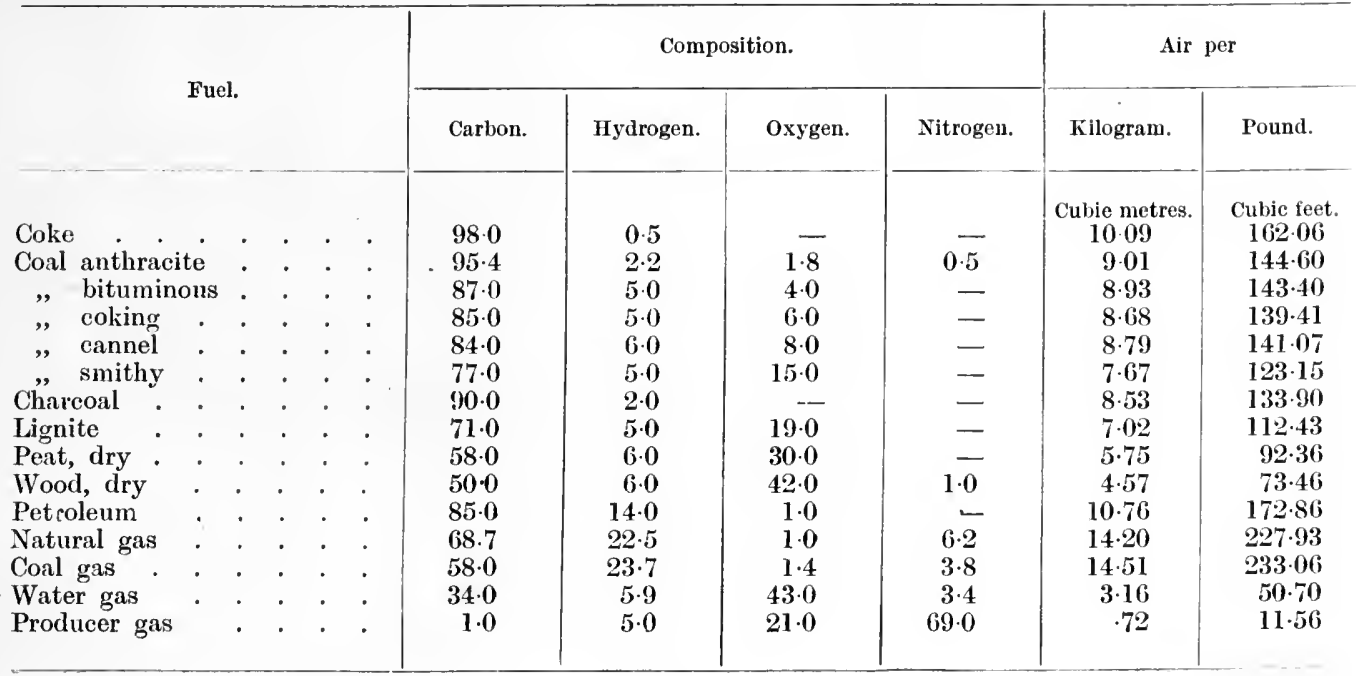




\section{LIQUID FUEL AND ITS COMBUSTION}

'TABLE No. XXXIII. Of the heat of combustion and air consumed by various Fuels.

\begin{tabular}{|c|c|c|c|c|c|c|c|c|c|c|}
\hline \multicolumn{6}{|c|}{ Fuel. } & $\begin{array}{c}\begin{array}{c}\text { Oxygen per } \\
\text { pound of fuel. }\end{array} \\
\begin{array}{l}\text { lb. } \\
8.0\end{array}\end{array}$ & \multicolumn{2}{|c|}{ Air per ponnd of fuel. } & $\begin{array}{l}\text { Total heat per } \\
\text { Jb. of fuel. } \\
\begin{array}{l}\text { B.Th.U. } \\
62100\end{array}\end{array}$ & $\frac{\begin{array}{c}\text { Evaporation from } \\
\text { and at } 212^{\circ} \mathrm{F} .\end{array}}{\mathrm{jb} .}$ \\
\hline $\begin{array}{l}\text { Hydrogen } \\
\text { Carbon to } \mathrm{CO}_{2} \\
\text { Average Coal } \\
\text { Coke . } \\
\text { Petroleum . }\end{array}$ & & & & & & $\begin{array}{l}\text { Ib. } \\
8.0 \\
2 \cdot 66 \\
2 \cdot 45 \\
2 \cdot 49 \\
3 \cdot 29\end{array}$ & $\begin{array}{l}11.8 \\
34 \cdot 8 \\
11 \cdot 6 \\
10 \cdot 7 \\
10 \cdot 81 \\
14 \cdot 33\end{array}$ & $\begin{array}{c}\text { Cubic feet. } \\
457 \\
152 \\
140 \\
142 \\
188\end{array}$ & $\begin{array}{l}\text { B.Th.U. } \\
62100 \\
14647 \\
14700 \\
13548 \\
20411\end{array}$ & $\begin{array}{l}\text { Jb. } \\
62 \cdot 4 \\
15 \cdot 0 \\
15 \cdot 22 \\
14 \cdot 02 \\
21 \cdot 13\end{array}$ \\
\hline
\end{tabular}

TAmLe XXXIV. Theoretical Flame Temperatures.

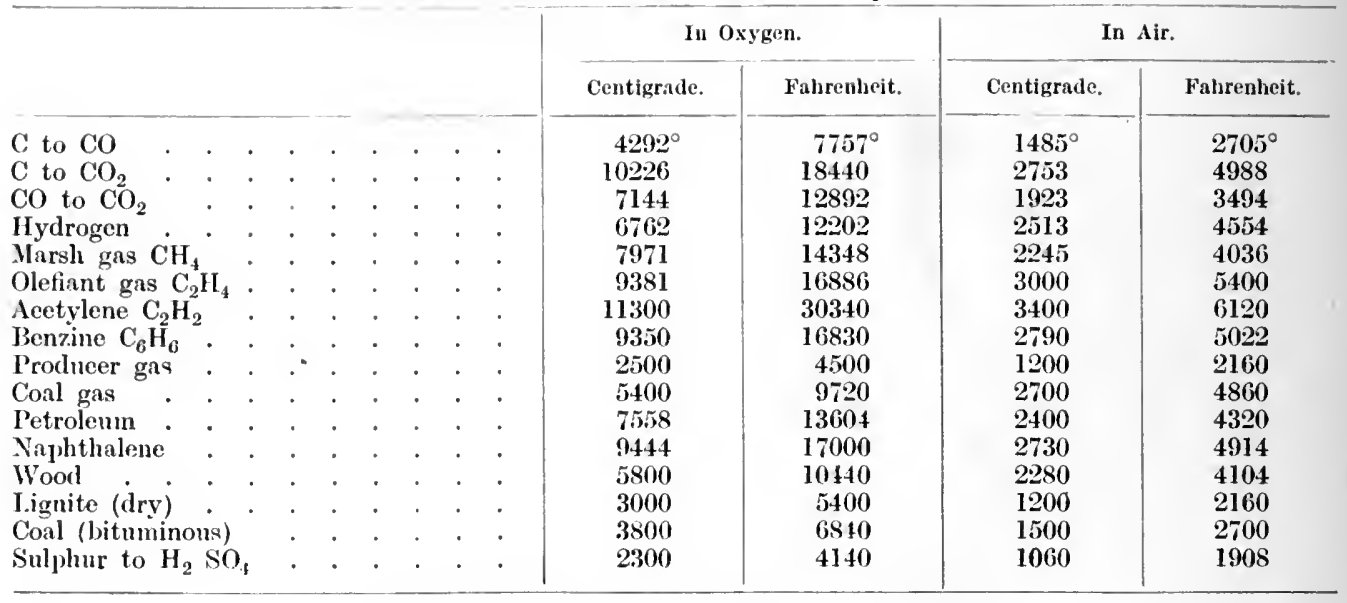

TABLE XXXV. Weight and Volume of Gases.

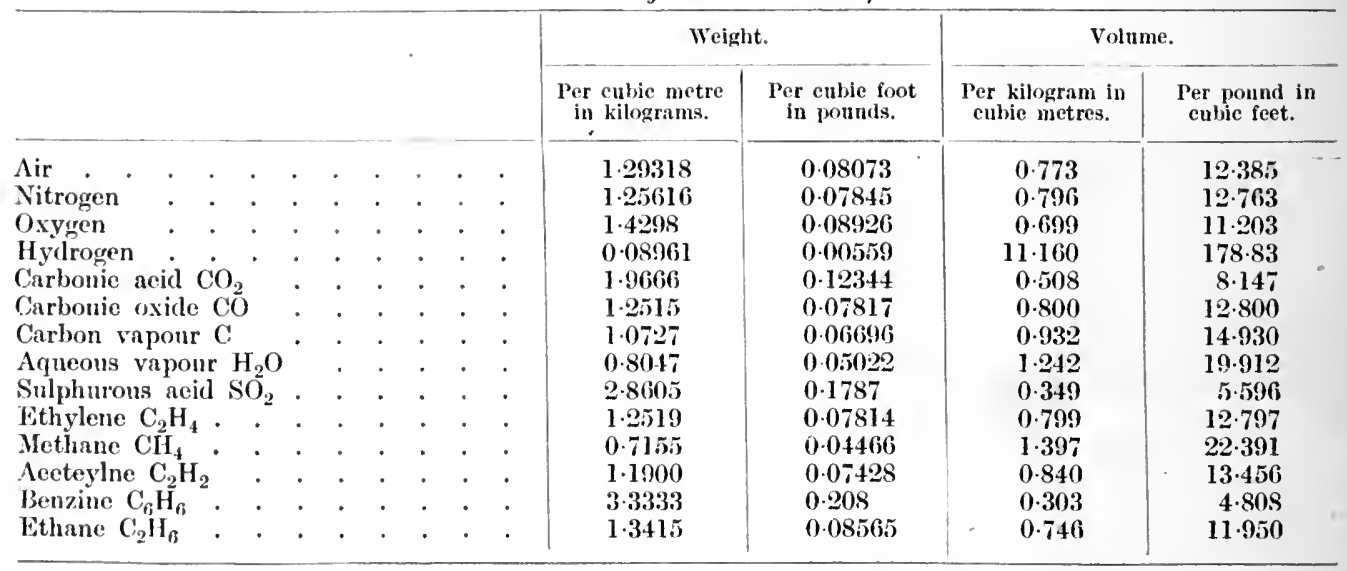

TAR1. XXXVI. Average Composition of Fuel Gases by Weight and Volume.

\begin{tabular}{|c|c|c|c|c|c|c|c|c|c|c|}
\hline & & & \multicolumn{2}{|c|}{ Natural Gas. } & \multicolumn{2}{|c|}{ Coal Gas. } & \multicolumn{2}{|c|}{ Water Gas. } & \multicolumn{2}{|c|}{ Produce Gas. } \\
\hline & & & Weight. & Volume. & Weight. & Volume. & Weight. & Volume. & Weight. & Volume \\
\hline Hydrogen . . & . & . & 0.268 & $2 \cdot 18$ & $8 \cdot 21$ & $46: 00$ & $5 \cdot 431$ & 45.00 & 0.458 & $6 \cdot 60$ \\
\hline Marsh gas $\mathrm{CH}_{4}$. & . & & $910 \cdot 383$ & $92 \cdot 60$ & 57.20 & 40.00 & 1.931 & $2 \cdot 00$ & $1 \cdot 8.31$ & $3 \cdot 00$ \\
\hline Carbonie oxide $\mathrm{CO}$ & . & . & 0.857 & 0.50 & 15.02 & $6 \cdot 00$ & $16 \cdot 041$ & $45 \cdot 00$ & 25.095 & $23 \cdot 50$ \\
\hline Olefiant gas $\mathrm{C}_{2} \mathrm{H}_{4}$ & . & . & 0.531 & 0.31 & $10 \cdot 01$ & $4 \cdot 00$ & 0.000 & 0.00 & 0.000 & 0.00 \\
\hline Carbonie acil $\mathrm{CO}_{2}$ & . & . & $0 \cdot 700$ & $0 \cdot 26$ & 1.97 & $0 \cdot 50$ & $10 \cdot 622$ & $4 \cdot 00$ & $2 \cdot 517$ & 1.50 \\
\hline Nitrogen $\cdot$. & $\cdot$ & . & 6.178 & $3 \cdot 61$ & 3.75 & $1 \cdot 50$ & $3 \cdot 380$ & $2 \cdot 00$ & $69 \cdot 413$ & $65 \cdot 00$ \\
\hline Oxygen $: 5$ & - & . & 0.666 & $0 \cdot 31$ & $1 \cdot 43$ & $0 \cdot 50$ & 0.965 & $0 \cdot 50$ & 0.000 & 0.00 \\
\hline Water vapour $\mathrm{H}_{2} \mathrm{O}$ & . & & 0.000 & $0 \cdot 00$ & $2 \cdot 41$ & $1 \cdot 50$ & $1 \cdot 630$ & $1 \cdot 50$ & 0.686 & 1.00 \\
\hline Relative values & $\therefore$ & $\therefore$ & 1000 & 1000 & 949 & 666 & 292 & 292 & $76 \cdot 5$ & 130 \\
\hline $\begin{array}{l}\text { Total product of } 100 \\
\text { burned }\end{array}$ & $\begin{array}{l}0 \text { enb. } \\
. \quad .\end{array}$ & ft. $\}$ & $879 \cdot 16$ & - & $565 \cdot 526$ & - & $257 \cdot 816$ & - & $169 \cdot 945$ & - \\
\hline Weiglit of water evap & orated & · & $893 \cdot 25$ & - & $591 \cdot 00$ & - & $262 \cdot 00$ & 一 & 115.000 & - \\
\hline
\end{tabular}




\section{APPENDIX}

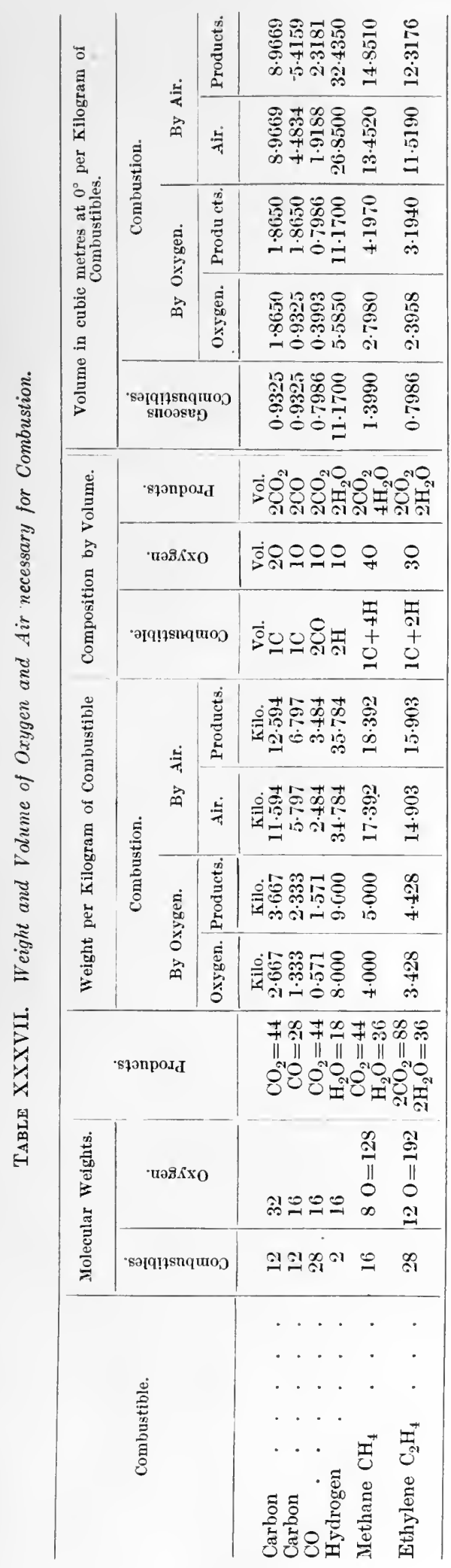

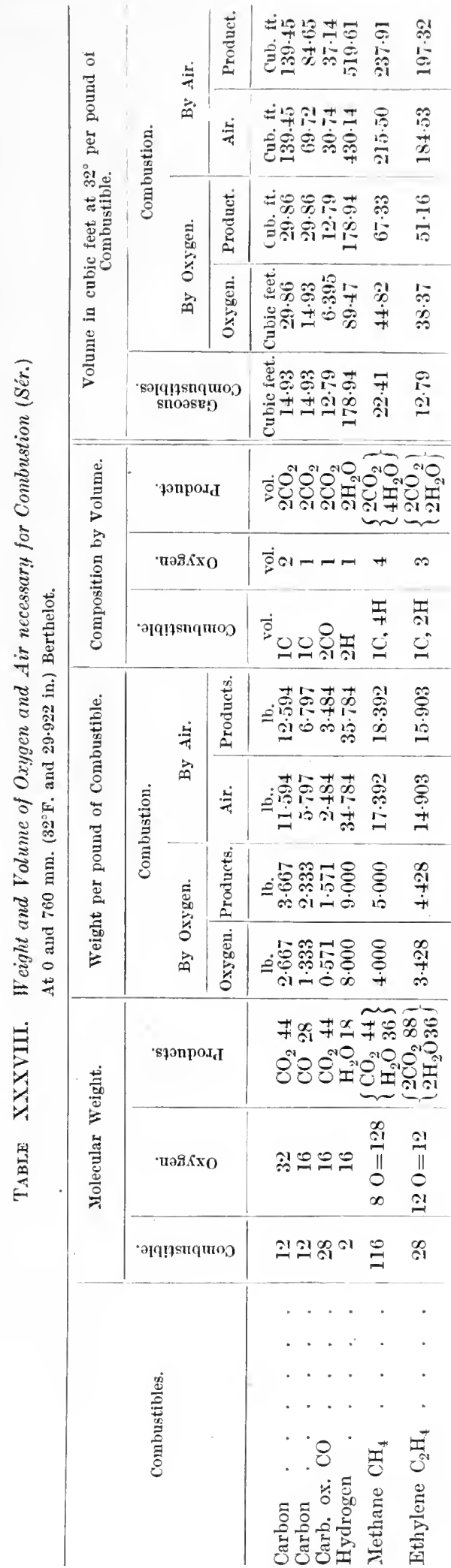




\section{LIQUID FUEL AND ITS COMBUSTION}

TABLE XXXIX. Heat of Combustion of Gases by Weight and Volume. At 0 and $760 \mathrm{~mm} .\left(32^{\circ} \mathrm{F}\right.$. and $29.922 \mathrm{Jn}$.) Berthelot.

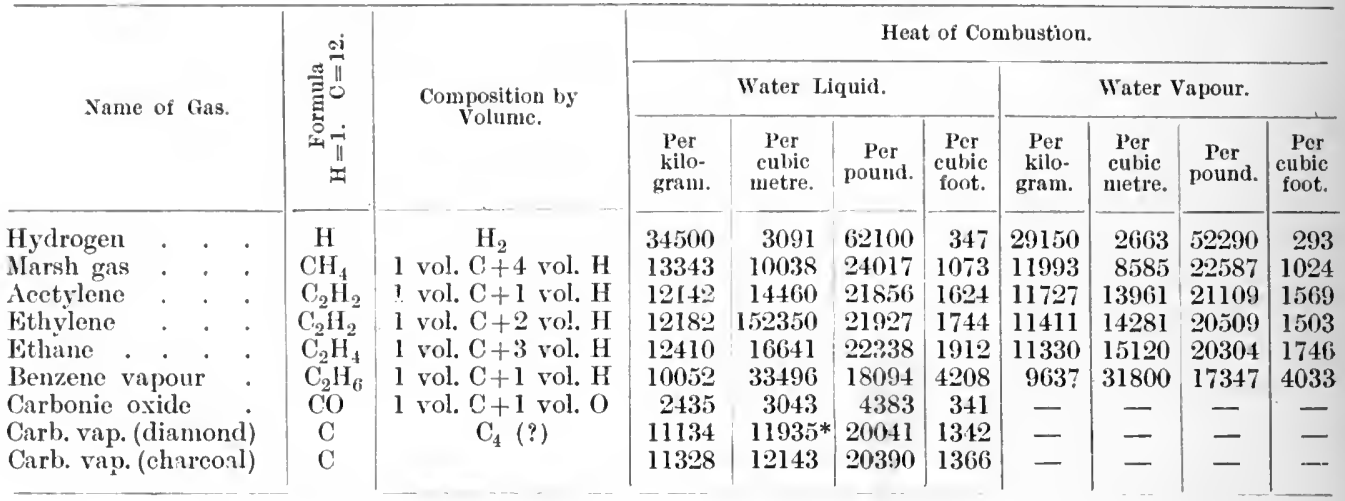

TABI.E XL. Specific Heat of Gases, referred to Water.

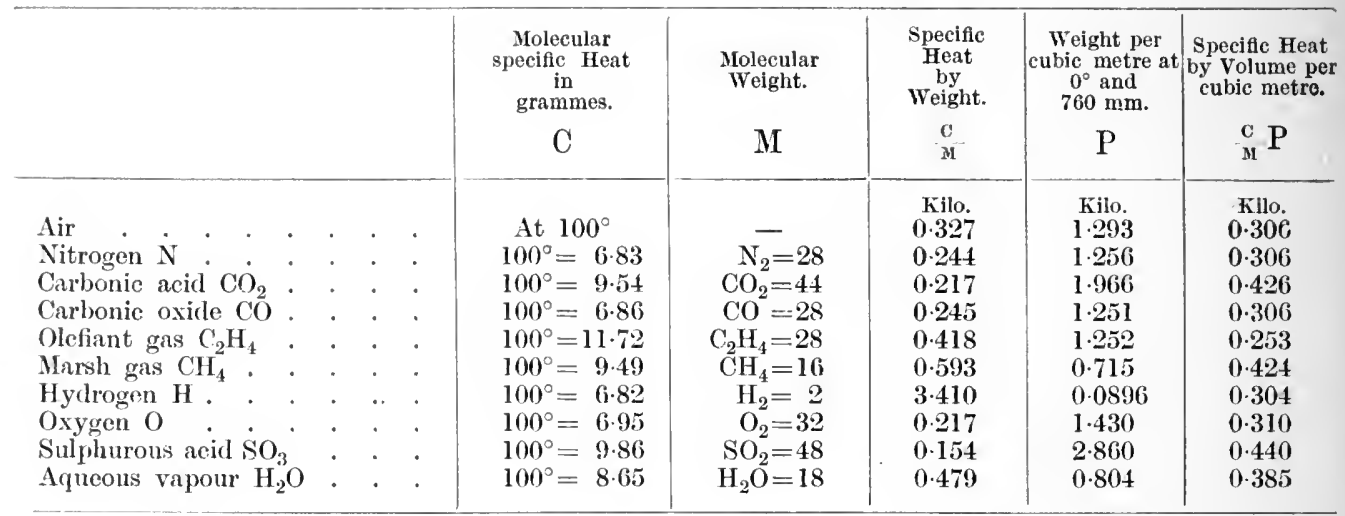

Table XLI. Table of Specific Heat of Gaseous products of Combustion referrcd to the proportion of Carboric Acid.

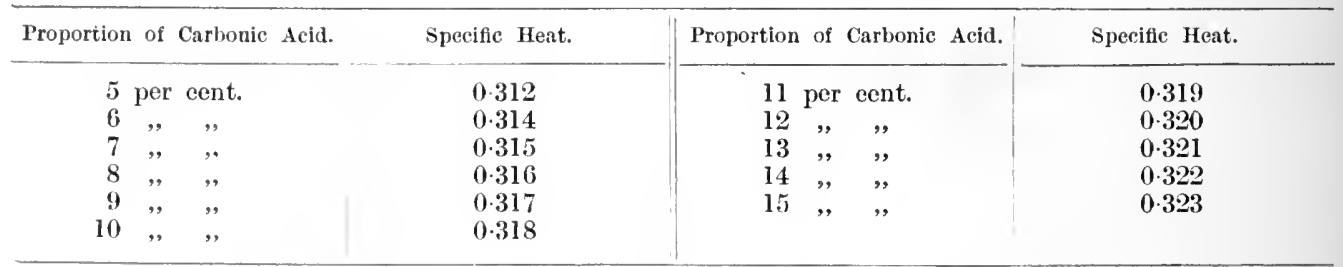

Table XIII. Specific Heat of Water. (Regnault.)

\begin{tabular}{|c|c|c|c|}
\hline Temperature. & Specific Heat. & Temperature. & Speciffe Heat. \\
\hline $0^{\circ} \mathrm{C}=32^{\circ} \mathrm{F}$ & 1.0000 & $110^{\circ}=230^{\circ} \mathrm{F}$ & 1.0153 \\
\hline $10^{\circ}=50$ & 1.0005 & $120^{\circ}=248$ & 1.0177 \\
\hline $20^{\circ}=68$ & 1.0012 & $130^{\circ}=266$ & 1.0204 \\
\hline $30^{\circ}=86$ & 1.0020 & $140^{\circ}=284$ & 1. 0232 \\
\hline $40^{\circ}=104$ & 1.0030 & $150^{\circ}=302$ & 1. 0262 \\
\hline $50^{\circ}=122$ & 1.0042 & $160^{\circ}=320$ & 1.0294 \\
\hline $60^{\circ}=140$ & 1.0056 & $170^{\circ}=338$ & 1.0328 \\
\hline $70^{\circ}=158$ & 1.0072 & $180^{\circ}=356$ & 10364 \\
\hline $80^{\circ}=176$ & 1.0098 & $190^{\circ}=374$ & 1.0401 \\
\hline $90^{\circ}=194$ & 1.0109 & $200^{\circ}=392$ & 1.0440 \\
\hline $100^{\circ}=212$ & 1.0130 & & \\
\hline
\end{tabular}




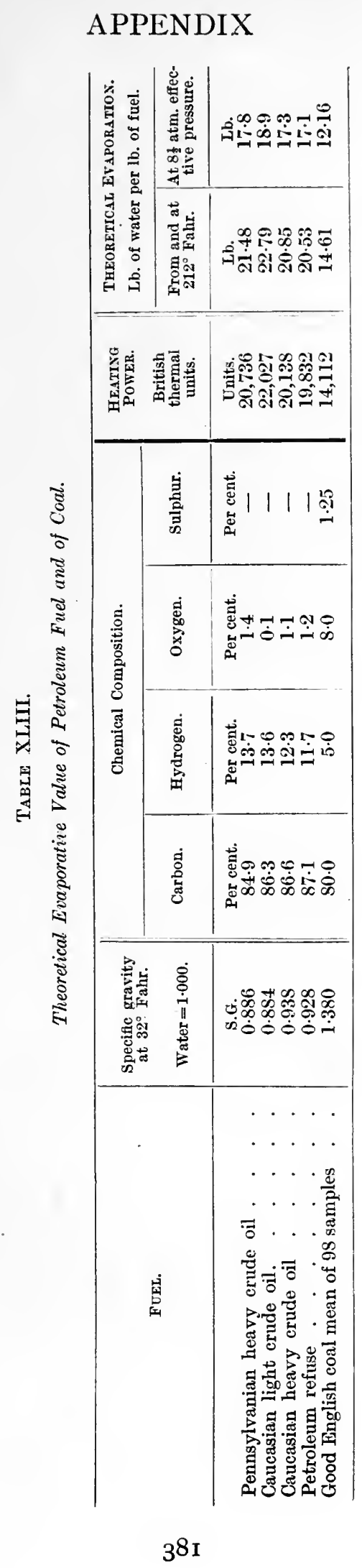




\section{LIQUID FUEL AND ITS COMBUSTION}

Table XIIV. Ignition Point of Gases (Mayer and Munch).

\begin{tabular}{|c|c|c|c|c|c|c|c|c|c|c|c|c|c|c|c|c|c|}
\hline 9 & & & & & & & & & & & & & & & & & $667^{\circ} \mathrm{C}$ \\
\hline e $\mathrm{C}_{2} \mathrm{H}_{4}$ & & . & . & . & - & & • & & . & . & & & & & & & \\
\hline $10 \mathrm{C}_{3} \mathrm{H}_{8}$ & & . & . & . & . & & . & . & . & . & . & & & & & & \\
\hline cetylene $\mathrm{C}_{2} \mathrm{H}_{2}$ & . & . & . & . & & . & . & . & . & . & . & & & & • & • & 580 \\
\hline ropylene $\mathrm{C}_{3} \mathrm{H}_{6}$ & & & . & & & & . & . & & . & . & & & & . & . & 504 \\
\hline
\end{tabular}

Table XLV. World's Production of Petroleum.

Barrels of 42 U.S. $=35$ Imp. gallons.

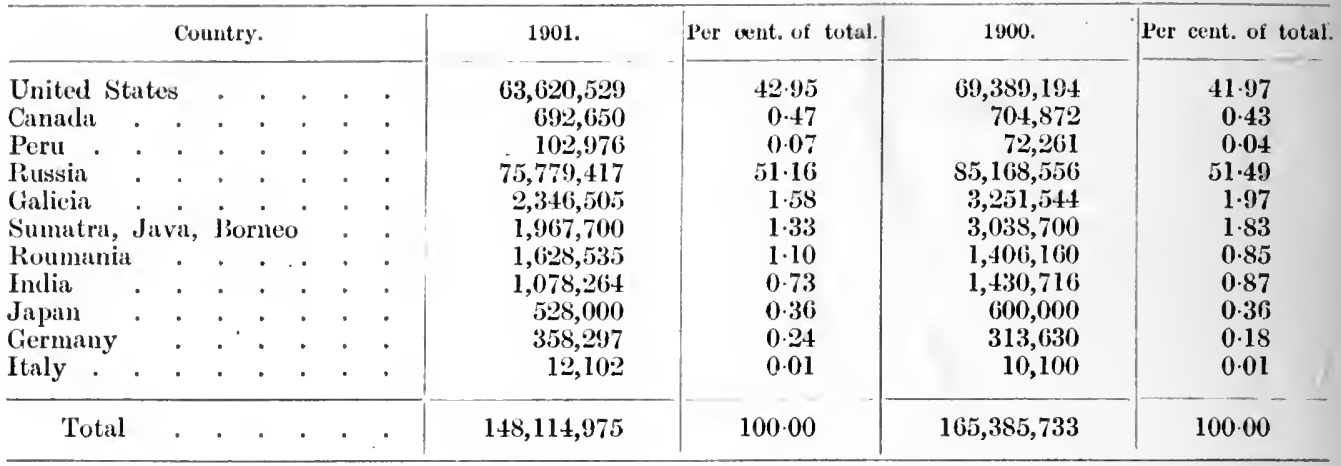

T'ABLE XLVI

Kilos per square metre $\times \cdot 2048=$ pounds per squaro foot.

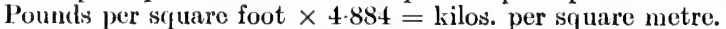

Kilos. per square em. $\times 14 \cdot 2: 23=$ pounds per square inch.

Pounds per square ineh $\times .0703=$ kilos. per square cin.

Evaporation from $16^{\circ} \mathrm{C}$. at 12 kilos. $\times 0.8222=$ evaporation from and at $100^{\circ} \mathrm{C}=212^{\circ} \mathrm{F}$.

Fivaporation from and at $100^{\circ} \mathrm{C} .=212^{\circ} \mathrm{F} \times 1.216=$ evaporation from $16^{\circ} \mathrm{C} .=61^{\circ} \mathrm{F}$. at 12 kilos.

. Metres $\times 3 \cdot 281=$ feet.

Square metres $\times 10 \cdot 764=$ square feet.

Feet $\times 0 \cdot 3048=$ metres.

Square feet $\times 0.9308=$ square metres.

Giallons $\times 4.546=$ litres.

Litres $\times 0.21998=$ gallons.

Cubic metres $\times 16.38(;=$ eubic $\mathrm{cm}$.

, cm. $\times 0.061027=$ eubie inches.

Gallons (Imp.) $\times 1.2012=$ American gallon.

American gallons $\times 0.83226=$ English Imp. gallons.

American gallons $\times 3 \cdot 784=$ litres.

litres $\times 0.2642=$ American gallons.

Inches water gauge $\times 25.4=$ millimetres water gauge.

Imp. gallons $\times 0.1606=$ cubic feet.

Cubic feet $\times 6 \cdot 288=$ gallons.

Feet of water head $\times 0.43=$ pounds per square incl.

Pounds per square ineh $\times 2 \cdot 326=$ feet head of water.

" " " , $\times 27.907=$ inches heal of water.

Inches water gauge $\times 0.0358=$ pounds per square inch.

Inehes water gauge $\times 0.572=$ ounces per square ineh.

Ounees per square inch $\times 1.744=$ inches hend of water.

Kilos per metre $\times 2.015=$ pounds per yard.

l'ounds per yarl $\times 0.4962=$ kilos. per motre.

Calories per $\mathrm{ML}^{3} \times 0 \cdot 11 \cdot 2 \mathrm{l}=\mathrm{B}$.Th. U. per $\mathrm{ft}^{3}$

B.Th.U. per ft. ${ }^{3} \times 8.92=$ cal. per M. ${ }^{3}$

Calories per $\mathrm{M}^{2} \times 0 \cdot 3686=$ B.Th. U. per $\mathrm{ft}^{2}{ }^{2}$

B.Th.U. per ft. ${ }^{2} \times 2.713=$ cal. per Metre ${ }^{2}$ 


\section{APPENDIX}

Table XLVII. Specific Gravity of various Materials.

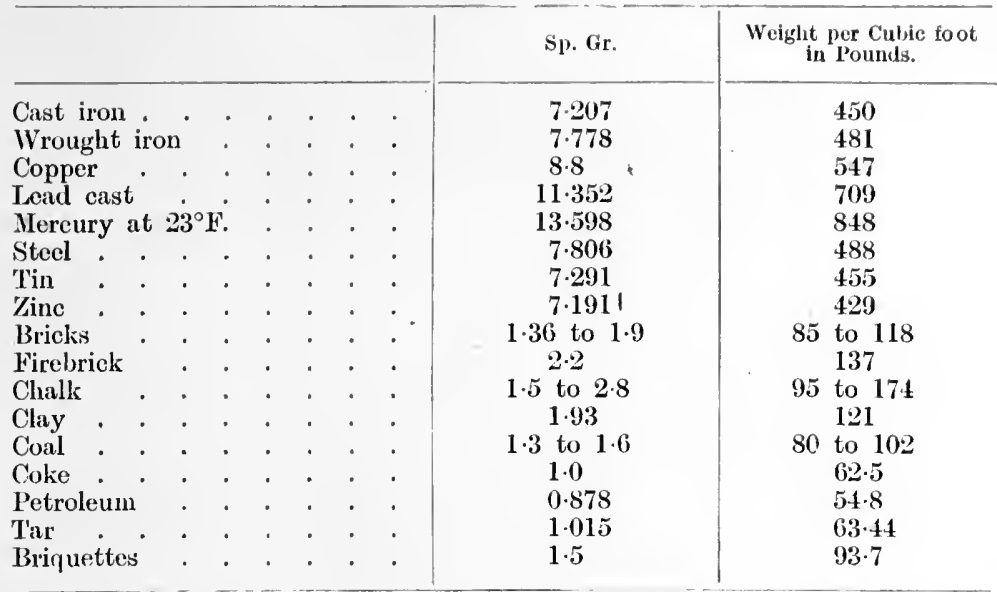

The copyright tables No. XI.VIII to LIX which follow are reprinted by permission of Messrs. T. \& T. Vicars from their stokel catalogue.

Table XI.VIII. Height of Water Column due to Unbalanced Pressures in Chimney 100 feet high.

\begin{tabular}{|c|c|c|c|c|c|c|c|c|c|c|c|}
\hline \multirow{2}{*}{$\begin{array}{c}\text { Temp. } \\
\text { in } \\
\text { Chininey. }\end{array}$} & \multicolumn{11}{|c|}{ TEMPERATURE OF ATMOSPHERE. } \\
\hline & $0^{\circ}$ & $10^{\circ}$ & $20^{\circ}$ & $30^{\circ}$ & $40^{\circ}$ & $50^{\circ}$ & $60^{\circ}$ & $70^{\circ}$ & $80^{\circ}$ & $90^{\circ}$ & $100^{\circ}$ \\
\hline 200 & .453 & .419 & 38.1 & 353 & 321 & .292 & 263 & $23 t$ & .209 & $\cdot 182$ & $\cdot 157$ \\
\hline 220 & .488 & .453 & .419 & $\cdot 388$ & .355 & .326 & .298 & .269 & 244 & .217 & .192 \\
\hline 240 & .520 & $\cdot 488$ & $\cdot 451$ & $\cdot 421$ & 388 & $\cdot 359$ & $\cdot 330$ & 301 & $\cdot 276$ & .250 & 12025 \\
\hline 260 & .555 & .528 & .484 & .453 & 420 & $\cdot 392$ & $\cdot 363$ & 334 & $\cdot 309$ & .282 & .257 \\
\hline 280 & .584 & .549 & .515 & .482 & .451 & .422 & 394 & 365 & 340 & .313 & .288 \\
\hline 300 & .611 & 576 & .541 & .511 & $\cdot 478$ & -449 & .420 & .392 & $\cdot 367$ & $\cdot 340$ & 315 \\
\hline 320 & .637 & .603 & .568 & $\cdot 538$ & 505 & 476 & .447 & .419 & .394 & $\cdot 367$ & .342 \\
\hline 340 & $\cdot 662$ & $\cdot 638$ & .593 & .563 & 530 & .501 & $\cdot 472$ & $\cdot 443$ & -419 & $\cdot 392$ & .367 \\
\hline 360 & .687 & $\cdot 653$ & .618 & .588 & .555 & .526 & .497 & .468 & .444 & .417 & .392 \\
\hline 380 & .710 & .676 & $6+1$ & .611 & .578 & .549 & .520 & -492 & .467 & -440 & 415 \\
\hline 400 & .732 & 697 & .662 & .632 & .598 & .570 & .541 & .513 & .488 & .461 & 436 \\
\hline 420 & .753 & 718 & .684 & .658 & .620 & .591 & .563 & .534 & .509 & .482 & 457 \\
\hline 440 & .774 & .739 & .705 & .674 & 641 & 612 & .584 & .555 & .530 & .503 & .478 \\
\hline 460 & $\cdot 793$ & $\cdot 759$ & .724 & $\cdot 694$ & $\cdot 660$ & .632 & 603 & .574 & $\cdot 549$ & .522 & .497 \\
\hline 480 & $\cdot 810$ & .776 & $\cdot 741$ & .710 & 678 & $\cdot 649$ & 620 & .591 & $\cdot 566$ & .540 & .515 \\
\hline 500 & .829 & $\cdot 791$ & $\cdot 760$ & $\cdot 730$ & 697 & .669 & .639 & .610 & .586 & .559 & .5 .34 \\
\hline
\end{tabular}

For any other chimney height than the $100 \mathrm{fect}$, water column is directly proportional to height of chimney: velocity created by draught, and volume of air moved, however, vary as the square root of the height.

TABLE XILX. To determine Temperature by Fusion of Metals.

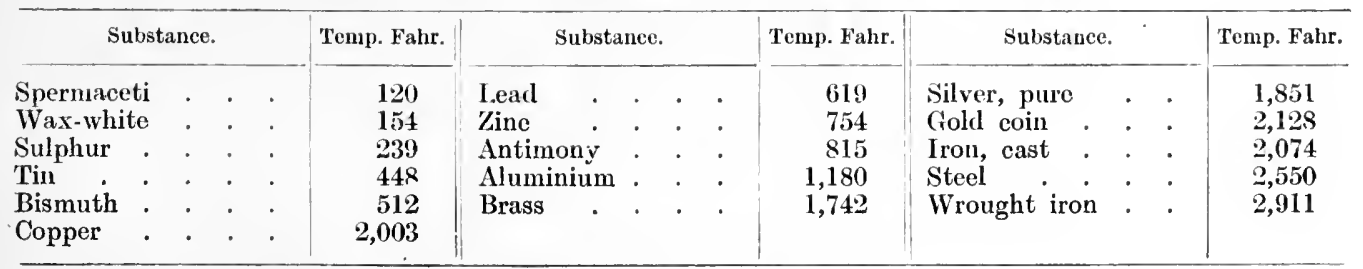

Where different temperatures are given by different authorities, mean taken. 


\section{LIQUID FUEL AND ITS COMBUSTION}

Tabie L. Air Required for Combustion of Fuels.

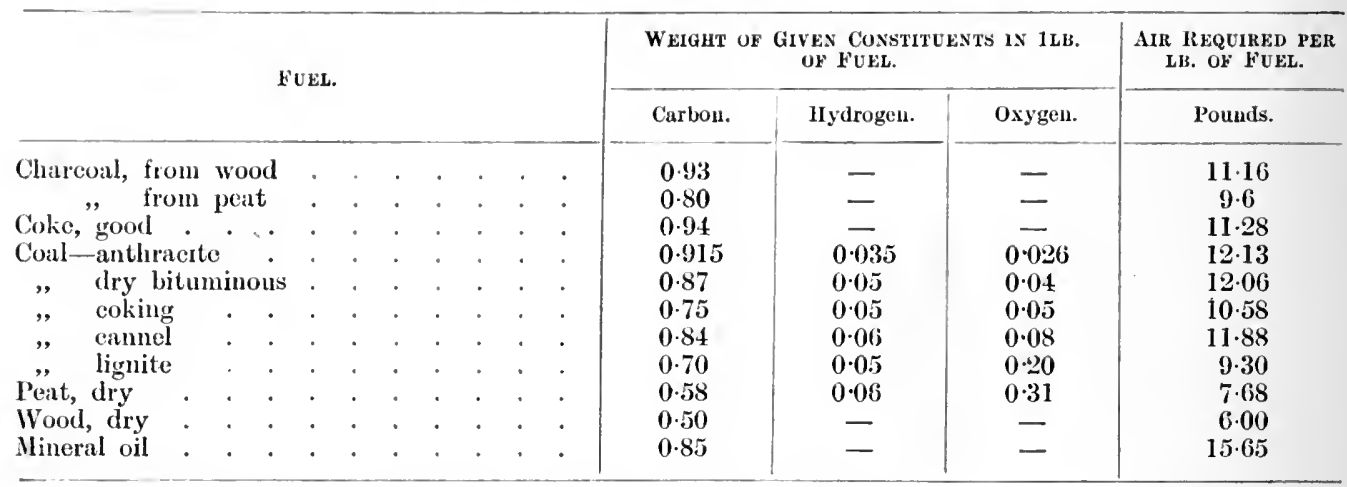

For ealculating the above from analysis of the fuels the following formula is used-

$$
\text { Weight of air required }=12 \mathrm{C}+36\left(\mathrm{H}-\frac{\mathrm{O}}{8}\right)
$$
and $\stackrel{\text { In. }}{\mathrm{O}}$.

In the above equation the weights of Carbon, Hydrogen, and Oxygen are represented respectively by their symbols C, H,

Tabie LI. Volume and Weight of Dry Air at Different T'emperatures under a Constant Atmospheric Pressure of $29.92 \mathrm{in}$. of Mercury, the Volume at $32 \mathrm{Deg}$. Fahi being 1.

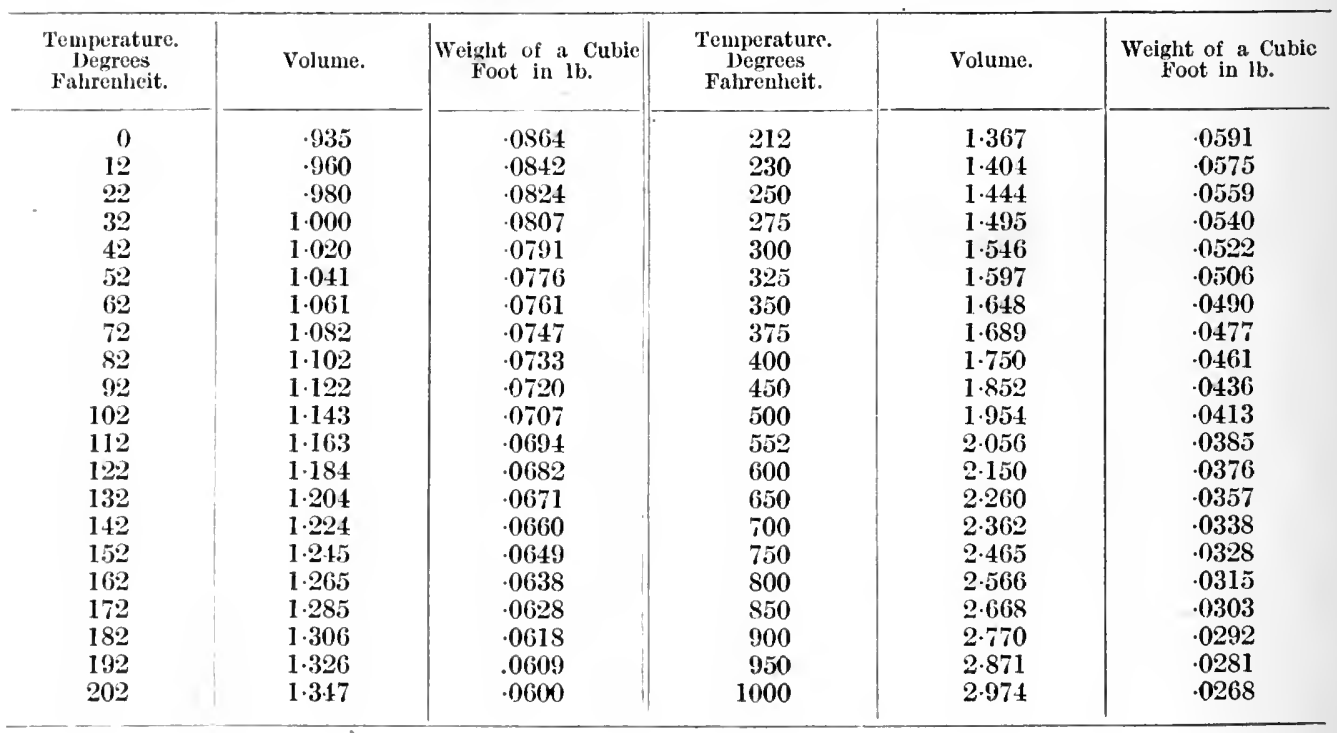




\section{APPENDIX}

TABLE LII. Table showing Number of British Thermal Units contained in one pound of pure Water at varying temperatures and densities, and pounds per gallon.

\begin{tabular}{|c|c|c|c|c|c|c|c|}
\hline $\begin{array}{c}\text { Temperature. } \\
\text { Degrees } \\
\text { Fahr. } \\
1\end{array}$ & $\begin{array}{l}\text { Density or } \\
\text { Weight of } \\
1 \text { Cubie Foot. } \\
\text { Pounds. } \\
2\end{array}$ & $\begin{array}{l}\text { Number of } \\
\text { Thermal Units } \\
\text { in } 1 \text { pound of } \\
\text { Water. } \\
3\end{array}$ & $\begin{array}{c}\text { Pounds Weight } \\
\text { per Gallon. } \\
4\end{array}$ & $\begin{array}{c}\text { Temperature. } \\
\text { Degrees } \\
\text { Fahr. } \\
1\end{array}$ & $\begin{array}{l}\text { Density or } \\
\text { Weiglit of } \\
1 \text { Cubie Foot. } \\
\text { Pounds. } \\
2\end{array}$ & $\begin{array}{l}\text { Number of } \\
\text { Thermal Units } \\
\text { in } 1 \text { pound of } \\
\text { Water. } \\
3\end{array}$ & $\begin{array}{c}\text { Pounds Weight } \\
\text { per Giallon. } \\
4\end{array}$ \\
\hline *32 & $62 \cdot 418$ & $32 \cdot 000$ & $10 \cdot 0101$ & 135 & 61.472 & $135 \cdot 217$ & 9.859 \\
\hline 35 & $62 \cdot 422$ & $35 \cdot 000$ & $10 \cdot 0102$ & 140 & $61 \cdot 381$ & $140 \cdot 245$ & $9 \cdot 844$ \\
\hline 45 & $62 \cdot 422$ & $45 \cdot 002$ & $10 \cdot 0103$ & 155 & $61 \cdot 096$ & $155 \cdot 339$ & $9 \cdot 799$ \\
\hline 50 & $62 \cdot 409$ & $50 \cdot 003$ & 10.0087 & 160 & 60.991 & $160 \cdot 374$ & 9.781 \\
\hline 55 & $62 \cdot 394$ & 55.006 & $10 \cdot 0063$ & 165 & $60 \cdot 843$ & $165 \cdot 413$ & 9.757 \\
\hline 60 & $62 \cdot 372$ & 60.009 & 10.0053 & 170 & $60 \cdot 783$ & $170 \cdot 453$ & $9 \cdot 748$ \\
\hline 65 & $62 \cdot 344$ & $65 \cdot 014$ & 9.9982 & 175 & $60 \cdot 665$ & $175 \cdot 497$ & $9 \cdot 728$ \\
\hline 90 & $62 \cdot 133$ & 90.055 & $9 \cdot 964$ & 200 & $60 \cdot 081$ & $200 \cdot 753$ & $9 \cdot 635$ \\
\hline 95 & $62 \cdot 074$ & $95 \cdot 067$ & $9 \cdot 955$ & 205 & 59.93 & $205 \cdot 813$ & $9 \cdot 611$ \\
\hline 100 & (62.022 & $100 \cdot 080$ & $9 \cdot 947$ & 210 & $59 \cdot 82$ & $210 \cdot 874$ & $9 \cdot 594$ \\
\hline 105 & $61 \cdot 960$ & $105 \cdot 095$ & $9 \cdot 937$ & $\$ 212$ & $59 \cdot 76$ & $212 \cdot 882$ & $9 \cdot 565$ \\
\hline 110 & 61.869 & $110 \cdot 110$ & $9 \cdot 922$ & 230 & $59 \cdot 36$ & $231 \cdot 153$ & 9.520 \\
\hline 115 & $61 \cdot 807$ & $115 \cdot 129$ & $9 \cdot 913$ & 250 & $58 \cdot 75$ & $251 \cdot 487$ & $9 \cdot 422$ \\
\hline 120 & $61 \cdot 715$ & $120 \cdot 149$ & $9 \cdot 897$ & 270 & $58 \cdot 18$ & $271 \cdot 878$ & \\
\hline 125 & $61 \cdot 654$ & 125169 & $9 \cdot 887$ & 290 & $57 \cdot 59$ & $292 \cdot 329$ & \\
\hline 130 & $61 \cdot 563$ & $130 \cdot 192$ & $9 \cdot 873$ & & & & \\
\hline
\end{tabular}

* $32^{\circ} \mathrm{F}$. = Freezing point of water.

$\dagger 39 \cdot 1^{\circ} \mathrm{F} .=$ The temperature at which water is at its greatest density.

$\$ 212^{\circ} \mathrm{F}$. = Boiling point of water.

A British Thermal Unit (B.Th.U.) = that quantity of heat that is required to raise one pound of water through one degree Fahr. at or near $39 \cdot 1^{\circ} \mathrm{F}$.

\section{TABLE LIII. Saturated Steam.}

Saturated Steam is dry steam at the maximum pressure aud density, due to its temperature-not superheated. It is attained when all latent heat required for the steam has been taken up-this is called "Saturation Point." A vapour not near the saturation point behaves like a gas under changes of temperature and pressure; if it is compressed or cooled it reaches a point where it begins to condense ; it then no longer obeys the same laws as a gas.

Heat and Work required to Generate $1 \mathrm{lb}$. of Saturated Steam at $212^{\circ} \mathrm{F}$. from Water at $32^{\circ} \mathbf{F}$.

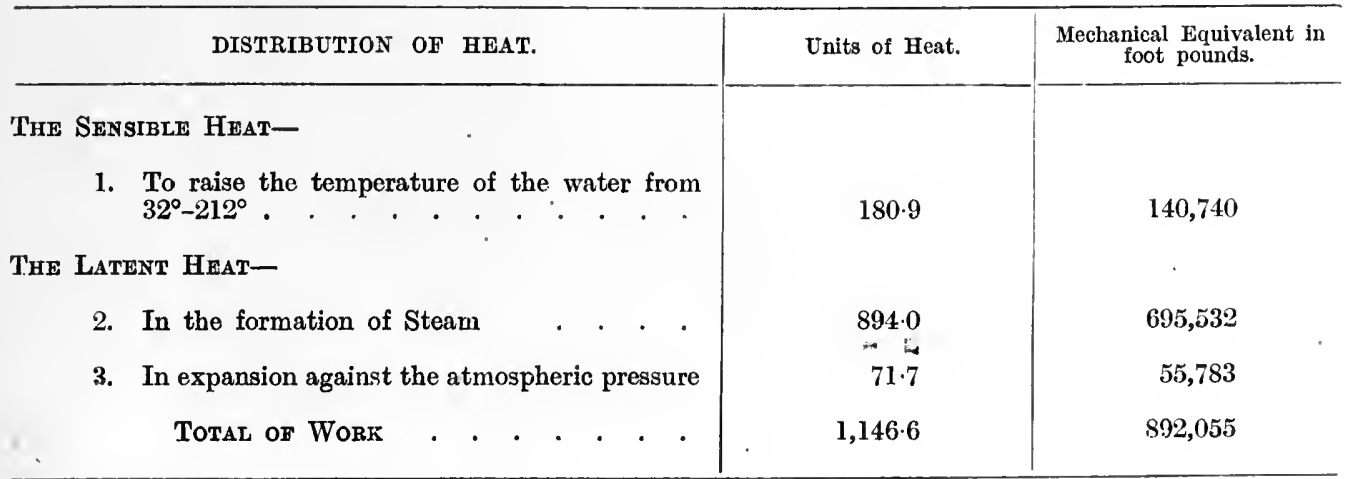




\section{LIQUID FUEL AND ITS COMBUSTION}

Table LIII. Properties of Saturated Stcam (continued).

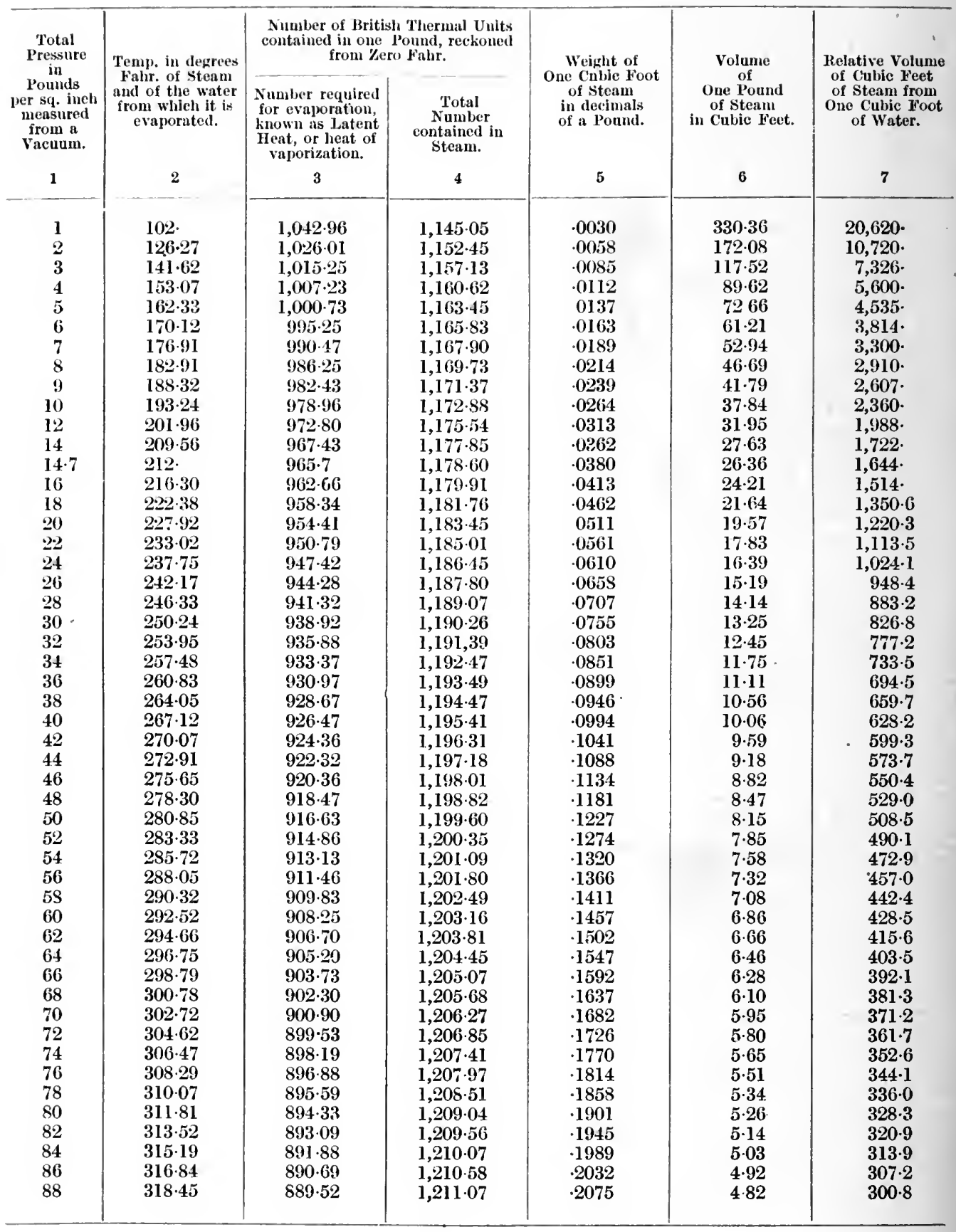




\section{APPENDIX}

Tarle LIII. Propertics of Saturated Steam (continued).

\begin{tabular}{|c|c|c|c|c|c|c|}
\hline \multirow{3}{*}{$\begin{array}{c}\text { Total } \\
\text { Pressure } \\
\text { in } \\
\text { Pounds } \\
\text { per sq. ineh } \\
\text { measured } \\
\text { from a } \\
\text { Vaeuum. } \\
\text {. } 1\end{array}$} & \multirow{2}{*}{$\begin{array}{l}\text { Temp. in degrees } \\
\text { Fahr. of Steam } \\
\text { and of the water } \\
\text { from whieh it is } \\
\text { evaporated. }\end{array}$} & \multicolumn{2}{|c|}{$\begin{array}{l}\text { Number of British Thermal Units } \\
\text { eontained in one Pound, reekoned } \\
\text { from Zero Falır. }\end{array}$} & \multirow{3}{*}{$\begin{array}{l}\text { Weight of } \\
\text { One Cubie Foot } \\
\text { of Steam } \\
\text { in decimals of a } \\
\text { Pound. }\end{array}$} & \multirow{3}{*}{ 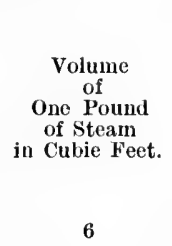 } & \multirow{2}{*}{$\begin{array}{c}\text { Relative Volunie } \\
\text { of Cubie reet } \\
\text { of Steam from } \\
\text { One Cubie Foot } \\
\text { of Water. }\end{array}$} \\
\hline & & $\begin{array}{l}\text { Number required } \\
\text { for evaporation, } \\
\text { kuown as Latent } \\
\text { Heat, or heat of } \\
\text { - vaporization. }\end{array}$ & $\begin{array}{c}\text { Total } \\
\text { Number } \\
\text { contained } \\
\text { in Steam. }\end{array}$ & & & \\
\hline & 2 & 3 & 4 & & & 7 \\
\hline 90 & $320 \cdot 04$ & $888 \cdot 38$ & $1,211 \cdot 55$ & $\cdot 2118$ & 472 & $294 \cdot 7$ \\
\hline 92 & $321 \cdot 60$ & $887 \cdot 25$ & $1,212 \cdot 03$ & .2161 & $4 \cdot 63$ & 288.9 \\
\hline 94 & $323 \cdot 13$ & $886 \cdot 14$ & $1,212 \cdot 49$ & 2204 & 4.54 & $283 \cdot 3$ \\
\hline 96 & $324 \cdot 63$ & 885.04 & $1,212.95$ & .2245 & $4 \cdot 44$ & $278 \cdot 0$ \\
\hline 98 & $326 \cdot 1]$ & $883 \cdot 97$ & $1,213 \cdot 40$ & $\cdot 2288$ & $4 \cdot 37$ & $272 \cdot 8$ \\
\hline 100 & 327.57 & 882.91 & $1,213 \cdot 85$ & .2330 & $4 \cdot 29$ & 267.9 \\
\hline 105 & $331 \cdot 11$ & $880 \cdot 34$ & $1,2] 4 \cdot 93$ & 2434 & $4 \cdot 11$ & $256 \cdot 5$ \\
\hline 110 & $334 \cdot 52$ & $877 \cdot 86$ & $1,215 \cdot 97$ & .2538 & 3.94 & 246.0 \\
\hline 115 & 337.81 & $875 \cdot 47$ & $1,216 \cdot 97$ & $\cdot 2640$ & $3 \cdot 79$ & $236 \cdot 3$ \\
\hline 120 & $340 \cdot 99$ & $873 \cdot 15$ & $1,217.94$ & .2743 & $3 \cdot 65$ & $227 \cdot 8$ \\
\hline 125 & 344.07 & 870.91 & $1,218 \cdot 88$ & .2843 & $3 \cdot 52$ & $219 \cdot 7$ \\
\hline 130 & 347.06 & $868 \cdot 73$ & $1,219 \cdot 79$ & $\cdot 2942$ & $3 \cdot 40$ & $212 \cdot 3$ \\
\hline 135 & $349 \cdot 95$ & $866 \cdot 62$ & $1,220 \cdot 68$ & $\cdot 3040$ & $3 \cdot 29$ & $205 \cdot 4$ \\
\hline 140 & $352 \cdot 77$ & 864.57 & $1,221 \cdot 53$ & $\cdot 3139$ & $3 \cdot 19$ & $199 \cdot 0$ \\
\hline 145 & $355 \cdot 50$ & $862 \cdot 57$ & $1,222 \cdot 37$ & .3239 & 3.09 & $193 \cdot 0$ \\
\hline 150 & $358 \cdot 16$ & $860 \cdot 62$ & $1,223 \cdot 18$ & $\cdot 3340$ & 2.99 & 187.5 \\
\hline 160 & $363 \cdot 28$ & $856 \cdot 87$ & $1,224 \cdot 74$ & .3521 & $2 \cdot 84$ & $177 \cdot 3$ \\
\hline 170 & $368 \cdot 16$ & $853 \cdot 29$ & $1,226 \cdot 23$ & $\cdot 3709$ & $2 \cdot 69$ & 168.4 \\
\hline 180 & $372 \cdot 82$ & $849 \cdot 87$ & $1,227 \cdot 65$ & $\cdot 3889$ & 2.57 & $160 \cdot 4$ \\
\hline 190 & $377 \cdot 29$ & $846 \cdot 58$ & $1,229 \cdot 01$ & .4072 & $2 \cdot 45$ & $153 \cdot 4$ \\
\hline 200 & $381 \cdot 57$ & $843 \cdot 43$ & $1,230 \cdot 32$ & .4250 & $2 \cdot 35$ & $147 \cdot 1$ \\
\hline 250 & $401 \cdot 07$ & $831 \cdot 22$ & $1,235 \cdot 73$ & .5464 & 1.83 & 114. \\
\hline 300 & $418 \cdot 22$ & $819 \cdot 61$ & $1,240 \cdot 74$ & $\cdot 6486$ & $1 \cdot 54$ & 96 \\
\hline 350 & $431 \cdot 96$ & $810 \cdot 69$ & $1,244 \cdot 58$ & $\cdot 7498$ & 1.33 & 83. \\
\hline 400 & $444 \cdot 92$ & $800 \cdot 20$ & $1,249.09$ & $\cdot 8502$ & $1 \cdot 18$ & 73 \\
\hline
\end{tabular}


Table LIV. Faclors of Evaporation.

\begin{tabular}{|c|c|c|c|c|c|c|c|c|c|}
\hline \multicolumn{10}{|c|}{ Gauge Pressure of Steam in pounds per Square Inch. } \\
\hline 0 & 20 & 40 & 50 & 60 & 70 & 80 & 90 & 100 & $\begin{array}{c}\text { Temp. of } \\
\text { Feed Water }\end{array}$ \\
\hline $1 \cdot 187$ & $1 \cdot 201$ & 1.211 & 1.214 & 1.217 & 1.219 & $1 \cdot 222$ & $1 \cdot 224$ & 1.227 & 32 \\
\hline $1 \cdot 184$ & $1 \cdot 198$ & 1.208 & $1 \cdot 211$ & 1.214 & $1 \cdot 216$ & $1 \cdot 219$ & $1 \cdot 221$ & $1 \cdot 224$ & 35 \\
\hline $1 \cdot 179$ & $1 \cdot 193$ & 1.203 & $1 \cdot 206$ & 1.209 & $1 \cdot 211$ & $1 \cdot 214$ & $1 \cdot 216$ & 1.219 & 40 \\
\hline 1.173 & $1 \cdot 187$ & $1 \cdot 197$ & $1 \cdot 200$ & $1 \cdot 203$ & $1 \cdot 205$ & $1 \cdot 208$ & $1 \cdot 210$ & 1.213 & 45 \\
\hline 1.168 & $1 \cdot 182$ & $1 \cdot 192$ & $1 \cdot 195$ & $1 \cdot 198$ & 1.200 & $1 \cdot 203$ & $1 \cdot 205$ & $1 \cdot 208$ & 50 \\
\hline $1 \cdot 163$ & $1 \cdot 177$ & $1 \cdot 187$ & $1 \cdot 190$ & $1 \cdot 193$ & 1.195 & $1 \cdot 198$ & 1.200 & $1 \cdot 203$ & 55 \\
\hline $1 \cdot 158$ & 1.172 & $1 \cdot 182$ & $1 \cdot 185$ & $1 \cdot 188$ & $1 \cdot 190$ & $1 \cdot 193$ & $1 \cdot 195$ & 1.198 & 60 \\
\hline $1 \cdot 153$ & $1 \cdot 167$ & $1 \cdot 177$ & $1 \cdot 180$ & $1 \cdot 183$ & $1 \cdot 185$ & $1 \cdot 188$ & $1 \cdot 190$ & $1 \cdot 193$ & 65 \\
\hline $1 \cdot 148$ & $1 \cdot 162$ & $1 \cdot 172$ & $1 \cdot 175$ & $1 \cdot 178$ & $1 \cdot 180$ & $1 \cdot 183$ & 1.185 & $1 \cdot 188$ & 70 \\
\hline $1 \cdot 143$ & $1 \cdot 157$ & $1 \cdot 167$ & $1 \cdot 170$ & $1 \cdot 173$ & 1.175 & $1 \cdot 178$ & $1 \cdot 180$ & 183 & 75 \\
\hline $1 \cdot 137$ & $1 \cdot 15 \mathrm{I}$ & $1 \cdot 161$ & $1 \cdot 164$ & $\mathrm{I} \cdot 167$ & $1 \cdot 169$ & $1 \cdot 172$ & $1 \cdot 174$ & $1 \cdot 177$ & 80 \\
\hline $1 \cdot 132$ & $1 \cdot 146$ & $1 \cdot 156$ & 1.159 & $1 \cdot 162$ & $1 \cdot 164$ & $1 \cdot 167$ & $1 \cdot 169$ & 1.172 & 85 \\
\hline $1 \cdot 127$ & $1 \cdot 141$ & $1 \cdot 151$ & $\mathrm{l} \cdot 154$ & $1 \cdot 157$ & $1 \cdot 159$ & $1 \cdot 162$ & $1 \cdot 164$ & $1 \cdot 167$ & 90 \\
\hline $1 \cdot 122$ & $1 \cdot 136$ & $1 \cdot 146$ & $1 \cdot 149$ & $\mathrm{l} \cdot \mathrm{l} 5 \mathrm{2}$ & $1 \cdot 154$ & $1 \cdot 157$ & $1 \cdot 159$ & $\mathrm{I} \cdot 162$ & 95 \\
\hline $1 \cdot 117$ & $1 \cdot 131$ & $1 \cdot 141$ & 1. 144 & $1 \cdot 147$ & $1 \cdot 149$ & $1 \cdot 162$ & $1 \cdot 154$ & $1 \cdot 157$ & 100 \\
\hline 1.111 & $1 \cdot 125$ & $1 \cdot 135$ & 1.139 & $1 \cdot 141$ & 1.143 & 1.146 & 1.148 & $1 \cdot 151$ & 105 \\
\hline $1 \cdot 106$ & $1 \cdot 120$ & $1 \cdot 130$ & $1 \cdot 133$ & $1 \cdot 136$ & $1 \cdot 138$ & $1 \cdot 141$ & $1 \cdot 143$ & $1 \cdot 146$ & 110 \\
\hline $1 \cdot 101$ & $1 \cdot 115$ & 1.125 & $\mathrm{l} \cdot 128$ & 1.13I & $\mathbf{1} \cdot 133$ & $\mathbf{1} \cdot 136$ & $1 \cdot 138$ & $1 \cdot 141$ & 115 \\
\hline 1.096 & $1 \cdot 110$ & $1 \cdot 120$ & $1 \cdot 123$ & $\mathrm{I} \cdot 126$ & $1 \cdot 128$ & $1 \cdot 131$ & $1 \cdot 133$ & $1 \cdot 136$ & 120 \\
\hline 1.091 & $1 \cdot 105$ & $1 \cdot 115$ & I. 118 & $1 \cdot 121$ & $\mathrm{I} \cdot \mathrm{I} 23$ & $\mathrm{I} \cdot 126$ & $1 \cdot 128$ & $1 \cdot 131$ & 125 \\
\hline 1.085 & 1.099 & $1 \cdot 109$ & 1.112 & $1 \cdot 115$ & $1 \cdot 117$ & $1 \cdot 120$ & $1 \cdot 122$ & $1 \cdot 125$ & 130 \\
\hline 1.080 & 1.094 & $1 \cdot 104$ & $1 \cdot 107$ & 1.110 & $1 \cdot 112$ & 1115 & $1 \cdot 117$ & $1 \cdot 120$ & 135. \\
\hline 1.075 & 1.089 & I. 099 & 1.102 & $1 \cdot 105$ & $1 \cdot 107$ & 1.110 & 1.112 & 1.115 & 140 \\
\hline 1.070 & 1. 081 & 1.094 & 1.097 & $1 \cdot 100$ & $1 \cdot 102$ & $1 \cdot 105$ & $1 \cdot 107$ & $1 \cdot 110$ & 145 \\
\hline 1.065 & 1.079 & 1.089 & 1.092 & 1.095 & 1.097 & $1 \cdot 100$ & $1 \cdot 102$ & l. 105 & 150 \\
\hline 1.059 & 1.073 & 1.083 & 1.086 & 1.089 & $\mathrm{I} \cdot 09 \mathrm{i}$ & $1 \cdot 094$ & 1.096 & 1.099 & 155 \\
\hline 1.054 & 1.068 & 1.078 & 1.081 & 1.084 & 1.086 & 1.089 & 1.091 & 1.094 & 160 \\
\hline 1.049 & 1.063 & 1.073 & 1.076 & 1.079 & 1.081 & I. 084 & 1.086 & 1.089 & 165 \\
\hline 1. 044 & 1.058 & 1.068 & 1.071 & 1.074 & $1 \cdot 076$ & 1.079 & $1 \cdot 081$ & 1.084 & 170 \\
\hline 1.039 & 1.053 & 1.063 & 1066 & 1.069 & 1.071 & 1.074 & 1.076 & 1.079 & 175 \\
\hline 1.033 & I. 047 & 1.057 & 1.060 & $1 \cdot 063$ & 1.065 & 1.068 & 1.070 & 1.073 & 180 \\
\hline 1.028 & 1.042 & 1.052 & 1.055 & 1.058 & 1.060 & 1.063 & 1.065 & I. 068 & 185 \\
\hline 1.023 & 1.037 & 1.047 & I. 050 & 1.053 & 1.055 & 1.058 & 1.060 & I. 063 & 190 \\
\hline 1.018 & 1.032 & 1.042 & 1.045 & $1 \cdot 048$ & $1 \cdot 050$ & 1.053 & 1.055 & $1 \cdot 058$ & 195 \\
\hline 1.013 & 1.027 & 1.037 & 1.040 & 1.043 & 1.045 & 1.048 & 1.050 & I. 053 & 200 \\
\hline 1.008 & 1.022 & 1.032 & $1 \cdot 035$ & 1.038 & 1.040 & 1.043 & $1 \cdot 045$ & $1 \cdot 048$ & 205 \\
\hline 1.004 & $1 \cdot 017$ & 1.027 & 1.030 & $1 \cdot 033$ & 1.035 & $\mathrm{I} \cdot 038$ & 1.040 & 1.043 & 210 \\
\hline 1.002 & 1.000 & & & & & & & & 212 \\
\hline
\end{tabular}

Formula from which the above figures are calculated-

$$
\begin{gathered}
\mathrm{H}=\mathrm{TS}-\mathrm{TW} . \\
\mathrm{F}=\frac{\mathrm{H}}{\mathrm{LS}}
\end{gathered}
$$

$\mathrm{TS}=$ Total amount of heat contained in one pound of steam at absolute steam pressure - column 4 Table LIII.

TW=Total heat of water at feed water temperature-column 3, Table LII.

$\mathrm{H}=$ Heat imparted to water (TW to eonvert into steam TS).

LS = Latent heat of steam at atmospheric pressure $965 \cdot 7$.

$\mathbf{F}=$ Factor of evaporation. 
TABLE LIV, Factors of Evaporation (continued).

\begin{tabular}{|c|c|c|c|c|c|c|c|c|c|}
\hline 110 & 120 & 130 & 140 & 150 & 160 & 170 & 180 & 190 & 200 \\
\hline $1 \cdot 229$ & $1 \cdot 231$ & $1 \cdot 232$ & $1 \cdot 234$ & $1 \cdot 236$ & $1 \cdot 237$ & $1 \cdot 239$ & $1 \cdot 240$ & $1 \cdot 241$ & $1 \cdot 243$ \\
\hline $1 \cdot 226$ & $1 \cdot 228$ & 1.230 & $1 \cdot 231$ & $1 \cdot 232$ & $1 \cdot 234$ & $1 \cdot 235$ & $1 \cdot 236$ & $1 \cdot 237$ & $1 \cdot 238$ \\
\hline $1 \cdot 210$ & $1 \cdot 212$ & $1 \cdot 214$ & $1 \cdot 215$ & $1 \cdot 217$ & $1 \cdot 218$ & $1 \cdot 220$ & $1 \cdot 221$ & $1 \cdot 223$ & $1 \cdot 224$ \\
\hline $1 \cdot 205$ & $1 \cdot 207$ & $1 \cdot 209$ & $1 \cdot 211$ & $1 \cdot 212$ & $1 \cdot 213$ & $1 \cdot 214$ & $1 \cdot 215$ & $1 \cdot 216$ & $1 \cdot 217$ \\
\hline $1 \cdot 200$ & $1 \cdot 202$ & $1 \cdot 203$ & $1 \cdot 205$ & $1 \cdot 207$ & $1 \cdot 208$ & $1 \cdot 210$ & $1 \cdot 211$ & $1 \cdot 212$ & $1 \cdot 214$ \\
\hline 1.195 & $1 \cdot 197$ & $1 \cdot 199$ & $1 \cdot 201$ & $1 \cdot 202$ & $1 \cdot 203$ & $1 \cdot 204$ & $1 \cdot 205$ & $1 \cdot 206$ & $1 \cdot 207$ \\
\hline $1 \cdot 189$ & $1 \cdot 191$ & $1 \cdot 193$ & $1 \cdot 194$ & $1 \cdot 196$ & $1 \cdot 197$ & 1.199 & $1 \cdot 200$ & $1 \cdot 202$ & $1 \cdot 203$ \\
\hline $1 \cdot 164$ & $1 \cdot 166$ & $1 \cdot 168$ & $1 \cdot 170$ & $1 \cdot 171$ & 1.172 & $1 \cdot 173$ & $1 \cdot 174$ & $1 \cdot 175$ & $1 \cdot 176$ \\
\hline $1 \cdot 158$ & $1 \cdot 160$ & $1 \cdot 162$ & $1 \cdot 164$ & $1 \cdot 165$ & $1 \cdot 167$ & $1 \cdot 168$ & $1 \cdot 170$ & $1 \cdot 171$ & $1 \cdot 172$ \\
\hline $1 \cdot 153$ & $1 \cdot 155$ & $1 \cdot 157$ & $1 \cdot 159$ & $1 \cdot 160$ & $1 \cdot 161$ & $1 \cdot 162$ & $1 \cdot 163$ & $1 \cdot 164$ & 1.165 \\
\hline $1 \cdot 148$ & $1 \cdot 150$ & $1 \cdot 152$ & $1 \cdot 153$ & $1 \cdot 155$ & $1 \cdot 156$ & $1 \cdot 158$ & $1 \cdot 159$ & $1 \cdot 160$ & $1 \cdot 162$ \\
\hline $1 \cdot 143$ & $1 \cdot 145$ & $1 \cdot 147$ & $1 \cdot 149$ & $1 \cdot 150$ & $1 \cdot 151$ & $1 \cdot 152$ & 1153 & $1 \cdot 154$ & $1 \cdot 155$ \\
\hline $1 \cdot 138$ & $1 \cdot 140$ & $1 \cdot 141$ & $\mathrm{I} \cdot 143$ & $1 \cdot 145$ & $1 \cdot 146$ & $1 \cdot 147$ & $1 \cdot 149$ & $1 \cdot 150$ & $1 \cdot 151$ \\
\hline $1 \cdot 133$ & $1 \cdot 135$ & $1 \cdot 137$ & $1 \cdot 139$ & $1 \cdot 140$ & $1 \cdot 141$ & $1 \cdot 142$ & $1 \cdot 143$ & $1 \cdot 144$ & $1 \cdot 145$ \\
\hline $1 \cdot 127$ & $1 \cdot 129$ & $1 \cdot 130$ & $1 \cdot 132$ & $1 \cdot 134$ & $1 \cdot 136$ & $1 \cdot 137$ & $1 \cdot 138$ & $1 \cdot 140$ & $1 \cdot 141$ \\
\hline 1.122 & $1 \cdot 124$ & $1 \cdot 125$ & $1 \cdot 127$ & $1 \cdot 129$ & $1 \cdot 130$ & $1 \cdot 131$ & $1 \cdot 132$ & $1 \cdot 133$ & $1 \cdot 134$ \\
\hline $1 \cdot 117$ & $1 \cdot 119$ & $1 \cdot 120$ & $1 \cdot 122$ & $1 \cdot 124$ & $1 \cdot 125$ & $1 \cdot 127$ & $1 \cdot 128$ & $1 \cdot 129$ & $1 \cdot 131$ \\
\hline $1 \cdot 112$ & $1 \cdot 114$ & $1 \cdot 116$ & $1 \cdot 118$ & $1 \cdot 119$ & $1 \cdot 120$ & $1 \cdot 121$ & 1.122 & $1 \cdot 123$ & $1 \cdot 124$ \\
\hline 1.065 & 1.066 & 1.068 & $1 \cdot 070$ & $1 \cdot 071$ & 1.073 & 1.074 & 1.076 & 1.077 & 1.078 \\
\hline 1.060 & 1.062 & 1.064 & 1.066 & $1 \cdot 067$ & $1 \cdot 068$ & 1.069 & 1.070 & 1.071 & 1.072 \\
\hline 1.054 & 1.056 & 1.058 & 1.059 & 1.061 & 1.063 & 1.064 & 1.065 & 1.067 & 1.068 \\
\hline 1.050 & 1.052 & 1.054 & 1.056 & $1 \cdot 057$ & 1.058 & 1.059 & 1.060 & $1 \cdot 061$ & 1.062 \\
\hline $1 \cdot 044$ & 1.046 & $1 \cdot 047$ & 1.049 & 1.051 & $1 \cdot 052$ & 1.053 & $1 \cdot 055$ & 1.056 & 1.057 \\
\hline
\end{tabular}

Saving effected by heating feed water.

The saving in fuel effected by heating feed water can be calculated by formula as below-

$$
\text { Percentage of saving }=\frac{100(\mathrm{~T}-\mathrm{t})}{\mathrm{H}-\mathrm{t}}
$$

in which $\mathrm{T}=$ heat units in one pound of feed water above $0^{\circ}$ after heating-column 3 , Table LII.

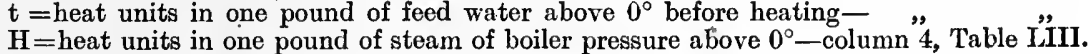




\section{LIQUID FUEL AND ITS COMBUSTION}

TABLE LV. Efficiency of Boiler.

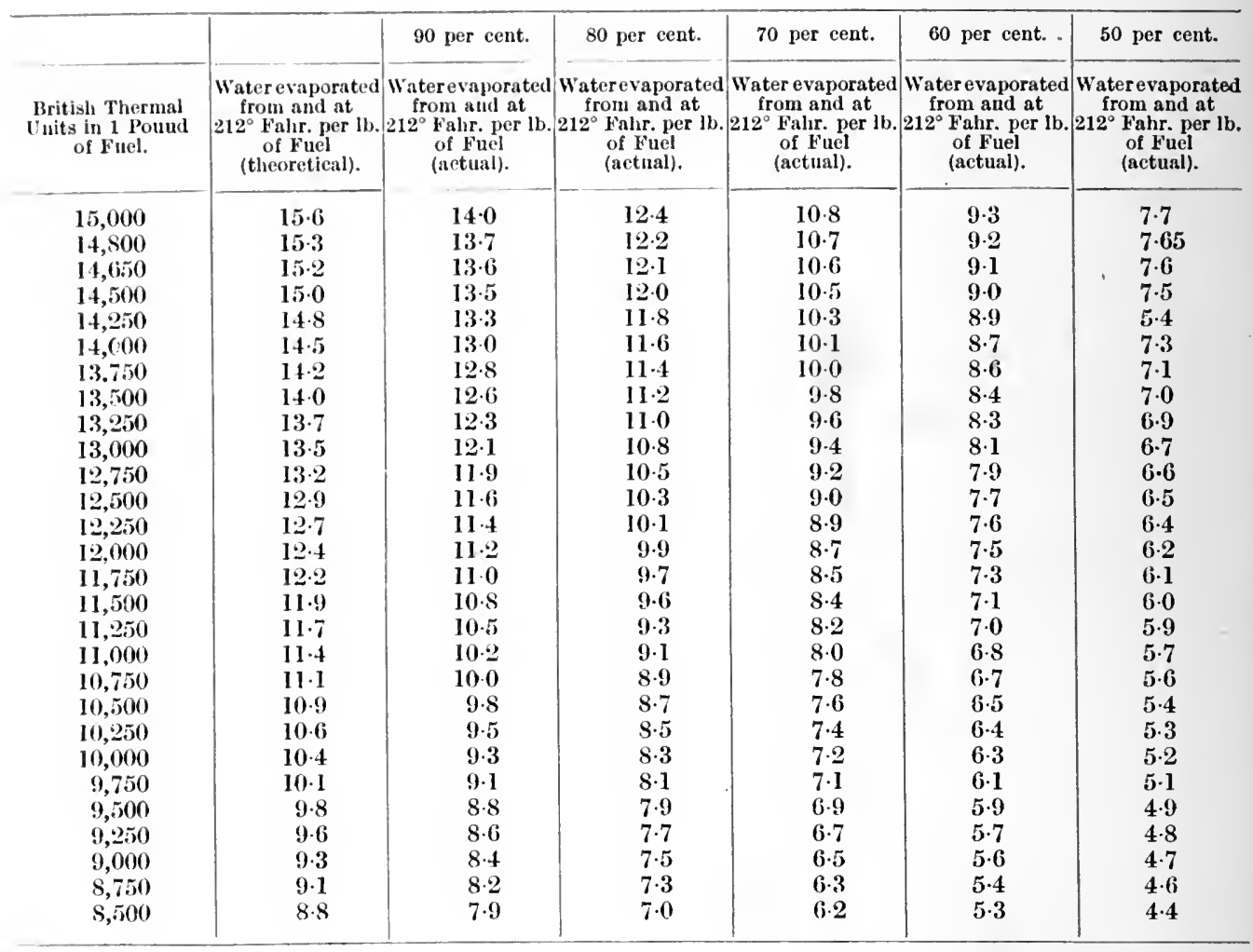

Table LVI. Loss of Combustible in burning $100 \mathrm{lb}$. of Fuel due to Unconsumed Combustible in Ash.

\begin{tabular}{|c|c|c|c|c|c|c|c|c|c|c|c|c|c|}
\hline \multirow{2}{*}{$\begin{array}{l}\text { Percentage of } \\
\text { unconsumed } \\
\text { combustible } \\
\text { in asl. }\end{array}$} & \multicolumn{13}{|c|}{ PER CENT. OF ASH IN COAL FIRED. } \\
\hline & 5 & 6 & 7 & 8 & 9 & 10 & 11 & 12 & 13 & 14 & 16 & 18 & 20 \\
\hline 50 & $5 \cdot 0$ & $6 \cdot 0$ & $7 \cdot 0$ & $8 \cdot 0$ & $9 \cdot 0$ & $10 \cdot 0$ & $11 \cdot 0$ & $12 \cdot 0$ & $13 \cdot 0$ & $14 \cdot 0$ & $16 \cdot 0$ & $18 \cdot 0$ & $20 \cdot 0$ \\
\hline 45 & $4 \cdot 0$ & $4 \cdot 8$ & $5 \cdot 7$ & $6 \cdot 6$ & $7 \cdot 3$ & 81 & $9 \cdot 0$ & $9 \cdot 8$ & $10 \cdot 6$ & $11 \cdot 4$ & $13 \cdot 0$ & $14 \cdot 7$ & $16 \cdot 3$ \\
\hline 40 & $3 \cdot 3$ & $4 \cdot 0$ & $4 \cdot 6$ & $5 \cdot 3$ & $6 \cdot 0$ & $6 \cdot 6$ & $7 \cdot 3$ & 8.0 & $8 \cdot 6$ & $9 \cdot 3$ & $10 \cdot 6$ & 12.0 & $13 \cdot 3$ \\
\hline 25 & $1 \cdot 6$ & $2 \cdot 0$ & $2 \cdot 3$ & $2 \cdot 6$ & $3 \cdot 0$ & $3 \cdot 3$ & $3 \cdot 6$ & $4 \cdot 0$ & $4 \cdot 3$ & $4 \cdot 6$ & $5 \cdot 3$ & $6 \cdot 0$ & $6 \cdot 6$ \\
\hline 20 & $1 \cdot 2$ & $1 \cdot 5$ & 1.7 & $2 \cdot 0$ & $2 \cdot 2$ & $2 \cdot 5$ & $2 \cdot 7$ & $3 \cdot 0$ & $3 \cdot 2$ & $3 \cdot 5$ & 4.0 & $4 \cdot 5$ & 5.0 \\
\hline 15 & 0.8 & $1 \cdot 0$ & $1 \cdot 2$ & $1 \cdot 4$ & $1 \cdot 5$ & $1 \cdot 7$ & 1.9 & $2 \cdot 1$ & $2 \cdot \overline{2}$ & $2 \cdot 4$ & $2 \cdot 8$ & $3 \cdot 1$ & $3 \cdot 4$ \\
\hline 10 & 0.5 & $0 \cdot 6$ & 0.7 & 0.8 & $1 \cdot 0$ & $1 \cdot 1$ & $1 \cdot 2$ & $1 \cdot 3$ & $1 \cdot 4$ & 1.5 & $1 \cdot 7$ & $2 \cdot 0$ & $2 \cdot 2$ \\
\hline 8 & 0.4 & 0.5 & $0 \cdot 6$ & 0.7 & 0.8 & 0.8 & 0.9 & 1.0 & $1 \cdot 1$ & $1 \cdot 2$ & $1 \cdot 3$ & 1.5 & $1 \cdot 7$ \\
\hline 6 & 0.3 & $0 \cdot 3$ & 0.4 & 0.5 & 0.5 & 0.6 & 0.7 & 0.7 & 0.8 & 0.8 & 1.02 & $1 \cdot 1$ & $1 \cdot 2$ \\
\hline
\end{tabular}

The actual heat value of uneousimed combustible in ash cau only be determined by calorimetrical test, as it depends on the pereentage of volatile matter in same and the actual heat value of the thed carbon. For ordinary purposes it is often taken to be erual in heat vialue to the coal used weight for weight. 


\section{APPENDIX}

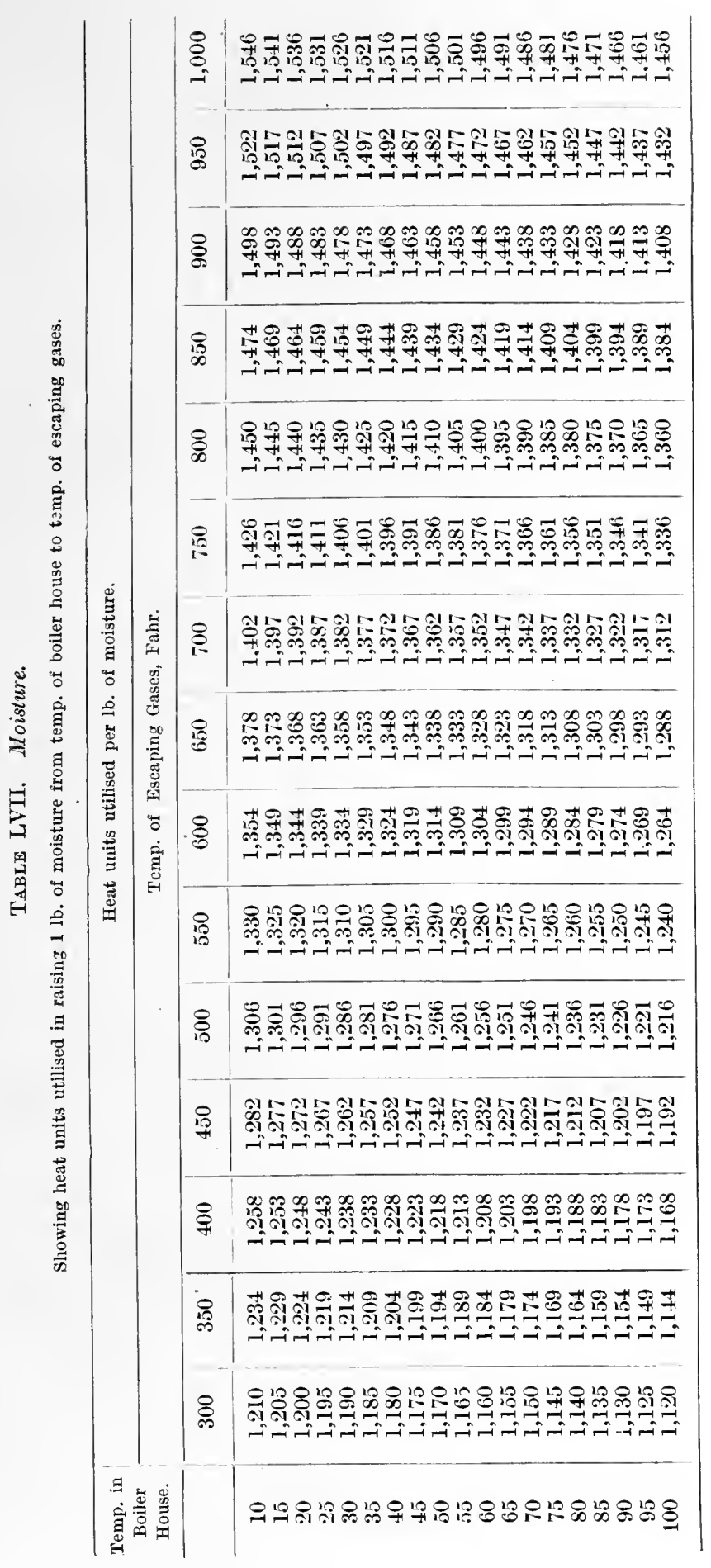




\section{LIQUID FUEL AND ITS COMBUSTION}

Table LVIII. Heat Balance or Distribution of the Heating Value of the Combustible.

Total heativg Value of 1 LB. of Combustible B.Th.U.

1. Heat absorbed by the boiler=evaporation from and at 212 degrees per $1 \mathrm{~b}$. of combustible $\times 965 \cdot 7$.

2. Loss due to moisture in coal $=$ per cent. of moisture referred to eombustible $\div 100 \times$ $[(212-t) \times 966 \times 0.48(\mathrm{~T}-212)] . \quad(\mathrm{t}=$ temperature of air in the boiler room, $\mathrm{T}=$ that of the flue gases).

3. Loss due to moisture formed by the burning of hydrogen = per cent. of hydrogen to combustible $\div$ by $100 \times 9 \times[(212-\mathrm{t} \times 966 \times 0.48)(\mathrm{T}-212)]$.

*4. Loss due to heat earried away in the dry chimney gases = weight of gas per lb. of eombustible $\times 0.24 \times(\mathrm{T}-\mathrm{t})$.

†5. Loss due to incomplete combustion of earbon $=\frac{\mathrm{CO}}{\mathrm{CO}_{2}+\mathrm{CO}}$

$$
\times \frac{\text { per cent. } \mathrm{C} \text { in combustible }}{100} \times 10 \cdot 150
$$

6. Loss due to unconsumed hydrogen and hydrocarbons, to heating the moisture in the air, to radiation, and unaccounted for.

(Some of these losses may be separately itemized if data are obtained from which they may be ealculated).

Totals

* The weight of gas per lb. of carbon burned may be calculated from the gas analysis as follows-

$$
\text { Dry gas per lb. carbon }=\frac{11 \mathrm{CO}_{2}+8 \mathrm{O}+7(\mathrm{CO} \mathrm{N})}{3\left(\mathrm{CO}_{2}+\mathrm{CO}\right)}
$$

in which $\mathrm{CO}_{3}, \mathrm{CO}, \mathrm{O}$, and $\mathrm{N}$ are the percentages by volume of the several gases. The weight of dry gas per lb. of combnstible is found by multiplying the dry gas per lb. of carbon by the percentage of carbon in the combustible and dividing by 100 .

Professor Jacobus recommends the use of the following formula for finding the weight of air per lb. of carbon:-

$$
\mathrm{C}=\frac{7 \mathrm{~N}}{3\left(\mathrm{CO}_{2}+\mathrm{CO}\right)} \div 0 \cdot 77
$$

$+\mathrm{CO}_{2}$ and $\mathrm{CO}$ are respectively the percentage by volume of carbonic acid and carbonic oxide in the flue gases. The quantlty $10.150=$ number of heat units generated by burniug to earbonic acid one lb, of carbon contained in carbonic oxide. 


\section{APPENDIX}

TABLI LIX.

Showing Heat Loss in Chimney Gases according to Percentage of Carbon Dioxide and Temperature. Efficiency.

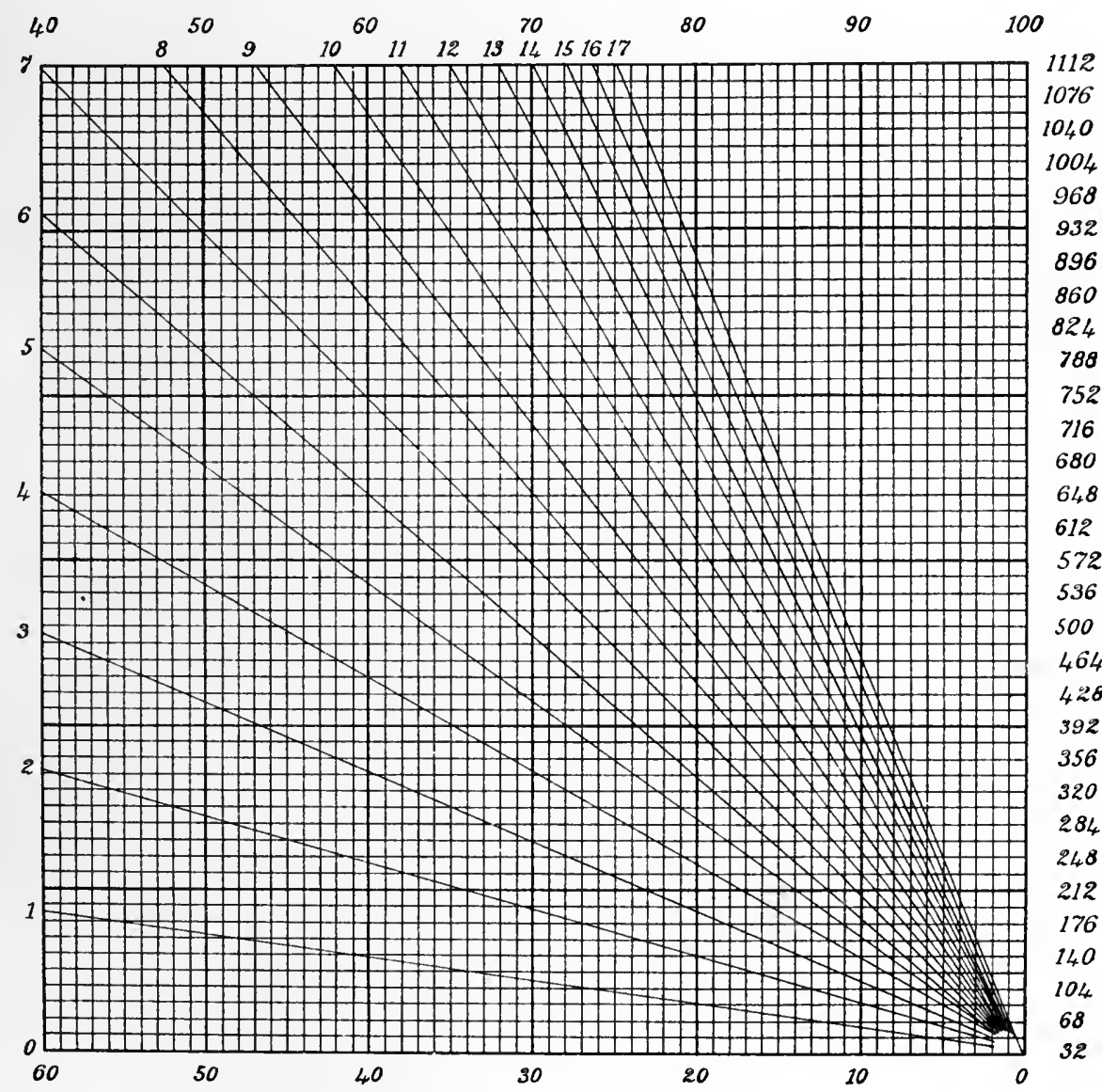




\section{Appendix 9}

\section{Steam Superheater with Oil Firing}

IN the direct firing of a steam superheater the difficulty has always been to control the amount of superheat and to preserve the pipes from overheating. The difficulty has been overeome in the Cruse Controllable Superheater by the use of solid-drawn steel pipes containing $U$ tubes of solid-drawn copper through which water is circulated, being drawn from the boiler, preferably at the bottom, and delivered back to the boiler at the water level. The steam which passes between the copper and steel pipes assumes a temperature approximately the mean of that of the water in the inside pipe and the gases outside the outer pipe. Control is secured by regulating the amount of water circulation and the proportion of feed water sent through the superheater. Direet firing can thus be safely applied, and in fig. 119 herewith is shown a suggested arrangement for 1 he direct firing of a superheater with liquid fuel. The fire-grate is removed and the bottom of the furnace is perforated for a supply of air below the flames, or the furnace bottom may be made in the form of a fire-grate and covered with fire-bricks set on edge loosely, the admission of air being controlled by a damper or register to close the air entrance. Provision is also made to admit air round the two atomisers. The direct action of the flame is kept from the lower water drums by the flank walls of the furnace, which are carried up sufficiently high for the purpose, and the flames make their first contact with the upper water drums and thence pass on at a lower temperature to the superheating pipes. Liquid fuel should be specially useful in a superheater because of the ease and perfection of the control which is possible over it.

In the illustration the following parts are lettered-

$a=$ Air inlet under flames.

$\mathrm{C}=$ Inlet (from boiler) steam collector and distributor.

$\mathrm{D}=$ Steel superheater tubes.

$\mathrm{D}^{1}=$ Pressed steel covers.

$\mathrm{E}=$ Superheated steam eollector.

$\mathrm{F}=$ Feed water inlet from economiser.

$\mathrm{F}^{1}=$ Combining box.

$\mathrm{G}=$ Down corner pipes to bottom drum.

$\mathrm{G}^{\mathrm{I}}=$ Distributing pipe inside drums $\mathrm{H}$.

$\mathrm{H}=$ Bottom drums.

$J=$ Intermediate drums.

$K=$ Down corner pipes from intermediate drums to bottom water eollector.

$\mathrm{L}=$ Bottom water eollector and distributor.

$\mathrm{N}=$ Top water collecting drum.

$\mathrm{N}^{1}=$ Water pipes from $\mathrm{N}$ to top drums $\mathrm{O}$.

$\mathrm{O}=$ Top drums.

$\mathrm{O}^{1}=$ Safety and water level valves. 


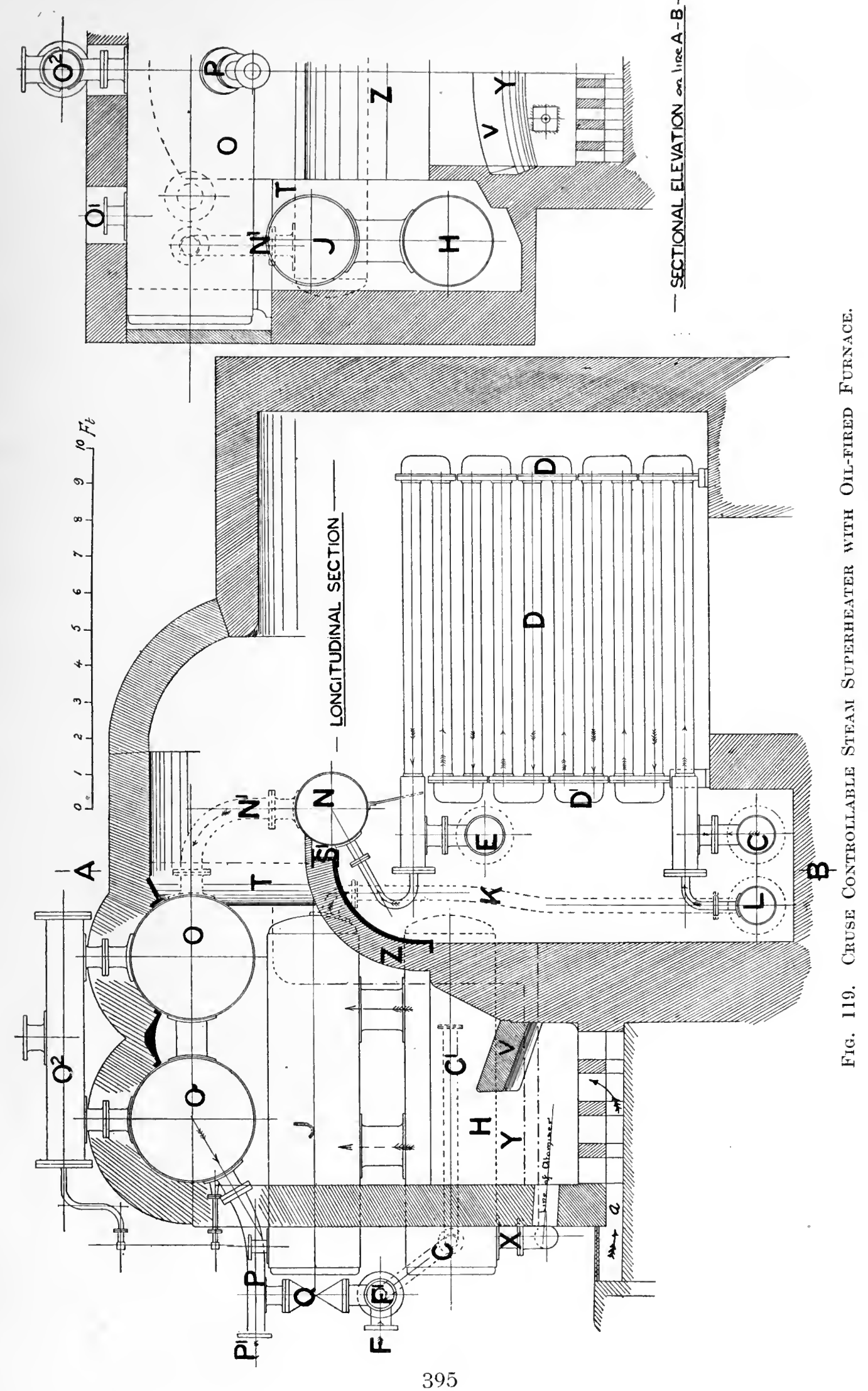




\section{LIQUID FUEL AND ITS COMBUSTION}

$\mathrm{O}^{2}=$ Drum and branch for drums $\mathrm{O}$.

$\mathrm{P}=$ Water outlet bend and combining box.

$\mathrm{P}^{1}=$ Heated water outlet.

$Q=B y-p a s s$ and valve from top to bottom drums.

$\mathrm{S}^{1}=$ Carrying girder.

$\mathrm{T}=$ Baffle wall.

$\mathrm{Y}=$ Furnace.

$\mathrm{X}=$ Blow-off and mud taps.

$Z=$ Bridge.

$\mathrm{V}=$ Fire $\operatorname{arch}$. 


\section{APPENDIX}

Table of Atomic Weights.

\begin{tabular}{|c|c|c|c|c|c|c|c|c|}
\hline \multicolumn{7}{|c|}{ Names of Elements. } & \multirow{2}{*}{$\begin{array}{c}\begin{array}{c}\text { Atomic } \\
\text { Weight. }\end{array} \\
27 \cdot 0\end{array}$} & \multirow{2}{*}{$\begin{array}{c}\text { Symbol. } \\
\text { A1 }\end{array}$} \\
\hline Aluminium & . & . & . & . & . & . & & \\
\hline Antimony & . & . & . & . & . & . & 120 & $\mathrm{Sb}$ \\
\hline Silver . & . & . & . & . & . & . & $107 \cdot 9$ & $\mathrm{Ag}$ \\
\hline Nitroger & . & . & . & . & . & . & $14 \cdot 04$ & $\mathrm{~N}^{\circ}$ \\
\hline Barium . & . & . & . & . & . & . & $137 \cdot 1$ & $\mathrm{Ba}$ \\
\hline Bismuth. & . & . & . & . & . & . & 208 & $\mathrm{Bi}$ \\
\hline Boron . & . & . & . & . & . & . & 11 & $\mathrm{~B}$ \\
\hline Calcium. & . & . & . & . & . & . & 40 & $\mathrm{Ca}$ \\
\hline Carbon . & . & . & . & . & . & . & 12 & $\mathrm{C}$ \\
\hline Chlorine. & . & . & . & . & . & . & $35 \cdot 5$ & $\mathrm{Cl}$ \\
\hline Copper. & . & . & . & . & . & . & $63 \cdot 3$ & $\mathrm{Cu}$ \\
\hline Tin. & . & . & . & . & . & . & 118 & Sn \\
\hline Iron & . & . & . & . & . & 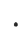 & 56 & $\mathrm{Fe}$ \\
\hline Hydrogen & . & . & . & . & . & & 1 & $\mathbf{H}$ \\
\hline Magnesium & . & . & . & . & . & . & 24 & $\mathrm{Mg}$ \\
\hline Mercury. & . & . & . & . & . & . & 200 & $\mathrm{Hg}$ \\
\hline Oxygen. & . & . & . & . & • & • & $15 \cdot 88$ & 0 \\
\hline Palladium & . & . & . & . & . & . & 106 & $\mathbf{P d}$ \\
\hline Phosphorus & . & . & . & . & . & & 31 & $\mathbf{P}$ \\
\hline Platinum & . & . & . & . & . & 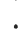 & 197 & $\mathbf{P} t$ \\
\hline Lead . & . & . & . & . & . & & 207 & $\mathrm{~Pb}$ \\
\hline Potassium & . & . & . & . & . & & $39 \cdot 14$ & $\mathbf{K}$ \\
\hline Silicon . & . & . & . & . & . & & 28 & $\mathrm{Si}$ \\
\hline Sodium. & . & . & . & . & . & 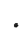 & 23 & $\mathrm{Na}$ \\
\hline Sulphur. & . & . & . & . & . & & $32 \cdot 07$ & $\mathrm{~S}$ \\
\hline Tungsten & . & . & . & . & . & & 184 & W \\
\hline Zinc . & . & . & . & . & . & . & $65 \cdot 0$ & $\mathrm{Zn}$ \\
\hline
\end{tabular}



INDEX. 



\section{I n d e x}

Abergele accident, 170

Accumulators, 356

Acetylene, 58

Acid water, 77

Adiabatic compression, 242

Admiralty flash tests, 349

Ados, $\mathrm{CO}_{2}$ recorder, 234

Advantages of Liquid Fuel, 5, 30, 115, 116

Aërated fucl systcm, 196, 26I

Air, atomizing by, 4, 160, 182, 194, 216, 220 240,265

- calculation of, 159

- compression, 249, 265

- compressor, 240,315

- efflux, 249, 257

- for atomizing, 4, 219, 240, 260, 321, 325

- for combustion, $12,14,58,87,93,99,101$, $139,151,159,162,207,302$

- for combustion, Kankine, 101

- for eombustion, Longridge, 101

- heater, 149,316

- heating, $149,216,309,325,337$

- heater, Ellis \& Eaves, 216

- low pressure, 197, 198

- power to compress, 240,248

- pressure diagram, 243

- properties of, 59

- regulator, 187

- tuyere, 180

Alabama coal, 30

Alcohol, 17

Allest atomizer, 267, 268

Allotropic forms of carbon, 54, 102

Alsace oil, 20, 29

American gallon, 36, 66

American locomotive practice, 166

- fire underwriters' rules, 344

- petroleum, 18, 20,94

- petroleum production, 8

- stationary practice, 182, 194

Amorphous carbon, 54, 55, 99, 102

Analysis of Borneo oil, 199

- chimney gas, 160, 217, 229

- coal, 297

- firebrick, 48

- fireclay, 48, 49, 50

- flame, 13, 104

- flue gases, 216

- fuel, 94, 300
Analysis, oil, 317, 328

- petroleum, 20, 24, 27, 94

- Texas oil, 24, 27

Angus Smith on water, 76

Animal oil, 15

Anthracite, 102, 171

Apparatus, Orsat's, 230

Archbutt-Deeley Process, 78

Arch, firebrick, 47, 52, 145, 146, 148, 156, 157, $158,168,174,177,178,192$

Area of ehimney, 258

Arlberg tunncl, 11, 157

Arndt econometer, 237

Artemeff atomizer, 271

Assay crucible, 276

Assay furnace, 276

Astatki, 4, 6, 12, 19, 171, 270

Atmosphere, 59, 81

Atmospheric carbon, 54

Atomizers, various, 260

Atomizer, Aërated Fuel Co., 196, 261

- Artemeff, 271

- Baldwin, 166, 261

- Bereznef, 11, 271

- Billow, 183

- Brandt, 269

- Chaukoff, 272

- Circular, 11

- d'Allest, 267, 268

- dimensions, 351

- elementary, 263

- flat jet type, 270

- Fvardofski, 268

- Grand Trunk Railway, 263

- Grundell Tucker, 262, 315

- Guyot, 266, 267

- Hayes, 262, 331

- Holden, 141, 145, 147, 149, 150, 151, 153, $155,157,158,260$

- horse power of, 351

- hydroleum, 262

- Issaieff, 12

- Kermode's, 202, 263

- Kirkwood, 194

- Körting, 131, 136, 263, 284

- Lenz, 270

- Nobel, 270

- nozzles, 266

- Oil City Boiler Co., 261, 327, 334

- Orde, 124 


\section{INDEX}

Atomizer, power of, 351

- proportions, I69, 351

- F. M. Reed, 262, 335

- Rivet furnace, 263

-.. Rusden-Eeles, 113, 120, 261

-. Soliani, 270

- Southern Pacifie Railway, 272

- Standart Russe, 270

- Swensson, 262, 263

--- types of, 325

-- Urculiart, 172, 176, 179, 261, 282

- Vetillard-Scherding, 270

- Williams, 34, 270

Atomizing, 3, 16, 17, 182, 260, 309

- M. Bertin on, 136

- agent, 265

- necessity of, $16,17,309$

- with air, 4, 160, 182, 194, 216, 220, 240, 260,321

- with steam, $4,147,160,182,194,217,219$, 240,260

Aude, 1', 266, 268

Austrian oil, 32

Automobile starting deviec, 215

Aydon, on liquid fuel, 3

\section{B}

Baku petroleum, 20, 29

Baldwin atomizer, 166, 261

- firebox, 168

- oil fucl system, 166

Ballast tanks, 112

Barges, 357

Barometer, 59

Barrels of oil produced, 29, 32

- and gallons, 22, 36

Beaumont oil, 13, 22, 35, 328

- tests, 35, 195

Beaumont, Worby, test of motor cars, 205

Bereznef atomizer, 11, 271

Berthelot on carbon, 55

Berthelot-Maller calorimeter, 81, 251

Berthelot on latent heat of carbon, 19

Bertin on air compressing, 248

Bertin on atomizing, 136, 248, 266

- on liquid fuel, 12,42

- on mixed system, 162,163

- on ratio of oil and coal, 12,163

Bickford Burner Co.'s furnace, 276

Billow atomizer, 183

- system, 182

Bituminous fuel combustion, 102

Blacksmith's fire, 282

Blast furnace gas, 197

- oil, 15, 21

Blast pipe, variable, Macallan's, 157, 259

Blocks, fireclay, 46

Board, National of Fire Underwriters, 353

Boiler, Belleville, 103, 272, 292

- Babcock, 296

- canoc, 207

- choice of, 7

— compounds, 78

- water, capacity of, 7

- Clicrbourg, 272
Boiler coil, 209

- Cornish, 153

- Du Temple type, 273

- efficiency, 8, 192, 273

- firefloat burner, 207

- French torpedo boat, 12, 164, 267

- Godard, 265

- grease in, 79

- Guyot, 164, 268, 273

- Heine, 193.

- Hohenstein, 295, 325

- hydroleum special, 203

- Lancashire, 7, 151, 130, 152, 181

- Lancashire, Orde's system, 127

- locomotive, 146, 148, 157, 158, 168, 171, $174,177,178,272$

- locomotive type, $154,157,158$

- marine, 118, 123, 129, 133, 216

- marine type, 199

- Niclausse, 272, 296

- Solignac, 7

- 'Thornycroft, 296

- underfired tubular, 190

- vertical, 154

- water eapacity of, 7

- water tube, $7,106,155,156,191,204$

- with grate, 14, 155, 191

- without grate, 14, 156, 204

- Weir, 14, 106

Boiling point of petroleum, 26

Borneo oil, 41, 146, 199

Brandt atomizer, 269

Brass furnace, 275, 276

Brick, see Firebrick

Brick arch, 47, 52, 145, 146, 148, 156, 157, 158, $168,174,177,178,191,272$

- linings, 106, 128

Bridge walls, 128

British Thermal Unit, 86

Buffle, 266

Bulkheads, 222

Bunker pipes of oil supply system, 124

Bunker pump, Weir's, 226

- fuel oil, 124

Burma oil, 41

Burner, Bickford burner furnace, 276

- Clarkson-Capel, 208 et seq.

Burners, see Atomizers

- installation of, 358

- construction of, 358

- Symon House, 264

Burning of firebrick, 48

Butane, 40

\section{C}

Calcium carbonate, 68

- sulphate, 64,73

Calculation of temperatures, 89

Californian petroleum, 18, 19, 29

Calorific formula, 88

Calorific power of Bormeo oil, 41

- Burma oil, 41

- carbon, 88, 93

- Caucasus oil, 41

- gases, 197 


\section{INDEX}

Calorific power, glycerine, 17

- hydrogen, 57, 58, 88

- liquid fuel, 18, 28, 41, 80, 93, 94, 329

- Clavenad on, 93

- Colonner and Lordior on, 94

- Goutal on, 94

- Mahler on, 94

- Texas oil, 28, 41, 329

Calorimetry, 251

Caloric, 86

Calorimeter, Berthelot-Mahler, 81, 251

- Thompson, 251

Canada oil, 20

Canoe, boiler for, 208

Capacity of boilers, water, 7

_tank, 361

Cap damper, chimney, 173

Car, test of, 205

- tank, 225

Carbolic acid, 20

Carbon, allotropic forms, 54, 102

- amorphous, 54, 55, 99, 102

- as fucl, 54

- atmospheric, 54

- atomic weight, 54

- bisulphide, 56

- calorific power of, 88, 93

- combustion of, 55,57

- diamond, 54, 55, 102

- dioxide, 55, 216

- gaseous, 55, 98, 102

- graphitic, 54, 55, 102

- heat of combustion, 102

- heat of conversion, 102

- in nature, 54

- liquid, 56

- monoxide, 55

- properties of, 56

- solid, 54,

- source of, 54

- vapour, 98

Carbonate of lime, 68

— magnesia, 73

Carbonic acid, 55

- oxide, 55

Carborundum, 45

Cargo steamer, ordinary with oil fuel, 112

Car hose, tank, 188

Carriage of oil, 23, 112, 285

Cast iron, 44

— furnace for, 276

Cement for oil pipes, 113

Centigrade thermometer, 83

Chalk on fire, 138

Chamber, combustion, 14, 106

Charcoal, see Amorphous carbon

Charges, freight, on oil, 22

Chaukoff atomizer, 272

Cliemical properties of air, 59

- carbon, 54

- hydrogen, 57

- nitrogen, 60

- oil, 24

- oxygen, 60

- petroleum, 24, 26, 40
Chemieal Texas oil, 24

Chemistry, Thermo-, 57, 80

Cherbourg, test at, 42, 136, 164, 233

- boiler, 272

Chicago Exhibition, 5

Chimney arca, 258

Chimney damper cap, 173

- clraught, 256

- gases, 160, 217, 229

Circular atomizers, 11, 260

Clark process of water softening, 77

Classification of fireclay goods, 53

Clarkson-Capel burner, 208

- preliminary heater, 209, 215

- open tank system, 208

- system, 208

Clavenad on calorific capacity of fuel, 93

Clay, see Fireclay

$\mathrm{CO}_{2}$ analysis, 229

- in furnace gases, $160,162,217,229$

- recorder, Ados, 234

- recorder, Arndt, 237

Coating of tanks; 355

Coal, analysis of, 300

- Alabama, 30

- anthracite, 102

- burning boiler, Hohenstein's, 295

- combustion, of, 163,164

- long-flaming, 99

- Newcastle, 99

- Pocahontas, 159, 300

- short-flaming, 99

- Welsh, 103, 159

- and oil furnace, 120

- and oil, comparative cost, $37,169,170,180$, 195

- production, 5

- tar, 15

- test, Melville's, 158, 295

Coefficient of expansion, oil, 43

- water, 62

- gases, 63

- Cofferdams, 112, 310

Coil boiler, 201

Coils, heating, 176, 208

Combustion, air for, 12, 14, 58, 87, 93, 99, 101, 302

- of anthracite, 102

- of bituminous fuel, 102

- calculations, 88

- smokeless, 96

- of carbon, 55, 57

- of hydrogen, 57,88

- chamber, refractory, 106

- chamber, 14, 106

- imperfect, 90

- heat of, 94

_ of liquid fuel, $13,16,336$

- of hydrocarbon, 96

- of vaporized liquids, 208

- principles of, 13,180

-.. temperature of, $12,89,92,336$

- volume of gases, 90

Comparative costs, oil and coal, $37,180,195$

Compounds, boiler, 78 


\section{INDEX}

Compounds, hyclrocarbon, 40, 41

Compression, adiabatie, 242

- of air, 249

- compound, 240

- diagrams, 243

- isothermal, 241

Compressor, air, 311

- electrically driven, 240

- duplex, 250

- Reavcll's, 240

Conversion, metamorphie, of carbon, 55, 102

Construetion of furnace, 189

Controlling valves, 354

Cooking apparatus, 357

Copper firebox, 147

- suelting, 284

Controllable superheater, Cruse systen, 394

Conveyers, oil, 357

Cornish boiler, 15:3

Corsicana petroleum, 22, 27, 28, 29

Cost, comparison of coal and oil, 37, 169, 170, 171

- of alterations, 180

- of oil, 10

"Cracking," 42

Cranes, oil, 223

Creosote, 15, 20

Cresylic acid, 20

Cromer express, 157

Crucible furnace, 275

Crude oil, 8, 13, 32, 169, 170

- permit to use, 340

Cruse superheater, 394

Curves of compression of air, 241

Curves of performance, Grazi-Tsaritzin Railway, 180

D

d'Allest's atomizer, 267, 268

Damper, chimney cap, 173

Danger of oil, 170, 352

Density of petroleum, 18, 27, 28, 29, 43

Denton, Prof., on Texas oil, 37

- evaporative duty, 37

- cost of oil, $3,4,5$

Desulphurizing, 345

Deterioration by storage, 31

Diamond, 54, 55, 102

Dinas firebrick, 45

Disincrustants, 78

Dissociation of steam, etc., $3,85,194$

- gases, 89

Dioxide of carbon, 55

Direet fired superheater, Cruse controllable, 394

Distillation, fractional, 24,27

Distribution of liquid fucl, 222, 225

Doncaster express, 140

Dowlais firebrick, 45

Down-draught furnace, 193

Draught, 256, 273

Draught gauge, 256

Dudley's formula for relative cost of oil and coal, 170

Dutch Navy, 114
Dillong's formula, 81, 87, 329

Duplex compressor, 250

\section{E}

Earnshaw on Texas oil, 27

Econometer, Arndt, 237

Economies of liquid fuel, 10, 195, 204

- soft water, 75

Efficiency of cvaporation, 3, 8, 93, 336

- boiler, 8, 191, 273

- Texas oil, 34

- thermal due to stcam, 336

Eftlux of air, 249

Electrically driven air compressor, 240

Elementary atomizer, 263

Ellis \& Eave's air heater, 216

- system, 216

Embankments, 354

Endothermism, 81

Endurance test, 331

English locomotive practice, 138 et seq.

- stationary practice, 199

Essential oil, 15

Ethane, 40, 58

Equivalent, Joule's, 86

- mechanical, of heat, 86

Evaporation, factors of, 388

- per unit of various fuels, 94

Evaporative duty, 37, 91, 145, 171, 273

- efficiency, $3,8,93,336$

Everhart on Texas oil, 25

Exothermism, 81

Expansion of oil, 43

- water, 62

Explosions, 173

Express, Doncaster, 140

\section{$\mathrm{F}$}

Factors of evaporation, 388

Factor, load, 7

Falırenheit thermometcr, 83

Feed, oil, 356

Filling pipe, 356

Firebox, American locomotive, 146

- Baldwin, 168

- Cherbourg boiler, 272

- copper, 147

- Cornish, 153

- Fvardovski, 268

- Holden, 148, 142

- Lancashire, 152

- locomotive, 146, 148, 142, 158, 168, 174, $176,177,178$

- Southern Pacific, 158

- Urquhart, 174, 177, 178

- Vanderbilt, 168

Firebricks, 45, 49

- aluminous, 53

Firebrick, analysis, 48

- arch, 46, 52, 145, 146, 148, 156, 157, 158, $168,174,178,191$

-- burning, 48

-. elassification, 53

-..- carborundum, 45

- carboniferous, 53 


\section{INDEX}

Firebrick, Dinas, 45

- Dowlais, 45

- French, 45, 47

- generaì particulars, 49

- Glenboig, 45

- manufacture, 46

- Newcastle, 49

- Page on, 50

- Pearson, 46

- silica, 47, 49

- Stourbridge, 45

Fireclay, analysis, 48, 49, 50

- blocks, 46

- Dinas, 45

- Dowlais, 45

- Gartcosh, 50

- Glenboig, 45, 49

- Kilmarnock, 45, 49

- Newcastle, 49

- Stourbridge, 45, 49

Firefloat, 208

Fire, forge, 282

- large forge, 283

Fire insurance rules, 344, 353

Fire test, 194

Fire underwriters' rules, 344, 353

Fish oil, 15

Flame, 12, 104

- testing, 13

- length, 104

Flannery-Boyd system of oil fuel, 121

- oil storage, 112

Forbin, test of, 165

Flash point, $11,13,43,115,171,348,352,353$, 357

Flue gas analysis, $160,217,228$

Fluoride of soda, 78

Forced draught, 137

Forge furnace, 282

Fractional distillation, 24, 27

Freight charges on oil, 22

French firebrick, 45, 47

French Navy tests, 136, 266, 268, 272

Fuel, evaporative, power of, 91

- gas, 197

— oil, 15, 18, 42, 353

- oil bunker, 124

- oil distribution, 222

- oil installation, 349

- oil permits, 344

- oil production, 33

- pumping, 184, 194, 196, 197

- punip, Weir's,

- oil tanks, 187, 194

- tank waggon, 187

Furieux, tests with, 164

Furnace, Ellis \& Eaves', 217

- assay, 276

- brass, 275, 276

- Bickford Burner Co., 276

- brickwork, walls, etc., 128, 131, 136, 146 , $152,155,156,157,158,168,174,177$, $178,191,199,204$

- construction, 189, 191, 199

- Cornish, 153
Furnace, crucible, 275

- crucible assay,

- Fvardofski, 268

- forge, 282

- Hawley down draught, 193

- for iron, 276,277

- Lancashire, 130, 152, 181

- firebricks, 45, 204

- lining, 14

- locomotive, $146,148,157,158,168,174$

- loco type, 154

- management, 172, 173

- marine, 118, 137

- oil and coal, 120

- oil,

- Schwartz, 277

- Siemens-Martin, 283

- temperatures, 99

- tyre, 261

- Rivet, 263, 275

- smith's hearth, 282, 283

- water tube, 155,156

Fvardofski atomizer, 268

- system, 268

G

Gallon, American, 36, 66, 353

- English, 36, 66, 353

Gallons, per barrel, 22, 36, 353

Galician oil, 20, 29

Ganister, 45

Gartcosh fireclay, 50

Gas, analysis, 217, 229

- blast furnace, 196

- density, 364

-. dissociation of, 89

- expansion of, 232

- fuel, 197

- hydrogen, 57

- marsh, 5, 40, 58

- solubility of, 62

- sp. heat, $84,103362,380$

- tar, water, 204

Gases, calorific capacity of, 196

- of combustion, volume of, 90

- chimney, 160, 217, 229

Gaseous carbon, 55, 98, 102

Gauge, draught, 256

- glasses, 356

Gear, marine furnace, 118

General arrangement, coal test, 299

- oil test, 325

- Körting system, 131

Gencral considerations, 5

German oil, 32

Glass, violet, 105

Glasses, gauge, 356

Glenboig clay, 45, 48, 49

Glycerine as fuel, 17

Godard boiler test, 164, 265

Gold Coast oil, 26

Grand Trunk Railway atomizer, 263

Grand Trunk Railway, rivet furnace, 263

Graphite, 55, 102

Grate, boilers with, 14, 155 


\section{INDEX}

Grate, boilers without, 14, 156

- small lighting up, 157

Gravity, 87

- specific, $18,19,20,21$

Grazi-Tsaritzin Railway, 4, 170, 171, 223, 281

- curves of performanee, 180

- fuel tank, 225

- locomotive, 174

- oil distribution, 224

- tender, 175

- tyre heating furnaee, 281

Grease in boilers, 79

Great Eastern Railway, 146, 149, 176

- locomotives, 142, 149, 157

- storage system, 223

- tender, 142, 148

- Grundell-Tueker atomizer, 262, 315

Guyot atomizer, 266, 267

- boiler, 164, 268

\section{H}

Hanover oil, 29

Hard water, 63,65

Hawley down draught furnace, 193

Hayes' atomizer, 262, 331

Howden's system, 119

Heat, 82

- of eombustion of carbon, 55, 102

- of eombustion of petroleum, ete., 94

- latent, of carbon, 55

- of dissociation, 85

- latent, 19, 82, 84, 85

- meehanical equivalents of, 86

- of metaphoric conversions, 55, 102

- quantity of, 82

- specifie, 83, 84, 85, 103

- tliermometric, 82

- units, 85, 197

Heater for automobile, 215

Heater, Clarkson-Capel preliminary, 208, 209, 215

- Ellis \& Eaves air, 216

Heating air, 149, 216, 309, 316, 325, 337

- coils, 6, 176, 208, 210

— oil, $6,131,136,176,270,280,309,325,337$

Heine boiler, 193

Holden atomizer, 141, 145, 147, 149, 150, 151, $153,155,157,158,260$

- system, 5, 145-59

Hohenstein boiler for coal, 292

- oil, 325

Hose, 188, 356

Hose, tank ear, 188

Howden's system, 136

Hydroearbon compounds, 40, 41

- combustion of, 96

Hydrogen, calorifie power of, 57, 58, 88

- combustion of, 57,88

- gas, 57

- properties of, 57

- temperature of ignition, 58

Hydroleun special boiler, 202

- atomizer, 262

- system, 203

- car, 205
I

Ignition temperature, 58, 105

Imperfect combustion, 90

Incrustation, 63, 67

Independently fired superheater, 392

Indieator, 355

Indian oil, 32

Individual equipments, 354

Indret, tests at, 162,266

Injector, see Atomizer

Installation of oil fuel, report by Schoen, 350

Interehange of coal and oil, 120

Iron, east, 44

Iron furnace, 276, 277

- in water, 76

Issaieff atomizer, 12

Isothermal compression, 241

Italian oil, 32

Javan oil, 32

Japan oil, 32

Japanese railways, 146

Jeanne d'Arc, the, 163

Joule, Dr. 86

Kieller, tests by, 11

Kelvin law, 8

Kermode's atomizer, 203, 263

- system, 199, 202

Kern River oil, 317

Kershaw, J. B. C., on calorific formulae, 95

Khodoung, s.s., 127

Kilmarnock fireclay, 45, 49

Kilns, oil fired, 50, 283

Kirkwood atomizer, 194

- system, 194

Körting atomizor, 131, 136, 263, 284

- system, 127, 131, 132

Koudako oil, 25

\section{I.}

Laeisz, F. C., s.s., 127

Lamp oil, 15, 16, 208, 210, 214

Lancashire boiler, 7, 127, 130, 151

Latent heat, $19,82,84,85$

Latitude and barometer, 59

Length of flame, 104

Lenz atomizer, 270

Levees, see Moat

Lighting up, 173

Lima oil, 170

Lime process of softening water, 69

— sulphate, 64,73

Lining furnace, 14

Liquid earbon, 56

- eombustion, 13, 16

Liquid fuel, 15,40

- advantages of, 30

- at sea, 114, 308, 324

- containing oxygen, 17

- distribution, 222

- conomies of, 10,195

- prieo of, 10

- production, 32 


\section{INDEX}

Liquid Fuel, properties of, 16

- system, Wallsend Shipway Co., 129

- varieties of, 15,17

Lloyd's rules for ships, 111, 343

Load factor, 7

Location of tank, 355

Locomotive, American, 145

- boiler, 146, 148, 157, 158, 177, 178, 272

- Cherbourg, 272

- firebox, 142, 146, 148, 158, 168, 174, 176

- Fvardofski, 269

- Great Eastern Railway, 142, 146, 149, 138

- practice, American, 166

- practice, English, 138, et seq.

- practice, Russian, 166

- Southern Pacific, 158

- typo boiler, 154

- Vanderbilt firebox, 168

- Vladi Kavkaz Railway, 136

- Urquhart, 171, 174, 176, 177, 178

Low pressure air, 197, 198

Los Angelos Railway, 171

Loss by excess of air, 238

\section{M}

Mabery on Texas oil, 26

Macallan variable blast pipe, 156, 139, 259

Magnesia salts, 76

Magnesium carbonate, 72, 76

Mahler on calorific capacity, 94

Management of furnace, 189

- plant, 189

Manhead, 355

Manufacture of firebrick, 46

Marine boiler, 118, 123, 129, 132

- type boiler, 200

- furnace gear, 118

- gear, 118

Mariposa, s.s., 262,313

- report on, 317

- test of, 313

Marsh gas, see Methano

Materials, 44

Mazout or Mazut, see Astatki

Mechanical stoking, 7

- equivalent of heat, 86

Melville's coal tests, 295

- oil fuel tests, 324

Metallurgy, application of liquid fuel to, 274

Metal and refining furnace, 277

Metamorphic conversion of carbon, 55, 102,

Methane, 5, 40, 58, 81

Meyer system, 160

Milan, test on, 165

Mixed system of coal and oil combustion, 120 162

Moat, round oil stores, 194, 348

Monoxide of carbon, 55

Motor car, with hydroleum system, 206

Murex, s.s., 111, 118, 119, 127

\section{$\mathrm{N}$}

Nacogdoches oil, 24, 27

Naphthalene, 20
National Board of Fire Underwriters, 353

National Fuel Oil Co.'s system, 182

Navy, British, 349

- Dutch, 114

- French, 265, 268

- German, 349

- Italian, 265

- Russian, 43

- U.S. coal trials, 158, 295

- U.S. liquid fuel trials, $158,295,324$

- U.S. Navy tests, 158, 295

Newcastle fireclay, 49

- coal, 99

Newyork, s.s., liquid fuel for, 121, 286

Nitrate of silver test of soft water, 78

Nitrogen, 60

- in atmosphere, 60

- properties of, 60

Nobel atomizer, 270

Nozzles of atomizers, 266

$\mathrm{O}$

Oil, Alsace, 20, 29

- American, 20, 26

- animal, 15

- Austrian, 32

- Baku, 20, 29, 32

- Beaumont, 13, 22, 35, 195, 328

- blast furnace, 15, 21

- Borneo, 41, 146, 199

- Burma, 41

- California, 18, 19, 29

- Canada, 20

- Corsicana, 22, 27, 28, 29

- creosote, 15, 20

- crude, $8,13,32,169,170$.

— drying, 149

- essential, 15

- fish, 15

- fuel, 15, 18, 42, 353

- Galicia, 20, 29

- German, 32

- Gold Coast, 26

- Great Britain, 32

- Hanover, 29

- Indian, 32

- Italian, 32

- Japan, 32

- Java, 32

- Kern River, 314

- Koudako, 25

- lamp, 15, 16, 208, 210, 214

- Lima, 170

- mineral, 15

- Nacogdoches, 24, 27

- Pennsylvania, 13, 20, 25, 29

- reduced, 18

- residuum, 18

- Roumanian, 20, 32

- Russian, 6, 19, 20, 28, 29, 41

- shale, 20

- Sour Lake, 27, 28

- Sumatra, 32

- Texas, $6,13,19,22,29,34,37,41,146,151$, 206 


\section{INDEX}

Oil, vegetable, 15

- Wyoming, 20

- Zante, 25

- analysis, 20, 26, 317, 328

- and coal, comparative cost, 37

- and coal furnace, 120

- burner, see Atomizers

- calorific power, 18

- carriage of, $23,112,285$

- City atomizer, 261, 327, 334

- eonveyors, 357

- eranes, 223

- expansion, 43, 113

- explosions, 147

- distribution, 222

- feed, 356

- fired superheator, 394

- fuel installation, 182

- fuel problem, 324

- fuel system, 129, 130

Oil furnaces, 275

- furnace, Baldwin, 168

- Cornish, 153

-- Holden, 148

- Laneashire, 152

- locomotive, 146, 148, 157, 158

- water tube boiler, 155,156

- installation, report by Sehoen,

Oil heating, 131, 149, 176, 280, 309, 325, 337

- pressure, 222, 351

- production, 32

- pipes, 65, 222, 349

- pump, 227, 314

- pumping system, 184, 194, 196, 197, 351

- ratio to coal, $6,12,195$

- regulation, 267

- regulator, $139,143,144,167$

- safety moat, 194,348

- serviee pumps, 315

- steamers, recent, 113, 286

- storage, 6, 31, 111, 114, 187, 194, 222, 226, 310,348

- stcrage report by Sehoen, 348

- tank steamer, 111, 285

- tank waggon, 187. 194, 285

- tank, 314

- U.S. Navy tests of, 158, 298

Oliphant on petroleum production, 33

Orde atomizer, 124

- boiler, Lancashire, 127

- on liquid fuel, 40

- system, 122, 130

- trunnion, 125

- water-tube boiler, 123

Orsat-Iunge apparatus, 231

Oxygen, 60

\section{P}

Packman, s.s., 119

Page, Mr., on fireclay, etc., 50

Pakin, test on, 165

Paraffin, 24, 25

Paul, Dr., on liquid fuel, 40

Pearson firebricks, 46

Pelouze and Cahours on hydrocarbons, 41
Pennsylvania oil, 13, 20, 25, 29

- railway, 170

Permits to use fuel oil, 344

Performance curves, Grazi-Tsaritzin Railway, 180

Petrol, car test, 205

Petroleum, 5, 26, 94

- Ameriean, 18, 20, 94

- analysis of, 20, 24, 27, 94

- Baku, 20, 29, 92

- Borneo, 41

- Burma, 41

- boiling point, 26

- California, 18, 19, 29

- combustion of, 94

- Corsicana, 22

- fuel, 18, 42, 92, 94

- production of, $8,32,33$

- properties of, $8,25,29,40,41$

- residuum, $6,18,94$

- Russian, 7,94

- storage precautions, 6

- Texas, 7, 28, 41

Phenolpthalein, test of soft water, 78

Phillips on Texas oil, 25

Physical properties of oil, 42

Pipes, 222, 349, 354, 356, 358

- bunker, 124

- jointing, 113,223

- jointing cement, 113, 356

- stand, 356

- water, 65

Poeahontas coal, 159

Pood, its equivalent, 225

Porter Clark process of water softening, 69

Power to compress air, 248

Preeautions in oil storage, 6

Preeautions for oil storage, 353

Preliminary heating, 208, et seq.

Pressure of oil supply, 351

Price of oil, 5, 10, 18, 37

- per barrel, 10

- per gallon, 18

Prineiples of liquid fuel combustion, 13, 15, 16

Produetion of coal, 5

- erude oil, 8, 32

- liquid fuel, 32

- tar, 15

Propane, 40, 58

Properties of air, 59

- Ameriean oil, 8

- Borneo oil, 41

- carbon, 56

- firebricks, 45

- fireelay, 45

- gases, 84, 103, 196

- hydrogen, 57

- liquid fuel, 16

- nitrogen, 60

- oxygen, 60

- petroleum, 8, 25, 29, 40, 41

- Russian oil, 29

- Texas oil, 29

- water, 62,65

Proportions of atomizers, 169 


\section{INDEX}

Propylene, 58

Pulverisers, sce Atomizer's

Pump, Weir's bunker, 226

- Weir's oil, 227

Pumping systems, 184, 194, 196, 197, 351

Pumps, oil, 314, 351, 354

Quantity of heat, 82

\section{2}

Ragosine effeet of steam on oil, 266

Railway tank wagon, 285

Ratio, oil to coal, 6, 12, 195

Réaumur's thermometer, 80

Receivers, 356

Reduced oils, 18

Reed Atomizer, 262, 335

Refining furnace, Sehwartz, 277

Refractory combustion chamber, 106

- linings, 14, 106

Regulating gear, 139, 149, 143

Regulation of oil, 267

Regulator, air, 186

- oil, Baldwin, 167

- oil, G.E. Rly, 139, 145, 143

Relative cost, oil and coal, 37, 169, 170, 171

Requirements of underwriters, 344,353

Residuum, 18, 20, 94, 171

Ringelmann's smoke chart, 290

Rivet furnace, 263, 275

- furnace atomizer, 263

Riveting, 113

Roumanian oil, 20, 32

Rules for liquid fuel ships, 111, 343

- of American Board of Fire Underwriters, 353

Rusden-Eeles atomizer, 113, 120, 261

Russe-Standart atomizer, 270

Russian locomotives, 166, 174

- Navy, 43

— oil, $6,19,20,28,41,171$

\section{$\mathrm{S}$}

Safety moat round tanks, 194, 348

St. Clair Deville, 89

Salts, solubility of, 64,65

Seale, 67

Schoen on oil storage, 348

- on individual installations, 350

Sehwartz furnace, 277

Sea water, 65

Seaports with oil supply, 114

Serpollet on vaporizing, 270

Service, oil pumps, 315

Sextane, 4

Shale oil, 20

- tar, 21

Shut-off valve, 356

Siemens-Martin furnace, 283

Siliea, 47, 49

Siloxicon, 53

Silver nitrate test of soft water, 78

Sithonia, s.s., 127

Small tube boiler, 268
Sinith, Dr. Angus, on Water, 76

Smoke, 96, 173, 176

- chart, Ringelmann's, 290

- prevention, 96

Soft water, $63,67,74,75,77$

- test for, 78

Soliani atomizer, 270

Soliguac boiler, 7

Solubility in water of gases, 62

- in water of salts, 64,65

Soot, 58

Sour Lake oil, 27, 28

Southern Pacific atomizer, 272

Speeifie gravity, 18, 19, 20, 21

Specifie heat, 83, 84, 85, 103

- gases, 84, 103

- ice, 83

- solids, 84

- water, 62,84

Sprayer, see Atomizer

Springfield system, 198

Standart-Russe atomizer, 270

Stationary practice, American, 182, 194

- English, 199

Stand pipes, 356

Starting device, automobile, 215

Steam, as fuel, 3, 63, 194, 336

- atomizing, 4, 147, 160,182, 194, 219

- ear with liquid fuel, 206

- dissociation by lieat, $3,63,85,194$

- per pound of oil, 194

- ships, F. C. Laeisz, 131

- Mariposa, 262, 313

- Murex, 111, 118, 119, 127

-- Newyork, 121, 286

- Sithonia, 127

- Strombus, 32

- Syrian, 127

- Tanglier, 119

- Trocas, 113, 121

Steam superheated, $147,194,394$

Steamer, eargo with oil fuel, 112

- recent oil, 113

— tank with oil fuel, 111, 286

Steel, 45

Steel tubes, 45

Storage of oil, 6, 31, 111, 114, 187, 194, 222, 310,348

- report by Schoen, 348

- safety moat, 194,348

— system, G.E. Rly., 223

- tank, oil, 187, 194, 222, 226, 357

- vault, 355,357

Stourbridge elay, 45, 49

- firebrieks, 45

Strombus, s.s., 32

Suez Canal, 114

Sulphate of lime, 64, 73

Sulphur in oil, 19, 37, 349

Sumatra oil, 32

Superheater, Cruse controllable, 394

— oil fired, 394

Superheated steam, 147, 194, 394

Supply of water, 63

— ports, oil, 114 


\section{INDEX}

Supply of tank, oil, 187, 194, 357

- system, bunker pipes, 124, 194

Surcouf, test of, 165

Swensson atomizer, 263

Syrian, s.s., 127

System, Aërated Fuel Co., 196

- Baldwin Co., 166

- Billow, 182

- Clarkson-Capel, 208

- distribution, 223, 225

- Ellis \& Eaves, 216

- Flannery Boyd, 112, 121

- Fvardofiki, 268

- Guyot, 265

- Holden's, 5, 138-59

- Howclen's, d19, 136

- liydroleum, 203

- Kermode's, 199, 202

- Kirkwood, 194

- Körting, 127, 131, 133, 160

- Meyer, 160

- mixed, 120, 162

- National Fuel Co., 182

- Oil City Boiler Co.'s, 261

- Orcle's, 122, 127, 130

- Pumping, 184, 194, 196, 197

- Rusden-Eeles, 113, 120

- Springfield, 198

- Symon House, 264

- Urquhart, 171, et seq., 225

- Wallsend Slipway Co.'s, 129

$\mathrm{T}$

Tanglier, s.s., 119

Tank, ear hose, 188, 356

- coating, 355

- eapacity, 354

- location, 348, 355

- material, 355

- oil supply, 187, 194, 353

- steamer, 111,286

- storage, 187, 194, 223, 226, 350, 353

- underground, 223

- wagon, 187, 194, 285

Tar, 15, 18, 21, 204

- properties of, 21

- water gas, test of, 204

- shale, 21

'Temperature, 82

- caleulation of, 89

- flame, 100

- furnace, 99

- of combination, $12,56,89,92$

- of ignition, 58

Tender, fuel,

- G.E. Rly., 142, 148

- Grazi-Tsaritsin Railway, 175

Test of air atomizing, 216, 266

- air compressor, 244

- Beaumont oil, 35, 195

- Borneo oil, 199

- ear, 20j

- endurance, 331

- Furicux, 164

- marine boiler, 218, 221, 326
Test of metal furnace, 277

- motor car, 205

- on Pennsylvania Railway, 170

- petrol, 205

- Russian Railway, 11

- soft water, 78

- s.s. Mariposa, 313

- Texas oil, 35, 195, 206, 218

- U.S. Navy, 158, 295, 326

- water gas tar, 204

Test:s at Cherbourg, 43, 164, 266

- at Indret, 162, 266

- Godard boiler, 164, 265

- Hohenstein boiler, 295, 326

- Rússian oil, 11, 203

Texas oil, 6, 13, 19, 22, 29, 34, 37, 41, 146, 151, 169,218

- analysis, 27

- ealorifie power of, $19,29,30,41,218$

-. earriage of, 22,24

- eliemistry of, 24

- costs, 22

- density of, 25,27

- effieiency of, 37,151

- specifie gravity of, $25,27,218$

- tests of, 35, 195, 206, 218

Thermal efficiency due to steam, 336

Thermal units, 86

Thermo-ehemistry, 57, 80

Thermometer, 82, 83

Thompson's ealorimeter, 251

Thiele on 'Texas oil, 27

Thwaite Storage tank, 226

Torpedo boat, 12, 164, 266

- boiler, Freneh, 267

Trocais, s.s., 113, 121

Tubular boiler, underfired, 190

Tunnels, Railway, 11, 157

Tuyere, air, 186

Tweddle on Texas oil, 30

Two-stage air compression, 240

Tyre heating furnaee, 261,281

\section{$\mathrm{U}$}

$\mathbf{U}$ gauge, 257

Underfired tubular boiler, 190

Underground vaults, 355,357

Underwriters, rules of Ameriean Board of Fire, 344,353

United States Navy Tests, 258, 295 et esq.

Units of heat, 85

- of length, 86

- thermal, 86

- weight, 86

- work, 86

Urquhart atomizer, 172, 261, 282

- locomotive, 174

- system, 4, 171 et seq., 225

- tender, 175

- tyre furnace, 281

Useful figures, 49, 64, 66

\section{V}

Valves, shut-off, 354, 356

Vanderbilt fire box, 168 


\section{INDEX}

Vaporization, heat of, 88, 100

Vaporized liquids, combustion of, 208

Vaporizing, 17, 270

- carbon, 55

Variable blast pipe, Macallan's, 256, 139, 259

Varieties of liquid fuel, 15, 17

Vaults, storage, 355

Vegetable oil, 15

Velocity of efflux of air, 249

- draught, 256, 259

- water in pipes, 65

Ventilation, 157, 222, 355, 357

Vent pipe, 349,355

Verein-Deutsche ingenieur, 81

Vertical boiler, 151

Vetillard-Seherding atomizer, 270

Violet rays in flame, 104

Volatile constituents of petroleum, 11, 13

Volume and weight of atmospheric gases, 59

- chimney gases, 90

- gases, 90

- petroleum, 18, 169

- of combustion gases, 90

\section{W}

Wagon, tank, 187, 194, 285

Wallsend Slipway Co., 113, 129, 130

- furnace brickwork, 129

Warming oil fuel, 6

War vessels, Sir F. Flannery on, 115

Water, acid, 77

- capacity of boilers, 7

- compressibility, 61

- data, 61, 64

- expansion by heat, 62

- flow of, 65

- gas tar, 203

- gauge, 257

- grease in, 79

- hardness, 63,65

- in oil, $40,41,43,147$

- iron in, 76

- latent heat of, 62
Water pipes, 65

- properties of, 61

- pure, 61

- purification, 67

- sewage in feed, 64

- softening, $67,74,75,77$

- solubility of salts in, 64,65

- solubility of gases in, 62

- source of, 61,62

- specific heat, 62

- supply, 63

- tests for soft, 78

Water tube boiler, Guyot, 268

- Heine's, 193

- Hohenstein's, 298

- Hydroleum, 203

- Orde's system for liquid fuel, 122

- Weir's 14, 106

- with grate, 155,191

- without grate, 156

- useful data, 66

- weiglit, 61,62

Weight of air, 59, 253

- hydrogen, 58

-- firebrick, 49

- oil, 18,169

- oil per barrel, 36

- oil per gallon, 18, 36

- oxygen, 60

- nitrogen, 60

- units, 86

- water, 61, 62

Weir's boiler, 14, 106

- oil pump, 226

Welsh coal, 103

Western Sugar Refinery, 194, 321

Williams atomizer, 34, 270

Winchell, Lieut. U.S. Navy, report on s.s Mariposa, 313

Work units, 86

Wyoming oil, 20

Zante oil, 25

\section{Z}




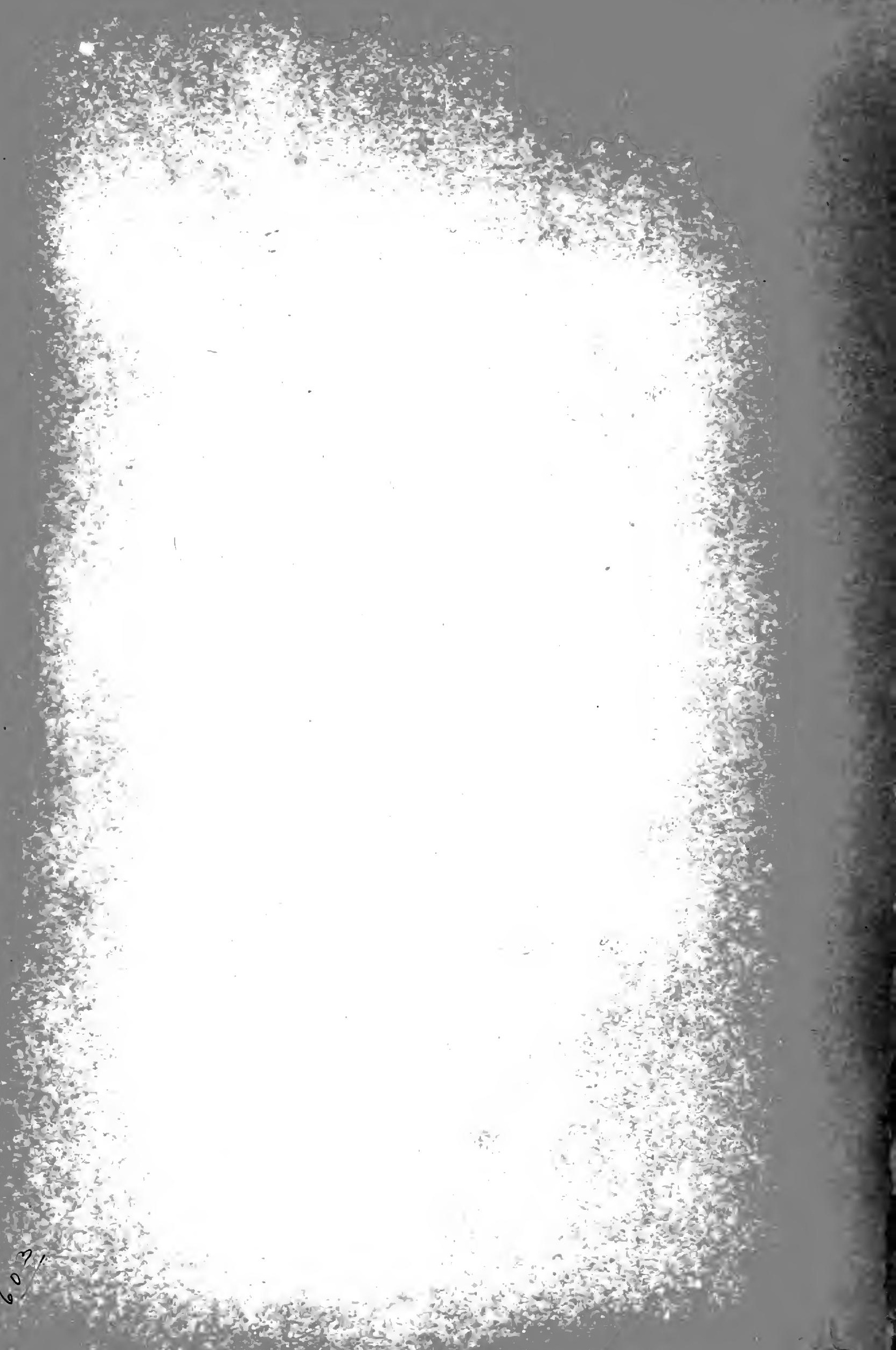





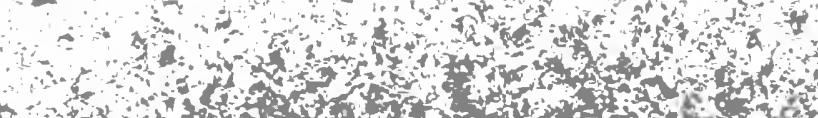

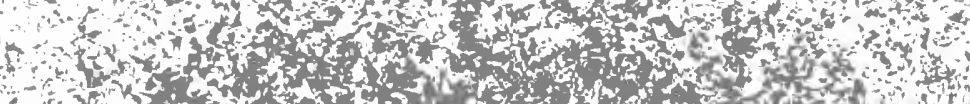

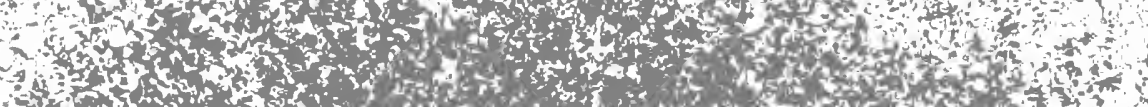
4.

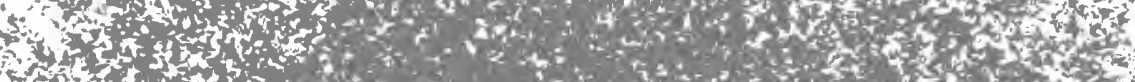

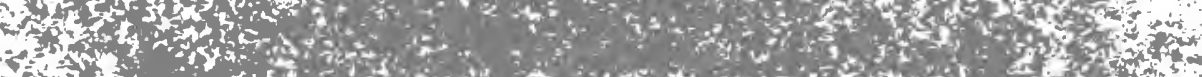

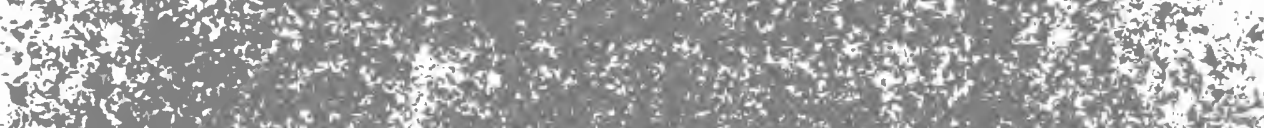
(1) a.t.

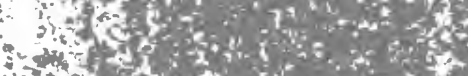

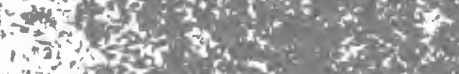

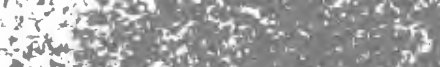
ing - 32 is $x^{2}$

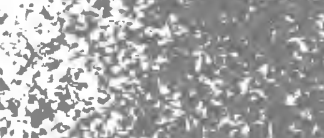
ton

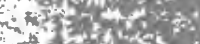

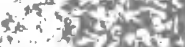

$w^{2}=0$

tog

ton

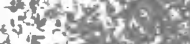

$f^{4}+70<-4$

is

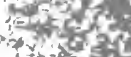

tos

ros

mis

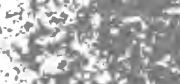

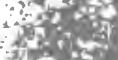

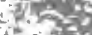

$\therefore$ a

$\because i$ i

tat?

$\therefore x+2$

ing

\section{Nisp}
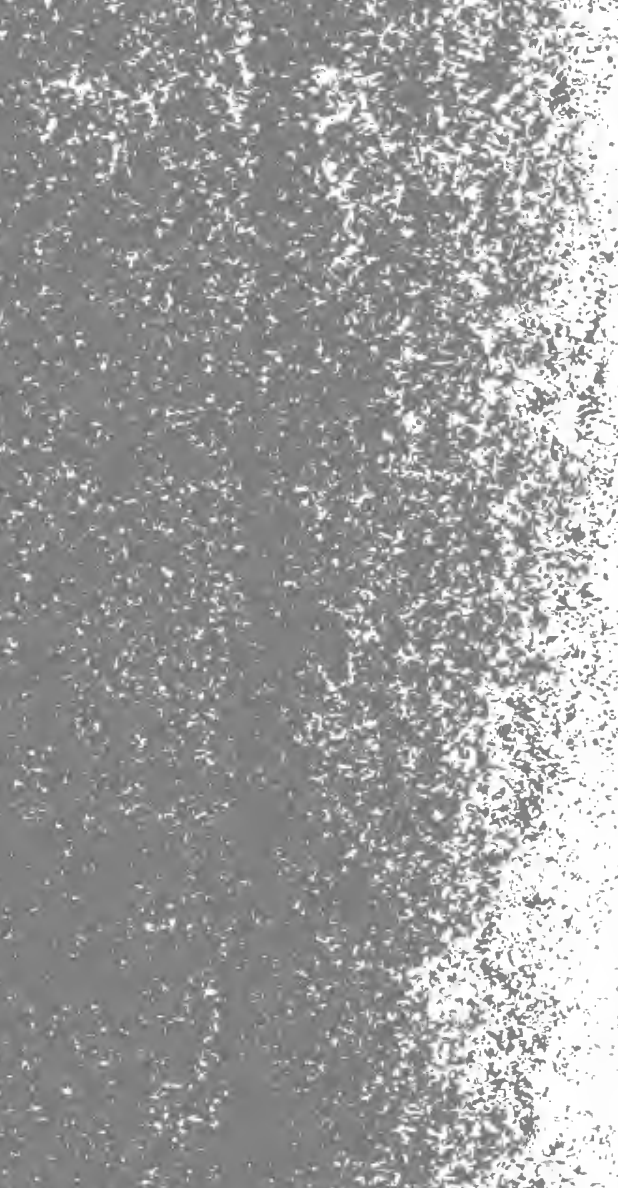


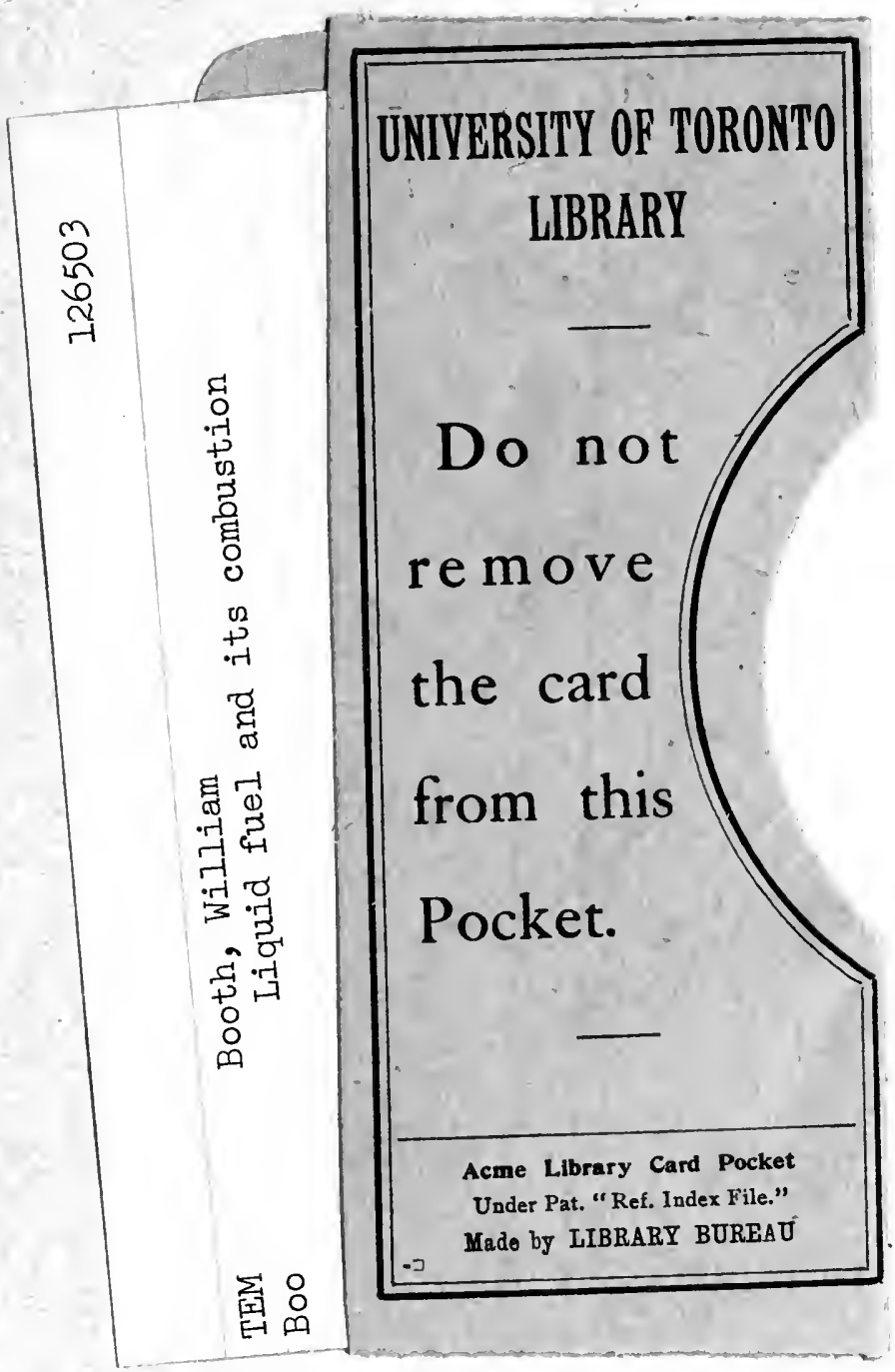


